Contribució al coneixement del medi natural $\mathbf{i}$

l'empremta humana de la Reserva Natural de les Illes Columbretes:

clima, fauna invertebrada i memòria

\title{
Eva Mestre-Forés
}
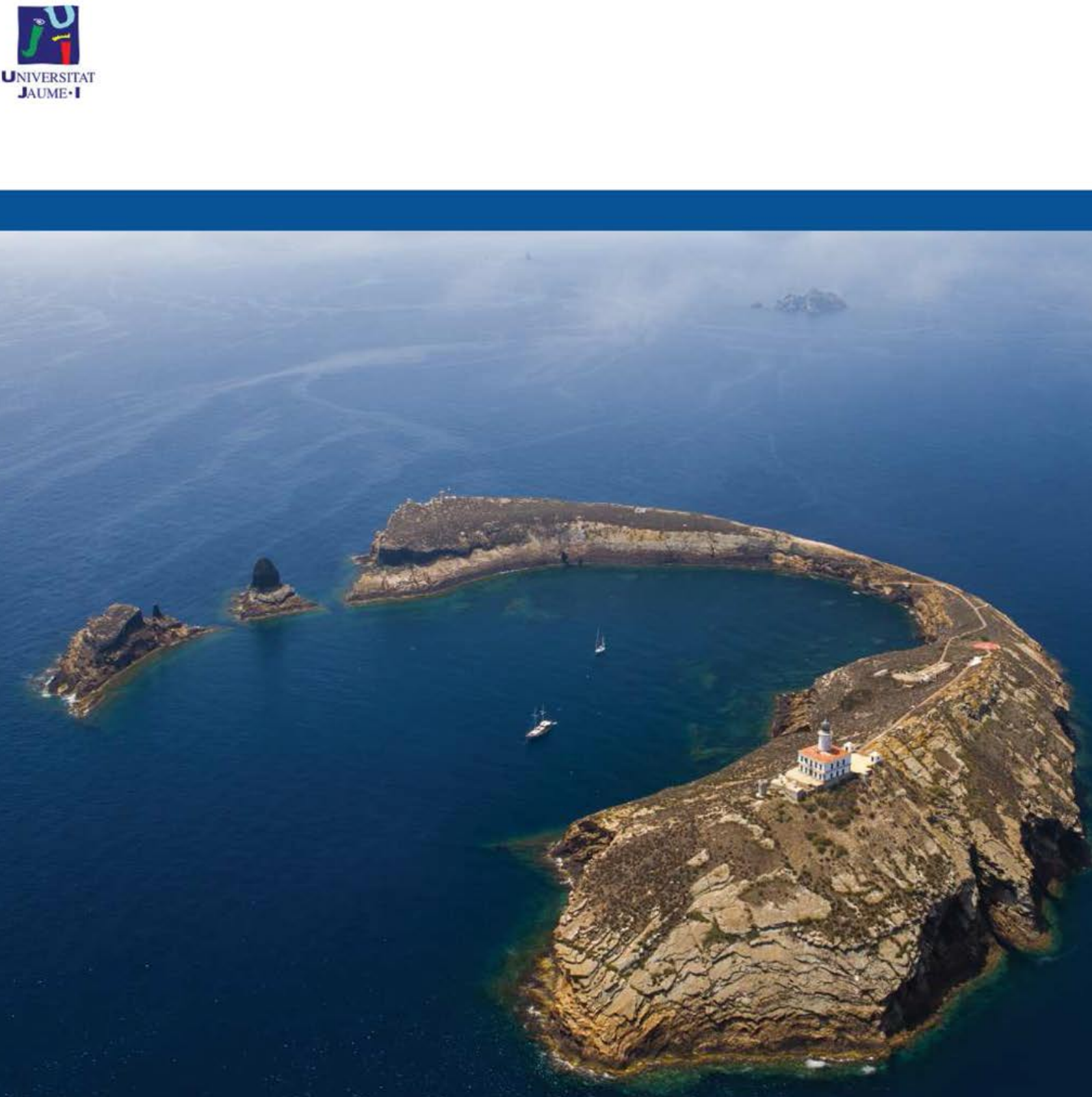


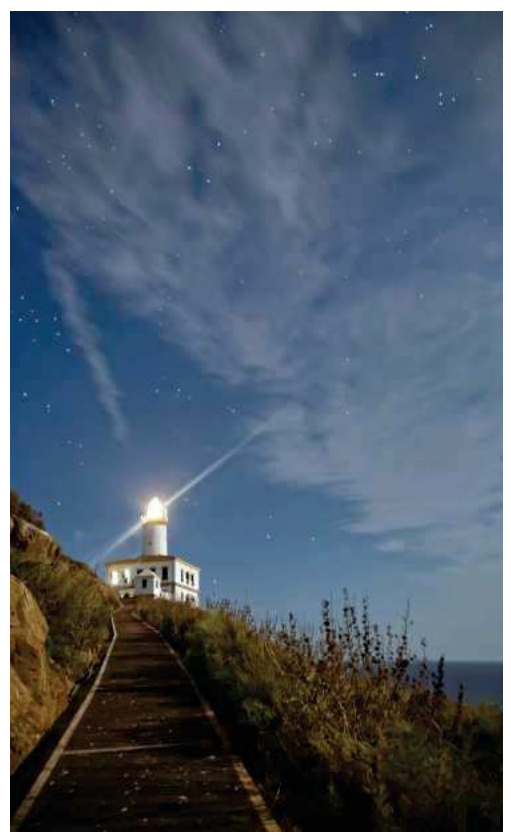

"Les Columbretes són petites, molt petites, tant com suggeridores. Viure a les illes no deixa immune i cada experiència es queda tatuada per sempre més a l'ànima dels seus habitants. Són històries grans dins un món petit, històries d'amor, de vida i de mort..."

Xavi del Senyor 
Escola Superior de Tecnologia i Ciències Experimentals

Departament de Ciències Agràries i del Medi Natural

Programa de Doctorat en Ciències

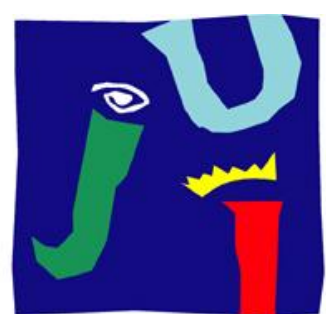

UNIVERSITAT

JAUME•I

Contribució al coneixement del medi natural i l'empremta humana de la Reserva Natural de les Illes Columbretes: clima, fauna invertebrada i memòria

TESI DOCTORAL

Memòria presentada per a optar al grau de DOCTORA per la Universitat Jaume I per

EVA MESTRE-FORÉS

Enginyera Agrònoma

Director: Dr. Josep A. Jaques Miret 
Als meus pares, per tot,

als guardes, voluntaris, monitors i tècnics que des de l'any 1987 han treballat amb il/lusió en la restauració, protecció i divulgació de les Illes Columbretes,

a la memòria d'aquells que hi van deixar la vida com Miguel, Rafael, Juan, Mercedes i Aurelio, i

a totes les persones que al llarg del temps s'hagen enamorat de les Columbretes, des dels antics grecs fins als guardes de hui en dia, passant per totes eixes dones i homes que van tindre la sort o la desgràcia d'habitar-les i que amb el temps, invariablement, les recordarien amb amor i nostàlgia, igual que jo...

Eva Mestre-Forés

Castelló de la Plana, 7 d’abril de 2017 
Totes les imatges que apareixen en aquesta tesi doctoral han estat realitzades per Eva MestreForés, excepte aquelles cedides, els retalls de periòdics i les següents imatges (se n'indica l'autoria):

imatges de les cobertes anterior i posterior de la tesi i figures 2 a 5, 7 i 3.11: Ramon Usó, imatge de la solapa de la coberta anterior: Carolina Gauxach, imatges de les portades del primer capítol i annexos, i figures 8, 13, 3.18, 3.19 i 3.23: Xavi del Señor,

figures 2.2, 2.28 i 3.12: Patricia González,

figura 2.9 i imatge de la solapa de la coberta posterior: Sheila Carbó,

figura 2.15 (dreta): Carles Fabregat,

imatge de la portada del tercer capítol i figura 3.10: Màxim Fallada, i

imatges de l'annex 2.4 (Material suplementari 1): Francisco J. Ferragut.

Les figures 2.4 a $2.7 \mathrm{i}$ el disseny de les cobertes del llibre i portades dels capítols han estat realitzats per Sergio Babiloni. 


\section{AGRAIIMENTS}

Voldria expressar el meu més sincer agraïment,

en primer lloc, al meu director de tesi, el Dr. Josep Anton Jaques Miret pel valuós temps que ha dedicat a aquest treball durant els últims cinc anys, per poder comptar amb la seva ajuda $\mathrm{i}$ experiència, i perquè cada moment passat amb ell ha sigut d'aprenentatge,

a la Dra. María Victoria Ibáñez Gual per ajudar-nos amb les anàlisis estadístiques del capítol del clima de Columbretes, $\mathrm{i}$

al Dr. Francisco José Ferragut Pérez per dirigir-me l'estudi per a obtindre el títol de Diploma d'Estudis Avançats, a la Universitat Politècnica de València, durant 2007 i 2008, el qual mostre a un annex d'aquesta tesi, i per cedir-me les imatges d'àcars que hi surten.

Des de l'any 1998 fins 2014, quan vaig decidir canviar de treball per començar una nova etapa professional, he passat moltes èpoques diferents a Columbretes. Romaníem a l'Illa Grossa durant 15 dies seguits amb les seues nits, i els molts companys i companyes de treball amb qui he conviscut es convertien en companys de pis, amics i, inclús, quasi família; les illes mateixes pareix que cobraven vida convertint-se, cadascuna d'elles, en una companya més. Ha sigut una de les etapes més boniques de la meua vida. Voldria expressar el meu agraïment a tots ells $\mathrm{i}$ elles per haver deixat una empremta en mi que va contribuir a formar-me com la persona que sóc avui en dia, i

molt especialment, als meus companys a les Illes durant els primers anys, Valentin Tena, Roque Belenguer, Jacobo Méndez, Vicente Ferrís, Josep Carda, Mar Prados, Rebeca Velasco i Diego Kersting, per tant com vaig aprendre amb ells, de la professió i de la vida,

a la Dra. Patricia González González i a Xavier Ferran del Senyor de la Gala, per tantes hores de feina compartides a l'oficina, al Centre d'Informació de les illes Columbretes, i a les Illes, per la música i les rialles, per l'amistat sincera, perquè gran part dels estudis d'aquesta tesi va ser concebuda amb ells, mentre vam ser companys tècnics mediambientals de la Reserva Natural de les Illes Columbretes fins a 2012. Ells van acompanyar-me en els primers passos de l'estudi del clima de Columbretes, van ser coautors de la recerca sobre l'empremta humana durant els anys inicials i en la traducció al format de documental de part del que forma el capítol tercer d'aquesta tesi; i per tantes altres coses, professionals i personals, tantes, que no cabrien en aquest paper.

També vull agrair a tota la resta de l'equip de Columbretes, companys i companyes de treball 
de la reserva natural i la reserva marina, per l'ajuda en el treball de camp i la identificació d'algunes espècies d'invertebrats, per recollir i passar-me les dades meteorològiques, per patronejar la llanxa pel trasllat a la resta d'illes o illots des de l'Illa Grossa, i per les bones hores que hem passat junts treballant i gaudint de les Columbretes, especialment a Vicent Castañer, Manli Viñes, José Luis Cimarra, Honorio Delgado, Bruno Sabater, Antonio Valero, Juan Torres, Juan Fenollosa, Kike Sánchez, Sheila Carbó, Pilar Luis i Raül Ramos, i als gestors de la reserva natural, Juan Jiménez, José Vicente Escobar i Constantino Simó.

Tornant a l'elaboració dels capítols de la tesi, voldria mostrar el meu agraïment

a Patricia, de nou, per la col·laboració en l'estudi d'invertebrats, mostrat al capítol segon, i a Sergio Montagud Alario, pel que fa a la part de l'elaboració del catàleg d'invertebrats i la determinació d'espècies amb el Dr. Lluc Garcia Socias, Gregorio Ros Montoliu, la Dra. Mạ Ángeles Marcos García, Eduardo Morano, Juan Antonio Zaragoza Miralles, Santiago Teruel, Daniel Sánchez, el Dr. Pablo Barranco Vega, el Dr. Ferran García-Marí i el Dr. César Monzó, a tots ells els agraïsc la col·laboració,

al Dr. Vicente Navarro Llopis, de I'Institut Agroforestal de la Mediterrània, CEQA, de la Universitat Politècnica de València, per presentar-me tan encertadament a Josep Jaques,

al Dr. Gerard Llansola, Tècnic de Gestió Documental de l'Autoritat Portuària de Castelló encarregat de l'arxiu del Port qui tan amablement em va atendre al llarg de totes les jornades en què vaig estar fotografiant les quasi mil pàgines pertanyents als arxius antics dels faroners de Columbretes $\mathrm{i}$ perquè sense el seu treball potser aquests arxius no hagueren estat disponibles,

al personal de la Delegació Territorial en la Comunitat Valenciana de l'Agència Estatal de Meteorologia, especialment a Antonio Torres, encarregat d'enviar-me les dades meteorològiques adquirides, i a José Ángel Núñez i a Juan José Vizcaíno per atendre-me’n,

a Nuria Faubel, de la base de dades de Biodiversitat de la Comunitat Valenciana, i a Iolanda Verdugo, per les seues aportacions sobre invertebrats,

a David Moré, historiador especialista en fars, per la gran quantitat d'històries de fars que ha recopilat, les quals pot contar com si fos un llibre obert, i per servir-nos de fil conductor en la recerca de l'empremta humana,

al Dr. Juan José Ferrer-Maestro, Catedràtic d'Història Antiga de la Universitat Jaume I per les referències de Columbretes en l'època antiga, sobretot pel que fa a la vida de Sertori, 
al Dr. Robert Arnau pels seus consells pel que fa al capítol de l'empremta humana,

a totes les persones que surten al tercer capítol i als documentals "Aïllats, la memòria de Columbretes" i "Continuem Aïllats": als pescadors i familiars de mariners Xisco Pérez, Màxim Fallada, Mạ Teresa Lluch i Antoni Cerdà, als investigadors, el Dr. José Sevilla Marcos, la Dra. Helga Schwendinger, al personal de la reserva natural Vicent Ferrís, Valetín Tena, Vicent Castanyer, Rebeca Velasco, Roque Belenguer, Santiago Sales i a l'ex-director Juan Jiménez, als actors Lucas Martínez, Luis Mestre, Vicent Olivares "Panollo" i Juan Carlos Usó, al locutor Alfonso Sales, al dissenyador Gabi Borràs, als escriptors Vicent Usó, Josep Porcar, David Trueba i el Dr. h. c. Manuel Vicent, als músics Salva el Mussennacitu, Lluís Martínez-Esbrí, José Galindo, Manel Brancal, Miquel Gil, cor Juan Ramon Herrero, noesruido (Fede Trillo i David Bueno), Miquel Gil i Tom Bombadil, i molt especialment als familiars de faroners Carmen Barreña, Gustavo Chao, Asunción Fernández, Alicia Fernández del Río, el Dr. Francesc Grimalt, Mercè Rigo, Encarna, Mercè i Vicentica Garcia, Ángeles, Ma José i Serafín Gandolfo Albaladejo, Javier Gea Gandolfo, Manuela Arribas, Pepita Llorenç, María Valero i José Gozalbo, i a Pilar Martínez i Ramón Roig (Tarzán y su compañera), per la preciosa història d'amistat que ens van brindar, $\mathrm{i}$ també, per descomptat, a Dolores Guerra, a qui vaig conèixer l'any 2010 i que quasi es va convertir en un membre de la meua família. Dolores ens va captivar amb les seues històries, i la seua força va contribuir a que portàrem endavant la recerca de l'empremta humana a les Columbretes i que realitzàrem el documental. Moltes vegades em va dir: “Ay, Eva, qué alegría me estáis dando, este proyecto vuestro me ha dado la vida, pero tenéis que acabar el documental antes de que me muera", i jo li contestava, "pero, Dolores, isi tú tienes energía para dar guerra durante muchos años más!"; i el cas és que, tristament, va morir just un any i mig després de l'estrena del documental. Dolores, sóc molt feliç d'haver-te trobat en el camí de la vida.

També voldria manifestar el meu sincer agraïment a Fernando Ramia, Carlos Lidón, Hugo Doménech i Jesús Moreno per fer-me veure que, efectivament, els resultats de la investigació sobre l'empremta humana podien ser contats en format documental, i molt especialment a Carolina Gauxach i Ramón Usó per les seues aportacions professionals i recolzament incondicional, des del primer moment en què vaig començar amb el projecte,

a les meues amigues i amics Iolanda, Gabi, Agnès, Paula, Alba, Laura, Míriam, Miguel, Pura, Javi, Sergio, Pilar, Rebeca, Begoña, Bárbara, Irina, Raquel, Ricardo, Manolo, Jamil, Pepe Albalat, Gonzalo Romero, Joan Antoni Vicent, Rafa del Voramar, Lucía de Columbretes, Carlos Fabregat i a la resta de micromecenes que van recolzar la creació del documental sobre l'estudi de l'empremta humana, 
al meu amor "perruno", Inca, perquè una abraçada a ella m'ompli d'energia positiva i de ganes de tirar endavant amb tot, i, perquè no, a Marcos i a Ayla, tot i que la vida ja ens va separar, van ser la meua família,

a Sergio Babiloni (el seu avi va treballar en les obres del camí de l'Illa Grossa als anys 50) per l'elaboració del dibuix $\mathrm{i}$ els mapes que apareixen en el capítol d'invertebrats, pel magnífic disseny de les portades de la tesi i els capítols, per ajudar-me amb el muntatge i la revisió final del llibre, pel seu amor i pels molts d’ànims que m’ha donat cada dia,

a la meua germana Susana, als meus corets, Jorge i Paola, i a la tia Felicita, perquè sentir la seua estima em dona energia,

a la memòria dels meus iaios, Manuel i Milagro, per l'amor a la terra i als animals que em van transmetre; i a la memòria de la tia Tere, que va ser la primera persona que em va parlar de les Columbretes i del personal que va començar a treballar-hi cap a l'any 87 , a qui els va vendre probablement la primera nevera a gas que va haver a les Illes; recorde que, tenint jo uns 11 anys, em va dir "Eva, com t'agradaria a tu treballar a les Columbretes!", qui m'havia de dir aleshores tots els anys de la meua vida que dedicaria a treballar en aquest paradís...,

i, per descomptat, als meus pares, Luis i Mila, els quals van passar dies i dies dictant-me els milers de dades meteorològiques aconseguits als arxius del Port i així facilitar-me la tasca de digitalitzar-los, i perquè sense ells res de tot açò hauria sigut possible. Gràcies per confiar en mi i recolzar-me en tot, i gràcies també per l'immens amor amb el que m'haveu cuidat cada dia. Us estimo moltíssim! 


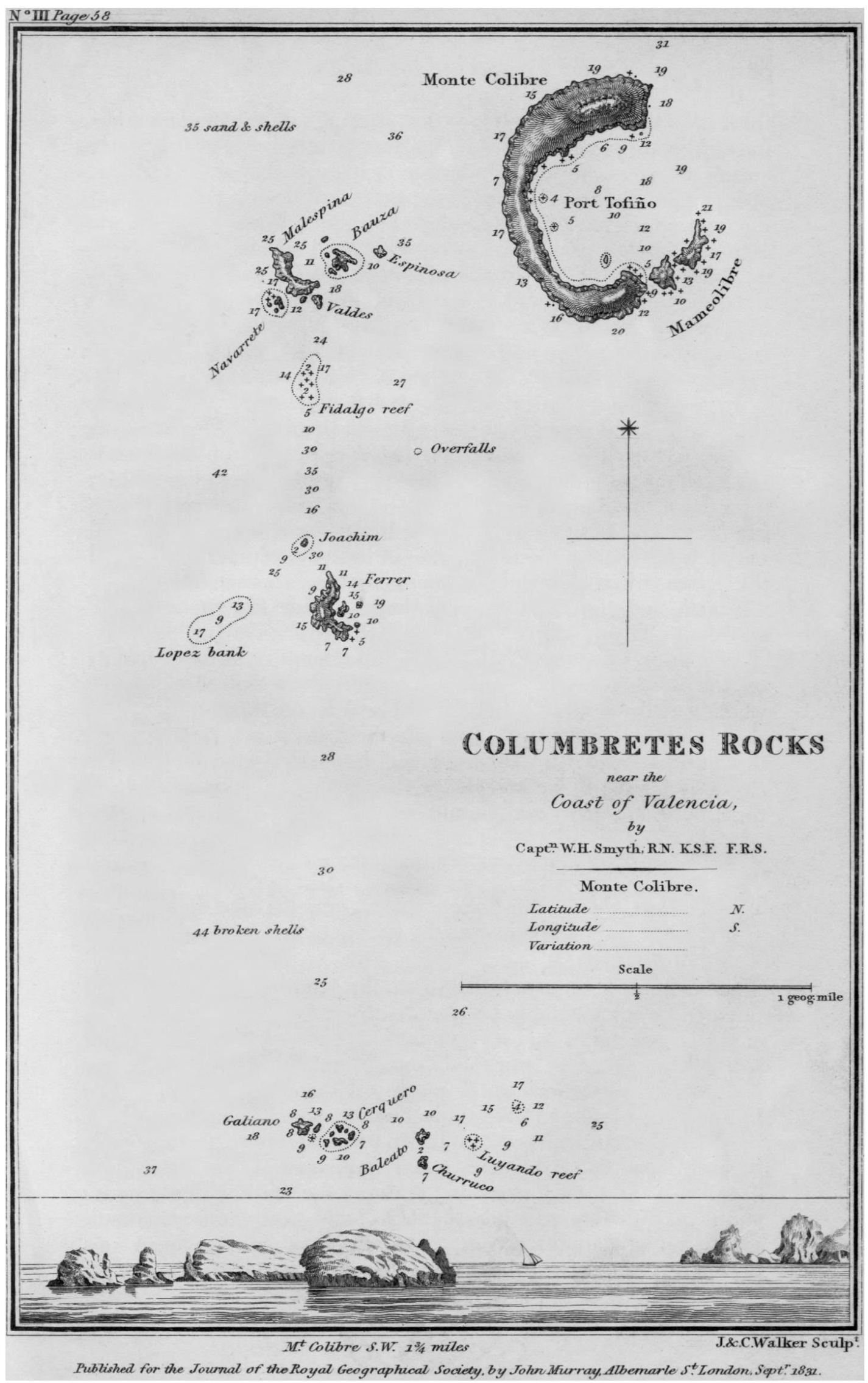

Figura 1. Mapa de les "Columbretes Rocks" del capità Smyth (1831). Font: arxiu C.I. Columbretes. 
Aquesta tesi doctoral va ser concebuda com a una totalitat. Els dos primers capítols són adaptacions dels articles que s'han redactat per a la seua publicació científica. Llevat de la llengua en que han estat redactats (el capítol del clima en anglès i el capítol d'invertebrats en castellà, i igualment, els annexos corresponents), el format, les figures, taules i referències dels articles s'han unificat per adaptar-les a la resta de la tesi doctoral.

Per a la denominació de les espècies, tant per a les noves com per a aquelles que ja havien sigut citades en anteriors estudis, es va seguir el mateix criteri. En el cas de la flora es va utilitzar la taxonomia presentada en la pàgina web de "The Euro+Med PlantBase", afegint l'any de la referència de la nomenclatura (http://ww2.bgbm.org/EuroPlusMed/). En el cas de la fauna, tant per a taxons superiors com per a la denominació d'espècies es va seguir el criteri de "Fauna Europea" (www.faunaeur.org). Quan açò no va ser possible es va acudir a la "Encyclopedia of Life", EOL (http://www.eol.org/) i a la pàgina web de la "Global Biodiversity Information Facility", GBIF (http://www.gbif.org/), igual que per a les espècies marines, i la base de dades d'àcars de la Universitat de Sao Paulo, ESALQ, de Brasil (http://www.lea.esalq.usp.br/). 
Transmetre la labor científica realitzada en espais naturals protegits a la ciutadania és bàsic perquè la ciutadania valore la importància de la seua conservació i siga conscient de la necessitat de seguir invertint en el seu estudi i protecció. Amb aquesta premissa ens hem endinsat en el món de les illes Columbretes, un enclavament únic dins la geografia valenciana, per conèixer-les més de prop i establir les possibles carències quant a estudis científics del medi terrestre i de la seua divulgació.

Aquestes illes volcàniques formen un arxipèlag situat mar endins, a unes 30 milles nàutiques de les costes de Castelló, de tan sols 19 hectàrees de superfície emergida. Estan protegides pel Govern Valencià des de 1988 i l'entorn marí, pel Govern Central des de 1990, essent reserva natural i reserva marina, respectivament. La informació generada al voltant de la reserva natural està centralitzada al Centre d'Informació de les Columbretes, ubicat al Grau (Castelló), des $d^{\prime}$ on es porten a terme també les tasques d'educació i divulgació mediambiental. Una peculiaritat d'aquest espai és que tots els visitants de l'llla Grossa han de desembarcar acompanyats del personal de la reserva en una visita guiada pel camí que uneix el port Tofiño amb el far, on hi ha un centre de visitants.

Quan es va començar aquesta recerca, l'any 2013, vam observar que des de l'establiment de l'arxipèlag com a espai natural protegit, el nombre de persones ateses a l'llla Grossa es mantenia dins un mateix rang des de 1997 que oscillava entre 2.416 i 3.731 visitants; no obstant això, el nombre de visitants atesos al Centre d'Informació havia minvat des de més de 15.000 en 2004 , fins a poc menys de 3600 , quan, observant els gràfics d'evolució, podríem considerar que el rang anual desitjable es podria fixar entre les 12.500 i les 15.500 . Per tal de mantindre el nombre de visitants dins els rangs proposats s'hauria de potenciar les activitats oferides des del Centre d'Informació, oferir-ne de noves i donar a conèixer noves dades sobre les Illes, fonamentals per tal d'impulsar de nou l'interès de les persones que ja les coneixen; i per descomptat, no desatendre la qualitat de les visites guiades a l'Illa Grossa, gestionant des de la mateixa Reserva i tenint en compte les seues peculiaritats, tant la quantitat com la qualitat dels treballadors, que són el nexe de les Columbretes amb els visitants.

Per contribuir a l'actualització de la informació disponible sobre la història natural i la història humana de les illes Columbretes vam triar temàtiques de les quals es tinguera menys informació. La majoria dels estudis científics publicats sobre la part emergida eren sobre aus i rèptils, a més, la informació del clima que es donava en aquests estudis s'havia publicat en 1987. Finalment, vam decidir la realització de l'estudi de la climatologia de les Columbretes, estudiar els invertebrats a la part emergida de les illes i la recopilació i documentació d'informació sobre l'empremta humana.

Vam recopilar i digitalitzar 28.324 noves dades de precipitació i temperatura enregistrades a l'estació meteorològica de l'Illa Grossa, obtingudes dels diaris mateixos dels faroners, i les vam afegir a les dades enregistrades per l'Agència Estatal de Meteorologia per obtindre sèries més completes. D'aquesta manera concloem que hui en dia el clima és més càlid, d'acord amb l'escalfament global del Planeta, però també més plujós que fa 60 anys, tendència observada també a estacions meteorològiques properes del nord-est de la Península, i que l'amplitud tèrmica ha disminuït en els últims cent anys (les temperatures màximes absolutes es mantenen mentre pugen els valors de les temperatures mínimes absolutes). Amb les noves dades obtenim una nova classificació climàtica: clima termo-mediterrani atenuat amb una època seca curta segons UNESCO-FAO, semi àrid càlid (BSh) segons Köppen-Geiger i semi àrid (BS) segons Köppen-Trewartha. 
Hem actualitzat la informació disponible sobre invertebrats no marins a les illes majors de les Columbretes i l'hem ampliada mitjançant les observacions i captures portades a terme des de 2004, reforçades amb la col·locació entre 2008 i 2011 de trampes de gravetat on van caure 13.556 invertebrats. Durant la realització d'aquesta tesi es va procedir a organitzar tot aquest material i identificar-lo mitjançant especialistes en els diferents grups. D'altra banda, es va realitzar una revisió sistemàtica dels diferents catàlegs existents i dels invertebrats citats en diferents estudis per tal d'ajuntar-los i, amb les nostres primeres cites, obtindre el primer catàleg d'invertebrats terrestres de les illes Columbretes, conformat finalment per 276 espècies, 60 de les quals són primeres cites per a l'arxipèlag o per a alguna de les illes.

Per tal de documentar l'empremta humana a l'arxipèlag s'han recollit de forma sistemàtica, tant la informació publicada en diversos suports, com original. Es van revisar els arxius històrics del Port de Castelló, l'arxiu municipal de Castelló de la Plana, I'hemeroteca de la Biblioteca Nacional, i es va contactar amb 52 persones relacionades amb les Columbretes (familiars de faroners, pescadors, investigadors o personal de la reserva) de les quals en vam entrevistar a 38 , que ens van contar les seues històries, vivències $i$ anècdotes succeïdes a les Columbretes 0 ens van transmetre les de tercers que hi van estar. En totes les entrevistes s'ha trobat coincidència en la descripció de la força dels temporals i les tempestes, la "convivència" amb els escorpins, l'abundància de pesca, o de pardalets migratoris en les èpoques de pas, les dures condicions de treball que hi havia, i sobretot l'aillament. Ara sabem qui va ser la primera xiqueta que va nàixer a les Columbretes en l'època dels faroners, o qui va construir el cementeri, entre altres. S'ha pogut fer una recopilació dels llistats dispersos de faroners que van exercir a les Illes Columbretes i, amb material inèdit recopilat en aquesta investigació, elaborar un únic llistat més complet de faroners de Columbretes. També es va prendre la decisió de preparar el documental "Aillats, la memòria de Columbretes", que va veure la llum l'any 2015, tot i que la recerca ha continuat fins 2017.

Tota aquesta nova informació i dades, incloent el documental, constitueixen un material que pot ser utilitzat en les xarrades i conferències impartides pels tècnics mediambientals per a la divulgació dels valors de les illes Columbretes i també pels guardes en les visites guiades que realitzen en la reserva natural. A més de que pot servir com a base per a l'elaboració de material de divulgació actualitzat, com la guia de flora i fauna que actualment estem preparant. 
Transmitir la labor científica realizada en espacios naturales protegidos a la ciudadanía es básico para que la ciudadanía valore la importancia de su conservación y sea consciente de la necesidad de seguir invirtiendo en su estudio y protección. Con esta premisa nos hemos adentrado en el mundo de las islas Columbretes, un enclave único dentro de la geografía valenciana, para conocerlas más de cerca y establecer las posibles carencias en cuanto a estudios científicos del medio terrestre y de su divulgación.

Estas islas volcánicas forman un archipiélago situado mar adentro, a unas 30 millas náuticas de las costas de Castellón, de tan sólo 19 hectáreas de superficie emergida. Están protegidas por el Gobierno Valenciano desde 1988, y el entorno marino por el Gobierno Central desde 1990, siendo reserva natural y reserva marina, respectivamente. La información generada alrededor de la reserva natural está centralizada en el Centro de Información de las Columbretes, ubicado al Grau (Castellón), desde donde se llevan a cabo también las tareas de educación y divulgación medioambiental. Una peculiaridad de este espacio es que todos los visitantes de la Illa Grossa deben desembarcar acompañados del personal de la reserva en una visita guiada por el camino que une el puerto Tofiño con el faro, donde hay un centro de visitantes.

Cuando se empezó esta búsqueda, el año 2013, observamos que desde el establecimiento del archipiélago como espacio natural protegido, el número de personas atendidas en la Illa Gorda se mantenía dentro un mismo rango desde 1997 que oscilaba entre 2.416 y 3.731 visitantes; no obstante, el número de visitantes atendidos en el Centro de Información había menguado desde más de 15.000 en 2004, hasta poco menos de 3600 , cuando, observando los gráficos de evolución, podríamos considerar que el rango anual deseable se podría fijar entre las 12.500 y las 15.500. Para mantener el número de visitantes dentro los rangos propuestos se tendría que potenciar las actividades ofrecidas desde el Centro de Información, ofrecer actividades nuevas y dar a conocer nuevos datos sobre las Islas, fundamentales para tratar de impulsar de nuevo el interés de las personas que ya las conocen; y por supuesto, no desatender la calidad de las visitas guiadas en la Illa Grossa, gestionando desde la misma Reserva y teniendo en cuenta sus peculiaridades, tanto la cantidad como la calidad de los trabajadores, que son el nexo de las Columbretes con los visitantes.

Para contribuir a la actualización de la información disponible sobre la historia natural y la historia humana de las islas Columbretes elegimos temáticas de las que se tuviese menos información. La mayoría de los estudios científicos publicados sobre la parte emergida eran sobre aves y reptiles, además, la información del clima que se daba en estos estudios se había publicado en 1987. Finalmente, decidimos la realización del estudio de la climatología de las Columbretes, estudiar los invertebrados de la parte emergida de las islas y la recopilación y documentación de 'información sobre la huella humana.

Se recopiló y digitalizó 28.324 nuevos datos de precipitación i temperatura registrados en la estación meteorológica de la Illa Grossa, obtenidos de los diarios mismos de los fareros, y se añadieron los datos registrados por la Agencia Estatal de Meteorología para obtener series más completas. De esta manera concluimos que hoy día el clima es más cálido, de acuerdo con el calentamiento global del Planeta, pero también más lluvioso que hace 60 años, tendencia observada también en estaciones meteorológicas próximas del nordeste de la Península, y que la amplitud térmica ha disminuido en los últimos cien años (las temperaturas máximas absolutas se mantienen mientras suben los valores de las temperaturas mínimas absolutas). Con los nuevas datos obtenemos una nueva clasificación climática: clima termo mediterráneo 
atenuado con una época seca corta según UNESCO-FAO, semiárido cálido (BSh) según Köppen-Geiger y semiárido (BS) según Köppen-Trewartha.

Se ha actualizado la información disponible sobre invertebrados no marinos en las islas mayores de las Columbretes y se ha ampliado mediante las observaciones y capturas llevados a cabo desde 2004, reforzadas con la colocación entre 2008 y 2011 de trampas de gravedad donde cayeron 13.556 invertebrados. Durante la realización de esta tesis se procedió a organizar todo este material y se identificó por parte especialistas en los diferentes grupos. Por otro lado, se realizó una revisión sistemática de los diferentes catálogos existentes y de los invertebrados citados en diferentes estudios para unirlos $y$, con nuestras primeras citas, obtener el primer catálogo de invertebrados terrestres de las islas Columbretes, formado finalmente por 276 especies, 60 de las cuales son primeras citas para el archipiélago o para alguna de las islas.

Para documentar la huella humana en el archipiélago se ha recogido de forma sistemática, tanto la información publicada en varios soportes, como original. Se revisaron los archivos históricos del Puerto de Castellón, el archivo municipal de Castelló de la Plana, la hemeroteca de la Biblioteca Nacional, y se contactó con 52 personas relacionadas con las Columbretes (familiares de fareros, pescadores, investigadores o personal de la reserva) de las que entrevistamos a 38, que nos contaron sus historias, vivencias y anécdotas sucedidas en las Columbretes o nos transmitieron las de terceros que estuvieron. En todas las entrevistas se ha encontrado coincidencia en la descripción de la fuerza de los temporales y las tormentas, la "convivencia" con los escorpiones, la abundancia de pesca, o de pajaritos migratorios en las épocas de paso, las duras condiciones de trabajo que había, y sobretodo el aislamiento. Ahora sabemos quién fue la primera niña que nació a las Columbretes en la época de los fareros, o quien construyó el cementerio, entre otros. Se ha podido hacer una recopilación de los listados dispersos de fareros que ejercieron en las Islas Columbretes y, con material inédito recopilado en esta investigación, elaborar un único listado más completo de fareros de Columbretes. También se tomó la decisión de preparar el documental "Aillats, la memoria de Columbretes", que vio la luz en 2015, aunque la investigación ha continuado hasta 2017.

Toda esta nueva información y datos, incluyendo el documental, constituyen un material que puede ser utilizado en las charlas y conferencias impartidas por los técnicos medioambientales para la divulgación de los valores de las islas Columbretes y también por los guardas en las visitas guiadas que realizan en la reserva natural. Además de que puede servir como base para la elaboración de material de divulgación actualizado, como la guía de flora y fauna que actualmente estamos preparando. 


\begin{abstract}
The dissemination of scientific outputs from natural protected areas to citizens is essential for citizens to value the importance of their conservation and to raise awareness of the need to continue investing in their study and protection. With this premise we have entered the world of the Columbretes Islands, a unique enclave in the Region of Valencia, to increase our knowledge and to detect deficiencies likely to occur in scientific studies of the terrestrial environment and its dissemination.
\end{abstract}

These volcanic islands form an archipelago located offshore, about 30 nautical miles off the coast of Castelló, covering just 19 emerged hectares. They were protected as a natural reserve in 1988 , by the Valencian Government, and the marine environment was protected as a marine reserve in 1990 by the Spanish Government. The information generated around the natural reserve is centralized in the Information Center of the Columbretes, located at El Grau (Castelló), where the staff also carries out educational tasks to enhance environmental awareness among visitors. All visitors to Illa Grossa should disembark accompanied by the staff of the reserve on a guided tour along the road that connects port Tofiño with the lighthouse, where the visitor center is located. This is a must of this reserve.

When this research began, in 2013, we observed that since the establishment of the archipelago as a protected natural area, the number of people visiting Illa Grossa was more or less stable since 1997, ranging from 2,416 to 3,731 visitors per year. However, the number of visitors at the Information Center dropped from more than 15,000 in 2004 to less than 3,600 annually. A desirable annual range could be set at 12,500 and 15,500 , respectively. To maintain the number of visitors within these ranges, it would be necessary to strengthen the activities offered by the Information Center, including new activities and new information about the Islands, which are fundamental requisites to elicit the interest of those who already know them. Additionally, the quality of guided tours in Illa Grossa can not be neglected. They are managed them from the same Reserve, taking into account their peculiarities, both the quantity and the qualification of the staff, who are the link between Columbretes and their visitors.

In order to contribute to the updating of the available information on the natural and human histories of the Columbretes Islands, we chose those subjects where deficiencies had been detected. Most of the published scientific studies on the emerged part of the archipelago centered on birds and reptiles. In addition, the information about the climate available had been published in 1987. Therefore, we decided to study the climatology of the Columbretes, the invertebrates of the emerged part of the islands, and the collection and documentation of the human footprint.

A total of 28,324 new precipitation and temperature records, which were gathered from the original diaries of the Columbretes lighthouse keepers, were added to those from the State Meteorological Agency in order to obtain temporal series as complete as possible. We concluded that the climate is nowadays warmer than 60 years ago, in agreement with the global warming trends of the Planet, but also rainier (a trend observed in nearby meteorological stations of the northeast of the Iberian Peninsula as well). Furthermore, the thermic amplitude of the islands has decreased in the last century (mean maximum temperatures have not changed but minimum values have increased). Based on these estimations, the current climatic classification of Columbretes is Thermo-Mediterranean attenuated with a shorter dry season, Hot Arid Steppe (BSh), and Semi-arid (BS), according to UNESCO-FAO, Köppen-Geiger and Köppen-Trewartha, respectively. 
Information on non-marine invertebrates in the larger Columbretes islands has been updated. The resulting catalogue is larger than when we started because of our observations and catches since 2004. Just between 2008 and 2011, 13,556 invertebrates fell into our pitfall traps. During the execution of this thesis, all this material was organized and identified by specialists on the different taxonomical groups. Moreover, a systematic review of the existing catalogues and invertebrates cited in different studies was carried out. When we joined all this information to obtain the first catalogue of terrestrial invertebrates of the Columbretes Islands, 276 species, 60 of which are first citations for either the archipelago or one of the islands were listed.

To document the human footprint in the archipelago, both the information published in different media, and original information have been systematically collected. The historical archives of the Port of Castellón, the municipal archives of Castelló de la Plana, and the newspaper collection (Hemeroteca) of the National Library were reviewed. Additionally, 52 persons connected to the Columbretes for different reasons (relatives of lighthouse keepers, fishermen, researchers or reserve staff) were identified and 38 of them were finally interviewed. They told us their stories, experiences and anecdotes (or those transmitted by their relatives) which had taken place in the Columbretes,. There was coincidence in the description of the strength of the storms, the "cohabitation" with scorpions, the abundance of fishing and migratory birds when migrations occurred, the hard working conditions, and above all, the isolation. Now we know who was the first person born in the Columbretes in the lighthouse keepers period, or who built the cemetery, among other stories. It has been possible to compile the dispersed lists of lighthouse workers in the Columbretes Islands and, with unpublished material collected in this investigation, to produce a unique more complete list of Columbretes lighthouse keepers. We also decided to prepare the documentary "Aillats, the memory of Columbretes", which came to light in 2015, even if our research continued until 2017.

All this new information, including the documentary, constitute a material that can be used in the by the staff of the natural reserve when delivering a talk or in their guided tours to achieve the goal of raising awareness among citizens on the values of the Columbretes Islands. Last but not least, all this material can serve as the basis for the development of new educational material, as a flora and fauna guide, which we are currently preparing. 
$\begin{array}{lr}\text { INTRODUCCIÓ } & 15\end{array}$

Les Illes Columbretes $\quad 15$

$\begin{array}{ll}\text { Apunts històrics } & 16\end{array}$

Les construccions humanes $\quad 19$

La protecció $\quad 22$

L'equip humà i la Junta de Protecció $\quad 24$

El medi natural $\quad 25$

$\begin{array}{ll}\text { La divulgació } & \mathbf{2 7}\end{array}$

OBJECTIUS

Capítol 1. Medi natural: el clima

Introduction $\quad 37$

Material and Methods $\quad 38$

Results and Discussion $\quad 39$

$\begin{array}{ll}\text { Conclusions } & 60\end{array}$

Capítol 2: Medi natural: catàleg d'invertebrats terrestres 61

Introducción $\quad 63$

Material y Métodos $\quad 65$

Trampas de gravedad $\quad 65$

Avistamientos y colectas $\quad \mathbf{7 0}$

Búsqueda bibliográfica $\quad \mathbf{7 1}$

Resultados y Discusión $\quad 72$

Catálogo $\quad 93$

$\begin{array}{ll}\text { Conclusiones } & 104\end{array}$

Capítol 3: Empremta humana i memòria 105

Introducció $\quad 107$

Material i Mètodes $\quad 111$

Resultats i Discussió $\quad 112$

De la cerca de contactes $\quad \mathbf{1 1 2}$

De la recerca bibliogràfica $i$ en arxius $\quad 117$

Recopilació de la informació $\quad 120$

Història del far $\quad 120$

Naixements/comunions $\quad 121$

Temporals/accidents 122

Fars de descans $\quad 123$

Exercicis de tir $\quad 123$

Naufragis de pescadors $\quad 123$

Altres naufragis $\quad 125$

Morts a l'llla $\quad 126$

Curiositats $\quad 128$

$\begin{array}{ll}\text { Conclusions } & 130\end{array}$

$\begin{array}{ll}\text { EPÍLEG I DISCUSSIÓ } & 132\end{array}$ 
$\begin{array}{ll}\text { REFERÈNCIES } & 136\end{array}$

$\begin{array}{ll}\text { ANNEXOS } & 151\end{array}$

ANNEX 1.1. Data sources of temperature and precipitation for the 153 different stations and time periods available

ANNEX 1.2. UNESCO-FAO bioclimatic classification (UNESCO-FAO, 1963) 157 of the Columbretes Islands

ANNEX 1.3. Köppen-Geiger climate classification (Koteck, 2006) of the 161 Columbretes Islands

ANNEX 1.4. Köppen-Trewartha climate classification (Belda, 2014) of the Columbretes Islands

ANNEX 1.5. Regression lines for each of the parameters in Columbretes (T $165-I$ = temperature; $\mathrm{P}=$ precipitation)

ANNEX 1.6. Comparison of the slopes of the regression lines for the parameters of each station in relation with the Columbretes station $(\mathrm{T}=$ temperature; $\mathrm{P}=$ precipitation)

ANNEX 2.1. Localización (coordenadas UTM, huso 31S) y código de las trampas de gravedad en la Illa Grossa, el Mancolibre, la Ferrera y la Foradada

ANNEX 2.2. Listado de especies de invertebrados registrados y número de referencias previas encontradas de cada una de ellas.

ANNEX 2.3. Catálogo de invertebrados terrestres de las Islas Columbretes, año de primera observación, localización (isla, islote), referencia, y observación en el presente estudio

ANNEX 2.4. Àcars de plantes dels Parcs Naturals de Castelló 195

Introducció 196

Material i Mètodes 197

Àrees objecte de l'estudi $\quad 197$

R.N. Illes Columbretes 198

P.N. Prat de Cabanes-Torreblanca 199

P.N. Serra d'Irta 199

P.N. Desert de les Palmes $\quad 200$

P.N. Serra d'Espadà $\quad 200$

P.N. Penyagolosa 200

P.N. Tinença de Benifassà 201

Metodologia dels mostreigs i extracció i preparació dels 201

àcars

Anàlisi dels resultats $\quad 202$

Resultats i Discussió 202

Abundància de les famílies d'àcars 202 
Material suplementari 1. Placa dorsal, plaques ventrals, espermateca i placa ventroanal dels àcars Typhloseiella isotricha, Kampimodromus aberrans, Euseius finlandicus, Euseius stipulatus, Neoseiulus umbraticus, Graminaseius lituatus, Amblyseius andersoni, Phytoseius plumifer, Proprioseiopsis bordjelaini, Typhlodromus phialatus, T. pyri, Typhlodromus (Anthoseius) athenas, T. (A.) foenilis, T. (A.) rhenanoides, Typhloseiulus carmon i Neoseiulella litoralis

Material suplementari 2. Nombre d'individus de cadascuna de les espècies d'àcars trobades i planta hoste en cadascun dels espais naturals protegits de la província de Castelló

ANNEX 3.1. Les làpides del cementeri de Columbretes: imatges i textos conforme a la posició a la corresponent làpida

ANNEX 3.2. Llistat de la informació bàsica a obtindre en les entrevistes realitzades als contactes

ANNEX 3.3. Transcripcions, anotacions, extractes o resums de les entrevistes realitzades $\mathrm{i}$ àudios aconseguits:

1. Aurelio Zacarías Naranjo, Faroner: entrevista a la dona, Dolores Guerra Guerrero, 17/06/2011

2. Higinio García Blasco, Faroner: entrevista a les netes, Encarna, Mercé i Vicentica García Gallén, 26/08/2011

3. José Gozalbo, Ajudant de Faroner: entrevista a la dona, María Valero, i el fill, Jose Ma Gozalbo Valero, 21/11/2011

4. José Llorenç Sol, Faroner: entrevista a la filla, Pepita Llorenç Arrufat, 21/11/2011

5. Juan Del Bosque Gutiérrez, Faroner: entrevista a la dona, Manuela Arribas, 13/12/2011

6. Família Gandolfo, Faroners: entrevista al descendent, Javier Zea Gandolfo, 20/01/12

7. Antonio Martínez Monto, Faroner: entrevista a la filla, Pilar Martínez, 23/01/2012

8. Juan Gellida Masip, Patró del vaixell d'abastiment: entrevista a la dona, Ma-Teresa Lluch, 31/01/2012

9. Tomás Mancisidor Arias-Valdés, Faroner: entrevista a la dona, Carmen Barreña, 30/04/2012

10. Màxim Fallada Solé, Pescador esportiu, 18/06/2012

11. Ramón Roig Monteagut, Faroner: entrevista al fill, Ramón Roig Sospedra, 05/11/2012

12. Antoni Cerdà Simonet, "Fogassa", familiar de pescadors mallorquins, 09/01/2013

13. José Hierro Delgado, Faroner: entrevista a Luisa Gutiérrez Hierro, neboda de María Hierro Viera, filla del faroner, realitzada i facilitada pel nebot/net de María, Gerardo Morales Gutiérrez

14. Francesc Grimalt Alou, Faroner: entrevista a la neta, 
Margarita Grimalt (realitzada en 1984 per Marc Ordeix), a la besneta, Mercé Rigó, i al net, Francesc Grimalt, 28/08/2014

15. Xisco Pérez, Pescador de l'Alcúdia, Mallorca, 28/08/2014

16. Francisco del Río de la Barrera, Faroner: entrevista als besnets, Alicia Fernández del Río i Gustavo Chao, 03/11/2014

ANNEX 3.4. Informació obtinguda als arxius del Port de Castelló sobre faroners de Columbretes

ANNEX 3.5. Alguns poemes inspirats en les Illes Columbretes

1. Versos del faroner Francisco Grimalt Alou, 1894

2. “El Torrero: Poema", Julio Fernández-Puente Varo, 1903

3. "A la Virgen de las Islas Columbretes", Carmen Gómez López, 1954

4. "Al peu del far de les Illes Columbretes", Josep Porcar, 2007

301

5. "Les Columbretes", Xavier Gimeno Alonso, 2009

302

6. Prosa a la "Mae de Deu Cagaeta", Joan Castany, 1991

ANNEX 3.6. Faroners que van exercir a les Illes Columbretes, any 305 d'entrada i de cessament i categoria professional 


\section{INTRODUCCIÓ}

\section{Les Illes Columbretes}

Al nord-oest de la mar Mediterrània, davant de les costes de Castelló, Espanya, se situen les Illes Columbretes, a 28 milles nàutiques $(57 \mathrm{Km})$ del cap d'Orpesa i sobre un fons marí que no arriba als $100 \mathrm{~m}$ de profunditat (Alonso, 1991). Aquest arxipèlag, de 19 ha de superfície emergida, està format per quatre grups de xicotetes illes volcàniques (unes 30 en total, entre illots i esculls) les quals són la part visible des de l'exterior de l'aigua d'un sistema volcànic la superfície del qual és extensa, $40 \times 90 \mathrm{Km}$ (Maillard \& Mauffret, 1993).

Segons va publicar el capità de la Marina Anglesa Smyth (1831) al seu article On the Columbretes, Volcanic Rocks near the coast of Valencia, Spain, al segle XIX l'arxipèlag ja es coneixia de manera generalitzada entre els navegants de la Mediterrània pel nom de Columbretes. L'origen d'aquesta denominació s'ha relacionat amb la presència de serps a l'Illa Grossa (Escolano, 1610; Smyth, 1831; Habsburg-Lorena, 1895; Del Hoyo et al., 1992). No obstant això, també s'ha relacionat amb el verb "colombrar" definit al Diccionari catalàvalencià-balear com "veure confusament per la distància o per l'escassesa de claror", i que equivaldria al castellà vislumbrar, divisar, columbrar (Alcover, 1962). D’altra banda, totes les illes i illots que formen l'arxipèlag es coneixen amb el nom tradicional valencià i alguns, a més, amb els noms que els va donar el capità Smyth, (1831), que corresponen a cognoms d'oficials espanyols de la Marina (Figura 1). Cadascun dels quatre grups d'illes que conformen l'arxipèlag es coneix amb el nom de l'illa més gran (Smyth, 1831; Servicio Geográfico del Ejército, 1986). Com que la diferència entre els mots illa i illot és subjectiva, en aquest treball anomenarem illa a la principal de cada grup, i illot a la resta. Aquests quatre grups són els següents:

- Grup de l'Illa Grossa (Figura 2): format per l'Illa Grossa (coneguda també com l'Illa, la Grossa o la Ferradura per la forma d'arc d'uns $1.250 \mathrm{~m}$ de longitud i que arriba als 67,48 m d'alçada al seu extrem nord, el punt més alt de l'arxipèlag), i els illots Mascarat, Senyoreta i Mancolibre, que es prolonguen a l'extrem sud, tots amb abruptes penya-segats (Andrés, 1991). A la badia, prop de la part sud de l'llla Grossa, es troba el baix Trencatimons, una zona rocallosa situada a poca profunditat, de manera que dificulta la navegació. El cim de I'Illa Grossa va ser conegut com a Môcolebira. Al s.XVI amb aquest nom es coneixia tot l'arxipèlag, nom que va derivar en "Monte Colibre" o "Columbrina" (Alonso, 1994).

- Grup de la Ferrera (Figura 3), format per la Ferrera (coneguda també com a Malaespina, amb poc més de $43 \mathrm{~m}$ d’alçada) i tres illots principals, Ferrereta (o Bauzà), Valdés, i Navarrete. 
- Grup de la Foradada (Figura 4), format per la Foradada (que també rep el nom de Horadada o Ferrer, amb una alçada de poc més de $55 \mathrm{~m}$ ) i tres illots, Foradadeta (o Lobo) i Méndez Núñez i, cap al nord, un poc més separat es troba Piedra Joaquín.

- Grup del Carallot (Figura 5) format pel Carallot (que rep també els noms de Bergantín o Galiano, amb 32 m d'alçada), i els illots Cerquero, Churruca, i Baleato i l'escull al qual Smyth, 1831, va anomenar Luyando.

El grup de l'Illa Grossa, situat més al nord, és el més gran, amb 14 ha de superfície emergida, que es va formar durant quatre episodis volcànics que van succeir fa entre 300.000 i 1 milió d'anys (Aparicio et al., 1991). És l'únic grup en què es pot identificar encara les restes de l'edifici volcànic (Muñoz et al., 2005) amb la forma d'una ferradura que alberga la badia de Port Tofiño, refugi de navegants. En els altres tres grups d'illots, les estructures volcàniques originals pràcticament no es reconeixen a causa de l'erosió marina que han patit (Muñoz et al., 2005) amb penya-segats que les fan quasi inaccessibles. Les seues edats encara han de ser determinades, però la seua morfologia suggereix que poden datar de la mateixa època que I'Illa Grossa (Aparicio et al., 1994).

\section{Apunts històrics}

Fins al segle XIX, les Columbretes van ser visitades per pescadors, contrabandistes i pirates, però la seua colonització no es va produir fins a mitjan d'aquell segle, amb la construcció del far de I'Illa Grossa (Figures 6 i 7). L’any 1856, en el punt més elevat de I'Illa, van començar les obres del far sota la direcció de l'enginyer Mullats. El far, catalogat com de primer ordre, es va inaugurar el 30 de juny de 1860 (Serrano, 1987) tot i que la data d'encesa va ser desembre de 1859, dins el Plan General de Alumbrado Marítimo de las Costas y Puertos de España e Islas Adyacentes de 1847 (Sánchez-Beitia, 2017). A partir d'aquell moment els faroners i les seues famílies van habitar I'llla de manera pràcticament ininterrompuda, a excepció d'alguns breus períodes marcats per la Guerra Civil (1936-39), durant 116 anys, fins 1975, quan es va automatitzar el far. Aquestes famílies mantenien contacte amb terra a través de precàries emissores de ràdio $\mathrm{i}$ gràcies al vaixell que abastia els illencs amb queviures i notícies amb una periodicitat regular si l'estat de la mar ho permetia. 


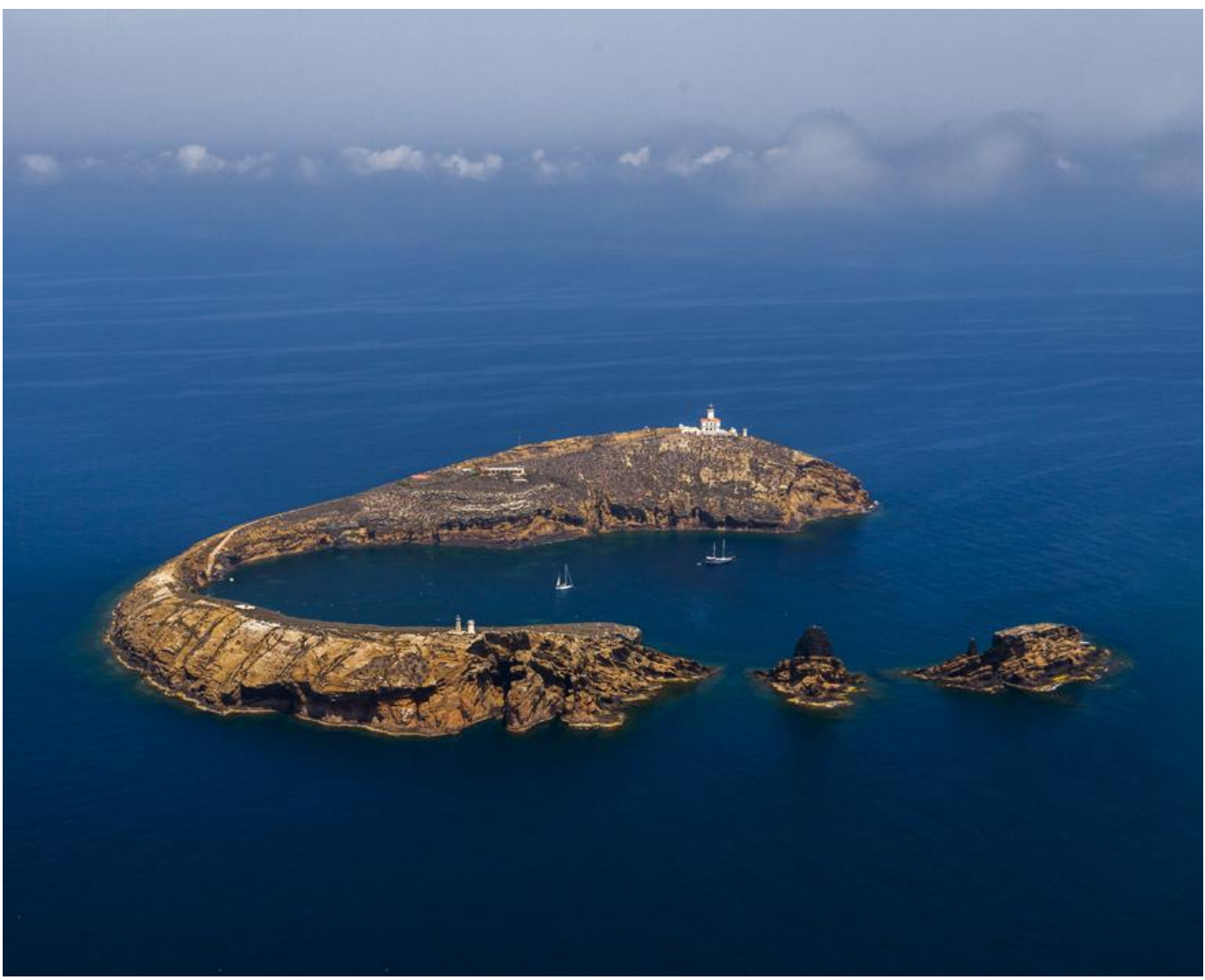

Figura 2. Grup de l'Illa Grossa, amb els illots Mascarat, Senyoreta i Mancolibre (d'esquerra a dreta).

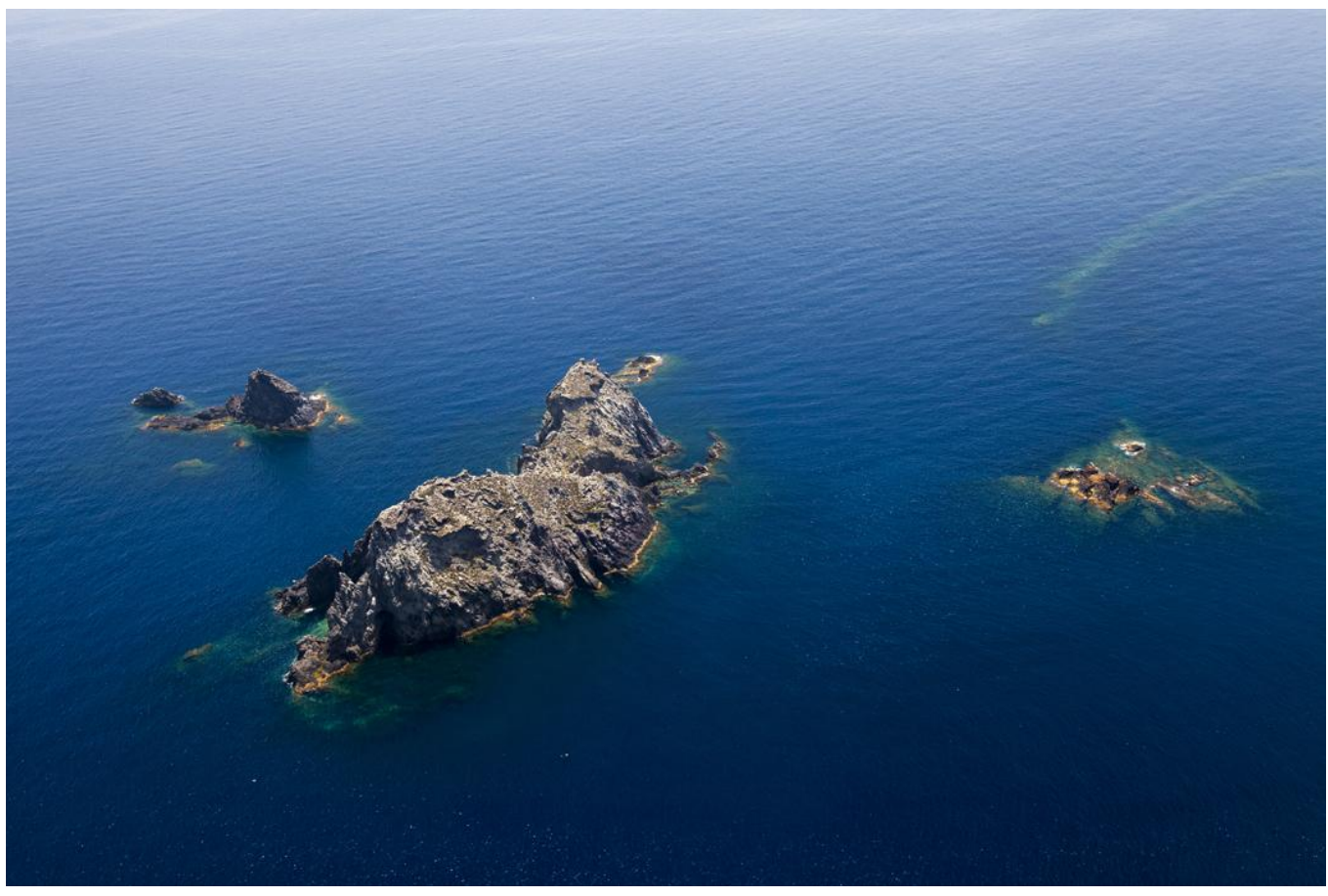

Figura 3. Grup de la Ferrera, amb els illots Ferrereta, Valdés i Navarrete (d'esquerra a dreta). 


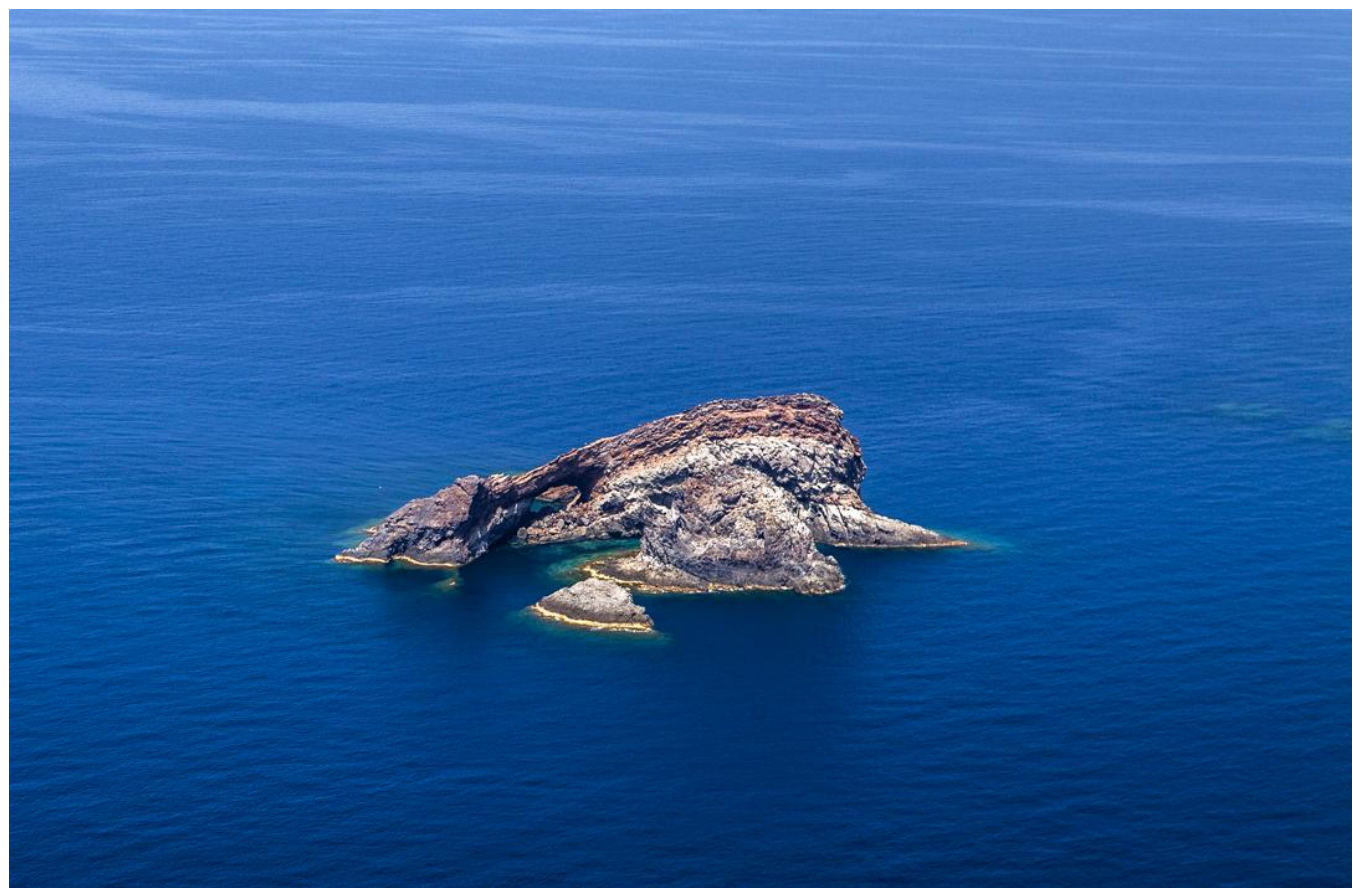

Figura 4. Grup de la Foradada, amb els illots Méndez Núñez i Lobo, situats davant la Foradada (d'esquerra a dreta).

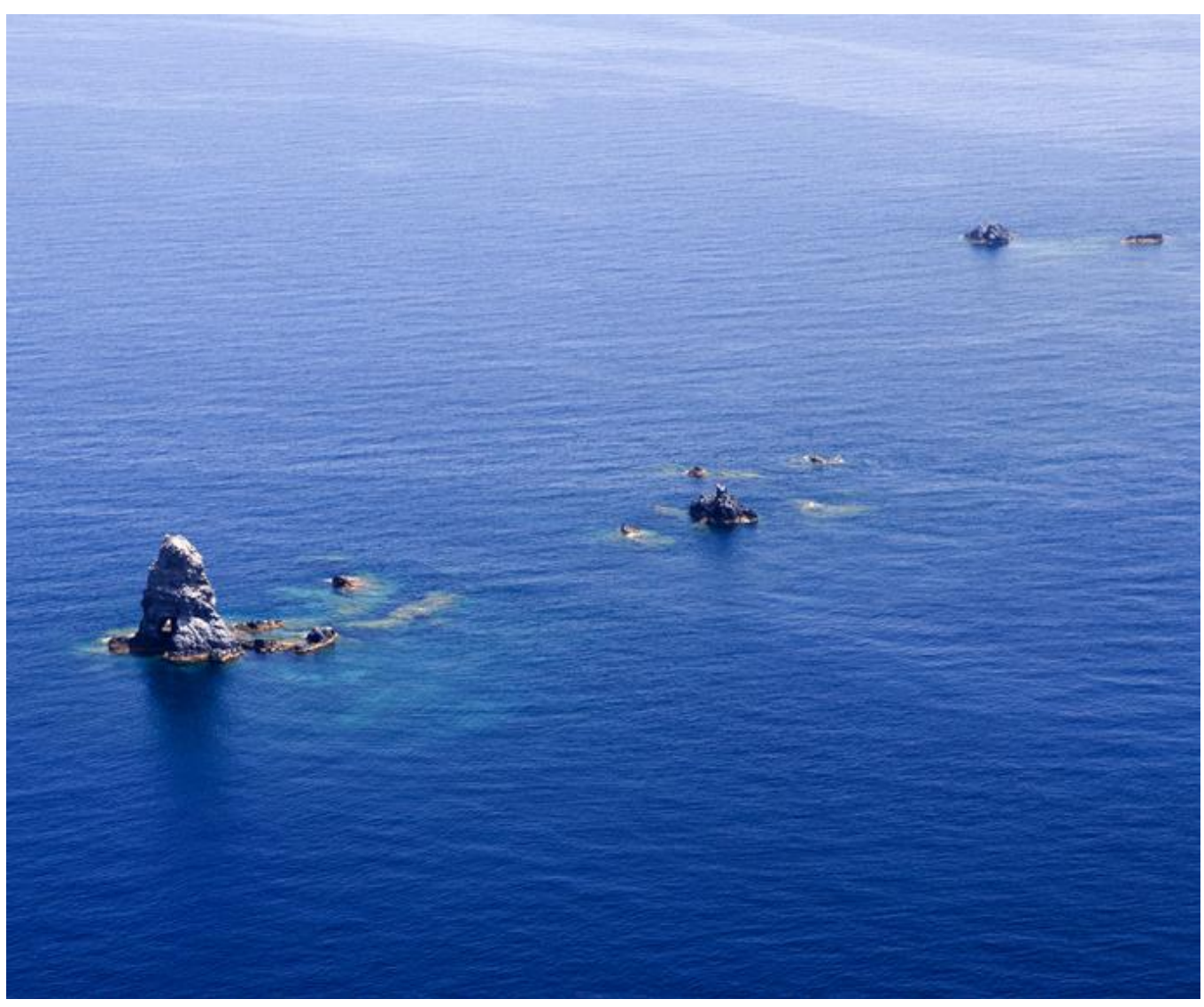

Figura 5. Grup del Carallot, format pels illots Carallot, Cerquero, Churruca i Baleato (d'esquerra a dreta). 
Els faroners eren funcionaris de l'Estat que pertanyien al "Cuerpo de Torreros de Faros", col·lectiu que en 1939 va passar a anomenar-se "Cuerpo de Técnicos Mecánicos de Señales Marítimas". L’any 1992 aquest cos va ser liquidat i la gestió dels senyals marítims va passar a un nou ens anomenat "Puertos del Estado" i exercida per personal contractat per les diverses autoritats portuàries (en l'actualitat als faroners se'ls denomina oficialment "Técnicos de Sistemas de Ayudas a la Navegación"). Les dones no van poder accedir al cos en igualtat de condicions que els homes fins l'any 1969. El treball dels faroners era principalment mantindre el far en bon estat, molt especialment el sistema d'enllumenat, que havia d'estar sempre encès a unes hores determinades. Aquest far ha sigut fonamental per a la seguretat de la navegació en la zona, ja que està situat entre les illes Balears i les costes de Castelló i València, amb la qual cosa sempre ha enregistrat un gran trànsit de vaixells (Moré, 2010). Des que el far es va automatitzar, les Illes van quedar deshabitades fins a la instal-lació dels primers servicis de vigilància establits per la Generalitat Valenciana en 1987.

Les illes Columbretes, que fins mitjan segle XX havien sigut terra nullius, van ser finalment incorporades al terme municipal de Castelló de la Plana el dia 28 d'octubre de 1955 per Decret del Ministeri de la Governació. Pareix que el fet que un bebè haguera nascut a les llles i fóra empadronat en aquesta ciutat (com es recull al capítol 3 d'aquesta tesi), va decantar la balança cap a aquesta ciutat, tot i que altres de més grans, com Palma de Mallorca o València, també ho havien demanat.

\section{Les construccions humanes}

A I'llla Grossa es troben les úniques construccions humanes de tot l'arxipèlag. Destaca el far, a l'extrem nord, la titularitat del qual és de "Puertos del Estado" (Ministeri de Foment, Govern d'Espanya), que ha estat catalogat com a far d'interès patrimonial (Sánchez-Beitia, 2017) i que avui en dia funciona amb energia solar. El far consta d'un edifici principal de dues altures -la segona planta va ser construïda l'any 1926 (Serrano, 1991)- i és de planta quadrada de 22×22 $\mathrm{m}$, previst en un inici per al servici de tres faroners, però que va acabar acollint fins a quatre famílies de faroners, i una torre de $21 \mathrm{~m}$ d'alçada sobre la cota del solar i uns $80 \mathrm{~m}$ sobre el nivell de la mar. Al punt més alt hi ha un vèrtex geodèsic que ho indica: $67,48 \mathrm{~m}$ sobre el nivell de la mar, prop del qual trobem el far i el seu aljub. Entre el far i la zona central es troba un altre aljub amb una caseta d'arreus i les casernes, antiga casa que va servir d'habitació als obrers que van construir el far (Serrano, 1987), i que hui en dia és el centre de treball i residència del personal de l’Administració Pública que treballa a l'arxipèlag. 


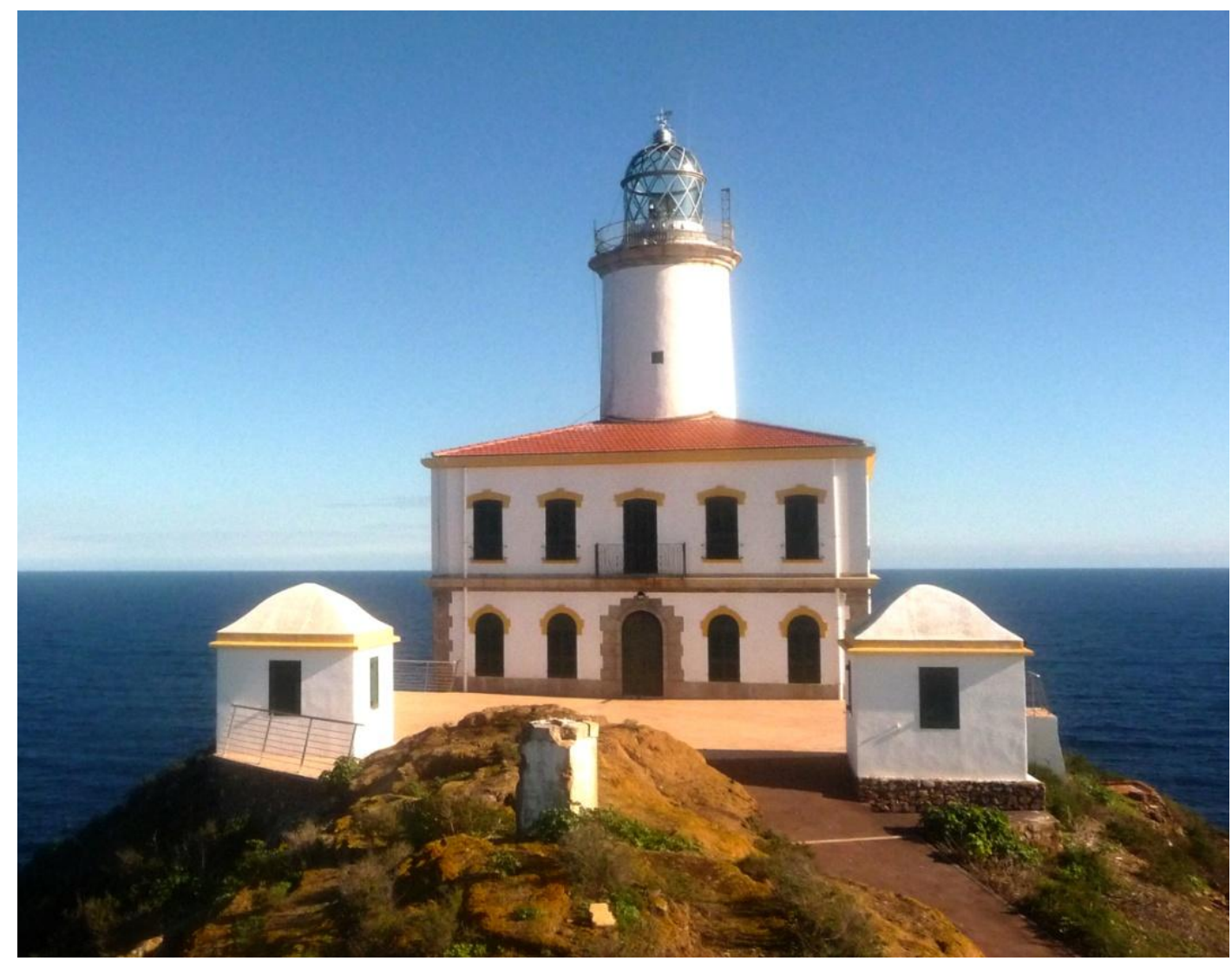

Figura 6. Far de l'Illa Grossa, l’any 2012, després de l'última restauració.

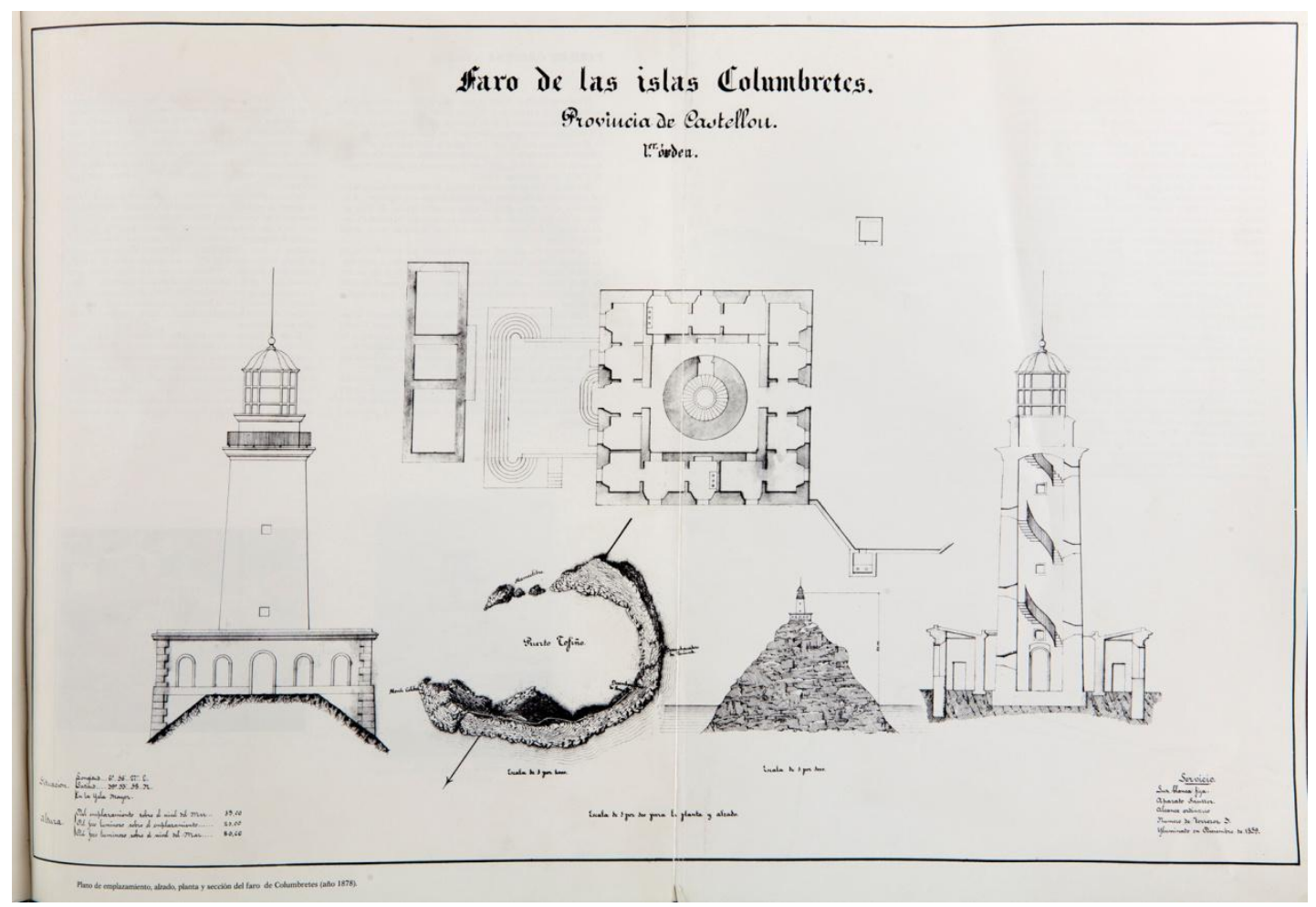

Figura 7. Plànols del far de l'Illa Grossa, 1878. L'any 1926 es va construir una segona planta per ampliar la vivenda. Font: arxiu C.I. Columbretes 


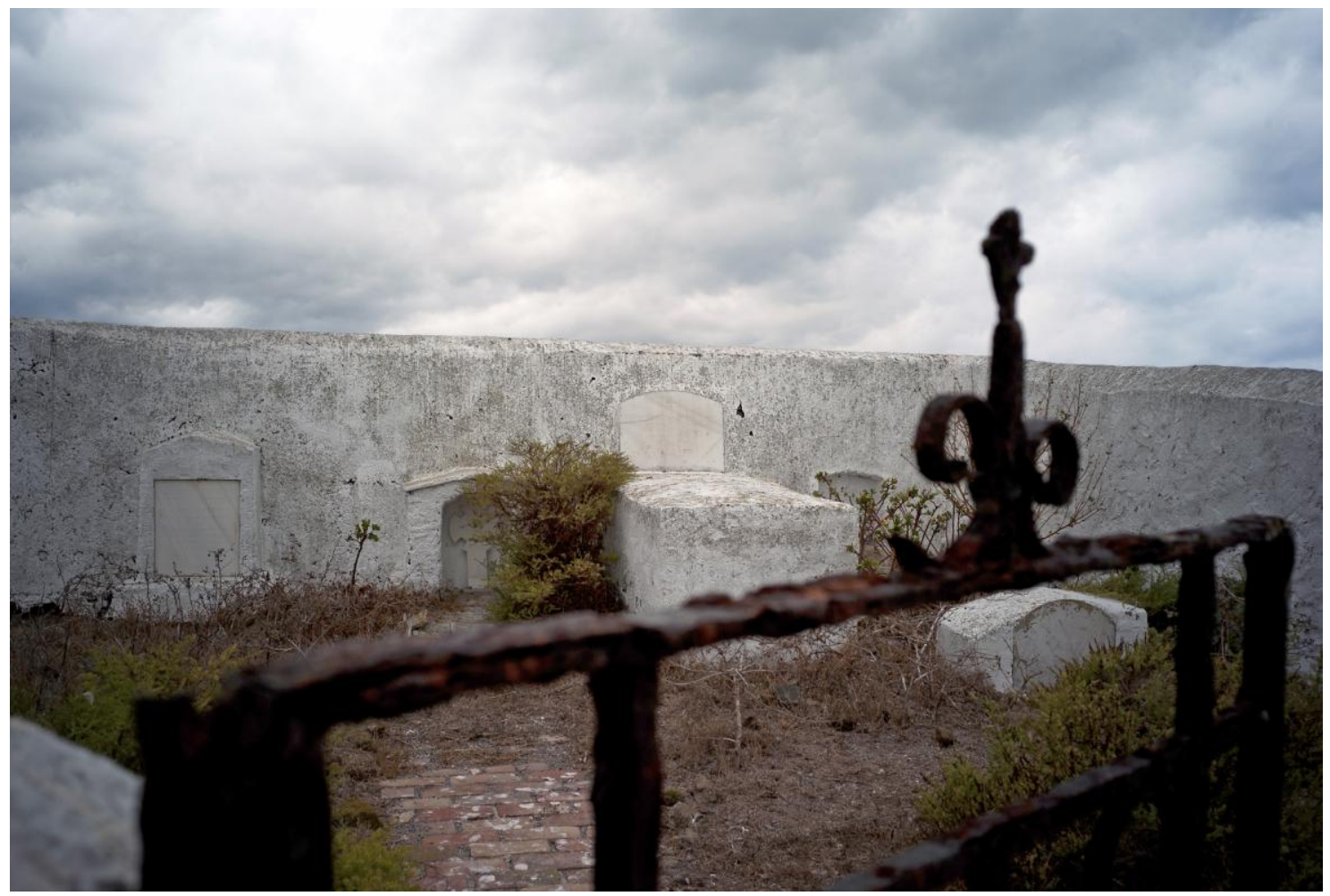

Figura 8. Cementeri de l'Illa Grossa, construït pels faroners Francisco del Río i Simón Miranda l'any 1862 per soterrar els dos fills de Francisco, que van morir de xarampió; i restaurat pels guardes a principi dels anys 90 .

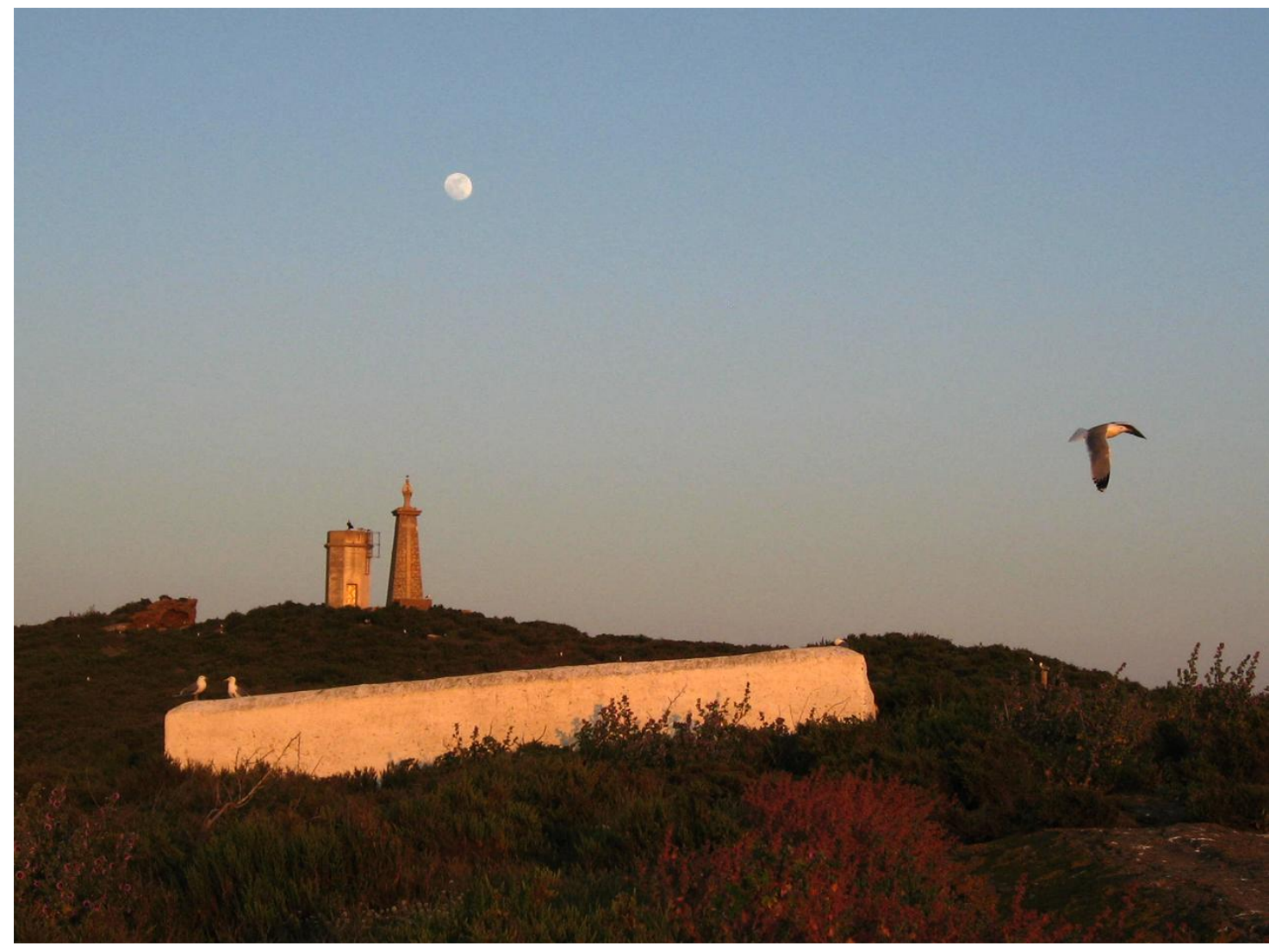

Figura 9. Cementeri de Columbretes, baix la lluna plena, durant la posta de sol. Al fons, Mare de Deu del Carme, col-locada en 1954, i torre/balisa. 
A l'altre extrem de la ferradura, a la zona sud de l'illa, es troba l'antic cementeri dels faroners (Figura 8) i dos aljubs actualment en desús. En aquest extrem es troba una estàtua erigida en els anys cinquanta del segle passat, que representa la Mare de Déu del Carme, patrona dels mariners, sobre un pedestal que mostra una creu de grans dimensions en un dels seus costats (Figura 9). Molt prop, hi ha una altra torre amb un llum roig al capdamunt que parpelleja quan es fa fosc. Una torre de les mateixes característiques però amb el llum de color verd es troba a l'altre extrem de l'Illa, al costat del gran aljub del far. A més, hi ha restes d'altres construccions entre la vegetació, segurament antics corrals.

Tallats a la roca de l'Illa Grossa i prop de la mar, es poden observar nombroses escales i camins, antics accessos de pescadors i navegants, però el que més crida l'atenció és el gran nombre de bol.lards de ferro, norais en l'argot mariner, amarraments que permetien fixar les embarcacions a la terra ferma.

\section{La protecció}

Les condicions d'aïllament geogràfic de l'arxipèlag i l'absència de poblacions humanes estables van influir en la preservació de l'ecosistema insular de les Columbretes, el qual hauria evolucionat durant milers d'anys de manera aïllada d'influències externes. Però a mitjan del segle XIX, quan comencen a habitar les illes els faroners i les seues famílies, l'Illa Grossa comença a patir agressions com les cremes de vegetació provocades intencionadament abans i durant la construcció del far i els primers anys de colonització, amb l'objectiu primordial d’acabar amb les serps i els escorpins de l'illa (Serrano, 1987), així com la introducció d'animals domèstics; porcs, conills, gallines i cabres, i l'ús dels arbustos existents per a llenya, que van fer que en pocs anys aquest ecosistema insular i per tant, fràgil front a les alteracions, canviara dràsticament. A més, fins a principis dels anys 80 del segle XX, les Columbretes van sofrir els impactes de nombrosos projectils en ser utilitzades com a camp de tir per les forces aèries espanyola i la nord-americana de la base de Saragossa que, tot i que no explotaven, provocaven danys a la flora i la fauna, pel soroll, les caigudes de pedres, i els incendis originats per les espurnes generades durant l'impacte. L'opinió pública a principis dels 80 estava en contra d'aquestes pràctiques militars, com ho prova l'abundància de publicacions en periòdics d'aquella època en contra i sol-licitant la protecció de l'arxipèlag, o la presència a les illes del vaixell de l'organització ecologista Greenpeace recolzant aqueixes protestes (Figura 10). Calia protegir els ecosistemes terrestres i marins per a preservar la gran riquesa i valor ecològic d'aquestes illes. 


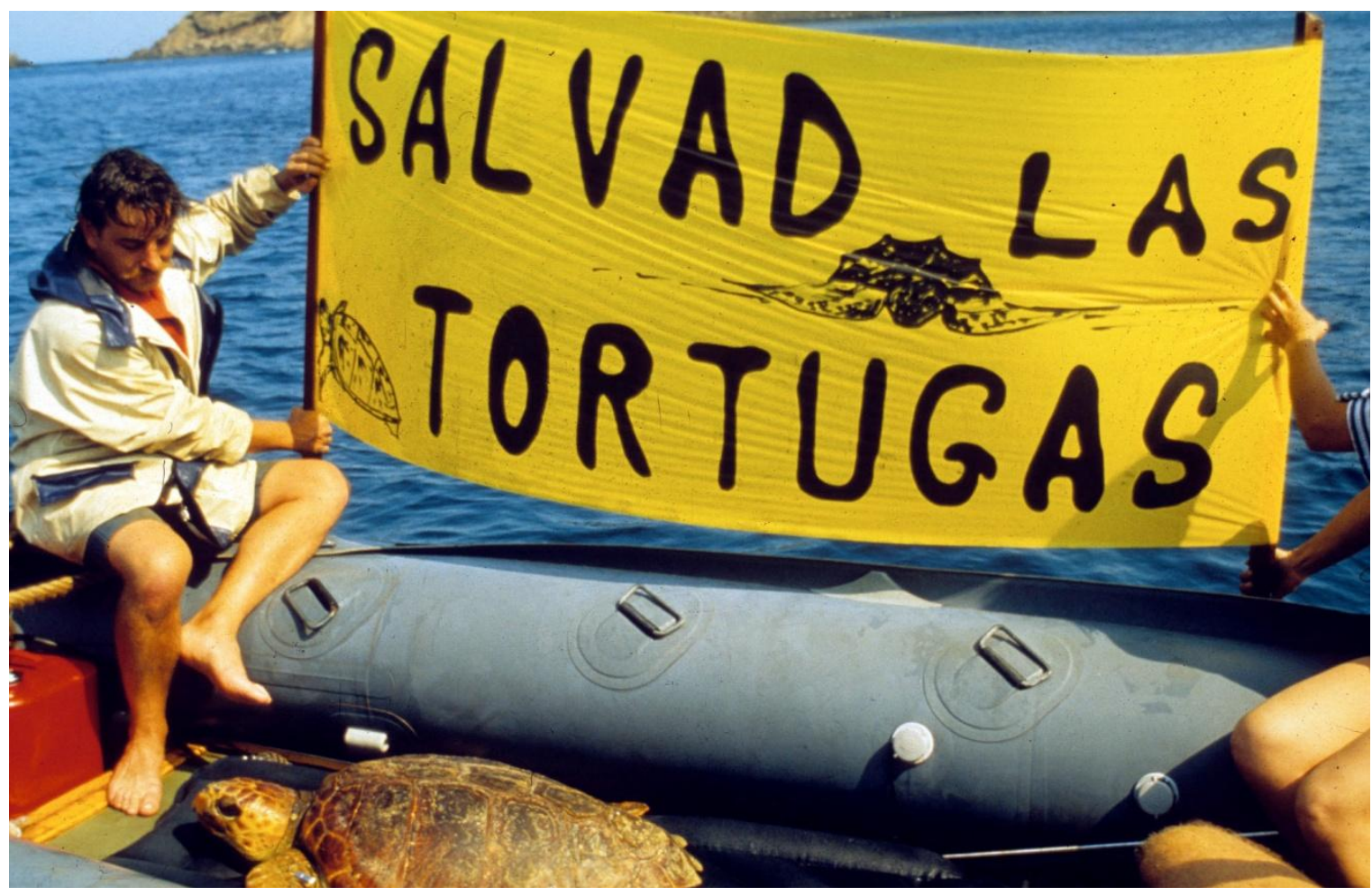

Figura 10. Vaixell de Greenpeace a Port Tofiño, anys 80. Font: Greenpeace.

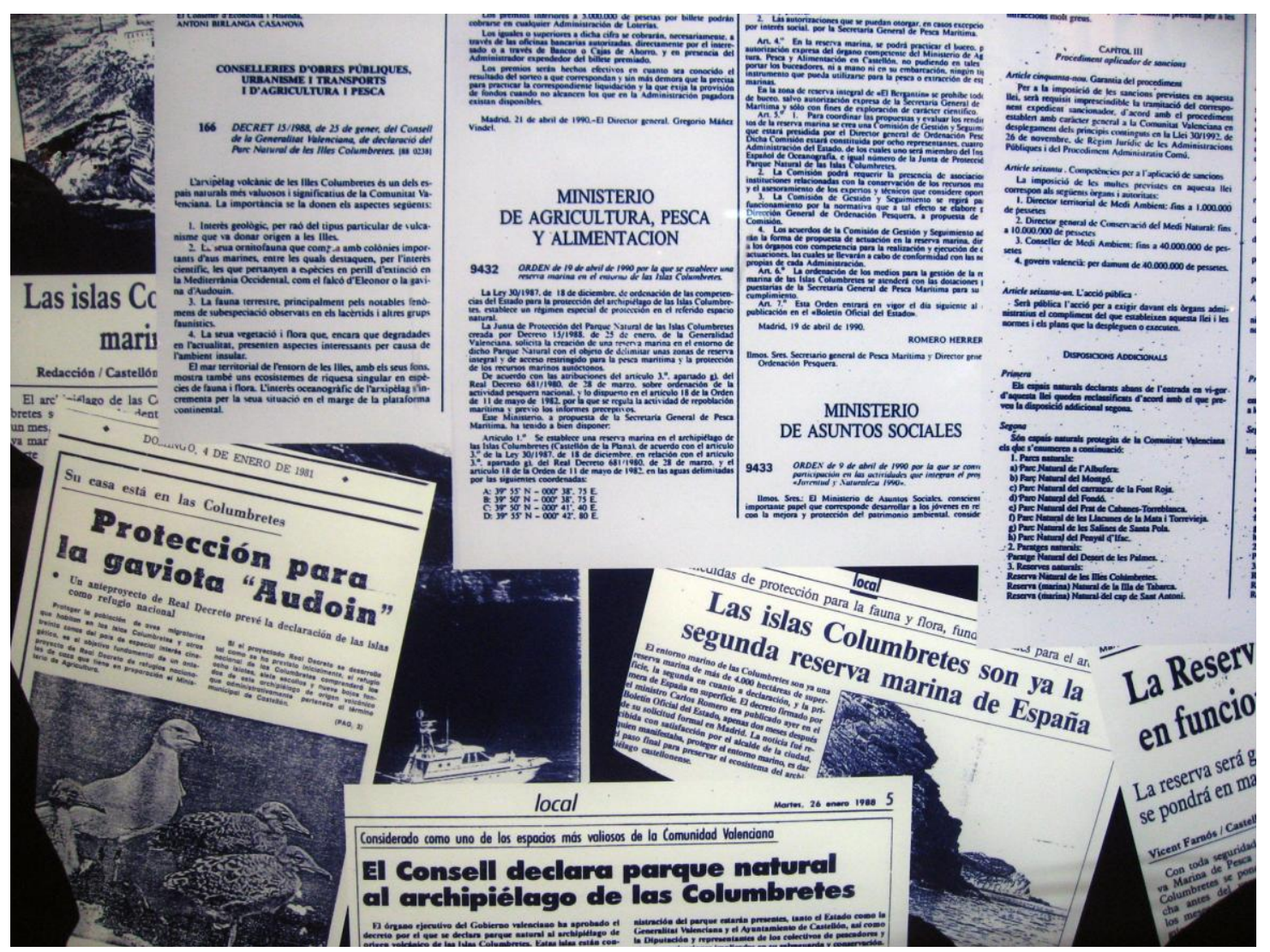

Figura 11. Els diaris anuncien la protecció de les Columbretes, declarades Parc Natural l'any 1988 i reserva marina, dos anys després. L'any 1994 es van re qualificar com a Reserva Natural. Font: arxiu C.I. Columbretes. 
Tot això va portar finalment a la declaració per part de la Generalitat Valenciana, en 1988, de les Illes Columbretes i el seu entorn marí com a Parc Natural (Decret 15/88). Les seues normes es regien per un Pla Especial que va ser aprovat al maig de 1990 i va tindre validesa fins a l'entrada en vigor del Pla Rector d'Ús i Gestió (PRUG) en 1994 (Decret 107/94), que segueix vigent hui en dia sense cap modificació. Aquell mateix any, el Parc Natural va ser re qualificat com a Reserva Natural per la Llei 11/94 d'Espais Naturals Protegits de la Comunitat Valenciana. En 1998, la Conselleria de Medi Ambient, va declarar dues micro-reserves vegetals a les Columbretes: una a la Ferrera i una altra a la Foradada, cadascuna d'un poc més de 1,5 ha de superfície. Anys més tard, en 2006, la Conselleria de Territori i Vivenda va aprovar per resolució un Pla de Prevenció d'Incendis.

D'altra banda, l'any 1990, l'entorn marí va passar a ser declarat Reserva Marina pel Govern Espanyol. Actualment la superfície protegida arriba a les 5.543 ha. En aquell moment, es va firmar un conveni de col·laboració entre l'Administració Central i l'Autonòmica per a la gestió compartida de l'espai marítimo-terrestre de l'arxipèlag de les Illes Columbretes, l'última revisió del qual va ser publicada en 2006 com a resolució de la Direcció General de Recursos Pesquers, amb un acord de pròrroga vigent fins a 2018. Paral-lelament, l'any 2006 es va publicar el conveni de col·laboració entre aquestes administracions i l'Autoritat Portuària de Castelló, en relació a l'ús de l'edifici que conté el far de les illes Columbretes; a partir del qual s'aconsegueix restaurar el far per al seu ús com a centre d'investigació i centre de visitants des del qual s'executen treballs d'educació ambiental.

A més a més, les Columbretes estan protegides per altres figures internacionals com són la Zona d'Especial Protecció i d'Interès del Mediterrani (ZEPIM o SPAMI en anglès) i la Zona d'Especial Protecció per a les Aus (ZEPA o SPA en anglès) en 2001, i el Lloc d'Interès Comunitari (LIC o SCl en anglès) en 2006.

\section{L’equip humà i la Junta de Protecció}

La direcció tècnica i la coordinació del personal així com de la gestió de la Reserva Natural de les Illes Columbretes va a càrrec del Director-Conservador, les funcions del qual apareixen detallades en la Llei 11/1994, d'Espais Naturals Protegits de la Comunitat Valenciana.

A més, el personal adscrit a la Reserva consta de dos equips de dos guardes que realitzen torns quinzenals a les illes durant tot l'any, treballant en conjunt, segons el conveni de col·laboració, amb dos equips de dos guardes de la reserva marina. Fins a l'any 2012, a aquest grup s'hi afegien tres tècnics pertanyents a l'equip de Promoció, Investigació i Treballs Tècnics, I'oficina 
dels quals es trobava al Planetari de Castelló, on se situa el Centre d'Informació de les Illes Columbretes. Actualment aquest equip ha desaparegut i una sola persona s'encarrega dels treballs de guia de la Reserva al Centre d'Informació. Aquest centre ha estat des dels orígens de la protecció de les Illes el lloc de referència en qüestions mediambientals de la Reserva. És el lloc des d' on el personal de la reserva realitza les tasques d'educació i divulgació mediambiental i on s'arxiva tota la documentació relacionada amb les illes, gràfica o escrita, que s'ha anat recopilant al llarg dels anys (escrits, fotografies, dibuixos, gravacions, documentació, memòries anuals, censos de fauna, observacions d'aus, etc.).

Per últim, el fòrum de discussió, col·laboració i assessorament en la gestió de la Reserva és la Junta de Protecció. Té caràcter d'òrgan col-legiat, adscrit a la Conselleria amb competències de Medi Ambient, i, al menys una vegada a l'any, es reuneixen els representants de les diferents administracions públiques implicades, així com la Universitat, la Federació Provincial de Confraries de Pescadors de Castelló, i les associacions de protecció i estudi de la natura, per tal de presentar la memòria de gestió anual, el pressupost i prendre decisions.

\section{El medi natural}

Les formacions volcàniques originals s'han anat modelant al llarg del temps. Els materials volcànics, cendres $\mathrm{i}$ escòries compactades que formen les Columbretes són fàcilment erosionats per l'acció de la mar, el vent i la pluja. A més, els forts pendents acceleren els processos erosius tan bon punt es perd la coberta vegetal.

Segons I'únic estudi climatològic publicat sobre les Columbretes fins ara (Gisbert, 1991), el clima de les Illes es caracteritza per una distribució irregular de pluges, la mitjana anual de les quals és de $265 \mathrm{~mm}$, repartits en 23 dies, i una temperatura mitjana anual de $16,8^{\circ} \mathrm{C}$. Aquestes estimacions, que es basen en les dades disponibles per a la primera meitat del segle XX, podrien haver canviat, entre altres raons per l'impacte de l'escalfament global (IPCC, 2014).

El clima, sens dubte, ha influït en la composició de la fauna i la flora de les Columbretes, però el seu aïllament ha sigut clau en l'aparició de noves espècies i subespècies endèmiques, la distribució mundial de les quals queda restringida a aquestes illes. Així, hi trobem espècies de plantes com Medicago citrina (Font Quer) Greuter, 1986 (alfals arbori de Columbretes), endemisme d'àrea restringida, Lobularia maritima subsp. columbretensis R. Fern., 1992 (caps blancs de Columbretes), subespècie endèmica (Serra, 2000), Podarcis atrata Boscà, 1916 (sargantana de Columbretes), espècie endèmica de l'illa, tot i que hi ha autors que la consideren Podarcis liolepis (Boulenger, 1905) (Roca, 2015; Geniez, 2014) i inclús citen la 
Introducció

subespecie P. liolepis atrata Boscà, 1916 (Carretero, 2016), a més de diverses espècies de coleòpters tenebriònids com Tentyria pazi Español, 1958 o Glabrasida bonacherai Español, 1958, o el caragol Xerocrassa (Xerocrassa) molinae (Hidalgo, 1883) (caragol de Columbretes) (Domingo, 2006).

En l'actualitat no hi ha vegetació arbòria a les Columbretes. A I'llla Grossa, la Ferrera i el Mancolibre hi predomina l'associació vegetal formada majoritàriament per Suaeda vera Forsskal ex J.F. Gmelin subsp. vera i Lavatera mauritanica Durieu, 1847, associació endèmica de Columbretes (Fabregat, 2011). A l'Illa Grossa també hi apareix un herbassar de port baix-mitjà dominat per l'endèmica L. maritima i Euphorbia terracina L., 1762; i a les zones més rocalloses s'hi troba un matollar mitjà-alt de Withania frutescens (L.) Pauquy, 1825 i Lycium intricatum Boiss, 1838 , les quals troben a les Columbretes la seua distribució més septentrional (Fabregat, 2011). També apareixen de manera més localitzada espècies reintroduïdes a finals dels anys 80 i principis dels 90 del s. XX, procedents de la Ferrera, com el Ilentiscle, Pistacia lentiscus L., 1753, i el margalló, Chamaerops humilis L., 1753, i de la Foradada, M. citrina. A la Ferrera s'hi troba un xicotet rodal de matollar escleròfil propi del litoral íbero-llevantí peninsular amb predomini de $P$. lentiscus junt amb $C$. humilis, que potser va cobrir en el passat bones extensions de I'llla Grossa (Fabregat, 2011). Excepte als vessants més costeruts de roca, hi predomina un matollar alt de M. citrina i Lavatera arborea L., 1753 a la resta de superfície de la Ferrera i a la Foradada, associació vegetal endèmica de Columbretes (Fabregat, 2011).

D'altra banda, les Illes tenen gran importància com a lloc de descans per a multitud d'aus migratòries en els seus viatges entre Àfrica i Europa i de nidificació per a espècies protegides com Larus audouinii Payraudeau, 1826 (gavina corsa), Calonectris diomedea Scopoli, 1769 (baldriga cendrosa), Phalacrocorax aristotelis desmarestii Payraudeau, 1826 (corb marí emplomallat) o Falco eleonorae Gené, 1839 (falcó de la reina). A les Columbretes s'hi han identificat 220 espècies d'aus diferents des que el personal que treballa a la reserva arreplega dades d'observacions (Castañer, 2001).

A més, cal no oblidar els ecosistemes marins, ja que les Columbretes presenten nombrosos tipus d'hàbitat molt ben preservats, com els bancs de Cladocora caespitosa Linnaeus, 1767, madrèpora mediterrània (Phyllum Cnidaria, classe Anthozoa, ordre Scleractinia i família Flaviidae), o les praderies de Cymodocea nodosa (Ucria) Ascherson, 1870, nimfa de les aigües marines (Phyllum Tracheophyta, classe Liliopsida, ordre Alismatales i família Cymodoceaceae), fons de maërl, gorgònies (Phyllum Cnidaria, classe Anthozoa i ordre Alcyonacea) (Paramuricea clavata (Risso, 1826), gorgònia vermella (família Paramuriceidae), Eunicella singularis (Esper, 
1791), gorgònia blanca, i Eunicella cavolinii (Koch, 1887), gorgònia groga (les dues de la família Gorgoniidae), esponges, algues brunes del gènere Cystoseira (Phyllum Ochrophyta, classe Phaeophyceae, ordre Fucales i família Cystoseiraceae) o l'alga endèmica del Mediterrani Laminaria rodriguezii Bornet 1888, (Phyllum Ochrophyta, classe Phaeophyceae, ordre Laminariales i família Laminariaceae) entre d'altres (ERENA, 2014; Linares, 2012). Moltes d'aquestes espècies estan incloses en la Directiva Europea d'Hàbitats (Directiva 92/43/CEE), la Convenció de Berna (Instrumento de Ratificación 25961, BOE nㅇ235), la Convenció de Barcelona (Decisió 77/585/CEE), la Llista Roja de la IUCN (IUCN, 2016), i la llista d'espècies d'especial protecció en la legislació espanyola (R.D.53/2011).

Per tant, la flora i la fauna de l'arxipèlag constitueixen un sistema complex en què les seues parts mantenen un fràgil equilibri. Això, a més fa que les illes Columbretes siguen un lloc ideal per a ser utilitzat com un gran laboratori natural on estudiar, per exemple, la influència del canvi climàtic o l'impacte d'espècies invasores.

Per a conèixer l'estat dels ecosistemes naturals és necessari realitzar el catàleg de la seua flora i fauna. Aquests inventaris són vitals en la presa de decisions per a la gestió del patrimoni i per a declarar la protecció dels espais naturals. Una de les més importants causes de protecció d'un espai natural és la fauna que acull, la seua vulnerabilitat i la de l'hàbitat que ocupa. Aquests criteris són, també, utilitzats en la presa de decisions en la gestió forestal i, sobretot, en la gestió dels Espais Naturals Protegits.

\section{La divulgació}

La divulgació de les Columbretes i les activitats d'educació ambiental es porten a terme per part del personal de la Reserva, tant durant les visites guiades a l'Illa Grossa (des de Port Tofiño fins al far, on hi ha el centre de visitants de l'Illa), com a les xarrades al Centre d'Informació (situat al Planetari del Grau de Castelló, on es troba l'exposició "Columbretes i la gent de la mar") o campanyes externes, on guardes i tècnics mediambientals de la reserva tracten de donar a conèixer els valors naturals, mediambientals, humans i històrics de les Columbretes.

A l'arxipèlag s'acosten navegant tant embarcacions privades com vaixells d'empreses contractats. L'àrea d'influència de les Illes compta amb 7 ports esportius i 2.182 amarraments en els 6 municipis pròxims, la qual cosa dóna una idea del volum de l'activitat nàutica al voltant de les Illes (ERENA, 2014), que solen ser visitades per pescadors esportius que solen dirigir-se als baixos de l'oest de l'arxipèlag, fora de la reserva marina, i/o embarcacions de recreació amb turistes. Entre els mesos d'abril i octubre hi ha un servici de visita a les Illes per part 
d'empreses privades en què destaquen dues golondrines, vaixells a motor de fins a 100 places que accedeixen a les Illes amb l'autorització prèvia per part de la Reserva Natural, des de Castelló, Orpesa o Peníscola. A més, hi ha nombroses embarcacions de fins a 12 places que ofereixen el servici de xàrter a les Illes i porten visitants i/o bussejadors en visites que poden estendre's des de les 10:00 fins a les 18:00 h, segons l'època de l'any. Els visitants que volen desembarcar a l'Illa Grossa ho han de fer amb un permís previ i a l'hora establida queden en el port Tofiño amb la persona que els farà de guia i realitzen la visita a l'illa, amb una durada de vora hora i mitja, pel camí que porta fins al far, amb el centre de visitants. És per aquest motiu que a l'Illa sempre hi ha d'haver almenys dos treballadors per a guiar i atendre a les visites.

Existeix un nombre màxim de persones que es poden autoritzar per desembarcar que, des de 2005 era de 24 a 69, en grups de fins a 12 persones, depenent de l'estació, caràcter festiu del dia, o que fóra cap de setmana, i que en 2011 es va ampliar fins a 78 a 120 persones, en grups de fins a 25 . Fora de les hores de visita, els visitants han de quedar-se a l'embarcació, des d' on poden, però, fer altres activitats com capbussar-se per veure els fons marins. Des de l'establiment de l'arxipèlag com a espai natural protegit, el nombre de visitants atesos a l'Illa Grossa ha oscil·lat entre els 2.574 en 2007 i els 3.731 en 2013 (Taula 1).

D'altra banda, al Centre d'Informació els tècnics mediambientals guien visites a l'exposició de les Columbretes i realitzen activitats de divulgació i educació ambiental dins i fora del Planetari (xarrades, taules informatives o altres activitats que es porten a terme tant al centre com a escoles, associacions culturals, etc). A més, des del Centre d'Informació es dona un servici de resposta a les sol-licituds d'informació per telèfon o correu electrònic. El tipus de treball de divulgació, el nombre de tècnics mediambientals i els horaris d'atenció ha anat variant al llarg del temps, passant de ser 2 persones fins a 2008, de 3 fins 2013 i només una persona des d'aquella data. L'evolució de les visites al Centre d'Informació des que es va protegir l'arxipèlag fins a 2013 (Taula 1, Figura 12) va patir una baixada dràstica fins a l'any 1999. Des d'aleshores fins a 2006, les visites es van mantindré un poc per baix dels 10.000 visitants. Des d'aquell moment, han seguit disminuint de forma continuada fins arribar a les 2.281 persones l'any 2012. Als inicis de la protecció, la novetat podria explicar la gran demanda de visites al Centre d'Informació, al Grau, però durant els anys 1999 fins 2004 el nombre de visites es va estabilitzar, al voltant de 5000 les informades, i entre 7500 i 10000 les concertades, per després continuar descendint (Figura 12). Per tant, podem considerar que el rang anual desitjable de visites, o persones ateses, al Centre d'Informació es podria fixar entre les 12.500 i les 15.500 dels anys 1999 fins 2004; i les 2.500 i 3.500 a l'llla Grossa (Taula 1), fomentant tant les noves visites com la repetició entre aquells visitants que ja hi han estat . 
Taula 1. Nombre de persones ateses a l'illa Grossa, al Centre d'Informació (C.I.) i en campanyes externes (xarrades o altres activitats fora del C.I.) des que es va protegir l'arxipèlag. Font: Arxiu C.I. Illes Columbretes.

\begin{tabular}{|c|c|c|c|c|}
\hline Any & $\begin{array}{c}\text { № persones ateses a } \\
\text { I'Illa Grossa }\end{array}$ & $\begin{array}{c}\text { № persones ateses } \\
\text { al C.I.* }\end{array}$ & $\begin{array}{l}\text { № persones ateses en } \\
\text { campanyes externes }\end{array}$ & Total \\
\hline 1988 & 589 & 0 & 0 & 589 \\
\hline 1989 & 752 & 0 & 0 & 752 \\
\hline 1990 & 1.619 & 0 & 0 & 1.619 \\
\hline 1991 & 1.956 & 0 & 0 & 1.956 \\
\hline 1992 & 1.077 & 0 & 0 & 1.077 \\
\hline 1993 & 1.098 & 33.694 & 0 & 34.792 \\
\hline 1994 & 1.751 & 43.236 & 0 & 44.987 \\
\hline 1995 & 1.042 & 32.447 & 0 & 33.489 \\
\hline 1996 & 1.041 & 26.044 & 0 & 27.085 \\
\hline 1997 & 2.615 & 19.982 & 500 & 23.097 \\
\hline 1998 & 3.268 & 13.144 & 240 & 16.652 \\
\hline 1999 & 2.854 & 13.057 & 2.320 & 18.231 \\
\hline 2000 & 2.620 & 15.483 & 3.473 & 21.576 \\
\hline 2001 & 2.992 & 13.764 & 3.160 & 19.916 \\
\hline 2002 & 3.121 & 13.307 & 2.375 & 18.803 \\
\hline 2003 & 3.346 & 12.595 & 2.000 & 17.941 \\
\hline 2004 & 3.477 & 15.492 & 200 & 19.169 \\
\hline 2005 & 2.826 & 10.124 & 200 & 13.150 \\
\hline 2006 & 3.355 & 12.274 & 300 & 15.929 \\
\hline 2007 & 2.574 & 10.071 & 300 & 12.945 \\
\hline 2008 & 2.416 & 8.893 & 1.000 & 12.309 \\
\hline 2009 & 3.104 & 6.962 & 1.440 & 11.506 \\
\hline 2010 & 2.809 & 6.413 & 1.477 & 10.699 \\
\hline 2011 & 3.319 & 6.074 & 949 & 10.342 \\
\hline 2012 & 3.009 & 2.281 & 611 & 5.901 \\
\hline 2013 & 3.731 & 3.589 & 482 & 7.802 \\
\hline Total & 62.361 & 318.926 & 21.027 & 402.314 \\
\hline
\end{tabular}

*Aquestes dades es troben desglossades a la Figura 12. 


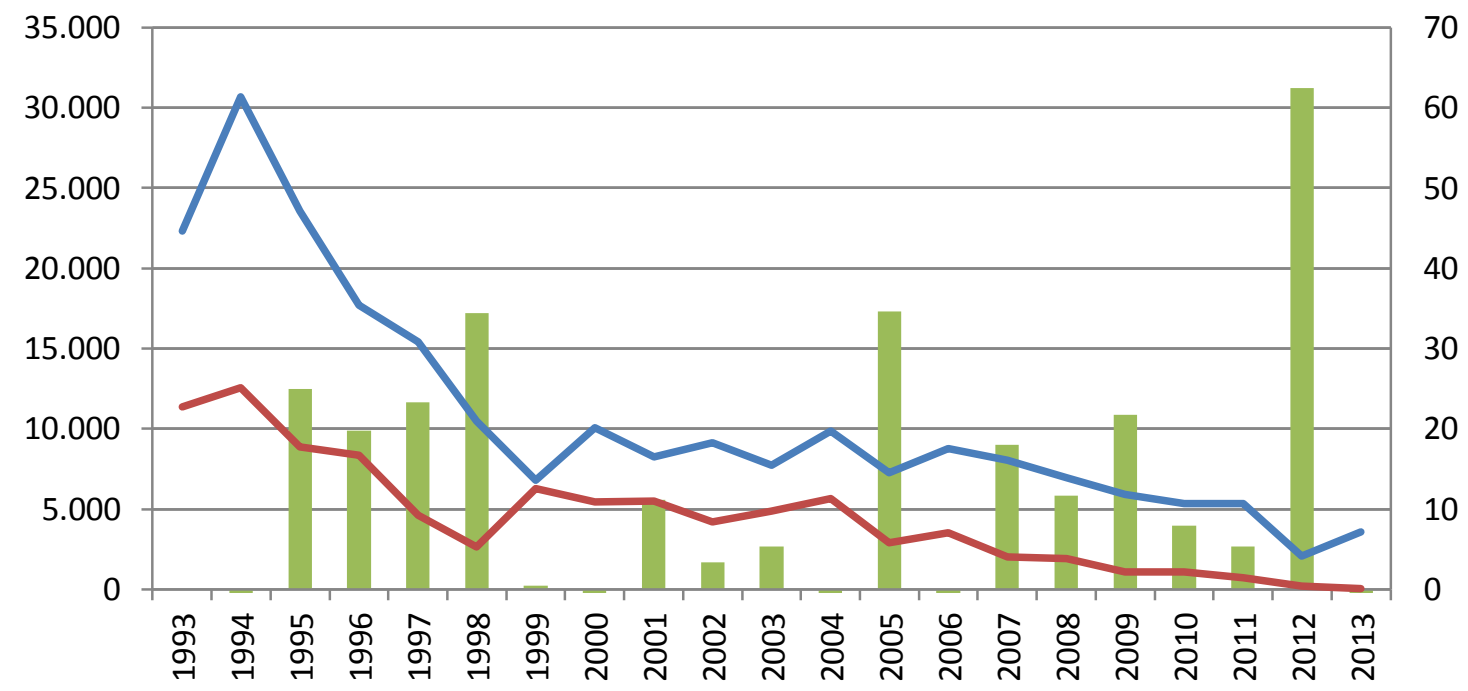

$\%$ descens del $n$ o visitants atesos respecte de l'any anterior

No visites concertades

No visites informades

Figura 12. Nombre de visitants atesos des del Centre d'Informació (C.I.) del Grau de Castelló des de la seua obertura l'any 1993 fins 2013. L'eix vertical esquerre mostra el nombre de vistes (visites concertades: aquelles de centres educatius o associacions que contacten prèviament amb el centre; visites informades: aquelles sense cita prèvia), i el dret mostra el percentatge.

Font: Arxiu C.I. Columbretes.

Per tal de mantindre el nombre de visitants dins els rangs proposats s'hauria de fer un esforç per a potenciar les activitats oferides des del Centre d'Informació, i no desatendre la qualitat de les visites a l'llla Grossa, gestionant des de la mateixa Reserva tant la quantitat com la qualitat dels treballadors per tal que tinguen una formació acadèmica adequada a les seues funcions. Això va lligat a la possibilitat d'oferir noves activitats i donar a conèixer noves dades sobre les Illes, fonamentals per tal d'impulsar de nou l' interès de les persones que ja les coneixen.

És per això que en el treball d'investigació d'aquesta tesi ens vam proposar revisar els estudis realitzats sobre diferents aspectes relacionats amb les Illes per tal d'actualitzar les dades disponibles i identificar possibles mancances que es pogueren cobrir en el temps d'execució de la tesi. Fins l'any 2000 s'havien autoritzat més de 30 estudis a la Reserva i es van generar al voltant de 50 publicacions científiques (Templado et al., 2002), dades que van augmentar fins arribar a 88 i 143, respectivament, fins febrer de 2009, la majoria dels quals sobre aus i rèptils (Mestre-Forés et al., 2009) (Taula 2). 


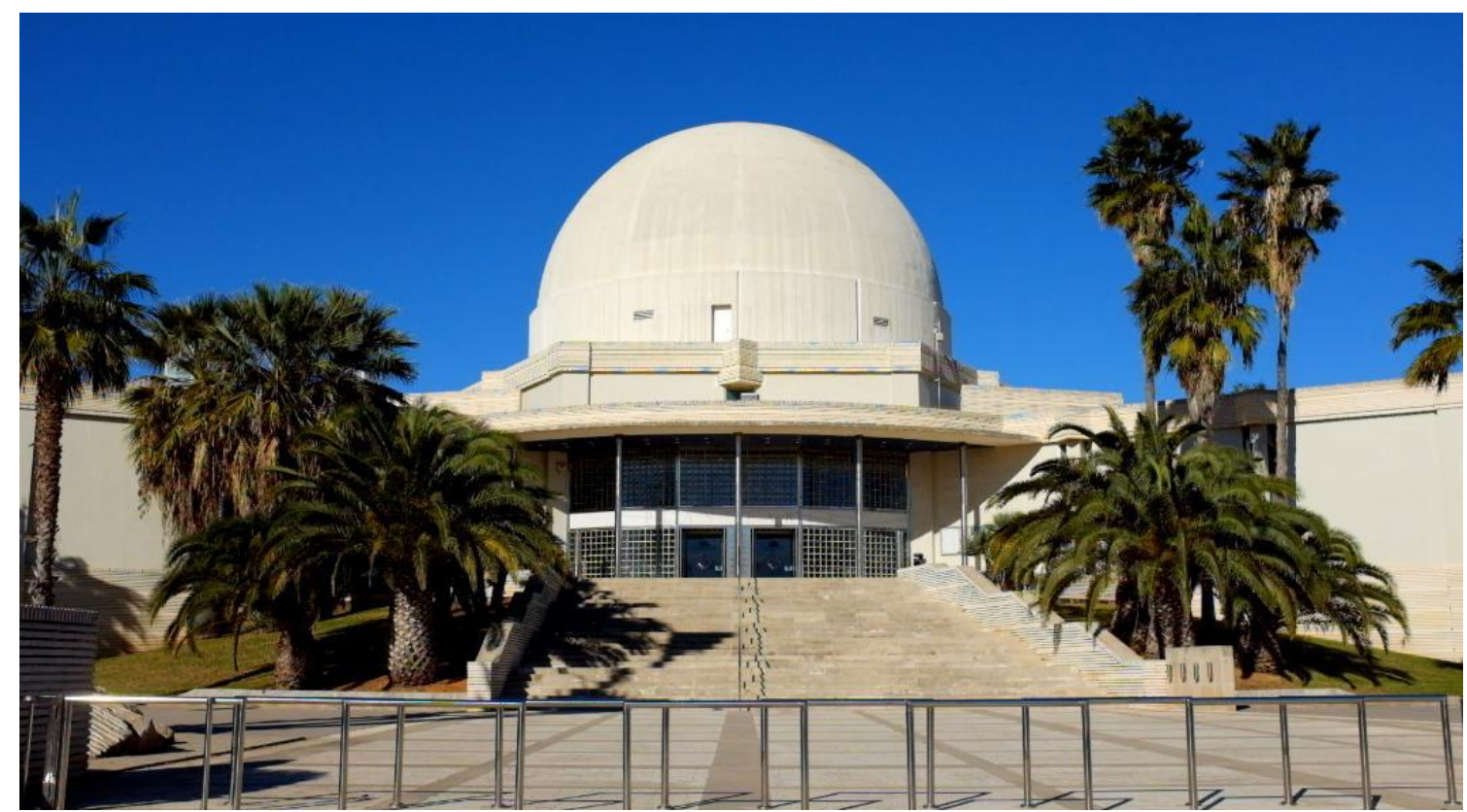

Figura 13. Planetari de Castelló, on s'ubica el Centre d'Informació de les Illes Columbretes

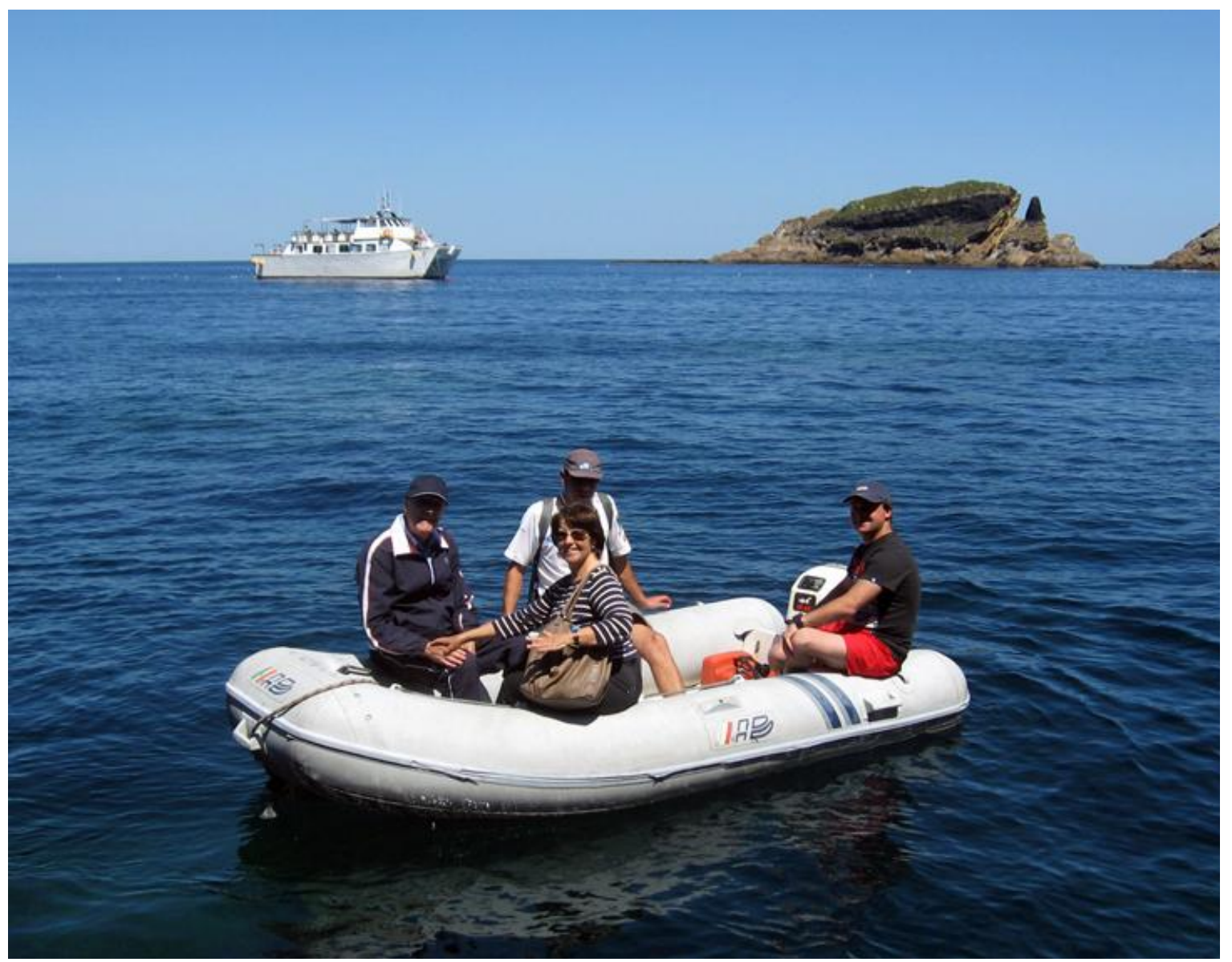

Figura 14. Vaixell tipus "golondrina" que porta visitants a Columbretes. Els visitants s'arrimen a terra per desembarcar amb una embarcació auxiliar. 
Taula 2. Nombre de publicacions científiques relacionades amb les Columbretes portades a terme durant les primeres dues dècades de protecció de l'arxipèlag (1988-2009) ordenades per temàtica.

\begin{tabular}{lcc}
\hline \multirow{2}{*}{ Temàtica } & Nombre de treballs d'investigació entre $\mathbf{1 9 8 8}$ i 2009 \\
\cline { 2 - 3 } & Autoritzats per la reserva natural & Publicats \\
\hline Aus & 38 & 57 \\
Rèptils & 12 & 35 \\
Mamífers & - & 2 \\
Vegetació & 13 & 14 \\
Invertebrats & 12 & 13 \\
Geologia & 4 & 13 \\
Arqueologia - història & 2 & 4 \\
Ecologia - conservació & 7 & 5 \\
\hline Total & $\mathbf{8 8}$ & $\mathbf{1 4 3}$ \\
\hline
\end{tabular}

En el cas dels invertebrats terrestres, no existeix un catàleg complet que reculla tota la informació disponible. Els estudis més complets van ser portats a terme ja fa uns 30 anys, igual que l'estudi sobre la climatologia de les Columbretes, dins d'una Monografia que reunia i actualitzava tota la informació que fins aleshores existia sobre el medi terrestre i marítim de l'arxipèlag, publicada en 1a edició a l'any 1987 (Alonso et al, 1991). La iniciativa de l'elaboració d'aquesta monografia va ser de la Universitat Politècnica de València amb el suport de la Conselleria d’Obres Públiques, Urbanisme i Transports de la Generalitat Valenciana, i va permetre que un nombrós grup d'investigadors, com José Luis Carretero, Francisco Ferragut, Herminio Boira, Fernando García-Marí, Josep Costa-Comelles o Juan M. Gisbert, accediren a les Illes entre 1984 i 1985.

Transmetre la labor científica realitzada en espais naturals protegits a la ciutadania és bàsic perquè la ciutadania valore la importància de la seua conservació i siga conscient de la necessitat de seguir invertint en el seu estudi i protecció. Amb aquesta premissa, l'objectiu final a mitjà termini d'aquesta tesi doctoral és que els resultats obtinguts puguen servir de base per a l'elaboració de material de divulgació actualitzat per a la reserva natural. Així, els nostres objectius han estat els següents: 


\section{Objectiu general:}

Actualitzar la informació disponible sobre la història natural i la història humana de les illes Columbretes i identificar possibles mancances, amb la finalitat que tot això servisca de base per a l'elaboració de material de divulgació (una guia) actualitzat.

\section{Objectius específics:}

1. Caracterització de:

a. la climatologia de les Columbretes, recopilant dades enregistrades per l'Agència Estatal de Meteorologia, així com altres fonts originals (llibres dels faroners, base de dades de la reserva natural), que permeta contrastar els resultats publicats el 1991 (Gisbert, 1991) i comprovar si el canvi climàtic està afectant aquest arxipèlag,

b. els invertebrats terrestres, especialment insectes $\mathrm{i}$ aràcnids, presents a les Columbretes, que permeta actualitzar la informació disponible (García-Marí et al., 1991; Robles, 1991).

2. Recopilació d'informació sobre la història humana de les illes Columbretes, tant publicada en diversos suports, com original (entrevistes, fotografies), per tal de documentar l'empremta humana a l'arxipèlag. 

Capítol 1

Medi natural: El clima 
Capítol 1

Aquest capítol està previst que done origen a la següent publicació: Mestre-Forés, E., M.V. Ibáñez-Gual \& J.A. Jaques. Global Warming impact on the climate of a small Mediterranean island: the Columbretes archipelago. 


\section{Introduction}

The first reference to the climate of the Columbretes Archipelago dates back to 1894, when Archduke Ludwig Salvator von Habsburg-Lothringen included monthly temperature values recorded between September 1891 and August 1894 in his book "Columbretes" (HabsburgLothringen, 1895). These data originally came from the chief engineer Ricardo Bruquetas, an engineer from the Spanish Ministerio de Fomento, who at that time was in charge of lighthouse keepers, including those settled in the main Columbretes island Illa Grossa. Based on these data, the climate at Columbretes was defined as "Tempered. Very similar to the climate of the nearby Valencia".

No further reports appeared until 1991, when Gisbert (1991) published the chapter "Climate and soil of the Columbretes Islands" in a monograph on the Islands natural history published by the Valencian Government. In that chapter, the climate is described as presenting a mean temperature of $16.8^{\circ} \mathrm{C}$ and an irregular distribution of rainfall along the year ( $50 \%$ in autumn), with a mean of $265.19 \mathrm{~mm}$ and 23 rainy days, which, according the UNESCO-FAO classification (UNESCO-FAO, 1963), resulted in a Mesomediterranean climate accentuated with a long dry season. The meteorological data used in that study came from the period 1920-56, including many gaps which resulted in three complete periods (1920-22, 1927-35 and 1941-56) covering 28 years. However, the same author stated in his study that many data were missing and only the final 16-year period (1941-56) could be used for rainfall calculations. This situation adds uncertainty to his conclusions. Furthermore, in the same publication there is another chapter on the vegetation of the Columbretes, where Boira (1991), based on Rivas-Martínez classifications (1982), describes the climate as a semi-arid Thermomediterranean. These results have been repeated in subsequent publications (Domingo et al, 2007; Cartagena \& Galante, 2002; Templado et al, 2002; Bordera, 1998; Laguna \& Jiménez, 1997; Del Hoyo et al, 1992; Robles, 1991; Castilla \& Bawens, 1991) without any further attempt to update these values. Therefore, we decided to gather all available sources of climatic data from the Columbretes Islands, starting with the values given by Habsburg-Lothringen (1895) and finishing with those from the Spanish Meteorology Agency (AEMET). Further, we compared the climate of the archipelago with those from nearby Spanish meteorological stations to check the similarities between them and whether any changing pattern, which could be attributed to climate change (IPCC, 2016) had occurred in that region of the Northwestern Mediterranean Basin). 


\section{Material and Methods}

The data set originally used in this study consists of temperature and precipitation measurements at 5 locations obtained from 12 different climatic stations. The bulk of the data comprises monthly records obtained for these stations from the Spanish Agencia Estatal de Meteorología for the period 1940- 2015 (http://www.aemet.es). In the case of Columbretes, in order to obtain longer time series for our analyses, we combined the data from the only two climatic stations on Illa Grossa, which were active during different time periods, Columbreteslighthouse (ETRS89/UTM zone 30N coordinates: 815144, 4423138; altitude: $63 \mathrm{~m}$ ) and Columbretes-casernes (UTM coordinates: 815041, 4422976; altitude: 36 m). Likewise, we combined Palma Montesion (UTM coordinates: 985851, 4395345; altitude: 19 m), Palmainstitute (UTM coordinates: 985166, 4396325; altitude: $20 \mathrm{~m}$ ), Palma-jefatura (UTM coordinates: 986048, 4395265; altitude: $17 \mathrm{~m}$ ) and Palma de Mallorca-CMT (UTM coordinates: 983435, 4393329; altitude: 3 m), as well as Castelló de la Plana (UTM coordinates: 752725, 4430723; altitude: $25 \mathrm{~m}$ ) and Castelló-Almassora (UTM coordinates: 750113, 4427117; altitude: $43 \mathrm{~m}$ ), and Almería-seismological (UTM coordinates: 548614, 4078438; altitude: 65 m), Almería (UTM coordinates: 548550, 4076276; altitude: 7 m), and Níjar (UTM coordinates: 570692, 4091335; altitude: $356 \mathrm{~m}$ ). Finally, we also processed the data from Alacant (UTM coordinates: 718904, 4250120; altitude: $81 \mathrm{~m}$ ).

In the case of Columbretes, additional data sources were checked: the original diaries of lighthouse keepers deposited at Port of Castelló (daily records from January 1919 to November 1956 for precipitation and to December 1957 for temperature) (Figure 1.1 to 1.4), the original daily climate database from the guardians of the Natural Reserve (daily records from May 2002 to December 2015) (Figure 1.5), as well as the monthly temperature values recorded between September 1891 to August 1894 by Habsburg-Lothringen (1895) (Figures 1.6 and 1.7, Annex 1.1 (Tables 1.1, 1.2 and 1.3). The 125 years extending from 1891 to 2015 resulted in just 57 and 53 complete years for temperature and precipitation, respectively. Because these complete years were not continuous, we identified two continuous subsets extending from 1940 to 1957, and from 1992 to 2015 (see Annex 1.1 / Table 4 for the origin and completeness of the series used in the present study). These data were combined to obtain different monthly values of temperature (absolute maximum and minimum temperatures, mean maximum and minimum temperatures and mean temperatures) and precipitation (number of days of rain, monthly mean accumulated precipitation, maximum precipitation in 24 hours and annual mean accumulated precipitation) comparable to those directly obtained from AEMET for the additional stations. We also calculated seasonal mean temperatures, and seasonal rainfall 
percentages, and identified coldest months, days of snow, hail and frost comparable to those reported by Habsburg-Lothringen (1895) and Gisbert (1991). Seasonal data were calculated considering autumn as extending from September 1 to November 30, winter until the end of February, spring until May 31 and summer for the remaining time period.

In order to investigate long-term changes in the parameters considered, linear regressions of different temperature and rainfall values with time for the whole 125 years were computed. When the slope of these lines were significantly different from zero $(P<0.05)$, we further adjusted new separate lines to the periods 1940-1957 and 1992-2015. To compare the trends observed in Columbretes with those in the four additional locations, different ANCOVA analyses were performed using the software " $R$ " version 3.3.2 (R Core Team, 2016).

Based on the results above, ombrothermic diagrams (UNESCO-FAO, 1963) were produced and the climate of Columbretes was classified according to UNESCO-FAO (the same climate classification used by Gisbert in 1991), Köppen-Geiger, and Köppen-Trewartha climate classification systems (UNESCO-FAO, 1963; Koteck, 2006; and Belda, 2014, respectively).

\section{Results and Discussion}

A total of 963 pages from the original diaries of the Columbretes lighthouse keepers covering the period 1919-1957 were screened and the meteorological data extracted. In total, 19,602 values of daily temperature $(10,164$ values of daily maximum temperature and 9,438 values of daily minimum temperature) and 8,580 of daily precipitation were retrieved from which we calculated the mean daily temperature. We also digitalized the data published by the Archduke (Habsburg-Lothringen, 1895), a total of 142 monthly data of temperature covering the period 1891-1894. Subsequently, monthly values for each of the parameters considered in our study were calculated. These data together with those from the additional sources mentioned above (Annex 1.1 / Table 4) were further processed to obtain data comparable between stations (Tables 1.1 to 1.5 ). 

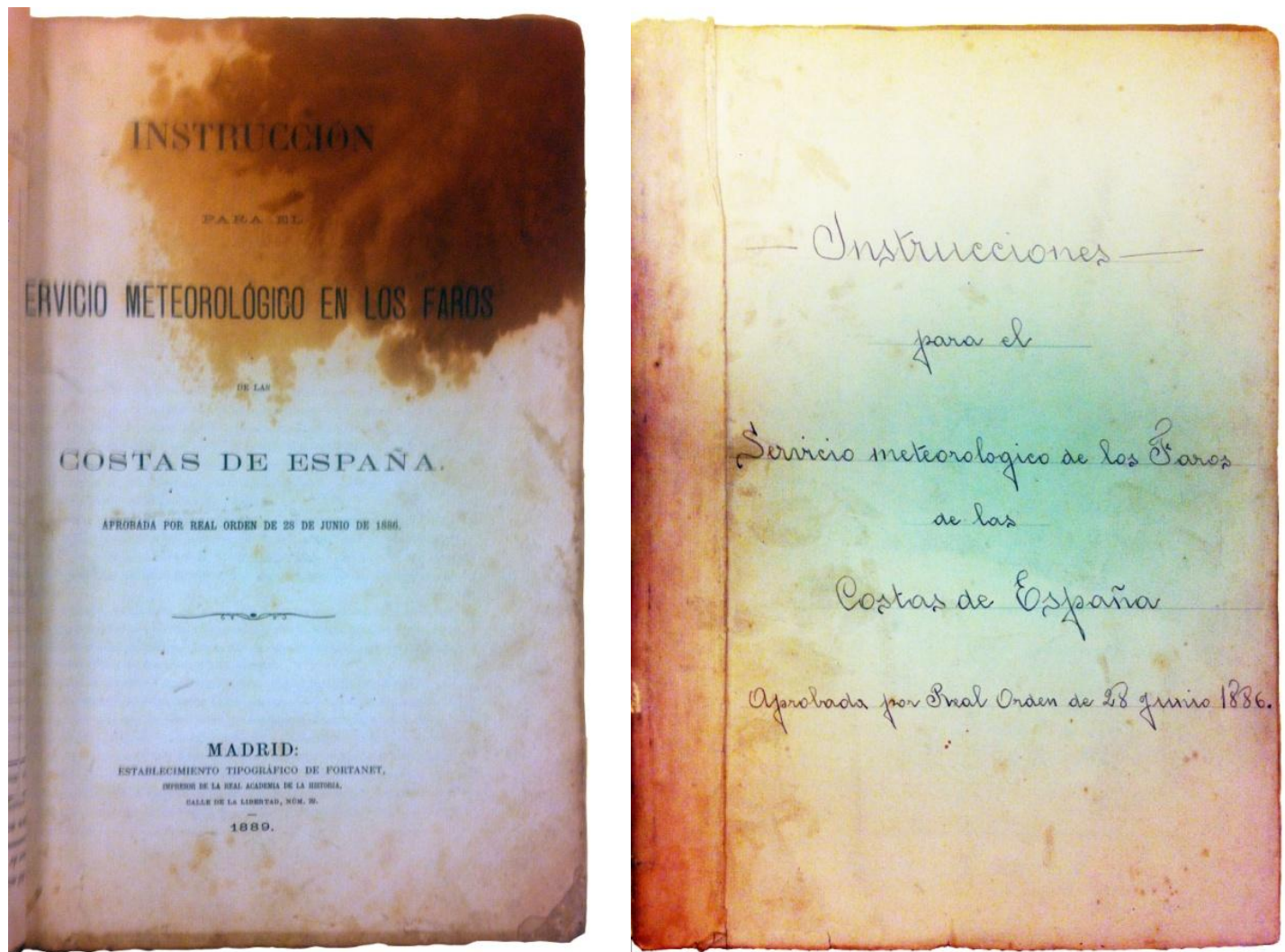

Figure 1.1. Instructions for the meteorological service in the Spanish lighthouses from 1889.

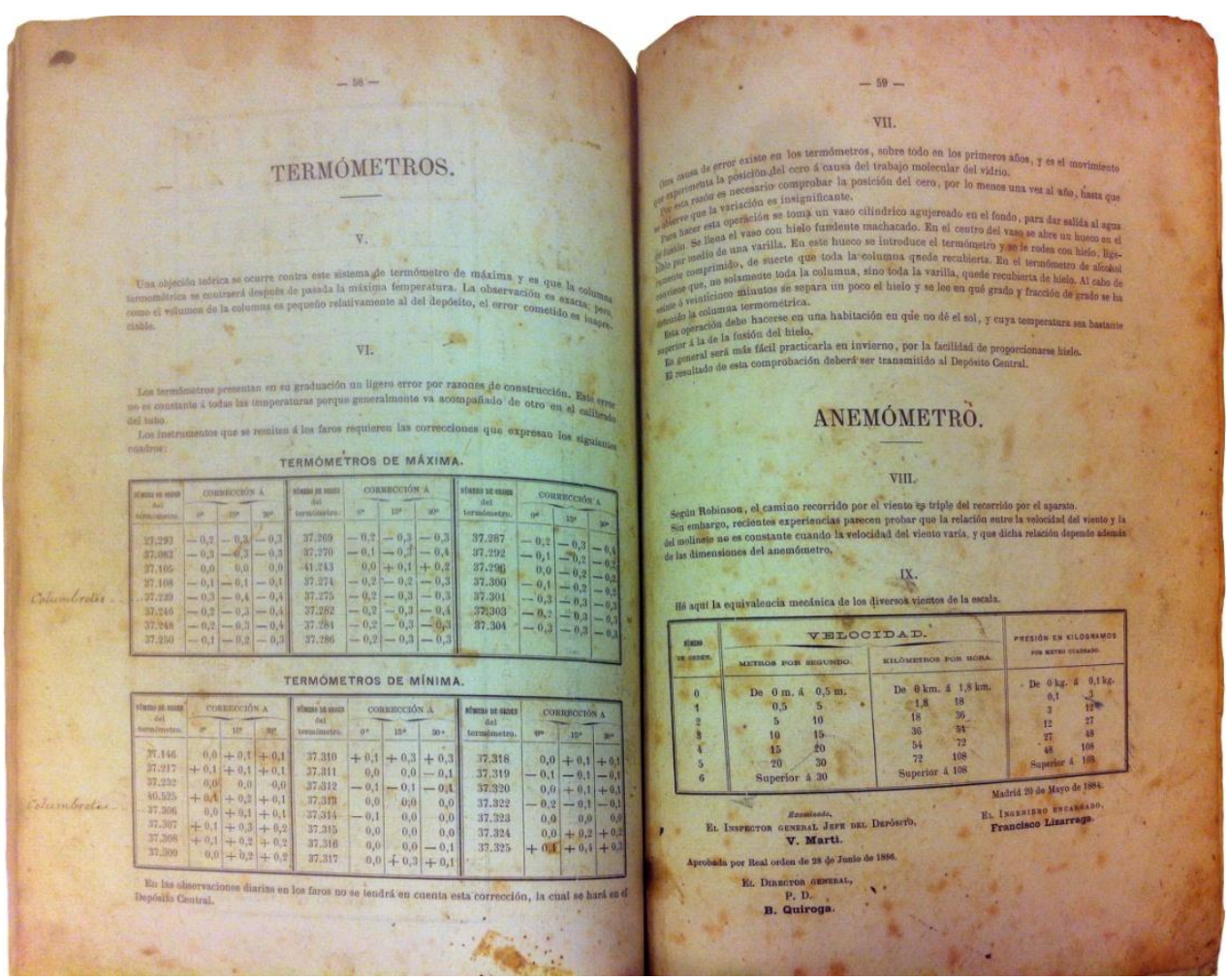

Figure 1.2. Inner image of the instructions for the meteorological service in the Spanish lighthouses from 1889. 


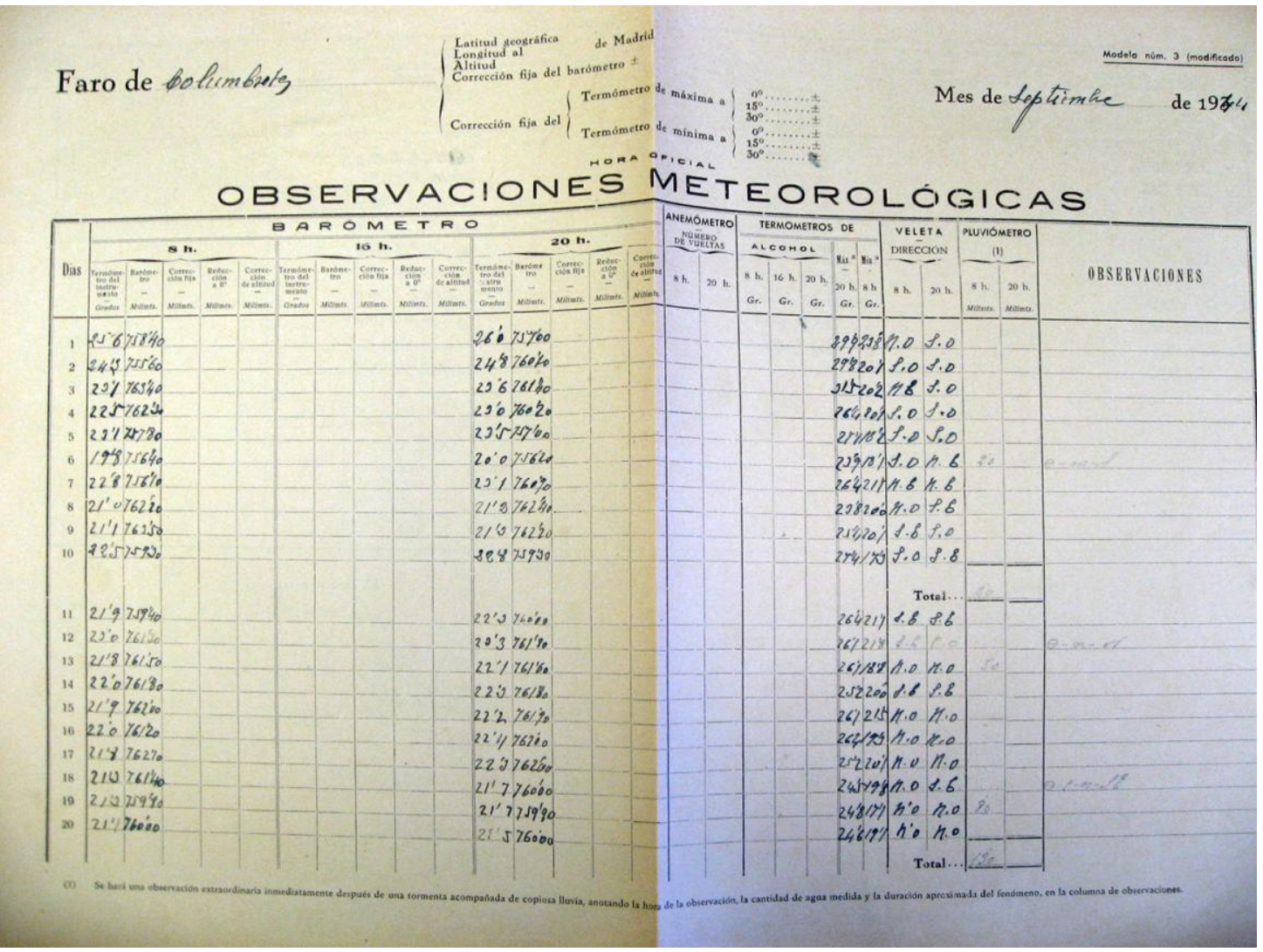

Figure 1.3. Daily weather observation record of the lighthouse keepers, front page.

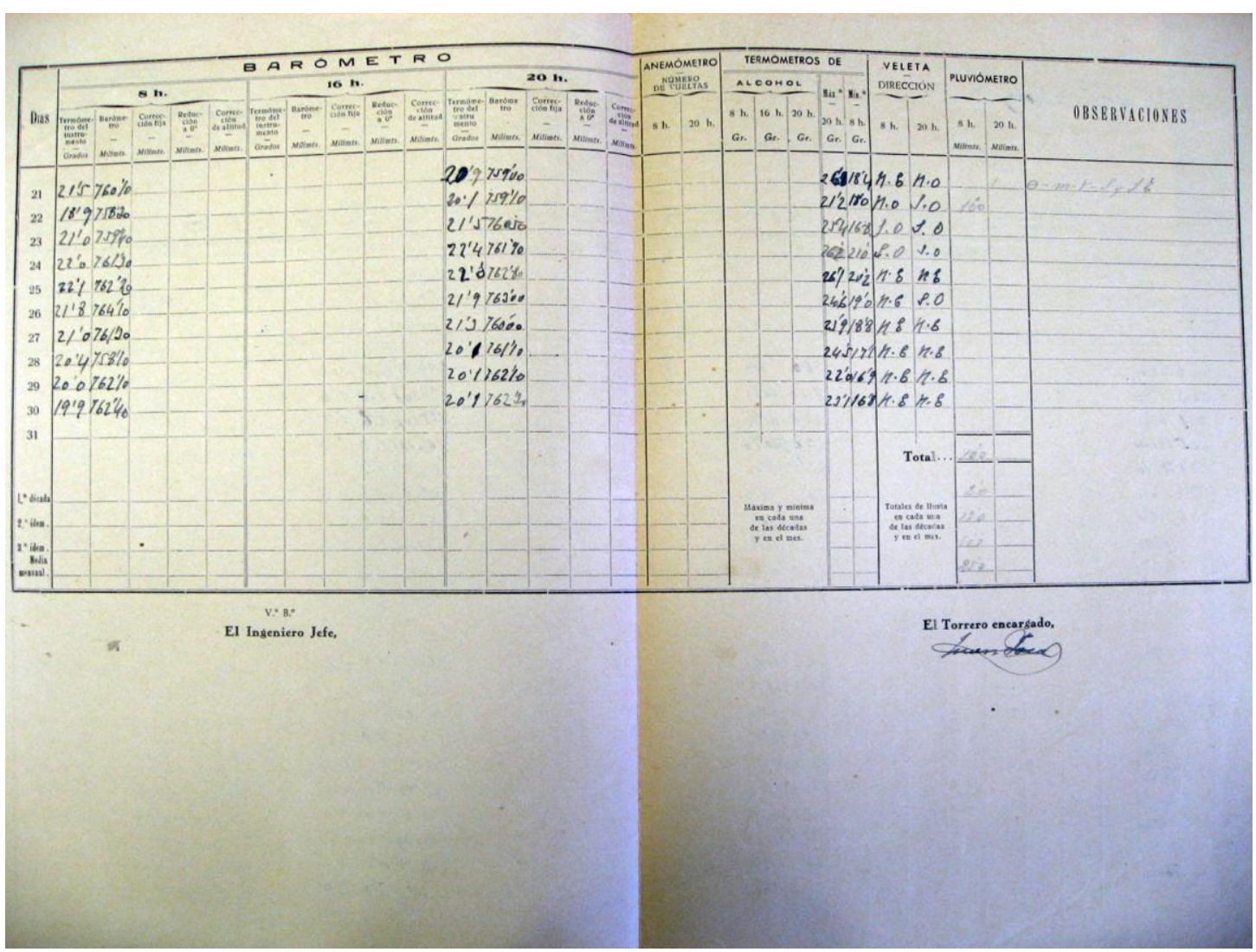

Figure 1.4. Daily weather observation record of the lighthouse keepers, back page. 


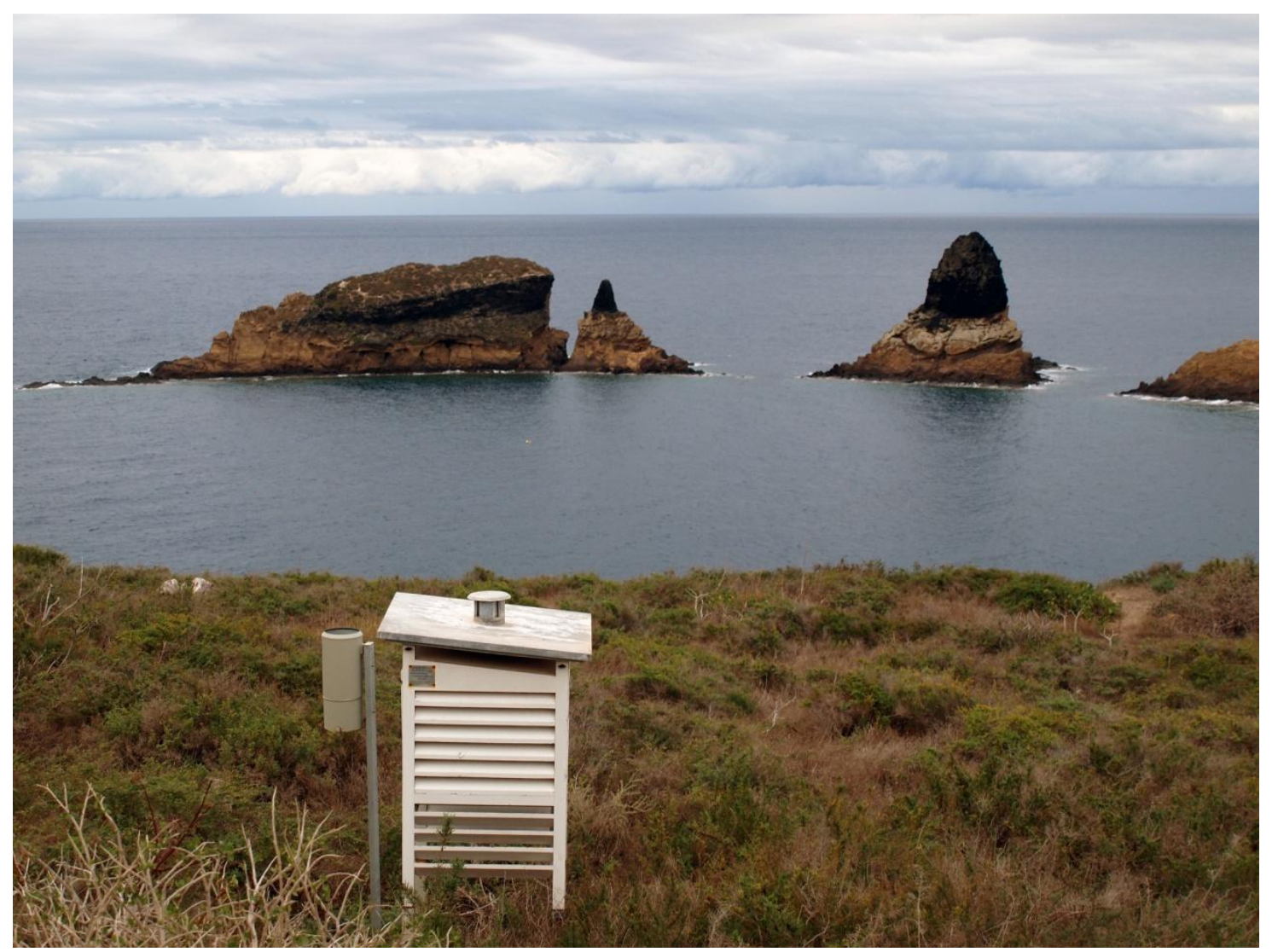

Figure 1.5. The Stevenson box (made of wood painted in white, with double layer screens) used to shield meteorological instruments in Columbretes.
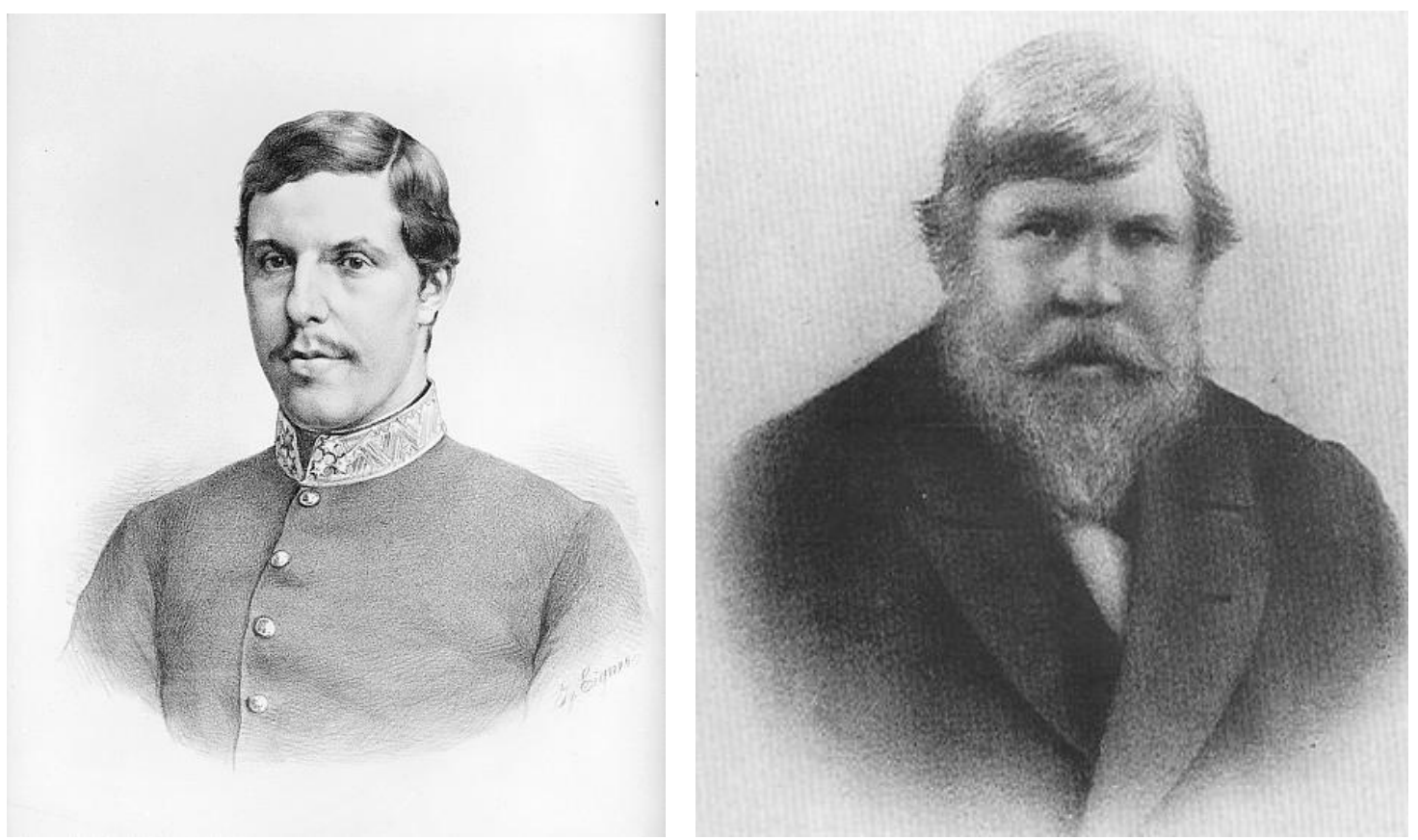

Figure 1.6. Young and older archduke Ludwig Salvator portraits. Source: Columbretes C.I. archive. 


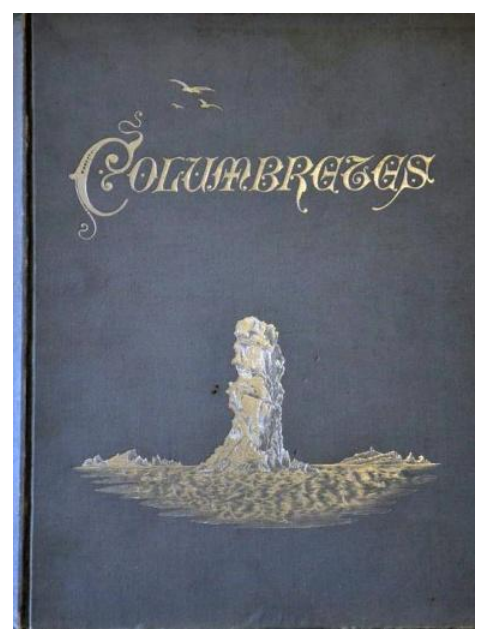

Figure 1.7. Columbretes book cover page (Habsburg-Lothringen, 1895).

Table 1.1. Different values of temperature $\left({ }^{\circ} \mathrm{C}\right)$ in Columbretes comparable to those published by Habsburg-Lothringen (1895) and Gisbert (1991) ( $T$ = temperature; total series: 01.09.189131.12.2015; 1st period: 1940-1956/1957; 2 nd period: $1992-2015 ; \mathrm{n}=$ number of values; V.C. $=$ variation coefficient):

\begin{tabular}{|c|c|c|c|c|c|}
\hline Columbretes T & $\begin{array}{c}\text { Habsburg-Lothringen } \\
\text { (1895) }\end{array}$ & $\begin{array}{l}\text { Gisbert } \\
(1991)\end{array}$ & $\begin{array}{l}\text { Total } \\
\text { series }\end{array}$ & $\begin{array}{l}\text { This study } \\
\text { 1st period }\end{array}$ & 2nd period \\
\hline \multirow[t]{2}{*}{ Absolute maximum $\mathrm{T}$} & \multirow[t]{2}{*}{34.00} & \multirow[t]{2}{*}{35.0} & 37.0 & 37.0 & 35.0 \\
\hline & & & $30.85 \pm$ & $30.75 \pm$ & $27.71 \pm$ \\
\hline \multirow[t]{3}{*}{$\begin{array}{l}\text { Monthly mean absolute } \\
\text { maximum } T\end{array}$} & \multirow[t]{3}{*}{24.06} & \multirow[t]{3}{*}{ NA } & $\begin{array}{c}1.21 \\
(n=12)\end{array}$ & $\begin{array}{c}1.22 \\
(n=12)\end{array}$ & $\begin{array}{c}1.48 \\
(n=12)\end{array}$ \\
\hline & & & V.C. $=0.14$ & V.C. $=0.14$ & V.C. $=0.19$ \\
\hline & & & $20.93 \pm$ & $21.17 \pm$ & $20.74 \pm$ \\
\hline \multirow[t]{3}{*}{ Monthly mean maximum $T$} & \multirow[t]{3}{*}{21.30} & \multirow[t]{3}{*}{ NA } & $\begin{array}{c}1.56 \\
(n=12)\end{array}$ & $\begin{array}{c}1.60 \\
(n=12)\end{array}$ & $\begin{array}{c}1.53 \\
(n=12)\end{array}$ \\
\hline & & & V.C. $=0.26$ & V.C. $=0.26$ & V.C. $=0.26$ \\
\hline & & & $18.00 \pm$ & $17.57 \pm$ & $18.41 \pm$ \\
\hline \multirow[t]{3}{*}{ Monthly mean T } & \multirow[t]{3}{*}{18.35} & \multirow[t]{3}{*}{16.8} & $\begin{array}{c}1.48 \\
(n=12)\end{array}$ & $\begin{array}{c}1.49 \\
(n=12)\end{array}$ & $\begin{array}{c}1.48 \\
(n=12)\end{array}$ \\
\hline & & & V.C. $=0.29$ & V.C. $=0.29$ & V.C. $=0.28$ \\
\hline & & & $15.11 \pm$ & $14.04 \pm$ & $16.08 \pm$ \\
\hline \multirow[t]{2}{*}{ Monthly mean minimum T } & \multirow[t]{2}{*}{15.64} & \multirow[t]{2}{*}{ NA } & $\begin{array}{c}1.40 \\
(n=12)\end{array}$ & $\begin{array}{c}1.39 \\
(n=12)\end{array}$ & $\begin{array}{c}1.43 \\
(n=12)\end{array}$ \\
\hline & & & V.C. $=0.32$ & V.C. $=0.34$ & V.C. $=0.31$ \\
\hline \multirow{2}{*}{$\begin{array}{l}\text { Monthly mean absolute } \\
\text { minimum T }\end{array}$} & \multirow{2}{*}{11.47} & \multirow{2}{*}{ NA } & $\begin{array}{c}3.42 \pm 1.59 \\
(n=12)\end{array}$ & $\begin{array}{c}3.42 \pm 1.59 \\
(n=12)\end{array}$ & $\begin{array}{c}8.27 \pm 1.33 \\
(n=12)\end{array}$ \\
\hline & & & V.C. $=1.61$ & V.C. $=1.61$ & V.C. $=0.56$ \\
\hline Absolute minimum $\mathrm{T}$ & 1.30 & NA & -6.0 & -6.0 & 2.0 \\
\hline
\end{tabular}


Table 1.2. Different values of mean temperature $\left({ }^{\circ} \mathrm{C}\right)$ comparable to those published by the Habsburg-Lothringen (1895) and Gisbert (1991) ( $T=$ temperature; total series: 01.09.189131.12.2015; 1st period: 1940-1956/1957; 2nd period: 1992-2015):

\begin{tabular}{|c|c|c|c|c|c|}
\hline \multirow{2}{*}{ Columbretes T } & \multirow{2}{*}{$\begin{array}{l}\text { Habsburg-Lothringen } \\
\text { (1895) }\end{array}$} & \multirow{2}{*}{$\begin{array}{l}\text { Gisbert } \\
(1991)\end{array}$} & \multicolumn{3}{|c|}{ This study } \\
\hline & & & Total series & 1st period & 2nd period \\
\hline \multirow{4}{*}{$\begin{array}{l}\text { Spring and autumn } \\
\text { mean } \mathrm{T}\end{array}$} & \multirow{4}{*}{18.02} & \multirow{4}{*}{16.8} & $17.70 \pm$ & $17.38 \pm$ & $18.01 \pm$ \\
\hline & & & 0.20 & 0.53 & 0.12 \\
\hline & & & $(n=51)$ & $(n=18)$ & $(n=24)$ \\
\hline & & & V.C. $=0.08$ & V.C. $=0.13$ & V.C. $=0.03$ \\
\hline \multirow{4}{*}{ Spring mean $\mathbf{T}$} & \multirow{4}{*}{16.12} & \multirow{4}{*}{ Nice* } & $15.63 \pm$ & $15.23 \pm$ & $15.98 \pm$ \\
\hline & & & 0.23 & 0.64 & 0.15 \\
\hline & & & $(n=54)$ & $(n=18)$ & $(n=24)$ \\
\hline & & & V.C. $=0.11$ & V.C. $=0.18$ & V.C. $=0.05$ \\
\hline \multirow{4}{*}{ Autumn mean $\mathrm{T}$} & \multirow{4}{*}{19.91} & \multirow{4}{*}{ Nice* } & $19.80 \pm$ & $19.52 \pm$ & $20.04 \pm$ \\
\hline & & & 0.20 & 0.49 & 0.16 \\
\hline & & & $(n=55)$ & $(n=18)$ & $(n=25)$ \\
\hline & & & V.C. $=0.08$ & V.C. $=0.11$ & V.C. $=0.04$ \\
\hline \multirow{4}{*}{ August mean $\mathrm{T}$} & \multirow{4}{*}{26.23} & \multirow{4}{*}{25.0} & $25.72 \pm$ & $25.04 \pm$ & $26.28 \pm$ \\
\hline & & & 0.22 & 0.55 & 0.19 \\
\hline & & & $(n=51)$ & $(n=17)$ & $(n=23)$ \\
\hline & & & V.C. $=0.06$ & V.C. $=0.09$ & V.C. $=0.03$ \\
\hline
\end{tabular}

*Gisbert did not provide a figure but described these means as "agradable".

Table 1.3. Different values of precipitation $(\mathrm{mm})$ in Columbretes comparable to those published by Gisbert (1991), except monthly mean accumulated precipitation and number of days of rain $(\mathrm{P}=$ precipitation; total series: 01.09.1891-31.12.2015; 1st period: $1940-$ 1956/1957; 2nd period: 1992-2015):

\begin{tabular}{|c|c|c|c|c|}
\hline \multirow{2}{*}{ Columbretes P. values } & \multirow{2}{*}{$\begin{array}{l}\text { Gisbert } \\
(1991)\end{array}$} & \multicolumn{3}{|c|}{ This study } \\
\hline & & Total series & 1st period & 2nd period \\
\hline \multirow{3}{*}{$\begin{array}{l}\text { Annual mean } \\
\text { accumulated } P\end{array}$} & \multirow{3}{*}{$265.19 *$} & $337.89 \pm 24.38$ & $234.89 \pm 29.15$ & $407.52 \pm 29.58$ \\
\hline & & $(n=38)$ & $(n=13)$ & $(n=22)$ \\
\hline & & V.C. $=0.44$ & V.C. $=0.45$ & V.C. $=0.34$ \\
\hline \multirow{3}{*}{$\begin{array}{l}\text { Monthly mean } \\
\text { accumulated } P\end{array}$} & \multirow{3}{*}{ NA } & $28.68 \pm 4.70$ & $22.49 \pm 4.51$ & $34.09 \pm 2.63$ \\
\hline & & $(n=12)$ & $(n=12)$ & $(n=12)$ \\
\hline & & V.C. $=0.57$ & V.C. $=0.70$ & V.C. $=0.22$ \\
\hline \multirow{3}{*}{$\begin{array}{l}\text { Annual mean number of } \\
\text { days of rain }\end{array}$} & \multirow{3}{*}{23} & $40.70 \pm 2.98$ & $22.00 \pm 1.92$ & $54.70 \pm 2.04$ \\
\hline & & $(n=37)$ & $(n=14)$ & $(n=20)$ \\
\hline & & V.C. $=0.45$ & V.C. $=0.33$ & V.C. $=0.17$ \\
\hline \multirow{3}{*}{$\begin{array}{l}\text { Monthly mean number } \\
\text { of days of rain }\end{array}$} & \multirow{3}{*}{ NA } & $3.29 \pm 0.31$ & $2.01 \pm 0.25$ & $4.51 \pm 0.40$ \\
\hline & & $(n=12)$ & $(n=12)$ & $(n=12)$ \\
\hline & & V.C. $=0.33$ & V.C. $=0.44$ & V.C. $=0.31$ \\
\hline \multirow{2}{*}{ Maximum $P$ in 24h } & 80.20 & 121.20 & 80.20 & 121.20 \\
\hline & (Oct. 1953) $* *$ & (Sept. 2004) & (Oct. 1953) & (Sept. 2004) \\
\hline The two most rainy & September & Sept. $(59.33 \mathrm{~mm})$ & Oct. $(63.68 \mathrm{~mm})$ & Sept. (79.31mm) \\
\hline months & October & Oct. (57.99 mm) & Nov. $(30.67 \mathrm{~mm})$ & Oct. $(57.34 \mathrm{~mm})$ \\
\hline
\end{tabular}

* Period 1941-1956.

** Periods 1920-22, 1927-35 and 1941-1956. 
Table 1.4. Percentage in volume of station precipitation in Columbretes comparable to that published by Gisbert (1991) for autumn ( $P$ = precipitation; total series: 01.09.1891-31.12.2015; 1st period: 1940-1956/1957; 2nd period: 1992-2015):

\begin{tabular}{|c|c|c|c|c|}
\hline Columbretes P. values & $\begin{array}{l}\text { Gisbert } \\
\text { (1991) }\end{array}$ & Total series & $\begin{array}{l}\text { This study } \\
\text { 1st period }\end{array}$ & 2nd period \\
\hline & & $18.00 \pm 1.98$ & $15.66 \pm 2.54$ & $20.60 \pm 3.00$ \\
\hline \multirow[t]{3}{*}{ \% Spring P } & NA & $(n=44)$ & $(n=17)$ & $(n=24)$ \\
\hline & & V.C. $=0.73$ & V.C. $=0.70$ & V.C. $=0.71$ \\
\hline & & $12.11 \pm 1.34$ & $12.64 \pm 1.86$ & $12.03 \pm 2.09$ \\
\hline \multirow[t]{3}{*}{$\%$ Summer $\mathbf{P}$} & NA & $(n=44)$ & $(n=17)$ & $(n=24)$ \\
\hline & & V.C. $=0.73$ & V.C. $=0.63$ & V.C. $=0.85$ \\
\hline & & $45.32 \pm 2.73$ & $45.52 \pm 4.38$ & $44.37 \pm 3.83$ \\
\hline \multirow[t]{3}{*}{ \% Autumn P } & 50 & $(n=45)$ & $(n=17)$ & $(n=25)$ \\
\hline & & V.C. $=0.40$ & V.C. $=0.40$ & V.C. $=0.43$ \\
\hline & & $25.45 \pm 2.58$ & $26.18 \pm 4.59$ & $24.64 \pm 3.46$ \\
\hline \multirow[t]{2}{*}{ \% Winter $\mathbf{P}$} & NA & $(n=44)$ & $(n=17)$ & $(n=24)$ \\
\hline & & V.C. $=0.67$ & V.C. $=0.72$ & V.C. $=0.69$ \\
\hline
\end{tabular}

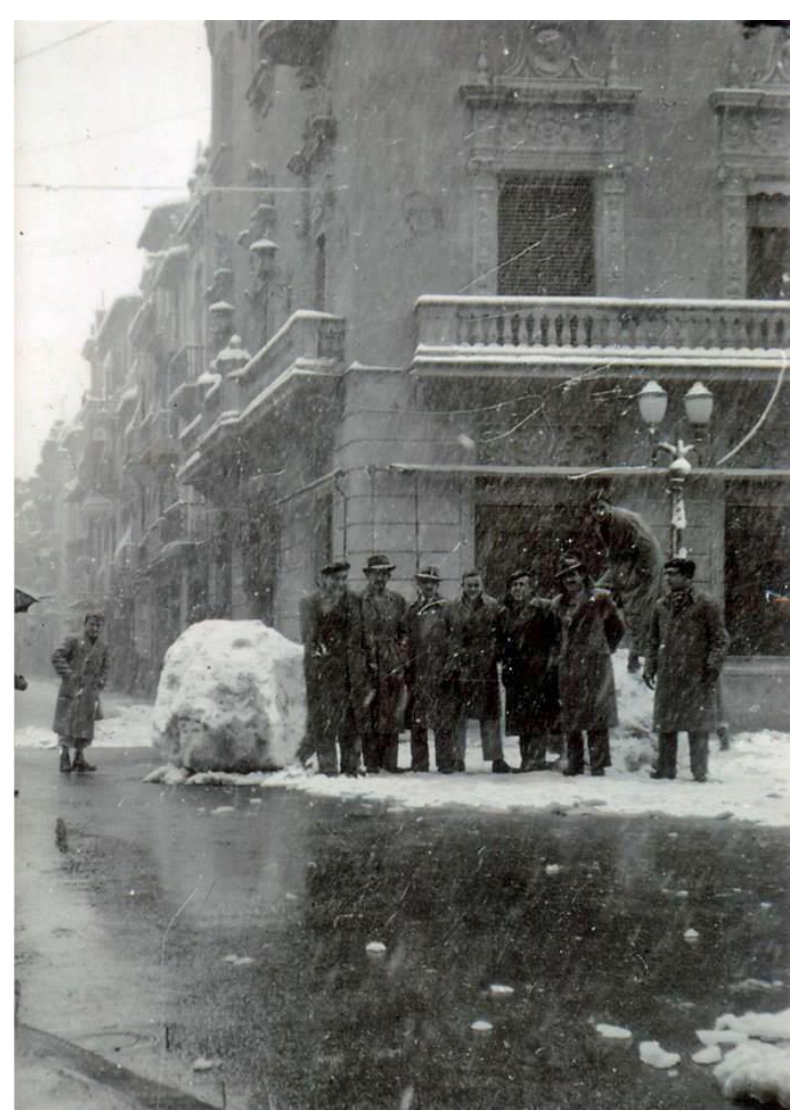

Figure 1.8. "La gran nevada" of Castelló de la Plana, saint Anthony's day (January, 17), 1946. Source: "Castellón Antiguo" Facebook page. 
Table 1.5. Number of days of different phenomena in Columbretes comparable to those published by Habsburg-Lothringen (1895) and Gisbert (1991) ( $T$ = temperature; 1st period: 1940-1956/1957; 2nd period: 1992-2015):

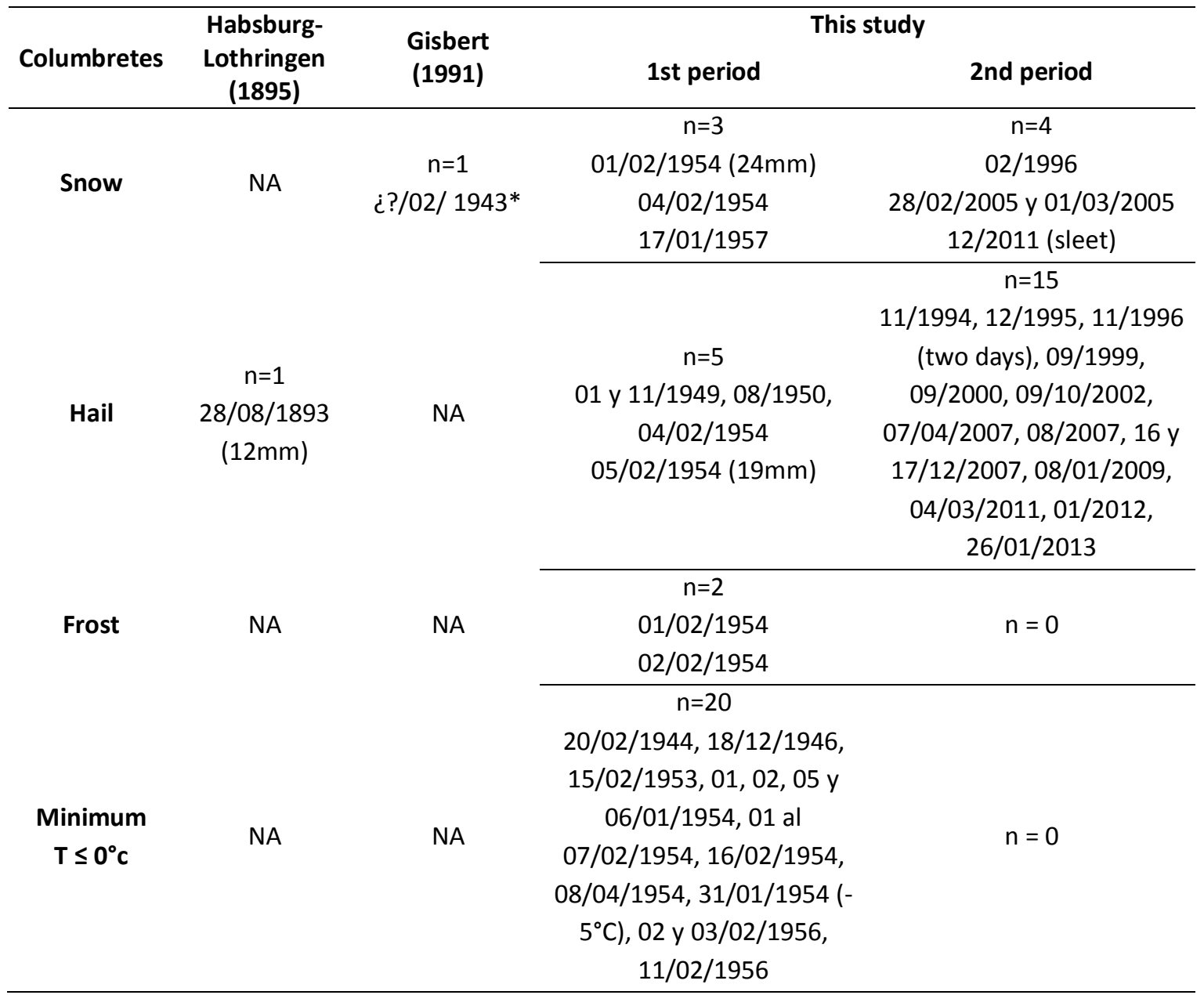

*Snowfall only was recorded one day in a period of 50 years (Gisbert, 1991)

The dates shown in the previous table correspond to those days in which it is documented that that meteorological event occurred.

The data for the total series: 01.09.1891-31.12.2015 coincides with the result of the summation of both periods.

\section{NOTES about low temperature records:}

In February, 1954, in the Castelló de la Plana station a minimum temperature of $-3.2^{\circ} \mathrm{C}$ was registered; and one day of January, 1957, it snowed.

Table 1.5.a: Years when $\mathrm{T}<-3^{\circ} \mathrm{C}$ in Castelló de la Plana, until 2015 (abs.min. T=absolute minimum T):

\begin{tabular}{ccc}
\hline Abs.min.T & Year & Month \\
\hline-7.3 & 1956 & 2 \\
-5.4 & 1946 & 1 \\
-5 & 1920 & 12 \\
-4.4 & 1985 & 1 \\
-3.2 & 1935 & 1 \\
-3.2 & 1954 & 2 \\
-3.1 & 1960 & 1 \\
-3 & 1938 & 12 \\
\hline
\end{tabular}


When we checked for the existence of any trend in the aforementioned parameters for Columbretes, except for mean absolute maximum and mean maximum values of temperature, which did not change during that period, there was a positive trend in all the remaining parameters (Table 1.6, Annex 1.5), which ranged from 0.011 to 2.216 units per year for mean medium temperature $\left({ }^{\circ} \mathrm{C}\right)$ and annual precipitation $(\mathrm{mm})$, respectively. These results could be partly attributed to how meteorological measurements were taken more than 50 years ago and now. As a consequence, we decided to split the study period in two (1940-1956/7 and 1992-2015) and proceed as before. In this case, all the linear regressions within each period were not significant except for absolute maximum and maximum mean values of temperature for the first period (Table 1.7, Annex 1.5) and mean minimum temperature during the second period (Table 1.8, Annex 1.5), with annual increases of $0.252,0.214$, and $0.089{ }^{\circ} \mathrm{C}$ per year, respectively. So, except for mean absolute maximum and mean maximum values of temperature, for which we could still use the data obtained for the whole period (no significant trend), it would be more realistic to use the data corresponding to the second period to describe the current climate of Columbretes, which resulted warmer and more humid than previously thought (Gisbert, 1991). Interestingly, our results are in agreement with the predictions for warmer temperatures in the Mediterranean (IPCC, 2016) but are in complete disagreement for a decrease of precipitation. Indeed, different predictions for the Mediterranean basin have forecasted a substantial warming (about 1.5 and $2{ }^{\circ} \mathrm{C}$ in winter and summer, respectively) and a significant decrease of precipitation (around 5\%) (Planton et al., 2012; Navarra \& Tubiana, 2013; Gualdi et al., 2013). This apparent contradiction may be taken as indicative that rainfall measurements may have been taken more accurately in recent years relative to measurements made more than 50 years ago, rather than as indicative of a true increase in precipitation. However, for temperature, our results would confirm that the climate of Columbretes, as that of the whole Mediterranean basin, has become warmer.

Based on our measurements, we concluded that the annual means of precipitation and temperature, which appear in most of the published documents on the Columbretes, are 407.5 $\mathrm{mm}$ and $18.4^{\circ} \mathrm{C}$, respectively. As expected (Table 1.6, Annex 1.5), both values are higher than those provided by Gisbert (Tables 1.1 and 1.3). In fact, the annual number of days of rain and the maximum precipitation in $24 \mathrm{~h}$ have also increased relative to the results provided by Gisbert (1991). We have computed 54.7 rainy days and $121.2 \mathrm{~mm}$ instead of 23 days and 80.2 $\mathrm{mm}$ (which coincide with what we have estimated for the first period), respectively. However, there is a full coincidence in the two rainiest months, which remain September and October (Table 1.3). 
In the case of temperatures, Gisbert (1991) did not clearly state where he obtained the data from and this adds further uncertainty about his results. Interestingly, our estimate of mean temperature is close to the mean calculated with the data published by Habsburg-Lothringen, (1895), which was $18.35^{\circ} \mathrm{C}$. Additional results were also closer to those presented by this author and higher than those presented by Gisbert (1991) (Table 1.2).

In the case of extreme temperatures we observed that maximum temperature did not significantly change along the series, with a mean of $20.93^{\circ} \mathrm{C}$ and a mean absolute of $30.85^{\circ} \mathrm{C}$ (Table 1.1). The absolute maximum temperature was $37^{\circ} \mathrm{C}$ and this temperature was registered three times in our time series: 10/08/1957, and 06 and 28/07/1958. However, minimum temperatures increased during the same period (Table 1.8, Annex 1.5), and this can be easily appraised by comparing the duration of frost-free period, which extended for 345 days during the first period but covered the whole year during the second (Table 1.5) (the absolute minimum temperatures registered were $-6^{\circ} \mathrm{C}$ in $01 / 02 / 1954$ in the first period, and $2^{\circ} \mathrm{C}$ in 27 and 28/01/2005 in the second period). Interestingly, actual minimum temperatures during the first half of the $20^{\text {th }}$ century may have been underestimated as lighthouse keepers sometimes just wrote in their diaries that temperatures were below $0^{\circ} \mathrm{C}$ and did not record the actual value reached. Therefore, we decided to compare these unusual low temperatures with absolute minimum temperatures registered in Castelló (Table 1.5.a). We could see that there was a good agreement between them and they actually coincide in February 1954, when the temperature in Castelló reached $-3.2^{\circ} \mathrm{C}$ in a series of more than 12 days with negative temperatures. The absolute minimum temperature ever recorded in Castelló is $-7.3^{\circ} \mathrm{C}$ and it was observed in February 1956. These dates also coincide with a cold period in Columbretes, with three days below $0^{\circ} \mathrm{C}$ (Table 1.5). However, there is no coincidence with the "gran nevada" occurred in 1946, which elder people in Castelló still remember (Figure 1.8).

Table 1.6. Regression line of the total series for each of the parameters in Columbretes ( $T=$ temperature; $\mathrm{P}=$ precipitation):

\begin{tabular}{lcccc}
\hline \multicolumn{1}{c}{ Parameter } & Estimate & Slope & $\boldsymbol{t}$ & $\boldsymbol{p}$ \\
\hline Monthly absolute maximum T & $14.453 \pm 11.638$ & $0.005 \pm 0.006$ & 0.837 & 0.403 \\
Monthly mean maximum T & $21.612 \pm 11.858$ & $-0.001 \pm 0.006$ & -0.059 & 0.953 \\
Monthly absolute minimum T & $-40.049 \pm 11.667$ & $0.026 \pm 0.006$ & 4.404 & $<0.001$ \\
Monthly mean minimum T & $-29.179 \pm 10,902$ & $0.022 \pm 0.006$ & 4.061 & $<0.001$ \\
Monthly mean T & $-4.459 \pm 11.283$ & $0.011 \pm 0.006$ & 1.990 & 0.047 \\
Number of days of rain & $-62.523 \pm 6.888$ & $0.033 \pm 0.003$ & 9.558 & $<0.001$ \\
Monthly mean accumulated P & $-279.165 \pm 97.843$ & $0.156 \pm 0.050$ & 3.148 & 0.002 \\
Maximum P in 24h & $-114.406 \pm 49,811$ & $0.066 \pm 0.025$ & 2.612 & 0.009 \\
Annual mean accumulated P & $-4,053.460 \pm 1,196.546$ & $2.216 \pm 0.605$ & 3.662 & $<0.001$ \\
\hline
\end{tabular}


Table 1.7. Regression line of the 1st period (1940-1957 for Te; $1940-1956$ for precipitation) for each of the parameters in Columbretes $(T=$ temperature; $\mathrm{P}=$ precipitation):

\begin{tabular}{lcccc}
\hline \multicolumn{1}{c}{ Parameter } & \multicolumn{1}{c}{ Estimate } & Slope & $\boldsymbol{t}$ & $\boldsymbol{p}$ \\
\hline Monthly absolute maximum T & $-467.493 \pm 140.988$ & $0.252 \pm 0.072$ & 3.490 & $<0.001$ \\
Monthly mean maximum T & $-396.601 \pm 148.502$ & $0.214 \pm 0.076$ & 2.813 & 0.005 \\
Monthly absolute minimum T & $-36.073 \pm 150.027$ & $0.024 \pm 0.077$ & 0.306 & 0.760 \\
Monthly mean minimum T & $-144.798 \pm 137,625$ & $0.082 \pm 0.071$ & 1.154 & 0.250 \\
Monthly mean T & $-256.231 \pm 141.909$ & $0.140 \pm 0.073$ & 1.930 & 0.055 \\
Number of days of rain & $-27.836 \pm 45.951$ & $0.015 \pm 0.024$ & 0.650 & 0.516 \\
Monthly mean accumulated P & $-872.962 \pm 886.790$ & $0.460 \pm 0.455$ & 1.010 & 0.314 \\
Maximum P in 24h & $-464.970 \pm 436,654$ & $0.245 \pm 0.224$ & 1.094 & 0.275 \\
Annual mean accumulated P & $-208.093 \pm 14,908.048$ & $0.229 \pm 7.658$ & 0.030 & 0.977 \\
\hline
\end{tabular}

Table 1.8. Regression line of the 2 nd period (1992-2015) for each of the parameters in Columbretes $(T=$ temperature; $\mathrm{P}=$ precipitation $)$ :

\begin{tabular}{lcccc}
\hline \multicolumn{1}{c}{ Parameter } & Estimate & Slope & $\boldsymbol{t}$ & $\boldsymbol{p}$ \\
\hline Monthly absolute maximum T & $-47.563 \pm 87.652$ & $0.036 \pm 0.044$ & 0.818 & 0.414 \\
Monthly mean maximum T & $-39.470 \pm 89.504$ & $0.030 \pm 0.045$ & 0.672 & 0.502 \\
Monthly absolute minimum T & $-165.068 \pm 87.626$ & $0.089 \pm 0.044$ & 2.026 & 0.044 \\
Monthly mean minimum T & $-125.577 \pm 83,589$ & $0.071 \pm 0.042$ & 1.694 & 0.091 \\
Monthly mean T & $-82.524 \pm 86.343$ & $0.050 \pm 0.043$ & 1.169 & 0.244 \\
Number of days of rain & $-22.010 \pm 55.456$ & $0.013 \pm 0.028$ & 0.478 & 0.633 \\
Monthly mean accumulated P & $-507.119 \pm 754.782$ & $0.270 \pm 0.377$ & 0.717 & 0.474 \\
Maximum P in 24h & $-188.958 \pm 387,476$ & $0.103 \pm 0.193$ & 0.534 & 0.594 \\
Annual mean accumulated P & $-5,656.006 \pm 7,600.172$ & $3.018 \pm 3.792$ & 0.796 & 0.436 \\
\hline
\end{tabular}

When we plotted the ombrothermic diagrams corresponding to the two periods and the complete series (Figures 1.9 to 1.11) and further classified the climate of Columbretes for the different periods according to UNESCO-FAO, Köppen-Geiger and Köppen-Trewartha (Tables 1.9 to 1.12; Annexes 1.2 to 1.4 ), we could see that there was an almost full coincidence between the classifications for the total and the second periods. The only exception was the UNESCO-FAO classification, which yielded a thermomediterranean climate attenuated with a shorter dry season climate for the second period but a long dry season for the whole period, which reflects the increased precipitation recorded in the most recent period. So, according to the Köppen-Geiger classification Columbretes belongs to group B, arid climate, more specifically to Bsh, Hot Arid Steppe Climate. This arid climate covers $28.4 \%$ of the total land area on Earth (Chan \& Chan, 2013). Finally, according to the Köppen-Trewartha climate classification, the archipelago belongs to the group BS, Semi-Arid or Steppe Climate. 

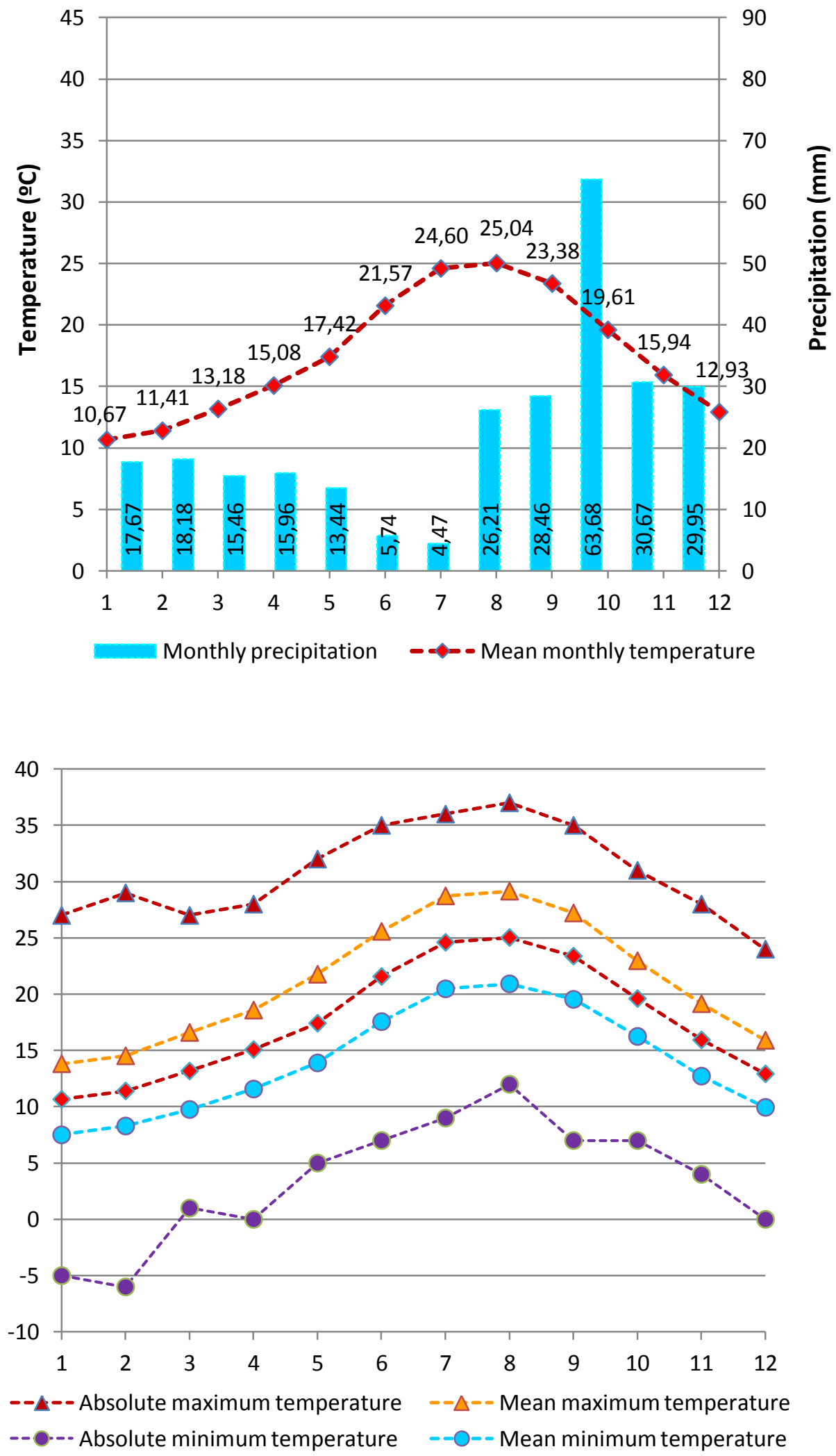

Figure 1.9. Ombrothermic diagram of the 1st period (01.01.1940-31.12.1957) 

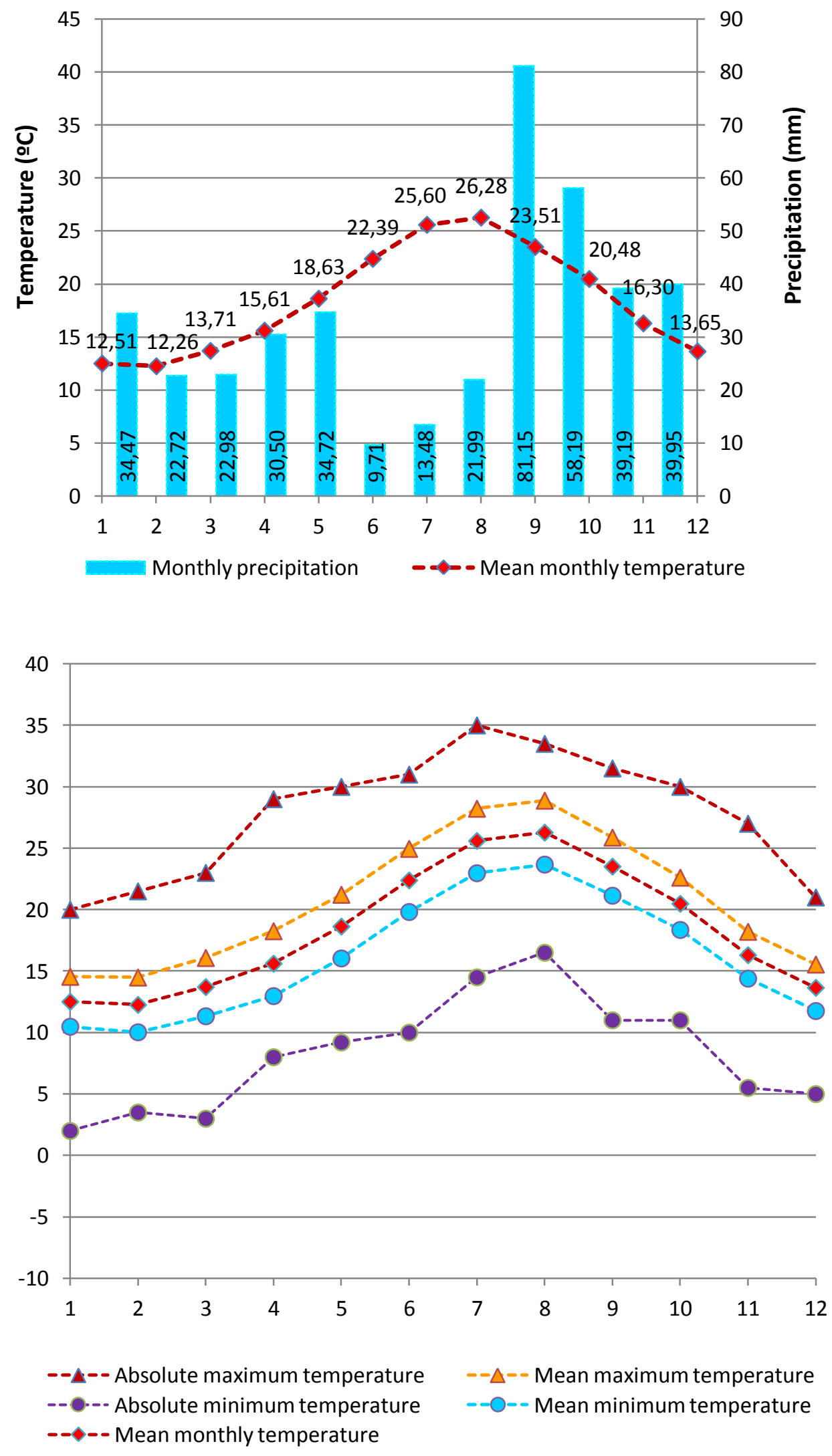

Figure 1.10. Ombrothermic diagram of the 2 nd period (01.01.1992-31.12.2015) 

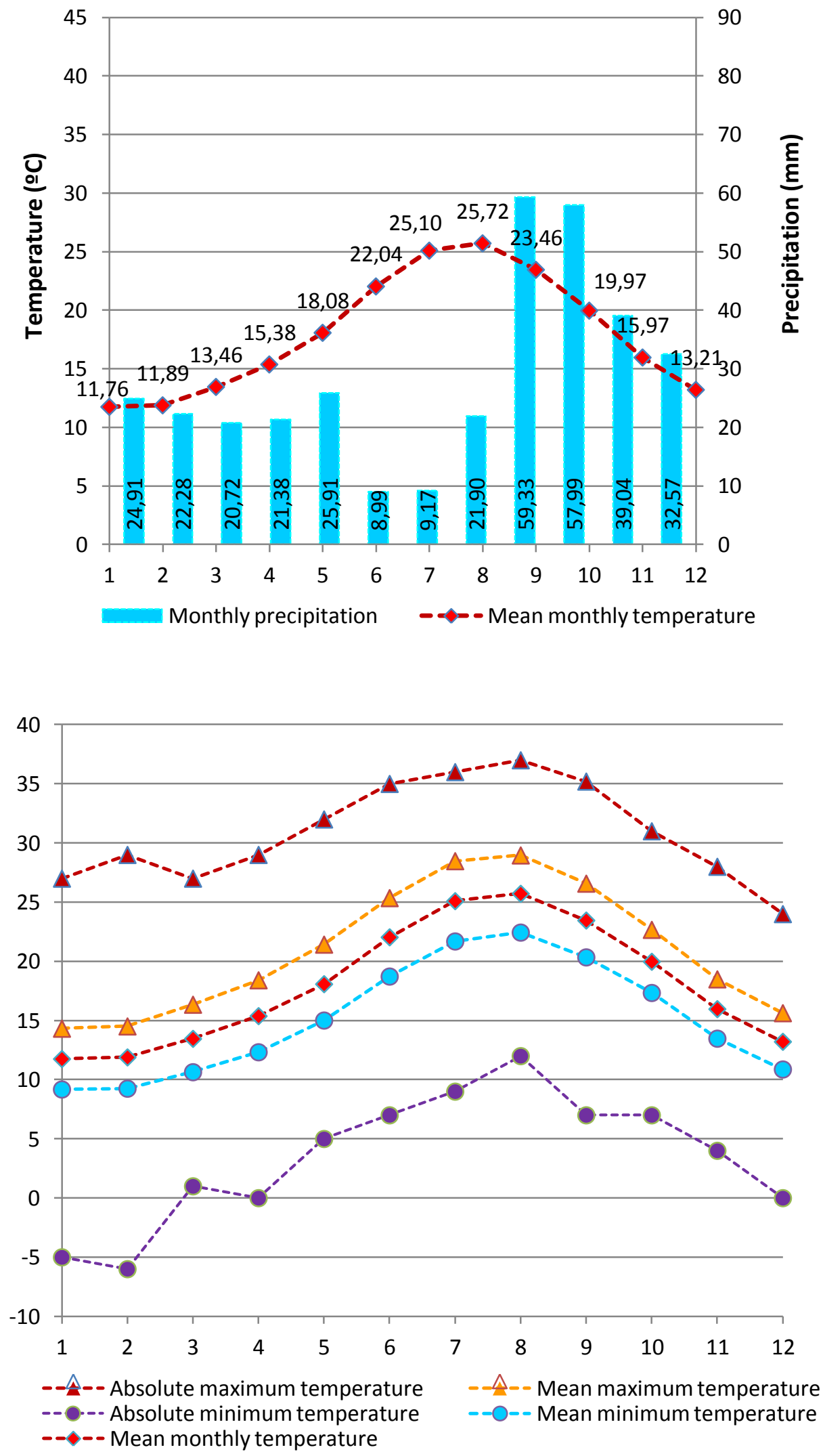

Figure 1.11. Ombrothermic diagram of the total series (01.09.1891-31.12.2015) 
Table 1.9. Climatic classification and Xerothermic index in Columbretes comparable to those published by Habsburg-Lothringen (1895) and Gisbert (1991) (Medit. = Mediterranean; total series: 01.09.1891-31.12.2015; 1st period: 1940-1956/1957; 2nd period: 1992-2015):

\begin{tabular}{|c|c|c|c|c|c|}
\hline \multirow[b]{2}{*}{ COLUMBRETES } & \multirow{2}{*}{$\begin{array}{l}\text { Habsburg- } \\
\text { Lothringen } \\
\text { (1895) }\end{array}$} & \multirow[b]{2}{*}{ Gisbert (1991) } & \multicolumn{3}{|c|}{ This study } \\
\hline & & & Total series & 1st period & 2nd period \\
\hline $\begin{array}{l}\text { UNESCO-FAO } \\
\text { bioclimatic } \\
\text { class. }\end{array}$ & $\begin{array}{l}\text { Tempered. } \\
\text { Very similar to } \\
\text { the climate of } \\
\text { the nearby } \\
\text { Valencia** }\end{array}$ & $\begin{array}{l}\text { Meso-medit. } \\
\text { accentuated } \\
\text { with a long dry } \\
\text { season }\end{array}$ & $\begin{array}{l}\text { Thermo medit. } \\
\text { with a Long Dry } \\
\text { Season }\end{array}$ & $\begin{array}{l}\text { Attenuated hot } \\
\text { sub-desert }\end{array}$ & $\begin{array}{l}\text { Thermo-medit. } \\
\text { attenuated } \\
\text { with a shorter } \\
\text { dry season }\end{array}$ \\
\hline $\begin{array}{l}\text { Köppen-Geiger } \\
\text { climate class. }\end{array}$ & NA & NA & $\begin{array}{c}\text { Hot Arid } \\
\text { Steppe Climate } \\
\text { (BSh) }\end{array}$ & $\begin{array}{c}\text { Cold Arid } \\
\text { Steppe Climate } \\
\text { (BSk) }\end{array}$ & $\begin{array}{c}\text { Hot Arid Steppe } \\
\text { Climate (BSh) }\end{array}$ \\
\hline $\begin{array}{c}\text { Köppen- } \\
\text { Trewartha } \\
\text { climate class. }\end{array}$ & NA & NA & $\begin{array}{l}\text { Semi-arid or } \\
\text { Steppe Climate } \\
\text { (BS) }\end{array}$ & $\begin{array}{c}\text { Arid (also } \\
\text { Desert) Climate } \\
\text { (BW) }\end{array}$ & $\begin{array}{c}\text { Semi-arid or } \\
\text { Steppe Climate } \\
\text { (BS) }\end{array}$ \\
\hline $\begin{array}{l}\text { Xerothermic } \\
\text { Index * }\end{array}$ & NA & $75-100$ & 130.95 & 204.84 & 116.17 \\
\hline
\end{tabular}

These classifications make the climate of Columbretes quite similar to that prevailing in most of south of the Iberian Peninsula, especially the southeastern provinces of Alacant, Almeria and Murcia. To further dig into these similarities, we decided to compare the climate of the Columbretes with those of a few selected locations (Palma de Mallorca, Castelló de la Plana, Alacant and Almeria) for the two aforementioned periods and the total extending from 1891 to 2015 .

When we compared the full time period, we observed that mean monthly temperatures showed the same trend at all five locations (Table 1.13, Annex 1.6). The same was true for maximum values except at Palma de Mallorca as well as for minimum records except at Castelló and Almería. These results confirm, as expected (IPCC, 2016), the increasing trends in temperatures in the Mediterranean (Bladé et al, 2010; Ramis, 2008) including Columbretes. Remarkably, though, when we compared precipitation values at the same five locations, the increasing trend could only be observed at Palma de Mallorca (where there were no differences in all precipitation-related parameters except for the number of days of rain). 
Table 1.10. UNESCO-FAO bioclimatic classification of the Columbretes islands:

\begin{tabular}{|c|c|c|c|c|}
\hline Parameters* & Studied period & Result & Criteria & Climate \\
\hline \multirow{3}{*}{ Hot season } & Total series (52 years) & From June to October & \multirow{3}{*}{$\mathrm{T}$ med $>20^{\circ} \mathrm{C}$} & \\
\hline & 1st period (18 years) & From June to September & & \\
\hline & 2nd period ( 24 years) & From June to October & & \\
\hline \multirow{3}{*}{$\mathrm{T}_{\min }$} & Total series (52 years) & $8.64^{\circ} \mathrm{C}$ & \multirow{3}{*}{$0^{\circ} \mathrm{C}<\mathrm{T} \min <10^{\circ} \mathrm{C}$} & \\
\hline & 1st period (18 years) & $7.25^{\circ} \mathrm{C}$ & & Temperate (Group I) \\
\hline & 2nd period ( 24 years) & $9.78^{\circ} \mathrm{C}$ & & \\
\hline \multirow{3}{*}{$\begin{array}{l}\text { Number of dry } \\
\text { seasons } * *\end{array}$} & Total series (52 years) & 1 & \multirow{6}{*}{$\begin{array}{l}\text { When the ombrographic curve } \\
\text { sinks below the thermic curve } \\
\qquad(\mathrm{P}<2 \mathrm{~T})\end{array}$} & Monoxeric \\
\hline & 1st period (16 years) & 2 & & Bixeric \\
\hline & 2nd period ( 24 years) & 1 & & Monoxeric \\
\hline \multirow{3}{*}{ Dry months** } & Total series (52 years) & From February to August & & Mediterranean*** \\
\hline & 1st period (16 years) & $\begin{array}{c}\text { From January to } \\
\text { September and November }\end{array}$ & & \\
\hline & 2 nd period ( 24 years) & From February to August & & Mediterranean*** \\
\hline \multirow{3}{*}{$\begin{array}{l}\text { Annual xerothermic } \\
\text { index } * * * *\end{array}$} & Total series (37 years) & 130.95 & $125<x<150$ & $\begin{array}{l}\text { Thermomediterranean with a long dry } \\
\text { season }\end{array}$ \\
\hline & 1st period (13 years) & $\begin{array}{l}204.84 \text { (Jan-Sept) } \\
22.10 \text { (Nov.) }\end{array}$ & & Attenuated hot sub-desert \\
\hline & $2 n d^{\text {nd }}$ period ( 24 years) & 116.17 & $100<x<125$ & $\begin{array}{c}\text { Thermomediterranean attenuated with a } \\
\text { shorter dry season }\end{array}$ \\
\hline
\end{tabular}

${ }^{*} \mathrm{~T}_{\min }=$ the monthly mean temperatures of the coldest months $\left({ }^{\circ} \mathrm{C}\right)$

**According to the ombrothermic diagrams

***Climates in Group I with dry seasons of from 1 to 8 months are classed as Mediterranean if the dry season coincides with the period of longest daylight.

$* * * *$ Summation of the index of hot weather drought of each dry month/year: $\mathrm{Xm}=(\mathrm{N}-(\mathrm{p}+(\mathrm{b} / 2)) \times f$ 
Table 1.11. Köppen-Geiger climate classification (Koteck, 2006) of the Columbretes islands:

\begin{tabular}{ccccccc}
\hline Studied period & $\mathbf{T}_{\min }\left({ }^{\circ} \mathbf{C}\right)$ & $\mathbf{P}_{\text {ann }}(\mathbf{m m})$ & $\mathbf{T}_{\text {ann }}\left({ }^{\circ} \mathrm{C}\right)$ & $\mathbf{P}_{\text {th }}$ & Criteria & Climate \\
\hline Total series & 8.64 & 337.89 & 18.00 & & $\mathrm{~T}_{\min }<18^{\circ} \mathrm{C}$ & Not Equatorial \\
1st period & 7.25 & 234.89 & 17.57 & $\left(2 \times \mathrm{T}_{\mathrm{ann}}\right)+14$ & $\mathrm{P}_{\mathrm{ann}}<10^{*} \mathrm{P}_{\mathrm{th}}$ & B. Arid climates \\
2nd period & 9.78 & 407.52 & 18.41 & & $\mathrm{P}_{\mathrm{ann}}>5^{*} \mathrm{P}_{\mathrm{th}}$ & BS. Steppe climate \\
\hline Total series & & & & & $\mathrm{T}_{\mathrm{ann}} \geq 18^{\circ} \mathrm{C}$ & BSh. Hot Steppe \\
1st period & & & & & $\mathrm{T}_{\mathrm{ann}}<18^{\circ} \mathrm{C}$ & BSk. Cold Steppe \\
2nd period & & & & & $\mathrm{T}_{\mathrm{ann}} \geq 18^{\circ} \mathrm{C}$ & BSh. Hot Steppe \\
\hline
\end{tabular}

$\mathrm{T}_{\min }=$ the monthly mean temperatures of the coldest months $\left({ }^{\circ} \mathrm{C}\right)$

$P_{\text {ann }}=$ accumulated annual precipitation ( $\mathrm{mm} /$ year)

$\mathrm{T}_{\mathrm{ann}}=$ annual mean near-surface $(2 \mathrm{~m})$ temperature

$P_{\text {th }}=$ dryness threshold $(\mathrm{mm})$

Table 1.12. Köppen-Trewartha (Trewartha, 1968 and Simons, 2001) climate classification of the Columbretes islands:

\begin{tabular}{ccccccccc}
\hline Studied period & $\mathbf{T}\left({ }^{\circ} \mathbf{C}\right)$ & $\mathbf{2 . 3 \times T}$ & $\mathbf{P}_{\mathbf{w}}(\mathbf{\%})$ & $\mathbf{0 . 6 4 \times \mathbf { P } _ { \mathbf { w } }}$ & $\mathbf{R}$ & $\mathbf{P}_{\text {mean }}(\mathbf{c m})$ & Criteria & Climate \\
\hline Total series & 18.00 & 41.40 & 25.45 & 16.29 & 66.11 & 33.79 & $\begin{array}{c}\mathrm{P}_{\text {mean }}<\mathrm{R} \text { and } \\
(\mathrm{R} / 2)<\mathrm{P}_{\text {mean }}<\mathrm{R}\end{array}$ & $\mathrm{BS}$ \\
\hline 1st period & 17.57 & 40.41 & 26.18 & 16.76 & 64.66 & 23.49 & $\begin{array}{c}\mathrm{P}_{\text {mean }}<\mathrm{R} \text { and } \\
\mathrm{P}_{\text {mean }}<\mathrm{R} / 2\end{array}$ & $\mathrm{BW}$ \\
\hline 2nd period & 18.41 & 42.34 & 24.64 & 15.77 & 67.57 & 40.75 & $\begin{array}{c}\mathrm{P}_{\text {mean }}<\mathrm{R} \text { and } \\
(\mathrm{R} / 2)<\mathrm{P}_{\text {mean }}<\mathrm{R}\end{array}$ & $\mathrm{BS}$ \\
\hline
\end{tabular}

$\mathrm{T}=$ mean annual temperature $\left({ }^{\circ} \mathrm{C}\right)$

$P_{\text {mean }}=$ accumulated annual precipitation $(\mathrm{cm} /$ year)

$\mathrm{P}_{\mathrm{w}}=$ percentage of annual precipitation occurring in winter

$\mathrm{R}=$ Patton's precipitation threshold, defined as $\mathrm{R}=(2.3 \times \mathrm{T})-\left(0.64 \times \mathrm{P}_{\mathrm{w}}\right)+41$ 
Therefore, our hypothesis that increasingly higher precipitation at Columbretes during the whole study period should be attributed to a deficient recording of daily precipitation remains doubtful, as this has been also the case for Palma de Mallorca and a few additional places in the NE of the Iberian Peninsula (Quereda, 1999). Such a trend is an exception to what predictions about climate change for the Mediterranean basin say (IPCC, 2016) and to what we have actually documented for the other three locations (Table 1.13, Annex 1.6). Further research aimed at confirming these results in this part of the Mediterranean are therefore needed.

When we further compared the results during the two time periods, we found that for the first period, the same trends were observed in all cases except for absolute maximum temperature (only Almeria responded as Columbretes) as well as for mean minimum temperature and number of days of rain for Almeria only (Table 1.14, Annex 1.6). In general, during this period, temperatures were closer to Palma de Mallorca and Castelló but precipitation was closer to the other two stations (Table 1.15). During the second period the same trends were observed at all five locations (Table 1.16, Annex 1.6). However, during that period both maximum and minimum temperatures showed a smaller range of variation in Columbretes than in the other stations, which may be attributed to the insularity of Columbretes with a much higher buffering effect of the sea on a relatively much smaller emerged area. Mean temperature and precipitation values closely matched the values registered in Castelló (Table 1.17).

The climate classification concept has been widely used in a large number of climate and climate change research (Chen \& Chen, 2013), physical geography, hydrology, agriculture, biology and educational aspects and the most frequently used climate classification map is that of Wladimir Köppen, presented in its latest version 1961 by Rudolf Geiger (Kottek et al, 2006). Kottek et al., 2006, published the first digital Köppen-Geiger world map for the second half of $20^{\text {th }}$ century. The Köppen-Geiger system (Köppen, 1936) or Köppen-Trewartha modification which adjusted the original temperature criteria and the thresholds separating wet and dry climates of the Köppen classification, are usually utilized (Belda et al., 2014). 
Table 1.13. Comparison of the slopes of the regression lines of the total series for the parameters of each station in relation with the Columbretes station ( $\mathrm{T}=$ temperature; $\mathrm{P}=$ precipitation):

\begin{tabular}{lcccccccc}
\hline \multicolumn{1}{c}{ STATION } & \multicolumn{2}{c}{ Palma (Mallorca) } & \multicolumn{2}{c}{ Alacant } & \multicolumn{2}{c}{ Castelló/Almassora } & \multicolumn{2}{c}{ Almeria/Níjar } \\
\hline \multicolumn{1}{c}{ Parameter } & $\boldsymbol{t}$ & $\boldsymbol{p}$ & $\boldsymbol{t}$ & $\boldsymbol{p}$ & $\boldsymbol{t}$ & $\boldsymbol{p}$ & $\boldsymbol{t}$ & $\boldsymbol{p}$ \\
\hline Monthly absolute maximum T & 2.130 & 0.033 & 0.333 & 0.739 & 1.683 & 0.092 & -0.155 & 0.877 \\
Monthly mean maximum T & 2.008 & 0.045 & 0.009 & 0.993 & 1.766 & 0.077 & 1.597 & 0.110 \\
Monthly absolute minimum T & -0.471 & 0.638 & -1.828 & 0.0677 & -3.088 & 0.002 & -1.761 & 0.078 \\
Monthly mean minimum T & -0.244 & 0.807 & -1.245 & 0.213 & -2.580 & 0.010 & -2.296 & 0.022 \\
Monthly mean T & 0.884 & 0.377 & -0.653 & 0.514 & -0.422 & 0.673 & -0.368 & 0.713 \\
Number of days of rain & -2.543 & 0.011 & -6.105 & $<0.001$ & -2.909 & 0.004 & -7.397 & $<0.001$ \\
Monthly mean accumulated P & -1.561 & 0.119 & -3.401 & $<0.001$ & -2.157 & 0.031 & -2.795 & 0.005 \\
Maximum P in 24h & -0.878 & 0.380 & -2.985 & 0.003 & -1.076 & 0.282 & -2.652 & 0.008 \\
Annual mean accumulated P & -1.679 & 0.094 & -4.053 & $<0.001$ & -2.654 & 0.008 & -3.453 & 0.001 \\
\hline
\end{tabular}

Table 1.14. Comparison of the slopes of the regression lines of the 1st period (1940-1957 for T; $1940-1956$ for $P$ ) for the parameters of each station in relation with the Columbretes station ( $\mathrm{T}=$ temperature; $\mathrm{P}=$ precipitation):

\begin{tabular}{lcccccccc}
\hline \multicolumn{1}{c}{ Station } & \multicolumn{1}{c}{ Palma (Mallorca) } & \multicolumn{2}{c}{ Alacant } & \multicolumn{3}{c}{ Castelló/Almassora } & \multicolumn{3}{c}{ Almeria/Níjar } \\
\hline \multicolumn{1}{c}{ Parameter } & $\boldsymbol{t}$ & $\boldsymbol{p}$ & $\boldsymbol{t}$ & $\boldsymbol{p}$ & $\boldsymbol{t}$ & $\boldsymbol{p}$ & $\boldsymbol{t}$ & $\boldsymbol{p}$ \\
\hline Monthly absolute maximum T & -2.673 & 0.008 & -2.059 & 0.040 & -2.609 & 0.009 & -0.063 & 0.950 \\
Monthly mean maximum T & -1.879 & 0.061 & -1.308 & 0.191 & -1.865 & 0.062 & -0.373 & 0.709 \\
Monthly absolute minimum T & 1.253 & 0.211 & 0.607 & 0.544 & -0.109 & 0.913 & -1.927 & 0.054 \\
Monthly mean minimum T & 0.059 & 0.953 & -0.309 & 0.757 & -0.904 & 0.366 & -2.400 & 0.017 \\
Monthly mean T & -0.848 & 0.396 & -0.757 & 0.449 & -1.326 & 0.185 & -1.304 & 0.193 \\
Number of days of rain & -0.880 & 0.379 & 0.439 & 0.660 & 1.151 & 0.250 & -2.727 & 0.007 \\
Monthly mean accumulated P & -0.577 & 0.564 & -0.164 & 0.870 & -0.459 & 0.647 & 0.846 & 0.398 \\
Maximum P in 24h & -0.061 & 0.951 & -0.149 & 0.882 & 0.220 & 0.826 & 1.395 & 0.163 \\
Annual mean accumulated P & -0.511 & 0.611 & -0.133 & 0.894 & 0.392 & 0.696 & 1.500 & 0.138 \\
\hline
\end{tabular}


Table 1.15. Comparison of the mean of the regression lines of the 1st period for the parameters of each station (the locations are Almeria, Alm; Palma de Mallorca, PM; Castelló, CS; and Alacant, Ala) in which there were no significant differences in slopes, in relation with the Columbretes station, Col ( $T$ = temperature; $\mathrm{P}=$ precipitation; $\mathrm{NA}=$ not available data):

\begin{tabular}{|c|c|c|c|c|c|c|c|c|c|}
\hline \multirow{2}{*}{$\begin{array}{c}\text { Station } \\
\text { Parameter }\end{array}$} & \multicolumn{2}{|c|}{ Palma (PM) } & \multicolumn{2}{|c|}{ Alacant (Ala) } & \multicolumn{2}{|c|}{ Castelló/Almassora (CS) } & \multicolumn{2}{|c|}{ Almeria/Níjar (Alm) } & \multirow{2}{*}{ Ranking } \\
\hline & $\mathbf{t}$ & p & $\mathbf{t}$ & $p$ & $\mathbf{t}$ & p & $\mathbf{t}$ & $p$ & \\
\hline Monthly absolute maximum T & NA & NA & NA & NA & NA & NA & 5.884 & $<0.001$ & $\mathrm{Col}<\mathrm{Alm}$ \\
\hline Monthly mean maximum $\mathrm{T}$ & -0.417 & 0.677 & 4.587 & $<0.001$ & 0.898 & 0.369 & 2.138 & 0.033 & $\mathrm{Col}=\mathrm{PM}, \mathrm{CS}<\mathrm{Ala}, \mathrm{Alm}$ \\
\hline Monthly absolute minimum T & -2.187 & 0.029 & -3.616 & $<0.001$ & -2.442 & 0.015 & -0.905 & 0.366 & $\mathrm{Col}=\mathrm{Alm}>\mathrm{PM}, \mathrm{Ala}, \mathrm{CS}$ \\
\hline Monthly mean minimum T & -2.205 & 0.028 & -3.522 & $<0.001$ & -2.282 & 0.023 & NA & NA & Col > Pm, Ala, CS \\
\hline Monthly mean T & -1.226 & 0.221 & 0.732 & 0.464 & -0.575 & 0.565 & 0.669 & 0.504 & Col = PM, Ala, CS, Alm \\
\hline Number of days of rain & 9.682 & $<0.001$ & 10.677 & $<0.001$ & 8.245 & $<0.001$ & NA & NA & $\mathrm{Col}<\mathrm{Pm}$, Ala, CS \\
\hline Monthly mean accumulated $\mathrm{P}$ & 3.726 & $<0.001$ & 1.292 & 0.196 & 3.501 & $<0.001$ & 0.744 & 0.457 & $\mathrm{Col}=\mathrm{Ala}, \mathrm{Alm}<\mathrm{PM}, \mathrm{CS}$ \\
\hline Maximum $P$ in $24 h$ & 0.285 & 0.775 & 0.764 & 0.445 & 0.966 & 0.334 & 0.618 & 0.536 & $\mathrm{Col}=\mathrm{PM}, \mathrm{Ala}, \mathrm{CS}, \mathrm{Alm}$ \\
\hline Annual mean accumulated $P$ & 4.392 & $<0.001$ & 2.468 & 0.016 & 4.839 & $<0.001$ & 1.643 & 0.105 & $\mathrm{Col}=\mathrm{Alm}<\mathrm{PM}, \mathrm{Ala}, \mathrm{CS}$ \\
\hline
\end{tabular}

Table 1.16. Comparison of the slopes of the regression lines of the 2 nd period (1992-2015) for the parameters of each station in relation with the Columbretes station ( $\mathrm{T}=$ temperature; $\mathrm{P}=$ precipitation):

\begin{tabular}{lcccccccc}
\hline \multicolumn{1}{c}{ Station } & \multicolumn{2}{c}{ Palma (Mallorca) } & \multicolumn{2}{c}{ Alacant } & \multicolumn{3}{c}{ Castelló/Almassora } & \multicolumn{3}{c}{ Almeria/Níjar } \\
\hline \multicolumn{1}{c}{ Parameter } & $\boldsymbol{t}$ & $\boldsymbol{p}$ & $\boldsymbol{t}$ & $\boldsymbol{p}$ & $\boldsymbol{t}$ & $\boldsymbol{p}$ & $\boldsymbol{t}$ & $\boldsymbol{p}$ \\
\hline Monthly absolute maximum T & -0.211 & 0.833 & 0.209 & 0.834 & 0.060 & 0.952 & -0.575 & 0.565 \\
Monthly mean maximum T & -0.167 & 0.867 & 0.066 & 0.948 & 0.044 & 0.965 & -0.902 & 0.367 \\
Monthly absolute minimum T & -1.111 & 0.267 & -0.797 & 0.426 & -0.288 & 0.773 & 0.253 & 0.800 \\
Monthly mean minimum T & -0.770 & 0.441 & -0.449 & 0.654 & -0.033 & 0.974 & 0.621 & 0.535 \\
Monthly mean T & -0.456 & 0.649 & -0.170 & 0.865 & 0.025 & 0.980 & 0.015 & 0.988 \\
Number of days of rain & 0.828 & 0.408 & -0.238 & 0.812 & -0.188 & 0.851 & -0.497 & 0.619 \\
Monthly mean accumulated P & 0.342 & 0.732 & -0.473 & 0.636 & -0.094 & 0.925 & -0.657 & 0.511 \\
Maximum P in 24h & 0.718 & 0.473 & -0.633 & 0.527 & 0.144 & 0.886 & -0.898 & 0.369 \\
Annual mean accumulated P & 0.283 & 0.778 & -0.417 & 0.678 & 0.052 & 0.959 & -0.549 & 0.584 \\
\hline
\end{tabular}


Table 1.17. Comparison of the mean of the regression lines of the 2 nd period for the parameters of each station (the locations are Almeria, Alm; Palma de Mallorca, PM; Castelló, CS; and Alacant, Ala) in which there were no significant differences in slopes, in relation with the Columbretes station, Col ( $T$ = temperature; $\mathrm{P}=$ precipitation):

\begin{tabular}{|c|c|c|c|c|c|c|c|c|c|}
\hline \multirow{2}{*}{$\begin{array}{c}\text { Station } \\
\text { Parameter }\end{array}$} & \multicolumn{2}{|c|}{ Palma (PM) } & \multicolumn{2}{|c|}{ Alacant (Ala) } & \multicolumn{2}{|c|}{ Castelló/Almassora (CS) } & \multicolumn{2}{|c|}{ Almeria/Níjar (Alm) } & \multirow{2}{*}{ Ranking } \\
\hline & $\mathbf{t}$ & $\mathbf{p}$ & $\mathbf{t}$ & $\mathbf{p}$ & $\mathbf{t}$ & $\mathbf{p}$ & $\mathbf{t}$ & $\mathbf{p}$ & \\
\hline Monthly absolute maximum $\mathrm{T}$ & 5.525 & $<0.001$ & 10.937 & $<0.001$ & 8.746 & $<0.001$ & 8.622 & $<0.001$ & Col < PM, Ala, CS , Alm \\
\hline Monthly mean maximum $T$ & 3.045 & 0.002 & 6.179 & $<0.001$ & 4.175 & $<0.001$ & 6.001 & $<0.001$ & Col < PM, Ala, CS, Alm \\
\hline Monthly absolute minimum $\mathrm{T}$ & -3.417 & $<0.001$ & -7.051 & $<0.001$ & -7.441 & $<0.001$ & -5.644 & $<0.001$ & PM, Ala, CS, Alm < Col \\
\hline Monthly mean minimum $T$ & -2.793 & 0.005 & -5.893 & $<0.001$ & -6.321 & $<0.001$ & -6.559 & $<0.001$ & $\mathrm{PM}, \mathrm{Ala}, \mathrm{CS}, \mathrm{Alm}<\mathrm{Col}$ \\
\hline Monthly mean T & 0.210 & 0.833 & 0.273 & 0.785 & -0.974 & 0.330 & -0.306 & 0.760 & Col = PM, Ala, CS, Alm \\
\hline Number of days of rain & 7.856 & $<0.001$ & 1.378 & 0.169 & 4.586 & $<0.001$ & -8.121 & $<0.001$ & Alm $<\mathrm{Col}=\mathrm{Ala}<\mathrm{PM}, \mathrm{CS}$ \\
\hline Monthly mean accumulated $\mathrm{P}$ & 1.444 & 0.149 & -3.384 & $<0.001$ & 0.476 & 0.634 & -3.632 & $<0.001$ & Ala, $\mathrm{Alm}<\mathrm{Col}=\mathrm{PM}, \mathrm{CS}$ \\
\hline Maximum $P$ in $24 \mathrm{~h}$ & -0.688 & 0.491 & -3.423 & $<0.001$ & -0.137 & 0.891 & -3.634 & $<0.001$ & Ala, $\mathrm{Alm}<\mathrm{Col}=\mathrm{PM}, \mathrm{CS}$ \\
\hline Annual mean accumulated $P$ & 2.153 & 0.034 & -3.305 & 0.001 & 0.965 & 0.337 & -3.785 & $<0.001$ & Ala, $\mathrm{Alm}<\mathrm{Col}=\mathrm{CS}<\mathrm{PM}$ \\
\hline
\end{tabular}




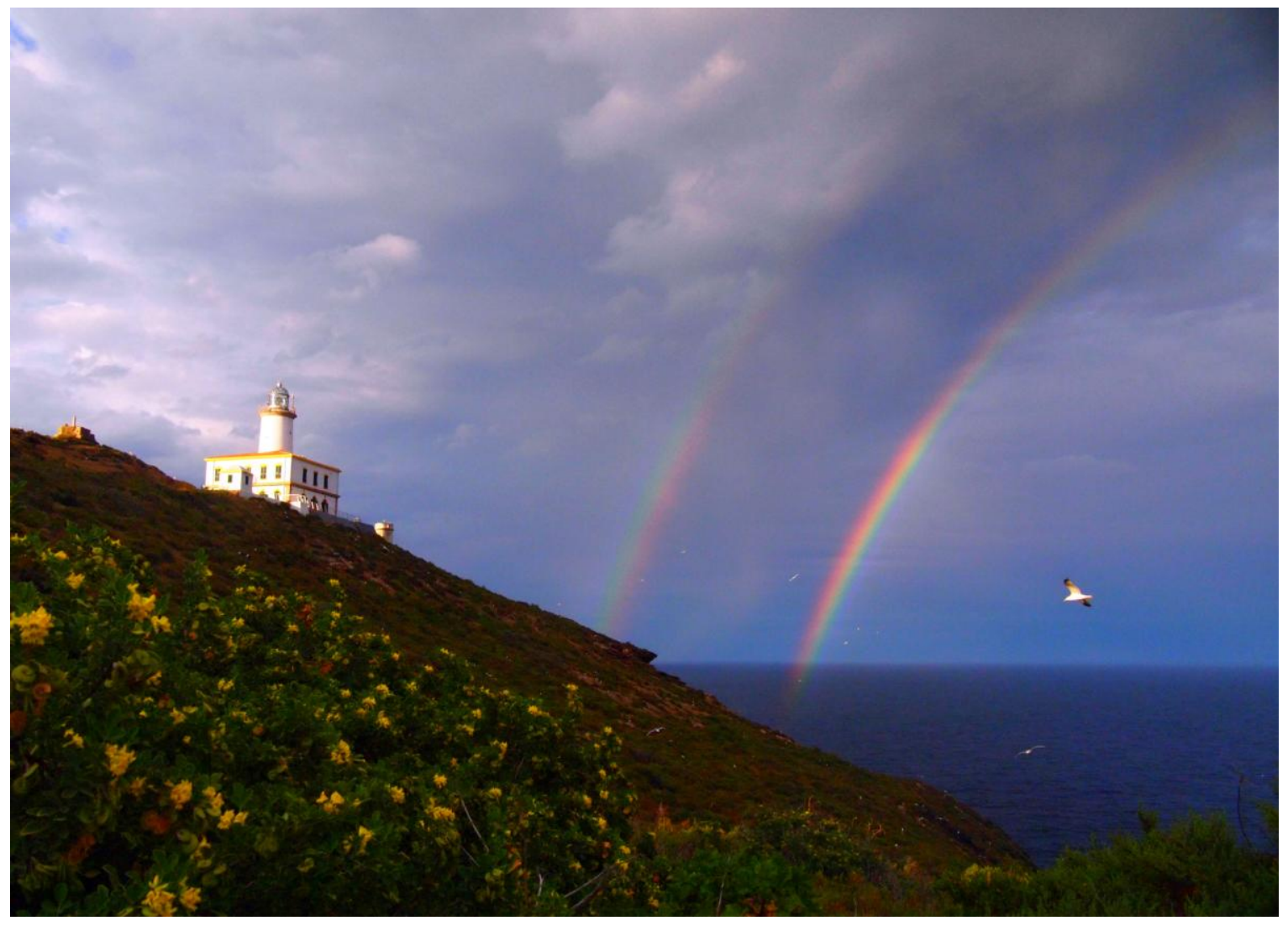

Figure 1.12. Double rainbow after the tempest.

\section{Conclusions}

The data gathered in this study have enormously increased the amount of data available for the classification of the climate of Columbretes (28,324 new records). Based on this new information, we have shown that the climate is now warmer and rainier than 60 years ago. Similar thermal trends have also been documented in nearby stations. However, increasing precipitation has been observed in NE Spain only. Although mean maximum temperatures have not changed in the last century, minimum values have increased, and therefore, nowadays the thermic amplitude of the islands has reduced. Present mean monthly temperature and precipitation values have been estimated at $18.41^{\circ} \mathrm{C}$ and $34.09 \mathrm{~mm}$ (annual mean of $407.52 \mathrm{~mm}$ and 54.70 days of rain per year). Based on these estimations, the current climatic classification of Columbretes is Thermo-Mediterranean attenuated with a shorter dry season, Hot Arid Steppe (BSh), and Semi-arid (BS), according to UNESCO-FAO, Köppen-Geiger and Köppen-Trewartha, respectively. Similar climatic trends have been observed in a few selected nearby climatic stations, with closely matching values corresponding to Castelló. 
Capítol 2

Medi natural:

Catàleg d'invertebrats terrestres 
Capítol 2

Aquest capítol està previst que done origen a dues publicacions: Mestre-Forés, E., S. Montagud, P. González \& J.A. Jaques. Catálogo de los Invertebrados terrestres de las Islas Columbretes, i Mestre-Forés, E., P. González \& J.A. Jaques. Los coleópteros tenebriónidos (Coleoptera, Tenebrionidae) de las Islas Columbretes y su relación con el estado de conservación del ecosistema insular. 


\section{Introducción}

Los invertebrados terrestres de Columbretes han sido objeto de diversos estudios. El primero de ellos fue el realizado por el Archiduque Luis Salvador de Habsburgo-Lorena y Borbón, que lo incluyó como parte de su monografía sobre Columbretes (Habsburg-Lothringen, 1895). Posteriormente, se publicaron los catálogos de Compte (1969) y García-Mari y colaboradores (1991) sobre artrópodos, así como los de Jaeckel (1952) y Robles (1991) sobre gasterópodos, y el de Español (1958), que incluyó información sobre ambos taxones. La primera aportación al conocimiento de la nematofauna de las islas Columbretes la publicó Gadea-Buisán (1974) estudiando las muestras de líquenes sobre roca volcánica básica recolectadas durante una expedición botánica por Xavier Llimona en mayo de 1973 en la Illa Grossa, la Ferrera y la Foradada.

A partir de su visita a la Illa Grossa, Español (1958) catalogó 63 especies de artrópodos, seis de ellas endémicas: los tenebriónidos (Coleoptera; Tenebrionidae) Tentyria pazi Español, 1958 (Figura 2.1), Alphasida bonacherai Español, 1958 (Figura 2.2), Heliopathes littoralis Español, 1958, y Heliopathes forcadelli Español, 1958, el curculiónido (Coleoptera; Curculionidae) Peritelus espanoli Roudier, 1958 y el antocórido (Hemiptera; Anthocoridae) Orius lindbergi Wagner, 1952. En 1964, Compte (1969) visitó la Ferrera y la Foradada, además de la Illa Grossa, y catalogó 11 nuevas especies de coleópteros, 2 de ellas endémicas; los mordélidos Mordellistena (Mordellistena) columbretensis Compte, 1969, y Mordellistenula plutonica Compte, 1969. Posteriormente, García-Marí y colaboradores (1991) publicaron un catálogo de especies de artrópodos de estas islas basado en dos expediciones en que se visitó la llla Grossa, la Ferrera y la Foradada en 1985, así como observaciones realizadas por Víctor Navarro, de la Estación Ornitológica de la Albufera, entre los años 1978 y 1985. En total, identificaron 87 especies de artrópodos, de las cuales, 29 fueron ácaros; y de esas 87 especies, 64 constituyeron nuevas citas para Columbretes, dos de ellas fueron ácaros nuevos para la Ciencia: los oribátidos Zygoribatula lenticulata Mínguez \& Subías, 1986 (Oribatulidae), y Latilamellobates columbreti Mínguez \& Subías, 1986 (Ceratozetidae). En 2008, para la obtención del Diploma de Estudios Avanzados, la autora de esta tesis doctoral realizó un estudio de los ácaros que habitan en especies vegetales de Columbretes y otros espacios naturales protegidos de la provincia de Castellón (Anexo 2.4). En este estudio, y para Columbretes, se identificó las especies de fitoseidos (Mesostigmata; Phytoseiidae) Graminaseius lituatus (Athias-Henriot, 1961), Kampimodromus aberrans (Oudemans, 1930), Typhlodromus (Anthoseius) foenilis Oudemans, 1930, Neoseiulella litoralis (Swirski \& Amitai, 1984) (citada por García-Marí, 1991, como Typhloctonus litoralis), Typhlodromus (Anthoseius) 
rhenanoides Athias-Henriot, 1960 y Typhlodromus (Typhlodromus) phialatus Athias-Henriot, 1960, las tres primeras fueron primera cita para Columbretes pero al no estar publicadas, no forman parte de ningún catálogo todavía. En total, pues, cuando se inició nuestro estudio, se habían catalogado en Columbretes 138 especies de artrópodos terrestres.

En cuanto a los gasterópodos, Jaeckel (1952) citó para Columbretes en su catálogo de los moluscos de las islas españolas del Mediterráneo los siguientes pulmonados: Milax gagates (Draparnaud, 1801) (Milacidae), el endemismo Xerocrassa molinae (Hidalgo, 1883) (Hygromiidae) (Figura 2.3), Ferussacia (Ferussacia) follicula (Gmelin, 1791) (Ferussaciidae), Theba pisana (Muller, 1774) y Cornu aspersum (Muller, 1774) (ambos, Helicidae), las tres últimas especies citadas ya por el archiduque (Habsburg-Lothringen, 1895). Más adelante, en su trabajo de 1958, Español añadió a esta lista de pulmonados a Lauria cylindracea (Da Costa, 1778) (Lauriidae) y Eobania vermiculata (Muller, 1774) (Helicidae). El catálogo se completó en 1991 (Robles, 1991), con las adiciones de Pomatias elegans (Muller, 1774) (Pomatiidae) y Lehmannia valentiana (Ferussac, 1822) (Limacidae). Además, Gasull (1981) puso en duda la filiación de $M$. gagates, y planteó la posibilidad de que en realidad se tratara de $M$. nigricans (Philippi, 1836), una especie más abundante en el litoral de Castellón. En total, pues, cuando se inició esta tesis doctoral, habían sido citadas en Columbretes nueve especies de gasterópodos, dos de las cuales se consideraron extintas (P. elegans y T. pisana) (Robles, 1991).

Respecto a los nematodos, Gadea-Buisán (1974) indicó que las especies obtenidas eran prácticamente las mismas en las tres islas principales, predominando en todas ellas Ditylenchus intermedius (De Man, 1880) (Anguinidae) y Filenchus (=Tylenchus) filiformis (Butschli, 1873) Meyl, 1961 (Tylenchidae), Plectus cirratus Bastian, 1865 (Plectidae), y Panagrolaimus rigidus (Schneider, 1866) (Panagrolaimidae).

En el presente trabajo se ha realizado una recopilación de todos las observaciones de invertebrados terrestres, es decir, no marinos, realizadas en el archipiélago durante el periodo 2004-2013, así como una exhaustiva búsqueda bibliográfica de toda la información publicada sobre la fauna invertebrada terrestre de las Islas Columbretes con el objetivo de actualizar los catálogos existentes, con la identificación de nuevas especies, la constatación de la presencia de especies ya inventariadas y contribuir a ampliar el conocimiento sobre las mismas. 


\section{Material y Métodos}

En este estudio se han utilizado tres métodos distintos para la captura e identificación de la artropodofauna de las Columbretes: trampas de gravedad, avistamientos y colectas.

\section{$\underline{\text { Trampas de gravedad }}$}

Dadas las características del archipiélago, se consideraron cuatro islas para este estudio: la Illa Grossa, el Mancolibre, la Ferrera y la Foradada.

A fin de obtener los resultados más representativos posibles, en la Illa Grossa se eligieron diferentes zonas de muestreo teniendo en cuenta el relieve, la presencia humana, y la mayor o menor cubierta vegetal, distinguiendo finalmente las siguientes 4 zonas (Figura 2.4):

- zona de matorral en el norte de la isla (IMN),

- zona de matorral en el sur de la isla (IMS), menos antropizado que el de la zona norte al estar más aislado y sin presencia de visitantes,

- zona de rocas (IR), y

- zona humanizada (IH), es decir, la que se encuentra alrededor de las casas donde viven los guardas, el faro y el cementerio).

En los otros tres islotes, debido a la dificultad de acceso y su vulnerabilidad, se realizaron muestreos esporádicos, siempre en zona de matorral. Los códigos utilizados fueron TMC, TFE y TFO para el Mancolibre, la Ferrera y la Foradada, respectivamente (Figuras 2.4 a 2.6).

La técnica de captura utilizada fue mediante trampas de gravedad (Figuras 2.7 y 2.8) que consistían en pequeños hoyos realizados en el suelo, en los que se colocó un contenedor en el cual los animales, normalmente artrópodos (aunque también puede utilizarse para anfibios, serpientes o mamíferos), pueden caer pero no pueden escapar (Southwood \& Henderson, 2000). Utilizamos botes de cristal de $6,6 \mathrm{~cm}$ de diámetro y no se colocó ningún tipo líquido conservador, ni atrayente. Los individuos se volvían a liberar tras su conteo/identificación siempre a más de 5 metros de la trampa para no favorecer su recaptura en el mismo dispositivo. En cada una de las zonas de muestreo elegidas, se colocaron tres trampas. Para evitar el brillo que suponía el borde del bote y para que no resultara atractivo para las gaviotas, animal muy abundante en este archipiélago durante todo el año, se colocó una estructura a modo de "tapa" que permitía la entrada de los artrópodos pero no el acceso a las gaviotas. Esta tapa también evitaba que, durante el día, aumentara demasiado la temperatura en las trampas. 
En la Illa Grossa se colocaron un total de 12 trampas, 3 en cada una de las 4 zonas (IMN, IMS, $I R, I H)$. La elección de los puntos donde colocar cada trampa dentro de cada hábitat fue realizada de manera aleatoria pero teniendo en cuenta que el acceso fuera fácil (Figura 2.4 y Anexo 2.1).

Se realizaron 3 ciclos anuales de muestreo, desde agosto 2008 hasta julio 2011, normalmente entre el 10 y el 15 de cada mes (salvo que las circunstancias lo impidieran), se realizó el proceso descrito a continuación:

- Día 1: se colocaban las trampas de caída al anochecer, que se mantenían abiertas y en su lugar durante las siguientes 72 horas.

- Días 2, 3 y 4: se realizaban dos visitas a las trampas cada día, a primera hora de la mañana y al anochecer, en las cuales se contaban ejemplares, se recolectaban y/o fotografiaban especies.

- Tras 72 horas de exposición se recogían las trampas al anochecer.

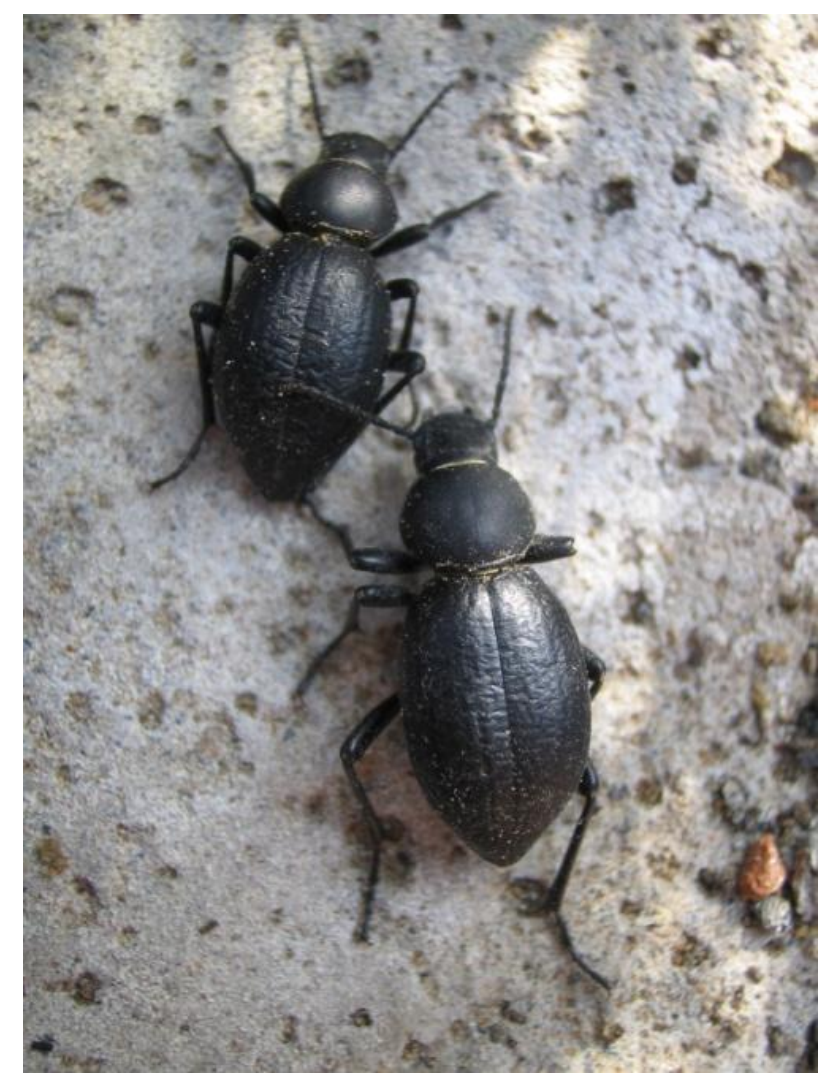

Figura 2.1. Tentyria pazi (Coleoptera; Tenebrionidae), endemismo de Columbretes, se encuentra en la Illa Grossa, el Mancolibre, la Ferrera y la Foradada. 
Medi natural: catàleg d'invertebrats terrestres

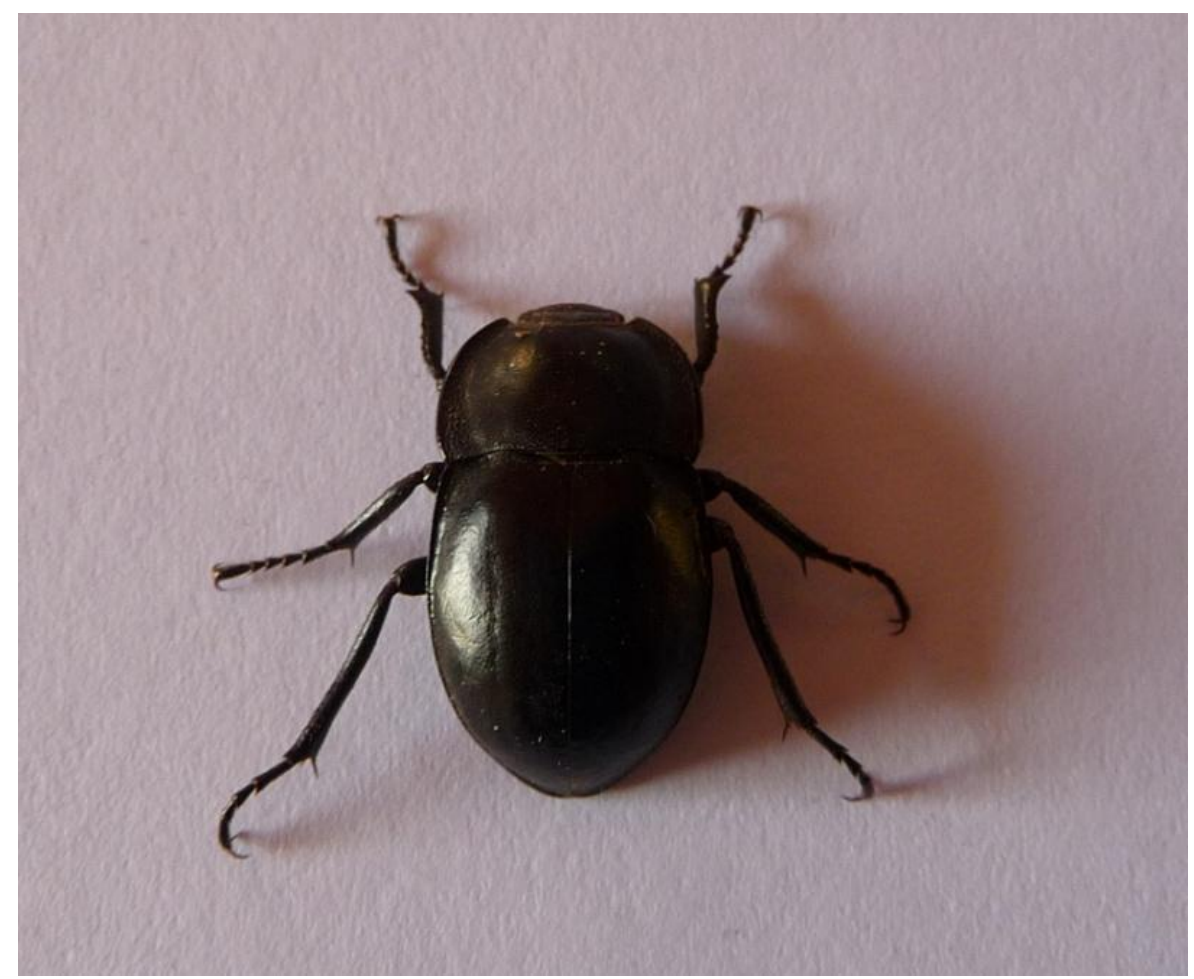

Figura 2.2. Alphasida bonacherai (Coleoptera; Tenebrionidae), endemismo de Columbretes, se encuentra en la Illa Grossa y en la Ferrera.

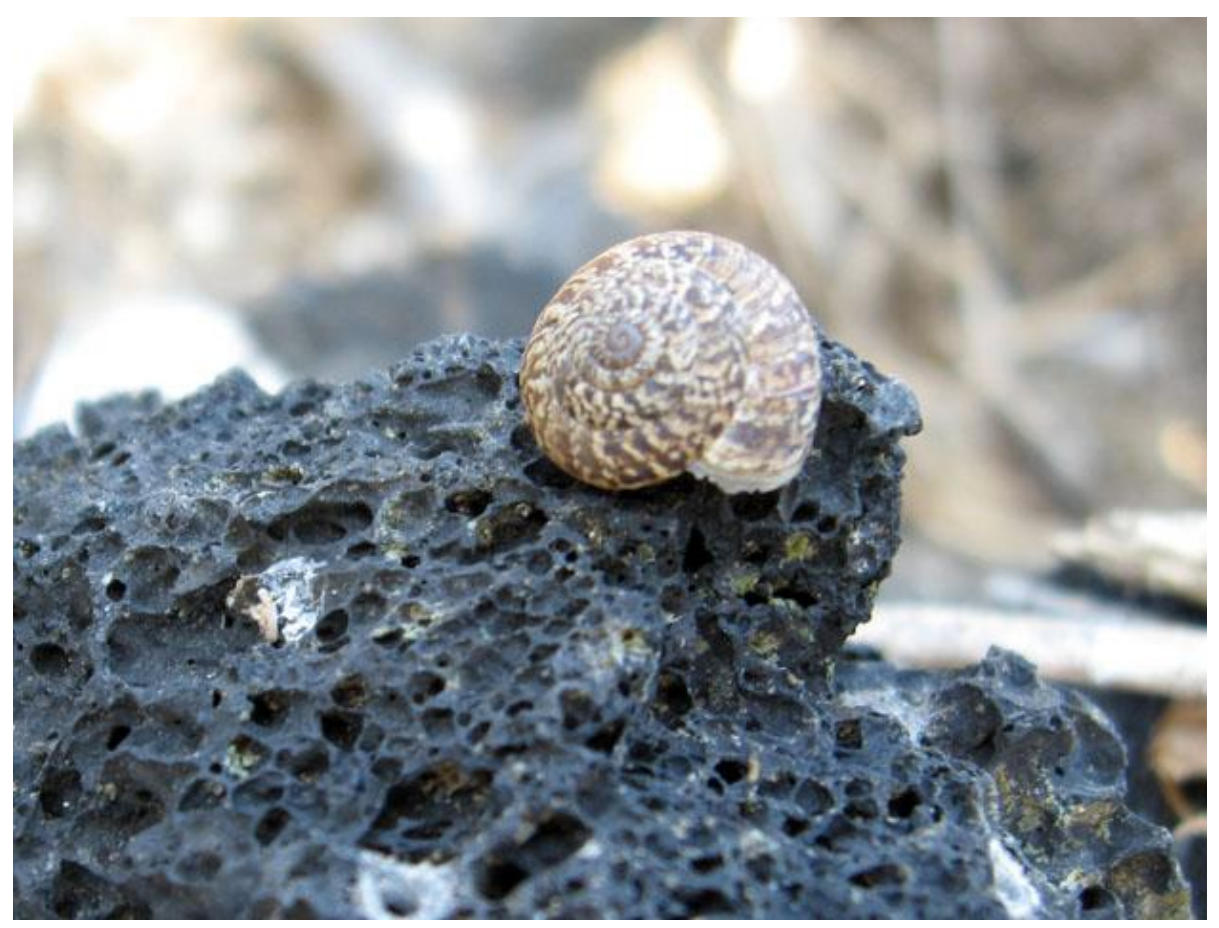

Figura 2.3. Xerocrassa molinae (Pulmonata; Higromiidae), endemismo de Columbretes, se encuentra en la Illa Grossa y en el Mancolibre. 


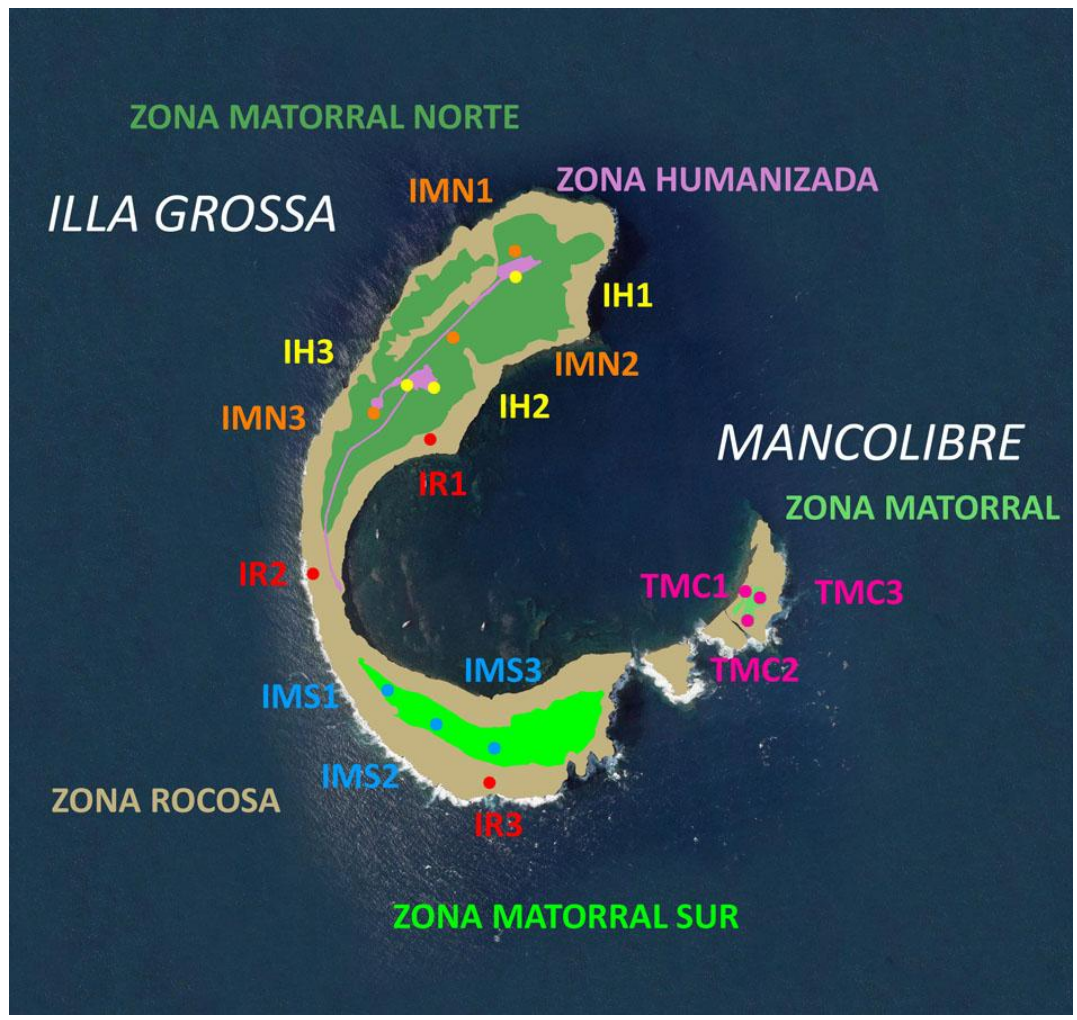

Figura 2.4. Localización de las diferentes zonas en que se dividió la Illa Grossa, de la zona de matorral del Mancolibre y ubicación de las trampas de gravedad.

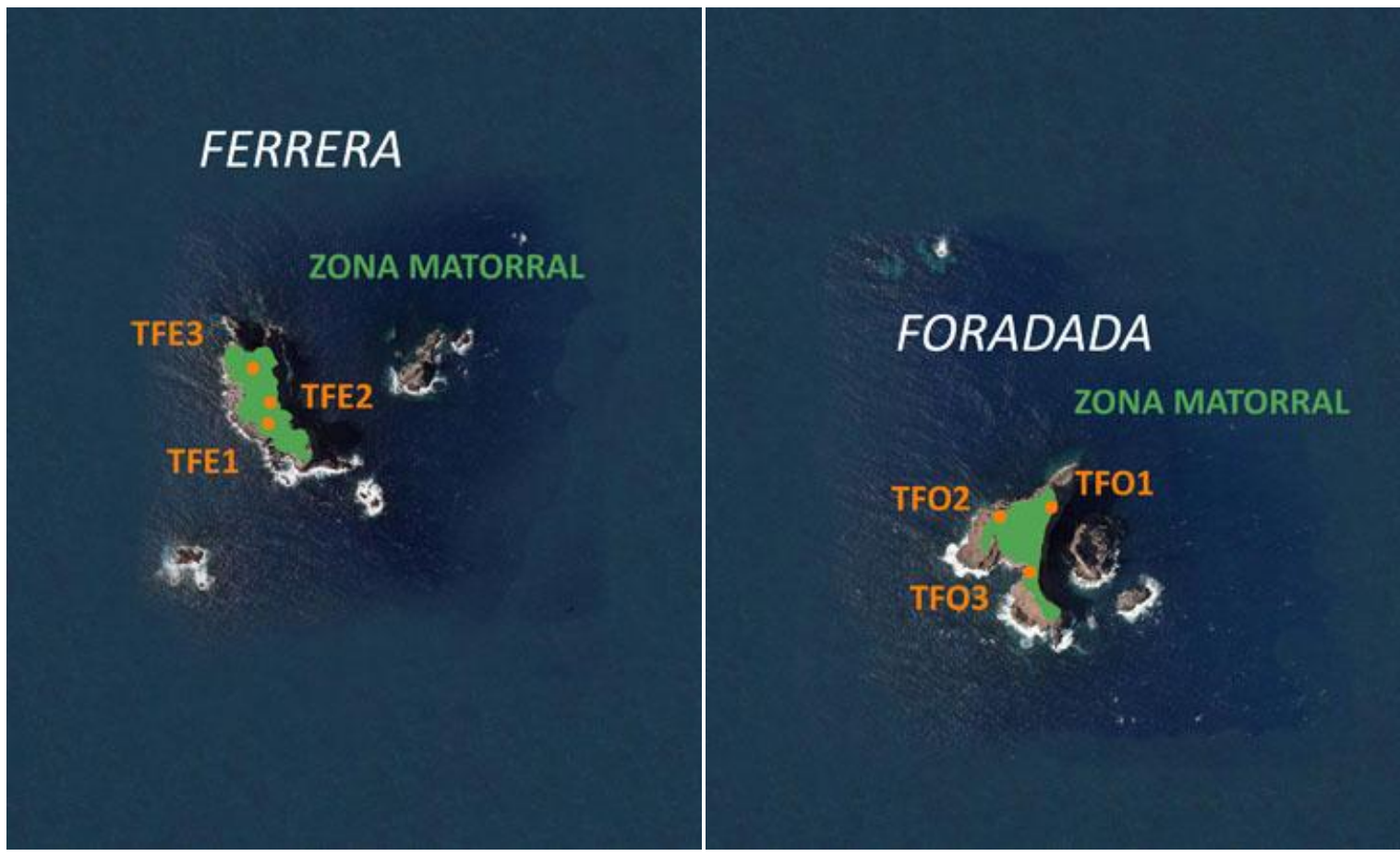

Figura 2.5. Localización de la zona de matorral de la Ferrera y ubicación de las trampas de gravedad.
Figura 2.6. Localización de la zona de matorral de la Foradada y ubicación de las trampas de gravedad. 
Medi natural:

catàleg d'invertebrats terrestres

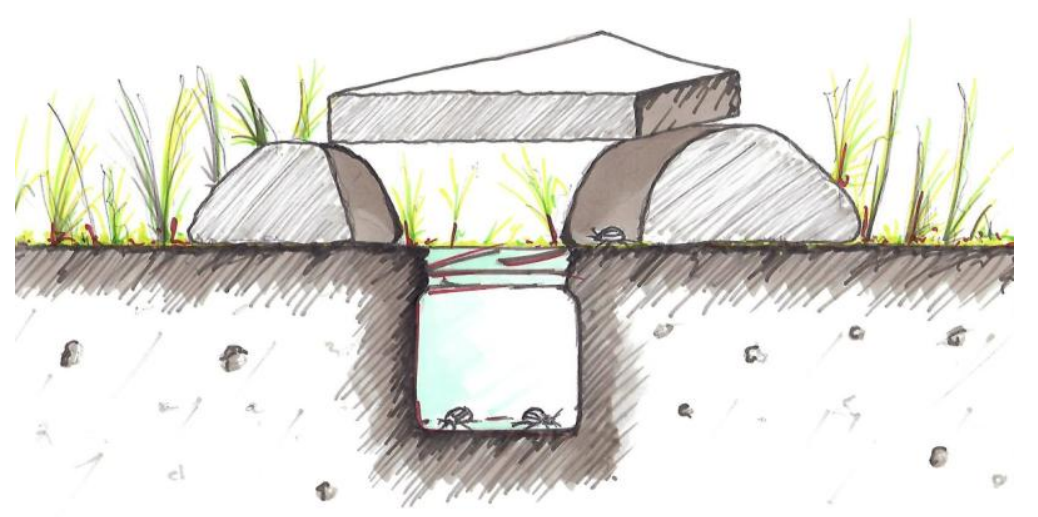

Figura 2.7. Trampa de gravedad.

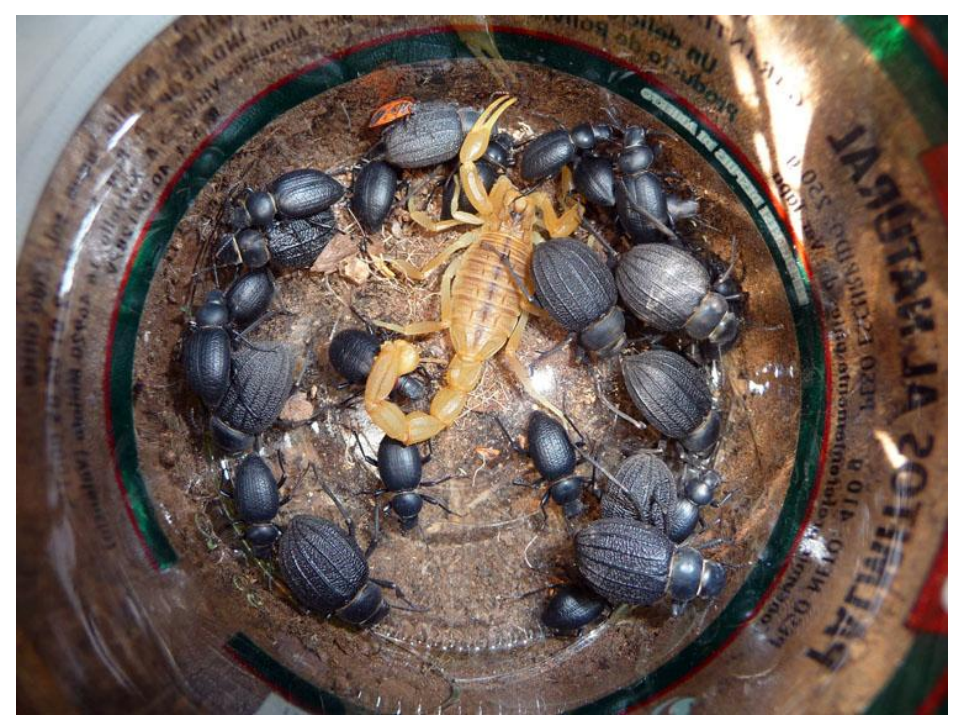

Figura 2.8. Interior de una trampa de gravedad en uno de los muestreos.

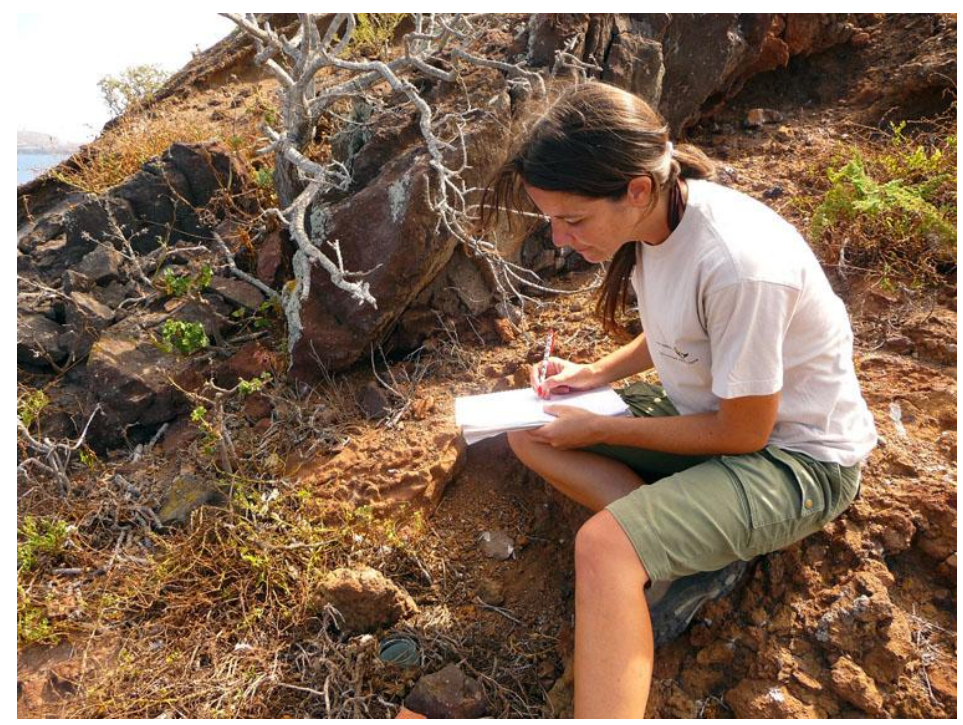

Figura 2.9. Revisando una trampa de gravedad en la Foradada. 
Este muestreo permitió ampliar el conocimiento sobre los hábitos diurnos o nocturnos de las especies capturadas, su abundancia y su diversidad.

Por motivos logísticos, la Ferrera, la Foradada y el Mancolibre se visitaron únicamente de 5-7 veces a lo largo de los tres años de estudio. En la Foradada se colocaron las trampas durante una noche en cada uno de los siguientes meses: junio y julio de 2008 , julio de 2009 , agosto y septiembre de 2010 y marzo de 2011. En la Ferrera, se colocaron las trampas durante una noche en cada uno de los siguientes meses: junio y julio de 2008 , julio de 2009 , mayo, agosto y septiembre de 2010 y marzo de 2011. En el Mancolibre, se colocaron las trampas durante una noche en cada uno de los siguientes meses: agosto de 2009, mayo, agosto y septiembre de 2010 y febrero de 2011. En estas ocasiones, los muestreos se realizaron durante 12 horas, tan sólo durante las horas nocturnas, ya que estas eran las de mayor actividad y, por la fragilidad de estas islas no era conveniente realizar más visitas que las estrictamente necesarias. Por tanto, se colocaron las trampas antes del anochecer para recogerlas a la mañana siguiente (Anexo 2.1 y Figuras 2.4 a 2.6).

En cada visita a las trampas, se anotaba el número total de ejemplares de cada especie (Figura 2.9) y se procedía a soltarlos tal como se ha descrito anteriormente. Los artrópodos que no estaban aún identificados se fotografiaban o se conservaban en botes en alcohol de 70 para su posterior identificación con la ayuda de especialistas. Dado que en las trampas de caída, en ocasiones se recogía gran cantidad de individuos de la misma especie, estos constituían un único avistamiento de la especie en cuestión por isla o islote y año a efectos de su catalogación.

Para cada una de las cuatro zonas en que se dividió la Illa Grossa, se calcularon las medias del número de invertebrados capturados por trampa y día. También se calcularon las medias para las capturas diarias por trampa en horario nocturno y diurno. Finalmente, y a partir de estos datos, se calcularon las medias mensuales durante los tres años de estudio. De forma análoga, se estudiaron las capturas de los dos órdenes de insectos más ampliamente representados en las capturas: los coleópteros y los hemípteros.

\section{$\underline{\text { Avistamientos y colectas }}$}

En el caso de la Illa Grossa, complementariamente a las trampas de gravedad, también se tuvo en cuenta las observaciones puntuales de invertebrados que entre 2004 y 2013 realizaron guardas, monitores y técnicos medioambientales de la Reserva Natural de Columbretes. La 
mayoría de estas observaciones tuvieron lugar en la zona IH de la Illa Grossa, alrededor de las casernas.

En todos los casos, o bien se capturaron y se fotografiaron, o se conservaron en alcohol 70응 dentro de pequeños frascos debidamente etiquetados (que es lo que denominaremos "colecta"), o bien se identificaron en el momento, se fotografiaron y se liberaron (es lo que denominaremos "avistamiento"). Al conjunto de avistamientos y colectas le llamaremos registro. Los datos de recogida de la muestra y fotografiado del individuo se introdujeron en una base de datos que incluía el código de la muestra o fotografía junto con fecha, lugar y comentarios. Las fotografías fueron introducidas en un programa informático debidamente codificadas. Las observaciones realizadas con anterioridad a 2008, de las cuales se disponía de fotografías, fueron introducidas en la misma base de datos siguiendo el procedimiento descrito. Los especímenes conservados en alcohol, así como las fotografías realizadas fueron identificadas con la ayuda de especialistas de la Fundación Entomológica Torres Sala, Museu Valencià d'Història Natural (MVHN), contando también con la ayuda de especialistas en determinados grupos de invertebrados (Anexo 2.2).

\section{Búsqueda bibliográfica}

Tomando como base la recopilación de publicaciones científicas sobre Columbretes realizada por Mestre y colaboradores en 2009 (Tabla 2, apartado "Introducció"), se revisó todos aquellos artículos sobre invertebrados mostrados en dicha recopilación y se amplió la revisión de estudios, publicados o no, hasta la actualidad, mediante búsquedas bibliográficas, consulta en el archivo de Columbretes, tesis doctorales, así como la consulta a las colecciones entomológicas, públicas o privadas, a las que se tuvo acceso.

Con todos los resultados obtenidos, se confeccionó el catálogo de invertebrados citados en las Columbretes, distinguiendo las nuevas especies, es decir, aquéllas encontradas en este estudio por primera vez y las que, aunque ya aparecieran citadas en algún artículo, nunca habían aparecido con anterioridad en ningún catálogo. 


\section{Resultados y Discusión}

A lo largo de los tres años de estudio, en las trampas de gravedad de la Illa Grossa, cayeron y se pudieron contabilizar un total de 13.556 invertebrados pertenecientes a los siguientes taxones (Tabla 2.1):

- Clase Insecta: órdenes Dictyoptera, Coleoptera, Diptera, Hemiptera, Hymenoptera, Orthoptera y Zygentoma

- Clase Malacostraca: orden Isopoda

- Clase Arachnida: órdenes Araneae y Scorpiones

- Clase Chilopoda: orden Scutigeromorpha

- Clase Gastropoda: orden Pulmonata

Del total, 2.004 capturas correspondieron a invertebrados que cayeron en las trampas durante las horas del día y 11.552 lo hicieron durante la noche (Tabla 2.1), por lo que la actividad nocturna parece mucho mayor que la diurna ( 82,5 frente al $17,5 \%$ de las capturas).

En las trampas de gravedad de la Ferrera, la Foradada y el Mancolibre (Tabla 2.2) cayeron un total de 1.275 invertebrados, 419, 424 y 432 en cada isla, respectivamente, de los órdenes Coleoptera (clase Insecta), Isopoda (clase Malacostraca) y Scorpiones (clase Arachnida); además de la orden Orthoptera (clase Insecta) en la Ferrera y de los órdenes Hemiptera, Hymenoptera y Diptera (clase Insecta) y Araneae (clase Arachnida) en la Foradada.

En la Illa Grossa, a lo largo de 3 años completos, se capturó una media de 1.129,67 invertebrados por trampa, de los cuales, 1.002,34 fueron coleópteros tenebriónidos, o lo que es lo mismo, 376,56 invertebrados y 334,11 coleópteros tenebriónidos por trampa y año. Cartagena (2002) realizó muestreos de tenebriónidos en tres islas del litoral valenciano, la Illa Grossa, la Illa de Benidorm y Tabarca, con trampas de gravedad también colocadas durante 72 h, y obtuvo un total de 1.354 tenebriónidos en las tres islas. Muestrearon un total de 30 meses ( 6 en Columbretes y 12 en cada una de las otras islas) en los que capturaron una media de 45,13 tenebriónidos al mes, lo que daría un total de 541,56 tenebriónidos capturados al año en cada isla que muestreó. Al no dar el dato de número de trampas colocadas, no podemos comparar este dato con los 334,11 tenebriónidos por trampa y año obtenidos en nuestro estudio. 
Tabla 2.1. Número de invertebrados caídos en las trampas de gravedad de la Illa Grossa durante el día y la noche, a lo largo de 3 años, agrupados por órdenes. Entre paréntesis se indica el porcentaje respecto a los totales por columna, salvo en el total diurno y nocturno, que se expresa sobre el total final.

\begin{tabular}{|c|c|c|c|c|c|}
\hline Phylum & Clase & Orden & $\begin{array}{c}\text { Caídos durante } \\
\text { el día }\end{array}$ & $\begin{array}{l}\text { Caídos durante } \\
\text { la noche }\end{array}$ & Total \\
\hline \multirow{11}{*}{ Arthropoda } & \multirow{7}{*}{ Insecta } & Coleoptera & $1.410(70,4)$ & $10.618(91,9)$ & $12.028(88,7)$ \\
\hline & & Hemiptera & $542(27,0)$ & $486(4,2)$ & $1.028(7,6)$ \\
\hline & & Zygentoma & 0 & $38(0,3)$ & $38(0,3)$ \\
\hline & & Diptera & $16(0,8)$ & $6(0,1)$ & $22(0,2)$ \\
\hline & & Hymenoptera & $1(<0,1)$ & $14(0,1)$ & $15(0,1)$ \\
\hline & & Dictyoptera & 0 & $11(0,1)$ & $11(0,1)$ \\
\hline & & Orthoptera & 0 & $1(<0,1)$ & $1(<0,1)$ \\
\hline & Malacostraca & Isopoda & $21(1,0)$ & $290(2,5)$ & $311(2,3)$ \\
\hline & \multirow{2}{*}{ Arachnida } & Scorpiones & $3(0,1)$ & $59(0,5)$ & $62(0,5)$ \\
\hline & & Araneae & $5(0,2)$ & $14(0,1)$ & $19(0,1)$ \\
\hline & Chilopoda & Scutigeromorpha & $5(0,2)$ & $14(0,1)$ & $19(0,1)$ \\
\hline Mollusca & Gastropoda & Pulmonata & $1(<0,1)$ & $1(<0,1)$ & $2(<0,1)$ \\
\hline Total & & & $2.004(17,5)$ & $11.552(82,5)$ & $13.556(100)$ \\
\hline
\end{tabular}

Tabla 2.2. Número de invertebrados caídos en las trampas de gravedad de la Ferrera, la Foradada y el Mancolibre durante la noche, agrupados por órdenes. Entre paréntesis se indica el porcentaje respecto del total de cada columna.

\begin{tabular}{cllccc}
\hline \multicolumn{1}{c}{ Phylum } & \multicolumn{1}{c}{ Clase } & Orden & Ferrera & Foradada & Mancolibre \\
\hline & & Coleoptera & $344(82,1)$ & $366(86,3)$ & $251(58,1)$ \\
& \multirow{4}{*}{ Insecta } & Hemiptera & 0 & $2(0,5)$ & 0 \\
\multirow{3}{*}{ Arthropoda } & Diptera & 0 & $1(0,2)$ & 0 \\
& & Hymenoptera & 0 & $1(0,2)$ & 0 \\
& & Orthoptera & $3(0,7)$ & 0 & 0 \\
\cline { 2 - 6 } & Malacostraca & Isopoda & $42(10,0)$ & $24(5,7)$ & $178(41,2)$ \\
\cline { 2 - 6 } & Arachnida & Scorpiones & $30(7,2)$ & $28(6,6)$ & $3(0,7)$ \\
& & Araneae & 0 & $2(0,5 \%)$ & 0 \\
\hline Total & & & $\mathbf{4 1 9}$ & $\mathbf{4 2 4}$ & $\mathbf{4 3 2}$ \\
\hline No meses de muestreo & & & 7 & 5 \\
\hline
\end{tabular}


Capítol 2

Para poder comparar los datos obtenidos en la Ferrera, la Foradada y el Mancolibre con los obtenidos en la Illa Grossa se han corregido las capturas nocturnas (ya que en los islotes sólo se muestreó durante la noche) por el número total de horas que la trampa se mantuvo en su sitio. Así, en la Illa Grossa, durante la noche, cayeron una media de 320,89 invertebrados y 294,94 coleópteros al mes; lo que equivale a 4,46 invertebrados y 4,10 coleópteros por hora nocturna; mientras que en la Ferrera cayeron 4,99 y 4,10 respectivamente, en la Foradada cayeron 5,89 y 5,08 respectivamente y en el Mancolibre, 7,2 y 4,18 respectivamente. Los datos de invertebrados caídos son algo mayores en la Foradada y sobre todo en el Mancolibre, donde cayó una cantidad mucho mayor de isópodos que en las otras islas (Tabla 2.2), mientras que el número de coleópteros fue bastante similar en todas salvo en la Foradada, donde fue algo mayor.

Respecto a órdenes, el de los Coleoptera (todos ellos, tenebriónidos) fue el más numeroso en todos los casos, alcanzando, en la Illa Grossa, un 88,7 \% del total de los invertebrados contabilizados, seguido de Hemiptera con un 7,6 \% e Isopoda con un 2,3 \%. Si contabilizamos únicamente los que cayeron durante el día en la Illa Grossa, el porcentaje cambia un poco, de manera que los Coleoptera descienden hasta el $70,4 \%$, aunque continúa siendo el grupo más numeroso, y continúa seguido de los Hemiptera, que aumentan hasta un $27,0 \%$, mientras que por la noche el porcentaje alcanzado por Coleoptera ascendió a un 91,9\%, seguido de los Hemiptera con un 4,2 \% y los Isopoda con un 2,5\%. En la Foradada, los Coleoptera supusieron el $86,3 \%$ de los invertebrados caídos en las trampas, el $82,1 \%$ en la Ferrera y el $58,1 \%$ en el Mancolibre. 


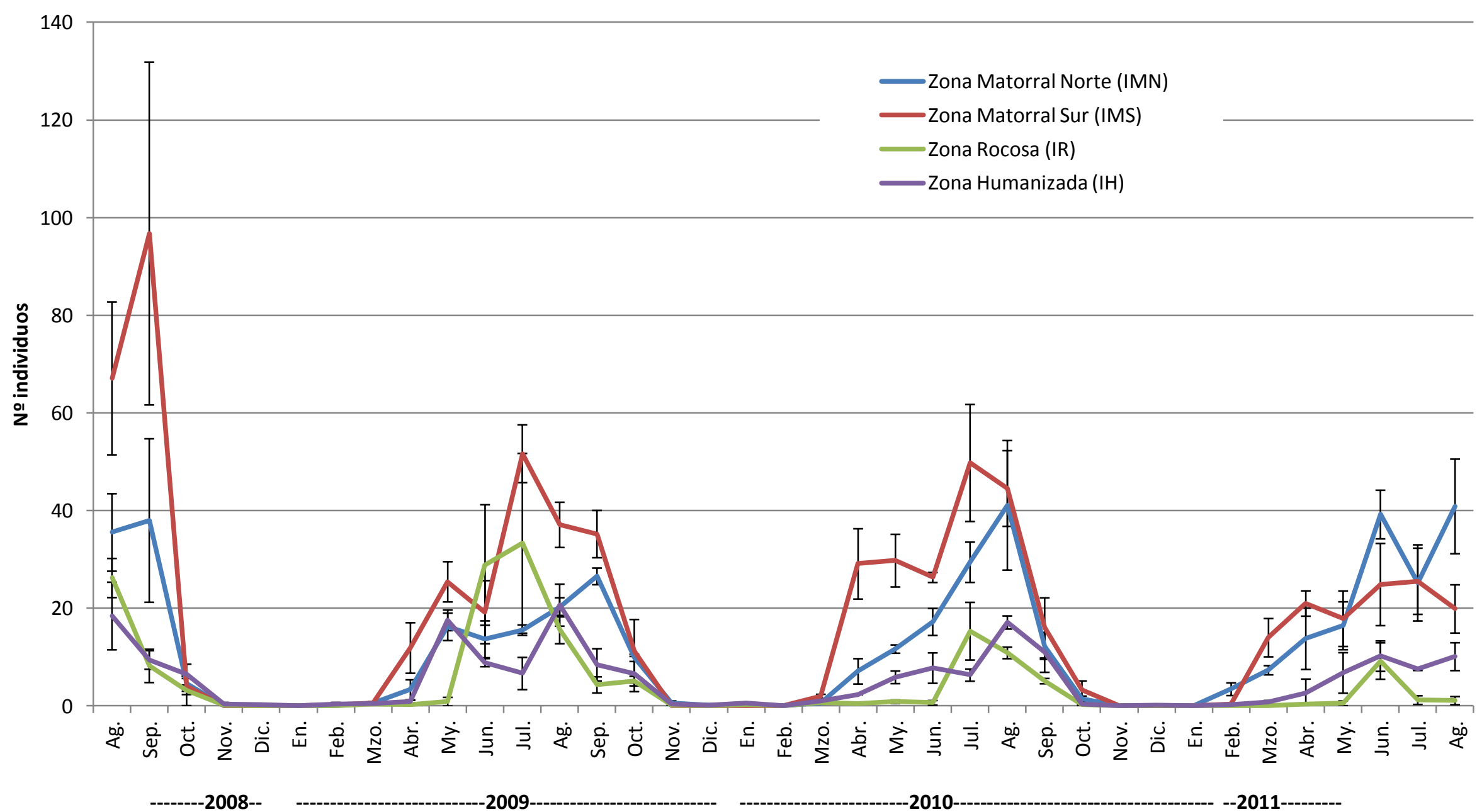

Figura 2.10. Medias del total de invertebrados caídos en las tres trampas de caída situadas en cada zona de la Illa Grossa a lo largo de los tres años de muestreo. 


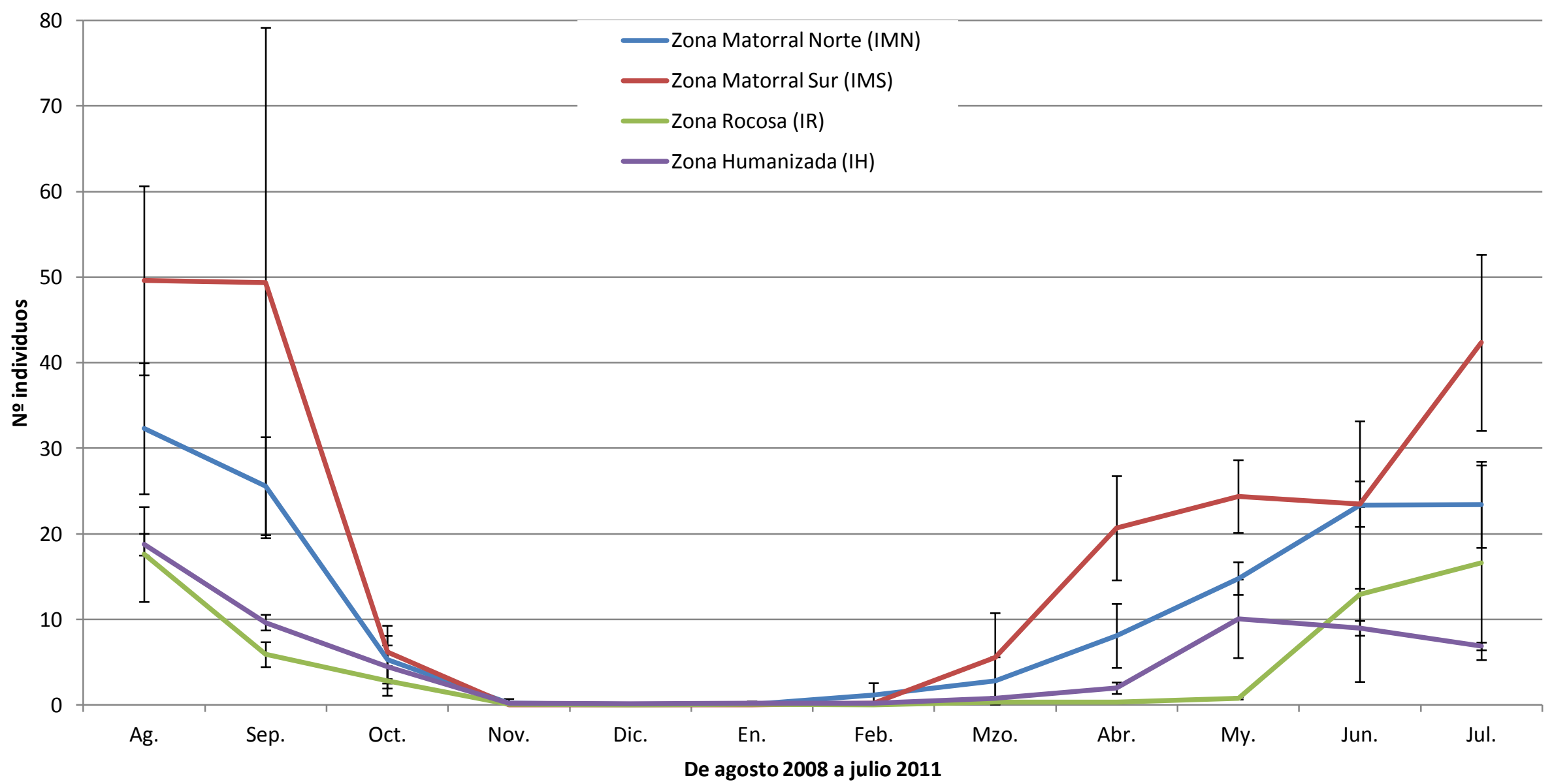

Figura 2.11. Medias mensuales del total de invertebrados caídos en las tres trampas de caída situadas en cada zona de la llla Grossa durante los tres años de muestreo. 
En el Mancolibre, el segundo grupo más numeroso fue el de los Isopoda con un 41,2 \% mientras que tanto en la Foradada como en la Ferrera fueron los Scorpiones, con un 6,6 y un 7,2 \% respectivamente. En estas dos islas, el grupo de los Isopoda alcanzó un 5,7 y un 10,0 \% respectivamente. El resto de familias citadas supusieron menos del 1,0 \% del total de invertebrados caídos en las trampas en cada caso.

Si analizamos la actividad de los invertebrados a lo largo del tiempo en función de las capturas en las trampas de las diferentes zonas de la Illa Grossa (Figura 2.10 y 2.11), se observa que existe un periodo de capturas prácticamente nulas (inferiores a 0,60 especímenes por trampa) entre noviembre y febrero para todas las zonas. Sólo la zona del matorral norte (IMN) en 2011, presentó capturas mayores durante el mes de febrero $(n=3,44$ especímenes, que corresponden a los tenebriónidos Pimelia interjecta Solier, 1836 y Tentyria pazi), lo que hizo que para la media de los 3 años (Figura 2.11) esa zona fuera la más temprana. A partir de marzo, las capturas aumentan de forma paulatina en el resto de zonas hasta que en junio, la zona rocosa, que es la que en general arroja valores más bajos, presenta ya capturas. Durante los tres años, en general, las capturas en las zonas de matorral (IMN e IMS) se han mantenido por encima de del resto, excepto en el mes de junio 2009, en el que las capturas en todas las zonas excepto la humanizada $(\mathrm{IH})$, se solapan. Esta última zona, en general, presenta valores muy parecidos a los de la zona rocosa (IR), y estas dos zonas, que solapan sus valores durante la mayor parte del año, se sitúan por debajo de las capturas en las dos zonas de matorral. Como se podía esperar, el máximo de capturas para todas las zonas se registró en verano (julio a septiembre) y la actividad decreció mucho en octubre, cuando los valores de las cuatro zonas se solaparon de nuevo, antes de caer definitivamente en noviembre para alcanzar los mínimos anuales.

Para estudiar las diferencias entre las capturas diurnas y nocturnas en las diferentes zonas y a lo largo de los 36 meses de estudio, se calcularon las medias (tres trampas por zona y tres visitas por mes) de los órdenes más numerosos, los Coleoptera (Figuras 2.12.a a 2.12.d) y los Hemiptera (Figuras 2.13.a a 2.13.d), que representaron el 88,7 y el $7,6 \%$ del total de las capturas de artrópodos, respectivamente (Tabla 2.1). Las capturas diurnas de los coleópteros fueron inferiores a las nocturnas (1.410 especímenes capturados durante el día frente a 10.618 durante la noche) especialmente en las zonas rocosa (24 frente a 538) y humanizada (68 frente a 1.425), donde fueron mucho menos abundantes que en las zonas de matorral. En éstas, las capturas fueron mayores en la zona sur (936 de día frente a 5.153 durante la noche), donde el acceso de las visitas está restringido y que se hallan a mayor distancia de las zonas humanizadas del norte de la isla (382 frente a 3.502). 


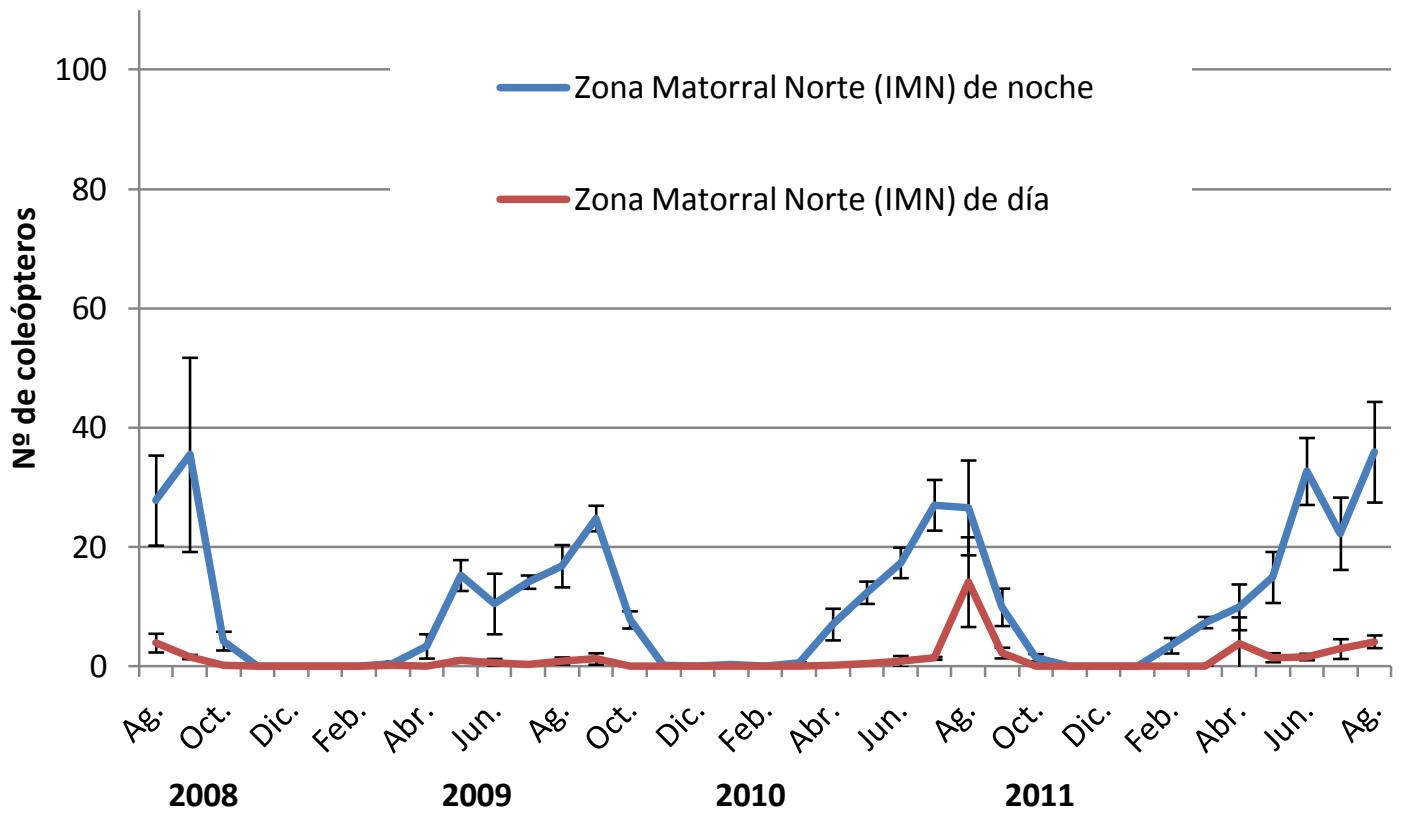

Figura 2.12.a. Media del no de capturas de Coleoptera en las trampas de gravedad de la zona IMN durante la noche y el día a lo largo de los tres años de muestreo.

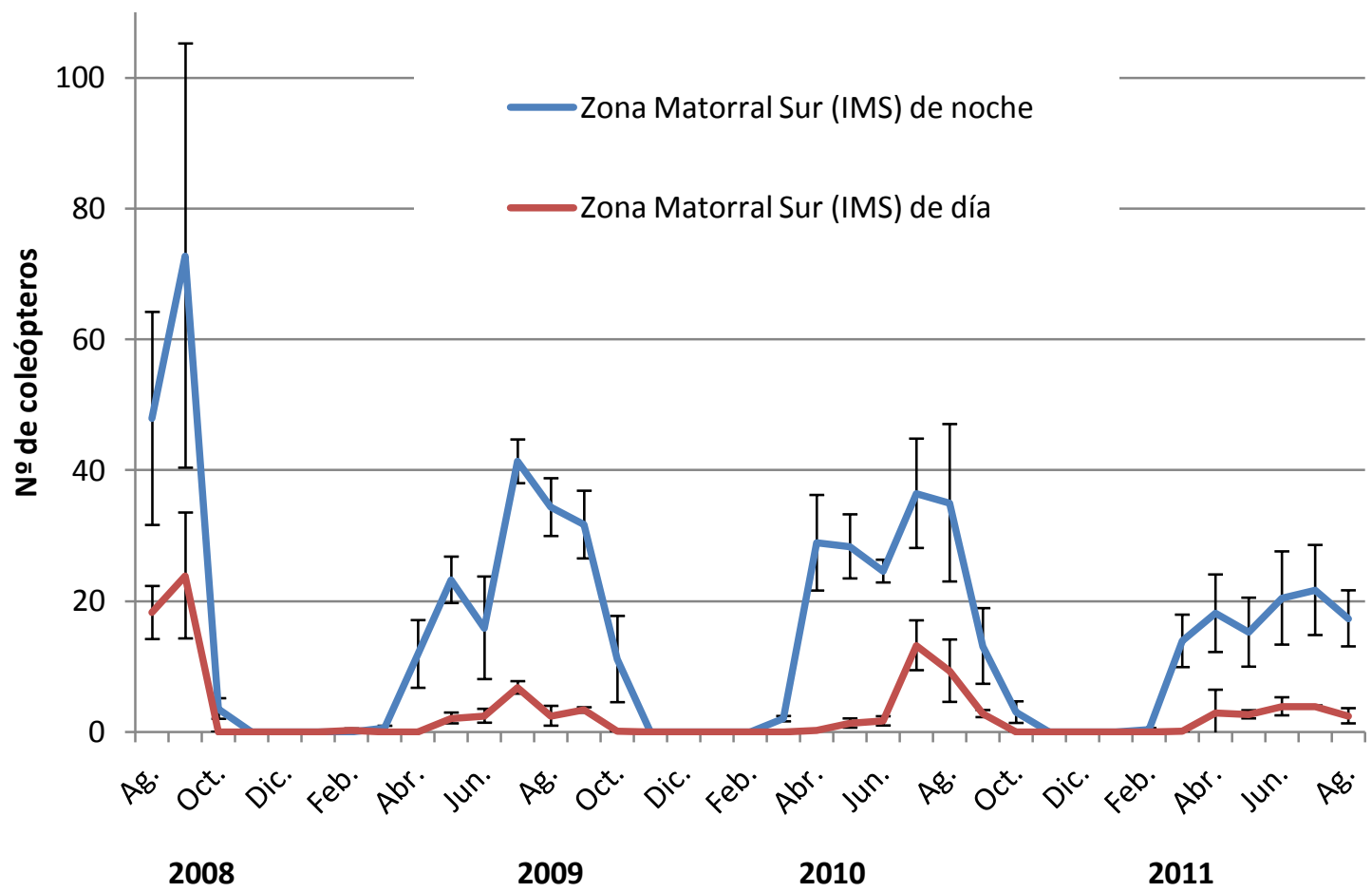

Figura 2.12.b. Media del $n$ o de capturas de Coleoptera en las trampas de gravedad de la zona IMS durante la noche y el día a lo largo de los tres años de muestreo. 


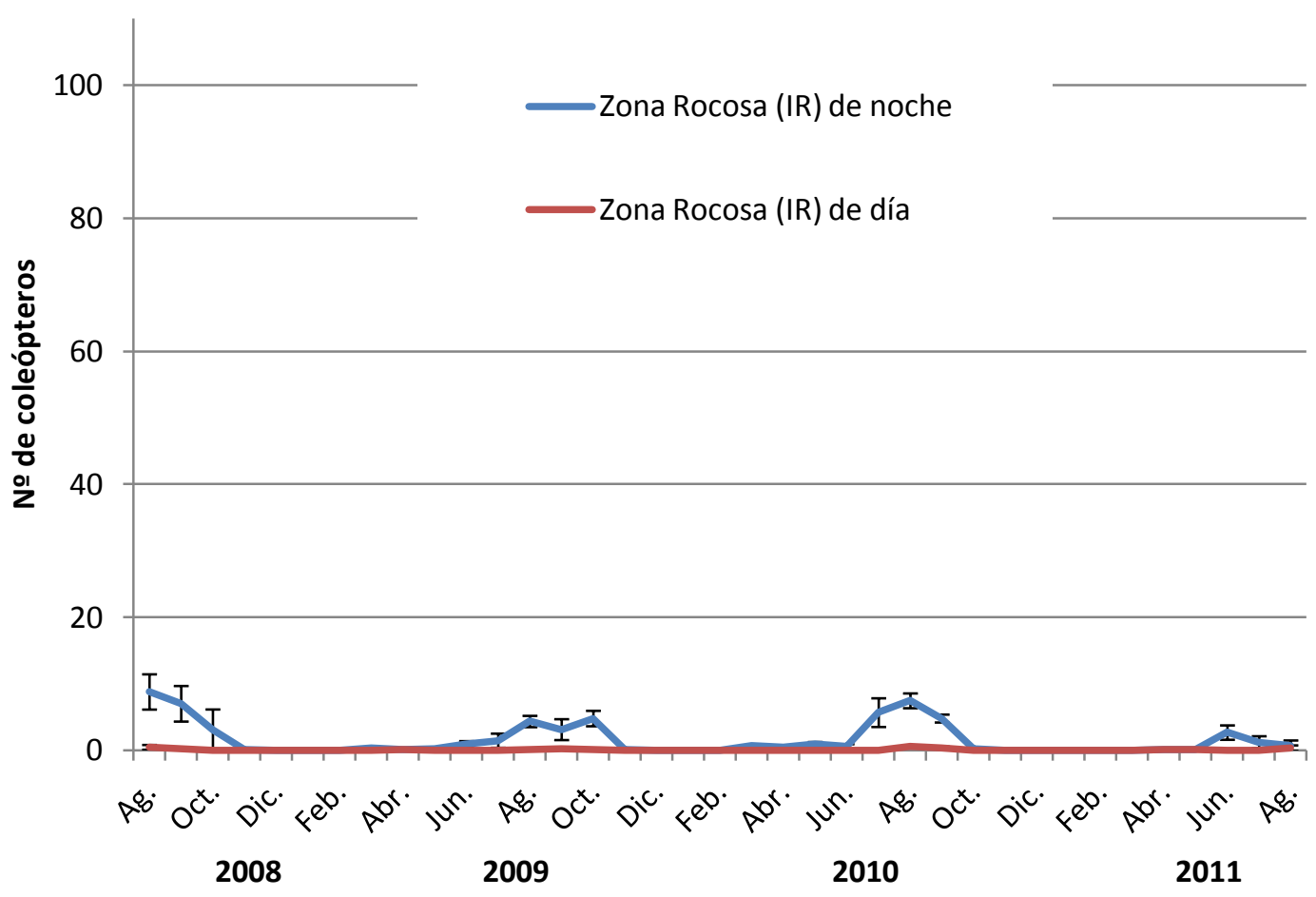

Figura 2.12.c. Media del $\mathrm{n}$ - de capturas de Coleoptera en las trampas de gravedad de la zona IR durante la noche y el día a lo largo de los tres años de muestreo.

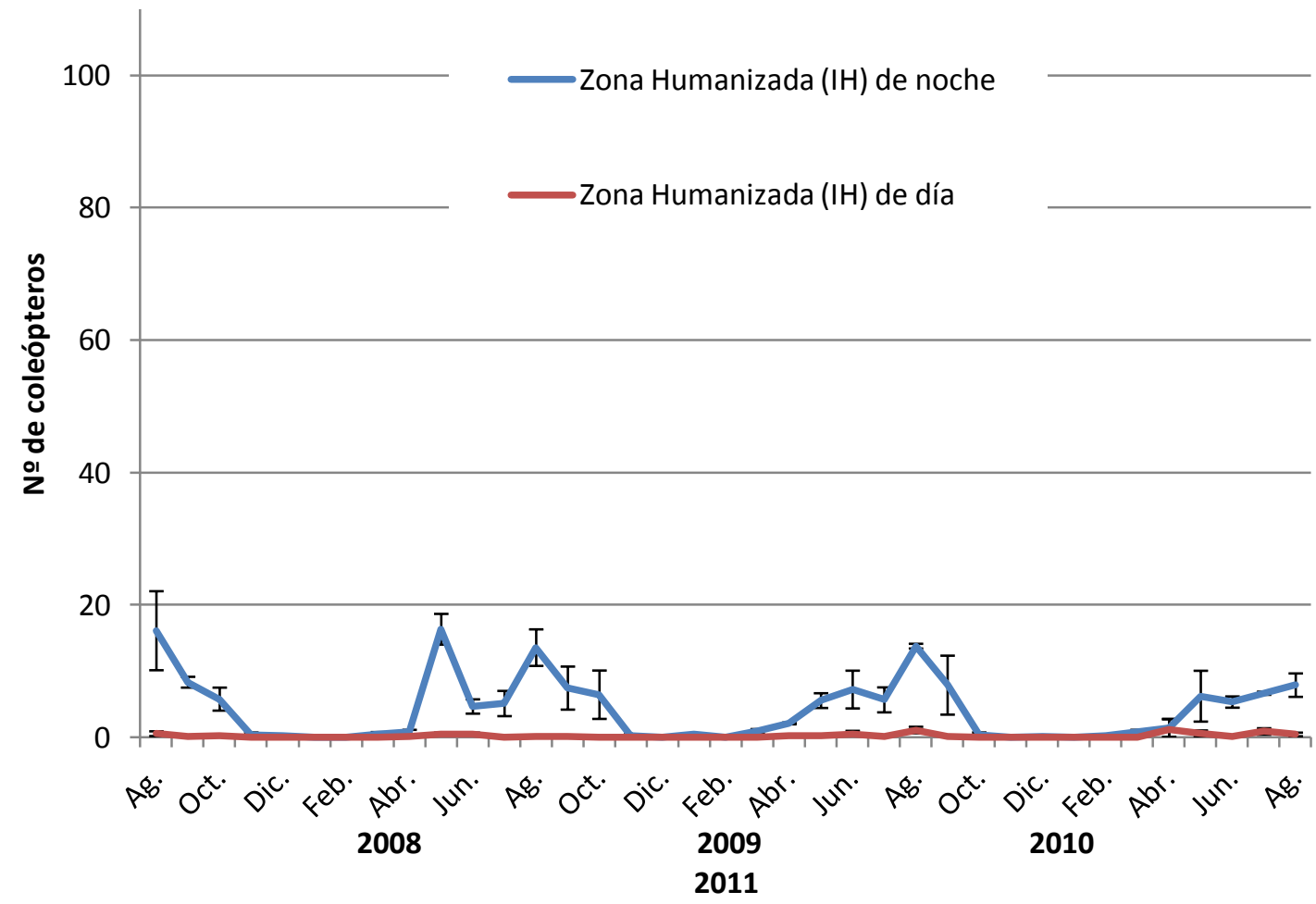

Figura 2.12.d. Media del $n$ o de capturas de Coleoptera en las trampas de gravedad de la zona IH durante la noche y el día a lo largo de los tres años de muestreo. 


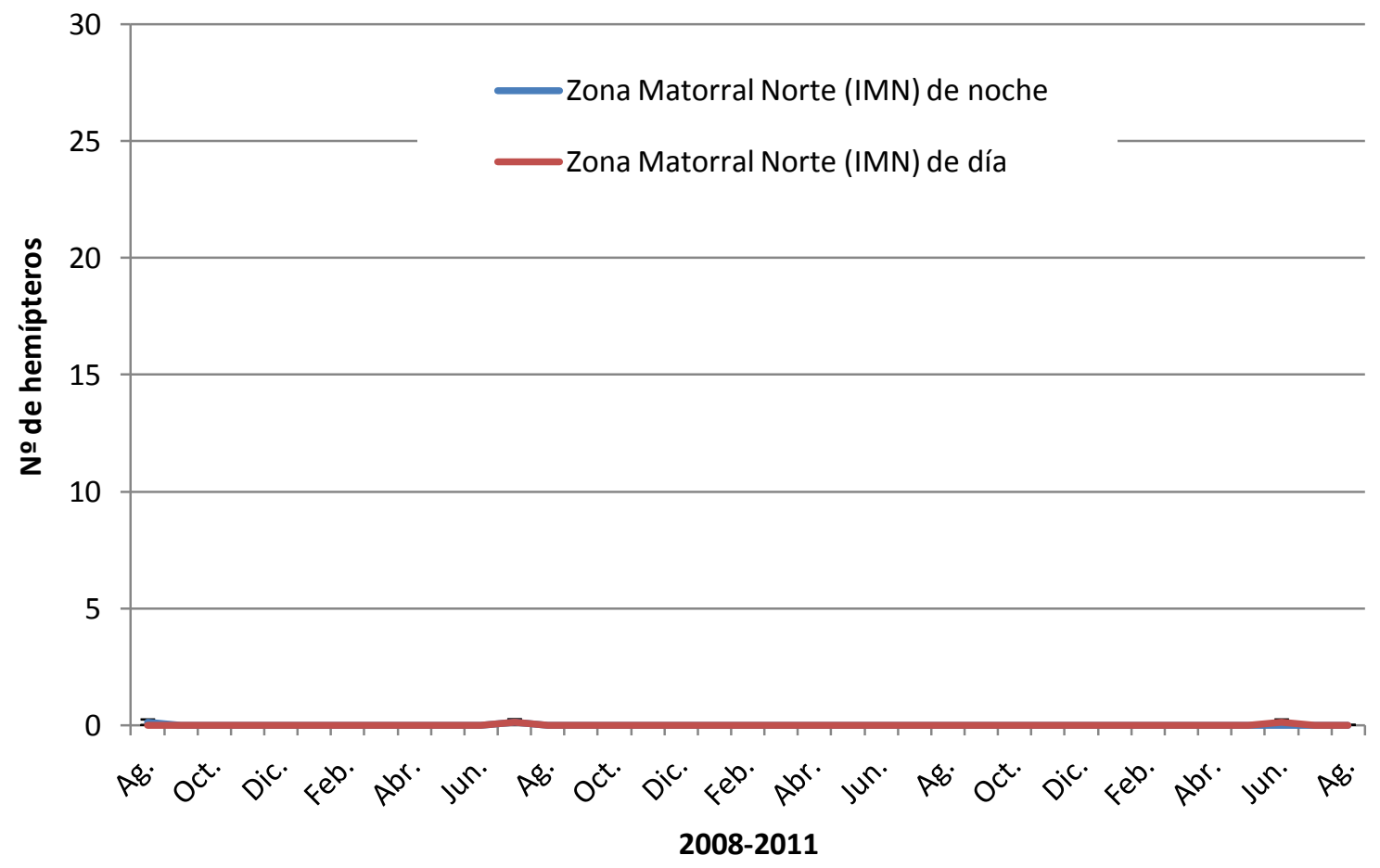

Figura 2.13.a. Media del $\mathrm{n}$ o de capturas de Hemiptera en las trampas de gravedad de la zona IMN durante la noche y el día a lo largo de los tres años de muestreo.

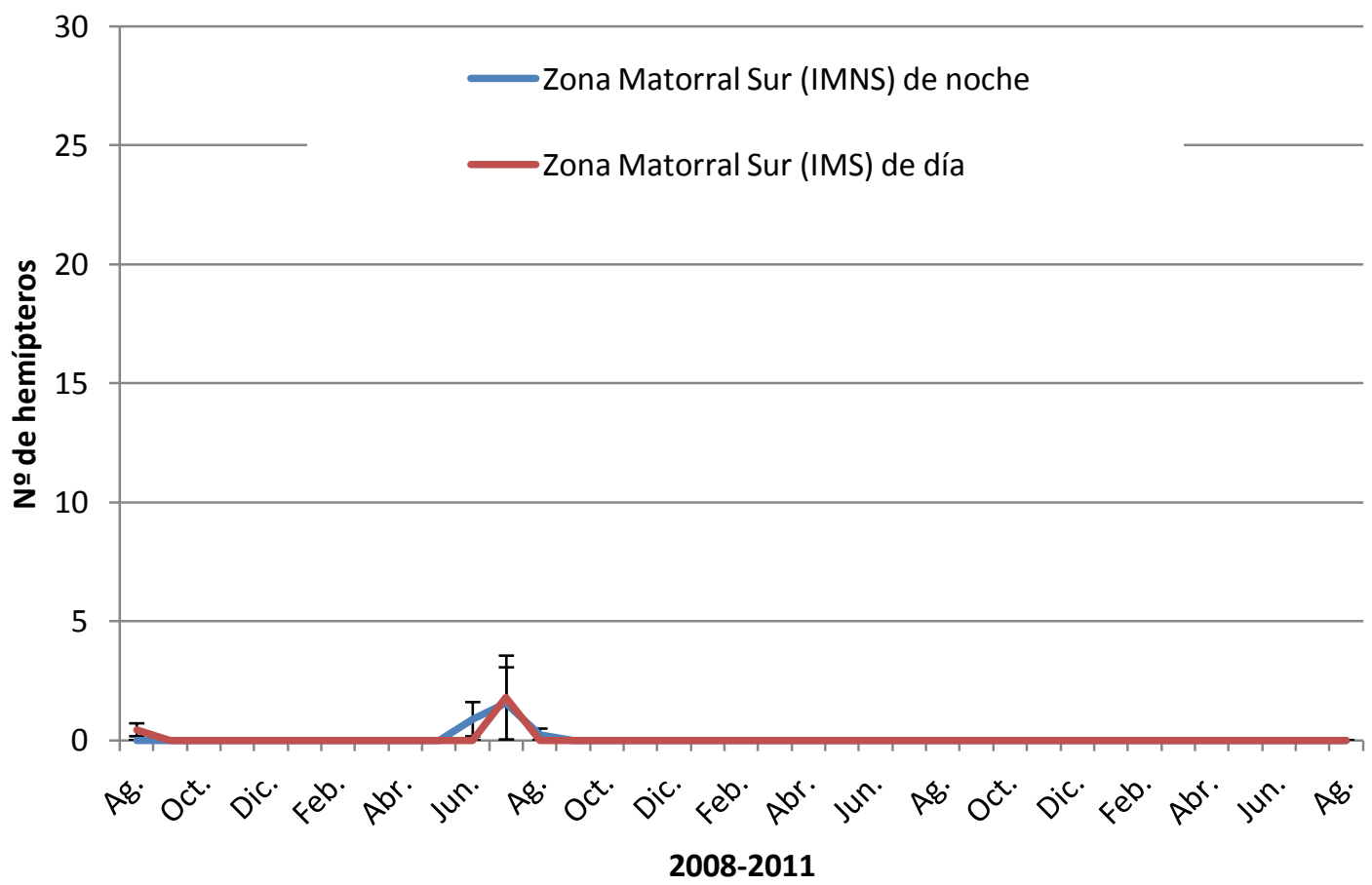

Figura 2.13.b. Media del $n$ o de capturas de Hemiptera en las trampas de gravedad de la zona IMS durante la noche y el día a lo largo de los tres años de muestreo. 
Medi natural: catàleg d'invertebrats terrestres

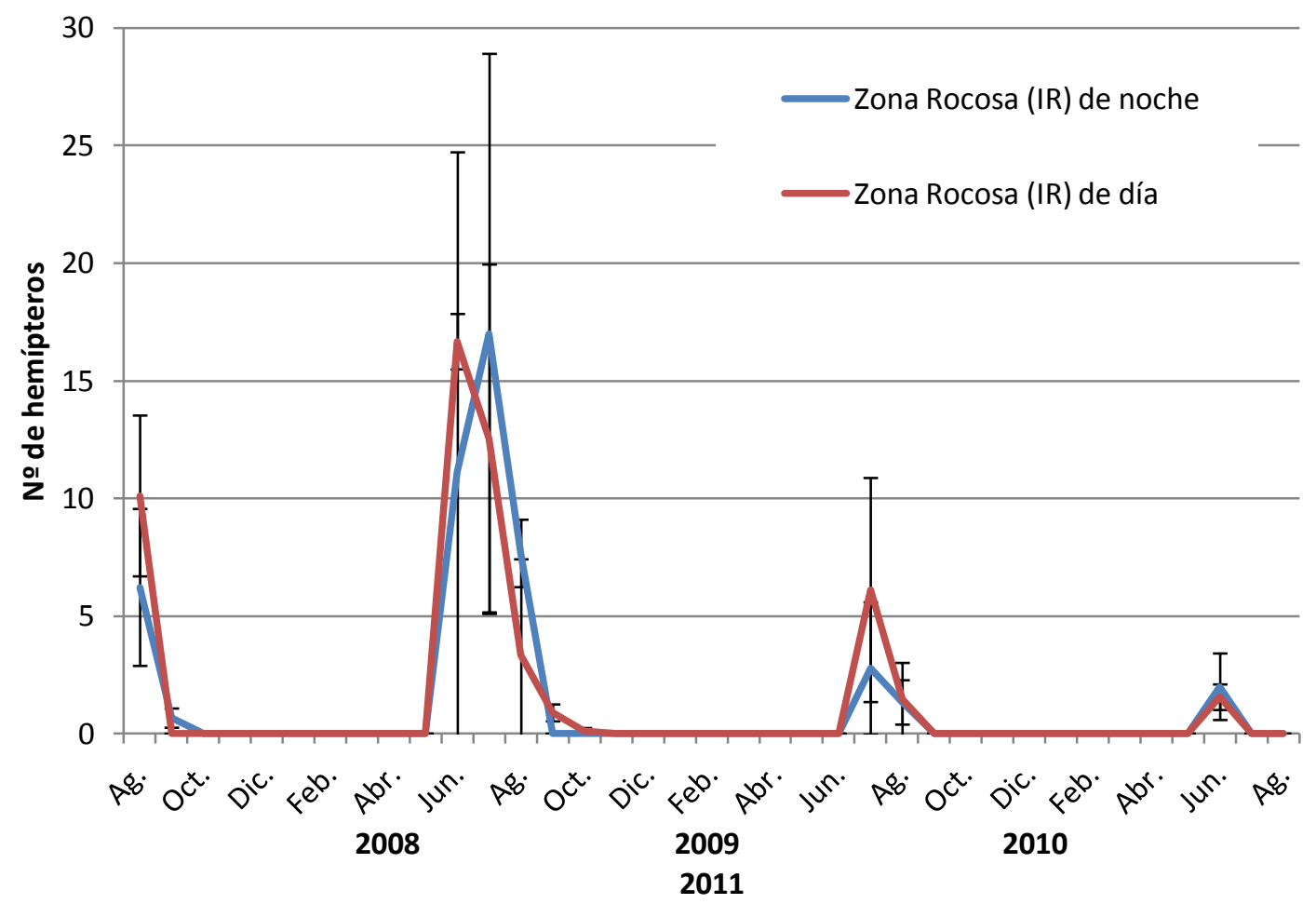

Figura 2.13.c. Media del $\mathrm{n}$ o de capturas de Hemiptera en las trampas de gravedad de la zona IR durante la noche y el día a lo largo de los tres años de muestreo.

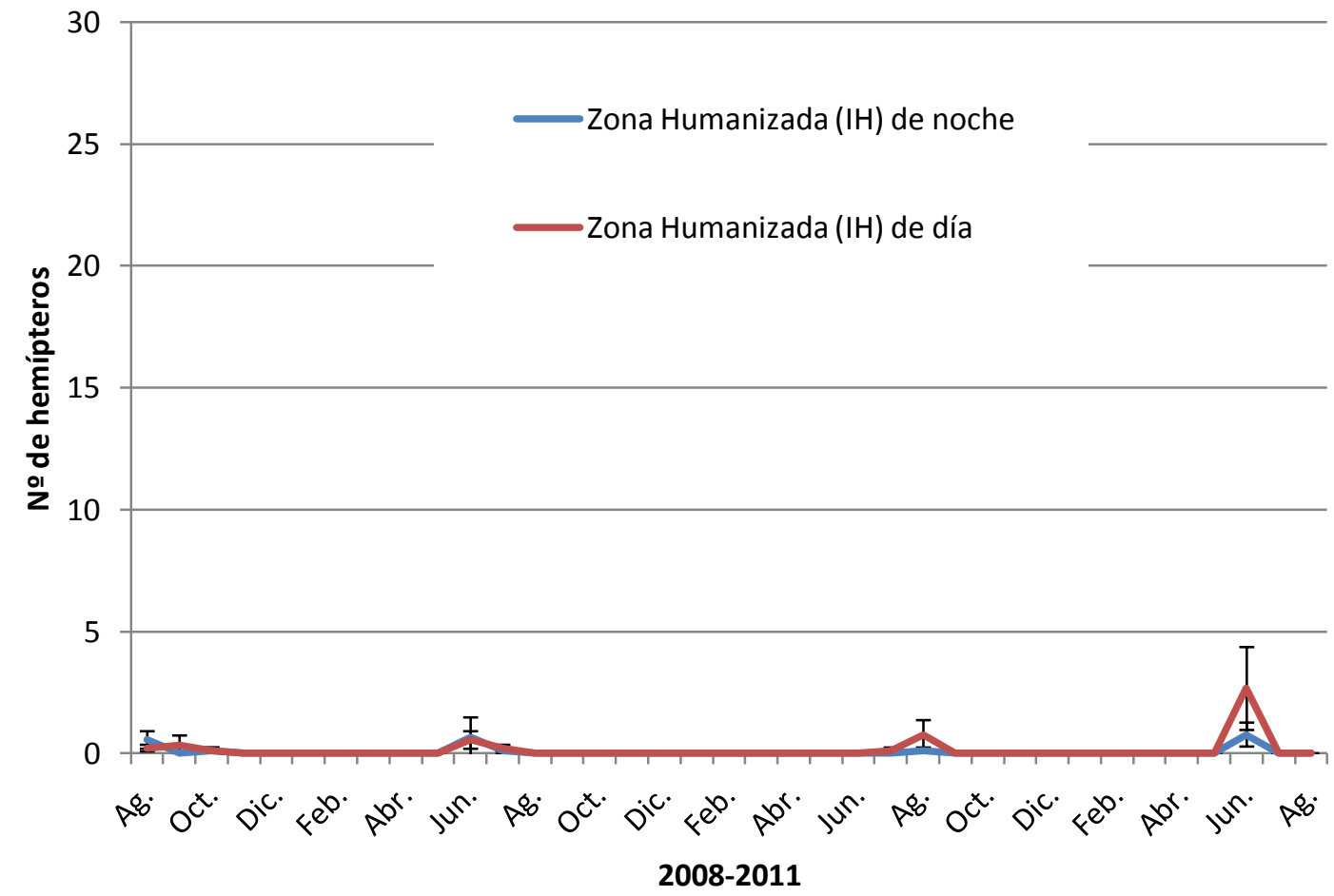

Figura 2.13.d. Media del no de capturas de Hemiptera en las trampas de gravedad de la zona IH durante la noche y el día a lo largo de los tres años de muestreo. 
Contrariamente, las capturas de hemípteros fueron similares durante el día y la noche (542 y 486 especímenes capturados, respectivamente), y mucho más numerosas en la zona rocosa (475 de día y 439 de noche) que en las otras tres (un total de 4 especímenes en el matorral norte, 44 en el matorral sur y 66 en la zona humanizada).

El 91 \% de los coleópteros capturados en la Illa Grossa corresponde a dos únicas especies (Figura 2.14), Pimelia interjecta (61 \%) (Figura 2.15), la cual se distribuye por el litoral mediterráneo desde el macizo del Garraf (sur de la provincia de Barcelona) hasta el norte de Castellón e islas Columbretes (Vinyolas, 1994 y Vinyolas, 2008), y Tentyria pazi (30 \%) (Figura 2.1), endemismo de Columbretes. Por otro lado, la totalidad de hemípteros caídos corresponde a dos especies de pirrocóridos (Figura 2.16), Pyrrhocoris apterus (Linnaeus, 1758), especie de hábitos gregarios en su etapa preimaginal y totalmente adaptada a una dieta seca compuesta de semillas maduras de plantas del orden de las Malvales (Socha, 1993), y Scantius aegyptius (Linnaeus, 1758), también asociada a una dieta relacionada con Malva parviflora (Bryant, 2009) y por tanto ambas relacionadas en las Columbretes con a las semillas de malva (Lavatera arborea L., 1753 y Lavatera mauritanica Durieu, 1847; Figura 2.15). Sin embargo, mientras que $P$. apterus se encuentra ampliamente distribuido por la Península Ibérica, $S$. aegyptius solo se encuentra en aquellas zonas de la península con influencia mediterránea (Mata et al, 2013). Además del Mediterráneo, ambas especies, especialmente S. aegyptius, han sido encontradas en California (Bryant, 2009). Relacionado con su dieta, cabe plantearse por qué en I'Illa Grossa, P. apterus y S. aegyptius no se encuentran en mayor cantidad en la zona de vegetación que en la de roca y probablemente sea porque en las zonas más degradadas, con una menor capa de suelo fértil debido al viento y a la erosión, el porcentaje de malvas (L. arborea y L. mauritanica) es muy superior sobre el resto de vegetación que en las zonas en las que ésta presenta una mayor cobertura; también en la zona central de l'illa Grossa, en la que hay poca vegetación, la malva predominante es la mauritánica; quizás estas dos especies de pirrocóridos poseen predilección por las semillas de esta especie por encima de las de la malva arbórea, lo que requeriría nuevos ensayos específicos. 
Medi natural: catàleg d'invertebrats terrestres

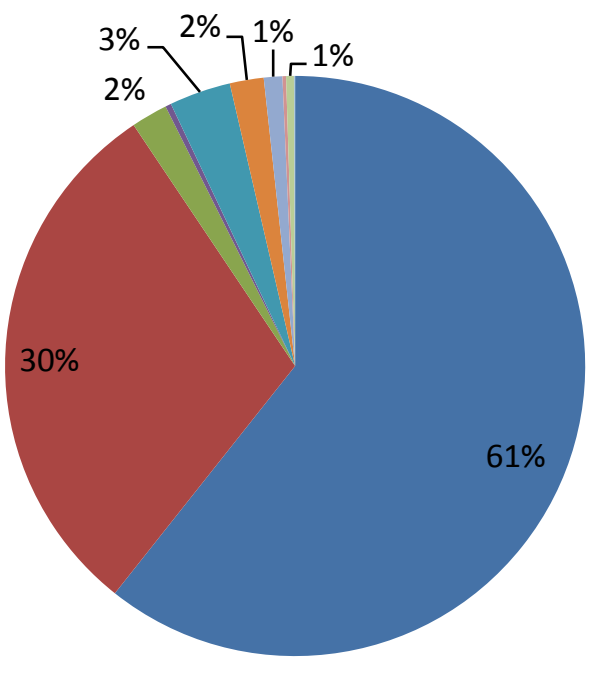

- Pimelia interjecta

- Tentyria pazi

Scaurus vicinus

- Scaurus rugulosus

Blaps gigas

Blaps lusitanica

- Heliopathes littoralis

Elenophorus collaris

Alphasida bonacherai

Alphitobius diaperinus

Figura 2.14. Especies de tenebriónidos capturadas en las trampas de gravedad respecto al total de coleópteros caídos en la Illa Grossa.
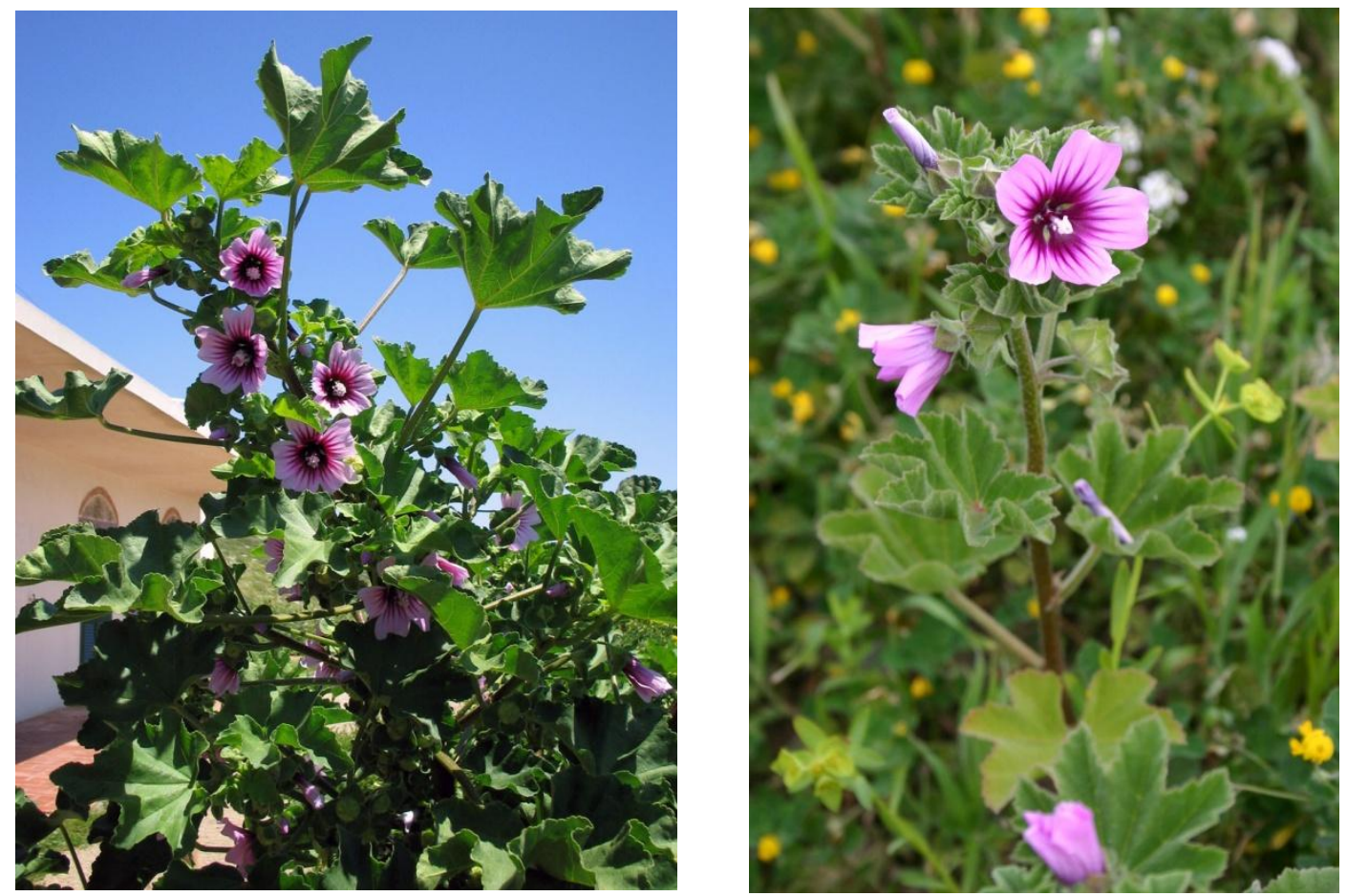

Figura 2.15. Lavatera arborea (izquierda), al lado de las casernas, y Lavatera mauritanica (derecha) (Malvales; Malvaceae), en la zona centro de la Illa Grossa. 
Dado que los datos presentados hasta ahora solamente proporcionan información sobre los invertebrados no alados, que son los que caen en las trampas de gravedad (Southwood \& Henderson, 2000), basar nuestras estimaciones de diversidad en estas capturas probablemente la subestimaría. Para solucionarlo habría que compensar además de con las observaciones directas (avistamientos y colectas) que hemos realizado en este estudio, las cuales comentamos a continuación, con otro tipo de trampas adecuadas para grupos alados como los dípteros, lepidópteros, ortópteros u odonatos (por ejemplo, trampas Malaise, o trampas de luz). Cabe plantearse, asimismo, cuál puede ser la causa de que haya caído en las trampas un número tan bajo de hormigas (himenópteros no alados). Ello podría deberse a que su abundancia en Columbretes fuera baja, o a que pudieran escapar de las trampas, ya que no se añadía ningún producto biocida en su interior, aunque esto último parece poco probable debido a las características del material de los botes.

Entre avistamientos y colectas, se obtuvieron 514 registros (Tablas 2.3 a 2.6), de los cuales 443 fueron en la Illa Grossa (40 colectas y 404 avistamientos), 14 en el Mancolibre (todos avistamientos), 31 en la Ferrera ( 2 colectas y 29 avistamientos), 25 en la Foradada (todos avistamientos) y 1 en la Senyoreta (Ligia italica Fabricius, 1798) (Figura 2.18). De estos avistamientos, 118 se enviaron al Banco de datos de Biodiversidad de la Comunitat Valenciana (BDB) para su publicación (http://bdb.cma.gva.es). De esta manera, en el presente estudio se identificaron un total de 96 especies en la Illa Grossa (Tabla 2.3), 7 en el Mancolibre (Tabla 2.4), 13 en la Ferrera (Tabla 2.5) y 12 en la Foradada (Tabla 2.6); que constituyen 100 especies diferentes ( 24 de las cuales sólo se pudieron identificar hasta género o familia, p. ej., por tratarse de inmaduros, o fotos en que no se apreciaban los caracteres necesarios), todas ellas se encuentran en la Illa Grossa, excepto Coccinella septempunctata Linnaeus, 1758 y Parasteropleurus sp. que tan sólo se han encontrado en la Ferrera, y un Asilidae, que tan sólo se ha encontrado en la Foradada. Han sido identificadas 11 especies de coleópteros tenebriónidos que coinciden exactamente con el dato dado por Cartagena (2002) y, al igual que en ese estudio, tampoco se ha encontrado Heliopathes forcadellii (citado por Español, 1958, Compte, 1969 y García-Marí et al., 1991) lo cual corrobora su posible extinción. 
Medi natural: catàleg d'invertebrats terrestres

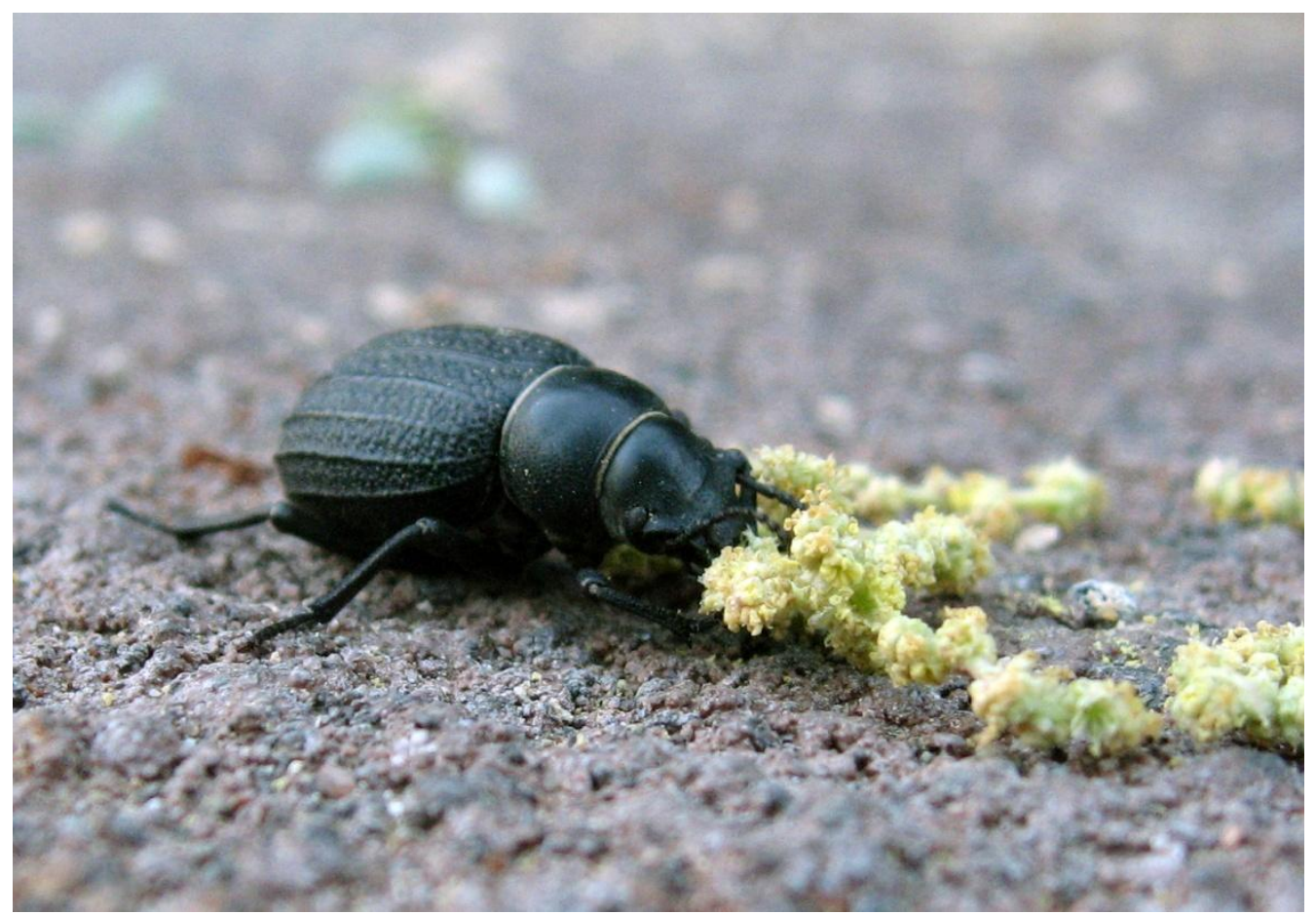

Figura 2.16. Pimelia interjecta (Coleoptera; Tenebrionidae) se encuentra en todas las islas mayores del archipiélago y en gran cantidad en la Illa Grossa. En la imagen, masticando flores de Atriplex halimus.

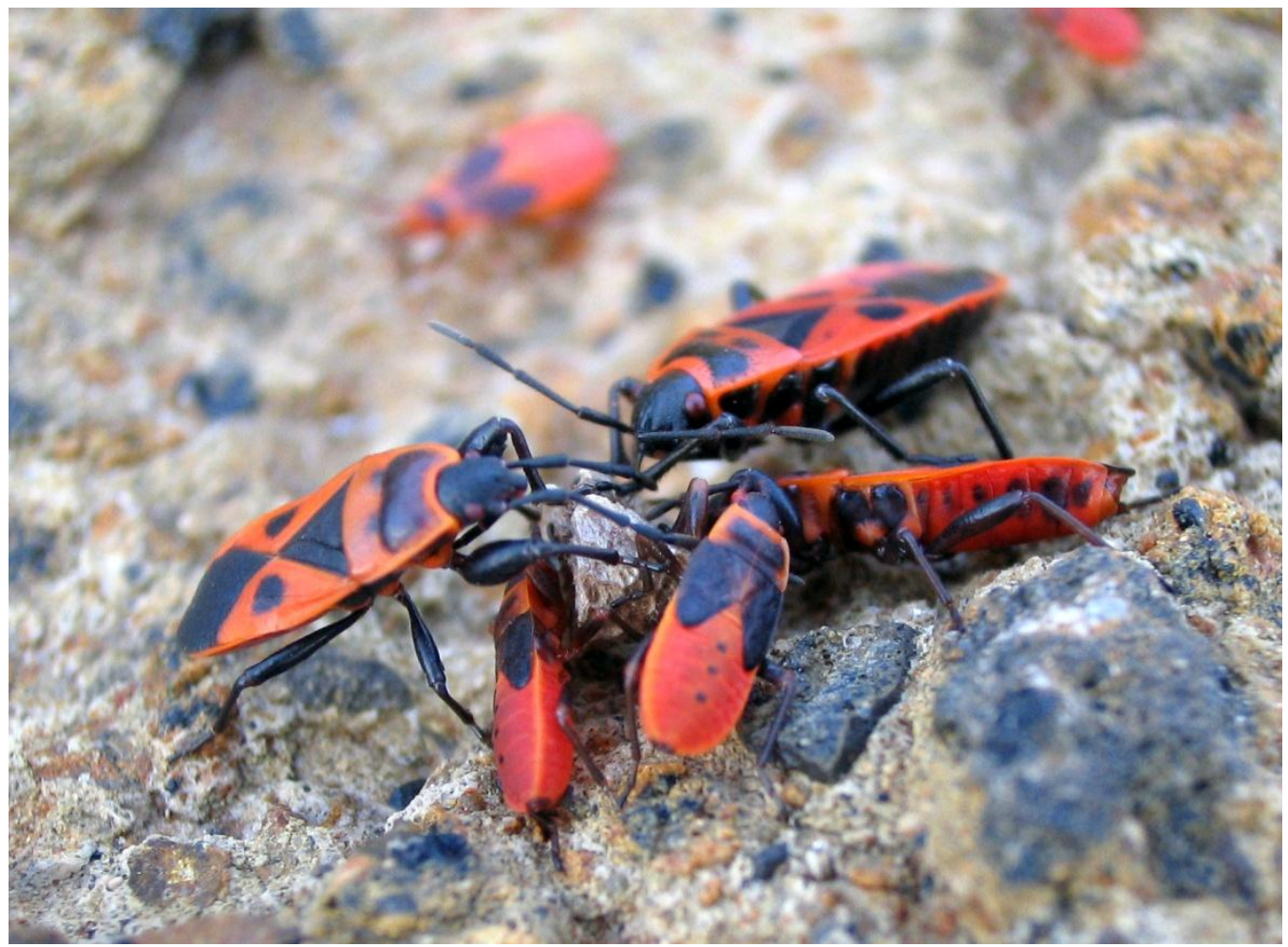

Figura 2.17. Ninfas y adultos de Pirrocoridae (Hemiptera) alimentándose de semillas de Lavatera arborea. 


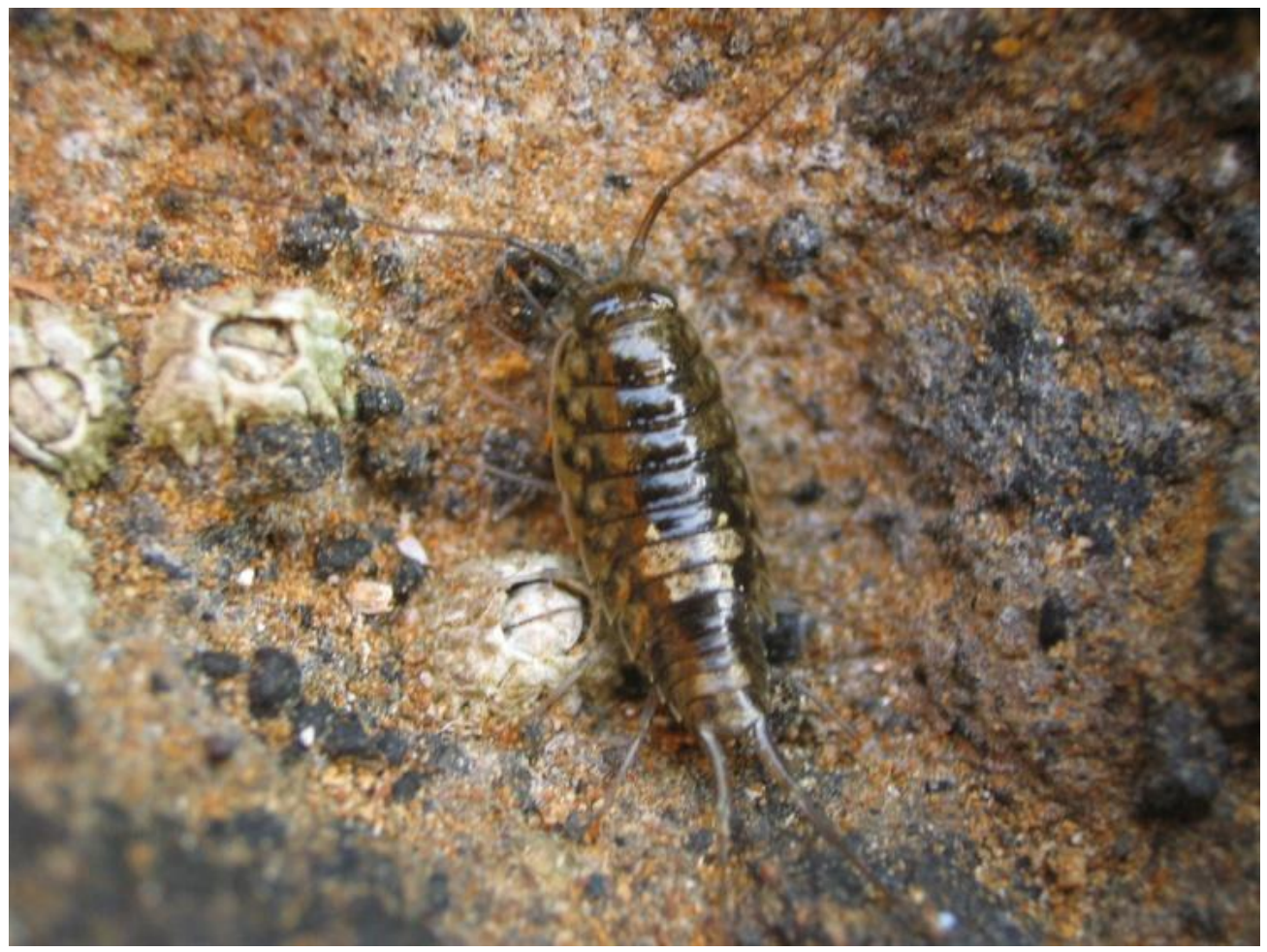

Figura 2.18. Ligia italica (Isopoda; Ligiidae), abunda en la zona de salpicadura de todas las islas e islotes de Columbretes.

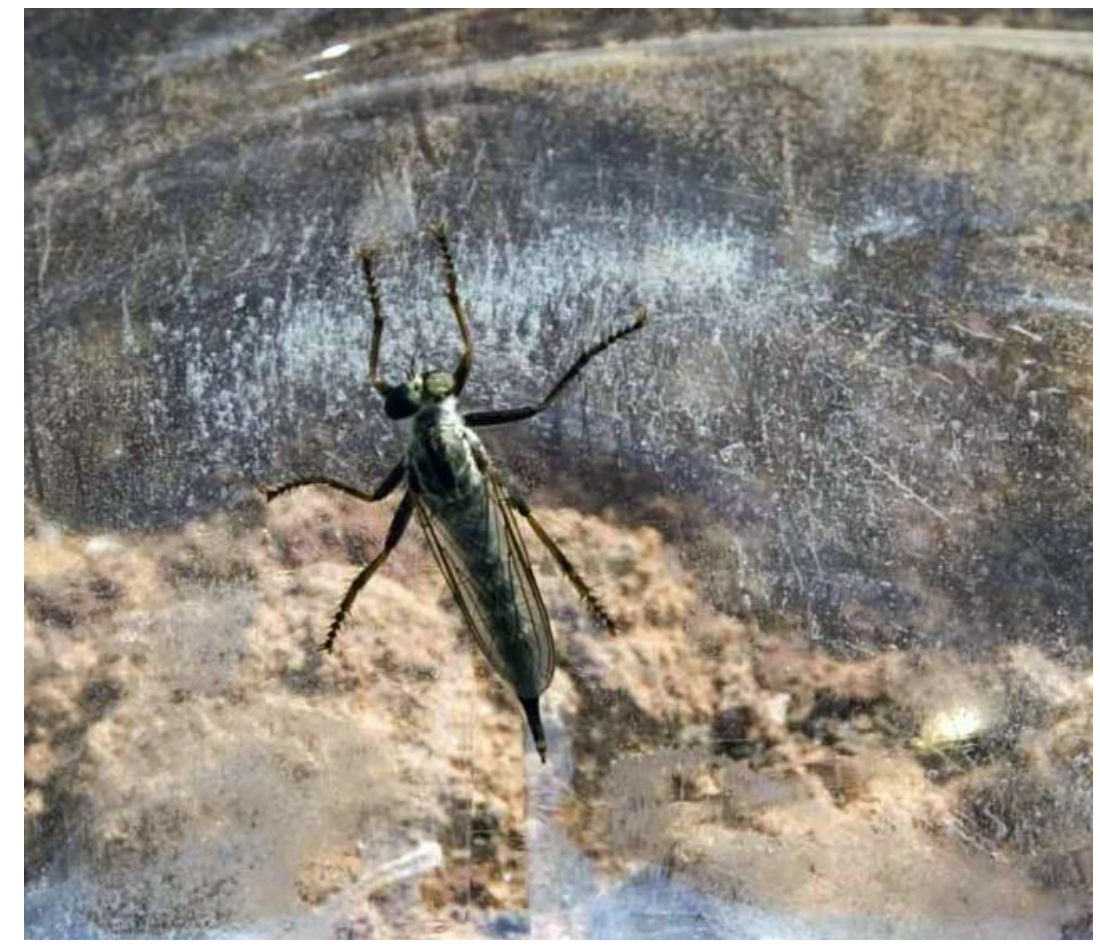

Figura 2.19. La familia Asilidae (Diptera) ha sido citada por primera vez en Columbretes, concretamente en la Foradada 
Tabla 2.3. Invertebrados observados en la Illa Grossa (2004-2013), año del primer registro tomado en este estudio y frecuencia de observaciones ( $n$ - de años observado a partir de ese primer registro y, entre paréntesis, número de años transcurridos entre ese primer registro y 2013):

\begin{tabular}{|c|c|c|c|c|c|c|}
\hline Phyllum & Clase & Orden & Familia & Especie & 10 registro & Frecuencia \\
\hline Arthropoda & Arachnida & Araneae & Araneidae & Argiope bruennichi (Scopoli, 1772) & 2004 & 10(10) \\
\hline Arthropoda & Arachnida & Araneae & Araneidae & Argiope lobata (Pallas, 1772) & 2004 & $10(10)$ \\
\hline Arthropoda & Arachnida & Araneae & Araneidae & Argiope trifasciata (Forskal, 1775) & 2006 & $3(8)$ \\
\hline Arthropoda & Arachnida & Araneae & Araneidae & Neoscona subfusca (C.L. Koch, 1837) & 2009 & $5(5)$ \\
\hline Arthropoda & Arachnida & Araneae & Clubionidae & Clubiona sp. & 2009 & $1(5)$ \\
\hline Arthropoda & Arachnida & Araneae & Dysderidae & Dysdera cf. crocota & 2009 & $1(5)$ \\
\hline Arthropoda & Arachnida & Araneae & Gnaphosidae & Zelotes sp. & 2008 & $1(6)$ \\
\hline Arthropoda & Arachnida & Araneae & Nemesiidae & Nemesia sp. & 2004 & $10(10)$ \\
\hline Arthropoda & Arachnida & Araneae & Pholcidae & Pholcus sp. & 2009 & $1(5)$ \\
\hline Arthropoda & Arachnida & Araneae & Segestriidae & Segestria $\mathrm{sp}$ & 2009 & $1(5)$ \\
\hline Arthropoda & Arachnida & Araneae & Therediidae & Steatoda sp. & 2008 & $3(6)$ \\
\hline Arthropoda & Arachnida & Araneae & Thomisidae & Thomisus onustus Walckenaer, 1805 & 2006 & $8(8)$ \\
\hline Arthropoda & Arachnida & Araneae & Thomisidae & Garypus beauvoisii (Audouin, 1826) & 2008 & $1(6)$ \\
\hline Arthropoda & Arachnida & Pseudoscorpiones & Garypidae & Garypus sp. & 2004 & $10(10)$ \\
\hline Arthropoda & Arachnida & Scorpiones & Buthidae & Buthus occitanus (Amoreux, 1789) & 2004 & $10(10)$ \\
\hline Arthropoda & Chilopoda & Lithobiomorpha & Lithobiidae & Lithobius sp. & 2009 & $1(5)$ \\
\hline Arthropoda & Chilopoda & Scolopendromorpha & Cryptopidae & Cryptops sp. & 2009 & $1(5)$ \\
\hline Arthropoda & Chilopoda & Scutigeromorpha & Scutigeridae & Scutigera coleoptrata (Linnaeus, 1758) & 2004 & $10(10)$ \\
\hline Arthropoda & Insecta & Coleoptera & Cerambycidae & Arhopalus syriacus (Reitter, 1895) & 2009 & $1(5)$ \\
\hline Arthropoda & Insecta & Coleoptera & Coccinellidae & Rodolia cardinalis (Mulsant, 1850) & 2004 & $10(10)$ \\
\hline Arthropoda & Insecta & Coleoptera & Dermestidae & Dermestes frischi Kugelann, 1792 & 2008 & $2(6)$ \\
\hline Arthropoda & Insecta & Coleoptera & Dynastidae & Phyllognathus excavatus (Forster, 1771) & 2010 & $1(4)$ \\
\hline Arthropoda & Insecta & Coleoptera & Elateridae & Cebrio superbus Jacquelin du Val, 1860 & 2006 & $8(8)$ \\
\hline Arthropoda & Insecta & Coleoptera & Tenebrionidae & Alphasida bonacherai Español, 1958 & 2006 & $8(8)$ \\
\hline Arthropoda & Insecta & Coleoptera & Tenebrionidae & Alphitobius diaperinus (Panzer, 1797) & 2011 & $1(3)$ \\
\hline Arthropoda & Insecta & Coleoptera & Tenebrionidae & Blaps gigas (Linnaeus, 1767) & 2004 & $10(10)$ \\
\hline
\end{tabular}




\begin{tabular}{|c|c|c|c|c|c|c|}
\hline Arthropoda & Insecta & Coleoptera & Tenebrionidae & Blaps Iusitanica Herbst, 1799 & 2008 & $6(6)$ \\
\hline Arthropoda & Insecta & Coleoptera & Tenebrionidae & Crypticus pubens Fairmaire, 1880 & 2008 & $3(6)$ \\
\hline Arthropoda & Insecta & Coleoptera & Tenebrionidae & Elenophorus collaris (Linnaeus, 1767) & 2008 & $6(6)$ \\
\hline Arthropoda & Insecta & Coleoptera & Tenebrionidae & Heliopathes littoralis Español, 1958 & 2008 & $6(6)$ \\
\hline Arthropoda & Insecta & Coleoptera & Tenebrionidae & Pimelia interjecta Solier, 1836 & 2004 & $10(10)$ \\
\hline Arthropoda & Insecta & Coleoptera & Tenebrionidae & Scaurus rugulosus Solier, 1838 & 2008 & $6(6)$ \\
\hline Arthropoda & Insecta & Coleoptera & Tenebrionidae & Scaurus vicinus Solier, 1838 & 2007 & $7(7)$ \\
\hline Arthropoda & Insecta & Coleoptera & Tenebrionidae & Tentyria pazi Español, 1958 & 2004 & $10(10)$ \\
\hline Arthropoda & Insecta & Dermaptera & Forficulidae & Forficula auricularia Linnaeus, 1758 & 2009 & $1(5)$ \\
\hline Arthropoda & Insecta & Dictyoptera & Blattidae & Blatta orientalis Linnaeus, 1758 & 2004 & $10(10)$ \\
\hline Arthropoda & Insecta & Dictyoptera & Blattidae & Periplaneta americana (Linnaeus, 1758) & 2010 & $1(4)$ \\
\hline Arthropoda & Insecta & Diptera & Calliphoridae & Lucilia sericata (Meigen, 1826) & 2009 & $5(5)$ \\
\hline Arthropoda & Insecta & Diptera & Syrphidae & Episyrphus balteatus (De Geer, 1776) & 2009 & $2(5)$ \\
\hline Arthropoda & Insecta & Diptera & Syrphidae & Eristalis sp. & 2009 & $2(5)$ \\
\hline Arthropoda & Insecta & Diptera & Syrphidae & Eristalis tenax (Linnaeus, 1758) & 2009 & $5(5)$ \\
\hline Arthropoda & Insecta & Hemiptera & Anthocoridae & Anthocoridae sp. & 2010 & $1(4)$ \\
\hline Arthropoda & Insecta & Hemiptera & Asterolecaniidae & Planchonia arabidis Signoret, 1878 & 2011 & $3(3)$ \\
\hline Arthropoda & Insecta & Hemiptera & Cydnidae & Byrsinus pilosulus (Klug, 1845) & 2009 & $1(5)$ \\
\hline Arthropoda & Insecta & Hemiptera & Cydnidae & Cydnus aterrimus (Forster, 1771) & 2009 & $5(5)$ \\
\hline Arthropoda & Insecta & Hemiptera & Margarodidae & Icerya purchasi Maskell, 1878 & 2004 & $10(10)$ \\
\hline Arthropoda & Insecta & Hemiptera & Pentatomidae & Brachynema cinctum (Fabricius, 1775) & 2009 & $1(5)$ \\
\hline Arthropoda & Insecta & Hemiptera & Pentatomidae & Nezara viridula (Linnaeus, 1758) & 2009 & $5(5)$ \\
\hline Arthropoda & Insecta & Hemiptera & Pyrrhocoridae & Pyrrhocoris apterus (Linnaeus, 1758) & 2004 & ¿? \\
\hline Arthropoda & Insecta & Hemiptera & Pyrrhocoridae & Scantius aegyptius (Linnaeus 1758) & 2004 & $\dot{\imath} ?$ \\
\hline Arthropoda & Insecta & Hemiptera & Pyrrhocoridae & Pyrrhocoridae sp. & 2004 & $10(10)$ \\
\hline Arthropoda & Insecta & Hymenoptera & Formicidae & Messor bouvieri Bondroit, 1918 & 2010 & $1(4)$ \\
\hline Arthropoda & Insecta & Hymenoptera & Formicidae & Pheidole pallidula (Nylander, 1849) & 2010 & $1(4)$ \\
\hline Arthropoda & Insecta & Hymenoptera & Ichneumonidae & Ophion sp. & 2010 & $1(4)$ \\
\hline Arthropoda & Insecta & Hymenoptera & Vespidae & Polistes sp. & 2009 & $1(5)$ \\
\hline Arthropoda & Insecta & Lepidoptera & Crambidae & Palpita vitrealis (Rossi, 1794) & 2012 & $1(2)$ \\
\hline
\end{tabular}




\begin{tabular}{|c|c|c|c|c|c|c|}
\hline Arthropoda & Insecta & Lepidoptera & Erebidae & Catocala coniuncta (Esper, 1787) & 2010 & $1(4)$ \\
\hline Arthropoda & Insecta & Lepidoptera & Erebidae & Ophiusa tirhaca (Cramer, 1773) & 2011 & $1(3)$ \\
\hline Arthropoda & Insecta & Lepidoptera & Erebidae & Utetheisa pulchella (Linnaeus, 1758) & 2010 & $1(4)$ \\
\hline Arthropoda & Insecta & Lepidoptera & Geometridae & Idaea sp. & 2010 & $1(4)$ \\
\hline Arthropoda & Insecta & Lepidoptera & Geometridae & Rhodometra sacraria (Linnaeus, 1767) & 2009 & $1(5)$ \\
\hline Arthropoda & Insecta & Lepidoptera & Lycaenidae & Lampides boeticus (Linnaeus, 1767) & 2012 & $1(2)$ \\
\hline Arthropoda & Insecta & Lepidoptera & Noctuidae & Autographa gamma (Linnaeus, 1758) & 2009 & $1(5)$ \\
\hline Arthropoda & Insecta & Lepidoptera & Noctuidae & Helicoverpa armigera (Hübner, 1808) & 2009 & $2(5)$ \\
\hline Arthropoda & Insecta & Lepidoptera & Noctuidae & Heliothis peltigera (Denis \& Schiffermüller, 1775) & 2010 & $1(4)$ \\
\hline Arthropoda & Insecta & Lepidoptera & Noctuidae & Mniotype spinosa (Chrétien, 1910) & 2008 & $1(6)$ \\
\hline Arthropoda & Insecta & Lepidoptera & Noctuidae & Mythimna vitellina (Hübner, 1808) & 2010 & $1(4)$ \\
\hline Arthropoda & Insecta & Lepidoptera & Noctuidae & Xanthodes albago (Fabricius, 1794) & 2009 & $1(5)$ \\
\hline Arthropoda & Insecta & Lepidoptera & Nymphalidae & Danaus chrysippus (Linnaeus, 1758) & 2009 & $1(5)$ \\
\hline Arthropoda & Insecta & Lepidoptera & Nymphalidae & Vanessa atalanta (Linnaeus, 1758) & 2006 & $2(8)$ \\
\hline Arthropoda & Insecta & Lepidoptera & Nymphalidae & Vanessa cardui (Linnaeus, 1758) & 2009 & $1(5)$ \\
\hline Arthropoda & Insecta & Lepidoptera & Pieridae & Colias croceus (Fourcroy, 1785) & 2009 & $1(5)$ \\
\hline Arthropoda & Insecta & Lepidoptera & Pterophoridae & Agdistis neglecta Arenberger, 1976 & 2010 & $1(4)$ \\
\hline Arthropoda & Insecta & Lepidoptera & Pterophoridae & Emmelina monodactyla (Linnaeus, 1758) & 2010 & $1(4)$ \\
\hline Arthropoda & Insecta & Lepidoptera & Pyralidae & Aglossa pinguinalis (Linnaeus, 1758) & 2009 & $1(5)$ \\
\hline Arthropoda & Insecta & Lepidoptera & Pyralidae & Pyralidae sp. & 2013 & $1(1)$ \\
\hline Arthropoda & Insecta & Lepidoptera & Sphingidae & Acherontia atropos (Linnaeus, 1758) & 2006 & $3(8)$ \\
\hline Arthropoda & Insecta & Lepidoptera & Sphingidae & Agrius convolvuli (Linnaeus, 1758) & 2008 & $1(6)$ \\
\hline Arthropoda & Insecta & Lepidoptera & Sphingidae & Macroglossum stellatarum (Linnaeus, 1758) & 2009 & $2(5)$ \\
\hline Arthropoda & Insecta & Neuroptera & Chrysopidae & Chrysoperla carnea (Stephens, 1836) & 2006 & $2(8)$ \\
\hline Arthropoda & Insecta & Odonata & Aeshnidae & Anax parthenope (Selys, 1839) & 2004 & $10(10)$ \\
\hline Arthropoda & Insecta & Odonata & Coenagrionidae & Ischnura elegans (Vander Linden, 1820) & 2013 & $1(1)$ \\
\hline Arthropoda & Insecta & Odonata & Libellulidae & Sympetrum fonscolombii (Selys, 1840) & 2007 & $7(7)$ \\
\hline Arthropoda & Insecta & Orthoptera & Acrididae & Anacridium aegyptium (Linnaeus, 1764) & 2004 & $10(10)$ \\
\hline Arthropoda & Insecta & Orthoptera & Gryllidae & Gryllomorpha uclensis Pantel, 1890 & 2009 & $1(5)$ \\
\hline Arthropoda & Insecta & Orthoptera & Gryllidae & Gryllus bimaculatus De Geer, 1773 & 2008 & $1(6)$ \\
\hline
\end{tabular}




\begin{tabular}{|c|c|c|c|c|c|c|}
\hline Arthropoda & Insecta & Orthoptera & Gryllidae & Oecanthus pellucens (Scopoli, 1763) & 2007 & $7(7)$ \\
\hline Arthropoda & Insecta & Zygentoma & Lepismatidae & Ctenolepisma sp. & 2009 & $1(5)$ \\
\hline Arthropoda & Malacostraca & Isopoda & Armadillidae & Armadillo officinalis Duméril, 1816 & 2009 & $1(5)$ \\
\hline Arthropoda & Malacostraca & Isopoda & Ligiidae & Ligia italica Fabricius, 1798 & 2004 & $10(10)$ \\
\hline Arthropoda & Malacostraca & Isopoda & Porcellionidae & Acaeroplastes melanurus (Budde-Lund, 1885) & 2004 & $10(10)$ \\
\hline Mollusca & Gastropoda & Pulmonata & Ferussaciidae & Ferussacia folliculus (Gmelin, 1791) & 2009 & $1(5)$ \\
\hline Mollusca & Gastropoda & Pulmonata & Helicidae & Cornu aspersum (O.F. Muller, 1774) & 2009 & $1(5)$ \\
\hline Mollusca & Gastropoda & Pulmonata & Hygromiidae & Xerocrassa molinae (Hidalgo, 1883) & 2004 & $10(10)$ \\
\hline Mollusca & Gastropoda & Pulmonata & Lauriidae & Lauria cylindracea (Da Costa, 1778) & 2009 & $1(5)$ \\
\hline Mollusca & Gastropoda & Pulmonata & Limacidae & Lehmannia valentiana (A. Ferussac, 1822) & 2009 & $1(5)$ \\
\hline
\end{tabular}

Tabla 2.4. Invertebrados observados en el Mancolibre (2009-2010), año del primer registro tomado en este estudio y frecuencia de observaciones ( $n$ o de años observado a partir de ese primer registro en función del número de años desde el 1ำ reg. hasta 2010, que se muestra entre paréntesis):

\begin{tabular}{lllllll}
\hline \multicolumn{1}{c}{ Phyllum } & \multicolumn{1}{c}{ Clase } & \multicolumn{1}{c}{ Orden } & \multicolumn{1}{c}{ Familia } & \multicolumn{1}{c}{ Especie } & 10 registro & Frecuencia \\
\hline Arthropoda & Arachnida & Scorpiones & Buthidae & Buthus occitanus (Amoreux, 1789) & 2009 & $1(2)$ \\
Arthropoda & Insecta & Coleoptera & Tenebrionidae & Elenophorus collaris (Linnaeus, 1767) & 2009 & $1(2)$ \\
Arthropoda & Insecta & Coleoptera & Tenebrionidae & Pimelia interjecta Solier, 1836 & 2009 & $2(2)$ \\
Arthropoda & Insecta & Coleoptera & Tenebrionidae & Scaurus rugulosus Solier, 1838 & 2009 & $1(2)$ \\
Arthropoda & Insecta & Coleoptera & Tenebrionidae & Tentyria pazi Español, 1958 & 2009 & $1(2)$ \\
Arthropoda & Malacostraca & Isopoda & Ligiidae & Ligia italica Fabricius, 1798 & 2009 & $2(2)$ \\
Mollusca & Gastropoda & Pulmonata & Hygromiidae & Xerocrassa molinae (Hidalgo, 1883) & 2009 & $2(2)$ \\
\hline
\end{tabular}


Tabla 2.5. Invertebrados observados en la Ferrera (2006-2010), año del primer registro tomado en este estudio y frecuencia de observaciones (no de años observado a partir de ese primer registro en función del número de años desde el 1 ㅇ reg. hasta 2010, que se muestra entre paréntesis):

\begin{tabular}{|c|c|c|c|c|c|c|}
\hline Phyllum & Clase & Orden & Familia & Especie & 10 registro & Frecuencia \\
\hline Arthropoda & Arachnida & Scorpiones & Buthidae & Buthus occitanus (Amoreux, 1789) & 2008 & $3(3)$ \\
\hline Arthropoda & Insecta & Coleoptera & Tenebrionidae & Alphasida bonacherai Español, 1958 & 2009 & $2(2)$ \\
\hline Arthropoda & Insecta & Coleoptera & Tenebrionidae & Blaps gigas (Linnaeus, 1767) & 2009 & $1(2)$ \\
\hline Arthropoda & Insecta & Coleoptera & Tenebrionidae & Blaps lusitanica Herbst, 1799 & 2009 & $1(2)$ \\
\hline Arthropoda & Insecta & Coleoptera & Coccinellidae & Coccinella septempunctata Linnaeus, 1758 & 2006 & $1(5)$ \\
\hline Arthropoda & Insecta & Coleoptera & Tenebrionidae & Crypticus pubens Fairmaire, 1880 & 2008 & $1(3)$ \\
\hline Arthropoda & Insecta & Coleoptera & Tenebrionidae & Pimelia interjecta Solier, 1836 & 2008 & $3(3)$ \\
\hline Arthropoda & Insecta & Coleoptera & Tenebrionidae & Scaurus rugulosus Solier, 1838 & 2010 & $1(1)$ \\
\hline Arthropoda & Insecta & Coleoptera & Tenebrionidae & Scaurus vicinus Solier, 1838 & 2010 & $1(1)$ \\
\hline Arthropoda & Insecta & Coleoptera & Tenebrionidae & Tentyria pazi Español, 1958 & 2008 & $3(3)$ \\
\hline Arthropoda & Insecta & Orthoptera & Bradyporidae & Parasteropleurus sp. & 2009 & $1(2)$ \\
\hline Arthropoda & Insecta & Zygentoma & Lepismatidae & Ctenolepisma sp. & 2008 & $1(3)$ \\
\hline Arthropoda & Malacostraca & Isopoda & Ligiidae & Ligia italica Fabricius, 1798 & 2006 & $5(5)$ \\
\hline
\end{tabular}


Tabla 2.6. Invertebrados observados en la Foradada (2008-2010), año del primer registro tomado en este estudio y frecuencia de observaciones ( $n$ o de años observado a partir de ese primer registro en función del número de años desde el 10 reg. hasta 2010, que se muestra entre paréntesis):

\begin{tabular}{|c|c|c|c|c|c|c|}
\hline Phyllum & Clase & Orden & Familia & Especie & 10 registro & Frecuencia \\
\hline Arthropoda & Arachnida & Araneae & Araneidae & Argiope lobata (Pallas, 1772) & 2009 & $1(2)$ \\
\hline Arthropoda & Arachnida & Scorpiones & Buthidae & Buthus occitanus (Amoreux, 1789) & 2008 & $3(3)$ \\
\hline Arthropoda & Insecta & Coleoptera & Tenebrionidae & Pimelia interjecta Solier, 1836 & 2008 & $3(3)$ \\
\hline Arthropoda & Insecta & Coleoptera & Tenebrionidae & Scaurus rugulosus Solier, 1838 & 2008 & $1(3)$ \\
\hline Arthropoda & Insecta & Coleoptera & Tenebrionidae & Scaurus vicinus Solier, 1838 & 2010 & $1(1)$ \\
\hline Arthropoda & Insecta & Coleoptera & Tenebrionidae & Heliopathes littoralis Español & 2010 & $1(1)$ \\
\hline Arthropoda & Insecta & Coleoptera & Tenebrionidae & Heliopathes sp. & 2008 & $1(3)$ \\
\hline Arthropoda & Insecta & Coleoptera & Tenebrionidae & Tentyria pazi Español, 1958 & 2010 & $3(3)$ \\
\hline Arthropoda & Insecta & Diptera & Asilidae & Asilidae sp. & 2008 & $1(3)$ \\
\hline Arthropoda & Insecta & Hemiptera & Pyrrhocoridae & Pyrrhocoridae sp. & 2009 & $1(2)$ \\
\hline Arthropoda & Insecta & Hymenoptera & Formicidae & Messor sp. & 2009 & $1(2)$ \\
\hline Arthropoda & Malacostraca & Isopoda & Ligiidae & Ligia italica Fabricius, 1798 & 2008 & $3(3)$ \\
\hline
\end{tabular}




\section{Catálogo}

Para la confección del catálogo de invertebrados terrestres de las Islas Columbretes, se tuvieron en cuenta tanto las capturas en las trampas, como los avistamientos y colectas en el periodo 2004-2013. Combinamos nuestros datos con los resultados de estudios anteriores para obtener un primer catálogo completo de la fauna invertebrada no marina del archipiélago. Añadiendo a nuestro listado las especies, géneros o familias publicados en esos anteriores estudios de invertebrados de Columbretes o aquellos presentes en las colecciones a las que tuvimos acceso (Colección Entomológica del "Instituto Cavanilles de Biodiversidad y Biología Evolutiva", Universitat de València, y Colección Entomológica del Dr. Roger Vila del Institut de Biología Evolutiva del CSIC, Barcelona) se obtuvieron un total 276 especies (32 de las cuales sólo se pudieron identificar hasta género, 15 hasta familia y dos hasta orden) que conforman el nuevo catálogo de invertebrados terrestres de las Islas Columbretes (Anexo 2.3).

De estas 276 especies, 46 citas hasta especie, 11 hasta género, dos hasta familia y una hasta orden, constituyen primeras citas para el archipiélago o para alguna de las islas. Todas las que aparecen en las islas menores o islotes, también aparecen en la Illa Grossa excepto la familia Asilidae y la especie Coccinella septempunctata, que tan sólo hemos encontrado en la Foradada y en la Ferrera, respectivamente (Anexo 2.2, Anexo 2.3 y Tabla 2.7).

Respecto a las islas menores (es decir, exceptuando la Illa Grossa) o islotes incluidas en el presente estudio, existen nueve especies catalogadas por primera vez en la Ferrera (dos de las cuales se identificaron hasta género y una, hasta orden), ocho en la Foradada (una de las cuales se identificó hasta género, dos, hasta familia y una, hasta orden), cinco especies en el Mancolibre y una en la Senyoreta (Anexo 2.3).

Tabla 2.7. Primeras citas (incluidos los taxones que no habían sido catalogados con anterioridad) en cada una de las islas, la cual se indica a continuación del nombre, a menos que haya aparecido en la Illa Grossa únicamente. En el caso de las citas identificadas hasta género, familia u orden, se consideran primeras citas si no se había identificado con anterioridad ninguna especie de los correspondientes grupos. Se han ordenado alfabéticamente y se muestra el orden entre paréntesis.

\begin{tabular}{l|l}
\hline \multicolumn{1}{c|}{$\begin{array}{c}\text { Primeras citas hasta } \\
\text { género/familia/orden }\end{array}$} & \multicolumn{1}{c}{ Primeras citas hasta especie } \\
\hline (ARA) Clubiona sp. & (SCU) Acaeroplastes melanurus (Budde-Lund, 1885) \\
(SCO) Cryptops sp. & (LEP) Agdistis neglecta Arenberger, 1976 \\
(ZYG) Ctenolepisma sp. - Illa Grossa y & (LEP) Agrius convolvuli (Linnaeus, 1758) \\
\hline
\end{tabular}




Ferrera ( $1^{\text {as }}$ citas para el archipiélago)
(HYM) Messor sp.-Foradada
(ARA) Nemesia sp.
(HYM) Ophion sp.
(ORT) Parasteropleurus sp. - Ferrera $\left(1^{\text {a }}\right.$
cita para el archipiélago)
(HYM) Polistes sp
(ARA) Segestria sp
(ARA) Steatoda sp.
(ARA) Zelotes sp.
(DIP) Asilidae -Foradada
(1a cita para el archipiélago)
(HEM) Pyrrhocoridae-Foradada
Psocoptera-Ferrera y Foradada

Ferrera ( ${ }^{\text {as }}$ citas para el archipiélago)

(HYM) Messor sp.-Foradada

(ARA) Nemesia sp.

(HYM) Ophion sp.

(ORT) Parasteropleurus sp. - Ferrera $\left(1^{\mathrm{a}}\right.$

cita para el archipiélago)

(HYM) Polistes sp

(ARA) Segestria $\mathrm{sp}$

(ARA) Steatoda sp.

(ARA) Zelotes sp.

(DIP) Asilidae -Foradada

(1a cita para el archipiélago)

Psocoptera-Ferrera y Foradada
(ODO) Anax parthenope (Selys, 1839)

(ARA) Argiope trifasciata (Forskal, 1775)

(COL) Arhopalus syriacus (Reitter, 1895)

(COL) Blaps lusitanica Herbst, 1799-Ferrera

(HEM) Brachynema cinctum (Fabricius, 1775)

(ARA) Buthus occitanus (Amoreux, 1789)-Mancolibre

(LEP) Catocala coniuncta (Esper, 1787)

(COL) Cebrio superbus Jacquelin du Val, 1860

(COL) Coccinella septempunctata Linnaeus, 1758-

Ferrera (1을 cita para el archipiélago)

(HEM) Cydnus aterrimus (Forster, 1771)

(ARA) Dysdera cf. crocota

(COL) Elenophorus collaris (Linnaeus, 1767)-

Mancolibre

(LEP) Emmelina monodactyla (Linnaeus, 1758)

(MES) Graminaseius lituatus (Athias-Henriot, 1961)

(ORT) Gryllomorpha uclensis Pantel, 1890

(ORT) Gryllus bimaculatus De Geer, 1773

(LEP) Helicoverpa armigera (Hübner, 1808)

(LEP) Heliothis peltigera (Denis \& Schiffermüller, 1775)

(HEM) Icerya purchasi Maskell, 1878)-Illa Grossa,

Ferrera y Foradada (10 citas para el archipiélago)

(ODO) Ischnura elegans (Vander Linden, 1820)

(MES) Kampimodromus aberrans (Oudemans, 1930)

(LEP) Lampides boeticus (Linnaeus, 1767)

(ISO) Ligia italica Fabricius, 1798-Illa Grossa,

Mancolibre, Senyoreta, Ferrera y Foradada

(DIP) Lucilia sericata (Meigen, 1826)

(HYM) Messor bouvieri Bondroit, 1918

(LEP) Mniotype spinosa (Chrétien, 1910)

(LEP) Mythimna vitellina (Hübner, 1808)

(ARA) Neoscona subfusca (C.L. Koch, 1837)

(HEM) Nezara viridula (Linnaeus, 1758)

(ORT) Oecanthus pellucens (Scopoli, 1763)

(HYM) Ophiusa tirhaca (Cramer, 1773)

(LEP) Palpita vitrealis (Rossi, 1794)

(BLA) Periplaneta americana (Linnaeus, 1758)

(COL) Phyllognathus excavatus (Forster, 1771)

(COL) Pimelia interjecta Solier, 1836-Mancolibre y

Ferrera

(HEM) Planchonia arabidis Signoret, 1876

(HEM) Pyrrhocoris apterus (Linnaeus, 1758)

(LEP) Rhodometra sacraria (Linnaeus, 1767)

(COL) Rodolia cardinalis (Mulsant, 1850)-Illa Grossa y

Foradada (10 citas para el archipiélago)

(COL) Scaurus rugulosus Solier, 1838 -Mancolibre

(COL) Scaurus vicinus Solier, 1838-Ferrera y Foradada

(MES) Typhlodromus(Anthoseius) foenilis Oudemans, 1930

(LEP) Xanthodes albago (Fabricius, 1794) 
Para estudiar la continuidad de las observaciones de cada especie en el archipiélago se ha contabilizado el número de años en que se ha observado su presencia desde que esa especie se registró por primera vez (Tablas 2.3 a 2.6). El escorpión Buthus occitanus (Amoreux, 1789) (Figuras 2.21 a 2.23) y los tenebriónidos Pimelia interjecta, Scaurus vicinus Solier, 1838 (Figura 2.22) y Tentyria pazi, son las que se han observado de manera consistente todos los años (frecuencia del $100 \%$ ) desde el primer registro en la Illa Grossa, la Ferrera y la Foradada. $P$. interjecta ha ofrecido esta frecuencia, además, en el Mancolibre. Estas observaciones se han completado con las referencias bibliográficas encontradas divididas en tres épocas, antes de 1994, de 1994 a 2003 y de 2004 en adelante, así como las referencias en colecciones (Anexo 2.2). El recuento de referencias bibliográficas muestra que la gran mayoría de los estudios publicados, un $79 \%$, lo fueron antes de 1994, mientras que tan sólo un 10 y un 11 \% fueron publicados entre 1994 y 2003, y de 2004 en adelante, respectivamente. Del total de 276 referencias bibliográficas encontradas (Figura 2.20), las tres únicas especies que poseen referencias en las tres épocas son $P$. interjecta, así como las especies endémicas $T$. pazi y $X$. molinae (Anexo 2.2).

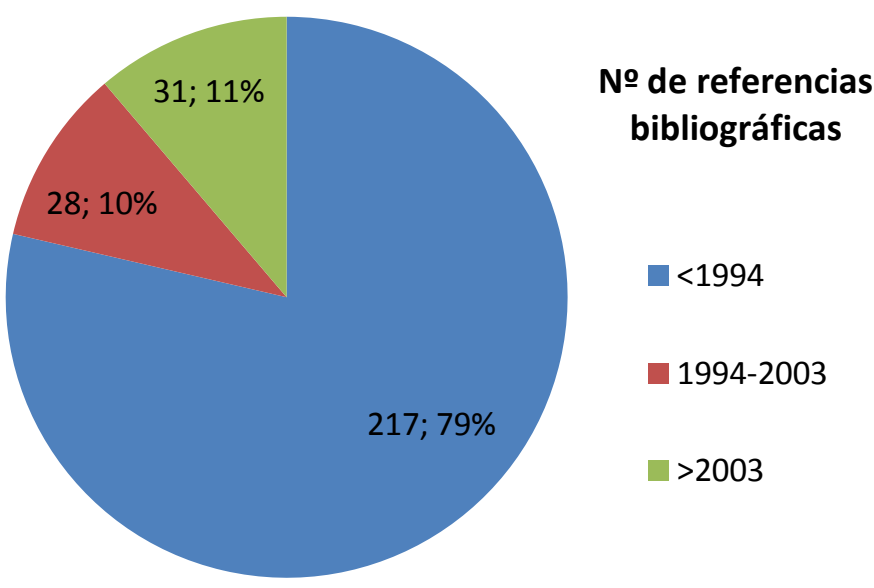

Figura 2.20. Número de referencias bibliográficas encontradas en función del año de publicación, dividido en tres épocas: publicados antes de 1994, entre 1994 y 2003 y después de 2003. 


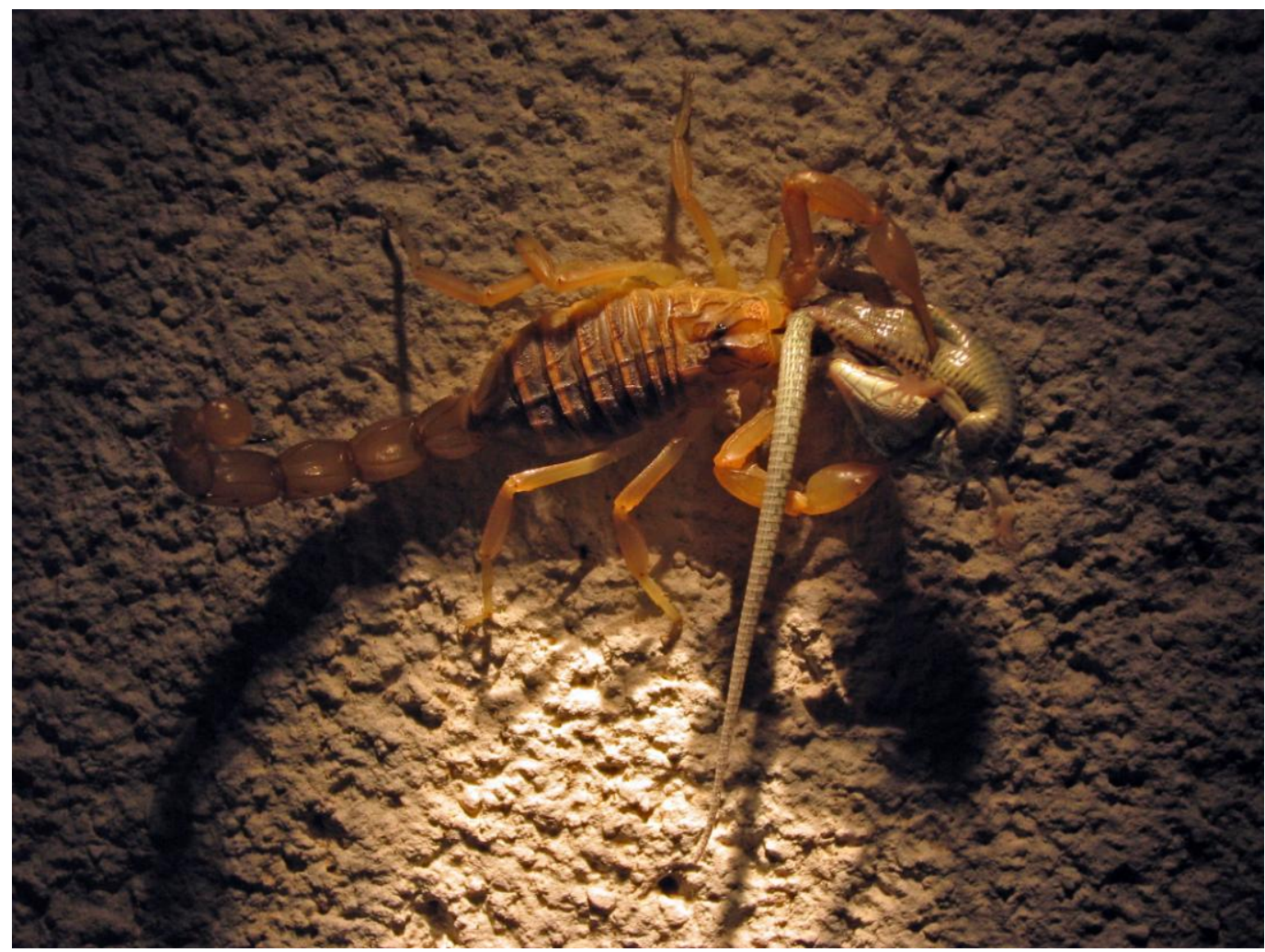

Figura 2.21. Durante la noche, los escorpiones, Buthus occitanus (Scorpiones; Bhutidae), pueden alimentarse de lagartijas, Podarcis atrata.

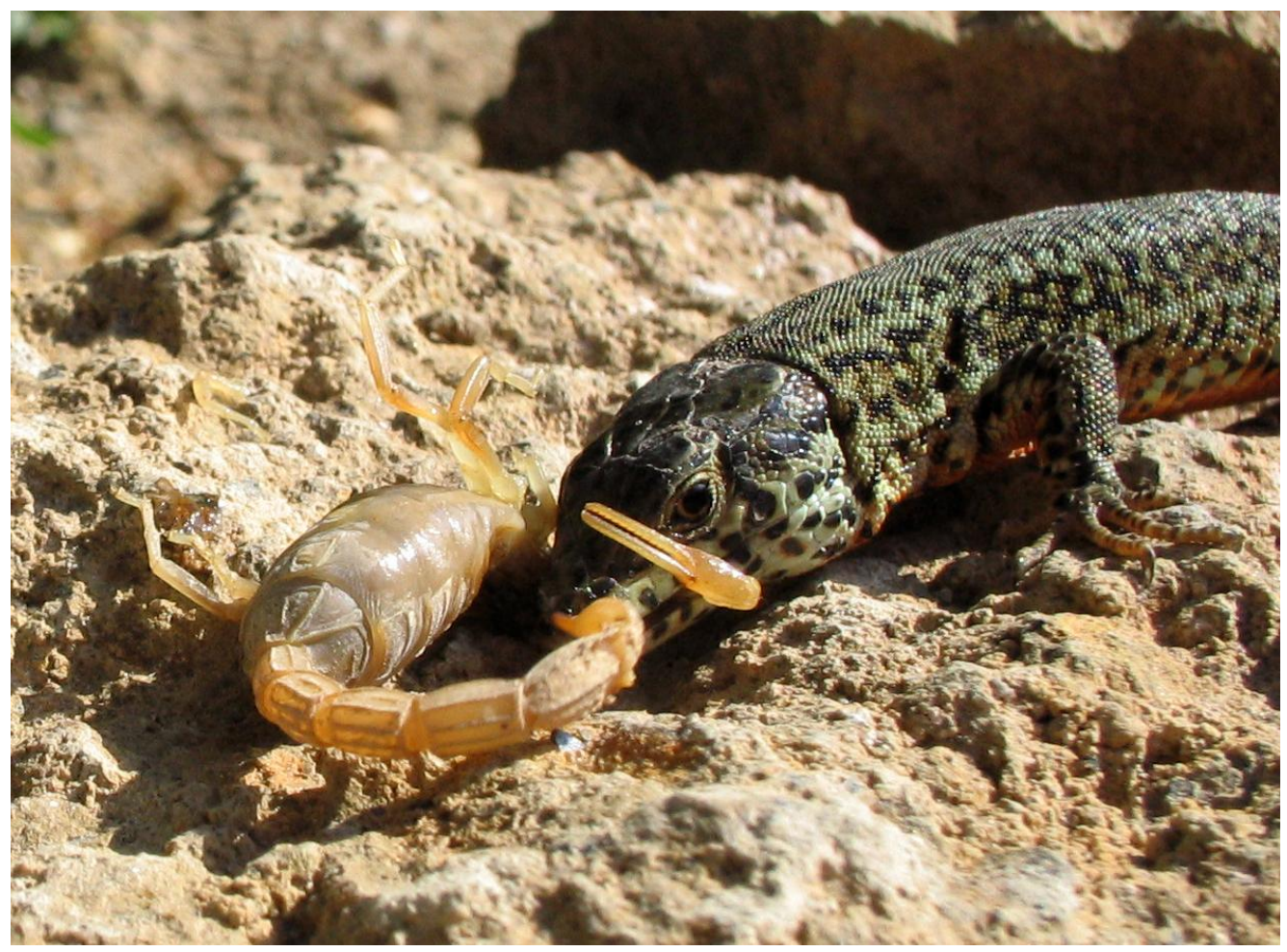

Figura 2.22. Durante el día las lagartijas, $P$. atrata (Squamata; Lacertidae), pueden alimentarse de escorpiones, $B$. occitanus. 
Medi natural: catàleg d'invertebrats terrestres

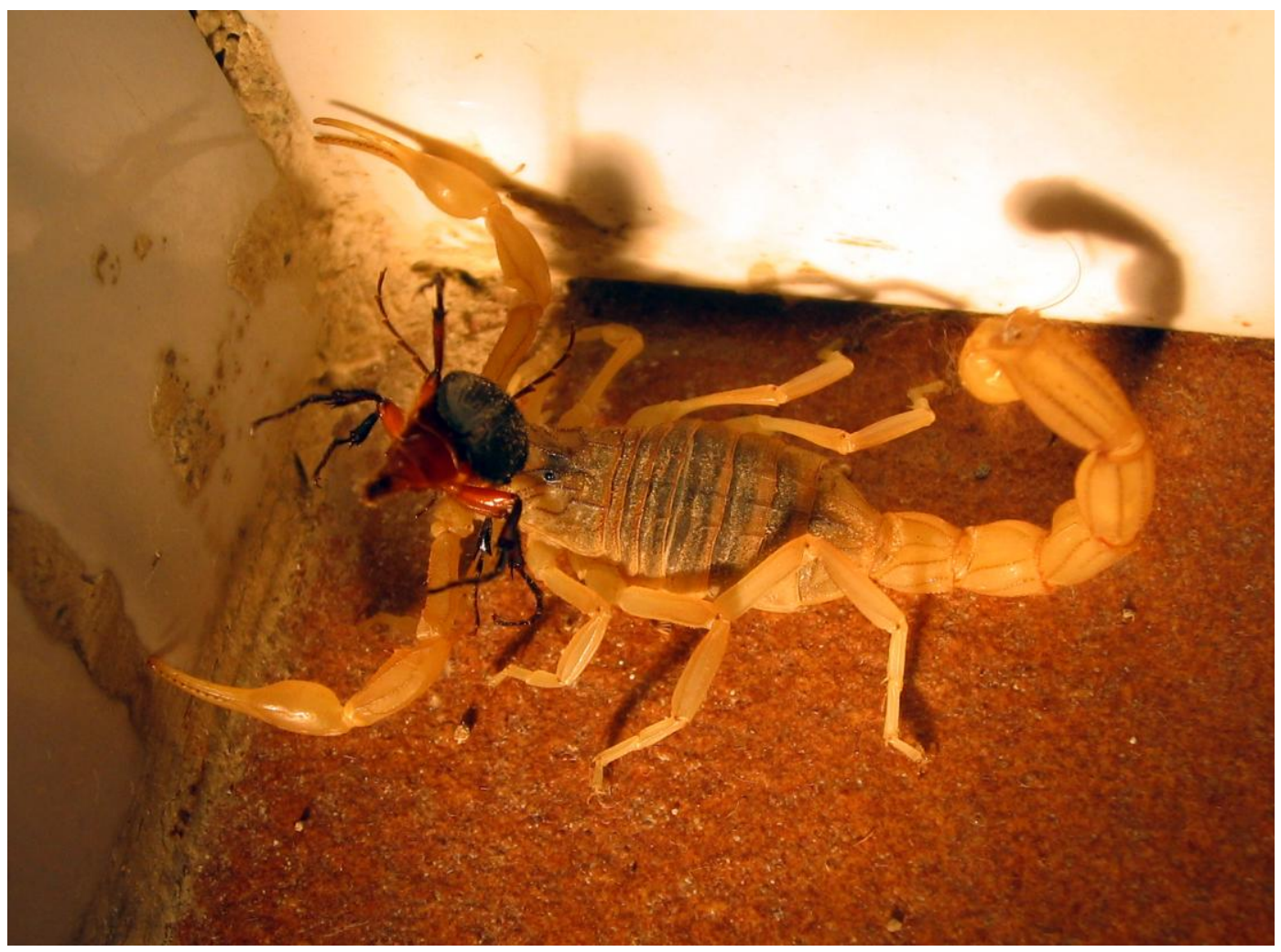

Figura 2.23. Los escorpiones, $B$. occitanus, campan a sus anchas por el interior de las casernas durante la noche. En la imagen, tras cazar al coleóptero elatérido Cebrio superbus (Coleoptera; Elateridae).

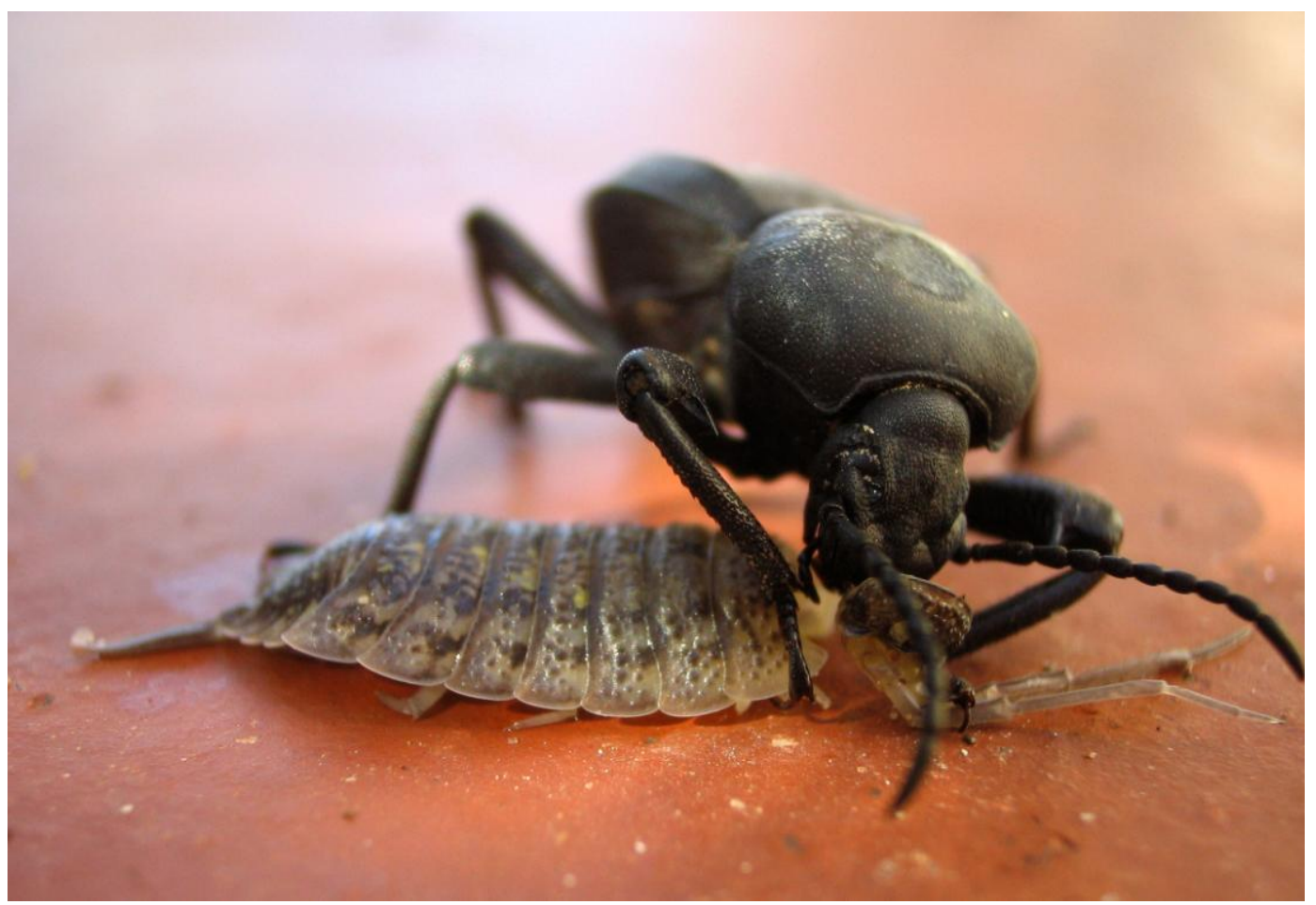

Figura 2.24. Scaurus vicinus (Coleoptera; Tenebrionidae), depredando al isópodo terrestre Porcellio violaceus (Isopoda; Porcellionidae). 


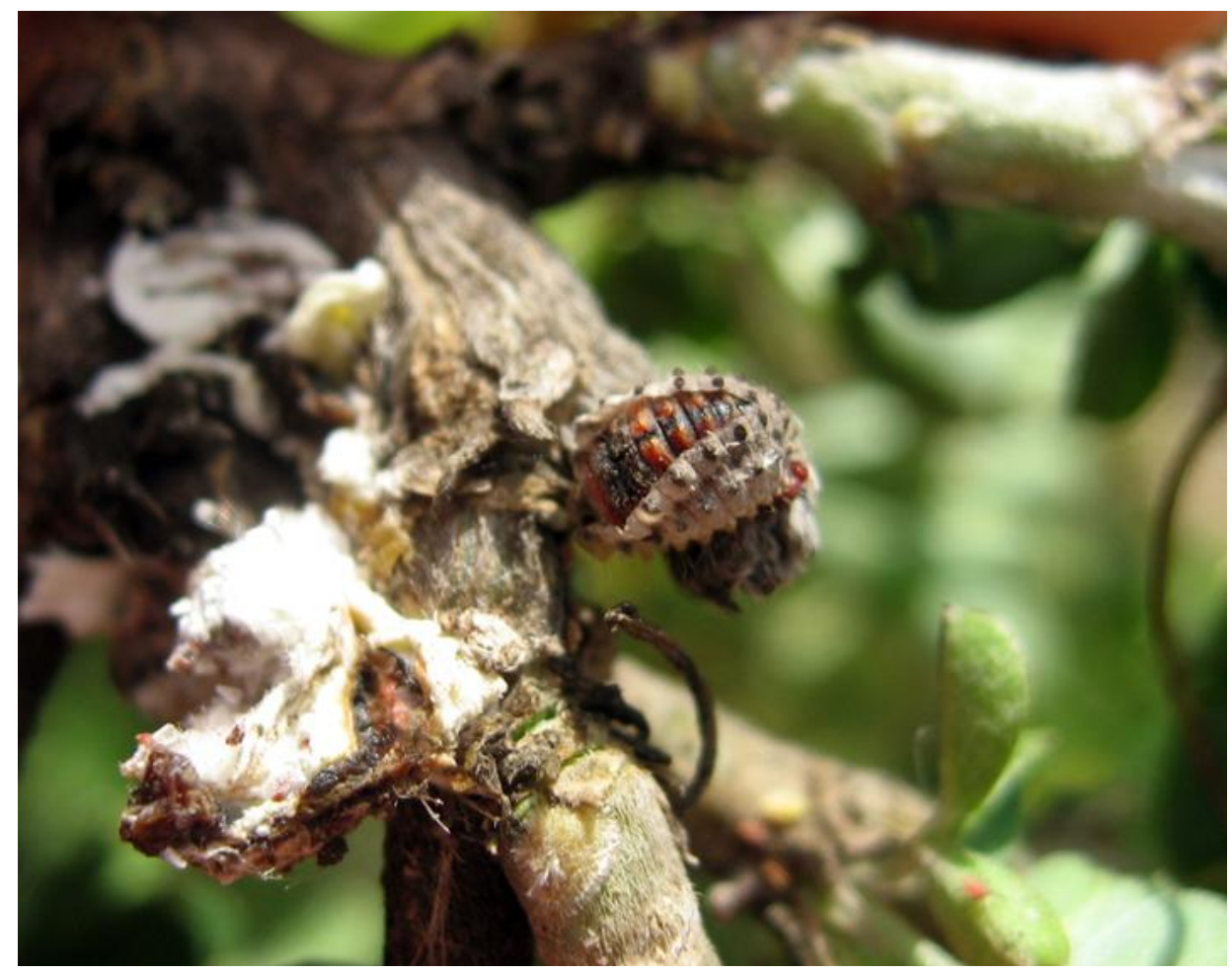

Figura 2.25. Pupa de Rodolia cardinalis (Coleoptera; Coccinallidae), depredador de Icerya purchasi (Hemiptera; Margarodidae).

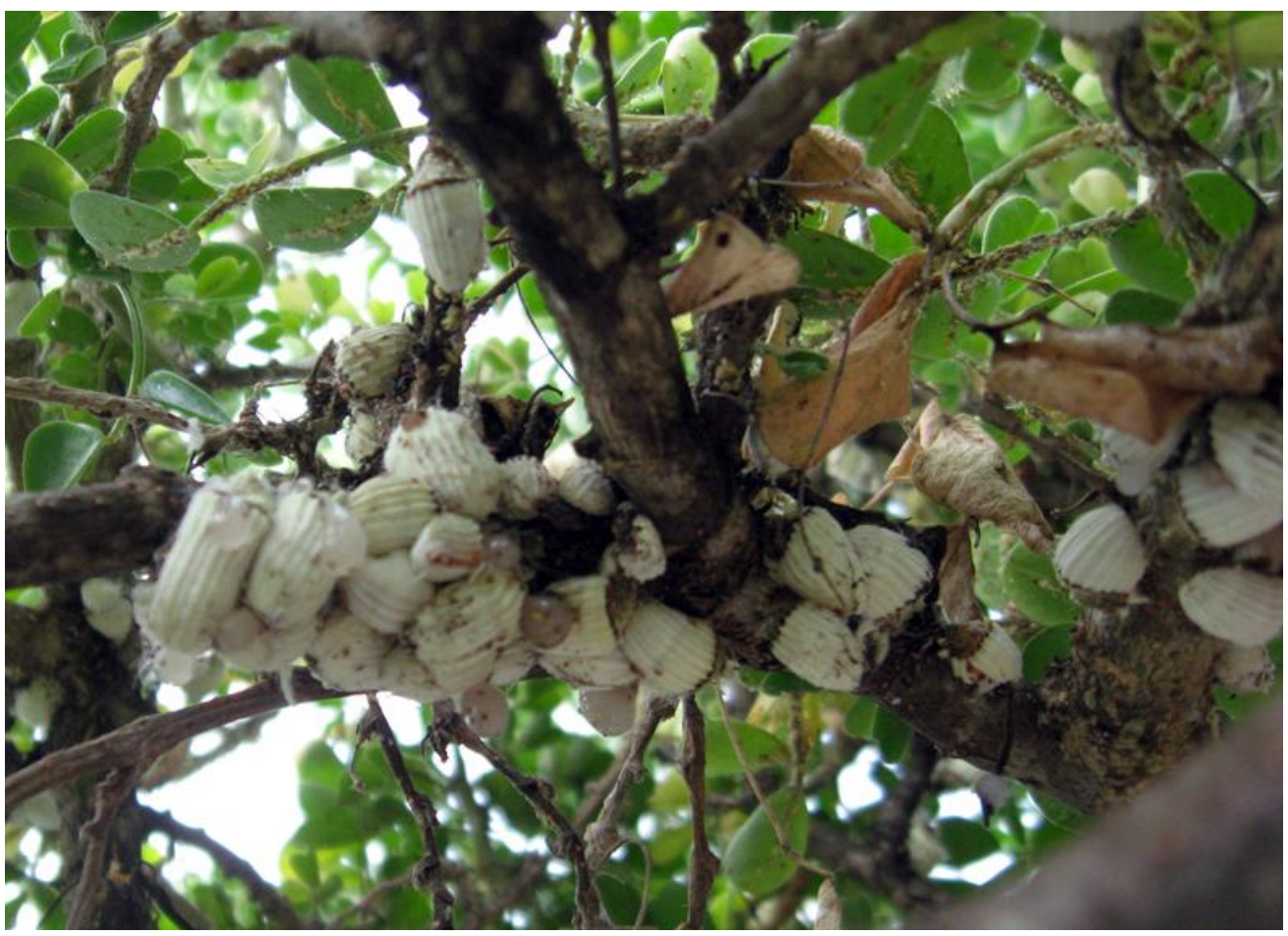

Figura 2.26. Hembras con ovisaco de Icerya purchasi, en grandes cantidades sobre los tallos y ramas de Medicago citrina (Fabales; Fabaceae). 
Medi natural:

catàleg d'invertebrats terrestres

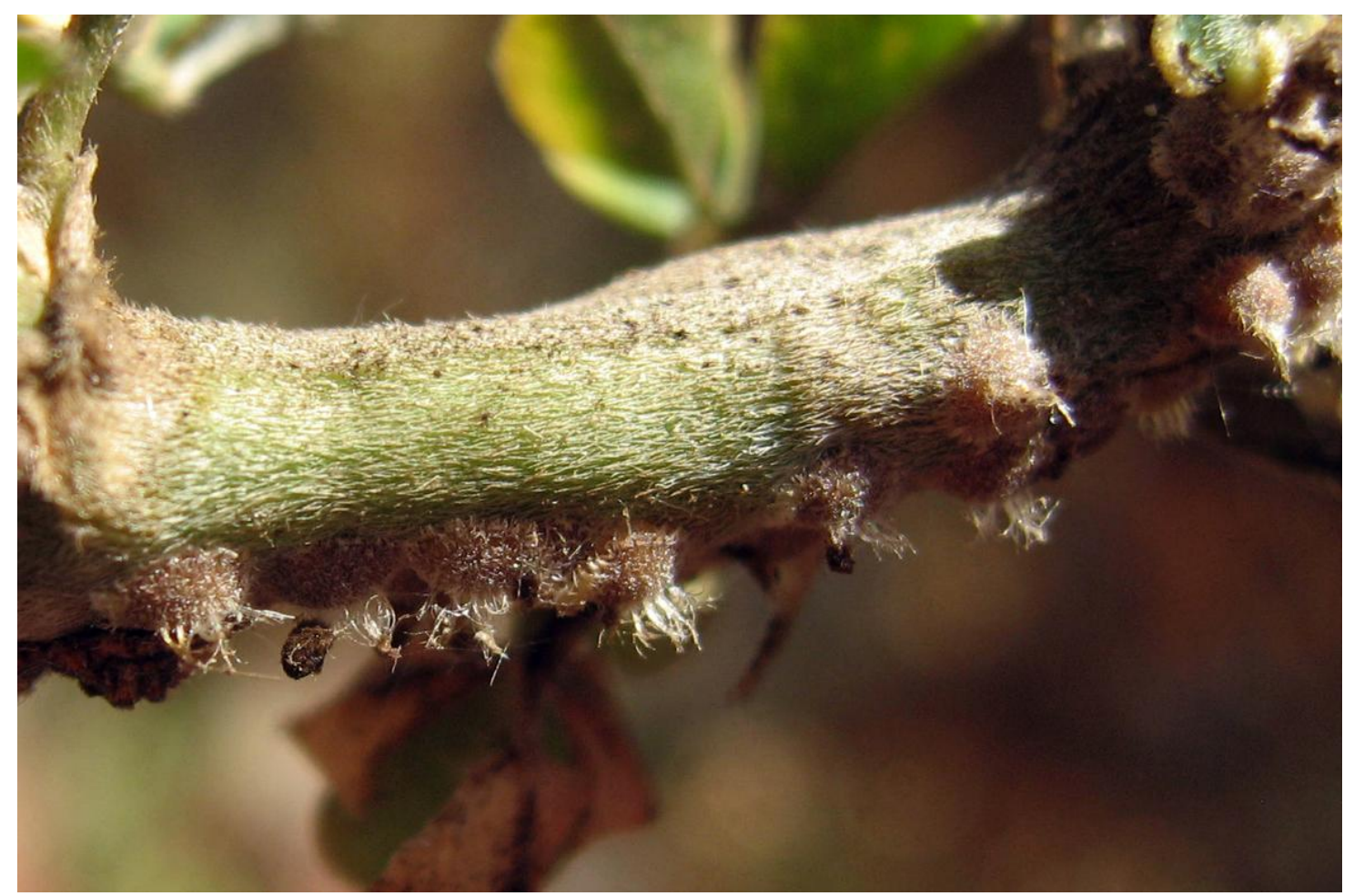

Figura 2.27. Planchonia arabidis (Hemiptera; Asterolecaniidae), detectada por primera vez en 2011, sobre ramas de M. citrina, por la guarda Manli Viñes.

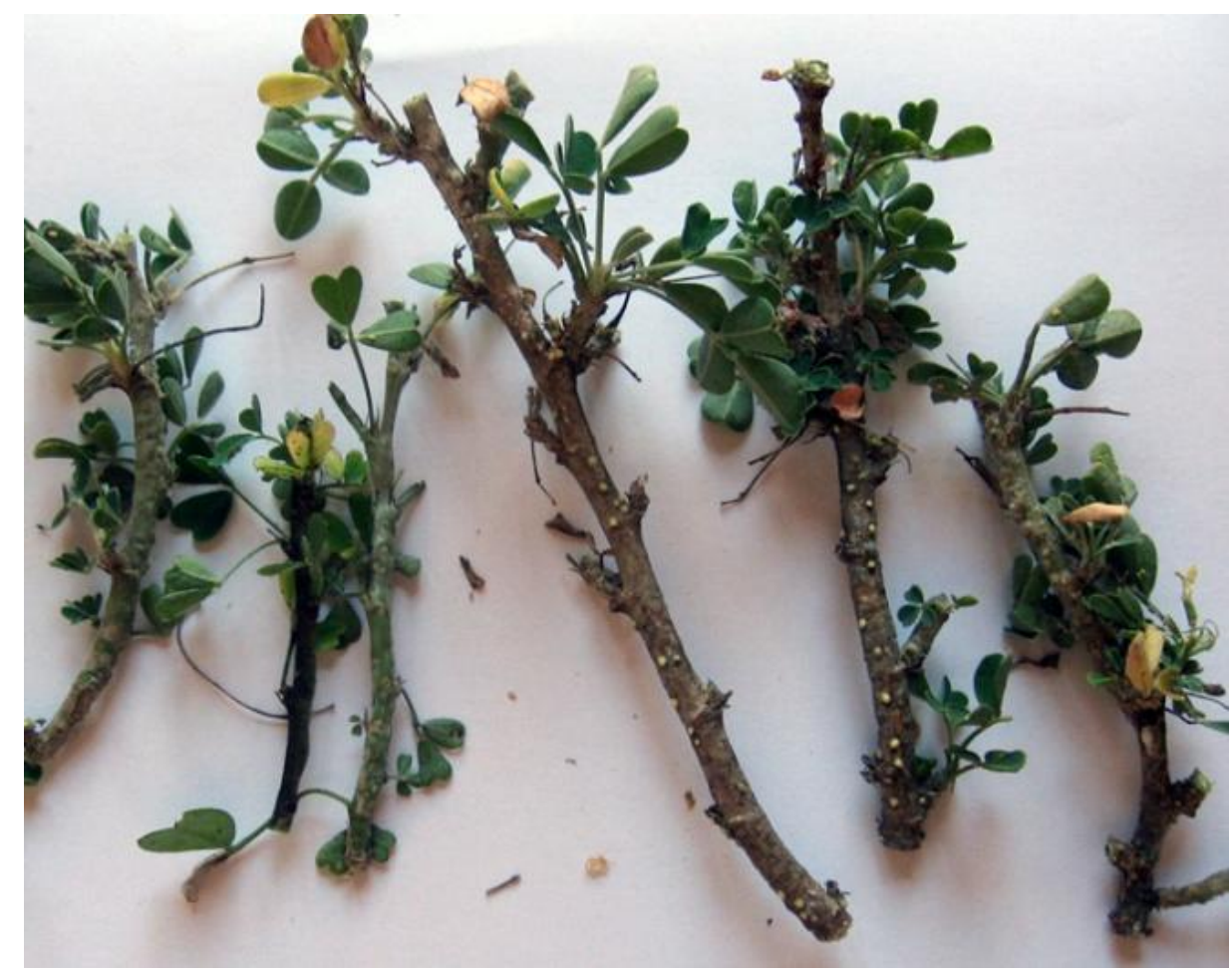

Figura 2.28. Planchonia arabidis, abundante sobre M. citrina. 
De las seis especies de insecto endémicas de Columbretes (Anexos 2.2 y 2.3), tan sólo los tenebriónidos $A$. bonacherai, $H$. littoralis y $T$. pazi, así como el el gasterópodo $X$. molinae han sido observados en el presente estudio. Español (1958) describió otra especie que consideró endémica, el hemíptero antocórido que él citó como Orius ovatus Español, 1958. Esta especie, posteriormente redescrita como Orius (Orius) lindbergi Wagner, 1952 (Ferragut \& González, 1994) y presente en Francia, España (incluido Alborán) y Sicilia (http://www.faunaeur.org/distribution_table.php), no se ha observado en el presente estudio.

Tampoco hemos observado las dos especies de gasterópodo citadas por Robles (1991) como quizás extintas: los moluscos Theba pisana y Pomatias elegans (Pulmonata y Neotaenioglossa, respectivamente), lo cual refuerza la teoría de Robles.

Respecto a las nuevas especies de fitoseidos catalogadas, Typhlodromus foenilis, que se encontró también en el Parque Natural del Penyagolosa, y Graminaseius lituatus son nuevas citas para la Comunitat Valenciana (Figuras 16 y 9 del Anexo 2.4). La primera especie presenta una distribución amplia, habiendo sido citada en el Mediterráneo, pero también en países distantes como Noruega y Canadá (GBIF, 2017), y ha sido estudiada con más detalle por su asociación con los viñedos europeos (Kreiter, 2012). En cuanto a G. lituatus, esta especie ha sido citada únicamente en España y en Italia (Demite et al, 2017). La tercera especie de fitoseido catalogada por primera vez en Columbretes, $K$. aberrans, presenta una distribución paleártica. Es frecuente en plantas con hojas pubescentes y ha sido citada como agente de control biológico de Panonychus ulmi (Koch, 1836) y Eotetranychus carpini (Oudemans, 1905) en viñedo (Tixier et al., 2013).

Una especie muy frecuente en Columbretes, y que sin embargo no había sido citada en ningún catálogo todavía, es el isópodo Ligia italica (Figura 2.18), especie propia de la zona supralitoral que coloniza los ambientes cercanos al nivel de mar, predominantemente en la zona de salpicadura (Pons et al., 1999) que, por tanto, se puede considerar como semi-terrestre. Junoy y Castelló (2003) la citan a lo largo del litoral mediterráneo de la Península Ibérica, isla de Alborán e islas Baleares en su catálogo de las especies ibéricas y baleares de isópodos marinos, pero no la citan en las Columbretes. Castilla y colaboradores (2008) la citan en Columbretes dentro de un estudio de la alimentación de la lagartija endémica Podarcis atrata (Bosca, 1916) (Figura 2.22), aunque no indican el nombre científico completo, igual que Templado (2002).

Una única especie de las catalogadas es fruto de una introducción intencionada en el archipiélago. Se trata de Rodolia cardinalis (Mulsant, 1850) (Figura 2.25), empleada en control biológico del hemíptero margaródido Icerya purchasi Maskell, 1878 (Figura 2.26), que 
constituye una plaga afectando mayoritariamente a la fabácea Medicago citrina (Font Quer) Greuter, 1986, endemismo de área restringida. Según las memorias anuales de gestión de la Reserva Natural, su primera introducción se efectuó el 28 de mayo de 1996 en la Foradada (se realizó una suelta de 130 ejemplares (entre adultos, larvas y pupas) y más recientemente se han realizando sueltas de manera regular, anualmente, desde el año 2001. Esta especie no se ha llegado a establecer en las Columbretes, quizás debido a las condiciones ambientales, o quizás a la gran cantidad de aves insectívoras migratorias que utilizan las islas como zona de descanso y alimentación en sus viajes. El invierno de 2007 a 2008 y en la primavera de 2009 se detectó la supervivencia de $R$. cardinalis en la Illa Grossa (observación personal) pero la dispersión no era eficaz y dado que los ataques de I. purchasi se intensificaron se decidió continuar con la suelta de $R$. cardinalis. En 2015 se produjo una gran mortandad de $M$. citrina, que pasó de 1.042 ejemplares censados en 2008 a 399 (Servei de Vida Silvestre, 2016), según este informe, debido a la sequía, que hace más vulnerable la planta frente a los ataques de la plaga. Si bien es cierto que en 2013 y 2014 hubo una pluviometría anual en Columbretes de 265,10 y 242,50 mm respectivamente, justo en el año 2015 la pluviometría anual se duplicó alcanzando los $509,50 \mathrm{~mm}$, aunque concentrada en el otoño $(365,7 \mathrm{~mm})$ y en verano $(112,9$ $\mathrm{mm}$ ), mientras que en invierno y primavera fue escasa (menos de $25 \mathrm{~mm}$ cada estación) (datos obtenidos del primer capítulo de la presente tesis doctoral).

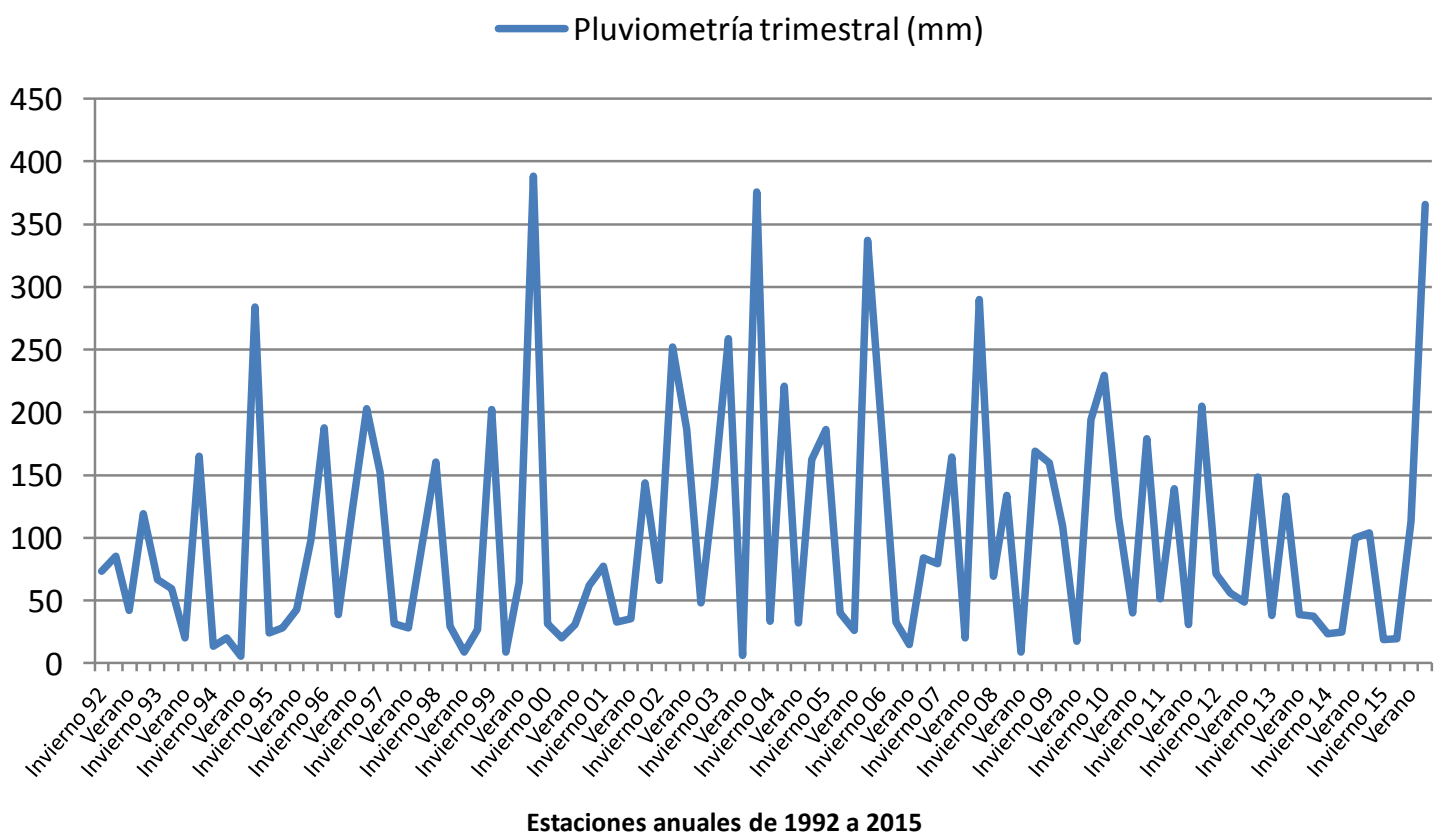

Figura 2.29. Pluviometría acumulada en Columbretes por estaciones anuales (1992-2015). Fuente: capítulo primero de la presente tesis doctoral. 
En la Figura 2.29 mostramos la evolución de la precipitación estacional acumulada desde 1992 y observamos que en toda la serie existen picos de subidas y bajadas estacionales a las que las M. citrina desarrolladas en el archipiélago deberían estar adaptadas. Ello parece indicar que otros factores debieron de jugar un papel importante en este episodio de mortandad. Uno de ellos pudo ser la disminución del número de individuos de $R$. cardinalis soltados en la Illa Grossa en los años 2014 y 2015. Además, la aparición sobre la misma planta huésped en 2011 del hemíptero diaspídido Planchonia arabidis Signoret, 1878 (Figura 2.27y 2.28), pudo haber agravado la situación de estrés. Cuando el control biológico no es efectivo y se teme por la suerte de las plantas, se aconseja realizar un tratamiento directo con vapor de agua sobre la plaga (Mariano Bueno, 2012, comunicación personal); dicho tratamiento físico se aconsejó ya en 2012 a los gestores de la Reserva pero no se ha utilizado todavía en el archipiélago.

Por último, en la Illa Grossa llaman la atención las arañas Argiope lobata (Pallas, 1772) y Argiope bruennichi (Scopoli, 1772) debido a los grandes tamaños que llegan a alcanzar en verano sus telas geométricas y las hembras que las tejen, antes de realizar la puesta y morir a la llegada del otoño. En estas telas pueden llegar a capturar presas de gran tamaño como libélulas, saltamontes e, incluso, pequeñas aves paseriformes, aunque, en este caso, no puedan llegar a alimentarse de ellas (Figuras 2.30 a 2.32).

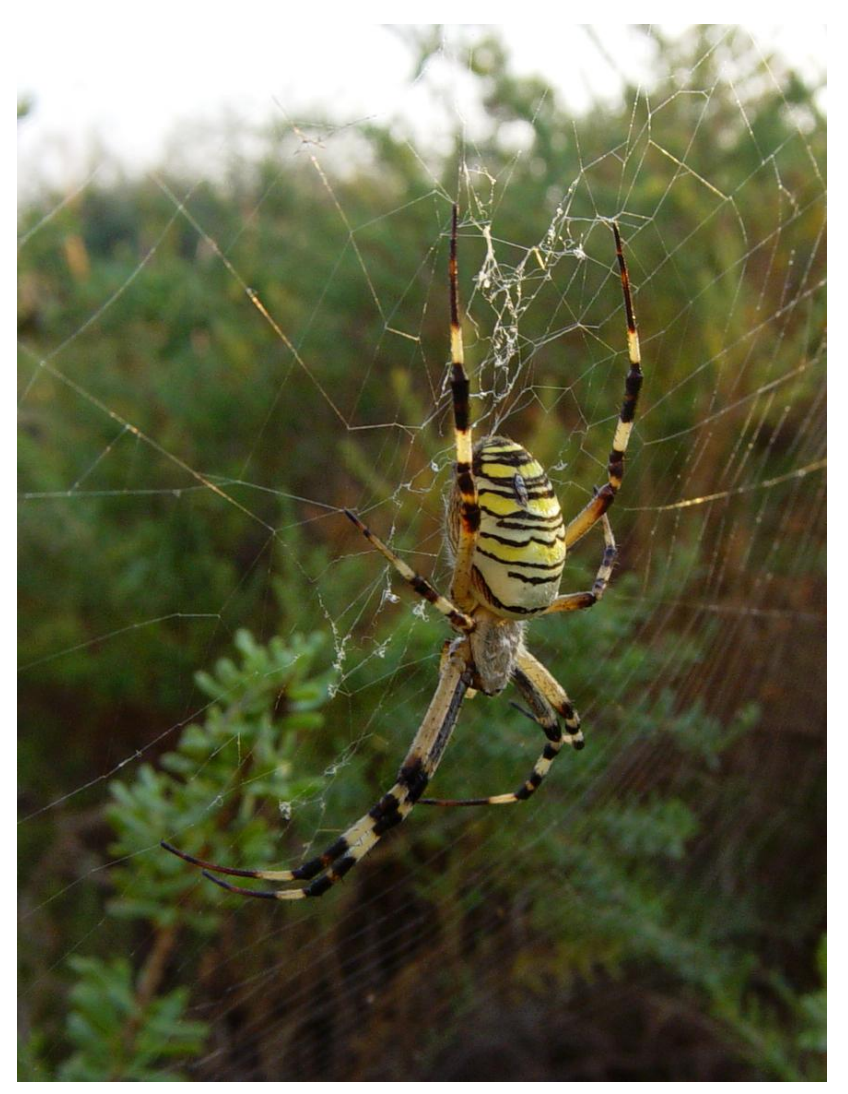

Figura 2.30. Hembra de Argiope bruennichi (Araneae; Araneidae). 
Medi natural: catàleg d'invertebrats terrestres

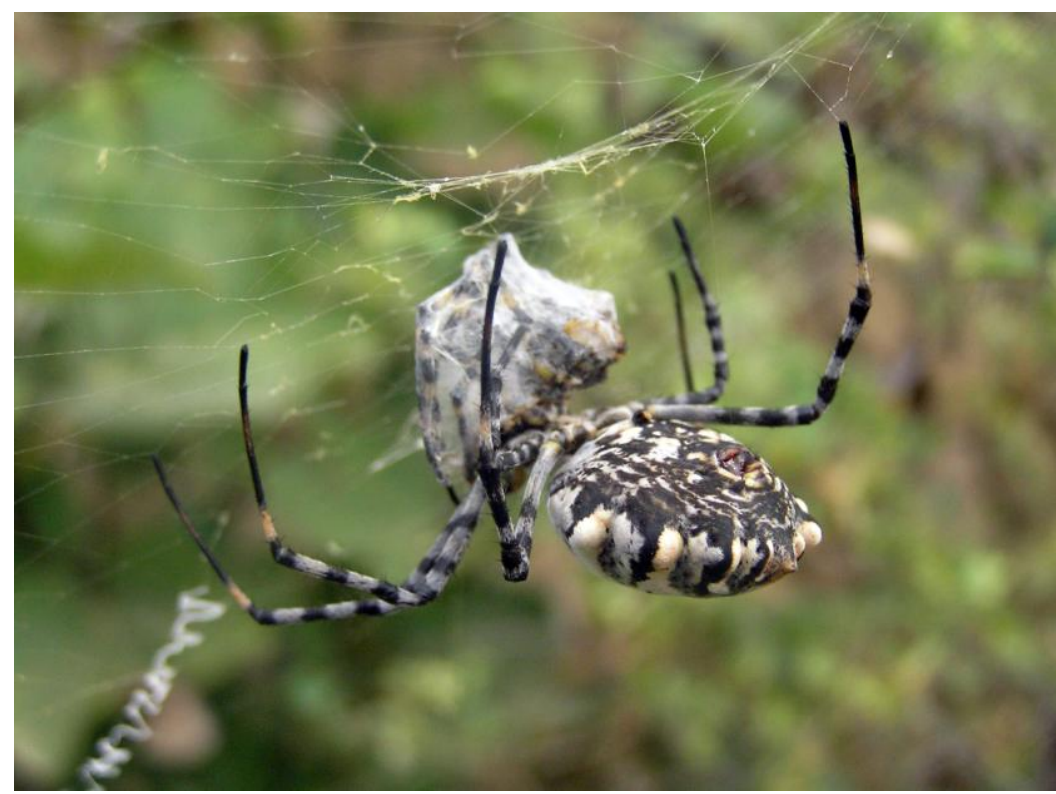

Figura 2.31. Canibalismo de Argiope lobata (Araneae; Araneidae).

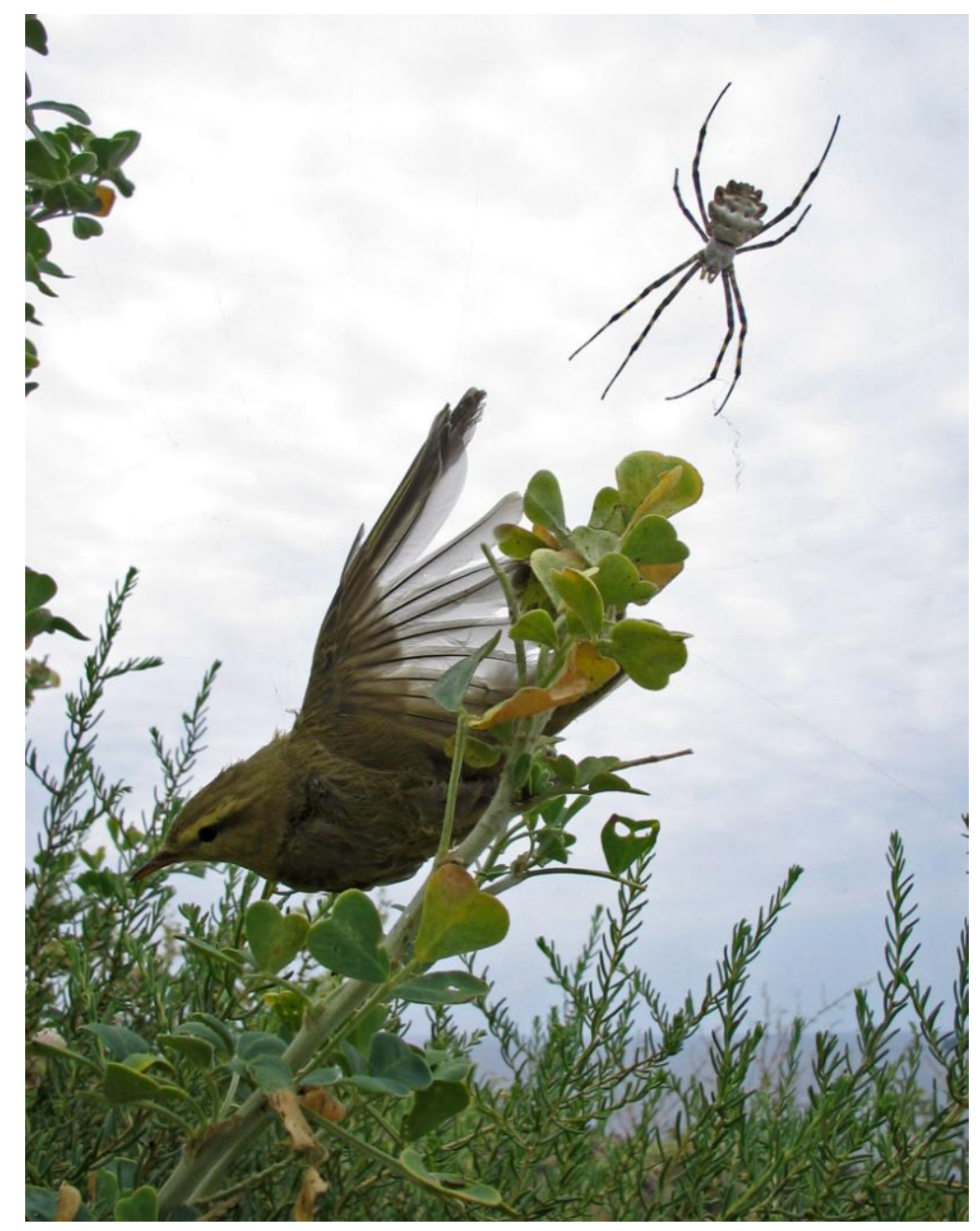

Figura 2.32. Mosquitero musical, Phylloscopus trochilus (Passeriformes; Sylviidae), atrapado en la tela de una A. lobata (Araneae; Araneidae) (28/08/2005). Puesto que había roto la tela intentando soltarse y la araña no iba a poder comérselo, procedimos a su liberación. 


\section{Conclusiones}

Dado que la mayoría de los estudios sobre la fauna invertebrada terrestre de las Columbretes se había realizado antes de 1994 (79 \% de los estudios son anteriores a esta fecha), el presente catálogo ha servido, por un lado, para constatar la presencia de especies observadas con anterioridad, especialmente endemismos, los cuales son buenos indicadores de la conservación de los espacios naturales (García-Barros et al, 2002), y por otro lado, a reunir en un único catálogo todas las especies de invertebrados citadas en Columbretes y que se encontraban dispersas en gran cantidad de estudios, ampliado con las observaciones realizadas en nuestro estudio.

La utilización de trampas de gravedad constituye una metodología adecuada para la captura de animales terrestres que hay que combinar con un gran esfuerzo en observación y, a ser posible, con otro tipo de trampas que permitan capturar invertebrados voladores. Estas trampas son muy efectivas para la captura de coleópteros tenebriónidos, los cuales son un grupo de insectos importantes en el funcionamiento de los ecosistemas insulares, que desempeñan un destacado papel en la descomposición de la materia orgánica y, por tanto, son indicadores del estado de conservación del ecosistema (Cartagena, 2002). Este autor incluyó dos nuevas citas de especies de tenebriónidos en su estudio, lo que dio un total de 11 especies pertenecientes a esta familia en las Columbretes. En nuestro estudio se han encontrado las mismas 11 especies. Puesto que la abundancia y composición en especies de tenebriónidos viene determinada por las condiciones del sustrato y la estructura de la vegetación (Stapp, 1997), parece que las políticas de protección del archipiélago que se comenzaron a aplicar en 1988, mostraron su efectividad en 2002, cuando Cartagena llevó a cabo su estudio, y continúan en la actualidad.

Por todo ello, sería conveniente la creación de un protocolo de actuación para la gestión y seguimiento de la fauna invertebrada de la Reserva, que estableciera actuaciones como el estudio de presencia de coleópteros cada cierto tiempo para comprobar la dinámica del ecosistema, la constatación de la presencia de invertebrados migratorios (realizado por el personal que está presente en las islas los 365 días del año) o la observación y captura de nuevas especies. Todo ello, con especial actuación en las islas menores, pues son las menos estudiadas. 
Capítol 3

\section{Empremta humana i memòria}

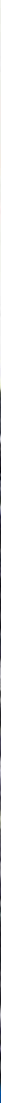


Capítol 3

Una versió d'aquest capítol s'ha preparat en format de pel-lícula documental de 50' de durada (MestreForés, E., González, P., del Señor, X. \& F. Ramia (Aïllats: la memòria de Columbretes).

Una versió d'aquest capítol s'ha preparat en format de pel-lícula documental de $30^{\prime}$ de durada (MestreForés, E., González, P. \& C. Gauxach (Continuem Aïllats). 


\section{Introducció}

Les referències més antigues que es coneixen sobre les Columbretes són dels clàssics Plini el Vell (23aC- $79 \mathrm{dC})$, Estrabó $(64 \mathrm{aC}-23$ ? dC) i Pomponi Mela (? - $45 \mathrm{dC})$, els quals es referien a unes illes anomenades "Ophiusa" o "Colubraria", per grecs i romans, respectivament, per la gran quantitat de serps que hi habitaven (Escolano, 1610; Habsburg-Lorena, 1895). Gaspar Escolano (1610) també indicava en la seua obra "Década primera de la historia de la insigne i coronada ciudad de Valencia" que molt a prop de les costes valencianes hi havia l'illa de Montcolobrer, envoltada de moltes illetes. No obstant, el primer article publicat sobre les Columbretes per algú que les havia visitades va ser "On the Columbretes, Volcanic Rocks near the coast of Valencia, in Spain" de W.H. Smyth (1831), capità de l'almirallat britànic, qui les va visitar probablement l'any 1823. En la seua descripció s'indica que:

"...what excited the greatest surprise, and indeed is very remarkable, was, that the seamen were actually impeded in their progress with the instruments, by the number of snakes which infested the whole space."

, i descriu aquestes serps com:

"...generally between two and three feet long, finely striated with dark zig-zag lines, on a bright yellow ground, blending whiter at the belly...",

però a banda d'aquesta relació entre ofidis i humans, no hi ha referències a cap resta de l'empremta humana. Nombrosos navegants passaven per les Columbretes $i$ es tenen referències de la seua condició, sobretot de la badia de l'Illa Grossa o les coves com la de la Foradada, com a lloc de refugi de pirates o, posteriorment de contraban. Aquest és el cas del brigadier de l'armada Vicente Tofiño de San Miguel i Wanderiales (1732-1795), el cognom del qual va donar nom a la badia de l'Illa Grossa, on galiots xabecs dels moros s'ocultaven per fer les seues pirateries (Serrano, 1991). També s'ha suposat que a les Illes podrien haver-s'hi refugiat en alguna ocasió persones que escapaven d’alguna epidèmia (Fernández, 1995) o nàufrags.

El primer assentament humà conegut va estar format pels faroners i les seues famílies. Una vegada es va començar a construir el far (Figures 3.1 i 3.2) l'any 1856, es van començar a generar notícies relacionades amb la vida a les Illes, de manera que molta informació es troba dispersa en la premsa i revistes de l'època. També la mort hi ha estat present. Prova d'això n'és el xicotet i blanc cementeri de l'llla Grossa (Figures 3.3 i 3.4), que acull diverses làpides de xiquets $i$ un adult (Annex 3.1), a més d'un indeterminat nombre d'enterraments sense làpida, $i$ 
que ha estat descrit com al cementeri més aïllat i trist del món. Hi ha bastant desconeixement sobre els faroners que hi van treballar. De fet ni tan sols existeix un llistat dels que han passat per Columbretes, com tampoc de cap altre far (Moré, 2010), i els noms d'aquells de qui normalment es parla no arriben a la mitja dotzena. També els pescadors han anat sempre a Columbretes a descansar del seu treball fondejant a la badia de Port Tofiño, o al vessant oest de les Illes si els temporals de l'est els obligaven. En altres casos, els pescadors passaven mesos a prop de les Columbretes, cas d'algunes barques mallorquines, vivint i treballant a la mar, però descansant a les Illes, sempre relacionant-se amb els faroners. Tant faroners com mariners van anar contant anècdotes que van passar de boca en boca i, amb el pas dels anys, van contribuir a engrandir la figura de Columbretes com a lloc llegendari i mitològic.

La primera aportació al coneixement dels assentaments humans dins d'un estudi publicat es troba a la Monografia de l'Arxiduc Lluís Salvador d'Habsburg-Lorena i Borbó-Dues-Sicílies, qui va visitar les Columbretes l'any 1894. L'erudit i il.lustrat arxiduc, tercer fill del Gran Duc Leopold II de Toscana, havia nascut a Florència, al famós Palazzo Pitti l'any 1837, i va fixar la seua residència a Mallorca, des d' on va recórrer molts punts de la Mediterrània per estudiar-los i descriure'ls des dels punts de vista mediambiental i humà. Va crear d'aquesta manera una extensa bibliografia, que inclou la monografia "Columbretes", publicada l'any 1895, on, entre altres aspectes de les illes, mostra una recopilació de la toponímia, geografia i història de les Columbretes. Particularment, dona detalls de la construcció del far i de la vida dels faroners amb els que va conviure (Habsburg-Lothringen, 1895). La següent publicació on també trobem referències sobre el vessant humà de les Columbretes és les "Notas de Caza" de Francisco Bru, que tot i que va publicar les seues notes l'any 1913, va estar a l'illa l'any 1886, abans que l'arxiduc, convivint 17 dies amb els faroners, amb l'objectiu de caçar tant com fóra possible.

No va ser fins als anys 90 del s. XX quan es van publicar algunes recopilacions de la història humana a Columbretes (Serrano, 1991; Urios \& Martín, 1997; Carda \& Del Moral, 1998). Durant la mateixa dècada, va ser notícia la trobada d'un cos humà soterrat a l'Illa Grossa, sense restes d'aixovar, sudari o objectes personals i mort per un fort traumatisme, de qui tan sols es pot assegurar que es tracta d'una troballa arqueològica d'edat moderna, s. XVII-XVIII (Fernández, 1995). Tot i que les històries contades han tirat mà de la fantasia per atribuir-lo a un pirata berber soterrat en l'Illa mirant cap a la Meca, Fernández (1995) indica l'enterrament en la direcció oposada, es a dir, a l'oest. Posteriorment, l'any 2002, el Ministeri d'Agricultura, Pesca i Alimentació va publicar una altra Monografia de Columbretes, encarregada al Museu Nacional de Ciències Naturals (CSIC), que, tot i estar centrada en el medi marí, conté un capítol sobre el medi emergit, part del qual tracta sobre l'acció dels humans i la conservació, i un altre 
sobre la història de la investigació a les Columbretes (Templado et al., 2002).

Finalment, dins la publicació de David Moré, llicenciat en Història i net del tècnic de fars Alberto Aguirre Martín, La vida en los faros de España. El Cuerpo de Torreros de Faros o de Técnicos Mecánicos de Señales Marítimas (1851-1992), publicada l’any 2010, hi ha nombroses referències i anècdotes sobre la vida al far de Columbretes repartides entre les d'altres fars.

L'empremta humana deixada pels faroners i les seues famílies a les Columbretes ha sigut de la màxima importància en la història de les Illes, però tot i que hi ha estudis publicats sobre la vida al far, hi ha molta més informació dispersa. Avui en dia encara es poden trobar testimonis vius de persones que hi van viure, bé com a faroners, les seues dones, fills o nets, bé com a mariners, que poden transmetre les seues vivències, els seus records i per què no, els seus sentiments, o ajudar-nos a comprendre quina part de veritat tenen eixes històries quasi màgiques contades per la gent de la mar. Al cap i ala fi ells també van formar part d'un ecosistema viu, menut i vulnerable en el qual van haver de viure i en alguna ocasió sobreviure. L'experiència acumulada durant quinze anys com a guia de la reserva de les Illes Columbretes, ens demostra que aquestes històries desperten un gran interès, potser en ocasions inclús més que la seua història natural. Per tant, aquestes històries que formen part de la memòria de les Illes, haurien de tindre cabuda dins la divulgació i l'educació ambiental de la Reserva.

Al llarg d'aquests anys de treball a les Illes hem tingut l'ocasió d'escoltar de primera mà algunes d'aquestes històries. Vam atendre, al menys en tres ocasions, al faroner Juan del Bosque (Figures 3.5 i 3.6) qui, malauradament, va morir poc abans d'entrevistar-lo per a aquest estudi, però ens va contar en alguna de les visites que el seu avi va estar present durant la construcció del far i que el seu oncle també va ser faroner de Columbretes. Però la persona que va desencadenar que ens Ilançàrem a fer aquesta cerca va ser sens dubte Dolores Guerra, dona del faroner Aurelio Zacarías (Figures 3.7 i 3.8). Vam conèixer a Dolores l'any 2010, quan ens va telefonar a l'oficina del Centre d'Informació de Columbretes per a sol-licitar autorització per poder visitar el cementeri i resar unes oracions al seu fill, mort a l'illa pocs dies després de nàixer $\mathrm{i}$ soterrat al cementeri sense làpida. Feia 60 anys que no havia tornat a les Columbretes, ella era la mare d'aquell primer xiquet nascut a les Illes i inscrit al registre civil de Castelló. Amb aquesta telefonada, havíem trobat el bebè Aurelio. La història que ens va contar la mare va desfer els dubtes que podíem tindre a l'hora d'escriure aquest capítol. Aquestes històries havien de ser contades. 


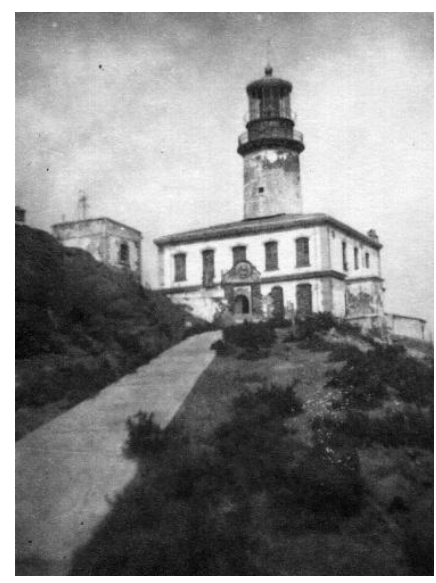

Figura 3.1. Far de Columbretes, 1947. Imatge cedida per Javier Zea Gandolfo.

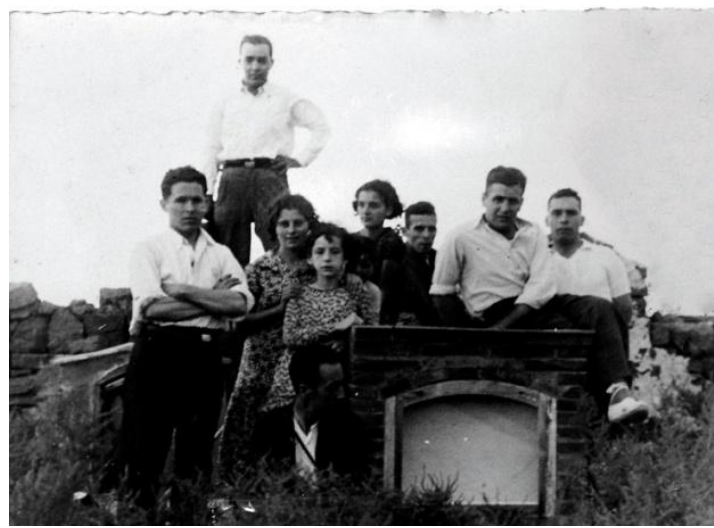

Figura 3.3. Cementeri de Columbretes, anys 50. La família envolta la tomba de la xiqueta Mercè Escortell. Font: arxiu del C.I. de les Columbretes

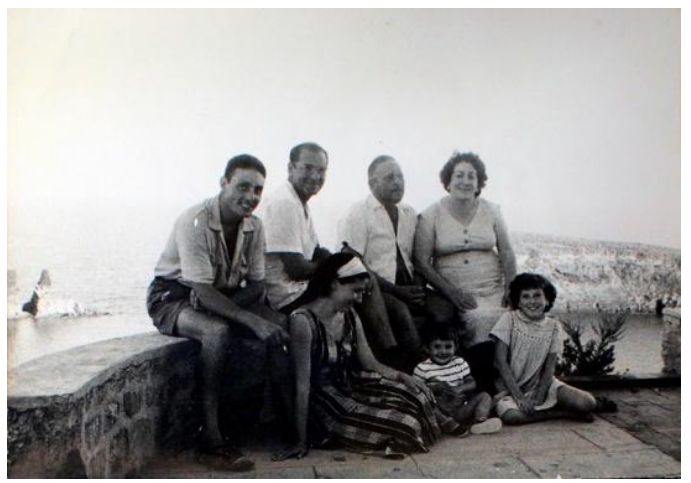

Figura 3.5. El faroner Juan del Bosque amb familiars a Columbretes, anys 50 . Imatge cedida per la seua dona, Manuela Arribas.

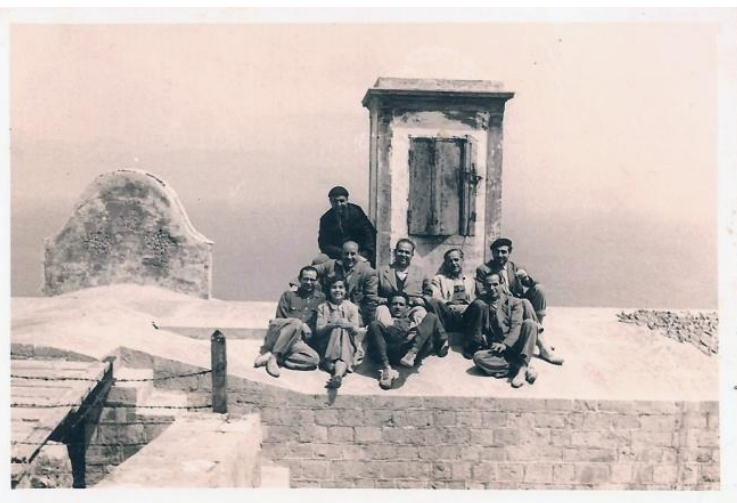

Figura 3.2. Aljub del far de Columbretes, 1953. Imatge cedida per Javier Zea Gandolfo.

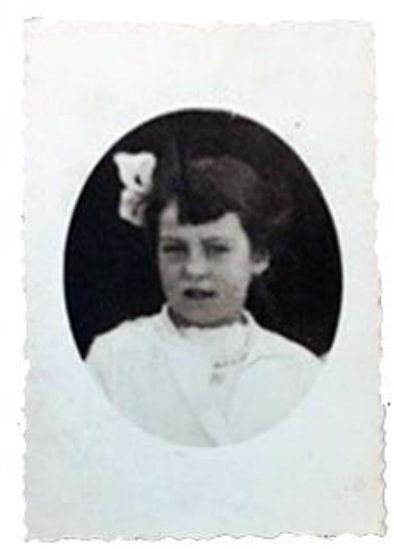

Figura 3.4. Mercè Escortell. Imatge cedida per la família.

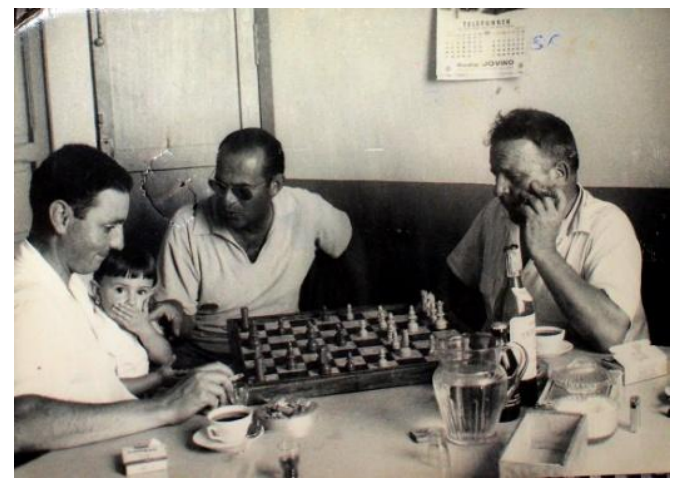

Figura 3.6. Ell jocs de taula eren un passatemps a Columbretes. En la imatge, el faroner Juan del Bosque. Imatge cedida per la seua dona, Manuela Arribas. 
Per tot el que acabem d'exposar, l'objectiu d'aquest treball ha estat la recopilació de materials publicats $i$ inèdits sobre la historia dels assentaments humans a Columbretes $i$ la seua empremta: qui van ser els faroners que hi van prestar els seus serveis, quines històries $i$ anècdotes van passar a les Illes, etc. La nostra finalitat és que les històries que de primera mà ens puguen contar els protagonistes o les persones relacionades no es perden en l'oblit i que puguen ser utilitzades tant per a les visites guiades pel personal de la reserva natural i per a les seues activitats de divulgació i educació ambiental, com per a arribar al públic en general en un altre format com podria ser un documental.

\section{Material i Mètodes}

La metodologia seguida va consistir en les següents accions, que es van portar a terme paral.lelament:

- cerca, selecció i contacte amb persones relacionades amb les Columbretes que podien ser rellevants per a la fi de l'estudi: faroners, familiars dels faroners, pescadors, patrons que portaven queviures, obrers, arqueòlegs, gestors, guardes, gestors, etc., que estigueren disposades a contar-nos la seua experiència, mitjançant entrevistes personals amb una sèrie de preguntes bàsiques predeterminades (Annex 3.2) $\mathrm{i}$ en ocasions, enregistrant l'entrevista,

- recerca bibliogràfica, tant de publicacions científiques (monografies, tesis doctorals, estudis, etc.) com de periòdics i revistes de l'època, en arxius, com el municipal de Castelló, o el del Port de Castelló, on també es van consultar les fitxes i documents oficials d'alguns faroners, i per Internet, on es troba molta informació antiga en hemeroteques digitals, sobre la història del far, com la de la Biblioteca Nacional de España, http://hemerotecadigital.bne.es. Es van utilitzar les següents paraules clau: "columbretes" i "colubraria", i

- col·lecta de tota la documentació, notícies i arxius interessants que vam trobar en paper, fotografies cedides per les persones entrevistades, i tot el material que consideràrem interessant (poesies, cançons, dibuixos, etc). 


\section{Resultats i Discussions}

De la cerca de contactes

Donat que els autors d'aquesta cerca treballàvem com a tècnics mediambientals de la reserva natural de les Illes Columbretes amb funcions d'atenció a les visites i teníem molta relació amb la gent de la mar, vam tindre l'oportunitat de contactar fàcilment amb moltes persones interessades a participar en l'estudi. A més, es va publicar el nostre treball en premsa amb unes pinzellades de la història de Dolores Guerra (Figura 3.8), la qual cosa va despertar un gran interès entre la població en general i va fer que inclús algunes persones contactaren amb nosaltres motu proprio oferint-nos la seva participació, com per exemple Juan Gozalbo García, que ens va explicar que el seu avi va ser faroner i que encara que ja no vivia, la seua àvia i son pare podien contar-nos detalls de l'època en què hi van viure. De fet, al llarg de la cerca i les entrevistes, vam ser notícia en els mitjans locals en diverses ocasions.

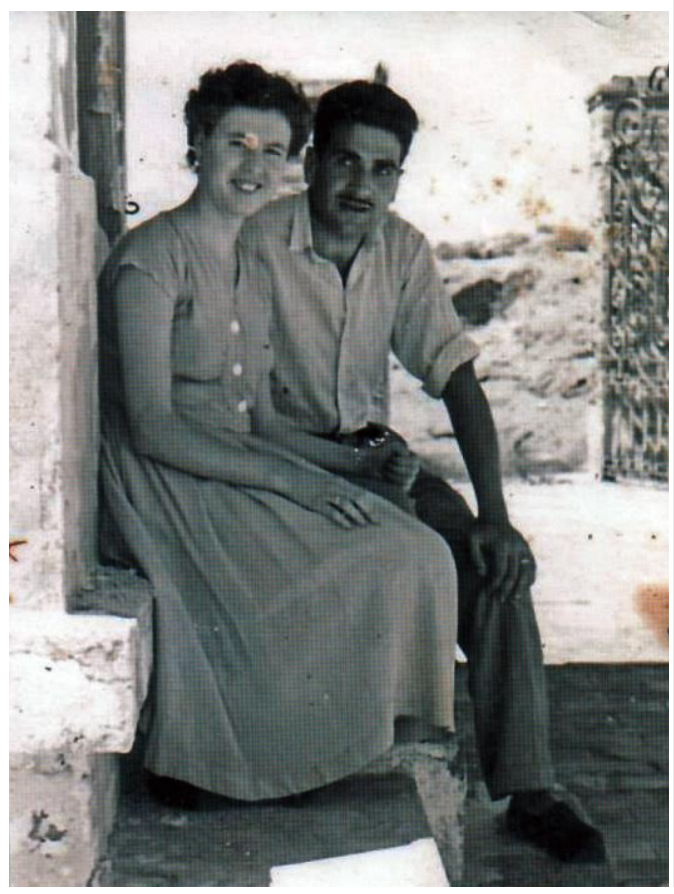

Figura 3.7. El faroner Aurelio Zacarías Naranjo i la seua dona Dolores Guerra Guerrero a Columbretes, 1953. Imatge cedida per Dolores.

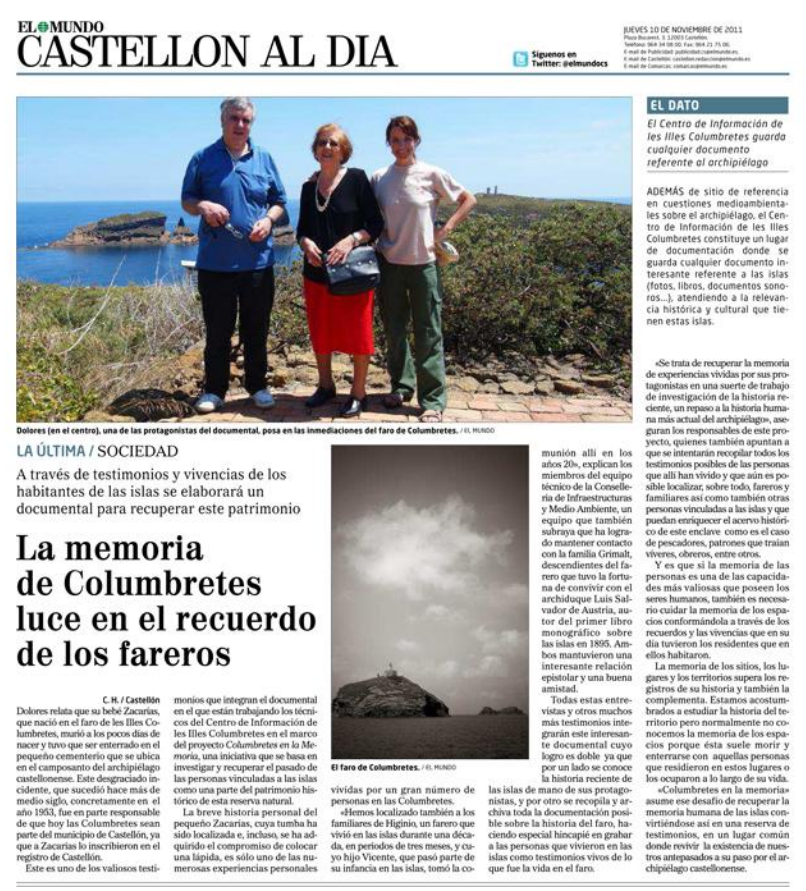

Figura 3.8. Notícia en el diari "El Mundo" (10/11/2011) sobre la cerca. En la fotografia apareix I'autora d'aquesta tesi amb Dolores Guerra i el seu fill Pedro Zacarías, en la primera visita de Dolores a les Columbretes després de 60 anys. Imatge facilitada per Carmen Hernández, "El Mundo". 
D’aquesta manera, el nombre de contactes considerats com a més rellevants va ser 52 (Taules 3.1 a 3.5), dels quals vam arribar a entrevistar-ne 38 (Taula 3.6), en unes poques ocasions telefònicament. D’aquests 38, són 17 els que hem considerats clau per la informació que ens van proporcionar (Annex 3.3). En aquestes reunions també vam intentar aconseguir la major quantitat possible de material gràfic i videogràfic. Finalment, ens vam trobar amb un recull de 91 fotografies cedides pels familiars dels faroners i persones relacionades amb les Illes. Aquestes fotos cobreixen un període que va des de 1891 (fotografia del xiquet Miquel Garau i Massanet, fill del faroner Climent i la seua dona Àngela, que va morir a l'Illa amb poc més d'un any) (Figura 3.9) fins als anys 70 del s. XX (fotografies de l'Illa Grossa cedides per Màxim Fallada, pescador esportiu, qui també ens va cedir imatges de vídeo de la mateixa època)

(Figura 3.10), just abans que les Illes foren protegides com a parc natural el 1988.

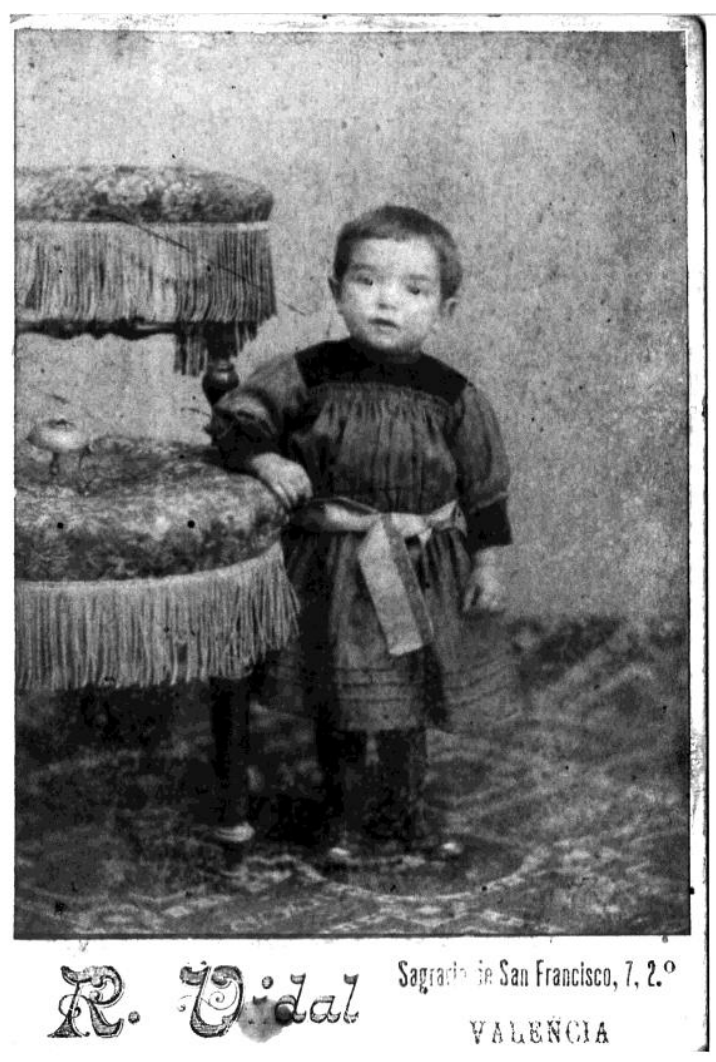

Figura 3.9. Miquel Garau i Massanet. Imatge cedida per Clemente Garau.

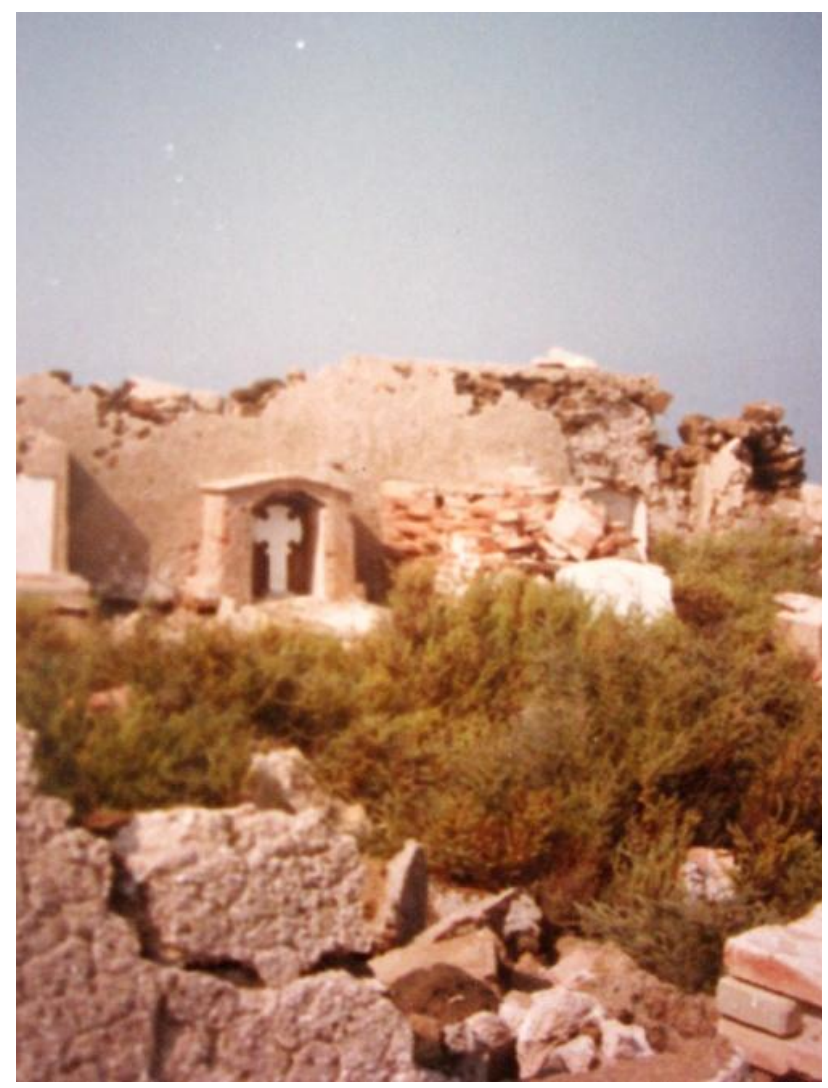

Figura 3.10. El cementeri descuidat als anys 80 , abans de la protecció de les Illes. 
Taula 3.1. Llistat de faroners dels quals vam obtindre informació mitjançant familiars, ordenada de manera cronològica segons els anys d'estada a Columbretes, període que hi van estar, relació de parentesc del contacte i la data de l'entrevista:

\begin{tabular}{|c|c|c|c|}
\hline $\begin{array}{l}\text { Període en } \\
\text { Columbretes }\end{array}$ & Nom del faroner & Contacte & $\begin{array}{c}\text { Data de } \\
\text { l'entrevista }\end{array}$ \\
\hline \multirow{2}{*}{1862} & \multirow{2}{*}{ Francisco del Río de la Barrera } & $\begin{array}{l}\text { La besneta: Alicia Fernández } \\
\text { del Río Ruiz del Cedro }\end{array}$ & $03 / 11 / 2014$ \\
\hline & & $\begin{array}{c}\text { El besnet: Gustavo Chao } \\
\text { Fernández }\end{array}$ & $03 / 11 / 2014$ \\
\hline 1864 & José Hierro Delgado & $\begin{array}{c}\text { La neta: María Hierro Viera } \\
\text { (entrevista realitzada pel } \\
\text { rebesnét: Gerardo Morales } \\
\text { Gutiérrez) }\end{array}$ & Desconeguda \\
\hline \multirow{3}{*}{$\begin{array}{c}1890 \text { i de } \\
1894 \text { a } 1915\end{array}$} & \multirow{3}{*}{ Francesc Grimalt Alou } & $\begin{array}{l}\text { La neta: Margarita Grimalt } \\
\text { (realitzada per Marc Ordeix) }\end{array}$ & 1984 \\
\hline & & $\begin{array}{c}\text { El net: Francesc Grimalt } \\
\text { Sancho }\end{array}$ & 28/08/2014 \\
\hline & & $\begin{array}{c}\text { La neboda: Mercè Rigo } \\
\text { Grimalt } \\
\end{array}$ & $28 / 08 / 2014$ \\
\hline $1910-20$ & José Llorenç Sol & La filla: Pepita Llorenç Arrufat & $21 / 11 / 2011$ \\
\hline $1921-34$ & Higinio García Blasco & $\begin{array}{l}\text { Les netes: Encarna, Mercè i } \\
\text { Vicentica García Gallén }\end{array}$ & $26 / 08 / 2011$ \\
\hline $1934-46$ & Ramón Roig Montagut & El fill: Ramón Roig Sospedra & $\begin{array}{c}05 / 11 / 2012 \mathrm{i} \\
18 / 10 / 2013\end{array}$ \\
\hline $1941-48$ & Antonio Martínez Monto & La filla: Pilar Martínez Silvestre & $\begin{array}{c}23 / 01 / 2012 \mathrm{i} \\
18 / 10 / 2013\end{array}$ \\
\hline $1950-53$ & Luis Gandolfo Fernández & & \\
\hline $1953-54$ & Luis Gandolfo Martínez & Familiar: Javier Gea Gandolfo & $20 / 01 / 12$ \\
\hline 1953 & Serafín Gandolfo Fernández & & \\
\hline $\begin{array}{c}\text { Setembre, } \\
1953-\text { març, } \\
1954\end{array}$ & Aurelio Zacarías Naranjo & $\begin{array}{c}\text { La dona: Dolores Guerra } \\
\text { Guerrero }\end{array}$ & $\begin{array}{c}17 / 06 / 2011 \text { i } \\
04 / 06 / 2013\end{array}$ \\
\hline $1958-60$ & Juan del Bosque Gutiérrez & La dona: Manuela Arribas & $13 / 12 / 2011$ \\
\hline 1961 i 1964 & $\begin{array}{c}\text { Tomás Mancisidor Arias- } \\
\text { Valdés }\end{array}$ & $\begin{array}{l}\text { La dona: Carmen Barreña } \\
\text { García }\end{array}$ & $30 / 04 / 2012$ \\
\hline $1962-67$ & José Gozalbo & $\begin{array}{c}\text { La dona: María Valero } \\
\text { El fill: Jose Ma Gozalbo Valero }\end{array}$ & $21 / 11 / 2011$ \\
\hline
\end{tabular}


Taula 3.2. Llistat de persones vinculades a les illes Columbretes, excepte faroners i familiars, de les quals vam obtindre informació, ordenada de manera cronològica segons el període que van tindre relació amb les Columbretes, el vincle i la data de l'entrevista (RN=reserva natural; $\mathrm{RM}=$ reserva marina):

\begin{tabular}{|c|c|c|c|}
\hline $\begin{array}{c}\text { Període } \\
\text { vinculat a } \\
\text { Columbretes }\end{array}$ & Nom & Vincle & $\begin{array}{l}\text { Data de } \\
\text { l'entrevista }\end{array}$ \\
\hline 1894 & José Sevilla Marcos* & $\begin{array}{l}\text { Propietari consort del palau de } \\
\text { Miramar** relacionat amb } \\
\text { l'Arxiduc Lluís Salvador }\end{array}$ & $27 / 08 / 2014$ \\
\hline Anys 1970 & María Teresa Lluch & $\begin{array}{c}\text { Dona de Juan Gellida Masip, } \\
\text { patró del vaixell d'abastiments } \\
\text { "Alcon" }\end{array}$ & $31 / 01 / 2012$ \\
\hline Anys 1970 & Màxim Fallada Solé & Pescador esportiu & $18 / 06 / 2012$ \\
\hline $1987-2000$ & Juan Jiménez Pérez & 1r Director de Columbretes & $03 / 03 / 2015$ \\
\hline $\begin{array}{c}1988 \mathrm{i} \\
\text { des de } 1995\end{array}$ & Vicent Ferrís Malonda & $\begin{array}{c}\text { Guarda de la RN i RM de } \\
\text { Columbretes }\end{array}$ & \\
\hline 1990-2007 & Valetín Tena Lázaro & $\begin{array}{c}\text { Guarda de la RN i RM de } \\
\text { Columbretes }\end{array}$ & $30 / 04 / 2012$ \\
\hline 1991-2013 & Xavier del Señor de la Gala*** & $\begin{array}{l}\text { Guia i tècnic mediambiental } \\
\text { de la RN de Columbretes }\end{array}$ & $30 / 04 / 2012$ \\
\hline 1987-2012 & Santiago Sales Traver & $\begin{array}{c}\text { Guarda de la RN i RM de } \\
\text { Columbretes }\end{array}$ & $27 / 02 / 2015$ \\
\hline 1998-2005 & Roque Belenguer Barrionuevo & $\begin{array}{c}\text { Guarda de la RN i RM de } \\
\text { Columbretes }\end{array}$ & $02 / 11 / 2014$ \\
\hline $2002-05$ & Rebeca Velasco García & $\begin{array}{c}\text { Guarda de la RN i RM de } \\
\text { Columbretes }\end{array}$ & $02 / 11 / 2014$ \\
\hline 1998-2014 & Eva Mestre-Forés & $\begin{array}{c}\text { Monitora i tècnica } \\
\text { mediambiental de la RN de } \\
\text { Columbretes }\end{array}$ & $01 / 06 / 2015$ \\
\hline $2008-13$ & Patricia González González & $\begin{array}{c}\text { Tècnica mediambiental de la } \\
\text { RN de Columbretes }\end{array}$ & $01 / 06 / 2015$ \\
\hline $2007-11$ & Vicent Castañer Franch & $\begin{array}{c}\text { Guarda de la RN de } \\
\text { Columbretes }\end{array}$ & $01 / 06 / 2015$ \\
\hline 2010 & David Moré Aguirre & Historiador especialista en fars & $25 / 08 / 2014$ \\
\hline
\end{tabular}

*Doctor en Medicina i membre de l'Escola Llul.lística de Mallorca, que agrupa els investigadors i estudiosos de la figura de Ramon Llull d'arreu del món.

**El Palau de Miramar, monestir fundant en 1276 per Jaume II a petició de l'escriptor mallorquí Ramon Llull i comprat per l'arxiduc en 1872, acull en la actualitat un museu on es troben alguns objectes, documents i obres d'art relacionades amb els mons que van viure Llull i l'Arxiduc Lluís Salvador.

${ }^{* * *}$ Entrevistat com a Llicenciat en Història. 
Taula 3.3. Llistat de persones que pogueren parlar-nos d'anècdotes, esdeveniments o temes concrets relacionats amb les illes Columbretes i data de l'entrevista:

\begin{tabular}{|c|c|c|}
\hline $\begin{array}{l}\text { Anècdotes/esdeveniments/temes } \\
\text { concrets }\end{array}$ & Contacte / entrevista prèvia a: & $\begin{array}{c}\text { Data de } \\
\text { l'entrevista }\end{array}$ \\
\hline \multirow[t]{2}{*}{$\begin{array}{l}\text { Pescadors naufragats als anys } 40 \text { del } \\
\text { s.XX }\end{array}$} & $\begin{array}{l}\text { Toni Cerdà Simonet "Fogassa", de } \\
\text { Pollença (Mallorca), germà menut de } \\
\text { dos pescadors, Tomeu i Biel, que } \\
\text { pescaven a les Columbretes }\end{array}$ & $09 / 01 / 2013$ \\
\hline & $\begin{array}{c}\text { Xisco Pérez, pescador de l'Alcúdia, } \\
\text { Mallorca }\end{array}$ & $28 / 08 / 2014$ \\
\hline $\begin{array}{c}\text { Imposició de la imatge de la Mare de } \\
\text { Déu en desembre de } 1954\end{array}$ & $\begin{array}{l}\text { Sergi Ferrer, escriptor (informació } \\
\text { facilitada per Josep Albalat) }\end{array}$ & - \\
\hline $\begin{array}{l}\text { Estudis d'Arqueologia ( vaixells afonats, } \\
\text { enterraments, etc.) des de } 1988\end{array}$ & $\begin{array}{c}\text { Asunción Fernández Izquierdo, } \\
\text { arqueòloga de la Diputació de } \\
\text { Castelló* }\end{array}$ & $18 / 10 / 2013$ \\
\hline $\begin{array}{l}\text { Literatura relacionada amb les } \\
\text { Columbretes }\end{array}$ & Vicent Usó & $27 / 02 / 2015$ \\
\hline $\begin{array}{c}\text { Les Columbretes des del punt de vista } \\
\text { d'un escriptor i cineasta }\end{array}$ & David Trueba & $31 / 03 / 2015$ \\
\hline
\end{tabular}

* Directora del Centre d'Arqueologia Subaquàtica de la Comunitat Valenciana.

Taula 3.4. Llistat dels faroners dels quals vam obtindre informació mitjançant familiars, ordenada de manera cronològica segons el període d'estada a Columbretes, contacte i relació de parentesc amb el faroner (no els vam poder entrevistar per diverses raons):

\begin{tabular}{ccc}
\hline Període en Columbretes & Nom del faroner & Contacte \\
\hline $189-92$ & Clemente Garau Melis & El besnet: Clemente Garau \\
\cline { 2 - 3 } $1918-24$ & José Escortell Ripoll & La besneta: Mercè Cumí \\
\cline { 2 - 3 } $1923-41$ & Juan Luís Callau Cros & La dona: Mercedes Verdera \\
\cline { 2 - 3 } $1950-53$ & Luis Gandolfo Fernández & $\begin{array}{c}\text { Familiars: Ángeles, Ma José } \\
\text { i Serafín Gandolfo Albaladejo }\end{array}$ \\
\cline { 2 - 3 } $1950-59$ i $1966-74$ & Francisco Bonachera Vázquez & La filla: Coro Bonachera \\
\cline { 2 - 3 } $1951-75$ i fins 1988 & Roque Serrano Adell & El fill: Roque Serrano Gallego \\
\cline { 2 - 3 } 1953 & Serafín Gandolfo Fernández & Familiars: Ángeles, Ma José \\
$1953-54$ & Luis Gandolfo Martínez & i Serafín Gandolfo Albaladejo \\
\cline { 2 - 3 } $1955-61$ & Restituto Degrado Martínez & El fill: Restituto Degrado \\
\hline
\end{tabular}


Taula 3.5. Llistat de persones vinculades a les illes Columbretes, excepte faroners i familiars, de les quals vam obtindre informació, als que no vam poder entrevistar per diverses raons, ordenada de manera cronològica segons el període que van tindre relació amb les Columbretes i el vincle:

\begin{tabular}{|c|c|c|}
\hline $\begin{array}{l}\text { Període vinculat a } \\
\text { Columbretes }\end{array}$ & Nom & Vincle \\
\hline 1894 & Helga Schwendinger* & $\begin{array}{l}\text { Doctora en Ciències Socials especialista en } \\
\text { la figura de l' Arxiduc Lluís Salvador }\end{array}$ \\
\hline Finals s. XIX & $\begin{array}{l}\text { Leocadio Chornet, astrònom } \\
\text { jubilat de l'ajuntament de } \\
\text { Castelló }\end{array}$ & $\begin{array}{l}\text { Apunts sobre la utilització de les } \\
\text { Columbretes en la medició del metre per } \\
\text { Pierre-André Méchain, astrònom francès }\end{array}$ \\
\hline Octubre, 1953 & Rosa Sanahuja & $\begin{array}{l}\text { Neboda de José Sanahuja, metge que va } \\
\text { atendre a Dolores Guerra després del part }\end{array}$ \\
\hline Anys 1960 & Javier Castroviejo & Investigador del CSIC \\
\hline Anys 1980 & José Vicent Martí & $\begin{array}{c}\text { Tinent d'alcalde de Castelló de } 1979 \text { a } \\
1988 \\
\end{array}$ \\
\hline
\end{tabular}

* Autora del llibre "El Archiduque Luis Salvador de Austria", Miguel Font Editor, 1991.

Taula 3.6. Nombre de persones entrevistades segons la tipologia, i percentatge sobre el total.

\begin{tabular}{lcc}
\hline \multicolumn{1}{c}{ Tipus de persona entrevistada } & Nombre & \% \\
\hline Familiars de faroners & 18 & 47,4 \\
Pescadors & 3 & 7,9 \\
Historiadors & 3 & 7,9 \\
Personal de la reserva natural & 9 & 23,7 \\
Altres (gestors, familiar del patró del vaixell & 5 & 13,2 \\
d'abastiments i escriptors) & 38 & $\mathbf{1 0 0}$ \\
TOTAL & & \\
\hline
\end{tabular}

De la recerca bibliogràfica i en arxius

A l'arxiu del Port de Castelló vam obtindre bàsicament documentació oficial i alguna carta personal d'alguns faroners (Annex 3.4). A l'arxiu municipal de Castelló vam tindre accés a les actes oficials de les sessions municipals i a edicions de periòdics com el "Mediterráneo" o "La Vanguardia" des de principis del segle XX (Taula 3.7). 
Taula 3.7. Esdeveniments sobre Columbretes que vam trobar a l'arxiu municipal de Castelló, amb la data en què van succeir, i el periòdic o llibre d'actes on els vam trobar:

\begin{tabular}{|c|c|c|}
\hline Data & Esdeveniments & Informació \\
\hline $26 / 10 / 1876$ & $\begin{array}{l}\text { Es destina al servici de Fars de Columbretes, al } \\
\text { personal afecte de les províncies de Balears, } \\
\text { Castelló i València }\end{array}$ & Real Orden \\
\hline 09/12/1906 & Naufragi barca "San Román" & Periòdic "La Vanguardia" \\
\hline 26/05/1916 & $\begin{array}{l}\text { Enfonsament del vapor "Cornigliano" torpedinat } \\
\text { per un submarí austríac. La tripulació arriba a les } \\
\text { costes d'Orpesa amb dos bots el dia } 26\end{array}$ & Periòdic "La Vanguardia" \\
\hline 20/10/1953 & El primer xiquet nascut a Columbretes & Periòdic “Mediterráneo" \\
\hline $\begin{array}{l}13,15,16,17,18 \\
20 \text { i } 21 / 10 / 1953\end{array}$ & $\begin{array}{l}\text { Meteorologia dels dies anteriors i posteriors al } \\
\text { naixement d'Aurelio }\end{array}$ & Periòdic “Mediterráneo" \\
\hline $22 / 10 / 1953$ & $\begin{array}{l}\text { Apartat "Índice demográfico": naixement } \\
\text { d'Aurelio }\end{array}$ & Periòdic “Mediterráneo" \\
\hline $30 / 10 / 1953$ & Apartat "Índice demográfico": defunció d’Aurelio & Periòdic “Mediterráneo" \\
\hline $01 / 12 / 1954$ & $\begin{array}{l}\text { Col-locació del monument de la verge del Carme } \\
\text { a les illes Columbretes }\end{array}$ & $\begin{array}{l}\text { Sessió ordinària de la } \\
\text { comissió municipal } \\
\text { permanent }\end{array}$ \\
\hline 01/12/1954 & $\begin{array}{l}\text { L'Ajuntament de Castelló accepta acudir als actes } \\
\text { d'inauguració del monument de la verge del } \\
\text { Carme a les illes Columbretes, convidats pel } \\
\text { Governador Civil de la Província de Castelló }\end{array}$ & $\begin{array}{l}\text { Sessió ordinària de la } \\
\text { comissió municipal } \\
\text { permanent }\end{array}$ \\
\hline 28/04/1955 & $\begin{array}{l}\text { Incorporació de les Illes Columbretes al municipi } \\
\text { Castelló de la Plana }\end{array}$ & $\begin{array}{l}\text { Sessió ordinària de la } \\
\text { comissió municipal } \\
\text { permanent }\end{array}$ \\
\hline 09/05/1962 & Delimitació de les Illes Columbretes & $\begin{array}{l}\text { Sessió ordinària de la } \\
\text { comissió municipal } \\
\text { permanent }\end{array}$ \\
\hline $10 / 10 / 1962$ & $\begin{array}{l}\text { Inscripció a favor de l'Ajuntament de Castelló de } \\
\text { les “Illes Columbretes" }\end{array}$ & $\begin{array}{l}\text { Sessió ordinària de la } \\
\text { comissió municipal } \\
\text { permanent }\end{array}$ \\
\hline
\end{tabular}

Vam trobar, a més de la bibliografia mostrada a les referències d'aquest capítol de la tesi, altres publicacions interessants sobre les Columbretes o en les quals se citen, com:

- la publicació "Toponímia i talasonímia mallorquina als Columbrets" (Universitat de les Illes Balears 1994) de Francesc Canuto Bauçà,

- el treball sense publicar "Orígenes del apellido Hierro en Canarias" de Gerardo Morales Gutiérrez, facilitat per ell mateix,

- els articles de Cosme Aguiló al Setmanari "Felanitx", 2317 de 16/10/1982 ("Els Columbrets. Viatge toponímic a unes illes oblidades", "Un faroler de s'Horta en Els Columbrets", "Els Columbrets i l'Arxiduc"),

- el text que va escriure Ma Carme Rigó i Grimalt, una de les entrevistades en aquest estudi, 
per a la revista "Dies i coses" (“De far en far: els Columbrets, 1a estada: 1894-1895"),

- els articles de David Moré a les revistes "Drassana" (desembre de 2008, pp. 70-84) i "Peñíscola" ("Los Torreros de Faros o Técnicos-Mecánicos de señales Marítimas. Una profesión singular", 155, pp.46-50 i "Torreros de Faros Peñiscolanos (I). Juan Ayza Fulladosa (1872-1952)", 156, pp.33-36),

- I'article on Salvador Bellés exposa alguns records de Roque Serrano, al periòdic “Mediterráneo" de 13/08/2005 ("Un bebè en les Illes Columbretes") o

- els articles trobats a l'hemeroteca digital de la Biblioteca Nacional d'Espanya (http://hemerotecadigital.bne.es).

Les Columbretes també apareixen en algunes obres literàries, com per exemple, en un capítol de la novel·la "Flor de Mayo" de Vicente Blasco Ibáñez, 1895, quan uns contrabandistes de tabac s'amaguen en aquestes illes, així com a "Madera de Héroe", 1987, de Miguel Delibes, on es narra l'arribada de l'armada franquista a les Columbretes l'any 1938. També hi ha referències a les Illes a les novel·les "León de Ojos Verdes" de Manuel Vicent, 2008, i “Les Veus i la Boira", de Vicent Usó, 2015. Part de l'obra de teatre "Los cuatro robinsones" de Pedro Muñoz Seca, 1917, també té lloc a les Columbretes. Aquesta obra va ver adaptada al cine per Eduardo García Maroto l'any 1939. Les Columbretes han aparegut inclús en una vinyeta del còmic "Mortadelo y Filemón" (Figura 3.11). Finalment, vam trobar un enregistrament en directe de la cançó el tango de Vinaròs, per Miquel Pablo (Rochil) (http://www.youtube.com/watch?v=tejJJ7DqnQQ). Aquesta cançó, amb lletra de Juan Barber (Joanet el Curiós), ja forma part de la cultura popular de Vinaròs sobre els pescadors.

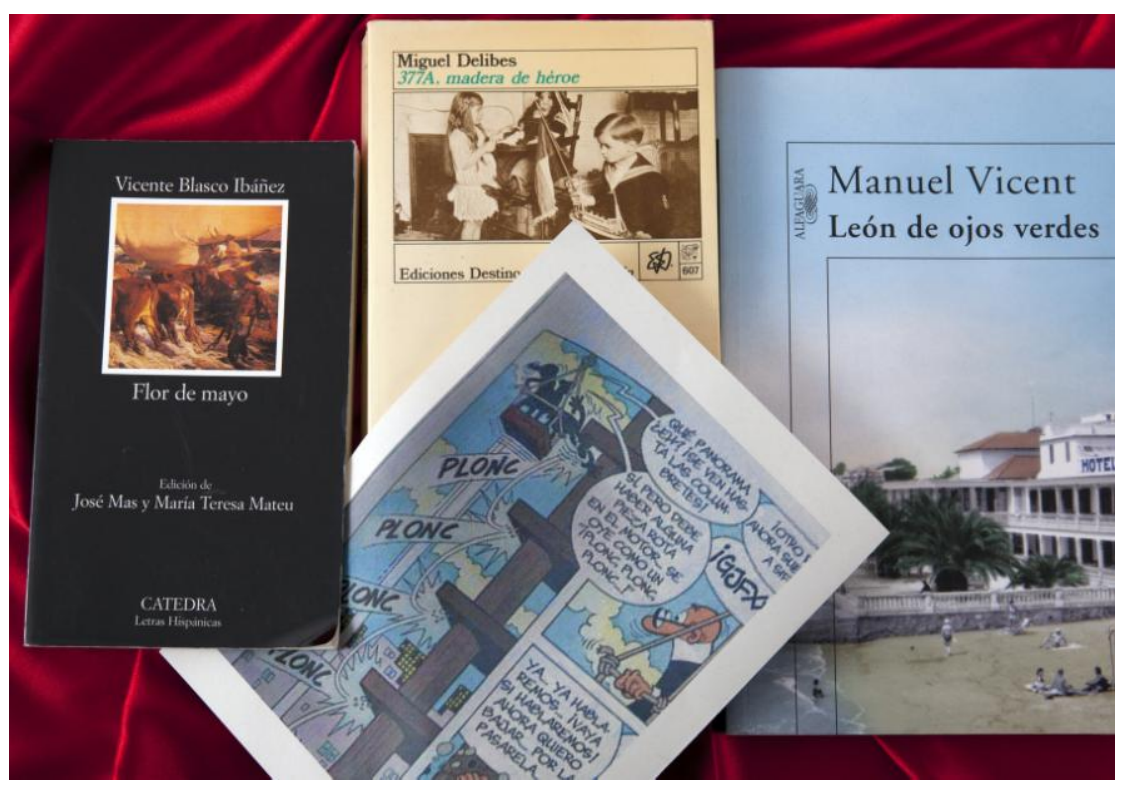

Figura 3.11. Les Columbretes estan presents a la literatura. 
Capítol 3

D'altra banda, vam trobar-nos que alguns dels faroners o familiars van trobar inspiració poètica en les Illes i van escriure poemes dedicats a la mare de déu del Carme, sobre la soledat, I'aillament, o la fam. També Xavier Gimeno, de l'Associació Cultural "Cardona Vives" o Josep Porcar van dedicar poesies a les Illes en el seu llibre de poemes "Els Estius", 2007 (Annex 3.5).

\section{Recopilació de la informació}

Amb tota la informació recopilada, s'ha pogut confegir un llistat dels faroners que van exercir a les Columbretes amb l'any d'entrada i de cessament $\mathrm{i}$, en alguns casos, categoria professional (Annex 3.6). El primer faroner que consta en el Ilistat és Domingo López Sanmartín, que va treballar a l'Illa des de l'1 de maig de 1861 fins a 1874. L'últim faroner, fins a l'automatització del far, va ser Roque Serrano Adell. Trobem al llistat de personal adscrit al far de Columbretes (Annex 3.6) dues dones, Manuela Orts García i Josefa Castelló Gómez, els anys 1926 i 1934 respectivament, adscrites als serveis del far com a "dependenta de servei". Tot i que les dones no van poder accedir al cos en igualtat de condicions que els homes fins l'any 1969 (Moré, 2010), moltes dones de la família del faroner, sovint feien les mateixes funcions i van arribar a ser bones professionals ajudant i en ocasions probablement substituint a marits i a pares. De fet, Gerardo Morales, rebesnet de la filla del faroner José Hierro Delgado, va escriure al seu llibre "Orígenes del apellido Hierro en Canarias":

"Era casi imprescindible que el torrero fuera casado y tuviera familia: así se tenía garantía de que "el faro con su luz" seguiría funcionando y atendido, aún en caso de enfermedad o muerte del torrero"

Seguidament es mostra una recopilació dels resultats basats en referències, les quals s'indiquen, o basats en comunicacions personals, organitzada segons les següents temàtiques: història del far, sistemes d'iluminació, naixements/comunions, flora, fauna i pesca, vaixell de subministrament, temporals/fam/accidents/guerra, fars de càstig/descans, contraban, bombardeigs/exercicis de tir, naufragis de pescadors, altres naufragis, morts a l'Illa o relacionades i curiositats. Mostrem alguns comentaris dels temes més desconeguts fins ara:

\section{Història del far:}

Les "casernes" construïdes perquè hi visqueren els constructors del far, també van ser ocupades pels faroners i les famílies durant algunes reparacions del far, com als anys 40, quan s'hi van habilitar tres casetes, cadascuna per a un faroner, una capelleta i un forn (Ramon 
Martínez, comunicació personal (Figura 3.12). El sòl de la capelleta era de pedres de riu que formaven una espècie de sanefa (Santiago Sales, comunicació personal).

Moltes vegades els faroners havien de tirar mà de l'astúcia i la inventiva per fabricar-se tota mena d'aparells o mecanismes que els facilitaren la vida, com José Gozalbo, que va idear uns mecanismes fets amb espills per a poder controlar des del llit si la llum del far estava encesa (María Valero, comunicació personal) o Antonio Martínez (Figura 3.13), que segons la seua filla era un manetes, aventurer i divertit, que es construïa les seues pròpies embarcacions i també va fer un "mirafondo" per pescar (Pilar Martínez, comunicació personal (Figura 3.12). Ramon Roig Montagut es va fer un aparell de ràdio galena i així es va assabentar de que havia esclatat la guerra civil (Ramon Roig Sospedra, comunicació personal).

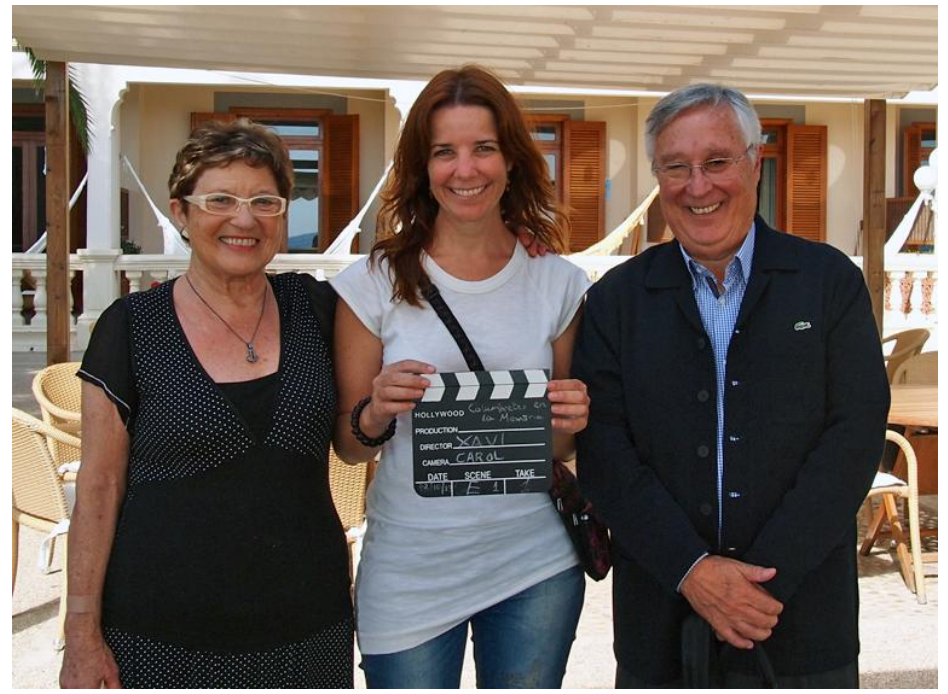

Figura 3.12. Pilar Martínez i Ramon Roig, després de les entrevistes, amb l'autora de la tesi.

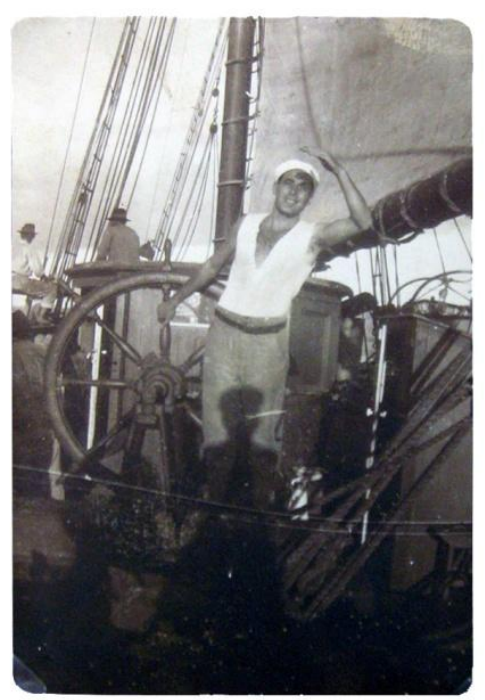

Figura 3.13. Antonio Martínez Monto, pare de Pilar, durant una de les seues aventures. Imatge cedida per Pilar Martínez.

\section{Naixements/comunions:}

El primer bebè que hem documentat que va nàixer a Columbretes va ser la xiqueta Mariana Miranda Coca, el 23 o 24 de març de 1862, que va ser batejada, després de 52 dies, a l'església del Cabanyal de València (Figura 3.14). El segon va ser Aurelio Zacarías Guerra, primer en ser inscrit al registre civil de Castelló de la Plana.

D'altra banda, als anys 20 del s. XX, els dos fills d'Higinio Garcia i les dues filles del faroner company (segurament, Josep Escortell) hi van prendre la comunió. Com a curiositat direm que al cap dels anys una de les filles i un dels fills van acabar casant-se (Encarna García, neta del faroner Higinio García, comunicació personal). 
El dia 14 de Marzo de 1862 desembarqué con mi familia en las islas de Columbretes, por baber sido arcendido á torrero ordinario con dastivo á aquel faro. Alli sólo los torrerus y sus familias babitan las islas, $y$ eada $6 ! 9$ ó 70 dias el rapor Destella visitaba el faro parn hacer profisiones de viveres. El dia $z 2$ del mismo mes $y$ ẵo esferrnó mi esposa, $y$ despues de dos dias de agonia lió ź luz una niña, que fué bantizadi, despues de 52 diss, en la iglesia del Cabañal de Valencia. A Ios 39 dias de haster marchato el rapor se desarrolló una grande epidemia entre los habitantes de las islas, 5 en tres dias murieron dos hijos del torrero tercoro D. Francisco del Río; yo hice los féretros y las sepulturas, $y$ enterré á los muertos; hice algunos dins el servicio solo, por estar los demis esfermos. Pedi autilio con la bocina $y$ bandera if un rapor de gran porte que a las seis de la majiana del dia 12 de Julio pasó por entre los islotes en ocasion de estar haciendo la segunda sepultura, pero pasó de largo.

Figura 3.14. Retall del periòdic "La Iberia", 1880, en el qual escriu Simon

Miranda sobre el naixement de la seua filla a les Columbretes i la epidèmia i mort dels dos fills del company Francisco del Río.

\section{Temporals/accidents:}

La primera referència sobre temporals o accidents la trobem a l'època antiga. Hi ha indicis que Quint Sertori, polític i militar romà (ca. 122 a.C.-72 a. C.), podria haver-se refugiat a les Columbretes en patir un atac naval a Eivissa per part de les tropes d'Ani i fugir després d'una gran borrasca que va trencar part de les seues fràgils naus contra les roques d'unes illes properes (Aguilar \& Pérez-Vilatela, 2004). Es pot donar per plausible la hipòtesi que van ser les Columbretes, ja que a l'edició grega de Plutarc es pot interpretar que eixes illes eren properes (Juan José Ferrer-Maestro, Catedràtic d'Història Antiga de la Universitat Jaume I, comunicació personal).

Els temporals sempre han estat molt presents a les vides dels faroners sobretot perquè, a més de ser imponents i esglaiadors, no permetien que el vaixell d'abastiment pogués arribar a l'llla i de vegades passaven fam, com narrava Margarita Grimalt, neta del faroner Francesc Grimalt, que va estar a l'Illa entre 1894 i 1915, en una entrevista que li va fer Marc Ordeix l'any 1984:

"En Columbretes a veces pasábamos hambre. Para comer a veces encargábamos bacalao por miedo a pasar hambre; porque no te podías acercar al mar siempre (...) En invierno no te podías acercar al mar. Hijita mía, teníamos unas cuantas gallinas, comíamos un par de huevos, la leche de la cabra. Y el pan lo hacíamos allá. Teníamos horno y nos llevaban una saca de harina y hacíamos pan mientras hubiera harina". 
"Había un farero que tenía muchos hijos y sólo tenía su paga; y no le enviaban lo que pedía. Le enviaban lo que sabían que cobraba. Y venía a pedirnos y le dábamos lo que teníamos porque allí o comíamos todos o no comía nadie. Allá tenías que tener para todos. Si tú tenías dos y el otro no tenía nada, pues le dabas". (...) "Una vez el abuelito hizo unos versos, esta vez que estuvo el barco 23 días sin venir, mientras estaba de servicio allá arriba en la torre. Porque en la torre, arriba del todo, debajo del aparato, tenían como una estancia pequeñita, un saloncito, con una mesita donde poder escribir cuando estaba el farero de servicio, y el abuelito le escribió los versos a la madre. No sé si aún deben de estar o no, los versos a la Mare de Dèu" (Annex 3.5).

\section{Fars de descans:}

Quan els faroners arribaven a una certa edat, podien sol-licitar un destí en "fars de descans", fars ben situats, on el treball no fóra massa dur. José Campos o Eustaquio Fernández van al-legar el fet d'haver estat al far de les Columbretes per a sol-licitar trasllat a algun altre far que reunira millors condicions.

\section{Exercicis de tir:}

En començar aquest treball, no sabíem exactament la data de començament i finalització de les pràctiques militars a les Columbretes. Ara tenim documentada la primera referència l'any 1901, quan un creuer anomenat "Lepanto" ja feia exercicis de tir en les Columbretes. Les últimes maniobres de les que es té referència són huit dies l'any 1982, per part del Ministeri de Defensa; i era conegut el seu propòsit de continuar utilitzant l'illot Bergantí com a blanc de tir (EI

País, 18/05/1982;

vist

en

http://elpais.com/diario/1982/05/18/espana/390520830 850215.html). També es coneix que hi va haver bombardejos des d'avions els dies 21 i 23 d'abril de 1982 (El País, 28/04/1982; vist en http://elpais.com/diario/1982/04/28/sociedad/388792809 850215.html).

\section{Naufragis de pescadors:}

Els besnets del faroner Francisco del Río, Alicia i Gustavo, ens van contar la història que els havia arribat de pares a fills però que no sabien si podia ser certa: el seu besavi amb els companys van salvar els membres d'una tripulació i els van acollir al far fins que anaren a recollir-los; com que va coincidir amb una època de mala mar, no podien anar a arreplegar-los i la convivència es va allargar; van passar els dies i es va acabar el menjar i, com que una de les filles del besavi estava malalta, pareix que els nàufrags se la volien menjar; finalment no ho van fer, però aquesta xiqueta va acabar morint a l'llla. 
Hem pogut comprovar que és cert que l'any 1862 van morir dos fills de Francisco, per una epidèmia, i la xiqueta a la que es referien era en realitat un xiquet, fill del company José Hierro, un dels primers faroners de Columbretes (Figura 3.14). La història va succeir l'any 1865, quan el faroner José Hierro i els companys van rescatar 18 membres d'una tripulació que havien naufragat. Quan es va acabar el menjar, van proposar menjar-se un dels fills. Així ho narrava Luisa Gutiérrez Hierro al seu besnebot Gerardo en una gravació. La història li I'havia contada sa tia María Hierro Viera, filla del faroner, que ho va viure en primera persona (Gerardo Morales, comunicació personal) (Annex 3.3, Figura 3.15):

"Ios primeros días muy bien, había comida, pero ya se fueron haciendo muchos días, muchos días, que la comida se iba siendo poca, y... ya el abuelo tuvo que decirles que buscaran ...algo que freir; claro, el faro trabajaba con aceite, no como hoy, y... cogían ratones para freírlos, cogían esas aguas vivas que hay en los charcos, que son así, como redondas; les daban harina, porque harina si tenían, un poco, y la mojaban, y... con eso iban escapando... iPero ya los últimos días,... ya ni se levantaban! Abuela... guardaba en los paños del faro, que yo me acuerdo de verlos, harina, y a la media noche le hacía algo a los hijos, polianas,... yo no sé cómo le llamaban;... y estaban algo más animosos".

Los marineros les decían, ustedes están comiendo, porque están más animosos que nosotros. $Y$ a nuestra bisabuela le dijo (el patrón): mire, usted tenga cuidado con ese niño, (que era abuelo), tenía seis años, dice, iporque cualquier día se lo comemos! iMisté, los tenían trancaos que no los dejaba ni salir!....Y así fue, que estaban ya casi muertos cuando apareció el barco; el barco tenía costumbre que izaba bandera y el faro le contestaba. Y.. .i contestó el faro, pero con un nudo en la punta de la bandera!...era una sábana blanca ... Eso parece que es una señal mala... Y el patrón cuando venía llegando, que saltaban en la lancha, dicen que les dijo, iquiten esa bandera de horror!, porque como los vía todos allí, ino sabía lo que pasaba!... Dice abuelo, isúbase usted pa tierra, pa que vea!

iiCasi muertos, estiraos allí, uno pa quí y otro pallí!!

Los cogieron y los llevaron pa ..., pa la tierra de ellos. Ya las mujeres tenían luto, porque apareció la lancha... pues en ellos ya no pensaban..." 


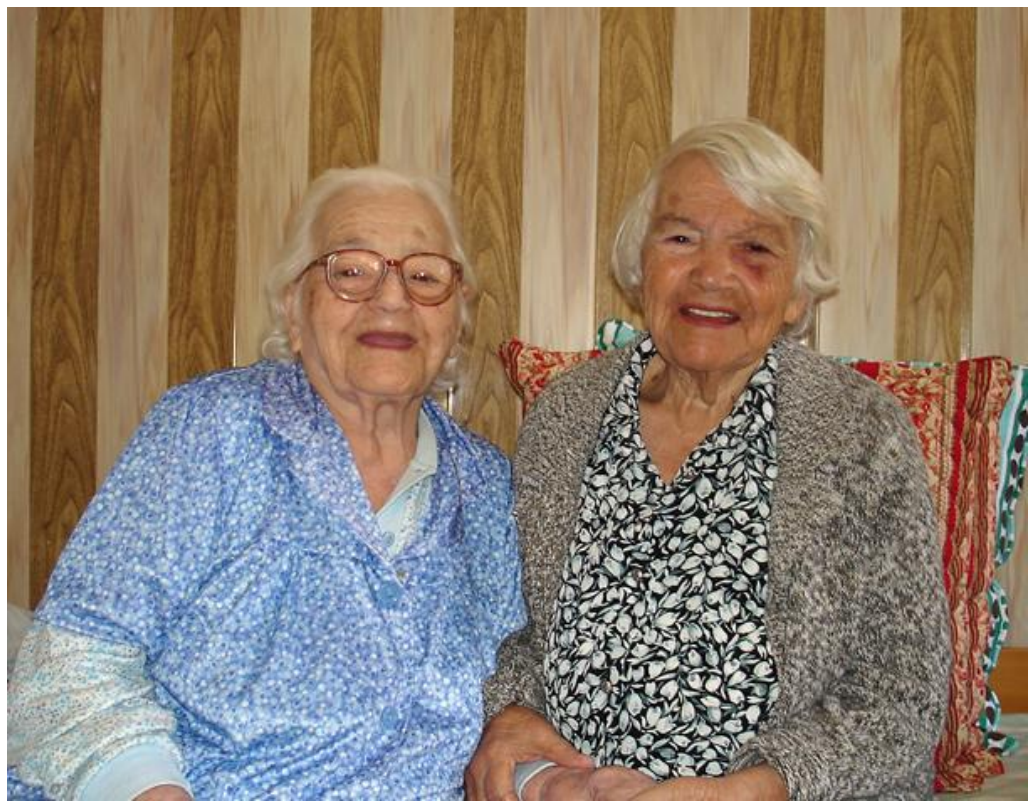

Figura 3.15. Luisa Gutiérrez Hierro, besneta de José Hierro, amb la seva germana menuda Consuelo. Imatge cedida per Gerardo Morales.

El vaixell naufragat el dia 28 de març de 1865 era el llaüt de pesca "Felipe", amb sis nàufrags que aconsegueixen arribar a l'Illa amb ajuda dels faroners. A I'llla s'hi van ajuntar 15 persones: set faroners i familiars, dos treballadors d'Estadística (el sergent d'enginyers de la Secció Geodèsica Cadastral, Manuel Pargada, i el peó de Topografia, Manzano) i els sis nàufrags. Van apagar el far com a senyal per a demanar ajuda, però no ho veien des d'Orpesa a causa a la intensa boira d'aquells dies (del 6 al 24 d'abril va estar apagat), tot i la sanció que els podien aplicar per fer-ho. Finalment el vaixell d'abastiments enviat des de Palma, "Amparo", va arribar a I'llla (Moré, 2010) després de 29 dies (Diario Mercantil de València (publicació de 27/04/1865). Aquesta situació és narrada posteriorment per l'Arxiduc en la seua monografia tot i que no parla sobre el possible canibalisme (Habsburg-Lothringen, 1895). Gràcies a aquesta malaurada història, la Direcció General d'Obres Públiques va dictaminar que a les Columbretes sempre hi havia d'haver un romanent d'abastiments per a tres mesos al menys.

\section{Altres naufragis:}

En plena $1^{\text {a }}$ Guerra Mundial, el 24 de maig de 1916, el faroner José Llorenç Sol estava treballant a l'illa quan un vapor italià, el "Cornigliano", va ser afonat per un submarí austríac. La tripulació al complet va ser rescatada pels faroners i hi van conviure fins al dia següent, quan van ser arreplegats des d'Orpesa. 


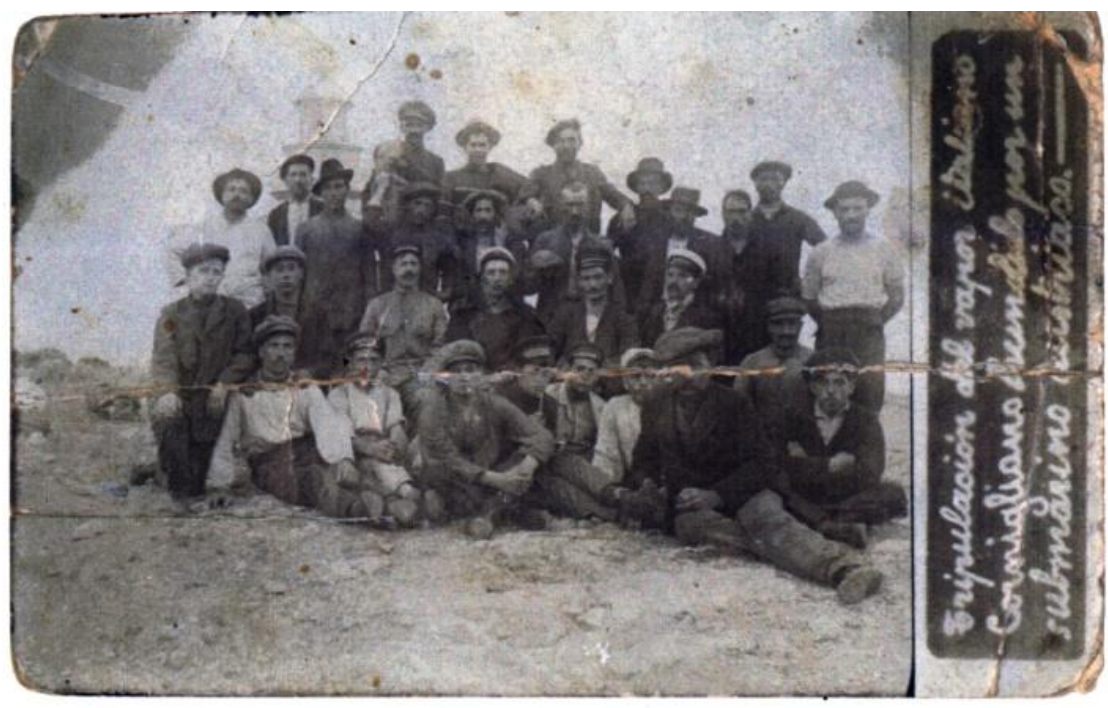

Figura 3.16. Tripulació del vapor “Cornigliano”. Imatge cedida per Pepita Llorenç Arrufat.

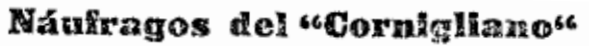

Castellón 25, á las 5 tarde.

El alcalde de Oropesa participa haber arribado á aguella playa dos botes con 31 tripulantes del vapor italiano Cornegliano, torpedeado ayer frente á las islas Columbretes por un submarino austriaco. El gobernador ha telegrafiado que se les atienda.-Castelló.

Figura 3.17. Retall del periòdic "La Vanguardia", 1916, sobre els nàufrags del "Cornigliano".

\section{Morts a l'llla:}

En juny de 1862 van morir els dos fills del faroner Francisco del Río per una passera de xarampió, segurament portada a l'llla per algun mariner malalt o, potser, algun faroner 0 familiar que hi va arribar amb el virus. El pare mateix, amb el company Simón Miranda, l'únic que no va emmalaltir, van construir el cementeri i els van soterrar sense làpida. Curiosament, Simon Miranda va ser el primer en portar vida a l'Illa, ja que la seua dona és la primera coneguda en tindre un xiquet a les Illes eixe mateix any, uns mesos abans de l'epidèmia (sembla que afortunadament tant xiqueta com mare devien estar a la península quan va haverhi la passera) (Figura 3.14). Just 30 anys després va morir el fill del faroner Clemente Garau, també de xarampió, sent la seva làpida la primera col·locada en aquest cementeri (Annex 3.1 i Figura 3.9). Dos xiquets més hi van morir, Rafael Baso Palomares, fill del faroner Santos Baso Garcia, i Mercè Escortell Ribes (Figura 3.4), filla del faroner Josep Escortell Ripoll, els anys 1907 i 1920, respectivament. Mercè també va morir de xarampió, així com un adult l'any 1908, el faroner Juan Batanero Romasanta, qui havia començat a treballar a les illes dos anys abans. També, que es conega, va ser soterrat al cementeri el bebè Aurelio Zacarías Guerra, fill del faroner Aurelio Zacarías Naranjo. La tomba d'Aurelio no tenia làpida. El 27 de juliol de 2012, gràcies als contactes que ja hem esmentat abans, es va aconseguir, amb el vist-i-plau de la 
direcció de la reserva natural, la col·locació d'una làpida (cedida per "Mármoles Cabedo") amb la presència de la mare, Dolores, qui va indicar el lloc del soterrament (Figura 3.18). Aurelio va ser el primer xiquet nascut a les Columbretes inscrit en el registre civil de Castelló de la Plana (fet que podia haver reforçat la decisió que les Columbretes, anys després, passaren a formar part del terme municipal de Castelló de la Plana, en comptes de d'altres municipis més importants com Palma de Mallorca o València), que també ho sol-licitaven. L'últim soterrament a l'Illa va ser el d'un dels guardes voluntari de les Columbretes, Alfonso Trillo, "Capi", I'any 1997. Tot i que no va morir a les Columbretes, part de les seues cendres descansen a l'Illa, com a testimoni de l'amor que hi sentia.

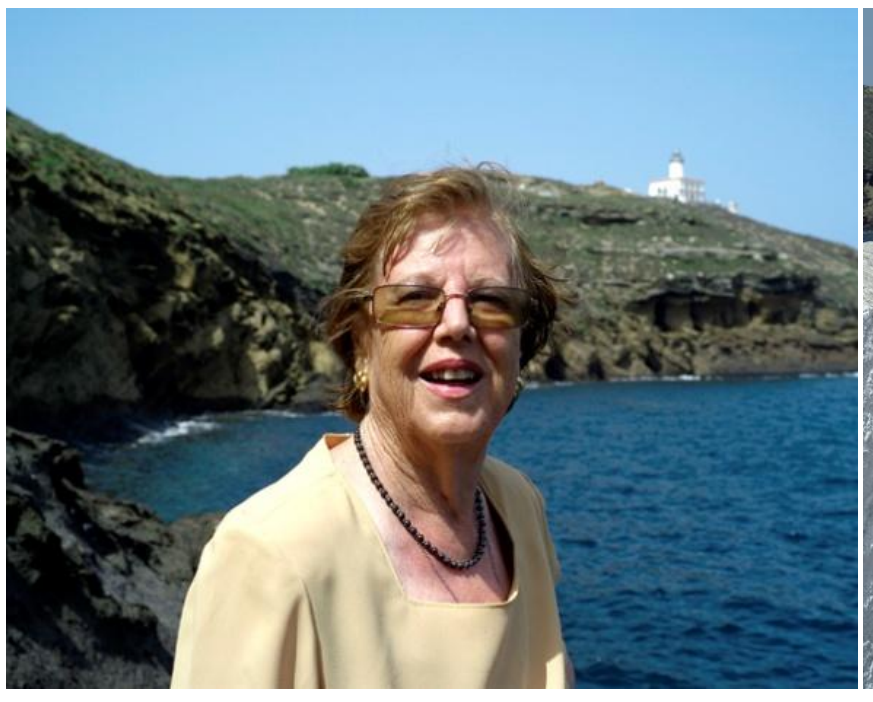

Figura 3.18. Dolores Guerra Guerrero en una de les tres visites que va fer a les Columbretes des de 2010.

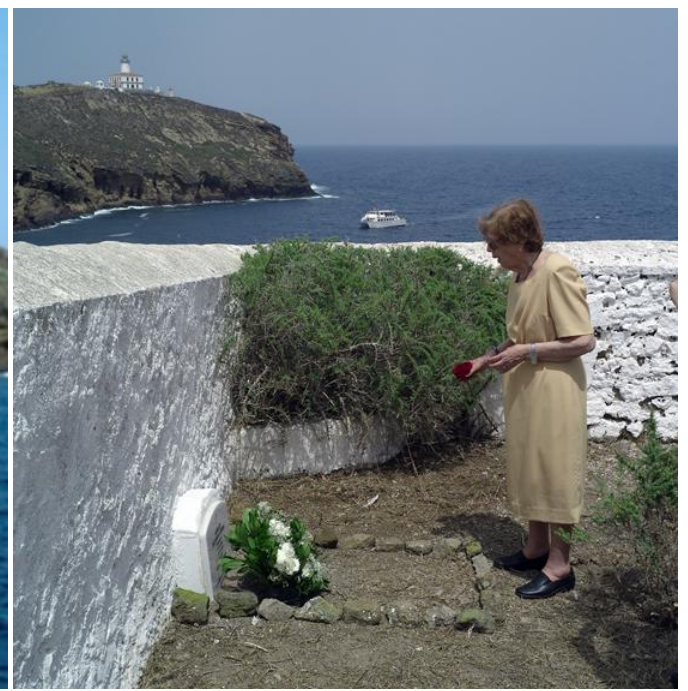

Figura 3.19. Acte de col·locació de la làpida a la tomba d'Aurelio Zacarías 59 anys després de la seua mort, amb la presència de sa mare Dolores.

També es coneix el cas d'algun xiquet molt malalt que es va curar, com el cas d'un xiquet que va agafar meningitis i es va salvar. Aquesta curació, segons Encarna García Gallén, neta del faroner Higinio García Blasco (Figura 3.20) (comunicació personal), s'atribueix al fet que li donaven banys d'aigua molt calenta intercalats amb banys d'aigua freda.

El fill menut de José Gozalbo es va fer un tall a la cama amb un tauler de parxís. Aquest tall, que li va deixar marca per a sempre, va ser curat i cosit amb grapes per Juan del Bosque, company del pare, ja que aquest es va desmaiar en veure el trau. L'endemà era el dia de relleu i una vegada en terra, el metge que els va atendre va dir que "millor no ho hauria fet ni ell mateix" (María Valero, dóna del faroner José Gozalbo, comunicació personal). 


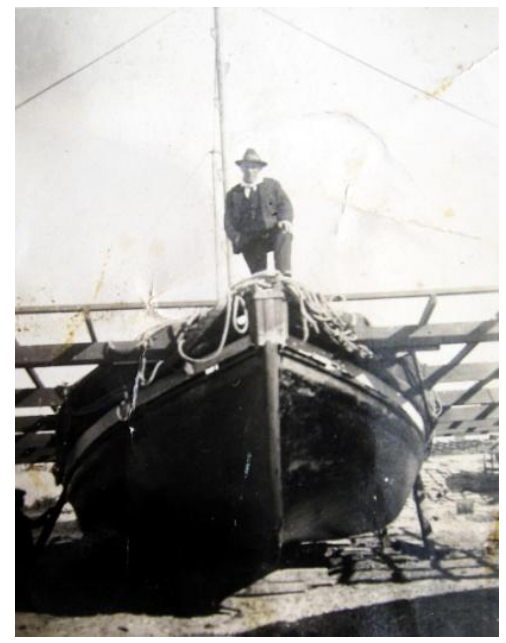

Figura 3.20. Higinio García Blasco. Imatge cedida per la neta Encarna García.
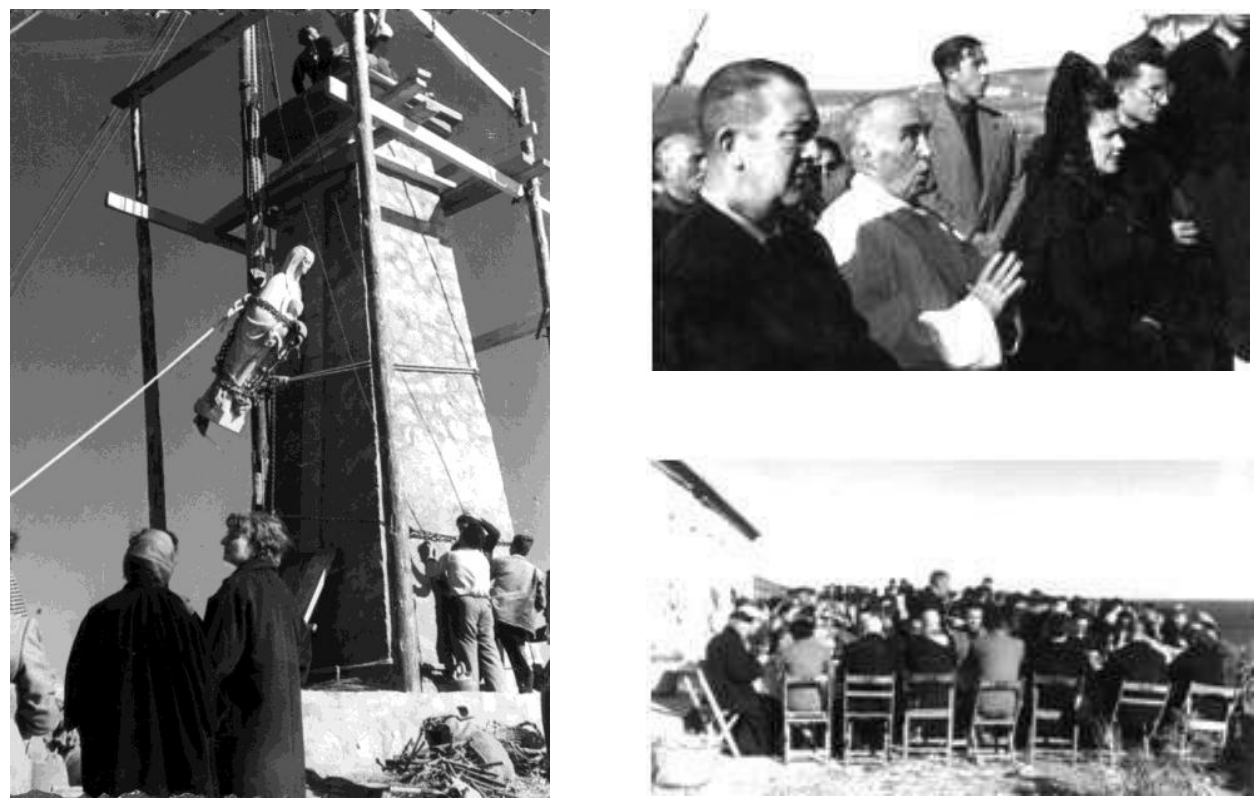

Figura 3.21. Acte de col·locació de l'estàtua de la Verge del Carme, desembre de 1954. Imatges cedides per Sergi Ferrer.

\section{Curiositats:}

A l'hora de descarregar material i pujar-lo al far disposaven d'un xicotet carro, que normalment empenyia un adult. Una vegada a l'any, arribaven un grup d'obrers, l'enginyer i un ajudant, que portaven una mula per pujar el material fins al far. La mula era descarregada amb la mateixa grua que descarregava els materials i queviures. Un dia, descarregant la mula amb la grua al port, la mula els va caure a l'aigua (Pilar Martínez, comunicació personal). Als anys 60, el carro havia desaparegut, i ho havien de pujar tot a mà (María Valero, comunicació personal). 
Alguns xiquets van aprendre a nadar a la badia de l'Illa Grossa, com el fill menut de José Gozalbo, a qui li posaven una corda amb suros al voltant de la cintura abans de tirar-lo a l'aigua (María Valero, comunicació personal).

El mes de desembre de 1954 es va procedir a fer l'acte de col·locació de l'estàtua de la verge del Carme a l'extrem sud de la Illa Grossa. Nombroses persones hi van acudir a bord de la fragata "Descubierta", posada a disposició d’aquest acte per la Marina de guerra espanyola. Joaquín Balaguer, cura arxipreste de Castelló, va beneir la imatge i, posteriorment, tots van orar pels soterrats al cementeri. Per finalitzar l'acte, la filla del faroner Francisco Bonachera, Coro, va recitar uns versos escrits per sa mare (Annex 3.5) i després, van dinar a l'esplanada de les casernes, on es van haver de muntar gran quantitat de taules degut al nombrós grup de comensals (Figures 3.21 a 3.23) (Ferrer, document inèdit).

En el Ilibre de signatures de I'Illa hi ha una foto, de l'any 1972, dedicada al faroner Francisco Bonachera per Francesca Romana Rivelli, més coneguda com a Ornella Muti, actriu italiana.

Hi ha d'altres històries curioses més recents, com que l'última restauració de les casernes (1998-99) va ser gràcies a una visita real, l'any 1997. Els reis Joan Carles i Sofia van visitar les Columbretes i van estar conversant amb els guardes d'una manera distesa (Figura 3.22). Es van adonar que les cases on vivien els guardes estaven en molt males condicions i els van dir que donarien indicacions per a solucionar-lo. Al mes següent ja estava tot llest per portar a terme la restauració (Juan Jiménez, comunicació personal).

A banda de la informació donada fins ara, pensem que seria interessant tractar en el possible documental els temes que mostrem a la Taula $\mathbf{3 . 8}$.

Taula 3.8. Selecció d'esdeveniments sobre Columbretes i any en què van ocórrer:

\begin{tabular}{|c|c|}
\hline Any & Tema \\
\hline 1893 & $\begin{array}{l}\text { Estada de l'arxiduc Lluís Salvador d' Habsburg-Lorena, il·lustrat i naturalista. Va escriure la } \\
\text { primera monografia sobre les Columbretes. }\end{array}$ \\
\hline 1938 & Refugiat de la guerra civil a Columbretes. \\
\hline Anys 40 & Pas de bombarders implicats en la 2a Guerra Mundial. \\
\hline 1941-46 & $\begin{array}{l}\text { Relació de Pilar Martínez i Ramon Roig: eren companys de jocs a l'illa i els deien "Tarzán y su } \\
\text { compañera"). La seua relació amb pescadors mallorquins. Naufragi i mort de pescadors després } \\
\text { d'una festa per fi de temporada al far. }\end{array}$ \\
\hline 1954 & Col·locació de l'estàtua de la Verge del Carme. \\
\hline 1955 & $\begin{array}{l}\text { Columbretes passen a formar part del terme municipal de Castelló. Visita de Franco a les Illes } \\
\text { (se'n fa ressò el NO DO). }\end{array}$ \\
\hline 1975 & Automatització del far i finalització de l’estada contínua dels faroners a l'Illa. \\
\hline 1988 & Protecció de l’arxipèlag i establiment de la guarderia de la Reserva. \\
\hline 2012 & $\begin{array}{l}\text { Acte de col·locació al cementeri de l'Illa Grossa de la làpida d’Aurelio Zacarías Guerra, cedida } \\
\text { per l'empresa "Mármoles Cabedo" de Castelló. }\end{array}$ \\
\hline
\end{tabular}




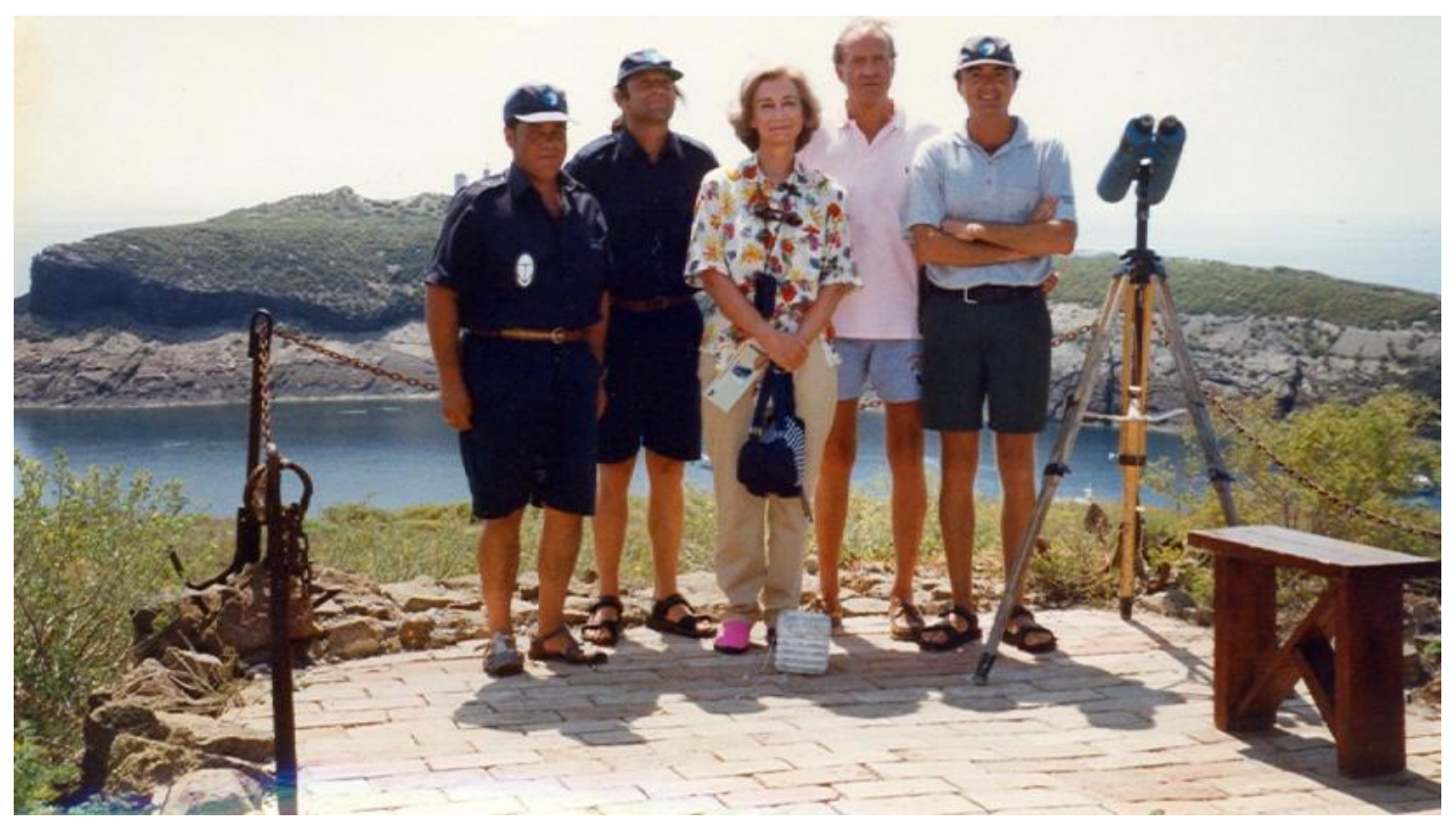

Figura 3.22. Els reis Joan Carles i Sofia en la seua visita a les Columbretes junt amb els guardes Vicente Ferrís i Santiago Sales i el monitor mediambiental Josep Carda, l'any 1997. Font: Arxiu C.I. Columbretes.

\section{Conclusions}

En totes les entrevistes s'ha trobat coincidència en la força dels temporals i les tempestes, la "convivència amb els escorpins", l'abundància de pesca, o de pardalets en les èpoques de pas. També ressaltaven les dures condicions de treball que hi havia, i sobretot l'aïllament, tal com també s'assenyala als documents oficials revisats, des de la construcció del far (s. XIX).

La idea preconcebuda que els testimonis ens transmetrien sobre tot records de tristesa i duresa en les seues vivències, contrasta vivament amb la constatació que, malgrat tot, aquests records eren generalment feliços, potser perquè està en la condició humana quedar-se amb els bons records i ser capaços d'oblidar els roïns.

Amb tota la informació recollida, es pren la decisió de començar a preparar el documental "Aïllats. La memòria de Columbretes", que veu la llum l’any 2015 (Figures 3.23 i 3.24). 


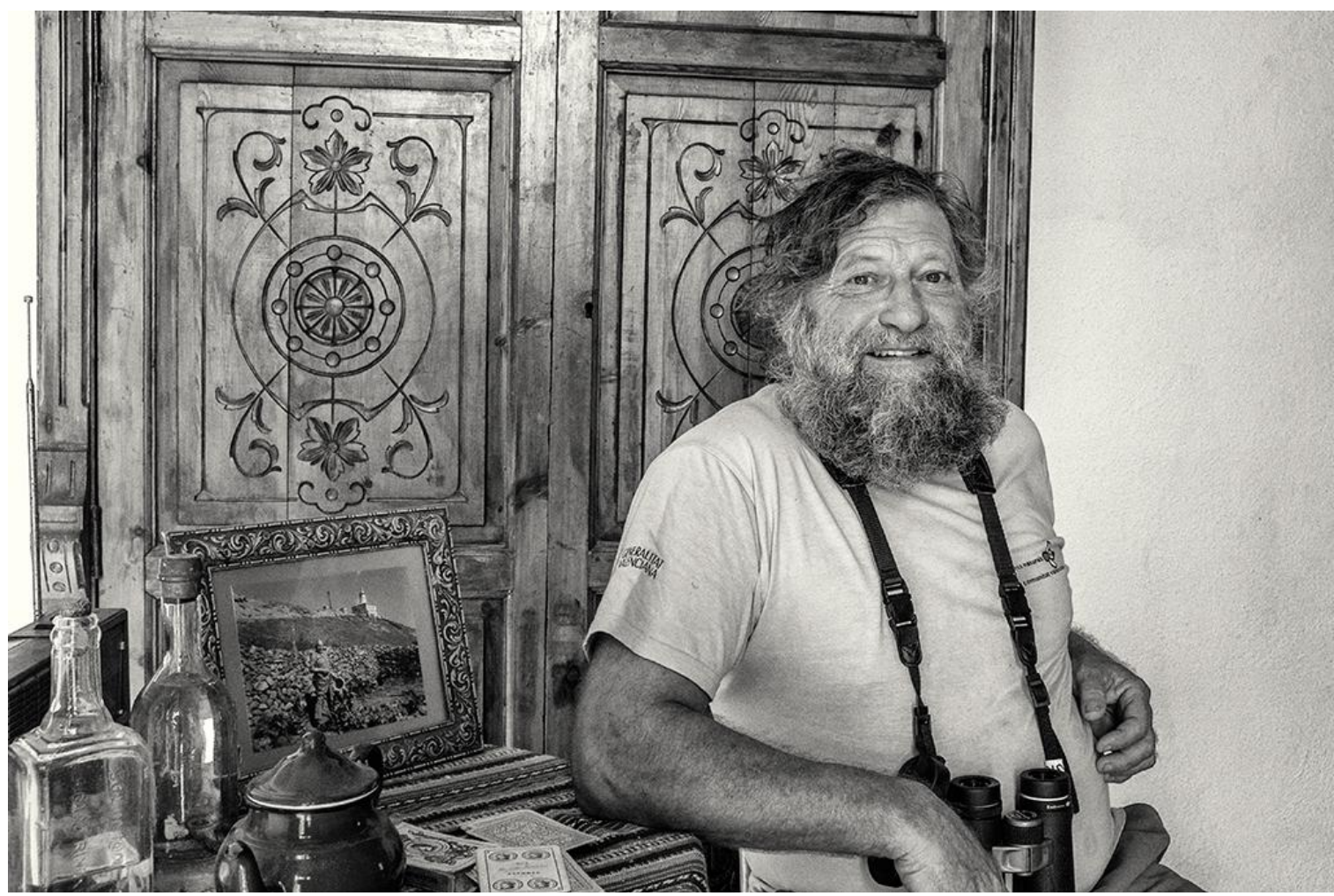

Figura 3.23. Vicente Ferrís, guarda de Columbretes, és un dels protagonistes del documental "Aïllats, la memòria de Columbretes"

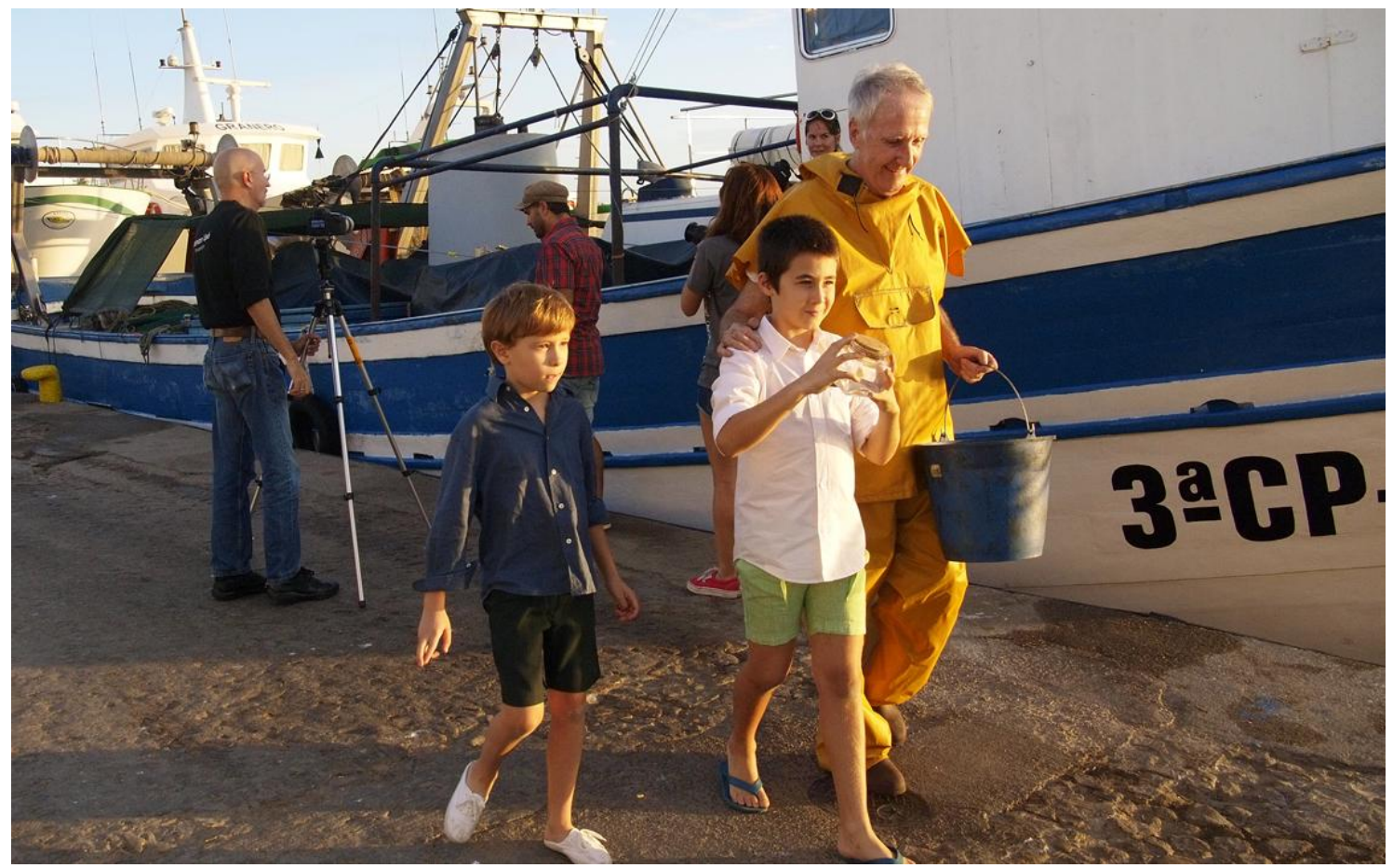

Figura 3.24. Luis Mestre, Lucas Martínez i Juan Carlos Usó són alguns dels actors que van participar en el rodatge del documental "Aïllats. la memòria de Columbretes". 


\section{EPÍLEG I DISCUSSIÓ}

Al llarg dels capítols anteriors, s'han presentat nombroses dades noves que seran molt valuoses a l'hora d'actualitzar la informació disponible sobre la història natural i humana de les Columbretes.

En primer lloc, s'ha ampliat considerablement el nombre de dades climatològiques disponibles i s'ha obtingut una caracterització climàtica actualitzada. També s'ha fet per primera vegada un catàleg d'invertebrats terrestres de Columbretes i s'ha inclòs un estudi sobre àcars de plantes, invertebrats quasi invisibles. Finalment s'ha recopilat nombrosa informació sobre la vida de les persones que han habitat les Illes. Per tant, hem aconseguit els objectius que ens vam marcar en començar aquesta tesi.

Tot i que la confecció d'una Guia de camp d'espècies de flora i fauna terrestres de les illes Columbretes i el documental sobre la història humana de les illes Columbretes estan fora de l'abast d'esta tesi, després de les investigacions i els anys dedicats, hem aconseguit fer el documental i estem en vies de fer la guia.

La guia de flora i fauna terrestres, estaria formada per fitxes, cadascuna d'una espècie importants des del punt de vista didàctic, i algunes de famílies o gèneres. A cada fixa es mostraria una senzilla descripció de les espècies, la història de cadascuna en l'illa, curiositats i fotografies. Com a introducció de la guia caldria donar una descripció de l'itinerari que fan les visites en el qual es nomenen totes les espècies de les quals seguidament es donarà la informació, destacant-les en negreta de manera que es puga anar en seguida a buscar la fitxa corresponent a l'índex alfabètic.

El documental es va arribar a portar a terme abans de la finalització d'aquesta tesi doctoral, amb la qual cosa es pot exposar seguidament un resum de la creació del mateix i quina divulgació s'ha portat a terme fins la data d'avui per divulgar i posar en valor la història humana de les Columbretes.

Després de la recopilació de les dades obtingudes es van triar els esdeveniments més rellevants. Es farien dos documentals, el primer seria el principal, d'una hora de duració, i l'altre, inclouria els extres del principal, seria de mig hora de duració, i se centraria en les històries ocorregudes des de la protecció de Columbretes. Se'n van idear els guions i els títols. Es va dissenyar els logotips del documental (Figura 15), es va preparar l'esborrany del guió, i de seguida va començar la fase de rodatge. Després es va haver de revisar tot l'enregistrat i procedir al muntatge de l'audiovisual (mitjançant una empresa professional). 


\section{Aiillats}

la memòria de Columbretes

\section{continum Aïllats}

la memòria de Columbretes

Figura 15. Logotips dels documentals "Aïllats, la memòria de Columbretes" $\mathrm{i}$

"Continuem Aïllats". Disseny: Gabi Borràs.

Per començar amb la divulgació es va crear un teaser (https://vimeo.com/89101572) el qual va servir també per promocionar el documental i obtindre finançament mitjançant una pàgina web de micromecenatge. També vam haver de fer una cerca de finançament i col·laboracions. Una vegada muntat, es va crear el tràiler (https://vimeo.com/160090117).

També es crea un grup en una xarxa social, per divulgar els valors històrics de les illes Columbretes (https://www.facebook.com/groups/574523539232843).

El dia 13 de maig de 2015 vam fer la presentació del documental principal al Museu de Castelló per a tots els col-laboradors i micro-mecenes, i vam començar a projectar-lo en diverses localitats (Taula 3 i Figura 16). El documental més curt surt al DVD del principal com a material extra. El dia 1 d'octubre de 2015 ens van entregar el premi "Vinaròs en curt".

Taula 3. Llistat de llocs on s'ha projectat el documental "Aïllats, la memòria de Columbretes", gran part d'ells amb representació d’algun o alguns dels autors i xicotet col·loqui al final:

\begin{tabular}{ll}
\hline Data & Lloc \\
\hline $13 / 05 / 2015$ & Museu de Castelló \\
$11 / 08 / 2015$ & Cine de Morella \\
$12 / 08 / 2015$ & Club Nàutic d'Orpesa \\
$28 / 08 / 2015$ & Club Nàutic de Borriana \\
$18 / 09 / 2015$ & Teatre Municipal de Benicàssim (2 passes) \\
$01 / 10 / 2015$ & Vinaròs \\
$18 / 02 / 2016$ & Sala d'Actes de la Ciutat Administrativa 9 d'Octubre \\
& (Conselleria de Medi Ambient, València) \\
$10 / 03 / 2016$ & Sala d'Actes del Centre Social de La Canyada (Paterna, València) \\
$08 / 04 / 2016$ & L'Auditori de Vila-real \\
& Sala d'actes del Centre Cultural La Marina del Grau, Castelló, \\
$17 / 05 / 2016$ & dins "L'HAM 2016" (I Setmana de la Cultura al Grau) \\
$23 / 05 / 2016$ & Residència de la 3a edat d'Almassora \\
$16 / 09 / 2016$ & Museu de la Mar de l'Ebre (Sant Carles de la Ràpita) \\
$21 / 09 / 2016$ & Teatre del Raval de Castelló \\
$14 / 10 / 2016$ & Sala SGAE, València, dins la “Mostra Viva del Mediterrani” \\
\hline
\end{tabular}



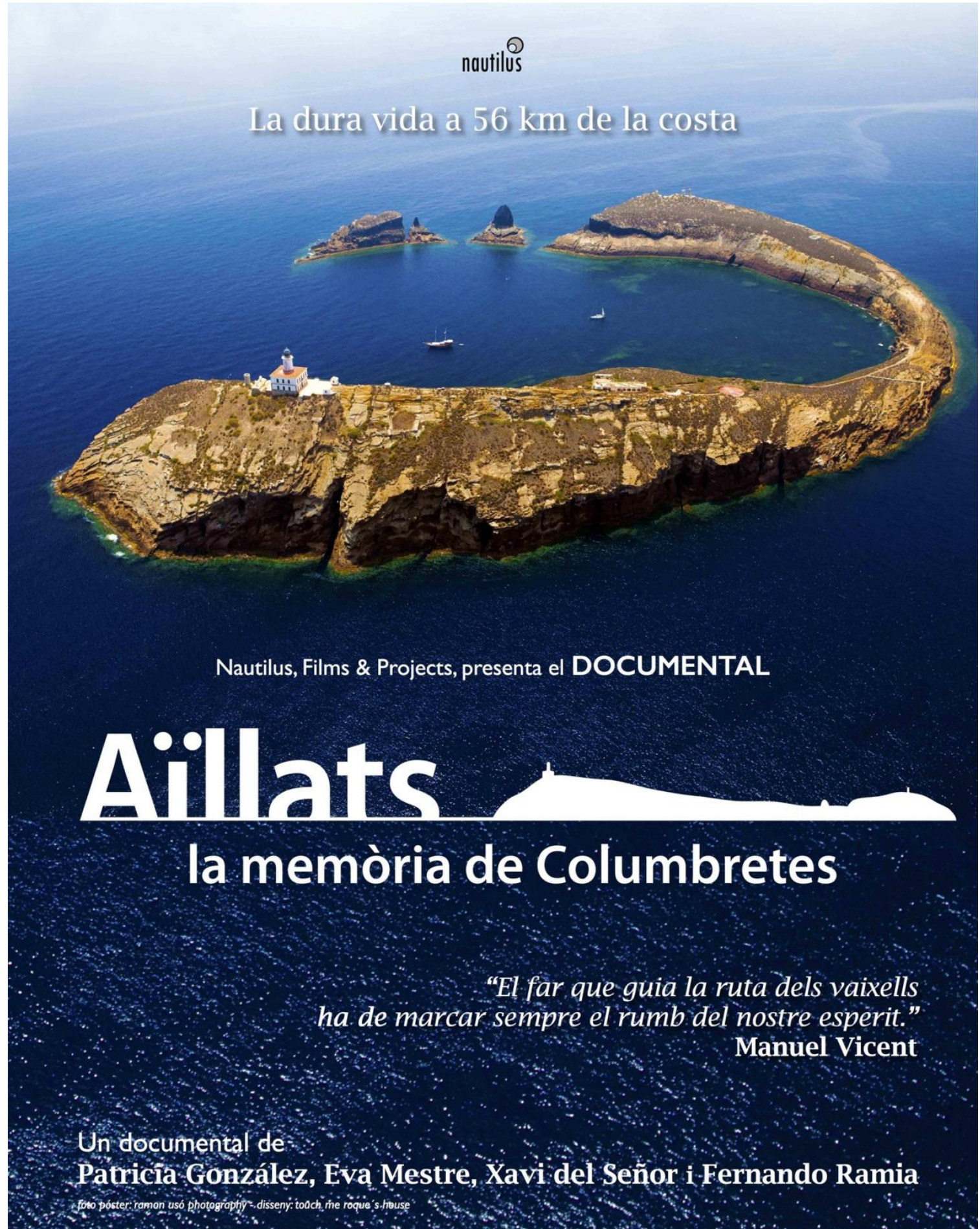


\section{CONCLUSIONS}

La recopilació de dades climàtiques noves i la seua anàlisi ens ha permès actualitzar la classificació climàtica de les Columbretes, que ha resultat en un clima més càlid i humit que el que s'havia descrit fins ara. Aquests resultats indiquen una tendència comuna a altres zones del nord-est peninsular, on el clima s'ha fet més càlid, d'acord amb l'escalfament global del Planeta, però també més plujós.

Amb tota la informació recollida s'ha pogut actualitzar el catàleg d'espècies d'invertebrats terrestres. Fins ara la informació era fragmentària. Ara està consolidada en un únic catàleg, on també s'han pogut incloure noves cites. Aquesta informació ha de servir tant per a poder gestionar millor aquesta diversitat, com per a poder divulgar-la i protegir-la.

Les històries que constitueixen la memòria de les Columbretes s'han recollit també de forma sistemàtica i ara constitueixen un material que pot ser contat en les xarrades i conferències impartides pels tècnics mediambientals per a la divulgació dels valors de les illes Columbretes $\mathrm{i}$ també pels guardes en les visites guiades que realitzen en la reserva natural. A més, el documental que s'ha fet amb tot aquest material servirà per a la mateixa finalitat. D'altra banda, s'ha pogut fer una recopilació dels llistats dispersos de faroners que van exercir a les Illes Columbretes i, amb material inèdit recopilat en aquesta investigació, elaborar un únic Ilistat més complet de faroners de Columbretes.

Donat que tota la informació obtinguda en aquest treball de documentació estarà disponible a la biblioteca i arxius del Centre d'Informació de la Reserva Natural, aquest no hauria de ser un punt i final, sinó una base des d' on continuar possibles estudis futurs. 


\section{REFERÈNCIES}

ADÁN, A., VIÑUELA, E. \& JACAS, J.A. 1991. Effects of agricultural impact on soil inhabiting Oribatid (Acari: Oribatida) communities. En: Modern acarology. Vol. 1: 403-409. Dusbabek \& Bukva eds. Academia, Prague \& SPB Academic, Czechoslovakia.

AGUILAR, R. M. \& PÉREZ-VILATELA, L (eds.). 2004. Plutarco. Vidas de Sertorio y Pompeyo. Ed. Akal, Madrid, pp. 59-61.

ALCOVER, A.M. \& DE BORJA MOLL, F. 1962. Diccionari català-valencià-balear (10 vols.). Ed. Moll 1962-68, Barcelona. Edició electrònica, 2015 (http://dcvb.iecat.net/)

ALONSO, L.A. 1991. Geología estructural del archipiélago de las Columbretes. En: L.A. ALONSO, J.L. CARRETERO \& A.M. GARCÍA CARRASCOSA (Coords.): Islas Columbretes: Contribución al estudio de su medio natural. Monografies 5 (19a Reimpressió, 1991): $27-$ 53. Generalitat Valenciana.

ALONSO, L.A., CARRETERO J.L. \& GARCÍA CARRASCOSA A.M. (Coords.). 1991. Islas Columbretes: Contribución al estudio de su medio natural. Monografies 5. 1a Reimpressió. Generalitat Valenciana.

ANDRÉS, R. 1991. Cartografía de las Islas Columbretes. En: L.A. ALONSO, J.L. CARRETERO \& A.M. GARCÍA CARRASCOSA (Coords.): Islas Columbretes: Contribución al estudio de su medio natural. Monografies 5 (1a Reimpressió, 1991): 19-25. Generalitat Valenciana.

ARIAS, M. 1971. Algunos nematodos de las islas Columbretes. Acta I Centenari de la Reial Societat Espanyola d'Història Natural (Biol.), Madrid, 6 p.

ARROIO, J., ITURRONDOBEITA, J.C., RAD, C. \& GONZALEZ-CARCEDO, S. 2003. Una aproximación al uso de taxones de artrópodos como bioindicadores de condiciones edáficas en agrosistemas. Butlletí de la SEA, 32: 73-79.

ARROIO, J., ITURRONDOBEITA, J.C., RAD, C. \& GONZALEZ-CARCEDO, S. 2005. Oribatid mite (Acari) communiti structure in steppic habitats of Burgos Province, central northern Spain. Journal of Natural History, 39 (39): 3453-3470.

BEHAN-PELLETIER, V.M. 1999. Oribatid mite biodiversiti in agroecosistems: role for bioindication. Agriculture, Ecosistems and Environment, 74: 411-423. 
BELDA, M., HOLTANOVÁ, E., HALENKA, T. \& KALVOVÁ, J. 2014. Climate classification revisited: from Köppen to Trewartha. Climate Research, Vol. 59: 1-13.

BLADÉ, I., CACHO, I., CASTRO-DÍEZ, Y., GOMIS, D., GONZÁLEZ-SAMPÉRIZ, P., MIGUEZ-MACHO, G., PEREZ, F., RODRÍGUEZ-FONSECA, B., RODRÍGUEZ-PUEBLA, C., SÁNCHEZ, E., SOTILLO, M.G., VALERO-GARCÉS, B. \& VARGAS-YÁÑEZ, M. 2010. Clima en España: pasado, presente y futuro. Informe de evaluación del cambio climático regional. Xarxa temàtica Clivar-España. URL http://www.clivar.es/files/informe_clivar_final.pdf

BOIRA, H. \& CARRETERO, J. L. 1991. Flora vascular de las Islas Columbretes. En: Islas Columbretes. Contribución al estudio de su medio natural: 109-128 (L. A. ALONSO, J. L. CARRETERO \& M. GARCÍA CARRASCOSA, Coords.). Conselleria d'Administració Pública, Agència del Medi Ambient, Generalitat Valenciana, Valencia.

BONET DE LOS HERREROS, P. 1916. El Archiduque de Austria Luis Salvador. En: Bolletí de la Societat Arqueològica Lul.liana, 433: 103-119. Estampa d’Amengual i Muntaner.

BORDERA, S. 1998. A new species of Fianoniella (Hymenoptera: Ichneumonidae) from the Columbretes Islands (Spain), with additional notes on F. laeviscutum. European Journal of Entomology, 95: 133-140.

BRIGNOLI, P.M. 1976. Beitrag zur Kenntniss der Scytodidae (Araneae). Revue Suisse de Zoologie, 83(1):125-191.

BRU, F. 1913. Notas de caza. València. 194 pp.

BRYANT, P.J. 2009. Invasion of Southern California by the Palearctic pyrrhocorid Scantius aegyptius (Hemiptera: Heteroptera: Pyrrhocoridae). The Pan-Pacific Entomologist, 85(4): 190-193.

CAMPO, A.M. \& DUVAL, V.S. 2014. Diversidad y valor de importancia para la conservación de la vegetación natural. Parc Nacional Lihué Calel (Argentina). Anales de Geografía, 34(2): 25-42.

CANUTO, F. 1994. Toponímia i talasonímia mallorquina als Columbrets. Universitat de les Illes Balears, p.36.

CARDA, J. \& DEL MORAL, E. 1998. Geografía e historia del Archipiélago de las Islas Columbretes. A: La Reserva Marina de las Islas columbretes, MAPA (eds). 
CARRETERO, J.L. \& BOIRA, H. 1987. La vegetación de las Islas Columbretes. En: Islas Columbretes. Contribución al estudio de su medio natural: 129-153 (L. A. ALONSO, J. L. CARRETERO \& M. GARCÍA CARRASCOSA, Coords.). Consellería d'Administració Pública, Agència del Medi Ambient, Generalitat Valenciana, Valencia.

CARRETERO, M. A. \& SALVADOR, A. 2016. Lagartija parda-Podarcis liolepis. En: Enciclopedia Virtual de los Vertebrados Españoles. Salvador, A., Marco, A. (Eds.). Museu Nacional de Ciències Naturals, Madrid. http://www.vertebradosibericos.org/

CARTAGENA, M.C. \& GALANTE, E. 2002. Loss of Iberian island tenebrionid beetles and conservation management recommendations. Journal of Insect Conservation, 6(2): 7381.

CARTAGENA, M.C. \& GALANTE, E. 2003. Ecología del género Blaps Fabricius, 1775 en el sudeste Ibérico (Coleoptera, Tenebrionidae). Sessió Conjunta d'Entomologia. ICHN- SCL, 12: 4353.

CARTAGENA, M.C. 2002. Medida del estado de conservación de los ecosistemas insulares a través de la utilización de los coleópteros tenebriónidos (Coleoptera, Tenebrionidae). Bolletí de l'Associació Espanyola d'Entomologia, 26: 177-192.

CASTILLA, A. M. \& BAUWENS, D. 1991. Observations on the natural history, present status and conservation of the insular lizard Podarcis hispanica atrata on the Columbretes archipelago, Spain. Biological Conservation, 58: 69-84.

CASTILLA, A.M. \& PONS, G.X. 2007. Primeros datos sobre la población de escorpiones (Buthus occitanus) en las islas Columbretes (Mediterráneo, España). Bolletí de la Societat d'Història Natural de les Balears, 50: 267-278.

CASTILLA, A.M. 1993. Los escorpiones (Buthus occitanus) de columbretes: abundancia relativa y distribución. En: Estudios de Biología-Parque Natural de las Islas Columbretes: 1-3. Projecte PNIC-3-1993. (Conselleria d'Agricultura i Pesca, Eds.). Generalitat Valenciana, Valencia.

CASTILLA, A.M., COOPER, W.E. \& PONS, G.X. 2010. The effect of moonlight variation on scorpion (Buthus occitanus) activity in the Columbretes Islands (Mediterranean, Spain). En: Islands and Evolution: 221-230 (V. PÉREZ-MELLADO \& Mạ. M. RAMÓN, Eds.). Institut Menorquí d’Estudis, Maó (Menorca, Spain). 
CASTILLA, A.M., GARCíA, R., VERDUGO, I., PONS, G.X. \& ESCOBAR, J.V. 2005. Primeros datos sobre la ecología y comportamiento de las arañas Argiope lobata y A. bruennichi de una población que ha colonizado recientemente las islas Columbretes (Mediterráneo, España). Bolletí de la Societat d'Història Natural de les Balears, 48: 61-69.

CASTILLA, A.M., HERREL, A. \& GOSÁ, A. 2009. Predation by scorpions (Buthus occitanus) on Podarcis atrata from the Columbretes Islands. Munibe (Ciencias Naturales-Natur Zientziak), 57: 299-302.

CASTILLA, A.M., PASTOR, E. \& PONS, G.X. 2006. Fluctuación anual de la densidad de arañas tejedoras del género Argiope en las islas Columbretes: Consecuencias sobre la lagartija endémica Podarcis atrata. Bolletí de la Societat d'Història Natural de les Balears, 49: 137-143.

CASTILLA, A.M., PONS, G.X. \& ESCOBAR, J.V. 2004. Consideraciones ecológicas y biogeográficas del género Argiope (Arachnida, Araneae) en las Islas Columbretes (Castellón, España). Bolletí de la Societat d'Història Natural de les Balears, 47: 101-110.

CASTILLA, A.M., PONS, G.X. \& GOSÁ, A. 2010. Seguimiento de una invasión de arañas del género Argiope (Arachnida, Araneae) en las Islas Columbretes. Bolletí de la Societat d'Història Natural de les Balears, 53: 123-132.

CASTILLA, A.M., VANHOOYDONCK, B \& CATENNAZI, A. 2008. Feeding behaviour of the Columbretes lizard Podarcis atrata, in relation to Isopoda (Crustaceae) species: Ligia italica and Armadillo officinalis. Belg. J. Zool., 138 (2): 146-148.

CHEN, D \& CHEN, H.W. 2013. Using the Köppen classification to quantify climate variation and change: An example for 1901-2010. Environmental Developement, 6: 69-79.

COMPTE, A. 1969. Los coleópteros de las islas Columbretes. Eos, 45: 97-135.

DEMITE, P.R., MORAES, G.J. DE, MCMURTRY, J.A., DENMARK, H.A. \& CASTILHO, R. C. 2017. Phytoseiidae Database. URL www.lea.esalq.usp.br/phytoseiidae. Recuperat el 10/04/2017.

DOGV. 1995. Llei 11/1994, de 27 de desembre, de la Generalitat Valenciana, d'Espais Naturals Protegits de la Comunitat Valenciana. Presidència de la Generalitat Valenciana. Publicat en DOCV no2423 de 09 de gener de 1995 i BOE no33 de 08 de febrer de 1995. 
DOMINGO, J., MONTAGUD, S. \& SENDRA, A. 2007. Invertebrados endémicos de la Comunitat Valenciana. Conselleria de Territori i Habitatge, Generalitat Valenciana. P.41 (254pp.).

ERENA, S. L. 2014. Espacio marino de llles Columbretes. Projecte LIFE + INDEMARES. Ed. Fundació Biodiversitat del Ministeri d’Agricultura, Alimentació i Medi Ambient, 2014.

ESCOLANO, G.J. 1610. Década Primera de la Historia de la Insigne, y Coronada Ciudad y Reyno de Valencia. Primera parte dirigida a los tres Estamentos, Eclesiástico, Militar, y Real, y por ellos a los Diputados. Impremta de Pedro Patricio Mey, València.

ESPAÑOL, F., 1958. Contribución al conocimiento de los artrópodos y moluscos terrestres de las Islas Columbretes. Miscel·lània Zoològica, 1: 3-37.

F.R.A. 2012. Global Ecological Zones for FAO Forest Reporting: 2010 update. FRA Working Paper 179. FAO, Roma (Novembre 2012)

FABREGAT, C. \& LÓPEZ-UDIAS, S. 2011. Propuesta I+D de realización de investigación aplicada a la evaluación del estado de conservación de la vegetación y propuesta para mejorar su gestión en la reserva natural de las islas Columbretes. Anualidad 2011. Generalitat Valenciana. Informe inèdit. 148 pp.

FAUNA EUROPEA. 2013. http://www.faunaeur.org/distribution_table.php. Última actualització: 29/08/2013, versió 2.6.2.

FERNÁNDEZ, A. 1995. Enterramiento humano hallado en L'Illa Gran (Islas Columbretes, Castellón de la Plana). Quaderns de prehistòria i arqueologia de Castelló 16: 301-305.

FERNÁNDEZ-PUENTE VARO, J. 1903. El Torrero: Poema. Ed. Ezequiel Rodríguez.

FERRAGUT, F. 1991. Aportaciones a la acarofauna española I. Tiphlodromus morellensis n. sp. (Acari, Phitoseiidae). Bol. Asoc. Esp. Entomologia, 15:289-296.

FERRAGUT, F. \& GONZÁLEZ, J.E. 1994. Diagnóstico y distribución de las especies de Orius Wolff 1811, peninsulares (Heteroptera, Anthocoridae). Bol. San. Veg. Plagas, 20: 89-101, 1994

FERRAGUT, F. GARCIA-MARI, F., NAVARRO, V., LABORDA, R. \& COSTA-COMELLES, J. 1988. Contribución al conocimiento de los artrópodos de las Islas Columbretes (Castellón). Actes III Congrés Ibèric d'Entomologia. Granada: 149-156.

FERRER, S. No publicat. La Virgen en las Columbretes. 
GADEA, E. 1974. Nematodos liquenícolas de Columbretes. Miscel-lània Zoològica, 3: 4.

GADEA, E. 1979. Els illots del litoral del País Valencià i llur poblament microfaunístic. Acta Geològica Hispànica 14: 542-544

GADEA-BUISÁN, E. 1974. Nematodos liquenícolas de Columbretes. Miscel-lània Zoològica, 3, n.4.

GARCÍA, F., PÉREZ, N., MIER, M.P. \& NIETO, J.M. 2004. Updated check-list of Iberian-Balearic Aphidini (Hemiptera, Aphididae). Graellsia 60(2): 197-214.

GARCÍA, R. \& VERDUGO, Y. 2006. Sequimiento del estado biológico de la especie Argiope lobata en la Illa Grossa de les Illes Columbretes. Informe intern. Arxiu de la Reserva Natural.

GARCíA-BARROS, E., GURREA, P., LUCIÁÑEZ, M.J., CANO, J.M., MUNGUIRA, M.L., MORENO, J.C., SAINZ, H., SANZ, M.J. \& SIMÓN, J.C. 2002. Parsimony analysis of endemicity and its application to animal and plant geographical distributions in the lbero-Balearic region (western Mediterranean). Journal of Biogeography, 29: 109-124.

GARCÍA-MARÍ, F., FERRAGUT, F., NAVARRO, V., LABORDA, R. \& COSTA-COMELLES, J. 1991. Nuevas aportaciones al conocimiento de los artrópodos de las Islas Columbretes. En: Islas Columbretes. Contribución al estudio de su medio natural: 155-179 (L. A. ALONSO, J. L. CARRETERO \& M. GARCíA CARRASCOSA, Coords.). Consellería d'Administració Pública, Agència del Medi Ambient, Generalitat Valenciana, Valencia.

GASULL, L. 1981. Fauna malacológica terrestre y de agua dulce de la Provincia de Castellón de la Plana. Bolletí de la Societat d'Història Natural de les Balears, 25: 55-102.

GBIF, Global Biodiversity Information Facility. 2017. GBIF Backbone Taxonomy. GBIF Secretariat. Checklist Dataset. URL https://doi.org/10.15468/39omei, via GBIF.org. Recuperat el 10/04/2017.

GENERALITAT. 2015. Flora i vegetació del Parc Natural del Prat de Cabanes-Torreblanca. Recuperat de: http://www.parquesnaturales.gva.es/ca/web/pn-prat-de-cabanestorreblanca/flora-y-vegetacion

GENERALITAT. 2015. Natura del Parc Natural de la Tinença de Benifassà. Recuperat de: http://www.parquesnaturales.gva.es/ca/web/pn-tinenca-de-benifassa/naturaleza-ycultura 
GENIEZ, P., SÁ SOUSA, P., GUILLAUME C.P., CLUCHIER, A. \& CROCHET, P.A. 2014. Systematics of the Podarcis hispanicus complex (Sauria, Lacertidae) III: valid nomina of the western and central Iberian forms. En: Zootaxa, 3794: 1-51.

GILLOTT, C. 2005. Entomology. Dordrecht. Springer.

GIMENO, X. 2009. Les Columbretes. Associació castellonenca Cardona Vives. URL http://www.cardonavives.com/artdocumentos.asp?id=3017. Recuperat el 26/07/2016.

GISBERT, J. M. 1991. Clima y suelo de las Islas Columbretes. En: Islas Columbretes. Contribución al estudio de su medio natural: 95-107 (L. A. ALONSO, J. L. CARRETERO \& M. GARCÍA CARRASCOSA, Coords.). Conselleria d’Administració Pública, Agència del Medi Ambient, Generalitat Valenciana, Valencia.

GOROCHOV, A. V. \& LLORENTE, V. 2001. Estudio taxonómico preliminar de los Grylloidea de España (Insecta, Orthoptera). Graellsia 57(2): 95-139

GUALDI, S., SOMOT, S., LI, L., ARTALE, V., ADANI, M. BELLUCCI, A., BRAUN, A., CALMANTI, S., CARILlo, A., DELL'AQUiLA, A., DÉQUÉ, M., DUBOIS, C., ELIZALDE, A., HARZALLAH, A., JACOB, D., L'HÉVÉDER, B.,MAY, W., ODDO, P., RUTI, P., SANNA, A., SANNINO, G., SCOCCIMARRO, E., SEVAULT, F. \& NAVARRA, A. 2013. The CIRCE simulations: Regional Climate Change Projections with Realistic Representation of the Mediterranean Sea. Bulletin of the American Meteorological Society, American Meteorological Society, 94 (1): 65-81.

HABSBURG-LOTHRINGEN VON, LUDWIG SALVATOR. 1895. Columbretes. Druck und Verlag von Heinr. En: Columbretes, Ludwig von Salvator (URIOS, G. \& NACHTWEY, J). Publicacions de l’Excelentíssim Ajuntament de Castelló de la Plana. 1990.

HERNÁNDEZ-PACHECO, F. \& ASENSIO-AMOR, L. 1966. Datos fisiográfico-sedimentológicos de la Columbrete Grande. Bolletí de la Reial Societat Espanyola d'Història Natural (Geol.), 64: 179-198.

HERNÁNDEZ-PACHECO, F. \& ASENSIO-AMOR, L. 1972. Accumulations éoliennes à Columbrete Grande. Rapport Commission Internationale Mer Mediterranee, 20 (4): 527-530.

HIDALGO, J. G. 1883. Description de deux espèces nouvelles d'Helix. Journal de Conchyliologie, 31: 57-58.

HOYO DEL, J., ORTA, J., CAMPRODÓN, J., CURCÓ, A., DEJAIFVE, P.A., DOMÍNGUEZ, M., LAGUNA, 
E., MAYOL, J., NEBOT, J.R., PRODON, R., RITA, J., SANSANO, V. \& TORRES, N.. 1992. El litoral català i valencià. En: Història Natural dels Països Catalans. Volum supernumerari. Espais Naturals. Carreras, J., R. Folch, J. Gosàlbez, X. Llimona, C. Puigdefàgregas i J. Terradas (Eds.). Enciclopèdia catalana, S.A. Barcelona. Pp. 50-54.

IPCC, Intergovernmental Panel of Climatic Change. 2014: Climate Change 2014: Synthesis Report. Contribution of Working Groups I, II and III to the Fifth Assessment Report of the Intergovernmental Panel on Climate Change [Core Writing Team, R.K. Pachauri and L.A. Meyer (eds.)]. IPCC, Geneva, Switzerland, 151 pp.

ITURRONdOBEITIA, J.C., SALONA, M.I., PEREDA, J., CABALlERO A.I. \& ANDRES, M.C. 1997. Oribatid mites as an applied tool in studies on bioindication: a particular case. Abhandlungen-und-Berichte-des-Naturkundemuseums-Goerlitz, 69(6): 85-96.

IUCN, Unió Internacional per a la Conservació de la Natura, 2016. The IUCN Red List of Threatened Species. Versió 2016-3. URL http://www.iucnredlist.org. Recuperat el $31 / 01 / 2016$.

JAECKEL, S. 1952. Die Mollusken der spanischen Mittelmeer Inseln. Mitteilungen Zoologisches Museum Berlin, 28: 55-143.

JUNOY, J \& CASTELLÓ, J. 2003. Catálogo de las especies ibéricas y baleares de isópodos marinos (Crustacea: Isopoda). Bolletí de l'Institut Espanyol d'Oceanografia, 19 (1-4): 293-325.

KÖPPEN, W. 1936. Das geographische System der Klimate. En: KÖPPEN, W., GEIGER R. (eds.). Handbuch der Klimatologie. Gebrüder Borntraeger, Berlin, p.1-44.

KOTTEK, M., GRIESER, J., BECK, C., RUDOLF, B. \& RUBEL, F. 2006. World Map of the KöppenGeiger climate classification updated. Meteorologische Zeitschrift, Vol. 15(3): 259-263.

KREITER, S. 2012. Phytoseiidae in European grape (Vitis vinifera L.): bio-ecological aspects and keys to species (Acari: Mesostigmata). Plazi.org taxonomic treatments database. Checklist Dataset. URL https://doi.org/10.11646/zootaxa.3721.2.1 via GBIF.org. Recuperat el 16/05/2017.

LAGUNA, E. \& JIMÉNEZ, J. 1995. Conservación de la flora de las Islas Columbretes (España). Ecologia Mediterranea, 21: 325-336. 
LAZARIDOU-DIMITRIADOU, M. \& DAGUZAN, J. 1981. Bude de l'effet du troupement, des individues chez Theba pisana (Mollusque Gastéropode Pulmoné Stylommatophore). Malacologla, 20 (2): 195-204.

linares, C., NAVARro, L., ASPIllaga, E., Kersting, D., hereu, B., teIXIDÓ, VIDAL, M., BALleSteros. E., Cebrián, E., GARRABOU, J., DíAZ. D., AMBlÁS. D. \& CANALS, M. 2012. Caracterización de las comunidades profundas dominadas por especies longevas (Paramuricea clavata, algas fucales y laminariales) en la Reseva Marina de las Islas Columbretes y su entorno. Informe final area LIFE+ INDEMARES (LIFE07/NAT/E/000732). Departament d'Ecologia, Universitat de Barcelona. Coordinació: Fundació Biodiversitat, Madrid, 134 pp.

MARTÍNEZ DE CASTILLA, A. 2005. Colonització de les Illes Columbretes per aranyes i el seu efecte sobre espècies de fauna endèmica amenaçada. Celsona, 429: 29.

MARTíNEZ-ORTí, A. \& PUENTE, A.I. 2011. Xerocrassa molinae. En: Atlas y Libro rojo de los Invertebrados amenazados de España (Especies Vulnerables), Vol. II: 968-970. (J. R. VERDÚ, C. NUMA \& E. GALANTE, Eds.). Direcció General de Medi Natural i Política Forestal, Ministeri de Medi Ambient, Medi Rural i Marí, Madrid.

MARTÍN-MATEO, M. P. 1977. Malófagos recogidos sobre aves marinas de las islas Columbretes. Bolletí de la Reial Societat Espanyola d'Història Natural (Secció Biològica), vol. 75: 149-159.

MATA, L., GROSSO-SILVA, J.M. \& GOULA M. 2013. Pyrrhocoridae from de Iberian Peninsula (Hemiptera: Heteroptera). Heteropterus Revista de Entomología, 13(2): 175-189.

MELIÀ MASIÀ, A. 2003. Estudio faunístico de los pulgones (Homoptera: Aphididae) de Castellón. Fundació Caixa Castelló-Bancaixa: 65-66.

MESTRE-FORÉS, E. \& FERRAGUT, F. 2008. Estudio del grupo faunístico Acaridae con especial atención a los ácaros fitoseidos en los Espacios Naturales Protegidos de la provincia de Castellón. Treball d'Investigació realitzat al Departament d'Ecosistemes Agroforestals de la Universitat Politècnica de València. No publicat.

MESTRE-FORÉS, E., GONZÁLEZ, P \& DEL SEÑOR, X. 2009. Investigación en la Reserva Natural de les Illes Columbretes (1988-2009). Equip de Promoció, Investigació i Treballs Tècnics, C.I. de les Illes Columbretes. Generalitat Valenciana. Informe intern. 
MESTRE-FORÉS, E., MONTAGUD, S. \& GONZÁLEZ, P. 2017. Catálogo de los Invertebrados terrestres de las Islas Columbretes. Article del present estudi, en preparació.

MíngUEZ, M. E. \& SUBÍAS, L. S. 1986. Nuevos oribátidos (Acari, Oribatida) de las islas Columbretes (España). Quaderns d'Investigació Biològica (Bilbao), 9: 75-88.

MONTAGUD, S. \& GARCÍA ALAMÁ, J.A. 2010. Mariposas diurnas de la Comunitat Valenciana. Conselleria de Medi Ambient, Aigua, Urbanisme i Haitatge, Generalitat Valenciana. València.

MORALES GUTIÉRREZ, G. No publicat. Orígenes del apellido Hierro en Canarias.

MORAZA, M.L. 2006. Efecto de la degradación de un encinar de Quercus rotundifolia en la comunidad de ácaros Criptostigmados y Mesostigmados (Acari: Criptostigmata, Mesostigamata). Revista Ibérica d'Aracnologia, 13: 171-183.

MORÉ, D. 2010. La vida en los faros de España. El Cuerpo de Torreros de Faros o de Técnicos Mecánicos de Señales Marítimas (1851-1992). Ed. Museu Marítim de Barcelona i Angle Editorial. 447 pp.: 17, 22, 30, 54, 72, 133, 134, 156, 163, 206, 209, 221, 223, 224, 268, $297,320,322,332,357,404$ a 407, 408, 410 i 430.

MUÑOZ, A., LASTRAS, G., BALLESTEROS, M., CANALS, M., ACOSTA, J. \& UCHUPI, E. 2005. Sea floor morphology of the Ebro Shelf in the region of the Columbretes Islands, Western Mediterranean. Geomorphology, 2005, Vol. 72. Pp. 1-18.

NAVARRA, A. \& TUBIANA, L. (eds.). 2013. Regional Assessment of Climate Change in the Mediterranean. Volume 2: Agriculture, Forests and Ecosystem Services and People. Springer, Dordrecht, The Netherlands.

NAVARRO, P., ESCRIBANO, V. \& LLUCH, J. 2015. Nematodos liquenícolas de Columbretes. Nematodos Tylenchina del norte de L'Illa Grossa (Reserva Natural de las Islas Columbretes, Comunidad Valenciana). Congrés, XXI. Reunió Biennal de la Reial Societat Espanyola d'Història Natural.

PAUL, C.R.C. 1982. An annotated check-list of the non-marine Mollusca of the Pityuse Islands, Spain. Journal of Conchology, 312: 79-86.

PÉREZ-BAÑóN, C. 2000. Biología de los sírfidos (Diptera: Syrphidae) de los ecosistemas insulares de la Comunidad Valenciana: aspectos de la relación sírfido-planta. Tesi Doctoral, Universitat d'Alacant. Alacant. 
PINEDO, M.C. \& LLORENTE, V. 1987. Orthopteroidea de la provincia de Castellón, con especial referencia a la marisma de Oropesa. Graellsia, 43: 93-109.

Planton, S., LiONello, P., ARTAle, V., AZNAR, R., CARRILlo, A., COlin, J., CONGedi, L., DUBOIS, C., ElizALDE, A., GUALDI, S., HeRTIG, E., JACOBEIT, J., JORDÀ, G., LI, L., MARIOTTI, A., PIANI, C., RUTI, P., SANCHEZ-GOMEZ, E., SANNINO, G., SEVAULT, F., SOMOT, S. \& TSIMPLIS, M. 2012. The Climate of the Mediterranean Region in Future Climate Projections. En: The Climate of the Mediterranean Region. From the Past to the Future. P. LIONELLO (Editor), Elsevier, pp 449-496.

PONS, G.X., PALMER, M. \& GARCIA LL. 1999. Isópodos terrestres (Isopoda, Oniscidea) de las Islas Chafarinas (N Africa, Mediterráneo Occidental). Bolletí de la Societat d'Història Natural de les Balears, 42. Pp. 139-146.

PORCAR, J. 2007. Els estius. Ed. Brosquil. URL http://www.porcar.net/llibres/els-estius-dejosep-porcar/.

PRIETO, M. \& HÁVA, J. 2013. Aportaciones corológicas del Museu de Ciències Naturals de Barcelona a la fauna iberobalear del género Dermestes Linnaeus, 1758 (Coleoptera, Dermestidae). Arxius de Miscel-lània Zoològica 11: 80-116.

PRIETO, M., PÉREZ, N., MIER, M.P. \& NIETO J.M. 2004. Updated check-list of iberian-balearic Aphidini (Hemiptera, Aphididae). Graellsia, 60(2): 197-214.

QUEREDA, J., MONTÓN, E. \& ESCRIG, J. 1999. La evolución de las precipitaciones en la cuenca occidental del Mediterráneo: ¿tendencia o ciclos?. Ponencia presentada en las Jornadas científicas sobre sequías en España organizadas por el Instituto Universitario de Geografía de la Universidad de Alicante en noviembre de 1999.

R CORE TEAM. 2016. $R$ : A language and environment for statistical computing. $R$ Foundation for Statistical Computing, Vienna, Austria. URL https://www.R-project.org/

RAMIS, C. 2008. Valoración de los impactos del cambio climático en el Mediterráneo: evidencias, incertidumbres y escenarios. Butlletí Ecos, 5. Novembre de 2008 - gener de 2009. Centre d'Investigació per a la Pau (Fuhem Ecosocial). URL http://www.fuhem.es/media/ecosocial/File/Boletin\%20ECOS/Boletin\%205/Valoracion _impactos_cclimatico_Mediterraneo_C.REMIS.pdf 
RIVAS-MARTínEZ, S. 1982. Series de vegetación de la región Eurosiberiana de la Península lbérica. Lazaroa, 4: 155-166.

ROBLES, F. 1991. Los gasterópodos terrestres de las Islas Columbretes. En: Islas Columbretes. Contribución al estudio de su medio natural: 155-A-161-A (L. A. ALONSO, J. L. CARRETERO \& M. GARCÍA CARRASCOSA, Coords.). Consellería d'Administració Pública, Agència del Medi Ambient, Generalitat Valenciana, València.

ROCA, V. 2015. Nematodos parásitos intestinales de Podarcis liolepis en las Islas Columbretes. Bol. Asoc. Herpetol. Esp. (2016) 27(1). P. 3-6.

ROUDIER, A. 1958. Artrópodos y moluscos de las Columbretes. Miscelllània Zoològica, 1: 26.

S.G.E., 1986. Islas Columbretes, escala 1:2000. Mapes del Servei Geogràfic de I'Exèrcit. 1ạ edició.

SÁNCHEZ-BEITIA, S. 2017. Catálogo de faros con valor patrimonial de España. Ministeri d’Educació, Cultura i Esport. Institut del Patrimoni Cultural d'Espanya.

SEÑOR DEL, X. 2007. La toma de las Islas Columbretes: un episodio poco conocido de la guerra civil española. No publicat

SERRA, L., FABREGAT, C., HERRERO-BORGOÑÓN, J.J. \& LÓPEZ S. 2000. Distribución de la flora vascular endémica, rara o amenazada en la Comunitat Valenciana. Conselleria de Medi Ambient. Generalitat Valenciana. 232 pp.

SERRANO, R. 1991. Historia de los asentamientos humanos en las Columbretes. En: ALONSO L.A., CARRETERO J.L. AND GARCÍA CARRASCOSA M. (Coords.), Islas Columbretes. Contribución al estudio de su medio natural. Consellería de Obras Públicas, Urbanismo y Transportes. Agència del Medi Ambient. Generalitat Valenciana, Valencia, pp. 13-18.

SERVEI DE VIDA SILVESTRE, 2016. Informe Tècnic 11/2016. Seguiment i evolució de les poblacions dels tàxons del Catàleg Valencià d'Espècies de Flora Amenaçada, any 2015. Generalitat Valenciana, Valencia.

SERVICIO GEOGRÁFICO DEL EJÉRCITO. 1986. Mapas E.1:2000 de las Islas Columbretes. En: ALONSO L.A., CARRETERO J.L. AND GARCÍA CARRASCOSA M. (Coords.): Islas Columbretes: Contribución al estudio de su medio natural. Monografies 5 (1aㅗ Reimpressió, 1991). Generalitat Valenciana. 
SIMONS, H. 2001. Global Ecological Zoning for the Global Forest Resources Assessment (FRA). 2000. FRA Working Paper 56. FAO, Roma.

SMYTH, Captain. 1831. V.-On the Columbretes, Volcanic Rocks near the coast of Valencia, in Spain. By Captain Smyth, R.N., R.F.S. Read the 10th of January, 1831. En: The Journal of the Royal Geographical Society of London, vol. 1. Pp: 58-62. www.jstor.org/stable/1797659 Consultat el 15/02/2017.

SOCHA, R. 1993. Pyrrhocoris apterus (Heteroptera) - an experimental model spacies: A review. Eur. J. Entomol. 90: 241-286.

SOUTHWOOD, T.R.E. \& HENDERSON, P.A. 2000. Ecological Methods. Blackwell Science Ltd. 3은 ed. Pp. 276-278.

STAPP, P. 1997. Microhabitat use and community structure of darkling beetles (Coleoptera: Tenebrionidae) in shortgrass prairie: Effects of season shrub and soil type. The American Midland Naturalist, 137 (2): 298-311.

TEMPLADO, J., CALVO, M., GARCÍA-CARRASCOSA, M., BOISSET, F \& JIMÉNEZ, J. 2002. Flora Y Fauna de la Reserva Marina de las Islas Columbretes. Ministeri d'Agricultura, Pesca i Alimentació, S.G. Pesca Marítima. Pp. 28, 48-49 i 60 (263pp.).

TIXIER, M.S., BALDASSAR, A., DUSO,C. \& KREITER, S. 2013. Phytoseiidae in European grape. (Vitis vinifera L.): bio-ecological aspects and keys to species (Acari: Mesostigmata). Zootaxa 3721 (2): 101-142.

TREWARTHA, G.T. \& HORN, L.H. 1980. Introduction to Climate. 5th edn. McGraw-Hill, New York.

UNESCO-FAO. 1963. Ecological study of the mediterranean zone. Bioclimatic map of the mediterranean zone. Explanatory notes. United Nations Educational, Scientific and Cultural Organization (UNESCO), Paris, i Food and Agriculture Organization (FAO), Roma.

URIOS, G. \& MARTíN, J. 1997. El santuario marino y terrestre de las islas Columbretes. Quercus 131: $20-22$

URONES, C. 1987. Las especies de Chiracanthium Koch, C.L., 1939 (Araneae: Clubionidae) en la Península lbérica. Graellsia. 43:139-152. 
URONES, C. 1995. Catálogo y Atlas de las arañas de la familia Philodromidae Thorell, 1870 de la Península Ibérica e Islas Baleares. Graellsia. 51:55-81.

VAN STRAALEN, N.M. 1997. Communiti structure of soil arthropods as a bioindicator of soil health. A: C.E. Pankhurst, B.M. Doube, V.V.S.R. Gupta (Eds.), Biological Indicators of Soil Health, CAB International, Wallingfors, pp. 235-264.

VIÑOLAS, A. \& CARTAGENA, M.C. 2006. Fauna de Tenebrionidae de la Península lbérica y Baleares, I: Lagriinae y Pimeliinae. Argania. Barcelona. 428 p

VIÑOLAS, A. 1994. El género Pimelia Fabricius, 1775 en la Península lbérica y Baleares, con nota sistemática sobre una especie de Canarias (Coleoptera, Tenebrionidae, Pimeliinae). Sessió Conjunta d'Entomologia ICHN-SCL, 8: 125-140.

VIÑOLAS, A. 2008. Pimelia interjecta Solier, 1836. En: Institució Catalana d'Història Natural, 2008. Invertebrats que requereixen mesures de conservació a Catalunya [en línea]. Barcelona: Institució Catalana d'Història Natural: 233-234. URL http://ichn.iec. cat/pdf/PROT_INV_ICHN_2008 (web).pdf 



\section{Annexos}

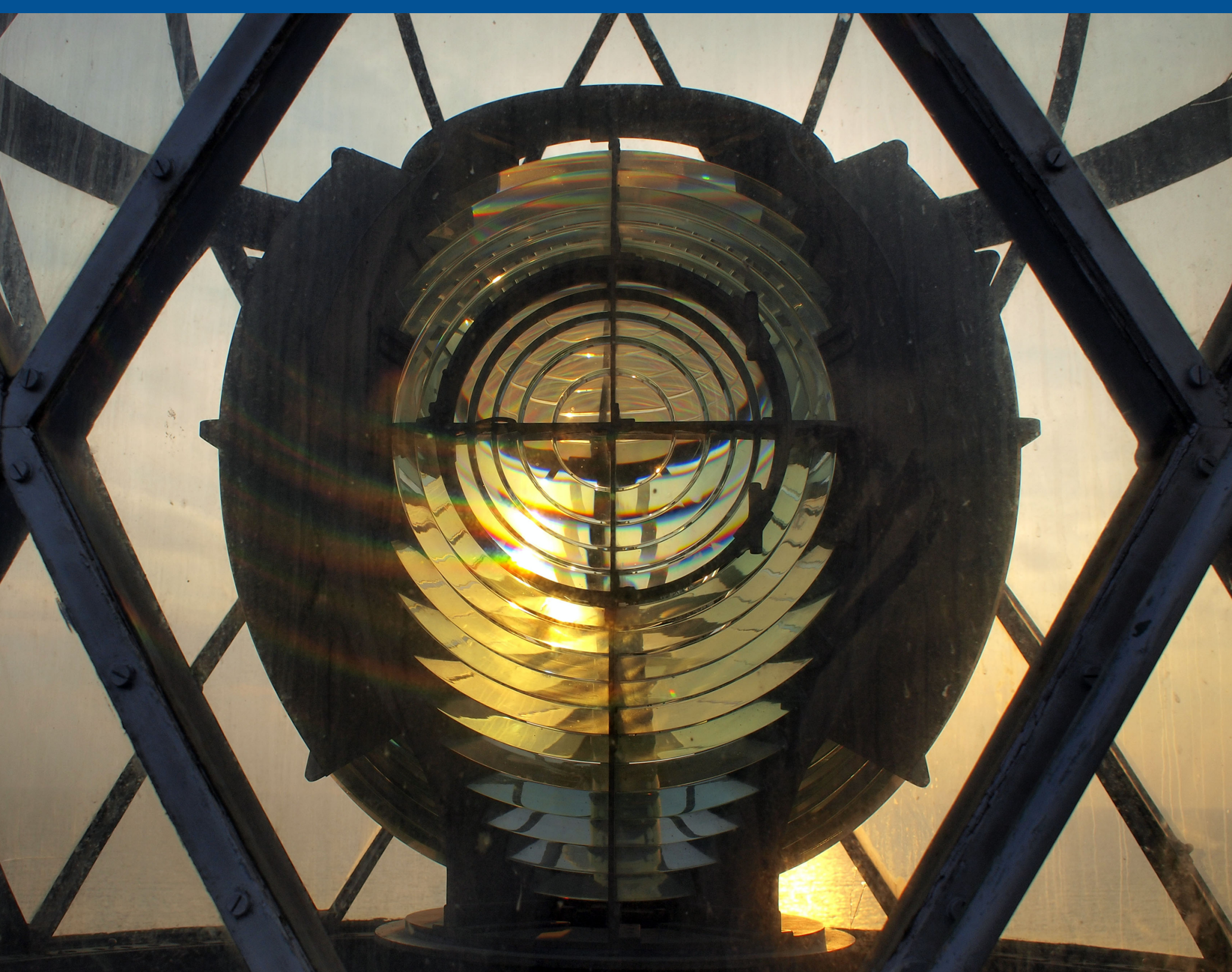



Annexos

ANNEX 1.1

Data sources of temperature and precipitation for the different stations and time periods available used in this thesis 
Table 1. Data sources of temperature for the different stations and the periods available (e.f.s.v.=except for several days; e.f.=except for). Stations eventually selected for the study are highlighted in red.

\begin{tabular}{|c|c|c|c|c|c|c|c|c|c|c|c|c|c|c|c|c|c|c|c|c|c|c|c|c|c|c|}
\hline STATION/YEAR & $\underset{\infty}{\mathscr{\Phi}}$ & $\underset{\mathbf{D}}{\vec{\alpha}}$ & & & $\stackrel{\circ}{\text { ğ }}$ & ఫิ & ఫे & $\overrightarrow{\underline{g}}$ & N & $\stackrel{m}{\stackrel{M}{\Xi}}$ & 兽 & & 高 & ळू̆ & 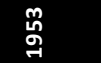 & 空 & 諹 & $\stackrel{2}{a}$ & ڤิ & $\stackrel{\infty}{9}$ & $\vec{g}$ & ฮू & ठั & 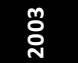 & & :ै \\
\hline Columbretes-lighthouse & & (sept & & & & & (Jan) & & & & & & & & & (Dec) & & & & & & & & & & \\
\hline Columbretes-casernes & & & & & & & & & & & & & & & & & & & & & (Jun) & AEMET (e.f.s.d.) & (May) & (Mar) & NR database + AEMET & $T(\mathrm{Dec})$ \\
\hline Palma Monteson & (Jan.) & AEME & & & (Dec. & & & & & & & & & & & & & & & & & & & & & \\
\hline Palma-institute & & & & & & (Jan.) & AEME & re.f.s.d & & & (Apr.) & & & & & & & & & & & & & & & \\
\hline Palma-jefatura & & & & & & & & & & & (May) & AEMET & & & & & & & (Dec.) & & & & & & & \\
\hline Palma de Mallorca-CMT & & & & & & & & & & & & & & & & & & & & $(\operatorname{Jan}) A$. & AEMET & & & & & (Dec) \\
\hline Alacant & & & & & & & & & & & Oct.) & AEMET & & & & & & & & & & & & & & (Dec) \\
\hline Castellóde la Plana & & & & & ) AEME & T(e.f.s & d., Jar & -April 15 & 52 and Jan & 1.1954) & & & & & & & (Dec.) & & & & & & & & & \\
\hline Castelló-Almassora & & & & & & & & & & & & & & & & & & (Jan.) & AEMET & & & & & & & (Dec) \\
\hline Almeria-seismological & & & & & & & & (Feb.) & AEMET (De & & & & & & & & & & & & & & & & & \\
\hline Almeria & & & & & & & & & & $(\operatorname{Jan})$. & T(e.f.Jun & ne-Dec. 1 & & (Jan.) & & & & & & & & & & & & \\
\hline Nijar & & & & & & & & & & & & & & & (Sept.) & AEMET & & & & & & & & & & (Dec) \\
\hline
\end{tabular}


Table 2. Data sources of monthly precipitation for the different stations and the periods available (e.f.s.v.=except for several days; e.f.=except for). Stations eventually selected for the study are highlighted in red.

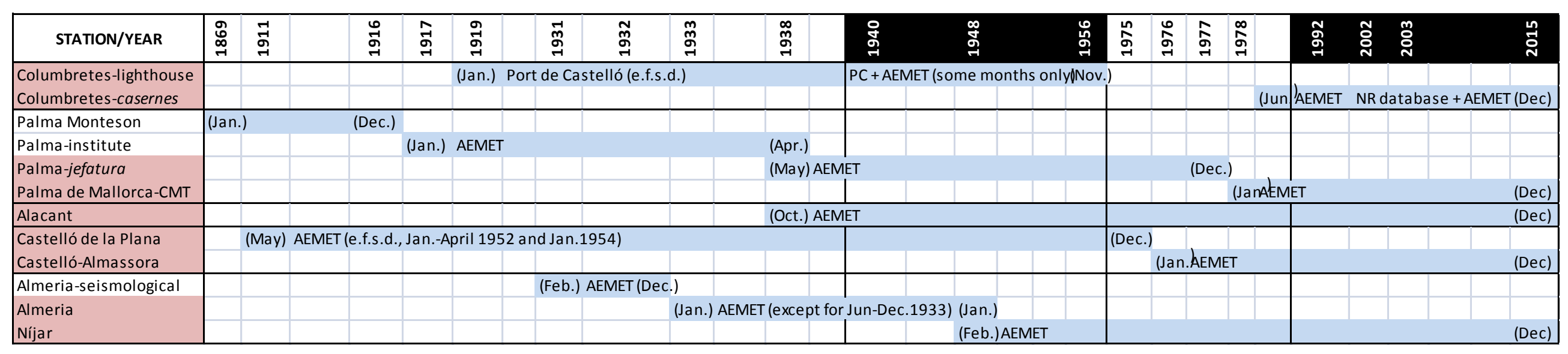

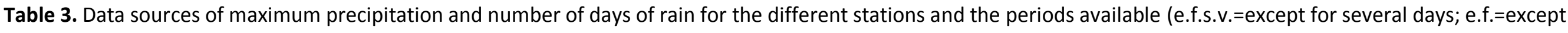
for). Stations eventually selected for the study are highlighted in red.

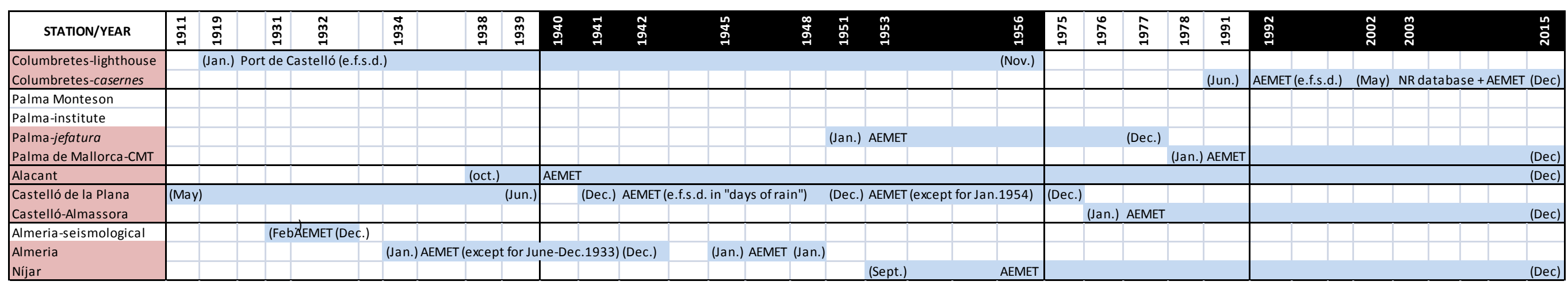


Table 4. Available months and years of the checked Columbretes parameters and their sources, depending on the different periods chosen in the research ( 10 period= 1940 to 1956 (precipitation) or 1957 (temperature) and 20 period= 1992 to 2015) (* means combined data between AEMET's and the original climate database from the guardians of the Natural Reserve; $T=$ temperature; $P=$ precipitation; $A b s=$ absolute; $\max =$ maximum; $\min =$ minimum):

\begin{tabular}{|c|c|c|c|c|c|}
\hline Period & Source & Abs. max. T, Max. T, Abs. min. T, Min.T, Mean T & № days of rain & Monthly P & Max. $P$ in $24 h$ \\
\hline \multirow{2}{*}{$\begin{array}{l}\text { Before the 1st } \\
\text { period }\end{array}$} & $\begin{array}{l}\text { Archduke (daily } \\
\text { data) }\end{array}$ & 09/1891 a 08/1894 (except for 11/1893 $\min \mathrm{T}$ ) & \multicolumn{3}{|c|}{ NA } \\
\hline & \multirow{2}{*}{$\begin{array}{l}\text { Original diaries } \\
\text { (lighthouse } \\
\text { keepers) } \\
\text { (daily data) }\end{array}$} & \multicolumn{4}{|c|}{$\begin{array}{l}01 / 1919 \text { to } 12 / 1921 \text { and } 01 / 1930 \text { to } 12 / 1939 \text { except for } 07 \text { and } 10 / 1930,04,06 \text { and } 12 / 1931,05 \text { and } 06 / 1932,08 / 1932 \text { to } 01 / 1934 \text {, } \\
\qquad 03,04,05,07,08 / 1934,10 / 1934 \text { to } 01 / 1935,02,07 \text { and } 08 / 1936,07 / 1937 \text { to } 08 / 1939\end{array}$} \\
\hline \multirow[t]{2}{*}{ 1st period } & & $\begin{array}{c}\text { 01/1940 A 12/1957 except for 06/1943, 09/1943, } \\
\text { 05/1954 (just missing abs and average max T), } \\
\text { 12/1954, 01/1955, 12/1955 }\end{array}$ & $\begin{array}{l}01 / 1940 \text { to } 12 / 1957 \text { except for } \\
06 / 1943,12 / 1954,01 / 1955\end{array}$ & \multicolumn{2}{|c|}{$\begin{array}{l}01 / 1940 \text { to } 12 / 1956 \text { except for } 06 / 1943,03 / 1948 \\
04 / 1948,12 / 1954,01 / 1955,12 / 1956\end{array}$} \\
\hline & $\begin{array}{l}\text { AEMET (monthly } \\
\text { data) }\end{array}$ & NA & \multicolumn{3}{|c|}{$06 / 1940$ to $11 / 1956$ : Some scattered months } \\
\hline \multirow[t]{2}{*}{$\begin{array}{l}\text { Between the } \\
\text { two periods }\end{array}$} & $\begin{array}{c}\text { Original diaries } \\
\text { (lighthouse } \\
\text { keepers) } \\
\text { (daily data) } \\
\end{array}$ & & $\begin{array}{l}04 / 1958 \text { to } 05 / 1959 \text { except for } \\
05,07 \text { and } 08 / 1958,01 \text { and } 04 / 1959\end{array}$ & & \\
\hline & $\begin{array}{c}\text { AEMET } \\
\text { (monthly data) }\end{array}$ & $06 / 1991$ to $11 / 1991$ & \multicolumn{3}{|c|}{$06 / 1991$ to $12 / 1991$} \\
\hline \multirow[t]{2}{*}{ 2nd period } & $\begin{array}{l}\text { AEMET } \\
\text { (monthly data) }\end{array}$ & $\begin{array}{l}\text { 01/1992 A 12/2015 except for 07/1993, } 08 \text { and } \\
\text { 09/1994, 05/1995, 03/1999, 01/2002 }\end{array}$ & $\begin{array}{l}\text { 01/1992 to } 01 / 2015 \text { except for } \\
05 / 1995,04 / 1998,09 / 1998 \\
03 / 1999,03 / 2000,03 / 2003\end{array}$ & $\begin{array}{c}01 / 1992 \text { to } 01 / 2015 \\
\text { except for } 05 / 1995 \text {, } \\
03 / 1999,03 / 2003\end{array}$ & $\begin{array}{l}01 / 1992 \text { to } 01 / 2015 \text { except } \\
\text { for 05/1995, 09/1998, } \\
\text { 03/1999, 03/2003 }\end{array}$ \\
\hline & $\begin{array}{c}\text { Climate database } \\
\text { (Natural Reserve) } \\
\text { (daily data) }\end{array}$ & $05 / 2002$ to $12 / 2015^{*}$ & \multicolumn{3}{|c|}{$05 / 2002$ to $12 / 2015$} \\
\hline
\end{tabular}


Annexos

ANNEX 1.2.

UNESCO-FAO bioclimatic classification (UNESCO-FAO, 1963) of the Columbretes Islands for the total series, first and second periods analyzed 
In this climate classification there are the following essential factors taken into account (UNESCO-FAO, 1963):

\section{Temperature:}

A hot month is a month in which the mean temperature is above $20^{\circ} \mathrm{C}$. A hot season is the period of consecutive hot months.

- Total series: June to October.

- 1st period: June to September.

- 2 2nd period: June to October.

A cold month is a month in which the mean temperature is $0^{\circ} \mathrm{C}$ or below. There are not cold months in Columbretes.

The mean temperature of the coldest month, $T_{\min }$ (total series, $n=52$ years):

$\mathrm{T}_{\min }=8.64{ }^{\circ} \mathrm{C}$, which means Temperate: $0^{\circ} \mathrm{C}<\mathrm{T}_{\min }<10^{\circ} \mathrm{C}$

The mean temperature of the coldest month, $T_{\min }$ (1st period, $n=18$ years):

$T_{\min }=7,25 \circ \mathrm{C}$, which means Temperate: $0^{\circ} \mathrm{C}<T_{\min }<10^{\circ} \mathrm{C}$

The mean temperature of the coldest month, $T_{\min }$ (2nd period, $n=24$ years):

$T_{\min }=9.78 \circ \mathrm{C}$, which means Temperate: $0^{\circ} \mathrm{C}<T_{\min }<10^{\circ} \mathrm{C}$

So, it belongs to Group I, which denotes that has a dry season lasting the greater part of the year.

\section{Precipitations and number of days of rain:}

The ombrothermic diagram (Figure 11, chapter $\mathbf{3}$ ) of the total series shows one dry season (when the ombrographic curve sinks below the thermic curve: $\mathrm{P}<2 \mathrm{~T}$ ): from February to August (7 months). Monoxeric climate.

The ombrothermic diagram (Figure 10, chapter 3 ) of the 1st period shows two dry seasons: from January to September (9 months). Monoxeric climate.

The ombrothermic diagram (Figure 9) of the 2nd period analyzed shows one dry season: from February to August (7 months), although the month of April is nearly no dry because Tmed $=15.61^{\circ} \mathrm{C}$ and mean of monthly precipitation $=30.50 \mathrm{~mm}$. Monoxeric climate.

Climates with a dry season from 9 to 11 months with $300<x<200$ (see below), are classed as hot sub-desert. Therefore, the climate of Columbretes based on the data from the first period corresponds to this classification. However, both for the whole period and the second one, the dry season is 7 and therefore, corresponds to a Mediterranean climate as the dry season coincides with the period of longest daylight. 


\section{Atmospheric humidity, mist and dew:}

Xerothermic index (index of hot weather drought):

$$
\mathbf{X m}=\mathbf{( N - ( \mathbf { p } + ( \mathbf { b } / \mathbf { 2 } ) ) * \mathbf { f }} \mid \begin{aligned}
& \mathrm{N}=\text { number of days of the month } \\
& \mathrm{P}=\text { number of days of rain } \\
& \mathrm{B}=\text { number of days of mist and dew } \\
& \mathrm{F}=\text { constant that depends on Relative Humidity }(\mathrm{RH})
\end{aligned}
$$

From the daily data obtained from the original climate database from the guardians of the Natural Reserve we get 2,760 daily data of relative humidity of July and August, from 2002 and of February, March, April, May and June, from 2003, with which we calculate de following relative humidity data: $\mathrm{AHfeb}=0.70 ; \mathrm{AHmch}=0.75 ; \mathrm{AHapr}=0.79 ; \mathrm{AHmay}=0.78 ; \mathrm{AHjun}=$ 0.76; $\mathrm{AHjul}=0.74$ and AHaug $=0.73$. They are all between 60.00 and $79.90 \%$, which is equivalent to $f=0.8$. We will use this constant in the calculations of $X$ in both periods and the total series.

We calculate $p$ and $b$ of the total series (1941-1956, exc.1946 and 1947, and 1992-2015) and we get the following data:

\begin{tabular}{lcccccc}
\hline Month & $\mathbf{N}$ & $\mathbf{p}$ & $\mathbf{b}$ & $\mathbf{f}$ & $\mathbf{X}_{\mathbf{m}}$ & $\mathbf{X}_{\text {annual }}$ \\
\hline February & 28.25 & 3.74 & 7.05 & 0.8 & 16.79 & \\
March & 31 & 3.56 & 9.81 & 0.8 & 18.03 & \\
April & 30 & 3.76 & 9.71 & 0.8 & 17.11 & \\
May & 31 & 3.71 & 10.25 & 0.8 & 17.74 & \\
June & 30 & 2.46 & 6.56 & 0.8 & 19.41 & \\
July & 31 & 1.53 & 5.48 & 0.8 & 21.38 & \\
August & 31 & 2.43 & 5.91 & 0.8 & 20.49 & $\mathbf{1 3 0 . 9 5}$ \\
\hline
\end{tabular}

$X_{\text {annual }}=130.95$, which means that for a Mediterranean climate, it belongs to the subdivision: Thermomediterranean with a long dry season, as it is between 125 and 150 .

We calculate $\mathrm{p}$ and $\mathrm{b}$ of the 1 st period and we get the following data:

\begin{tabular}{lcccccc}
\hline \multicolumn{1}{c}{ Month } & $\mathbf{N}$ & $\mathbf{p}$ & $\mathbf{b}$ & $\mathbf{f}$ & $\mathbf{X}_{\mathbf{m}}$ & $\mathbf{X}_{\text {annual }}$ \\
\hline 1st dry season & & & & & & \\
\hline January & 31.00 & 1.92 & 0.00 & 0.8 & 23.26 & \\
February & 28.25 & 2.07 & 0.14 & 0.8 & 20.89 & \\
March & 31.00 & 2.31 & 0.08 & 0.8 & 22.92 & \\
April & 30.00 & 1.50 & 0.00 & 0.8 & 22.80 & \\
May & 31.00 & 1.82 & 0.00 & 0.8 & 23.34 & \\
June & 30.00 & 1.91 & 0.00 & 0.8 & 22.47 & \\
July & 31.00 & 1.00 & 0.00 & 0.8 & 24.00 & \\
August & 31.00 & 1.92 & 0.00 & 0.8 & 23.26 & \\
September & 30.00 & 2.64 & 0.00 & 0.8 & 21.89 & 204.84 \\
\hline 2nd dry season & & & & & & \\
\hline November & 30.00 & 2.38 & 0.00 & 0.8 & 22.10 & 22.10 \\
\hline
\end{tabular}


$X_{\text {annual }}=204.84$ (monoxeric) or 226.94 (bixeric). Both mean that for a Group I climate, it belongs to the Attenuated hot sub-desert (it is between 200 and 250). But we don't select November because that would mean that the climate is bixeric which can mean that it is a transition between Tropical and Mediterranean climate. So, there may have been some error in the data collection during November in this period.

We calculate $p$ and $b$ of the 2nd period and we get the following data:

\begin{tabular}{lcccccc}
\hline Month & $\mathbf{N}$ & $\mathbf{p}$ & $\mathbf{b}$ & $\mathbf{f}$ & $\mathbf{X}_{\mathbf{m}}$ & $\mathbf{X}_{\text {annual }}$ \\
\hline February & 28.25 & 4.71 & 11.08 & 0.8 & 14.20 & \\
March & 31 & 4.33 & 15.30 & 0.8 & 15.22 & \\
April & 30 & 4.74 & 13.75 & 0.8 & 14.71 & \\
May & 31 & 4.61 & 15.62 & 0.8 & 14.86 & \\
June & 30 & 2.71 & 9.70 & 0.8 & 17.95 & \\
July & 31 & 1.75 & 8.10 & 0.8 & 20.16 & \\
August & 31 & 2.71 & 9.41 & 0.8 & 18.87 & $\mathbf{1 1 6 . 1 7}$ \\
\hline
\end{tabular}

$X_{\text {annual }}=116.17$, which means that for a Mediterranean climate, it belongs to the subdivision: Thermomediterranean attenuated with a shorter dry season, as it is between 100 and 125 .

So, according to the UNESCO-FAO bioclimatic classification the Columbretes islands have a thermomediterranean climate attenuated with a shorter dry season (2nd period) or with a long dry season (total series), and, as it belongs to Group I (for the total series and also for the two periods), the dry season lasts the greater part of the year. Although during the 1st period the climate was attenuated hot sub-desert. 
Annexos

ANNEX 1.3.

Köppen-Geiger climate classification (Koteck, 2006) of the Columbretes Islands for the total series, first and second periods analyzed 
The five vegetation groups of Köppen distinguish between plants of the equatorial zone (A), the arid zone (B), the warm temperate zone (C), the snow zone (D) and the polar zone (E). A second letter in the classification considers the precipitation (e.g. Df for snow and fully humid), a third letter the air temperature (e.g. Dfc for snow, fully humid with cool summer) (Koteck, 2006).

$\mathrm{T}_{\text {mon }}$ denotes the mean monthly temperature in ${ }^{\circ} \mathrm{C}$.

$\mathrm{T}_{\mathrm{ann}}=$ annual mean near-surface $(2 \mathrm{~m})$ temperature.

$\mathrm{T}_{\max }$ and $\mathrm{T}_{\min }=$ monthly mean temperatures of the warmest and coldest months, respectively.

$P_{a n n}=$ accumulated annual precipitation ( $\mathrm{mm} /$ year)

$P_{\min }=$ precipitation of the driest month ( $\mathrm{mm} /$ month)

$\mathrm{P}_{\text {smin }}, \mathrm{P}_{\text {smax }}, \mathrm{P}_{\mathrm{wmin}}$ and $\mathrm{P}_{\mathrm{wmax}}$ are defined as the lowest and highest monthly precipitation values for the summer and winter ( $\mathrm{mm} / \mathrm{month})$

$P_{\text {th }}=$ dryness threshold $(\mathrm{mm})$

All temperatures are given in ${ }^{\circ} \mathrm{C}$.

Total series:

$\mathrm{T}_{\min }=$ the monthly mean temperatures of the coldest months $(\mathrm{n}=52$ years $)=8.64^{\circ} \mathrm{C}$; $\operatorname{Tmin}<18^{\circ} \mathrm{C}$ : it is not Equatorial climates (A).

- $P_{\text {th }}=2 \times T_{\text {ann }}$ if at least $2 / 3$ of the annual precipitation occurs in winter,

- $P_{\mathrm{th}}=\left(2 \times \mathrm{T}_{\mathrm{ann}}\right)+28$ if at least $2 / 3$ of the annual precipitation occurs in summer,

- $P_{\mathrm{th}}=\left(2 \times \mathrm{T}_{\mathrm{ann}}\right)+14$ otherwise.

According to the ombrothermic diagrams (Figure 11) and according to the original data in this thesis, it is Hot Arid Steppe Climate (BSh):

\begin{tabular}{ccccccc}
\hline Source of data & $\mathbf{P}_{\mathrm{ann}}$ & $\mathbf{T}_{\mathrm{ann}}$ & $\begin{array}{c}\text { \% of annual } \\
\text { precipitation } \\
\text { in winter }\end{array}$ & $\begin{array}{c}\text { \% of annual } \\
\text { precipitation in } \\
\text { summer }\end{array}$ & Criteria & Pth \\
\hline $\begin{array}{c}\text { Ombrothermic } \\
\text { diagrams }\end{array}$ & 344.19 & 18.00 & 0.23 & 0.12 & $<0.67$ & $\begin{array}{c}\left(2 \times T_{\text {ann }}\right)+ \\
14\end{array}$ \\
$\begin{array}{c}\text { Original data in } \\
\text { this study }\end{array}$ & 337.89 & 18.00 & 0.25 & 0.12 & & \\
\hline
\end{tabular}

\begin{tabular}{ccc}
\hline $\mathbf{P}_{\text {th }}$ & Criteria & Climates \\
\hline \multirow{2}{*}{50.01} & $\mathrm{P}_{\text {ann }}<10^{*} P_{\text {th }}$ & B. Arid climates \\
& $P_{\text {ann }}>5^{*} P_{\text {th }}$ & BS. Steppe climate \\
& $T_{\text {ann }} \geq 188^{\circ} \mathrm{C}$ & BSh. Hot Steppe \\
\hline
\end{tabular}


1st period:

$\mathrm{T}_{\min }=$ the monthly mean temperatures of the coldest months $(\mathrm{n}=18$ years $)=7.25^{\circ} \mathrm{C}$;

$\operatorname{Tmin}<18^{\circ} \mathrm{C}$ : it is not Equatorial climates (A).

According to the ombrothermic diagrams (Figure 9), it is Cold Arid Steppe Climate (BSk):

\begin{tabular}{|c|c|c|c|c|c|c|}
\hline Source of data & $P_{\text {ann }}$ & $\mathbf{T}_{\mathrm{ann}}$ & $\begin{array}{c}\% \text { of annual } \\
\text { precipitation in } \\
\text { winter }\end{array}$ & $\begin{array}{c}\% \text { of annual } \\
\text { precipitation in } \\
\text { summer }\end{array}$ & Criteria & $\mathbf{P}_{\text {th }}$ \\
\hline $\begin{array}{c}\text { Ombrothermic } \\
\text { diagrams }\end{array}$ & 269.90 & 17.57 & 0.24 & 0.13 & & \\
\hline \multirow[t]{3}{*}{$\begin{array}{l}\text { Original data in } \\
\text { this study }\end{array}$} & 234.89 & 17.57 & 0.26 & 0.13 & $<0.67$ & $\left(2 \times T_{a n n}\right)+14$ \\
\hline & & $P_{\text {th }}$ & Criteria & Climates & & \\
\hline & & 49.14 & 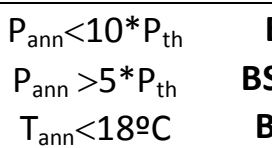 & $\begin{array}{l}\text { B. Arid climates } \\
\text { 3S. Steppe climate } \\
\text { BSk. Cold Steppe }\end{array}$ & & \\
\hline
\end{tabular}

2nd period:

$T_{\min }=$ the monthly mean temperatures of the coldest months $(n=24$ years $)=9.78^{\circ} \mathrm{C}$;

$\operatorname{Tmin}<18^{\circ} \mathrm{C}$ : it is not Equatorial climates (A).

According to the ombrothermic diagrams (Figure 10), it is Hot Arid Steppe Climate (BSh):

\begin{tabular}{ccccccc}
\hline Source of data & $\mathbf{P}_{\mathrm{ann}}$ & $\mathbf{T}_{\mathrm{ann}}$ & $\begin{array}{c}\text { \% of annual } \\
\text { precipitation in } \\
\text { winter }\end{array}$ & $\begin{array}{c}\text { \% of annual } \\
\text { precipitation in } \\
\text { summer }\end{array}$ & Criteria & $\mathbf{P}_{\mathrm{th}}$ \\
\hline $\begin{array}{c}\text { Ombrothermic } \\
\text { diagrams }\end{array}$ & 409.03 & 18.41 & 0.24 & 0.11 & & \\
$\begin{array}{c}\text { Original data in } \\
\text { this study }\end{array}$ & 407.52 & 18.41 & 0.25 & 0.12 & $<0.67$ & $\left(2 \times \mathrm{T}_{\mathrm{ann}}\right)+14$ \\
\hline
\end{tabular}

\begin{tabular}{ccc}
\hline $\mathbf{P}_{\text {th }}$ & Criteria & Climates \\
\hline \multirow{2}{*}{50.82} & $\mathrm{P}_{\mathrm{ann}}<10^{*} \mathrm{P}_{\text {th }}$ & B. Arid climates \\
& $\mathrm{P}_{\mathrm{ann}}>5^{*} \mathrm{P}_{\text {th }}$ & BS. Steppe climate \\
& $\mathrm{T}_{\mathrm{ann}} \geq 18 \mathrm{o}^{\mathrm{C}} \mathrm{C}$ & BSh. Hot Steppe \\
\hline
\end{tabular}

So, according to the Köppen-Geiger climate classification the Columbretes islands have a Hot Arid Steppe Climate (BSh) for the total series and for the 2nd period; although it was Cold Arid Steppe Climate (BSk) during the 1st period. 
Annexos

ANNEX 1.4.

Köppen-Trewartha climate classification (Belda, 2014) of the Columbretes Islands for the total series, first and second periods analyzed 
The advantage of the Köppen-Trewartha climate classification front Köppen-Geiger climate classification is a more detailed depiction of climate types (Belda, 2014). This classification has also been proven suitable for the creation of maps of Global Ecological Zones for the Forest Resources Assessment Programme of the United Nations Food and Agriculture Organization, FAO (Belda, 2014).

Characteristics and components of the FAO Global Ecological Zoning classification include the use of the Köppen-Trewartha system (1968), with some modifications, in combination with vegetation characteristics as a basis for the delineation of zones (Simons, 2001).

T denotes the mean annual temperature $\left({ }^{\circ} \mathrm{C}\right)$

$\mathrm{T}_{\text {mon }}=$ mean monthly temperature $\left({ }^{\circ} \mathrm{C}\right.$.)

$T_{\max }$ and $T_{\min }=$ monthly mean temperatures of the warmest and coldest months, respectively $\left({ }^{\circ} \mathrm{C}\right)$

$\mathrm{P}_{\text {mean }}=$ accumulated annual precipitation ( $\mathrm{cm} /$ year)

$\mathrm{P}_{\mathrm{w}}=$ percentage of annual precipitation occurring in winter

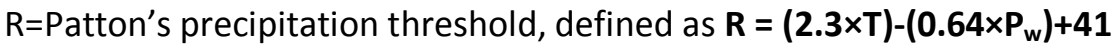

\begin{tabular}{ll}
\hline $\mathrm{B}$ & $\mathrm{P}_{\text {mean }}<\mathrm{R}$ \\
$\mathrm{BS}$ & $(\mathrm{R} / 2)<\mathrm{P}_{\text {mean }}<\mathrm{R}$ \\
$\mathrm{BW}$ & $\mathrm{P}_{\text {mean }}<(\mathrm{R} / 2)$ \\
\hline
\end{tabular}

According to the ombrothermic diagrams (see Figures 9, 10 and 11):

\begin{tabular}{cccccccc}
\hline & $\mathbf{T}\left({ }^{\circ} \mathbf{C}\right)$ & $\mathbf{2}^{\prime} \mathbf{3} \times \mathbf{T}$ & $\mathbf{P}_{\mathbf{w}}(\mathbf{\%})$ & $\mathbf{0}^{\prime} \mathbf{6 4 \times P _ { \mathbf { w } }}$ & $\mathbf{R}$ & $\mathbf{R} / \mathbf{2}$ & $\mathbf{P}_{\text {mean }}(\mathbf{c m})$ \\
\hline Total series & 18,00 & 41,40 & 23,17 & 14,83 & 67,57 & 33,79 & 34,42 \\
1st period & 17,57 & 40,41 & 24,38 & 15,60 & 65,81 & 32,90 & 26,99 \\
2nd period & 18,41 & 42,34 & 23,75 & 15,20 & 68,14 & 34,07 & 40,90 \\
\hline
\end{tabular}

According to the data calculated in this study:

\begin{tabular}{cccccccc}
\hline & $\mathbf{T}(\mathbf{O} \mathbf{C})$ & $\mathbf{2 . 3 \times T}$ & $\mathbf{P}_{\mathbf{w}} \mathbf{( \% )}$ & $\mathbf{0 . 6 4 \times \mathbf { P } _ { \mathbf { w } }}$ & $\mathbf{R}$ & $\mathbf{R} / \mathbf{2}$ & $\mathbf{P}_{\text {mean }}(\mathbf{c m})$ \\
\hline Total series & 18.00 & 41.40 & 25.45 & 16.29 & 66.11 & 33.06 & 33.79 \\
1st period & 17.57 & 40.41 & 26.18 & 16.76 & 64.66 & 32.33 & 23.49 \\
2nd period & 18.41 & 42.34 & 24.64 & 15.77 & 67.57 & 33.79 & 40.75 \\
\hline
\end{tabular}

$\mathrm{P}_{\text {mean }}<\mathrm{R}$ in the three cases, so, we are in group $\mathrm{B}$ : dry climates.

But, for the second letter, it depends on the period: for the first one it is $P_{\text {mean }}<R / 2$ : $B W$; and for the second one and the total series we get BS.

So, according to the Köppen-Trewartha climate classification, the Columbretes islands have Semi-arid or Steppe Climate (BS), but in the first period it was Arid (also Desert) Climate (BW). 
Annexos

\section{ANNEX 1.5.}

Regression lines of the total series (1891-2015 for Temperature, T; 1919-2015 for Precipitation, $P)$, the first period (1940-1957 for T; 1940-1956 for P) and the second period (1992-2015) for each of the parameters in Columbretes ( $\mathrm{T}=$ temperature; $\mathrm{P}=$ precipitation) 
Monthly absolute maximum $\mathrm{T}$, total series:

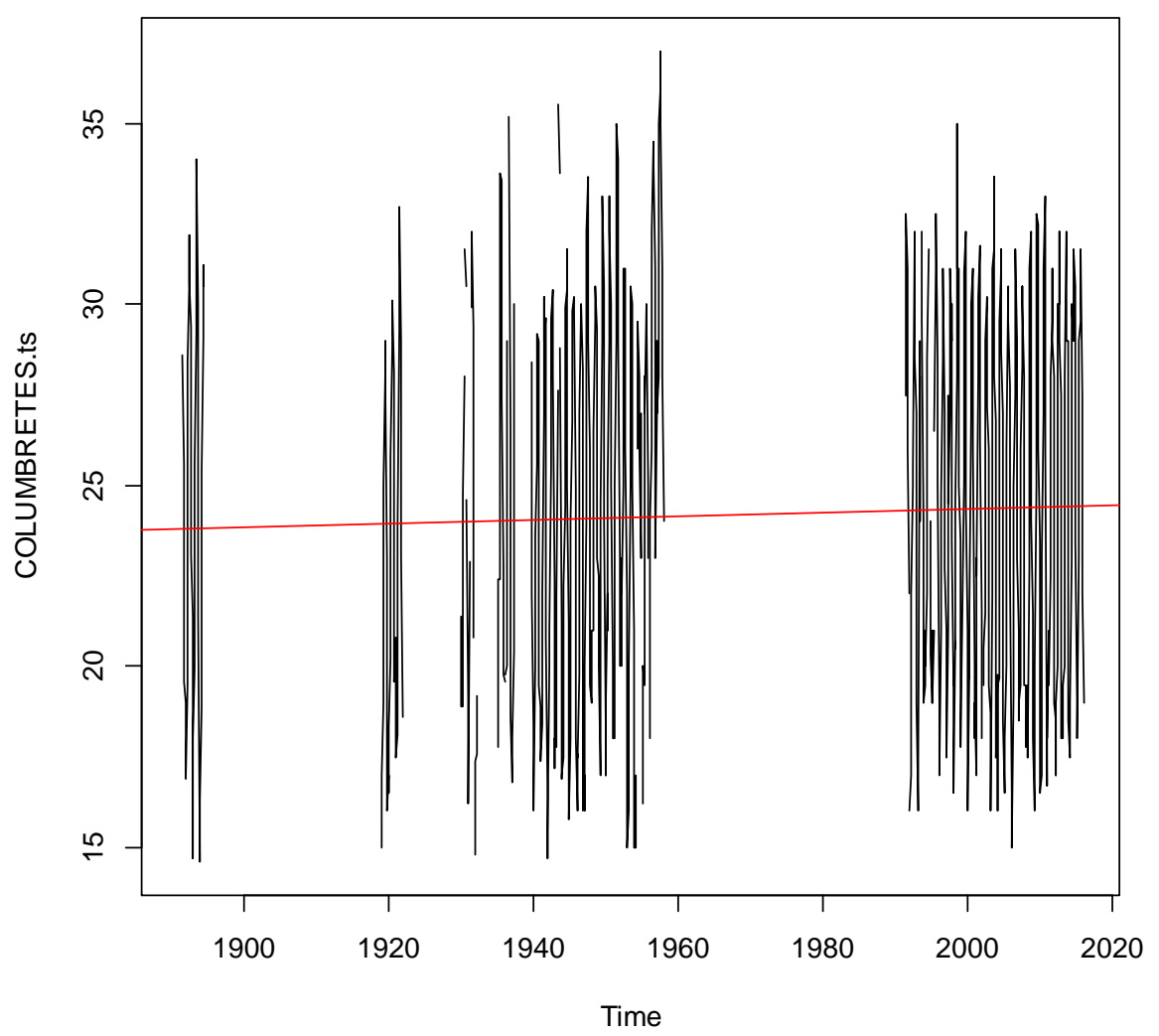

Monthly absolute maximum $\mathrm{T}$, first period:

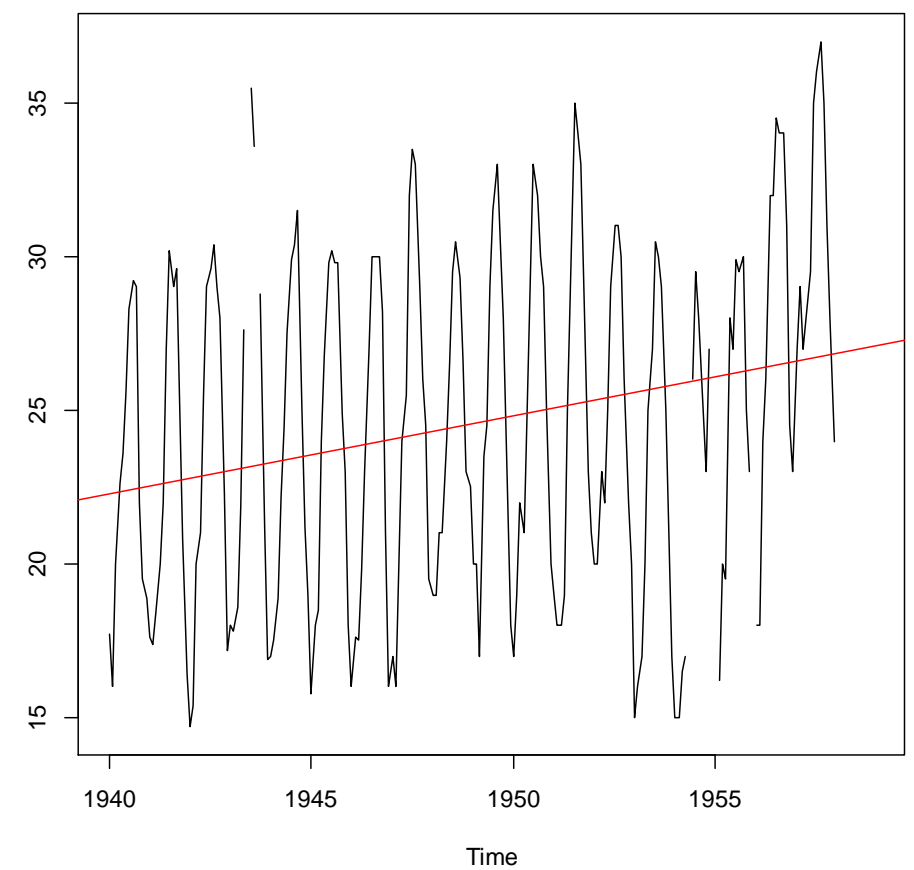


Annexos

Monthly absolute maximum $\mathrm{T}$, second period:

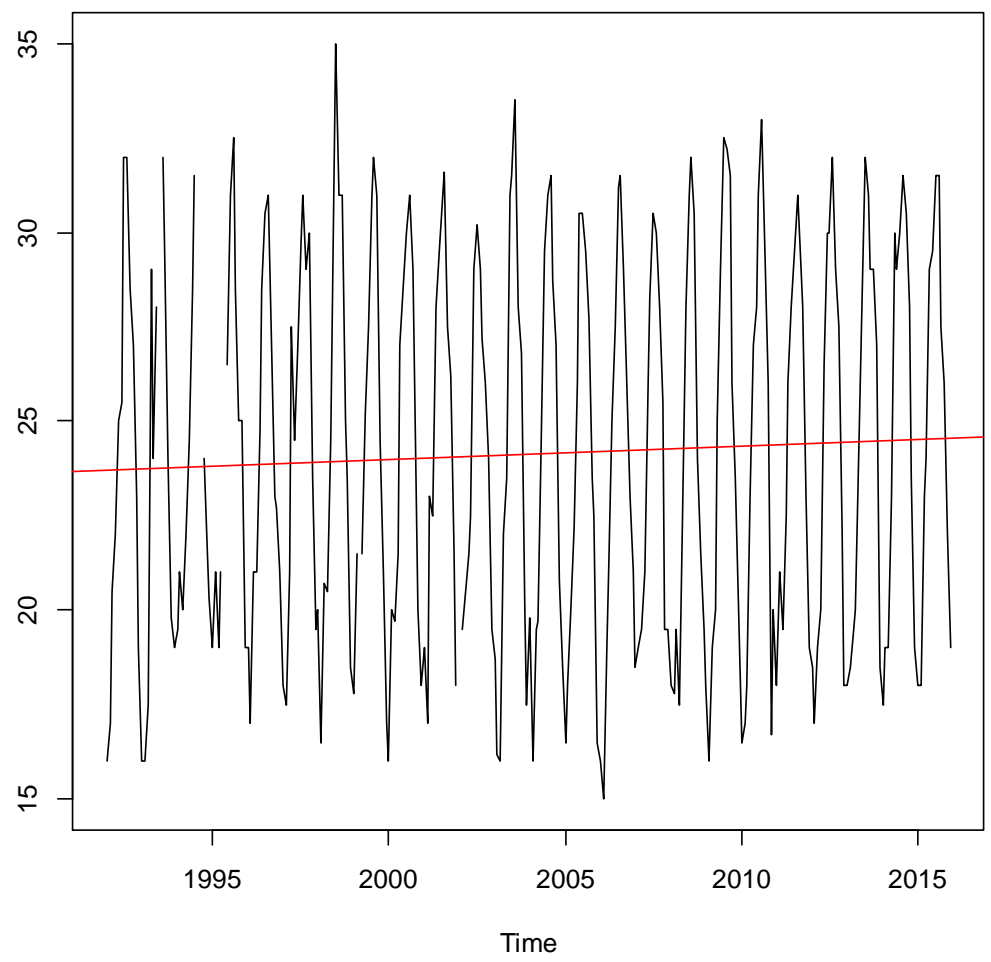

Monthly mean maximum $\mathrm{T}$, total series:

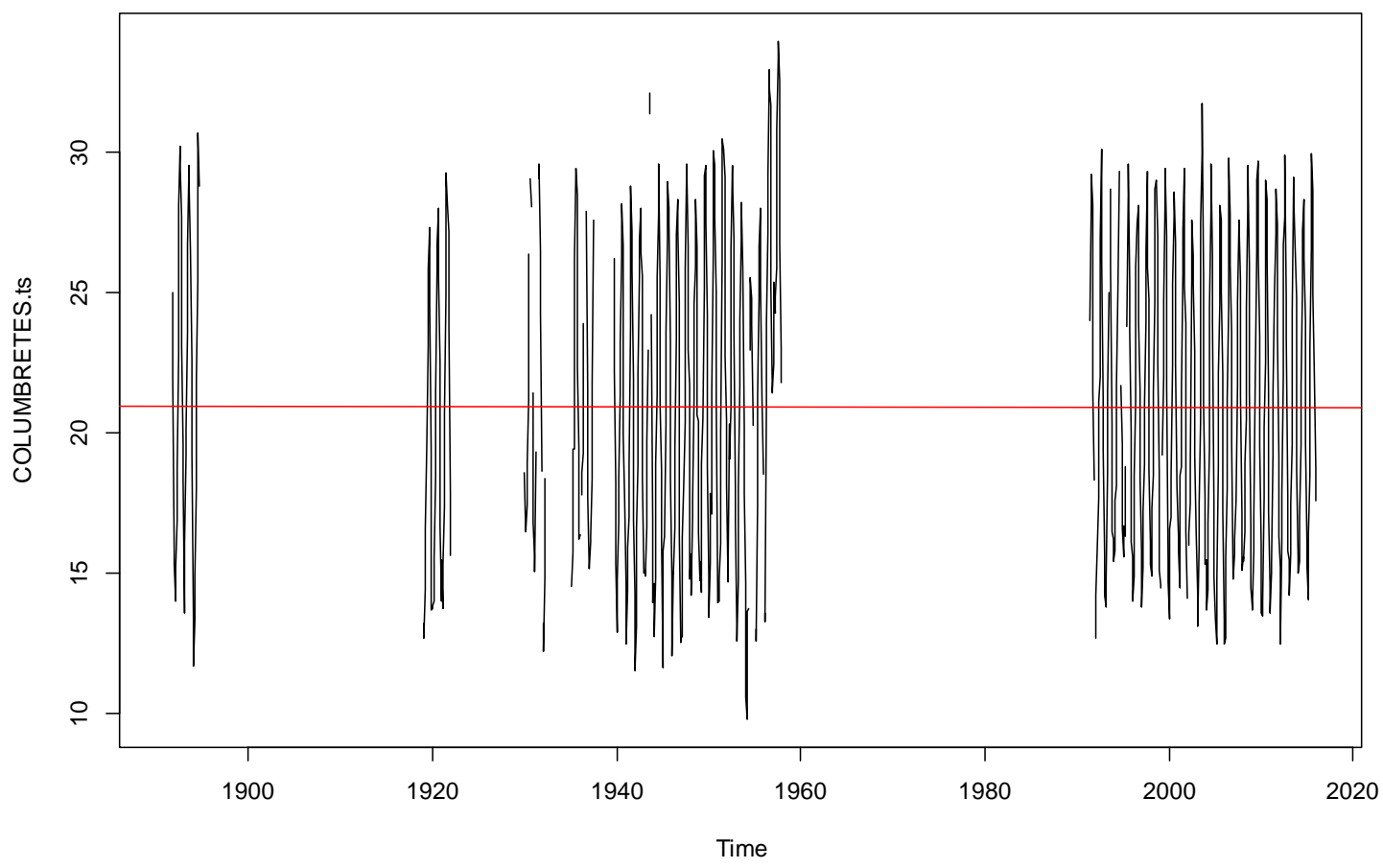


Monthly mean maximum $\mathrm{T}$, first period:

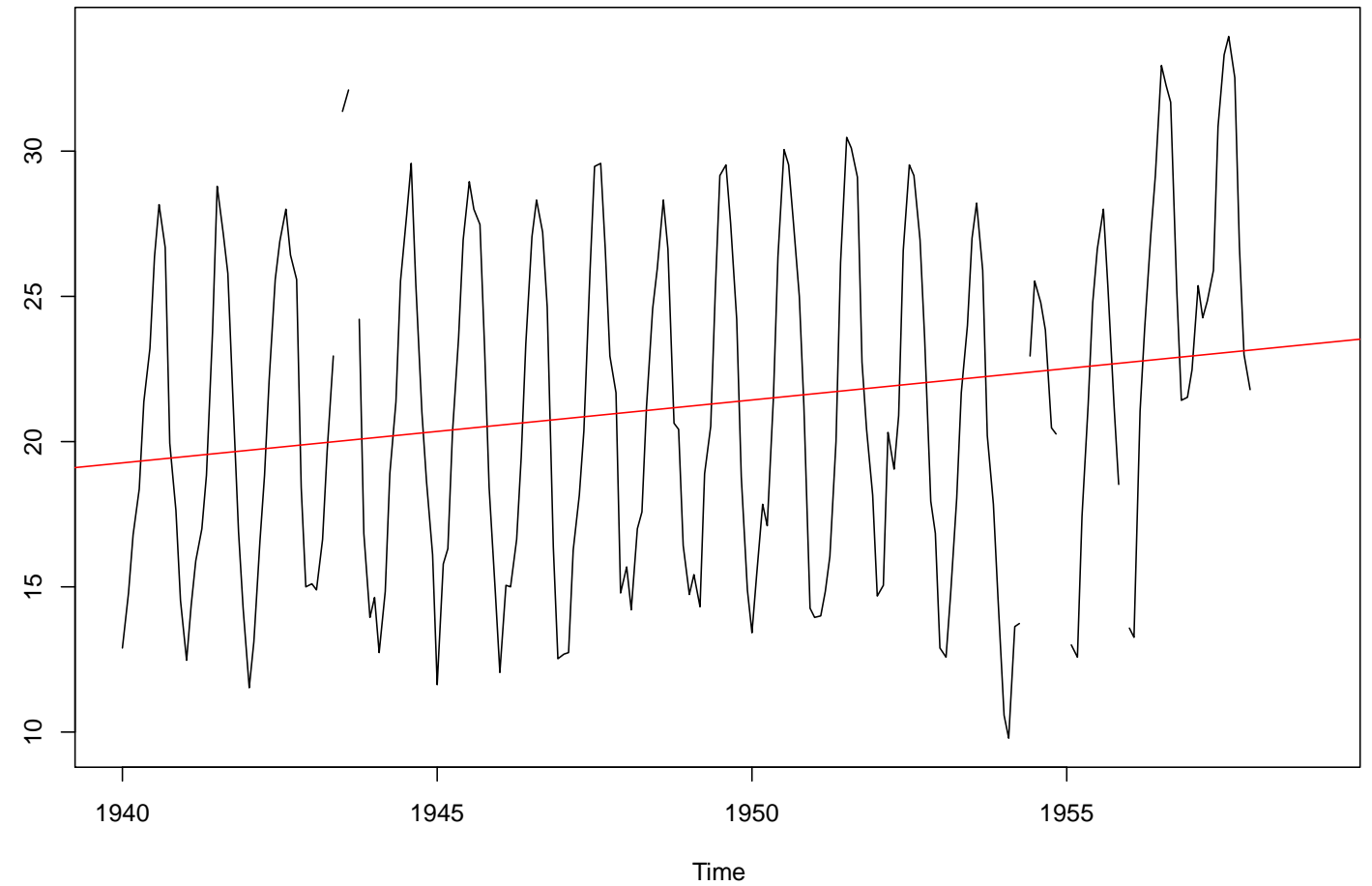

Monthly mean maximum $\mathrm{T}$, second period:

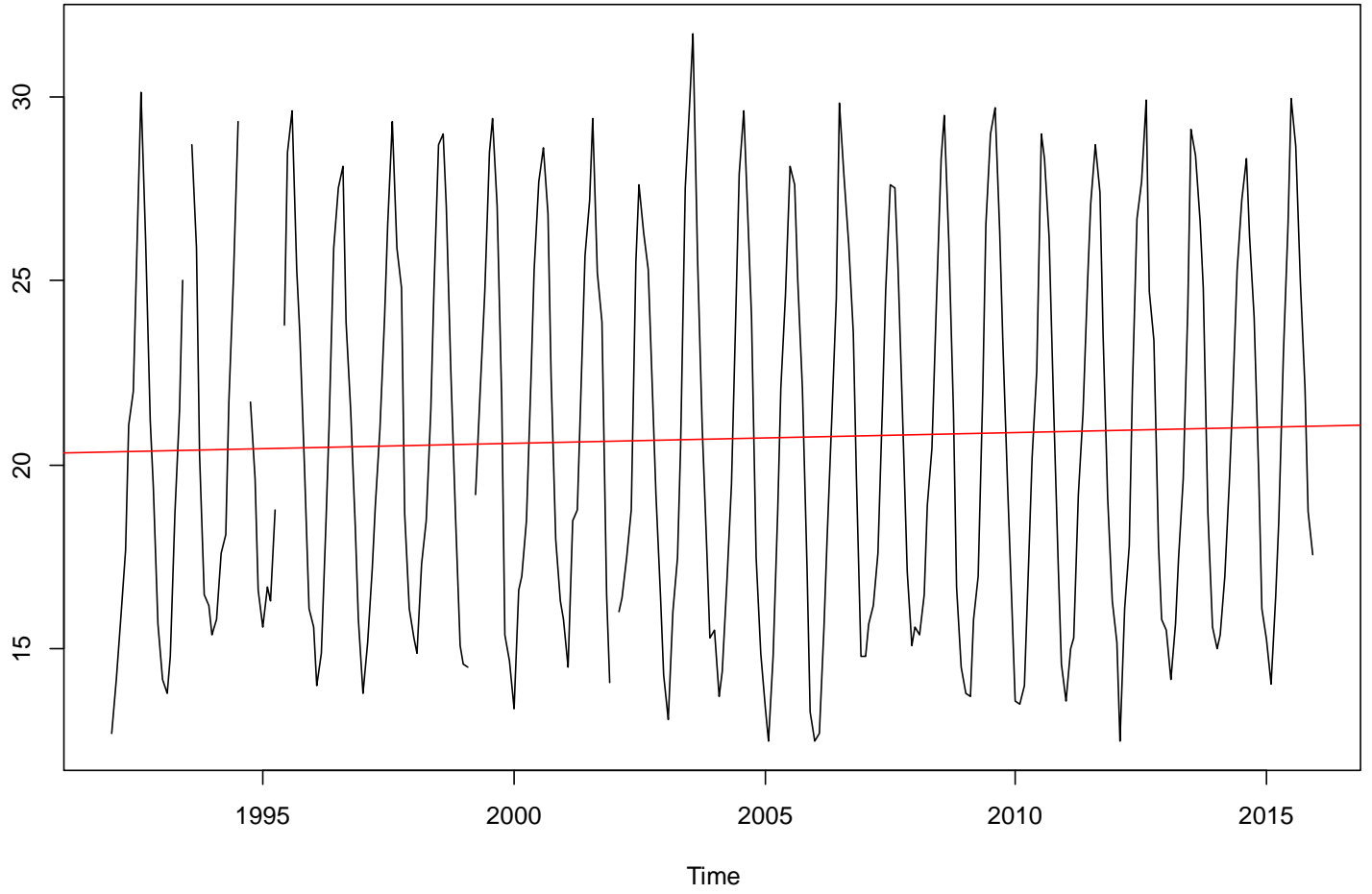


Annexos

Monthly absolute minimum $\mathrm{T}$, total series:

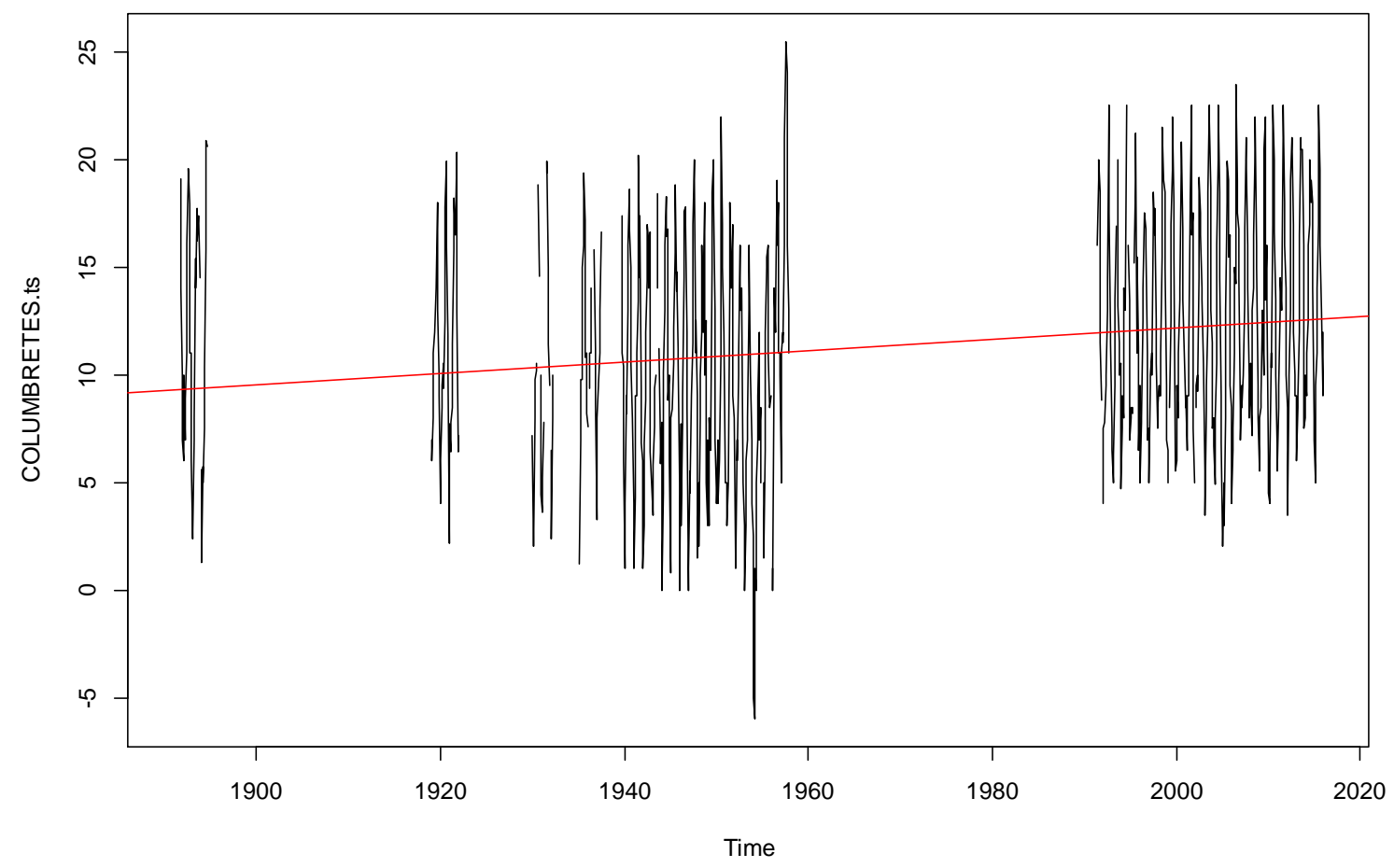

Monthly absolute minimum $\mathrm{T}$, first period:

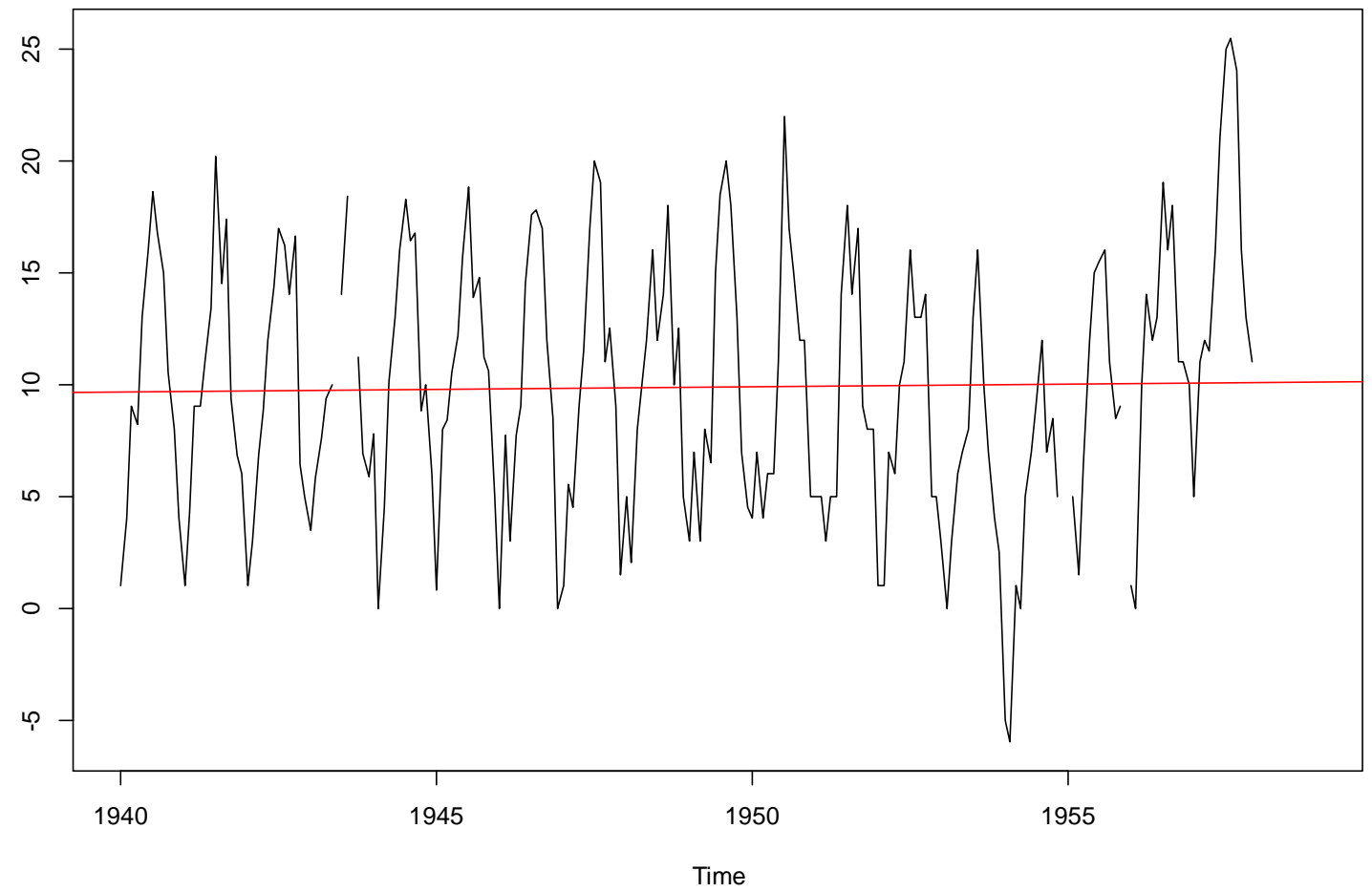


Monthly absolute minimum $\mathrm{T}$, second period:

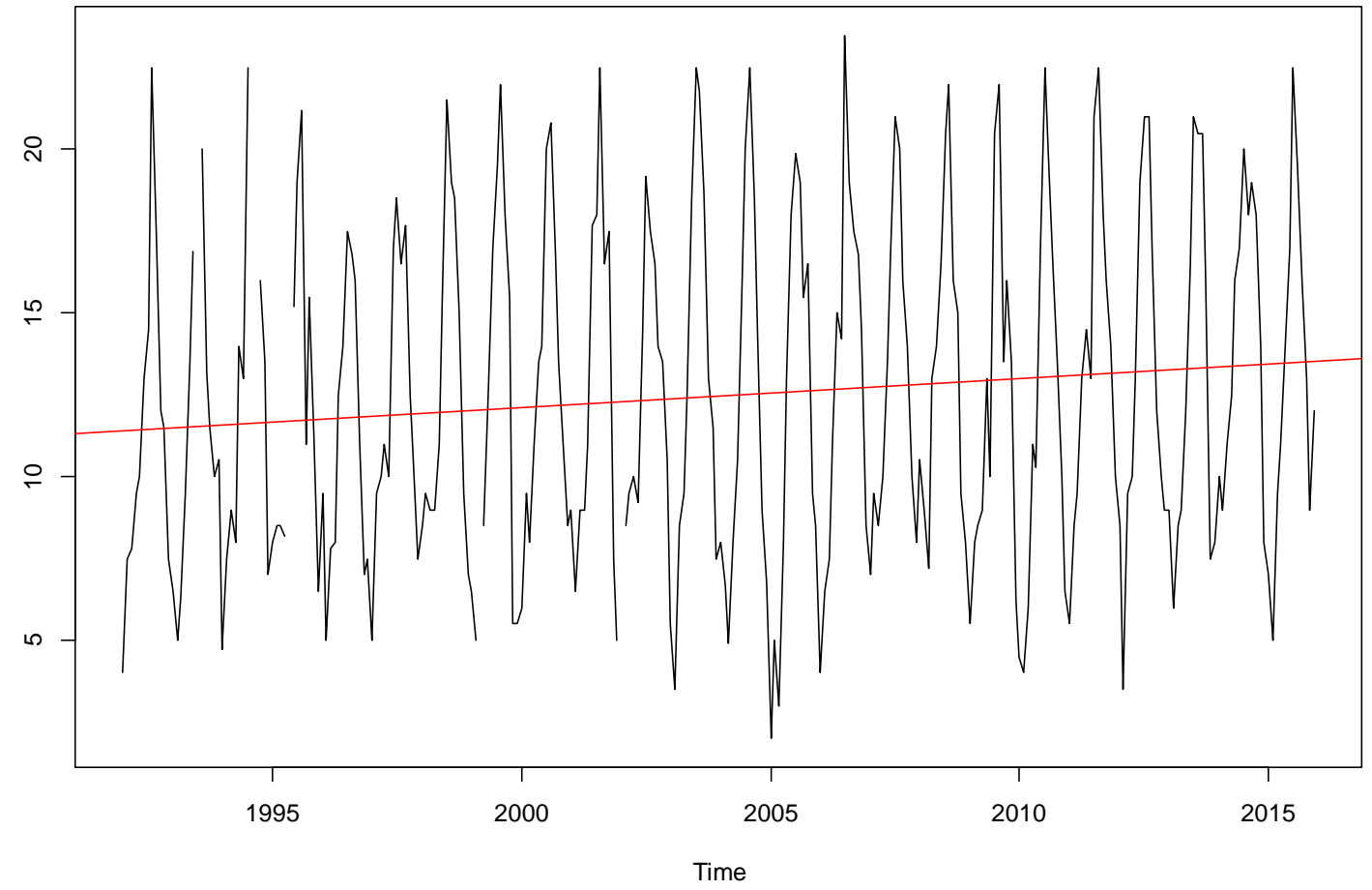

Monthly mean minimum $\mathrm{T}$, total series:

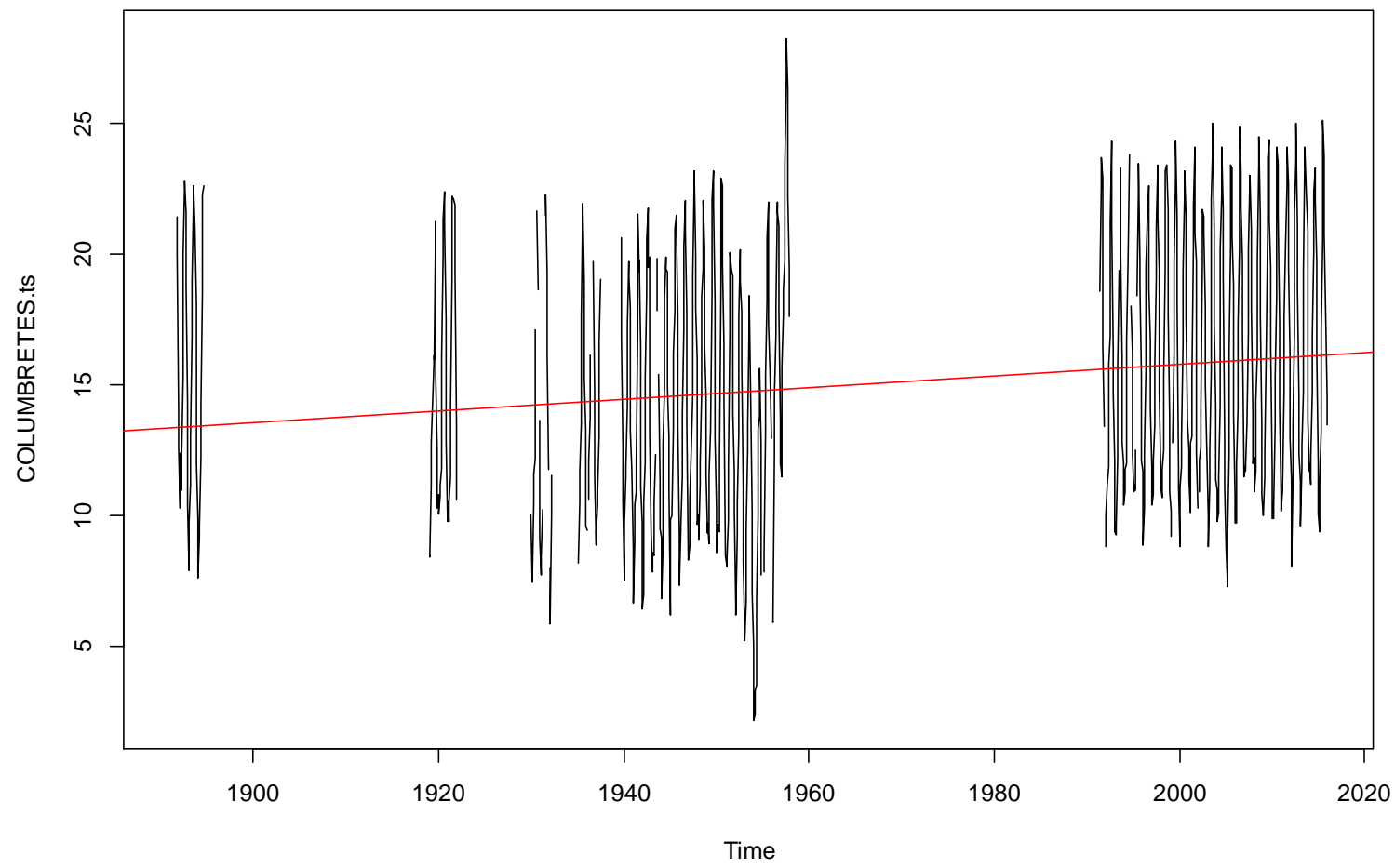


Annexos

Monthly mean minimum $\mathrm{T}$, first period:

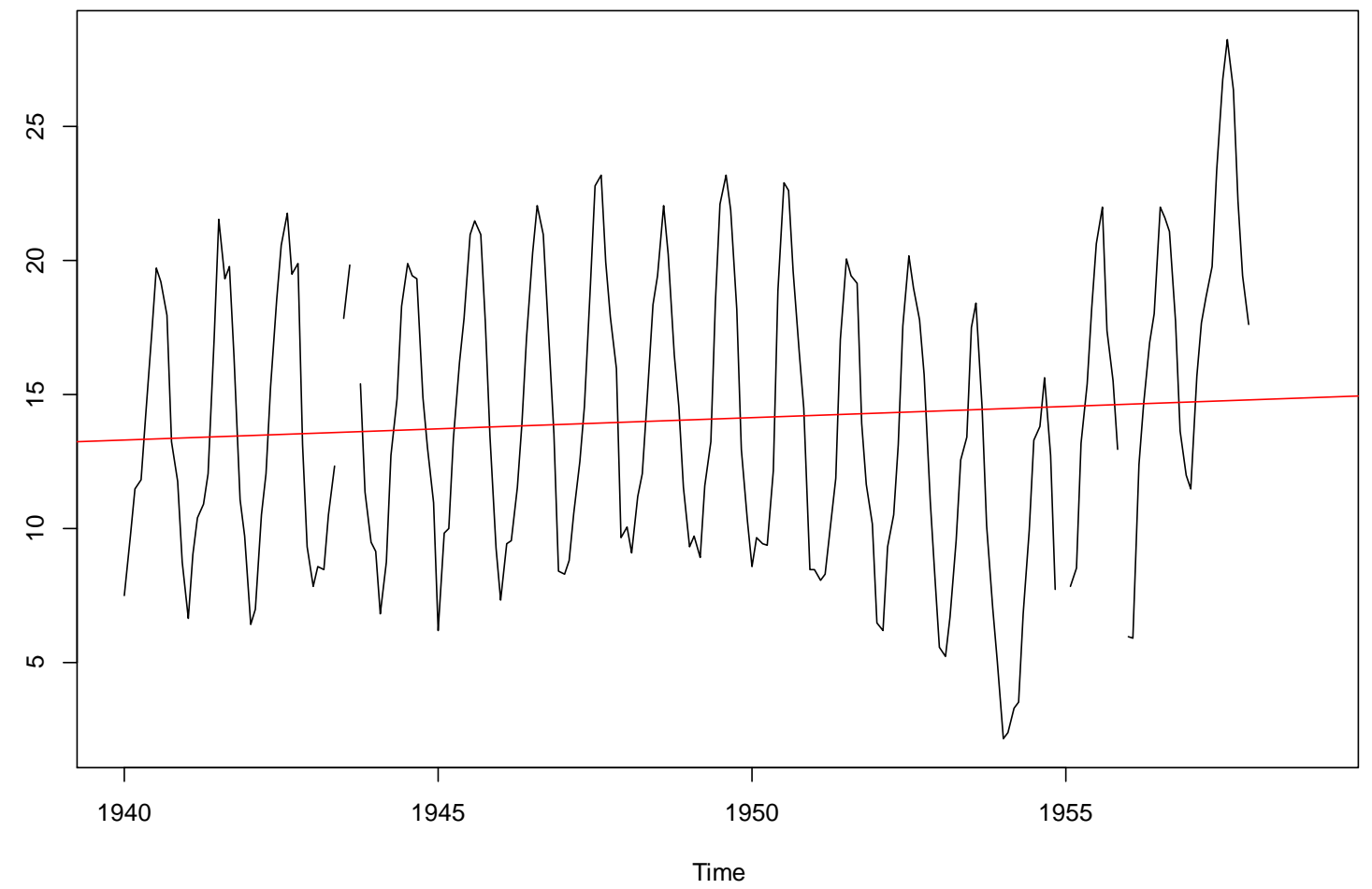

Monthly mean minimum $\mathrm{T}$, second period:

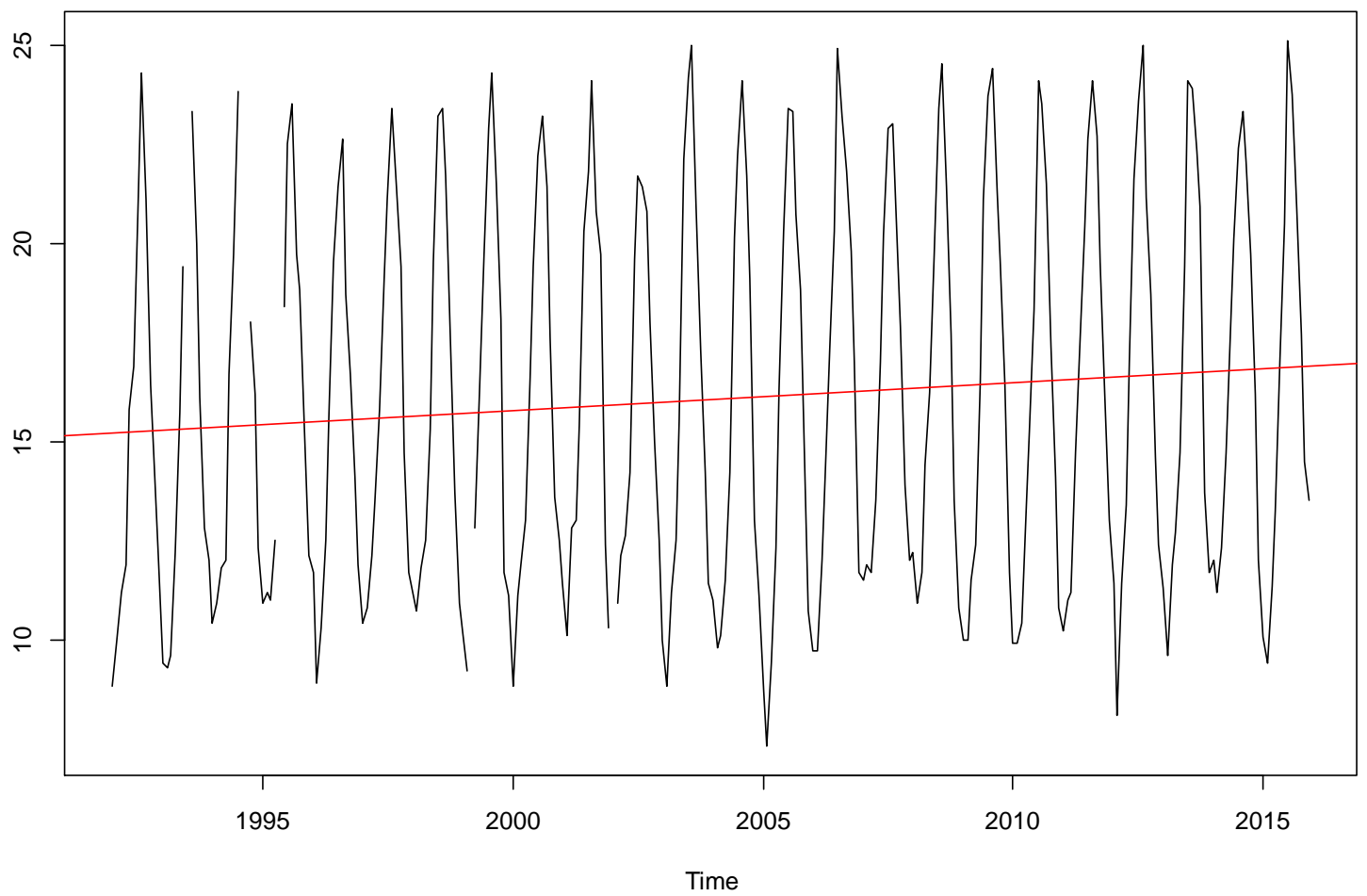


Monthly mean $\mathrm{T}$, total series:

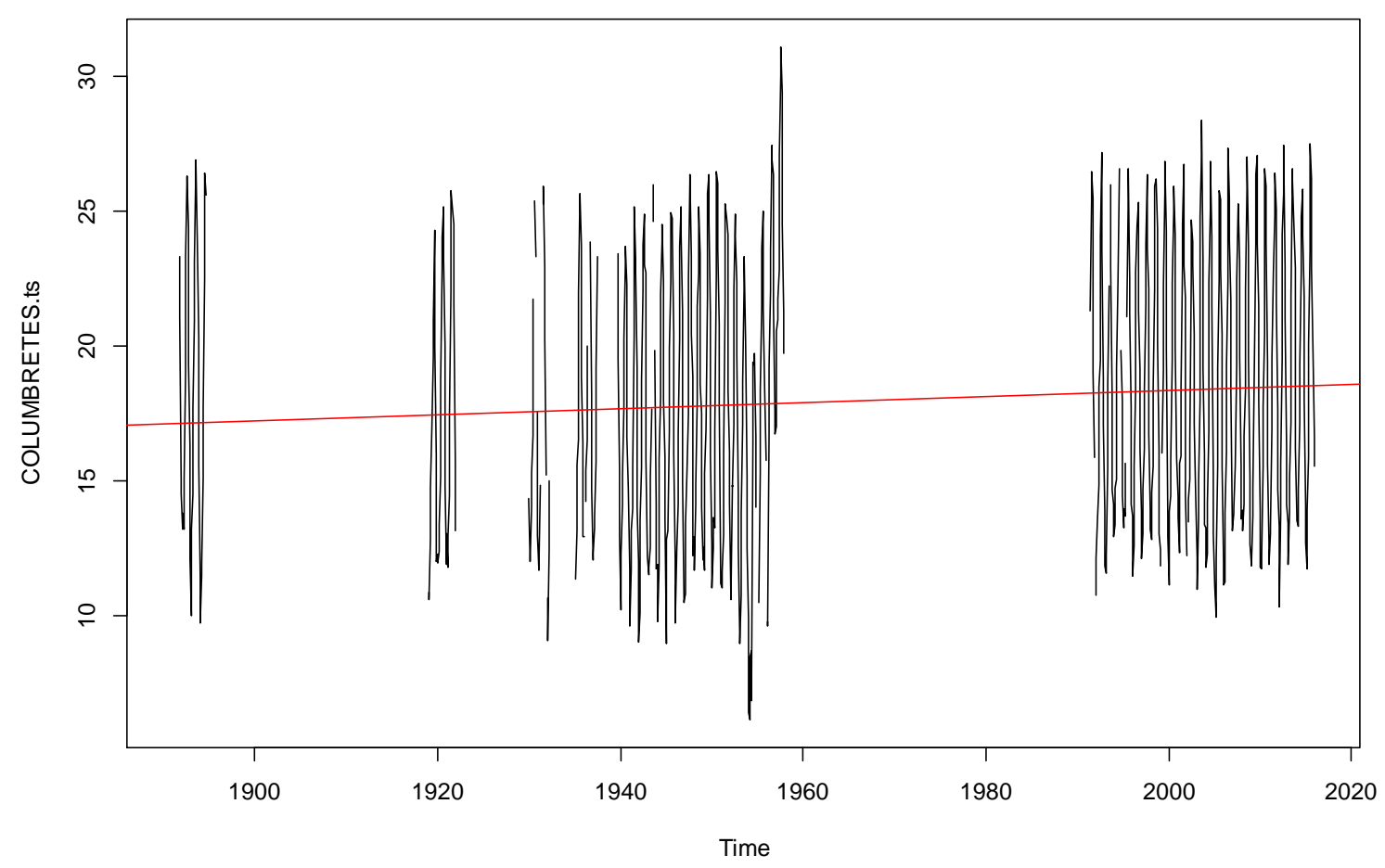

Monthly mean T, first period:

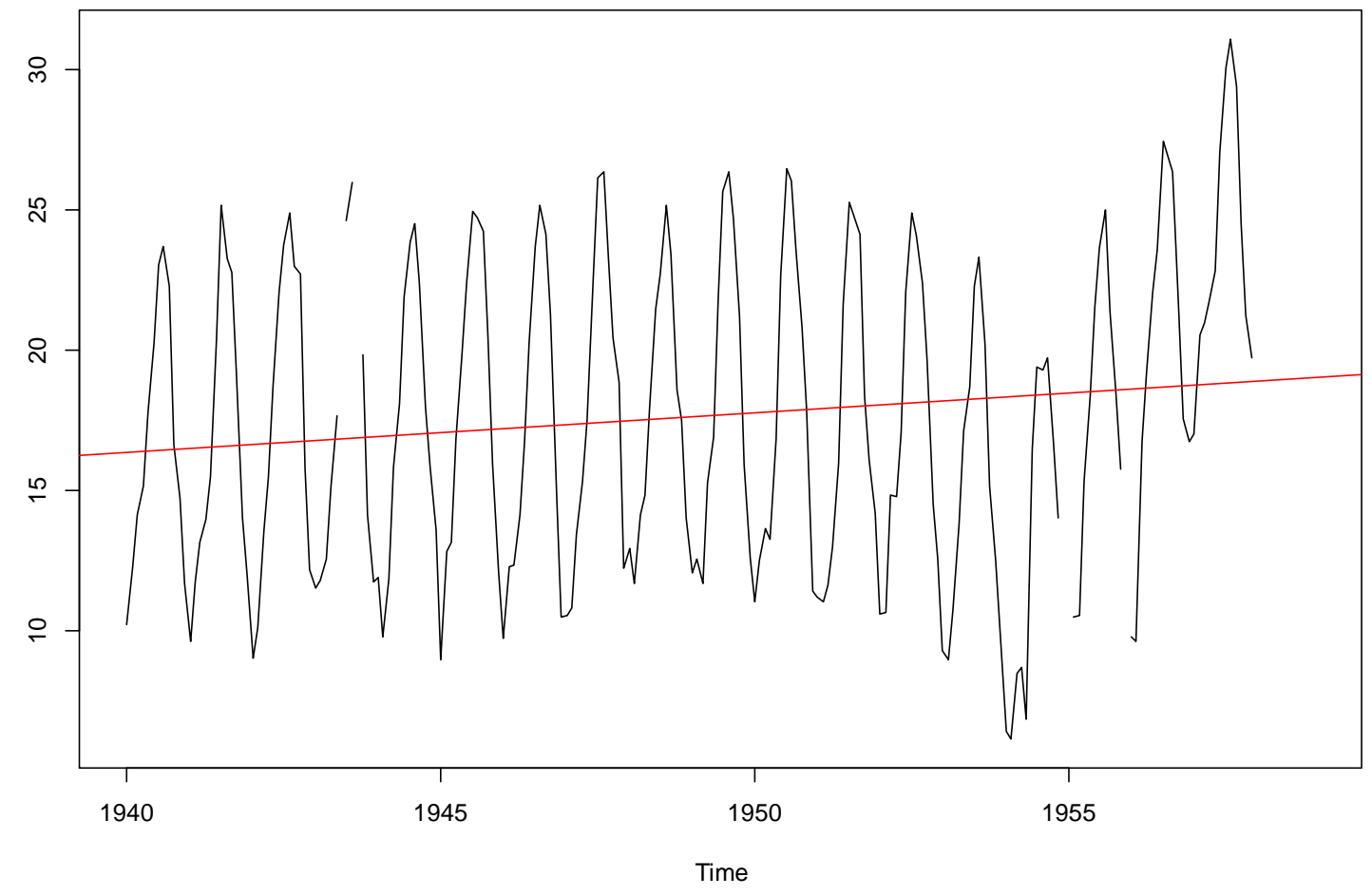


Annexos

Monthly mean $\mathrm{T}$, second period:

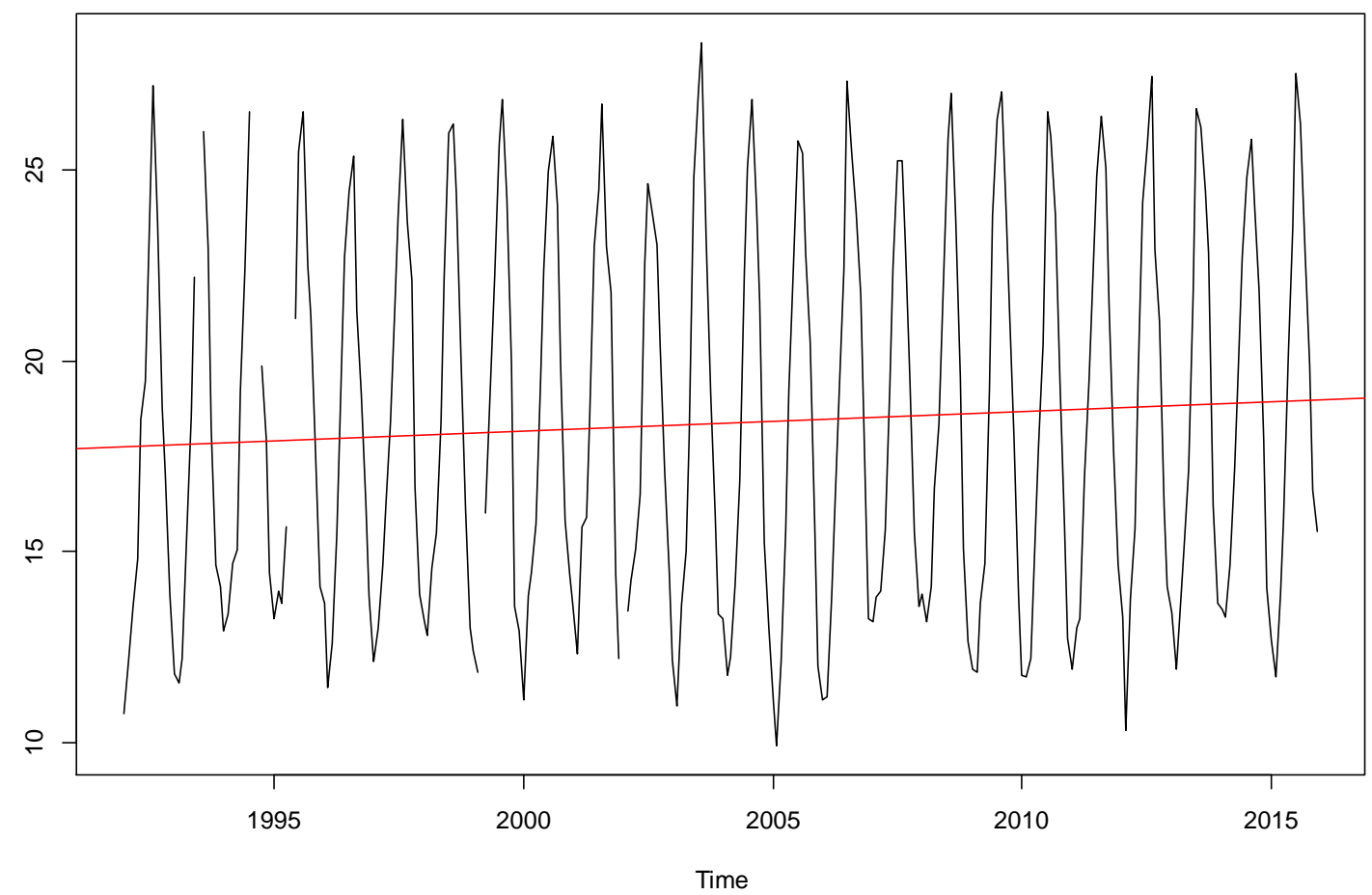

Number of days of rain, total series:

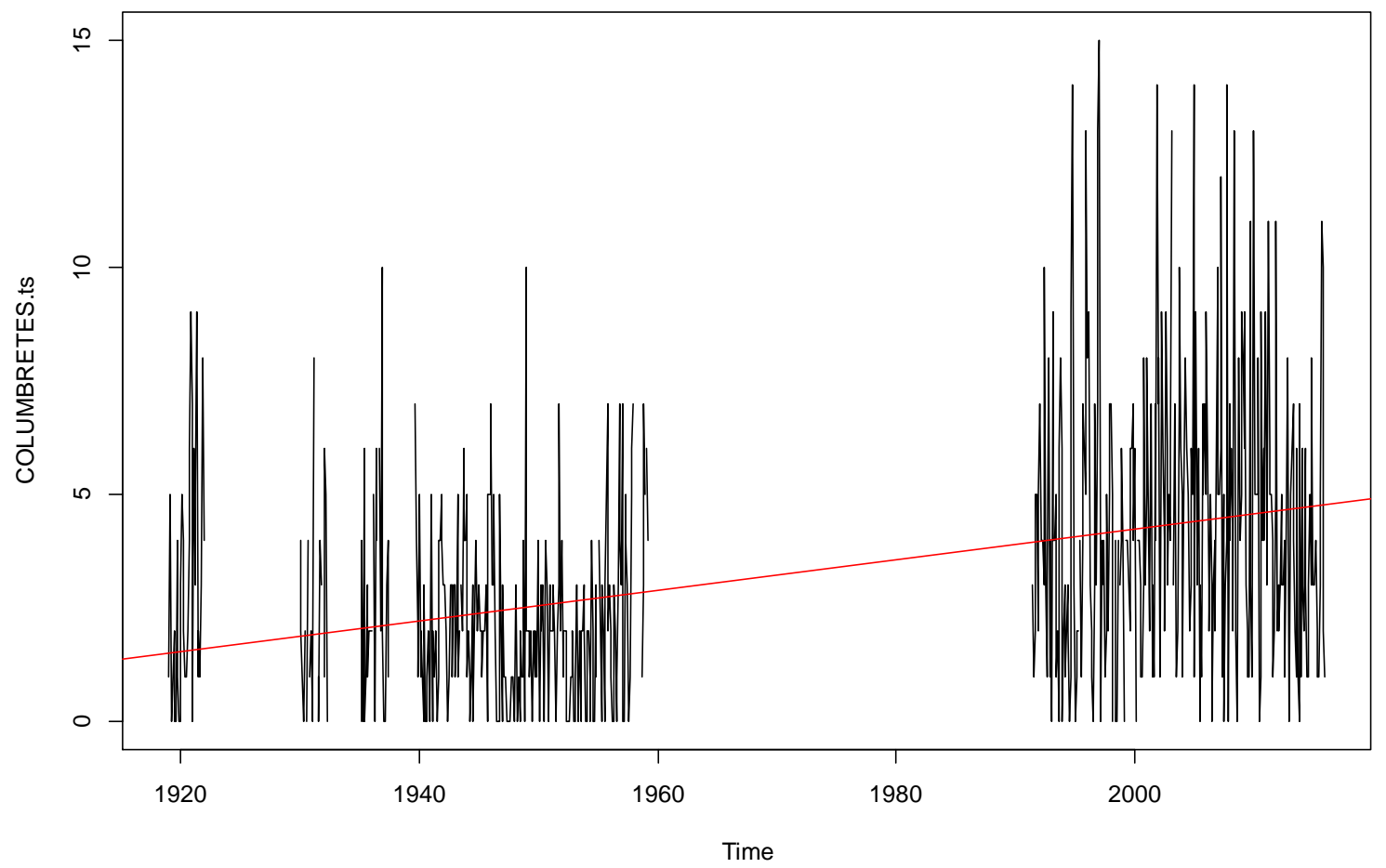


Number of days of rain, first period:

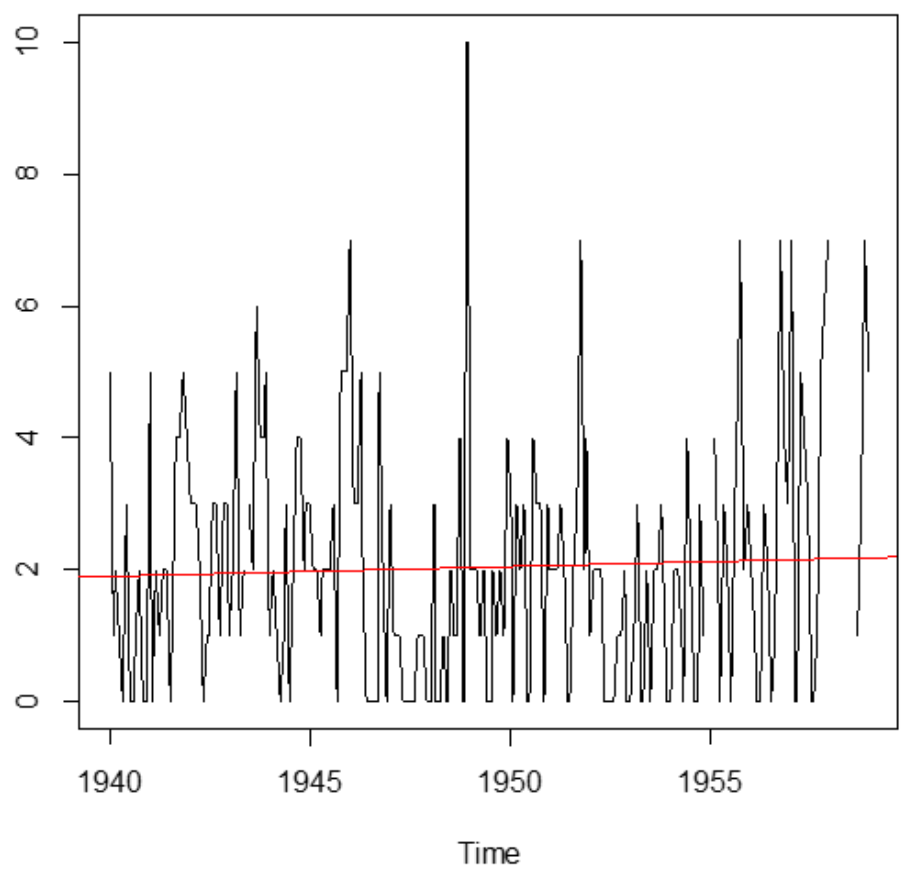

Number of days of rain, second period:

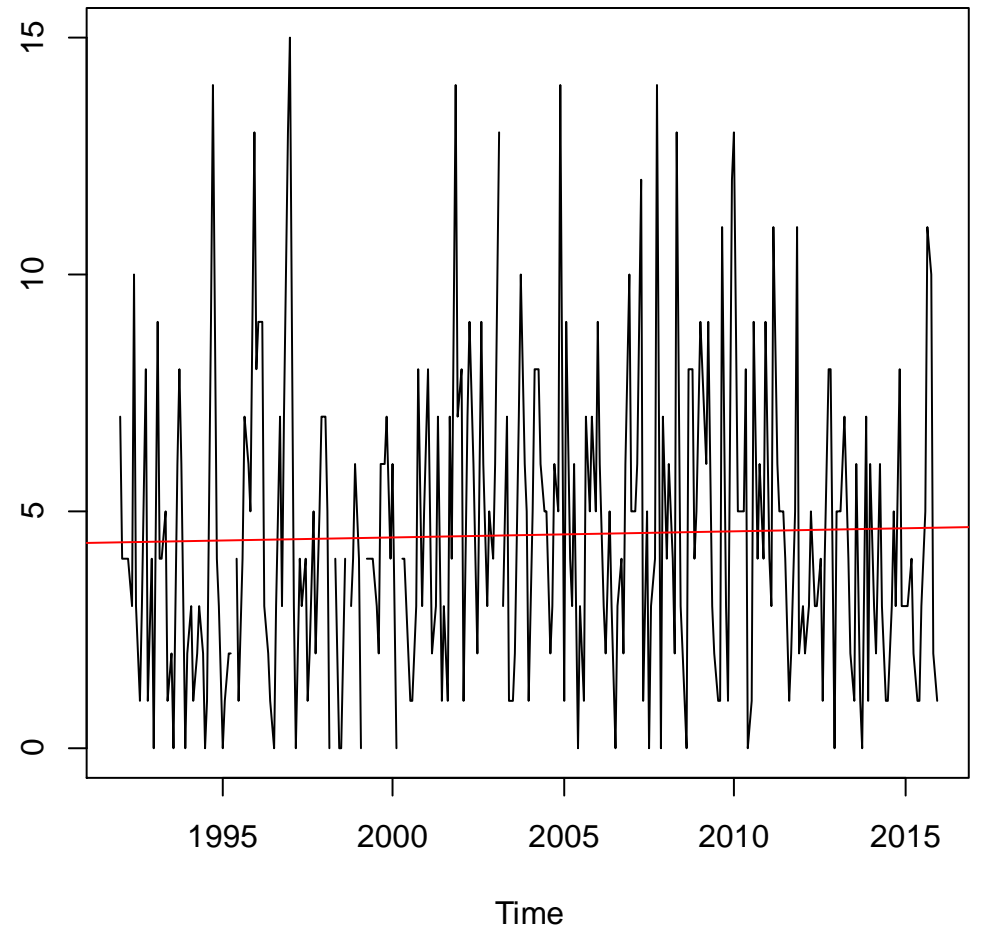


Annexos

Monthly mean accumulated $\mathrm{P}$, total series:

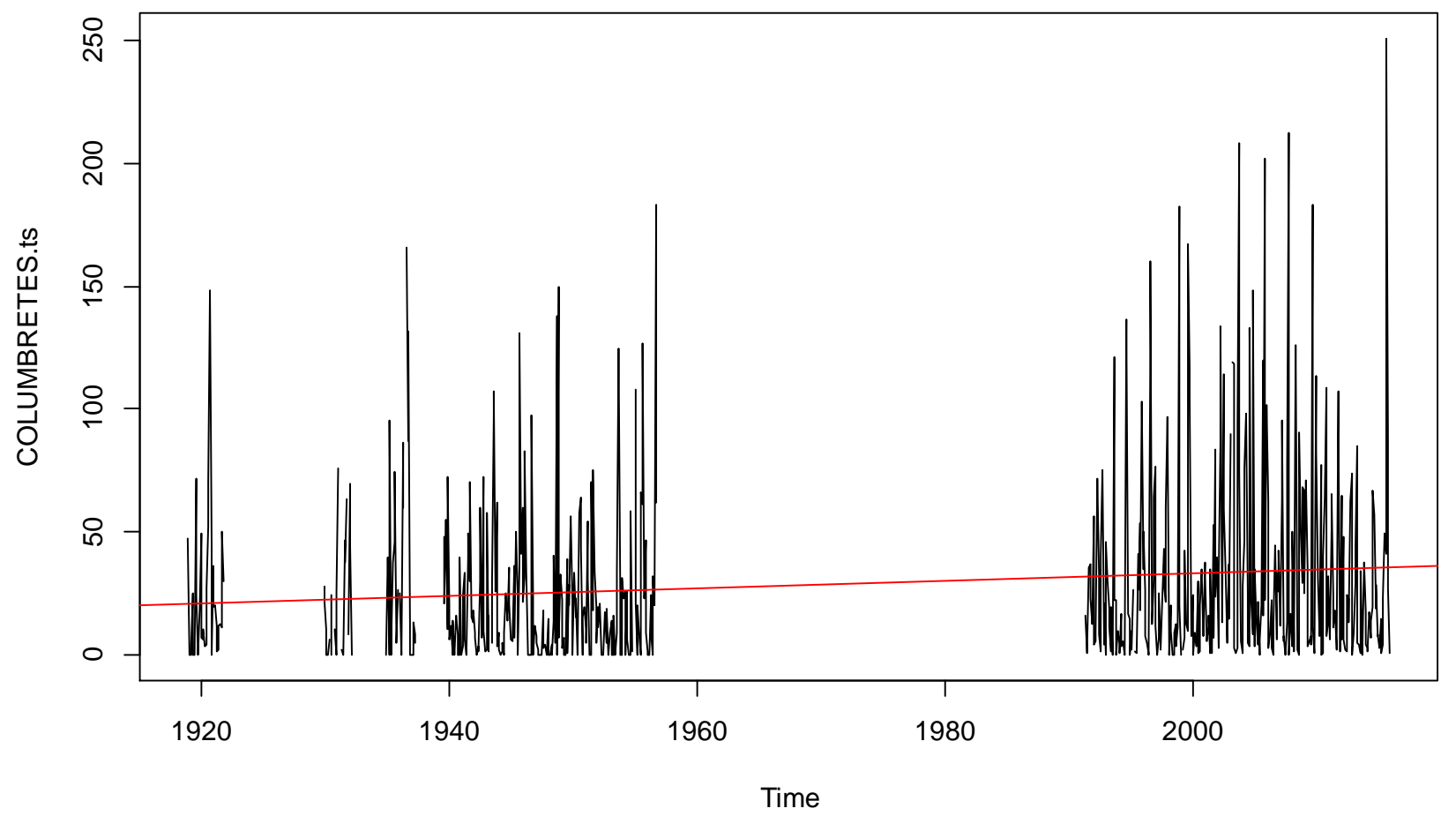

Monthly mean accumulated $P$, first period:

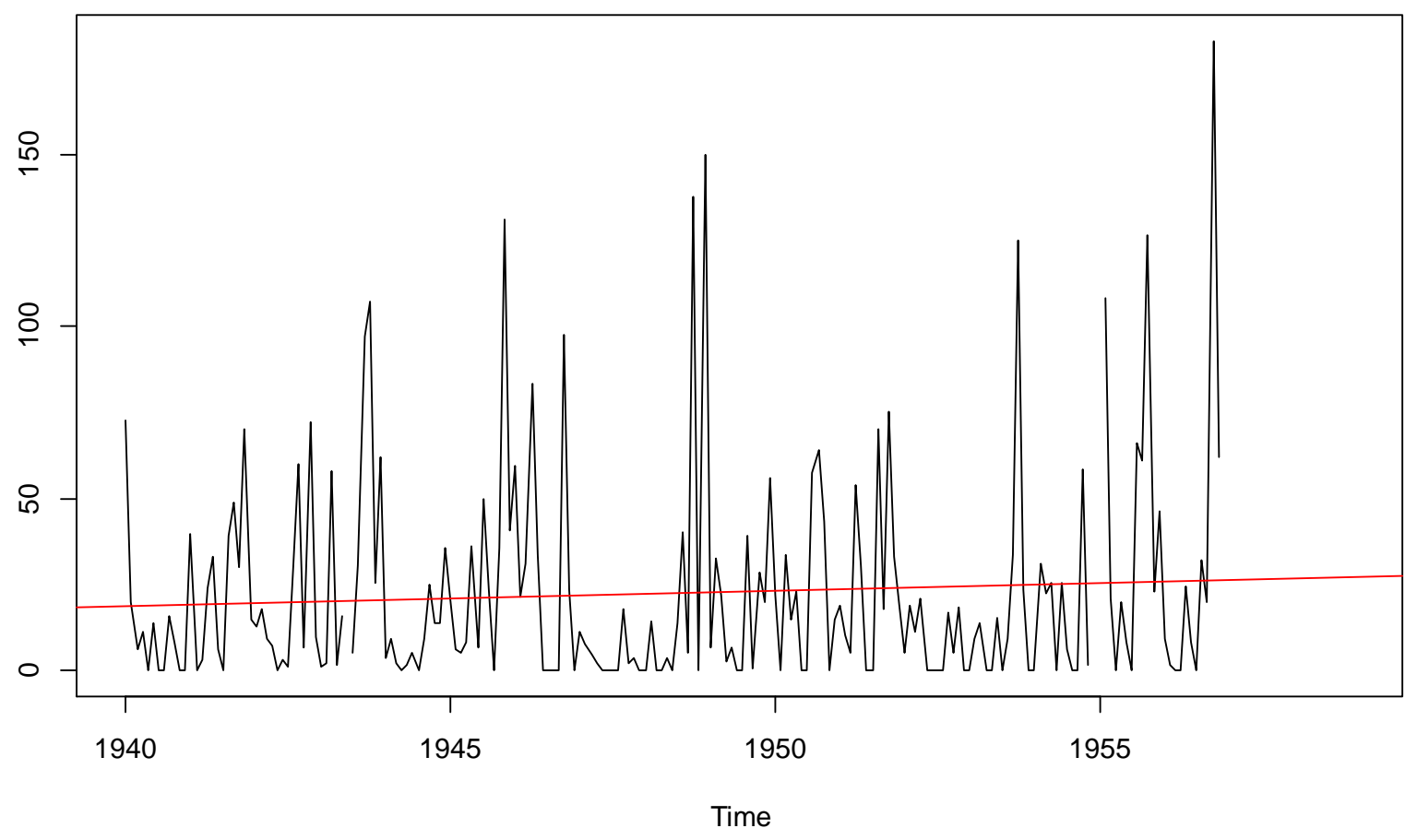


Monthly mean accumulated $\mathrm{P}$, second period:

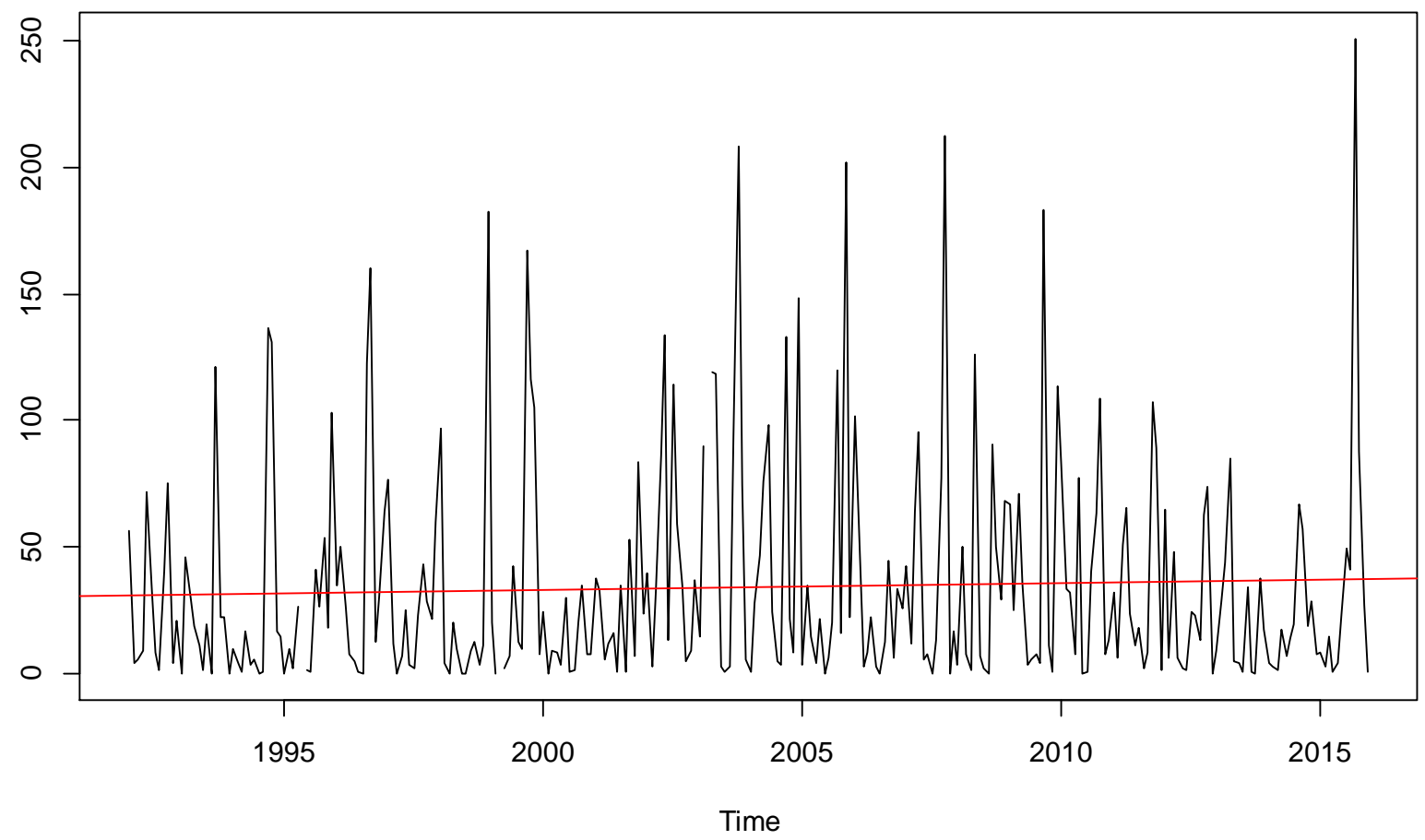

Maximum $P$ in $24 h$, total series:

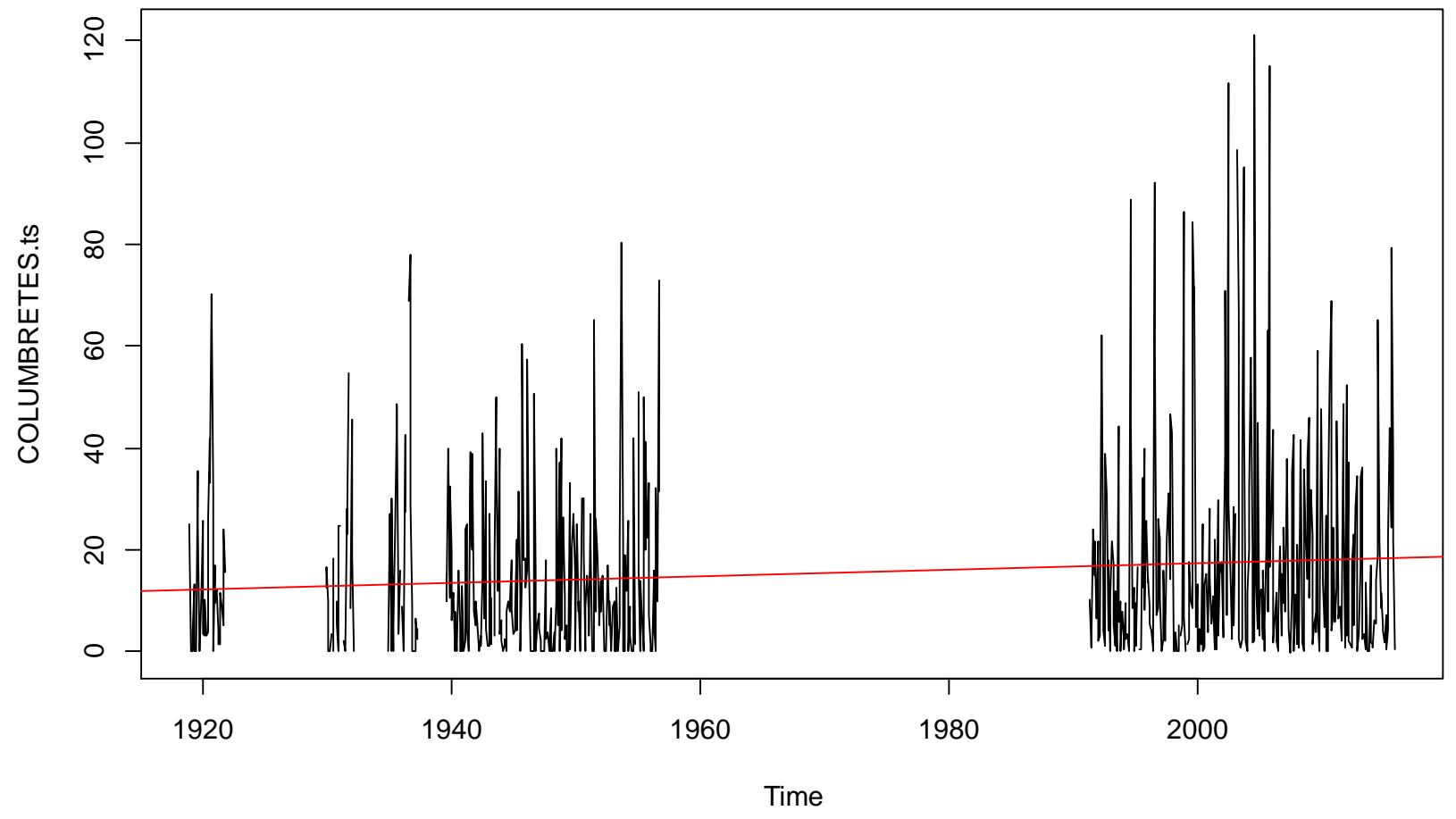


Annexos

Maximum $P$ in $24 h$, first period:

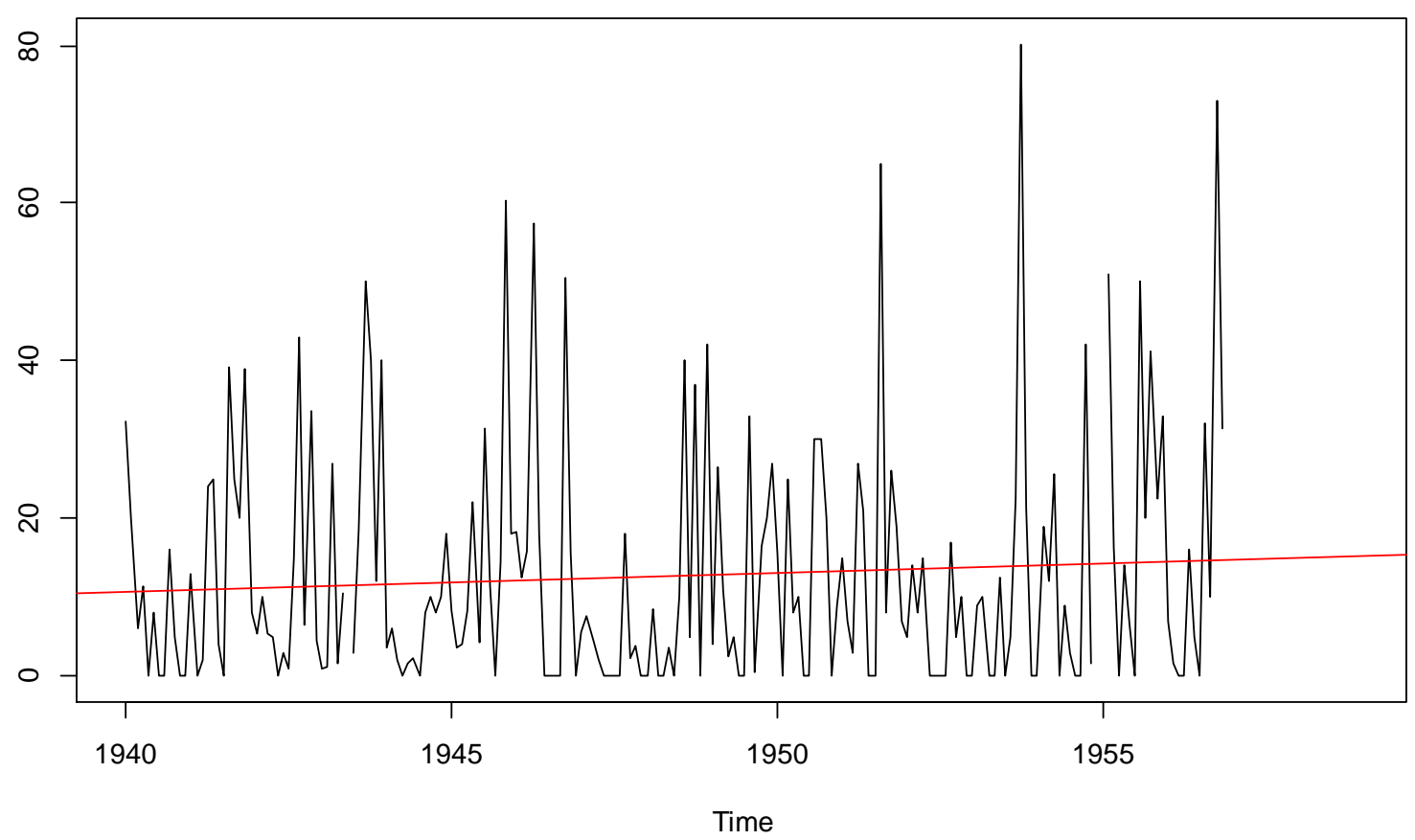

Maximum $\mathrm{P}$ in $24 \mathrm{~h}$, second period:

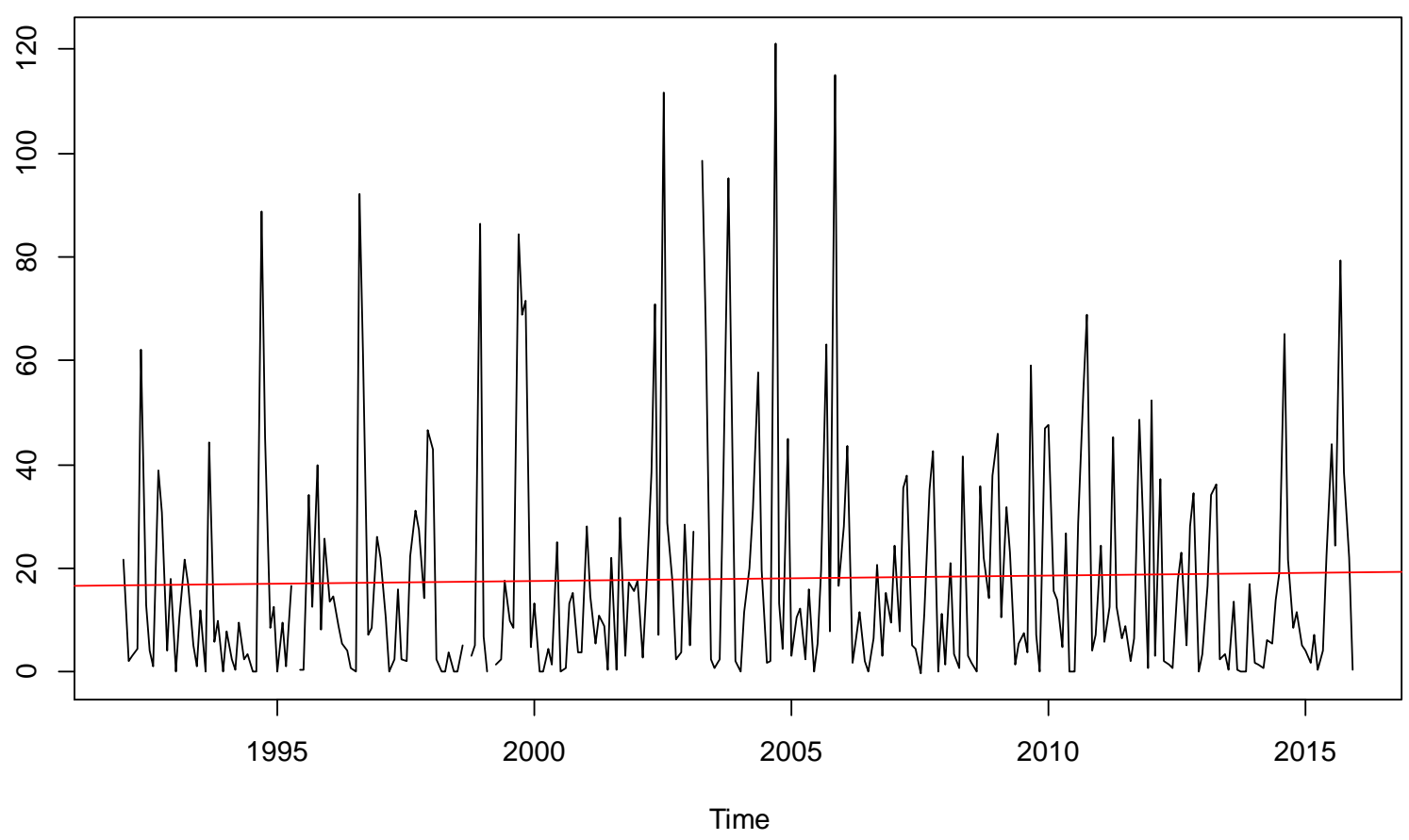


Annual mean accumulated $P$, total series:

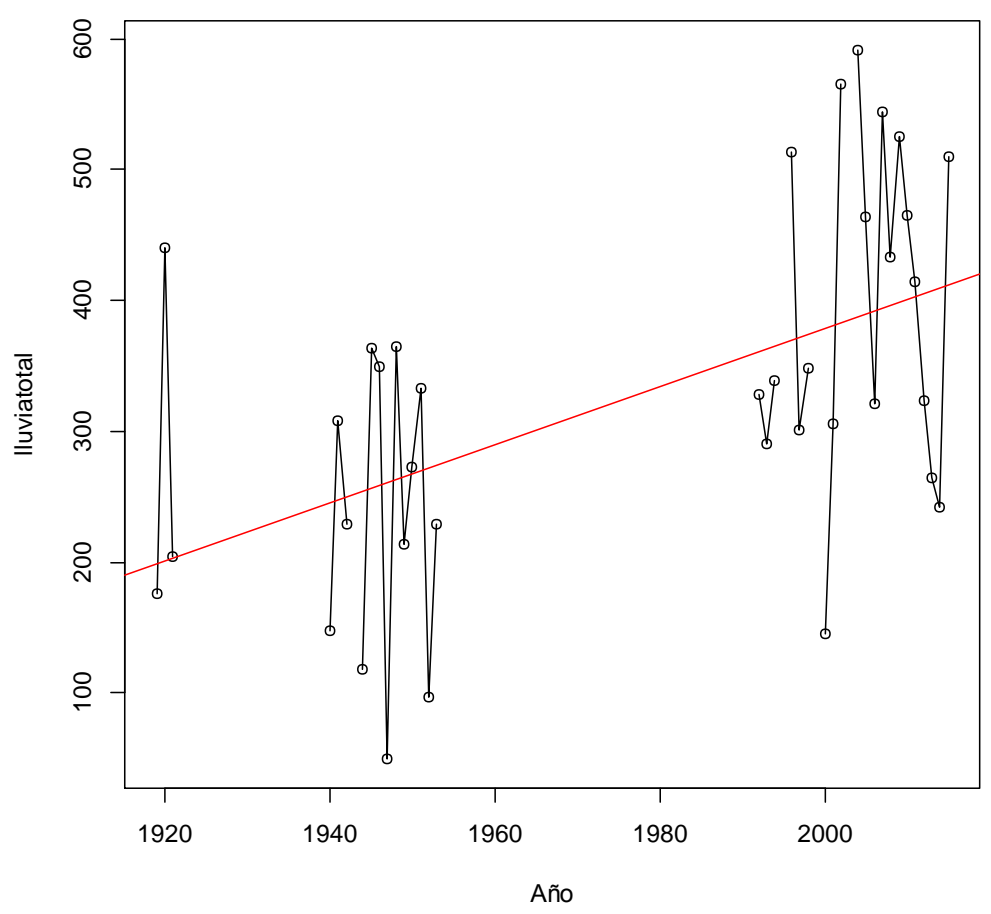

Annual mean accumulated $P$, first period:

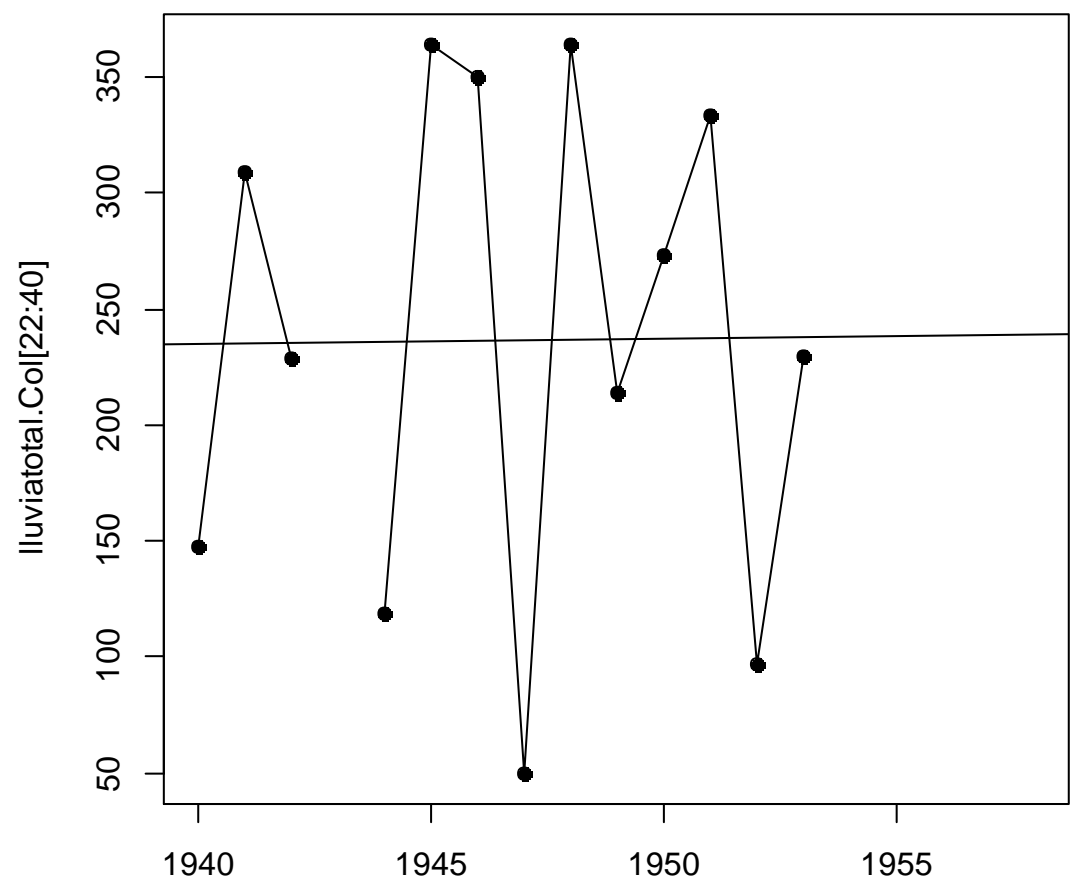


Annexos

Annual mean accumulated $\mathrm{P}$, second period:

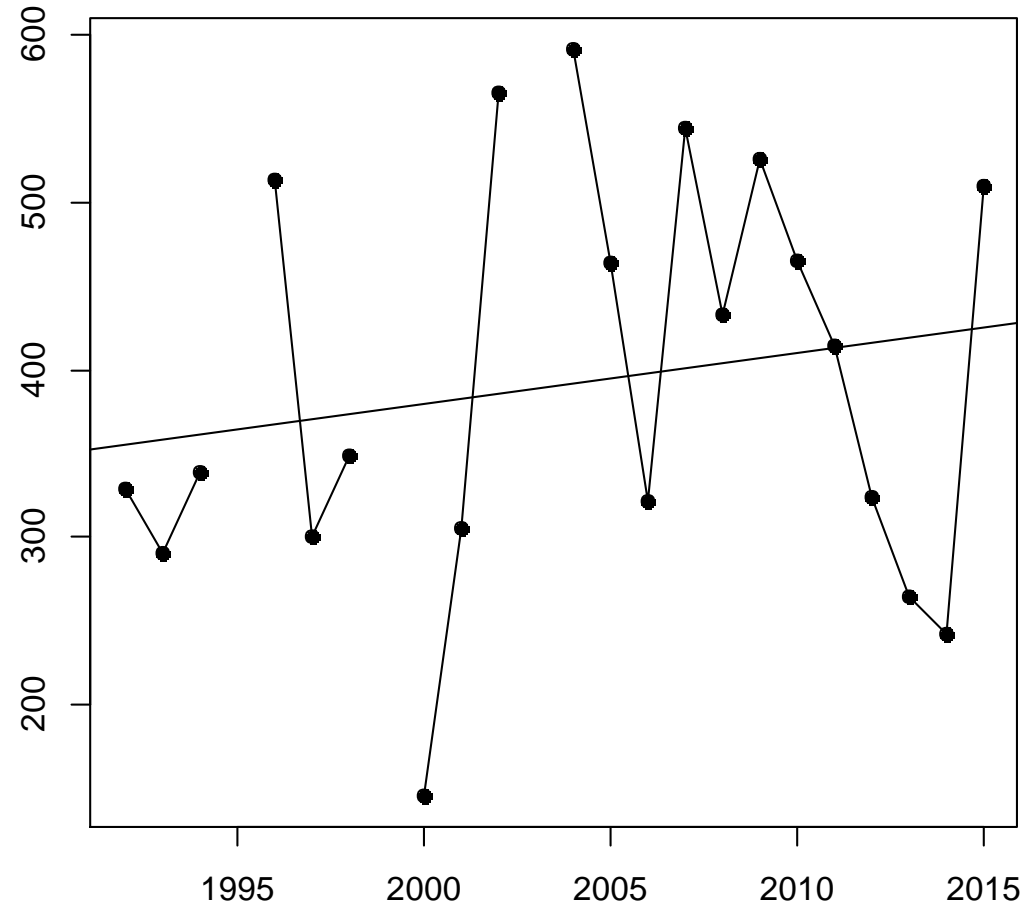


ANNEX 1.6.

Comparison of the slopes of the regression lines of the total series (1940-2015), the first period (1940-1957 for T; 1940-1956 for P) and the second period (1992-2015) for the parameters of each station in relation with the Columbretes station ( $\mathrm{T}=$ temperature; $\mathrm{P}=$ precipitation) 
Annexos

Monthly absolute maximum $\mathrm{T}$, total series:

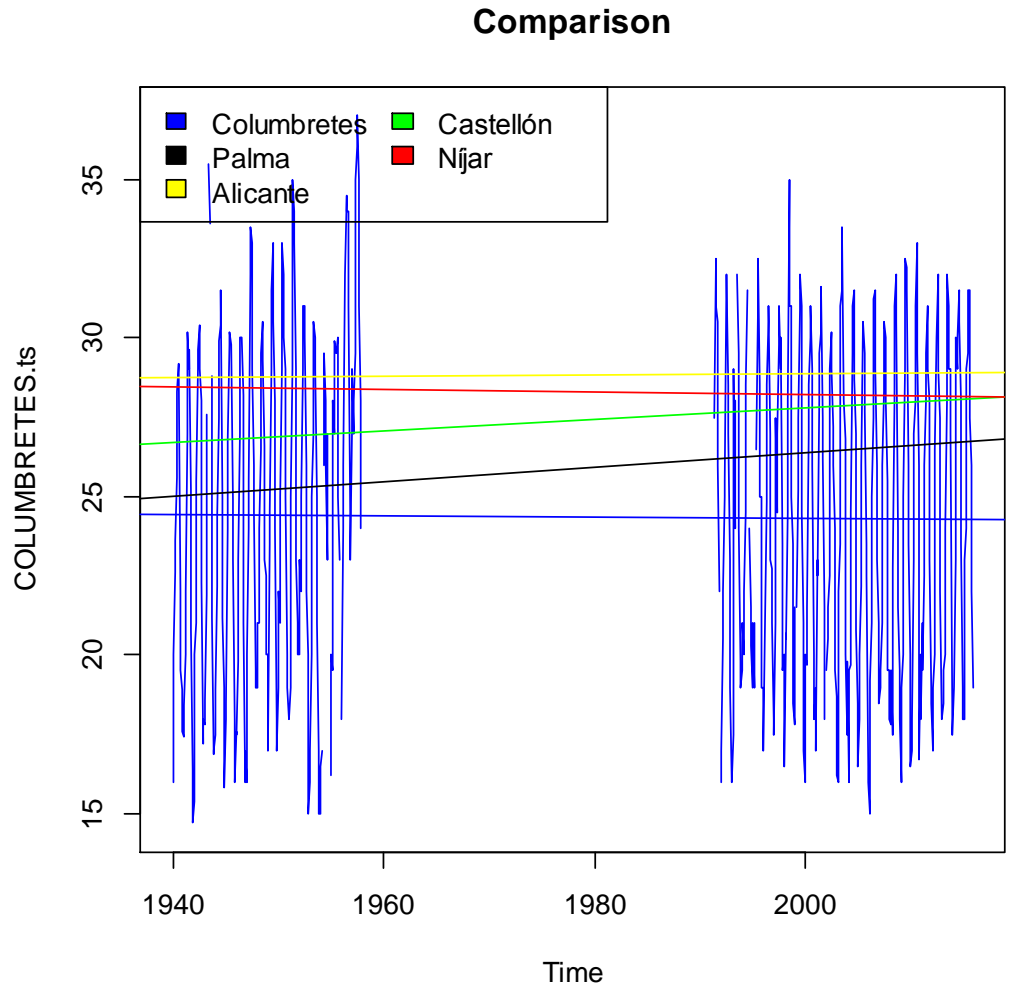

Monthly absolute maximum $\mathrm{T}$, first period:

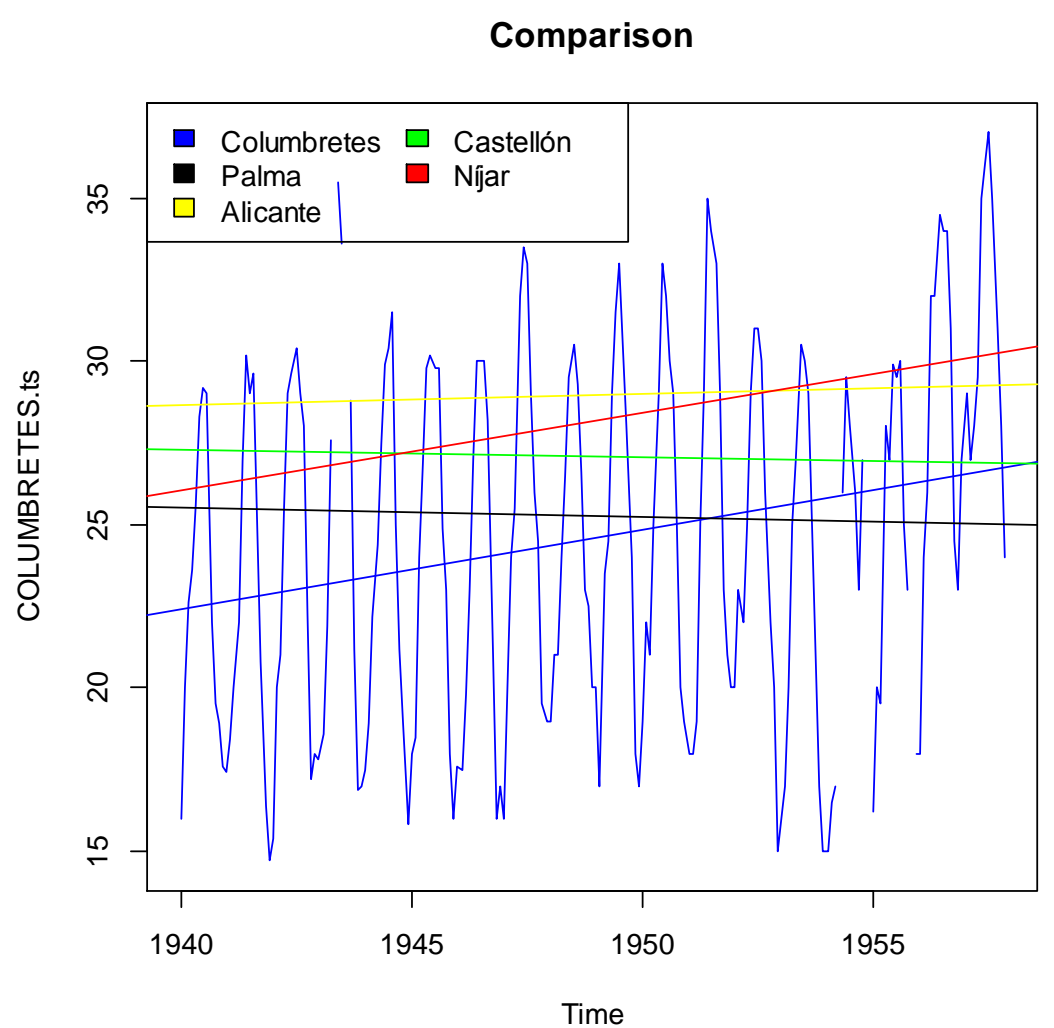


Monthly absolute maximum $\mathrm{T}$, second period:

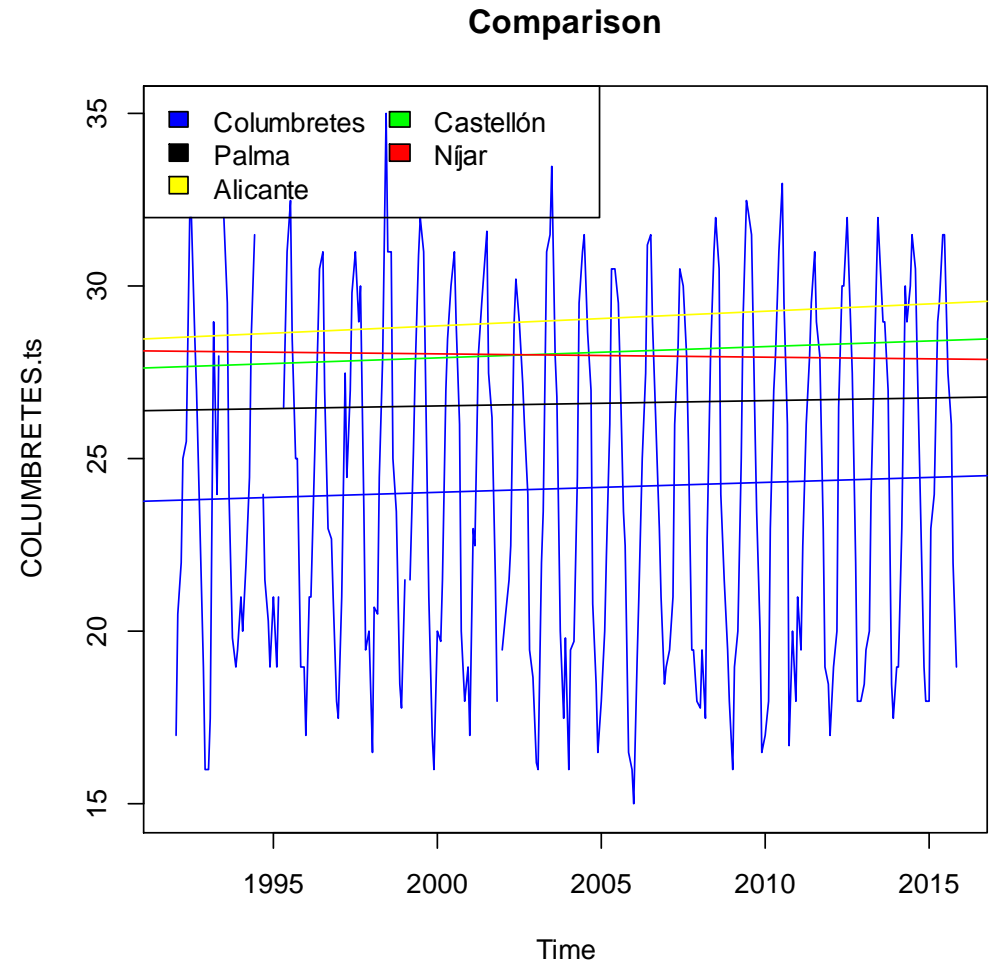

Monthly mean maximum $\mathrm{T}$, total series:

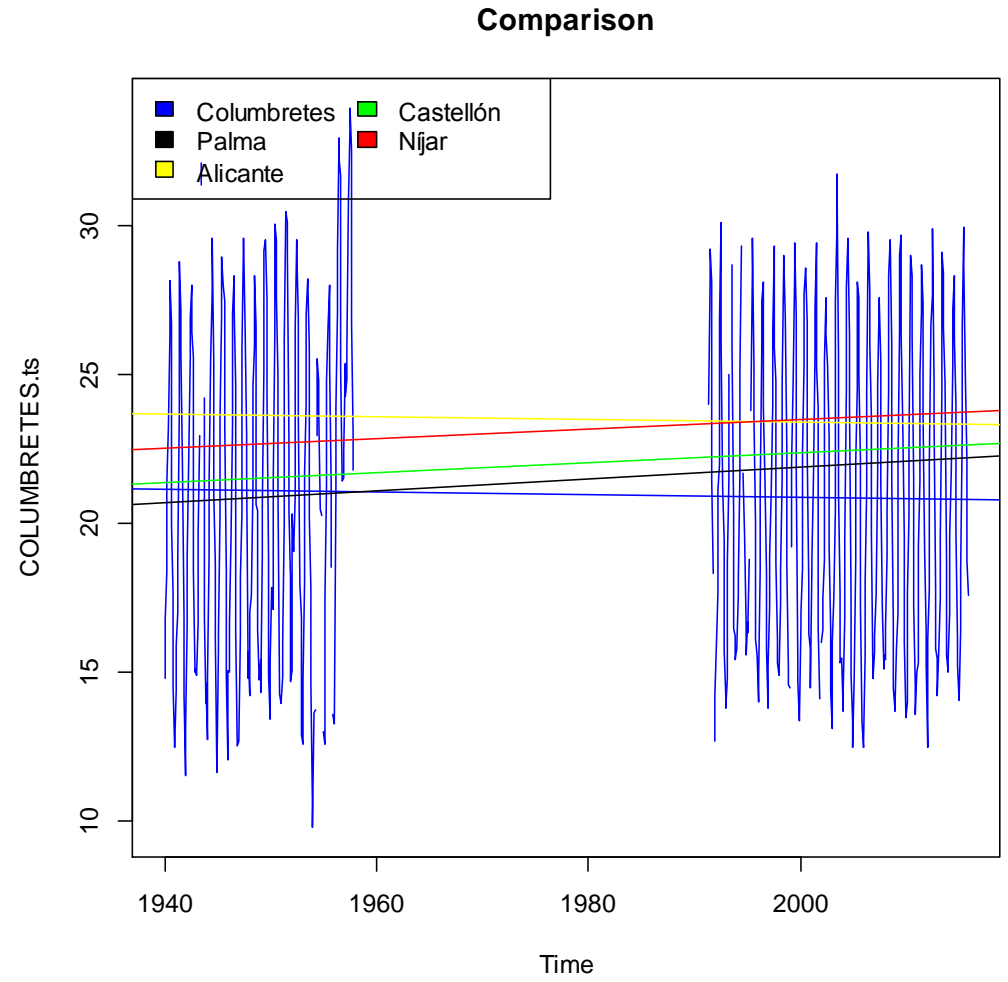


Annexos

Monthly mean maximum $\mathrm{T}$, first period:

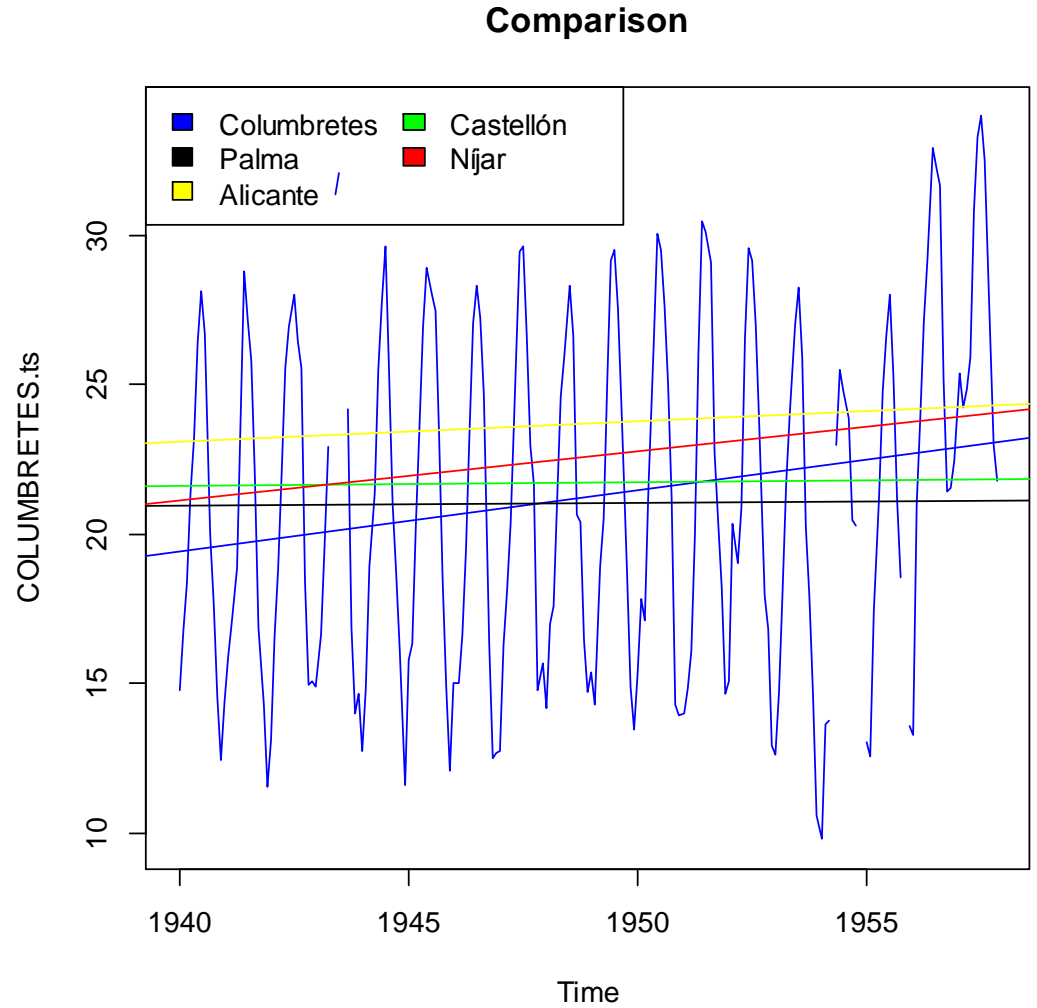

Monthly mean maximum $\mathrm{T}$, second period:

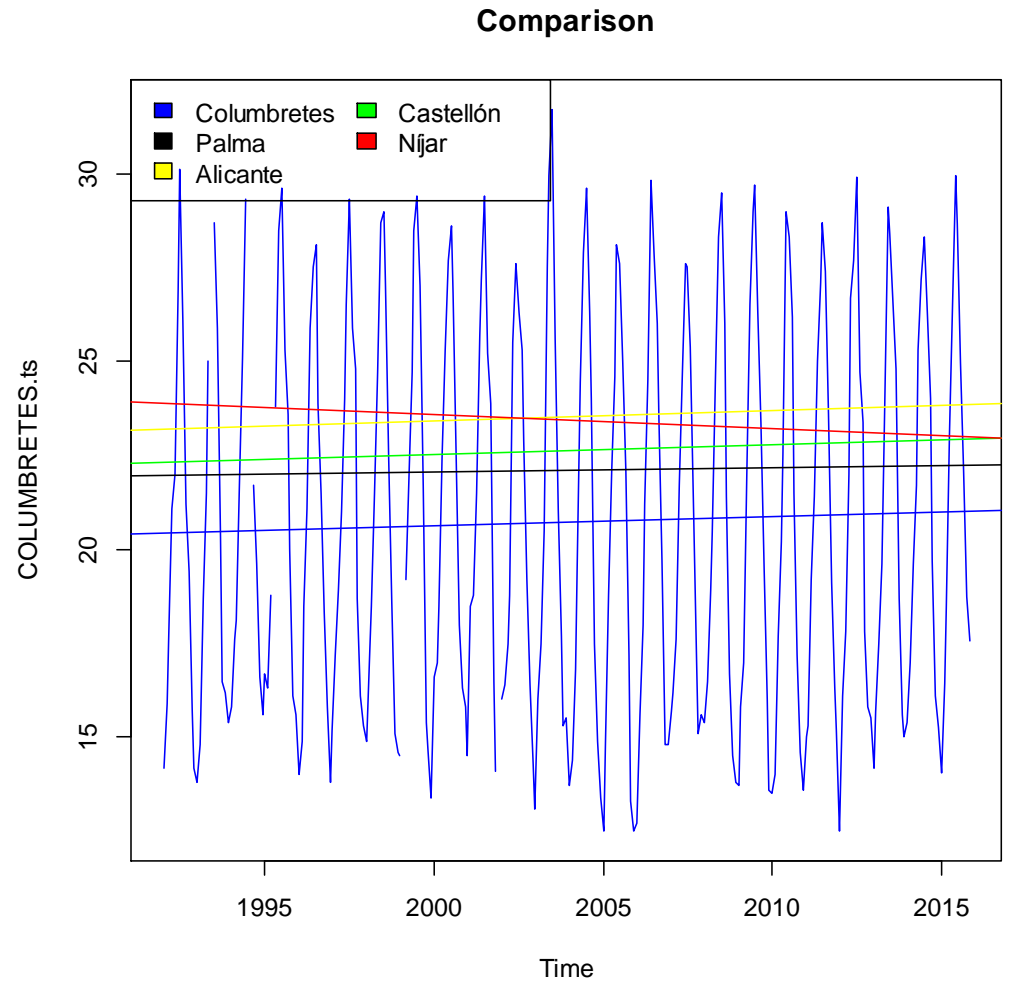


Monthly absolute minimum $\mathrm{T}$, total series:

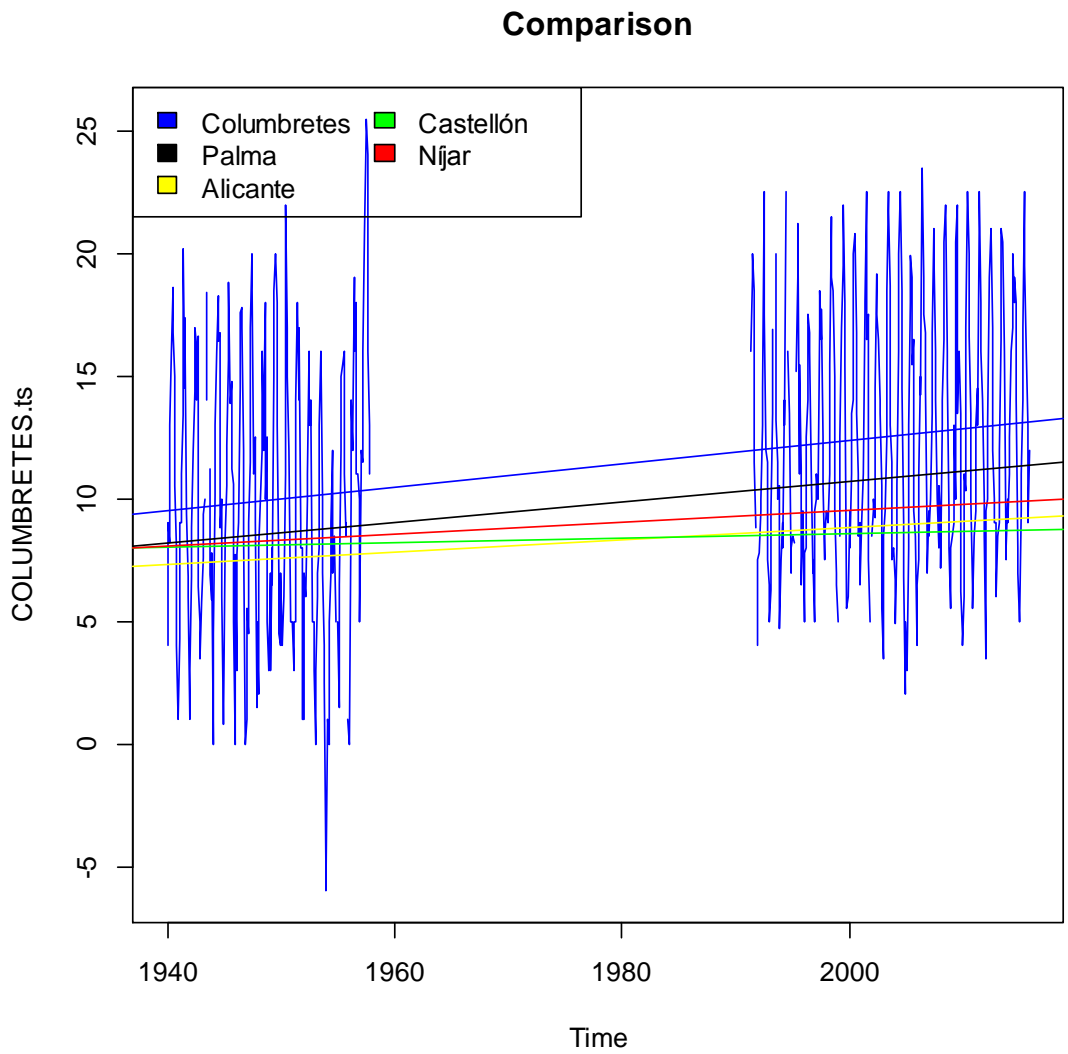

Monthly absolute minimum $\mathrm{T}$, first period:

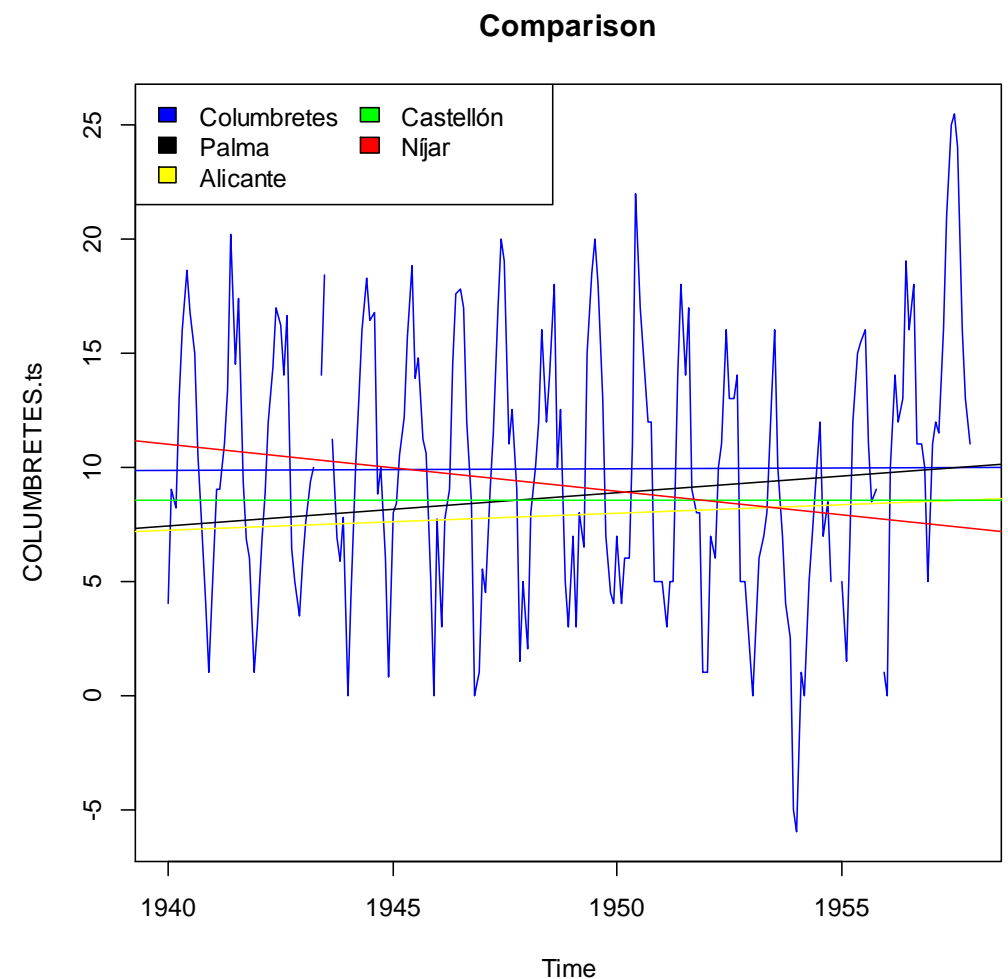


Annexos

Monthly absolute minimum $\mathrm{T}$, second period:

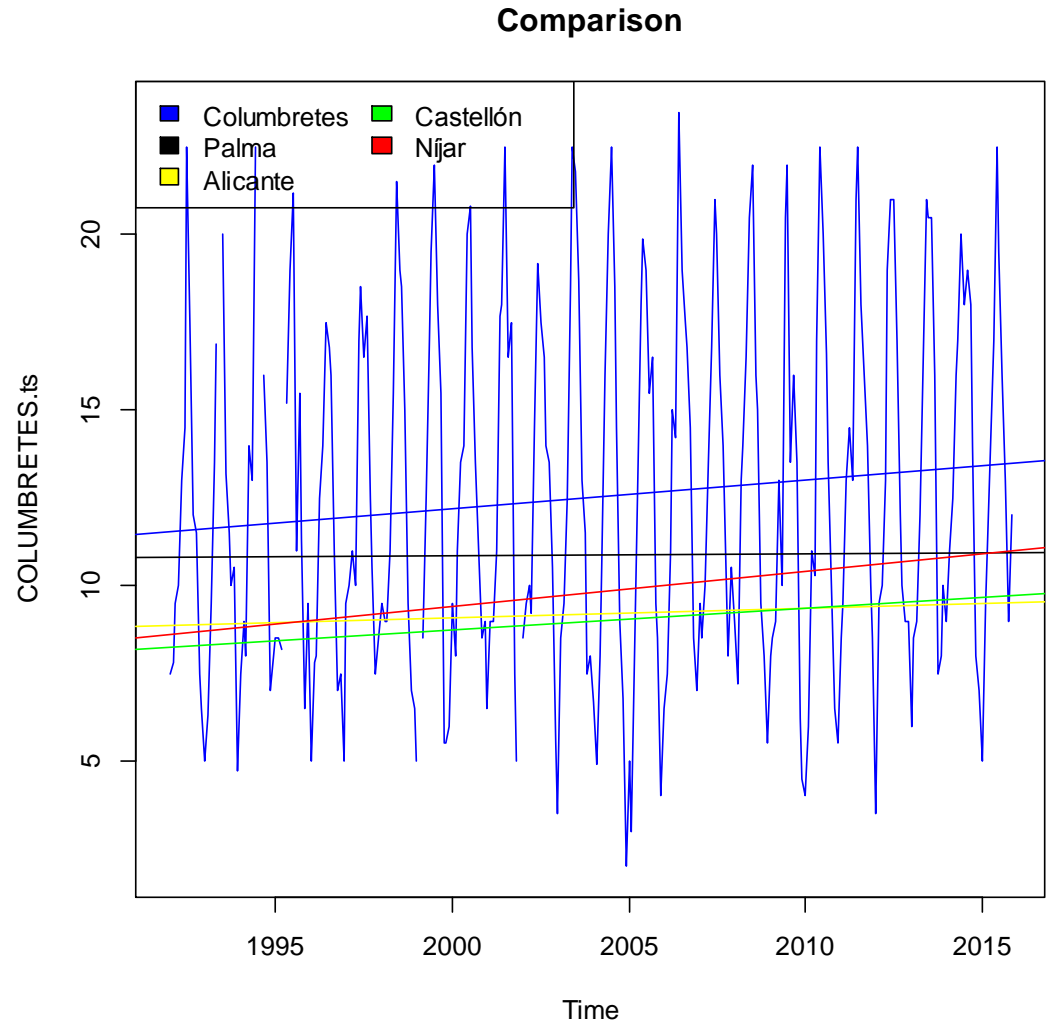

Monthly mean minimum $\mathrm{T}$, total series:

Comparison

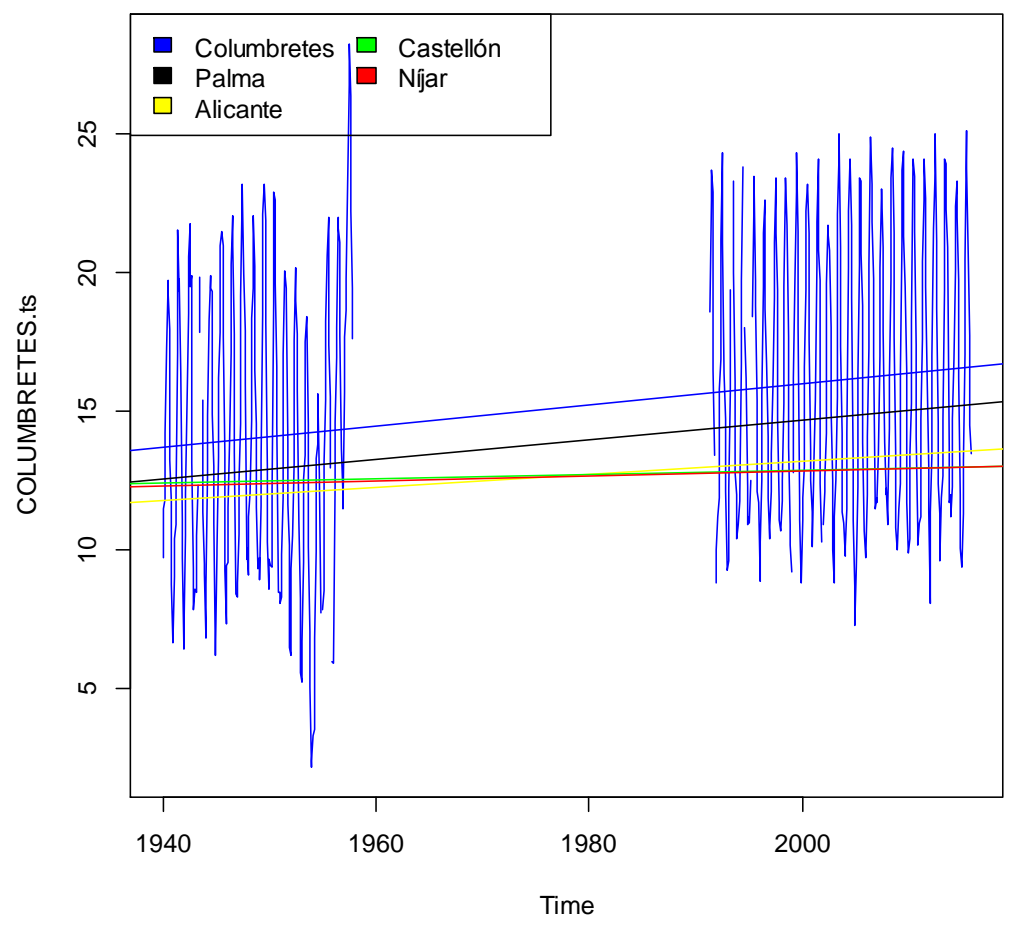


Monthly mean minimum $\mathrm{T}$, first period:

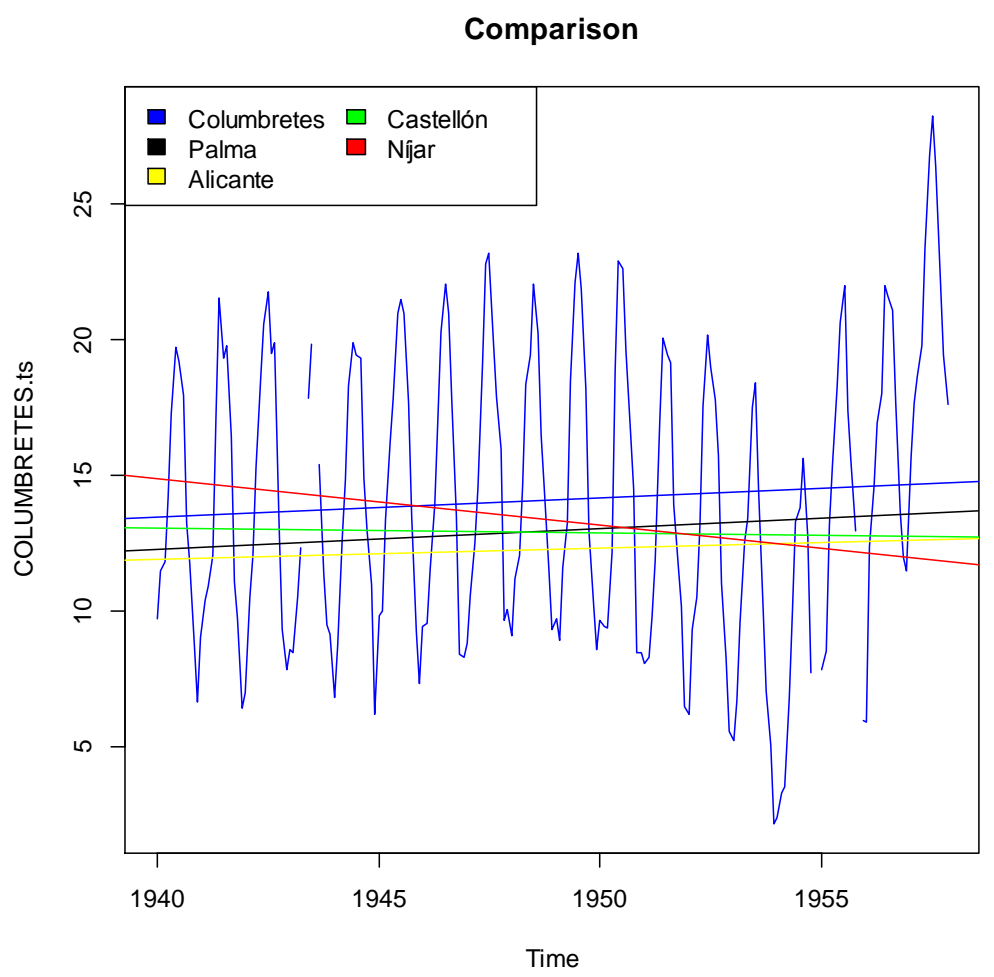

Monthly mean minimum $\mathrm{T}$, second period:

\section{Comparison}

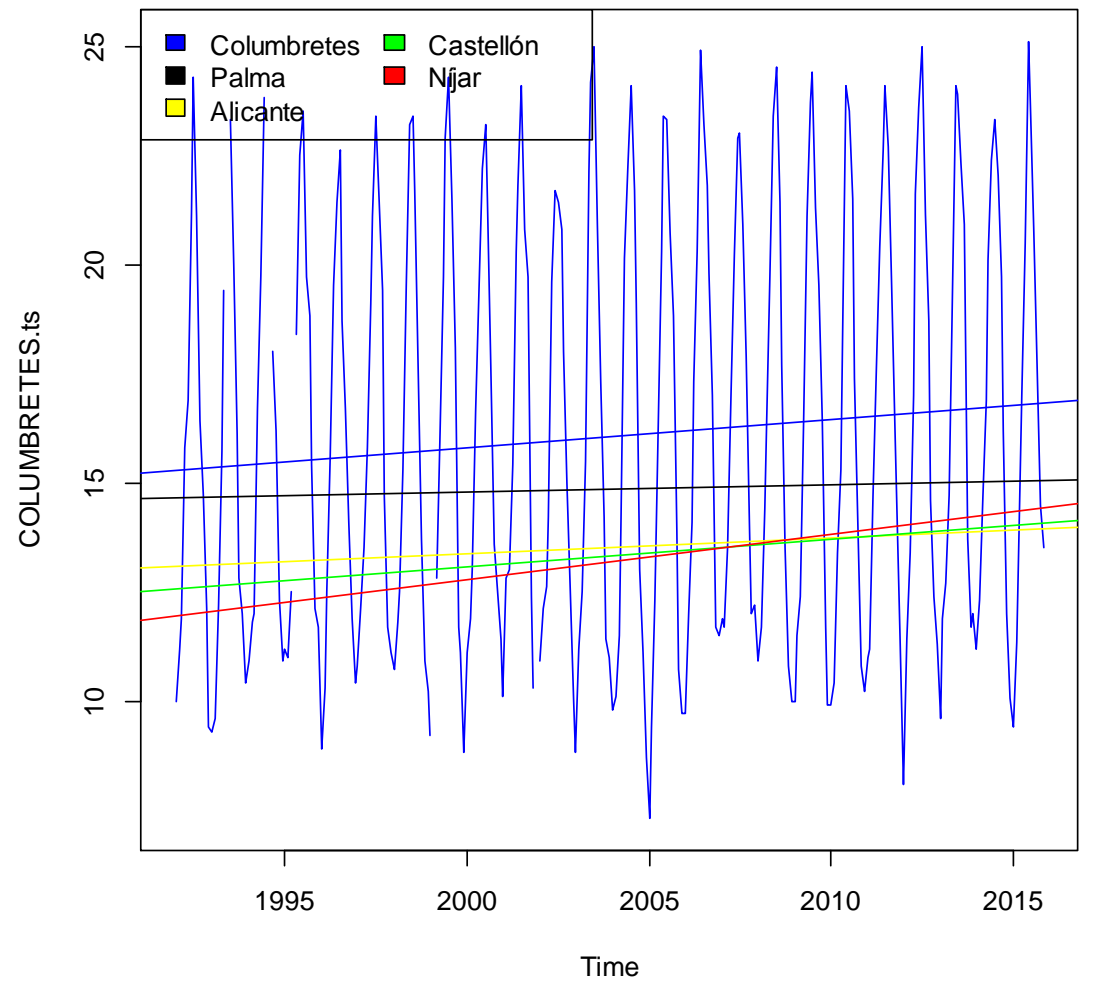


Annexos

Monthly mean $\mathrm{T}$, total series:

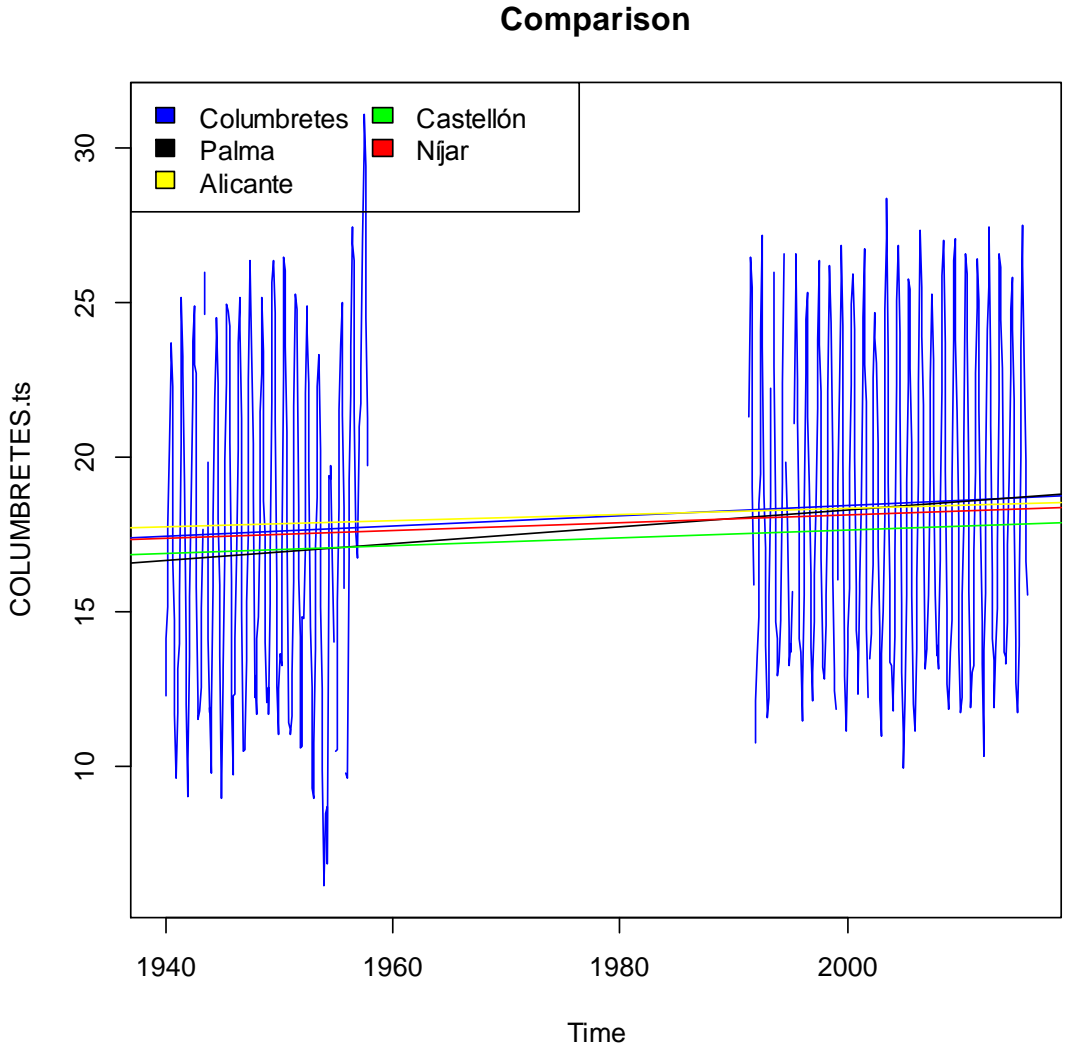

Monthly mean $\mathrm{T}$, first period:

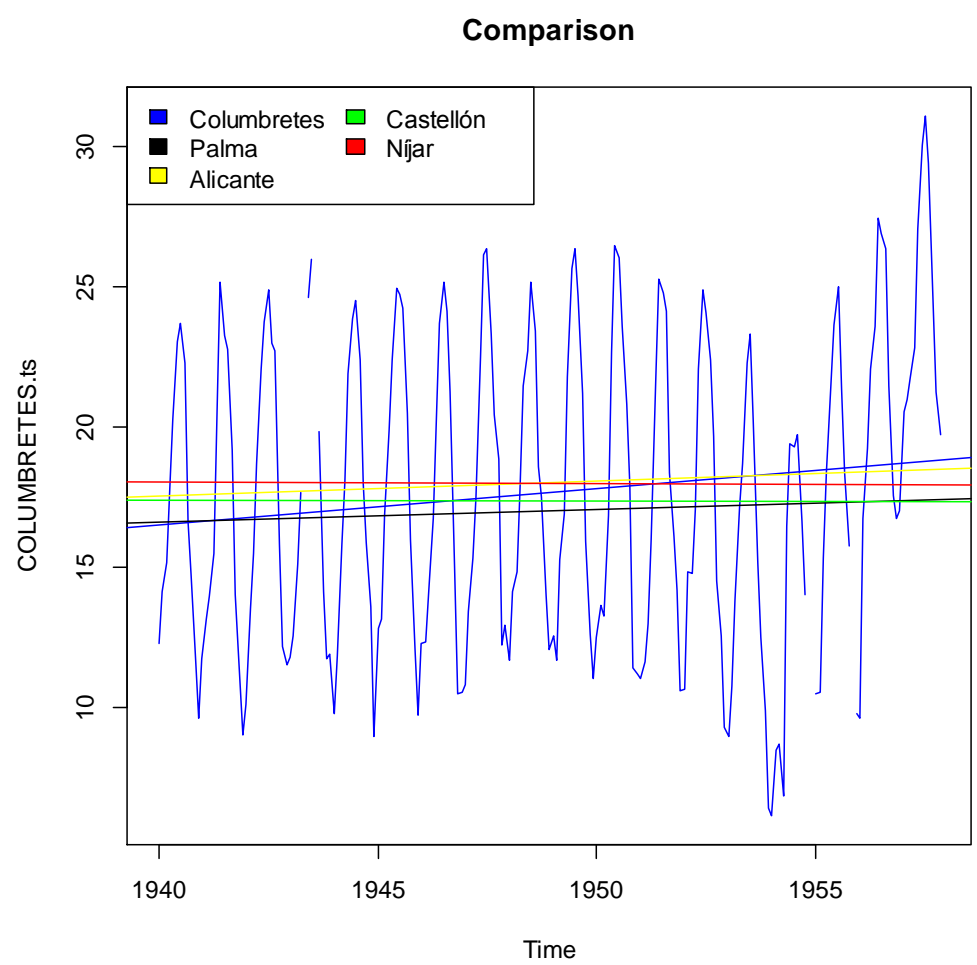


Monthly mean $\mathrm{T}$, second period:

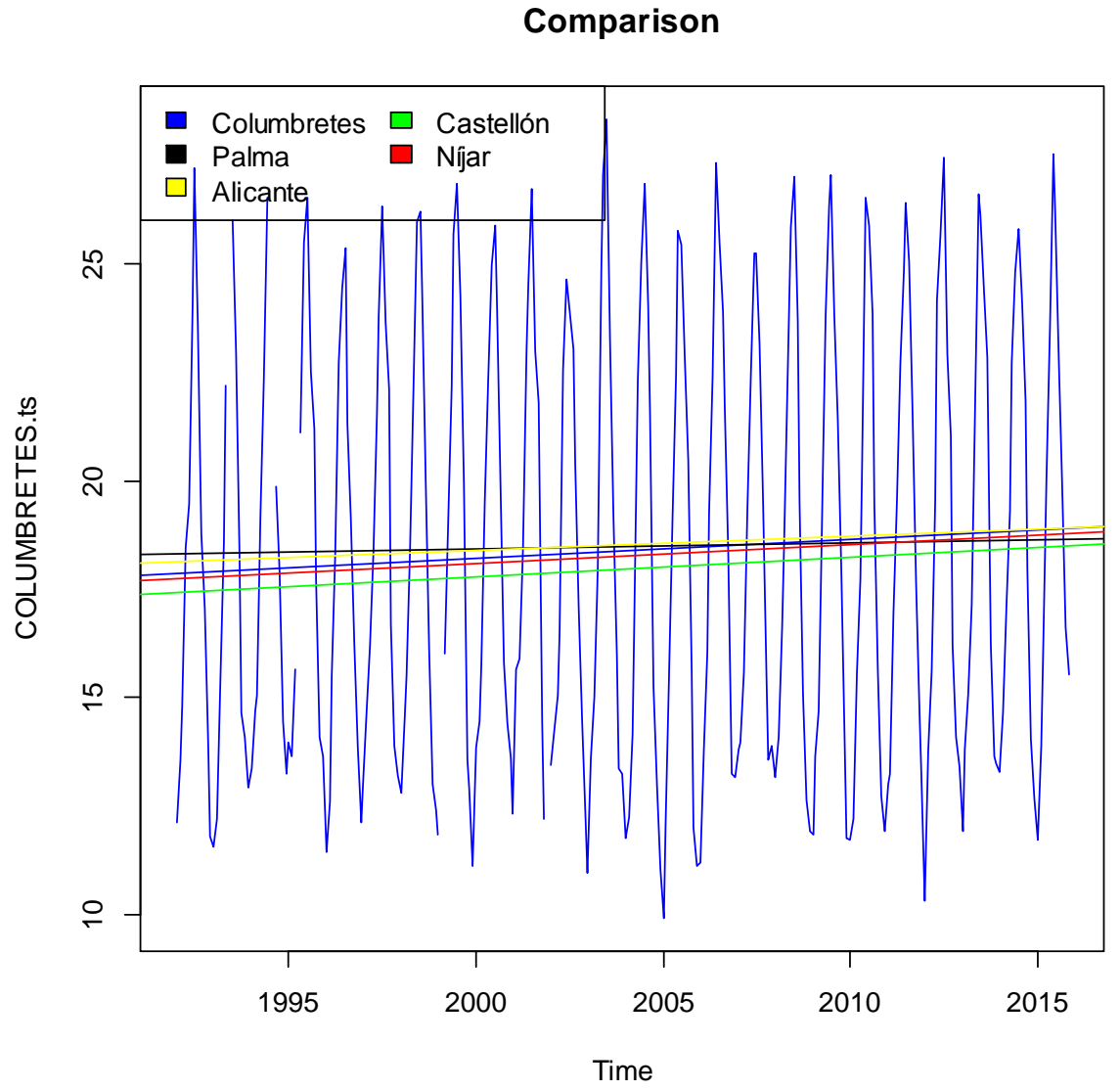

Number of days of rain, total series:

Comparison

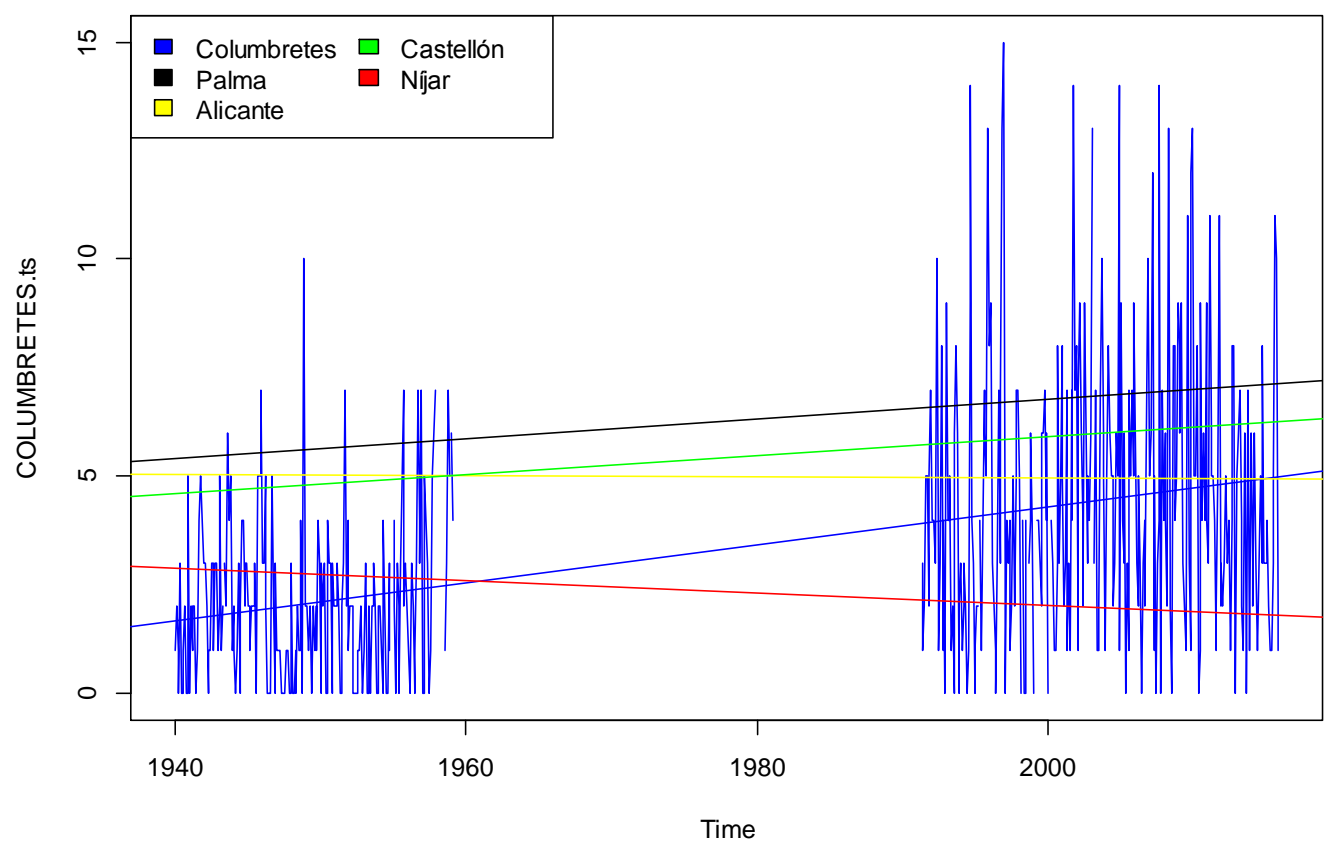


Annexos

Number of days of rain, first period:

Comparison

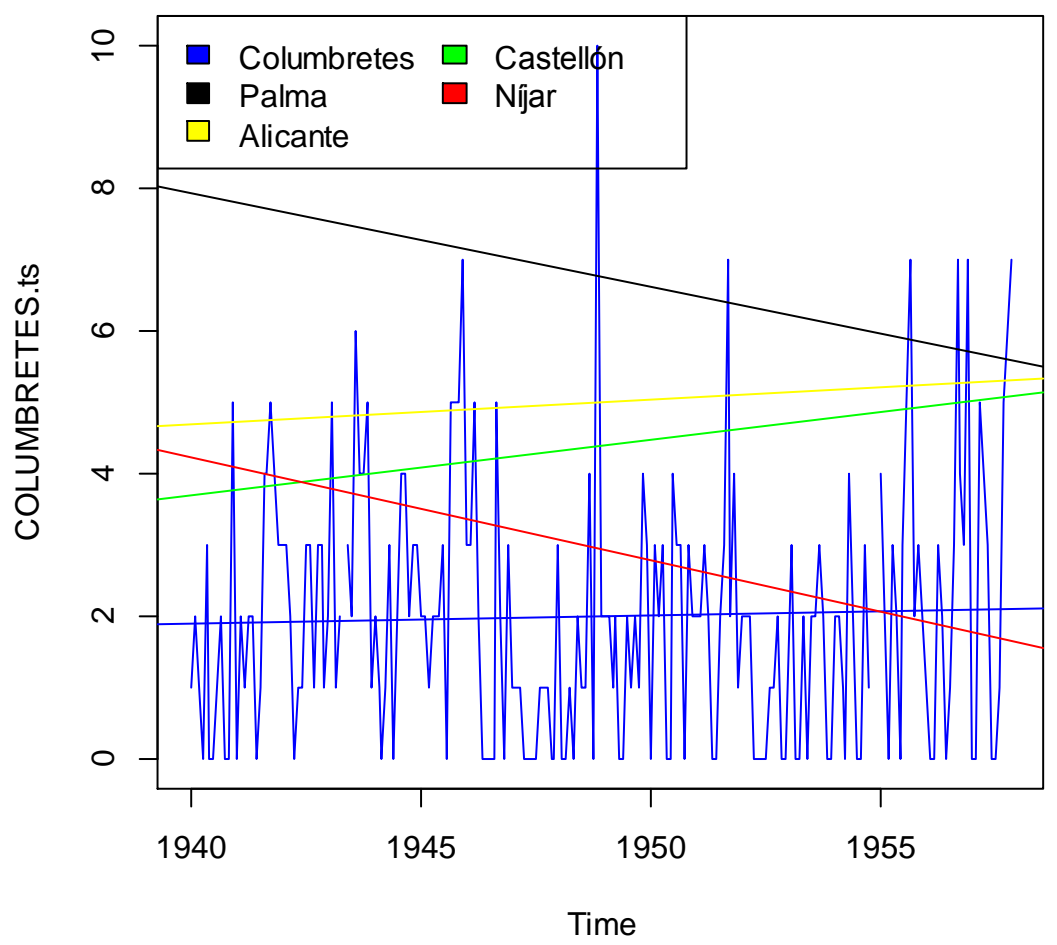

Number of days of rain, second period:

Comparison

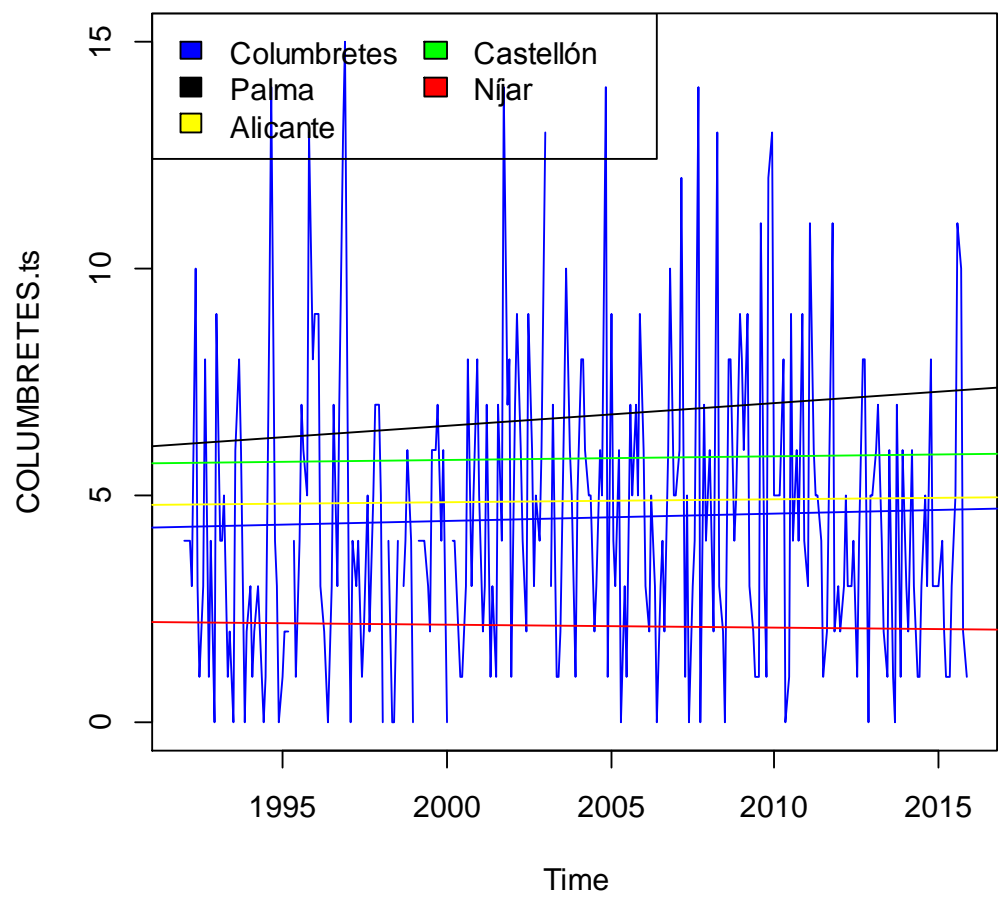


Monthly mean accumulated $\mathrm{P}$, total series:

Comparison

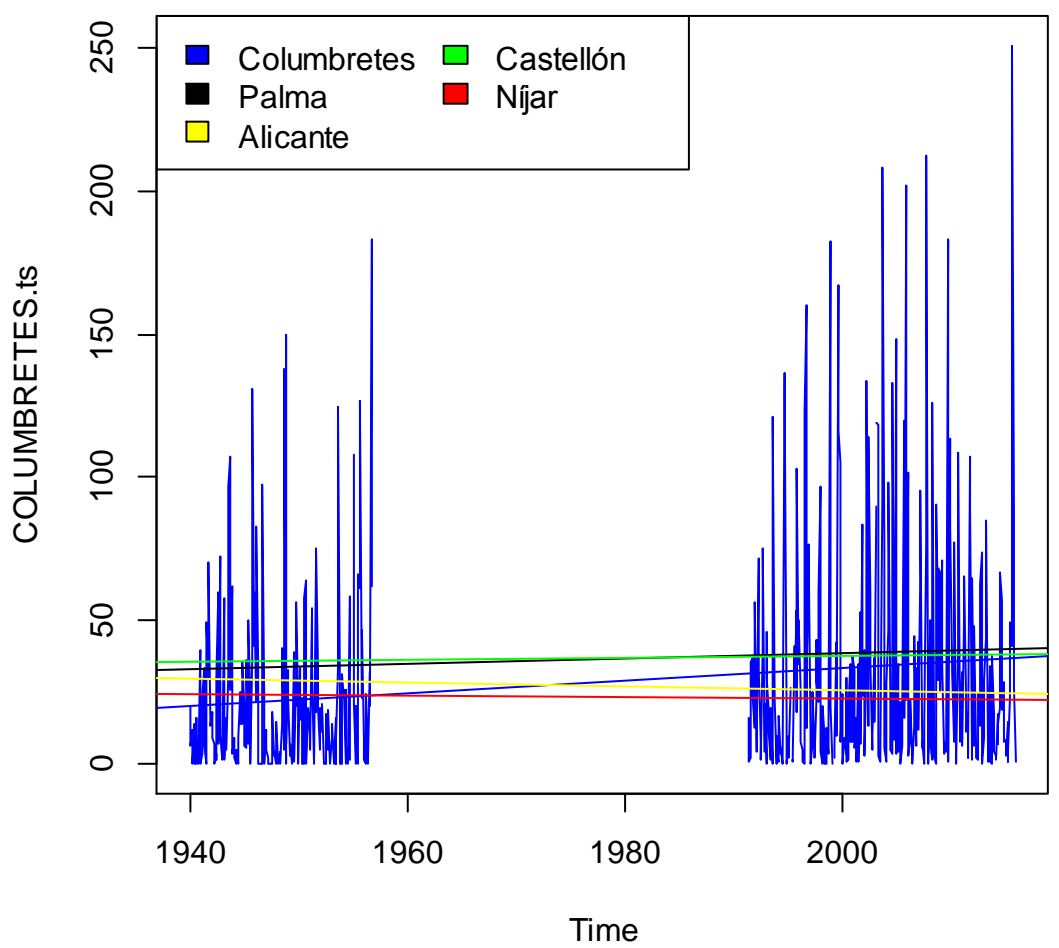

Monthly mean accumulated $\mathrm{P}$, first period:

Comparison

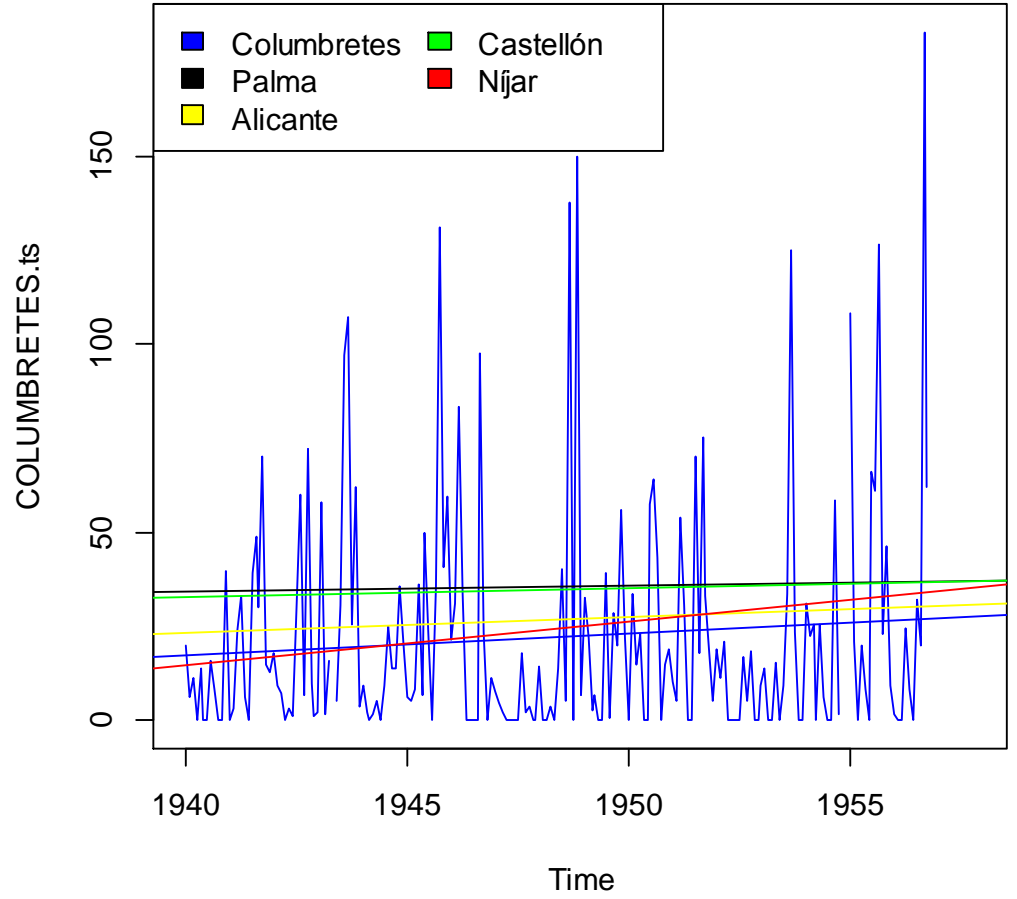


Annexos

Monthly mean accumulated $\mathrm{P}$, second period:

\section{Comparison}

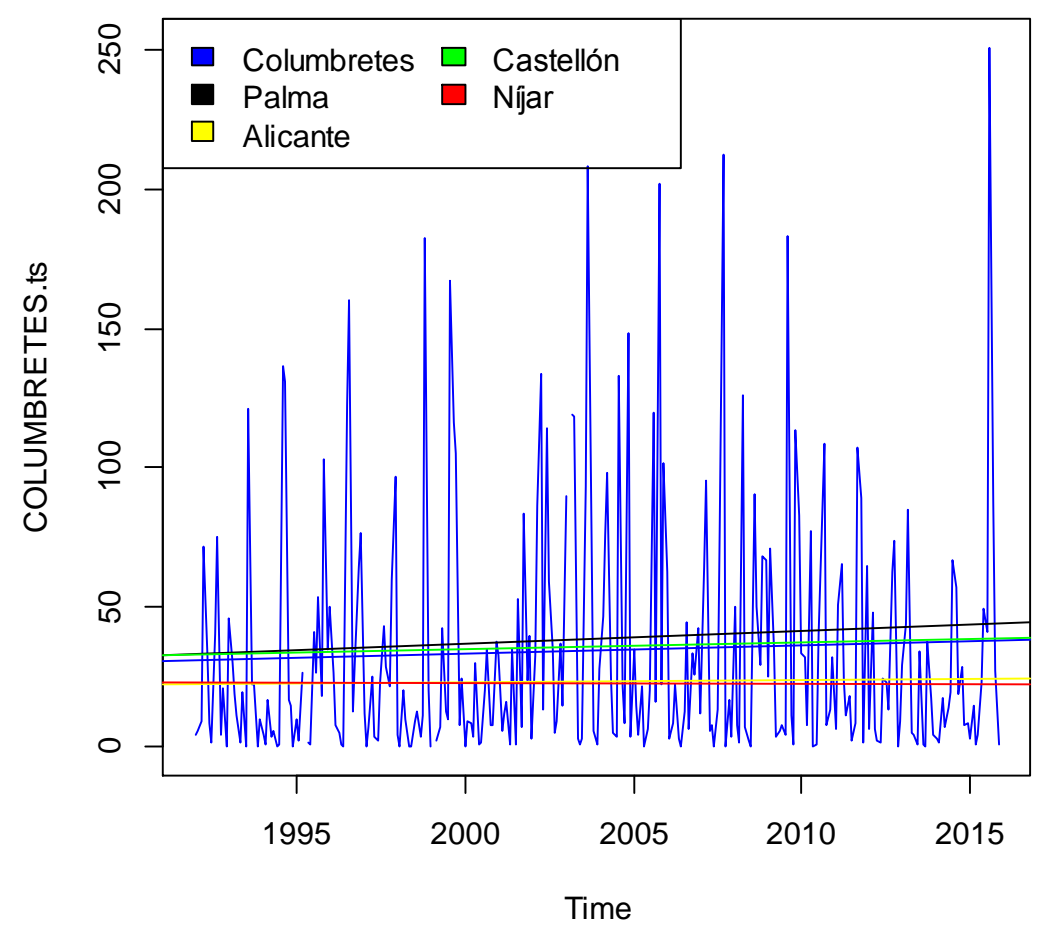

Maximum $P$ in $24 h$, total series:

Comparison

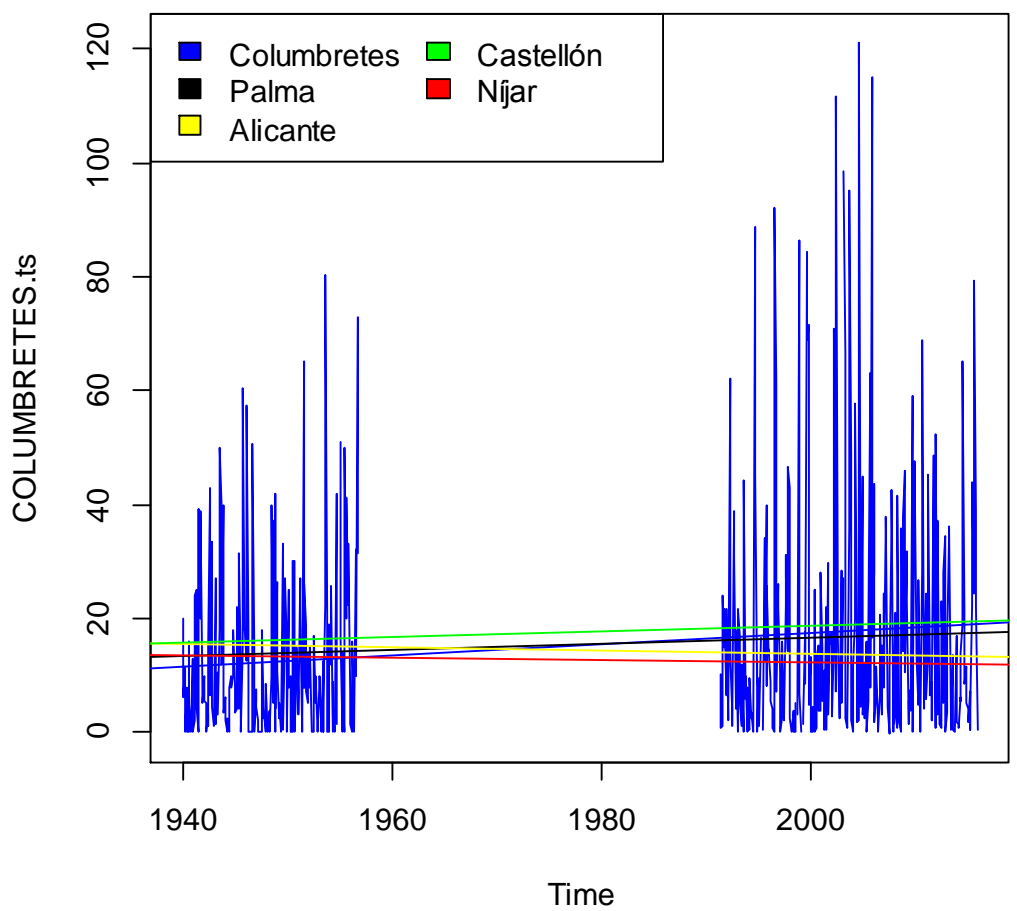


Maximum $P$ in $24 h$, first period:

Comparison

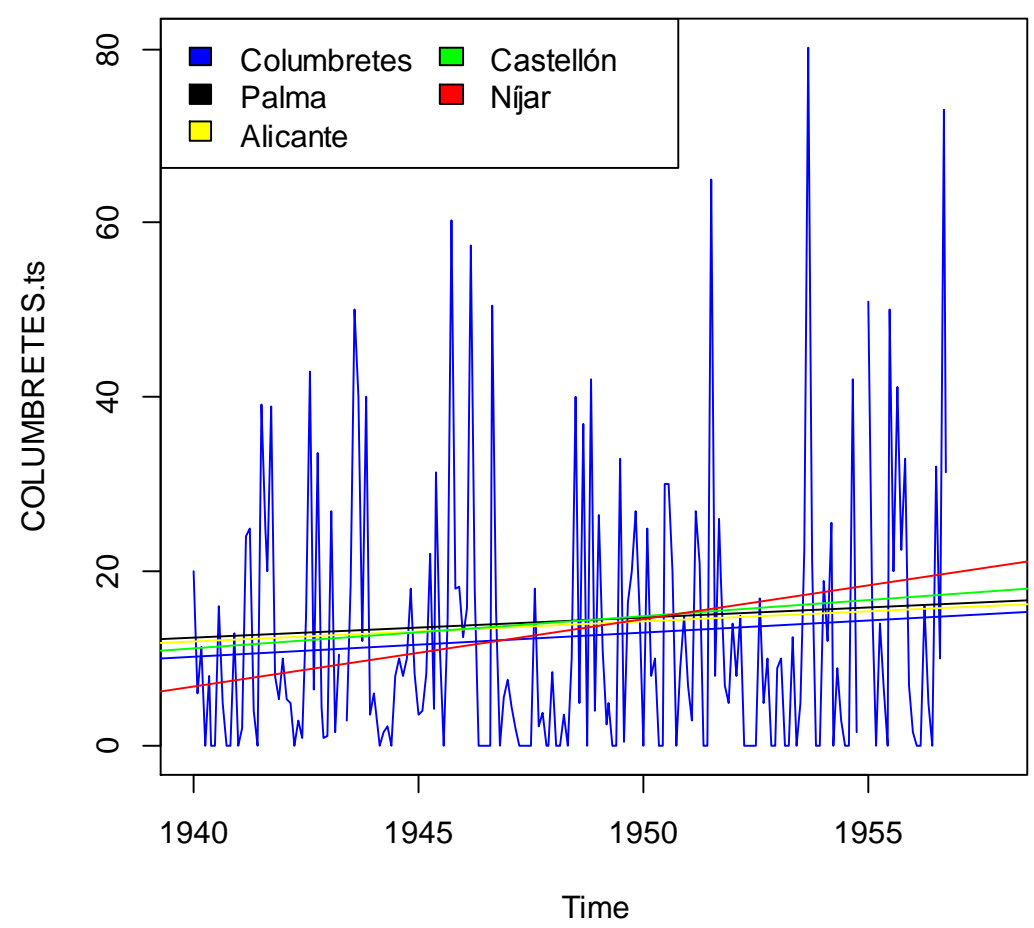

Maximum $\mathrm{P}$ in $24 \mathrm{~h}$, second period:

Comparison

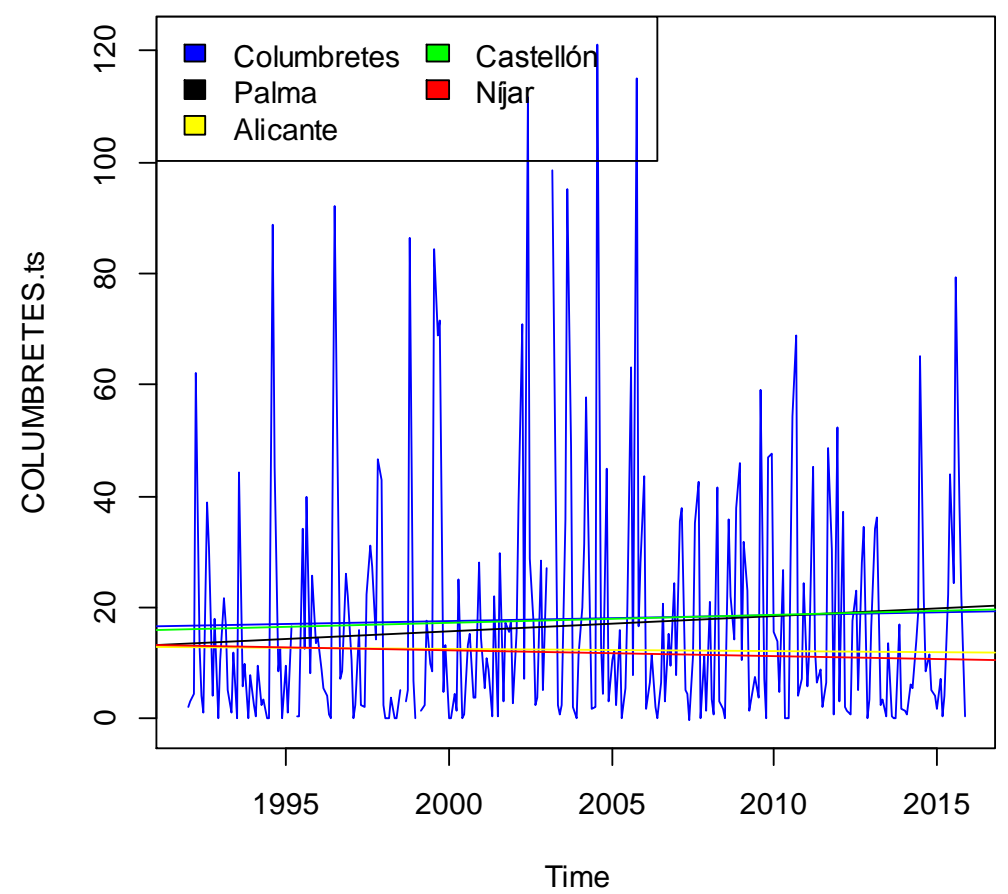


Annexos

Annual mean accumulated $\mathrm{P}$, total series:

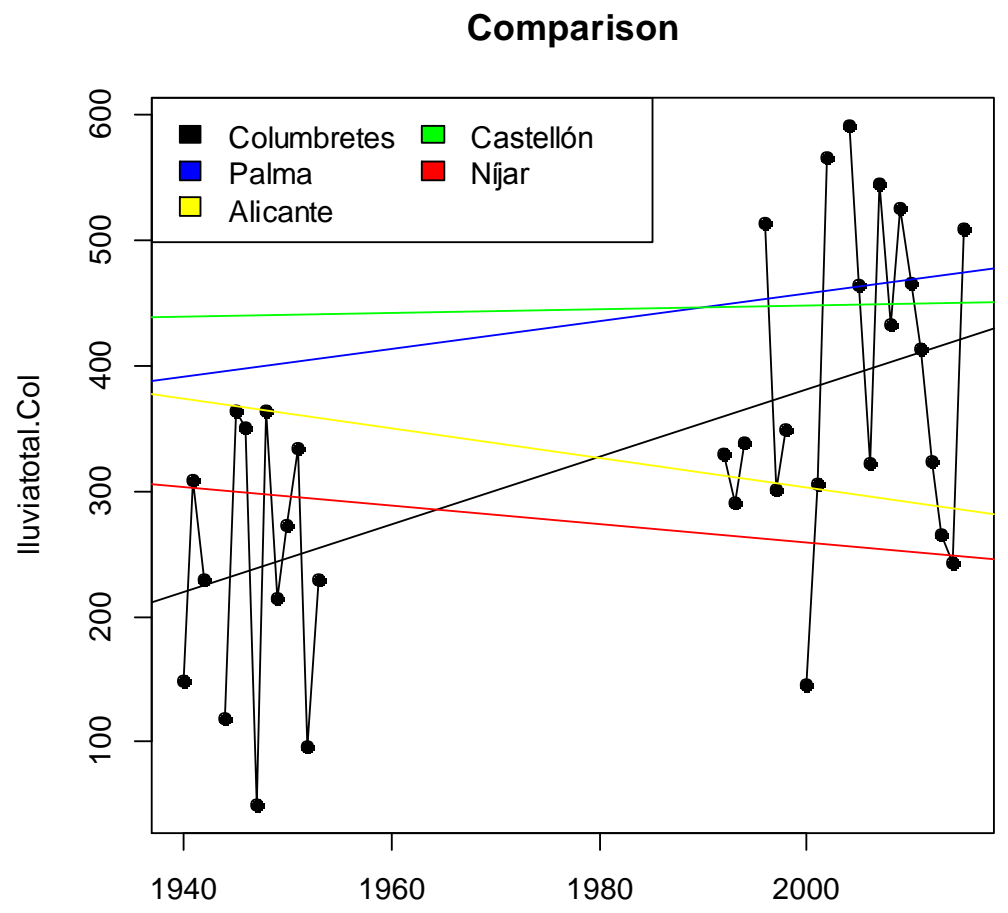

Annual mean accumulated $P$, first period:

Comparison

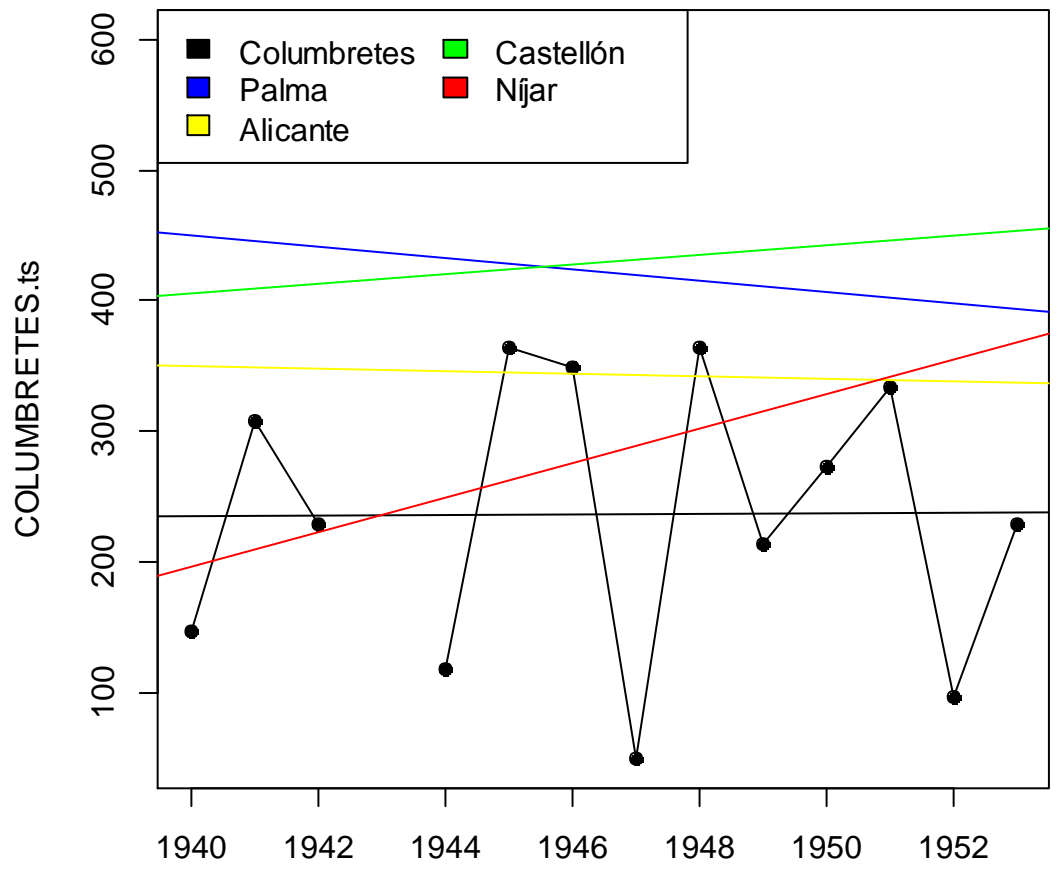


Annual mean accumulated $\mathrm{P}$, second period:

Comparison

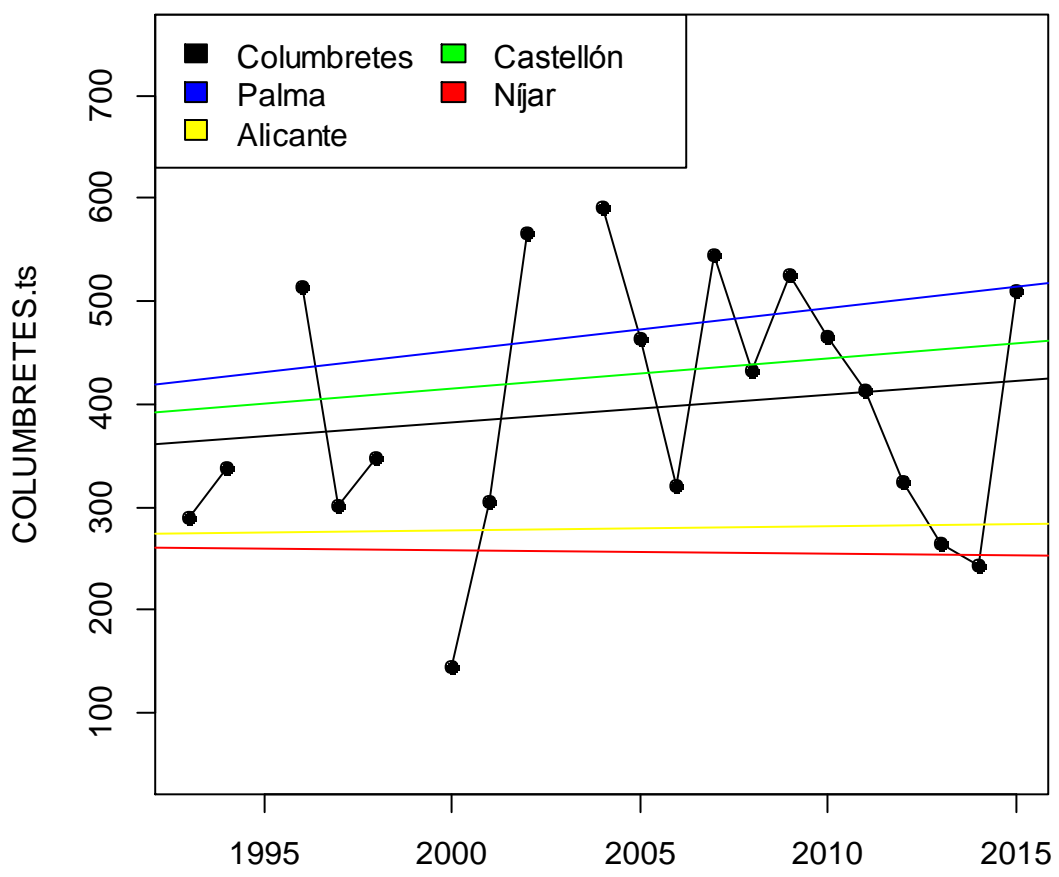


Annexos

ANNEX 2.1 .

Localización (coordenadas UTM, huso 31S) y código de las trampas de gravedad en la Illa Grossa, el Mancolibre, la Ferrera y la Foradada 


\begin{tabular}{|c|c|c|}
\hline Isla/islote & Zona & Coordenadas UTM \\
\hline \multirow{12}{*}{ Illa Grossa } & \multirow{3}{*}{ Matorral Norte } & IMN1 (0302303 / 4419404) \\
\hline & & IMN2 (0302208 / 4419319) \\
\hline & & IMN3 (0302096 / 4419215) \\
\hline & \multirow{3}{*}{ Matorral Sur } & IMS1 (0302093 / 4418840) \\
\hline & & IMS2 (0302157 / 4418794) \\
\hline & & IMS3 (0302202 / 4418755) \\
\hline & \multirow{3}{*}{ Roquedo } & IR1 (0302297 / 4419391) \\
\hline & & IR2 (0302157 / 4419250) \\
\hline & & IR3 (0302150 / 4419250) \\
\hline & \multirow{3}{*}{ Humanizada } & IH1 (0302182 / 4418761) \\
\hline & & IH2 (0302010 / 4419037) \\
\hline & & IH3 (0302207 / 4418713) \\
\hline \multirow{3}{*}{ Mancolibre } & \multirow{3}{*}{ Matorral } & TMC1 (0302592 / 4418957) \\
\hline & & TMC2 (0302571 / 4418903) \\
\hline & & TMC3 (0302599 / 4418911) \\
\hline \multirow{3}{*}{ Ferrera } & \multirow{3}{*}{ Matorral } & TFE1 (0300713 / 4418476) \\
\hline & & TFE2 (0300687 / 4418516) \\
\hline & & TFE3 (0300689 / 4418559) \\
\hline \multirow{3}{*}{ Foradada } & \multirow{3}{*}{ Matorral } & TFO1 (0300899 / 4416741) \\
\hline & & TFO2 (0300890 / 4416732) \\
\hline & & TFO3 (0300865 / 4416740) \\
\hline
\end{tabular}




\section{ANNEX 2.2.}

Listado de especies de invertebrados recopiladas en el presente estudio en Columbretes, ordenadas alfabéticamente, y número de referencias previas encontradas de cada una de ellas (№ref.bibl = número de referencias bibliográficas en las que se ha encontrado dicha especie, según hayan sido publicadas antes de 1994, desde 1994 hasta 2003 o después de 2003; №col = número de referencias de cada especie en otras colecciones).

En el caso de las especies registradas (observadas y/o capturadas) en el presente estudio, indicamos el identificador (E.C. = táxones identificados por el Equipo de Columbretes), el año de determinación y el número de registros realizados (№reg).

Se marca con un * aquéllas que no habían sido catalogados con anterioridad en Columbretes, en gris las que constituyen primeras citas, y se subraya las especies endémicas. 


\begin{tabular}{|c|c|c|c|c|c|c|c|}
\hline Familia & Especie & Determinador & Noreg & $<1994$ & $\begin{array}{l}\text { NNoref.bibl } \\
1994-2003\end{array}$ & $>2003$ & №col \\
\hline Erythraeidae & Abrolophus sp. & & & 1 & & & \\
\hline Porcellionidae & Acaeroplastes melanurus (Budde-Lund, 1885)* & LI. Garcia / 2016 & 1 & & & & \\
\hline Chrysomelidae & Acanthoscelides obtectus Say, 1831 & & & 1 & & & \\
\hline Acaridae & Acaridae sp. & & & 1 & & & \\
\hline Sphingidae & Acherontia atropos (Linnaeus, 1758) & E.C. / 2006 & 4 & 1 & & & \\
\hline Cephalobidae & Acrobeles complexus Thorne, 1925 & & & & & 1 & \\
\hline Cephalobidae & Acrobeloides bodenheimeri (Steiner, 1936) & & & & & 1 & \\
\hline Cephalobidae & Acrobeloides nanus (de Man, 1880) & & & & & 1 & \\
\hline Aeolothripidae & Aeolothrips tenuicornis Bagnall, 1926 & & & 1 & & & \\
\hline Cicadellidae & Agallia brachyptera (Boheman, 1847) & & & 1 & & & \\
\hline Cicadellidae & Agallia hispanica Horvath, 1900 & & & 2 & & & \\
\hline Pterophoridae & Agdistis neglecta Arenberger, $1976^{*}$ & S. Montagud / 2016 & 1 & & & & \\
\hline Pyralidae & Aglossa pinguinalis (Linnaeus, 1758) & E.C. / 2009 & 1 & 1 & & & \\
\hline Sphingidae & Agrius convolvuli (Linnaeus, 1758)* & S. Montagud / 2016 & 1 & & & & \\
\hline Silvanidae & Ahasverus advena (Waltl, 1834) & & & 1 & & & \\
\hline Gymnodamaeidae & Aleurodamaeus setosus (Berlese, 1883) & & & 1 & & & \\
\hline Tenebrionidae & Alphasida bonacherai Español, 1958 & $\begin{array}{l}\text { E.C. / } 2006 \\
\text { S. Montagud / } 2011\end{array}$ & 9 & 2 & 1 & & \\
\hline Tenebrionidae & Alphitobius diaperinus (Panzer, 1797) & E.C. / 2011 & 1 & & 1 & & \\
\hline Phytoseiidae & Amblyseius andersoni (Chant, 1957) & & & & 1 & & \\
\hline Phytoseiidae & Amblyseius stipulatus Athias-Henriot, 1960 & & & & 1 & & \\
\hline Apidae & Amegilla sp. & & & & 1 & & \\
\hline Acrididae & Anacridium aegyptium (Linnaeus, 1764) & $\begin{array}{l}\text { E.C. / } 2004 \\
\text { S. Montagud / } 2011 \\
\text { S. Montagud / } 2016 \\
\text { J. Jaques / } 2016\end{array}$ & 18 & 1 & & & \\
\hline Noctuidae & Anarta sodae (Rambur, 1829) & & & 1 & & & \\
\hline Aeshnidae & Anax imperator Leach, 1815 & & & 1 & & & \\
\hline Aeshnidae & Anax parthenope (Selys, 1839)* & E.C. / 2004 & 11 & & & & \\
\hline
\end{tabular}




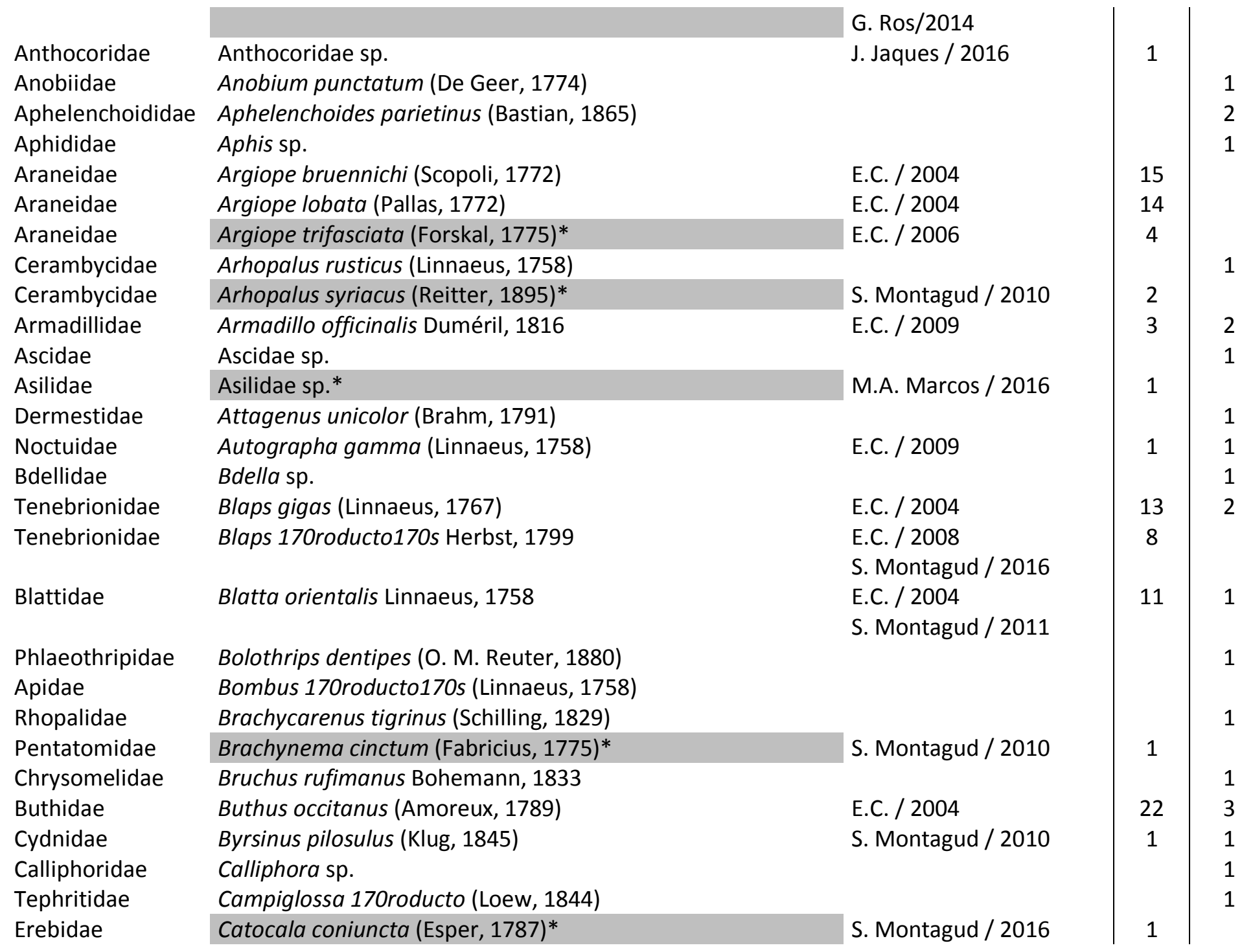




\section{Elateridae}

Tenuipalpidae

Aphididae

Miturgidae

Cheyletidae

Cheyletidae

Cephalobidae

Chrysopidae

Chrysopidae

Syrphidae

Cicadellidae

Clubionidae

Aphididae

Coccinellidae

Pieridae

Helicidae

Cosmochthoniida

Libellulidae

Tenebrionidae

Chrysomelidae

Cryptognathidae

Carabidae

Cryptopidae

Cryptopidae

Pulicidae

Lepismatidae

Cunaxidae

Cydnidae

Salticidae

Bdellouridae
Cebrio superbus Jacquelin du Val, 1860*

S. Montagud / 2016

Cenopalpus pterinus Pritchard \& Baker, 1958

Chaetosiphon alpestre Hille Ris Lambers, 1953

Cheiracanthium angulitarse Simon, 1878

Cheletogenes ornatus (Canestrini \& Fanzago, 1876)

Cheletomimus sp.

Chiloplacus minimus (Thorne, 1925)

Chrysopa sp.

Chrysoperla carnea (Stephens, 1836

Chrysotoxum intermedium (Meigen, 1822)

Circulifer dubiosus (Matsumura, 1908)

Clubiona sp.*

E.C. / 2006

Clypeoaphis suaedae Mimeur, 1934

Coccinella septempunctata Linnaeus, 1758*

Colias croceus (Fourcroy, 1785)

Cornu aspersum (O.F. Muller, 1774)

E. Morano / 2016

E.C. / 2006

E.C. / 2009

S. Montagud / 2016

E.C. / 2008

Crocothemis erythraea (Brullé, 1832)

Crypticus pubens Fairmaire, 1880

Cryptocephalus fulvus (Goeze, 1777)

Cryptognathus sp.

Cryptophonus tenebrosus (Dejean, 1829)

\section{Cryptops sp*}

S. Montagud / 2017

Cryptops trisulcatus Brolemann, 1902

Ctenocephalides canis (Curtis, 1826)

Ctenolepisma sp.*

S. Montagud / 2016

Cunaxoides biscutum (Nesbitt, 1946)

Cydnus aterrimus (Forster, 1771)*

E.C. / 2009

S. Montagud / 2010

Cyrba algerina (Lucas, 1846)

Cyta latirostris (Hermann, 1804) 
Nymphalidae Dermestidae

Anguinidae

Ostellidae

Dysderidae

Dysderidae

Ectopsocidae

Tenebrionidae

Embiidae

Pterophoridae

Helicidae

Syrphidae

Eriophyidae

Syrphidae

Syrphidae

Syrphidae

Cephalobidae

Syrphidae

Ferussaciidae

Ichneumonidae

Tylenchidae

Forficulidae

Garypidae

Garypidae

Geometridae

Phytoseiidae

Gryllidae

Gryllidae

Geometridae
Danaus chrysippus (Linnaeus, 1758)

Dermestes frischi Kugelann, 1792

Ditylenchus intermedius (de Man, 1880)

Drilocephalobus moldavicus Lisethkaja, 1968

Dysdera cf. crocota*

Dysdera crocata C.L. Koch, 1838

Ectopsocus briggsi McLachlan, 1899

Elenophorus collaris (Linnaeus, 1767)

E.C. / 2008

S. Montagud / 2010

Embia ramburi Rimski-Korsakow, 1905

Emmelina monodactyla (Linnaeus, 1758)*

S. Montagud / 2016

Eobania vermiculata (O.F. Muller, 1774)

Episyrphus balteatus (De Geer, 1776)

M.A. Marcos / 2016

Eriophyes sp.

Eristalis similis (Fallen, 1817)

Eristalis sp.*

M.A. Marcos / 2016

E.C. / 2009

M.A. Marcos / 2016

Eucephalobus hooperi Marinari-Palmisano, 1967

Eupeodes corollae (Fabricius, 1794)

Ferussacia folliculus (Gmelin, 1791)

Fianoniella stenognatha Bordera, 1998

E.C. / 2009

Filenchus filiformis (Butschli, 1873)

Forficula auricularia Linnaeus, 1758

Garypus beauvoisii (Audouin, 1826)

S. Montagud / 2016

J.A. Zaragoza / 2008

Garypus sp.

E. Morano / 2016

Geometridae sp.

Graminaseius lituatus (Athias-Henriot, 1961)

Gryllomorpha uclensis Pantel, 1890*

Gryllus bimaculatus De Geer, 1773*

S. Montagud / 2016

Gymnoscelis rufifasciata (Haworth, 1809)

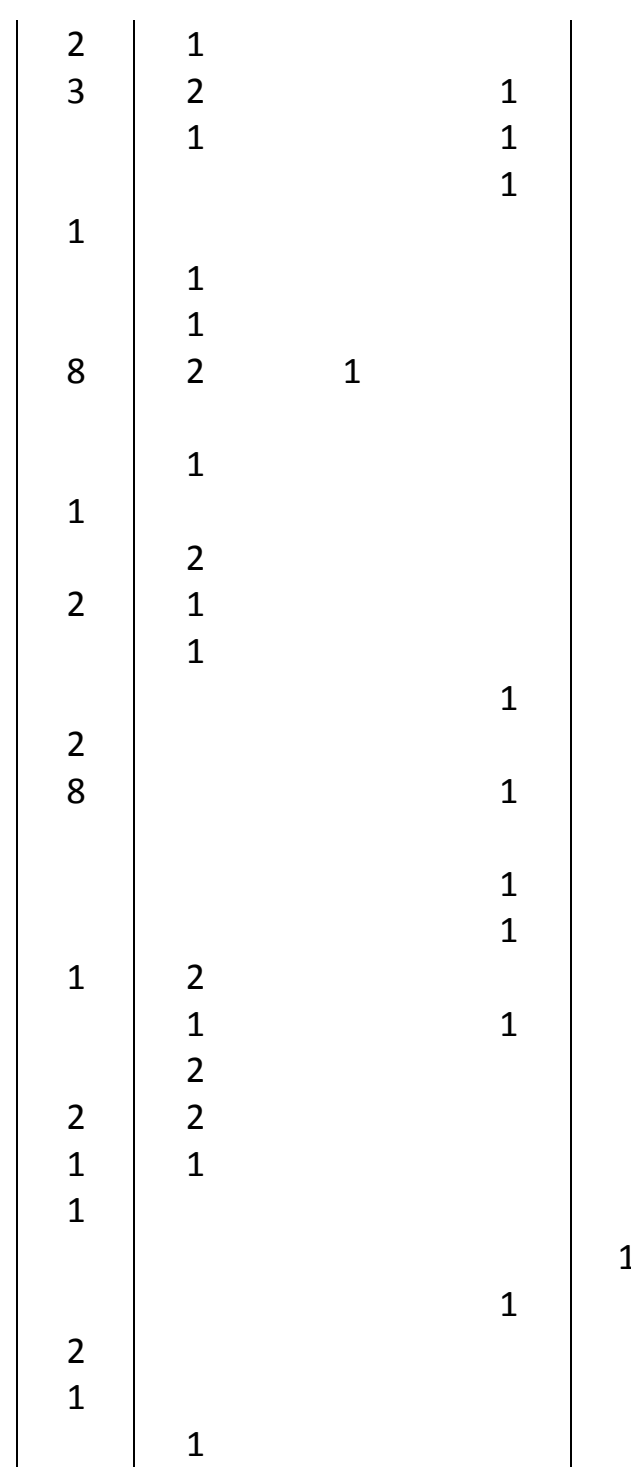


Philopteridae Oligotomidae

Noctuidae

Tenebrionidae Tenebrionidae Noctuidae

Syrphidae

Aphididae

Curculionidae

Curculionidae

Margarodidae

Geometridae

Geometridae

Coenagrionidae

Apionidae

Phytoseiidae

Lycaenidae

Anobiidae

Ceratozetidae

Lauriidae

Limacidae

Lepismatidae

Ligiidae

Linotetranidae

Lithobiidae

Lithobiidae
Halipeurus (Halipeurus) abnormis (Piaget, 1885)

Haploembia solieri (Rambur, 1842)

Helicoverpa 173rmígera (Hübner, 1808)*

E.C. / 2009

S. Montagud / 2010

S. Montagud / 2016

Heliopathes forcadelli Español, 1958

Heliopathes littoralis Español, 1958

E.C. / 2008

Heliothis peltigera (Denis \& Schiffermüller, 1775)*

S. Montagud / 2016

Helophilus trivittatus (Fabricius, 1805)

Hyalopterus pruni (Geoffroy, 1762)

Hypothenemus eruditus Westwood, 1836

Hypurus bertrandi (Perris, 1852)

Icerya purchasi Maskell, 1878* $\quad$ E.C. / 2004

S. Montagud / 2016

Idaea seriata (Schrank, 1802)

Idaea sp.

S. Montagud / 2016

Ischnura elegans (Vander Linden, 1820)*

E.C. / 2013

G.Ros / 2014

S.Teruel / 2016

Kalcapion semivittatum (Gyllenhal, 1833)

Kampimodromus aberrans (Oudemans, 1930)

Lampides boeticus (Linnaeus, 1767)*

S. Montagud / 2016

Lasioderma redtenbacheri (Bach, 1852)

Latilamellobates columbreti Minguez \& Subias, 1986

Lauria cylindracea (Da Costa, 1778)

Lehmannia valentiana (A. Ferussac, 1822)

S. Montagud / 2016

Lepisma sp.

Ligia italica Fabricius, 1798*

E.C. / 2009

E.C. / 2004

Linotetranus cylindricus Berlese, 1910

Lithobius Iusitanus Verhoeff, 1925

Lithobius sp.

E.C. $/ 2009$
5

2

2

1

1

10

1

1

1

1

1

20 
Tydeidae

Tydeidae

Sicariidae

Calliphoridae

Calliphoridae

Miridae

Sphingidae

Macronissidae

Carabidae

Syrphidae

Dorylaimidae

Limnephilidae

Formicidae

Formicidae

Cryptophagidae

Caeculidae

Cheyletidae

Milacidae

Milacidae

Noctuidae

Mordellidae

Mordellidae

Mordellidae

Noctuidae

Aphididae

Nabidae

Oedemeridae

Nematalycidae

Nemesiidae
Lorryia ferula Baker, 1944

Lorryia formosa Cooreman, 1958

Loxosceles rufescens (Dufour, 1820)

Lucilia caesar (Linnaeus, 1758)

Lucilia sericata (Meigen, 1826)*

M.A. Marcos / 2016

Lygus pratensis (Linnaeus, 1758)

Macroglossum stellatarum (Linnaeus, 1758)

E.C. / 2009

J. Jaques / 2016

Macronissidae sp.

Masoreus wetterhallii (Gyllenhal, 1813)

Meliscaeva auricollis (Meigen, 1822)

Mesodorylaimus bastiani (Butschli, 1873)

Mesophylax aspersus (Rambur, 1842)

Messor bouvieri Bondroit, 1918*

Messor sp.

D. García / 2016

S. Montagud / 2016

Micrambe ulicis (Stephens, 1830)

Microcaeculus hispanicus Franz, 1952

Microcheyla parvula Volgin, 1966

Milax gagates (Draparnaud, 1801)

Milax nigricans (Philippi, 1836)

Mniotype spinosa (Chrétien, 1910)*

E.C. / 2008

S. Montagud / 2017

Mordellistena columbretensis Compte, 1969

Mordellistena sp.

Mordellistenula plutonica Compte, 1969

Mythimna vitellina (Hübner, 1808)*

S. Montagud / 2016

Myzus persicae Sulzer, 1776

Nabis punctatus A. Costa, 1847

Nacerdes melanura (Linnaeus, 1758)

Nematalycidae sp.

Nemesia sp.* $\quad$ E. Morano / 2016

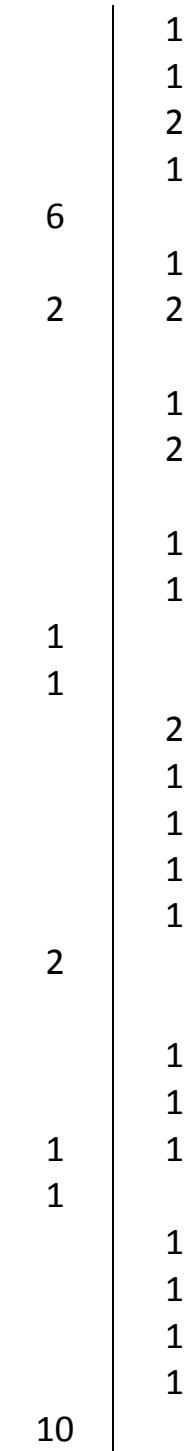


Araneidae
Phytoseiidae
Pentatomidae

Noctuidae

Cydnidae

Gryllidae

Oecophoridae

Anobiidae

Ichneumonidae

Erebidae

Oribatulidae

Anthocoridae

Miridae

Silvanidae

Crambidae

Panagrolaimidae

Bradyporidae

Blattidae

Curculionidae

Formicidae

Pseudococcidae

Philodromidae

Noctuidae

Pholcidae

Dynastidae

Pieridae

Tenebrionidae
Neoscona subfusca (C.L. Koch, 1837)*

E. Morano / 2016

Neoseiulella litoralis (Swirski \& Amitai, 1984)

Nezara viridula (Linnaeus, 1758)*

E.C. / 2009

S. Montagud / 2010

Noctua comes Hübner, 1813

Ochetostethus nanus (Herrich-Schäffer, 1834)

Oecanthus pellucens (Scopoli, 1763)*

E.C. / 2007

S. Montagud / 2010

Oecophoridae sp.

Oligomerus ptilinoides (Wollaston, 1854)

Ophion sp.*

E.C. / 2010

S. Montagud / 2017

Ophiusa tirhaca (Cramer, 1773)*

S. Montagud / 2016

Oribatula tibialis (Nicolet, 1855)

Orius lindbergi Wagner, 1952

Orthotylus moncreaffi (Douglas \& Scott, 1874)

Oryzaephilus surinamensis (Linnaeus, 1758)

Palpita vitrealis (Rossi, 1794)*

S. Montagud / 2016

Panagrolaimus rigidus (A. Schneider, 1866)

Parasteropleurus sp.

Periplaneta americana (Linnaeus, 1758)*

P. Barranco / 2017

E.C. / 2010

Peritelus espanoli Roudier, 1958

Pheidole pallidula (Nylander, 1849)

D. García / 2016

Phenacoccus sp.

Philodromus glaucinus Simon, 1870

Phlogophora meticulosa (Linnaeus, 1758)

Pholcus sp.

Phyllognathus excavatus (Forster, 1771)*

S. Montagud / 2016

Pieris rapae (Linnaeus, 1758)

Pimelia interjecta Solier, 1836

E.C. / 2004

S. Montagud / 2010 


\begin{tabular}{|c|c|c|c|c|}
\hline Pyralidae & Piralidae sp.* & S. Montagud / 2016 & 1 & \\
\hline Miridae & Plagiognathus sp. & & & 1 \\
\hline Asterolecaniidae & Planchonia arabidis Signoret, 1876* & F. García-Marí, GV / 2011 & 3 & \\
\hline Plectidae & Plectus cirratus Bastian, 1865 & & & 1 \\
\hline Plutellidae & Plutella xylostella (Linnaeus, 1758) & & & 1 \\
\hline Vespidae & Polistes sp.* & S. Montagud / 2016 & 1 & \\
\hline Pomatiidae & Pomatias elegans (O.F. Muller, 1774) & & & 1 \\
\hline Porcellionidae & Porcellio violaceus Budde-Lund, 1879 & Ll. Garcia / 2016 & 1 & 1 \\
\hline Porcellionidae & Porcellionides sexfasciatus (Koch, 1847) & & & 1 \\
\hline Phytoseiidae & Proprioseiopsis messor (Wainstein, 1960) & & & 1 \\
\hline Chernetidae & Pselaphochernes lacertosus (L. Koch, 1873) & & & 1 \\
\hline Mogoplistidae & Pseudomogoplistes squamiger (Fischer, 1853) & & & 1 \\
\hline Philopteridae & Puffinoecus peusi Eichler, 1949 & & & 1 \\
\hline Pyrrhocoridae & Pyrrhocoridae sp. & E.C. / 2004 & 10 & \\
\hline Pyrrhocoridae & Pyrrhocoris apterus (Linnaeus, 1758)* & $\begin{array}{l}\text { E.C. / } 2004 \\
\text { J. Jaques / } 2016\end{array}$ & 2 & \\
\hline Raphignathidae & Raphignathidae sp. & & & 1 \\
\hline Reduviidae & Reduvius personatus (Linnaeus, 1758) & & & 1 \\
\hline Rhabdolaimidae & Rhabdolaimus terrestris de Man, 1880 & & & 1 \\
\hline Cheliferidae & Rhacochelifer maculatus (L. Koch, 1873) & & & 1 \\
\hline Rhodacaridae & Rhodacaridae sp. & & & 1 \\
\hline Geometridae & Rhodometra sacraria (Linnaeus, 1767)* & $\begin{array}{l}\text { E.C. / } 2009 \\
\text { S. Montagud / } 2010\end{array}$ & 3 & \\
\hline Coccinellidae & Rodolia cardinalis (Mulsant, 1850)* & E.C. / 2004 & 11 & \\
\hline Salticidae & Salticus confusus Lucas, 1846 & & & 1 \\
\hline Adamystidae & Saxidromus delamarei Coineau, 1974 & & & 1 \\
\hline Syrphidae & Scaeva albomaculata (Macquqrt, 1842) & & & \\
\hline Syrphidae & Scaeva mecogramma (Bigot, 1860) & & & \\
\hline Syrphidae & Scaeva pyrastri (Linnaeus, 1758) & & & 1 \\
\hline Pyrrhocoridae & Scantius aegyptius (Linnaeus, 1758) & S. Montagud / 2017 & 1 & 1 \\
\hline Scathophagidae & Scathophaga stercoraria (Linnaeus, 1758) & & & 1 \\
\hline
\end{tabular}


Tenebrionidae Tenebrionidae Pentatomidae Bostrichidae Scutigeridae

Scutoverticidae Scutoverticidae Segestriidae

Dryophthoridae Smarididae

Syrphidae

Syrphidae

Tephritidae

Bdellidae

Spinturnicidae

Therediidae

Cephalobidae

Cephalobidae

Anobiidae

Stigmaeidae

Himantariidae

Muscidae

Libellulidae

Syrphidae

Syrphidae

Tarsonemidae

Erythracaridae

Tenebrionidae
Scaurus rugulosus Solier, 1838

Scaurus vicinus Solier, 1838

E.C. / 2008

E.C. $/ 2007$

Sciocoris macrocephalus Fieber, 1851

Scobicia chevrieri (Villa \& Villa, 1835)

Scutigera coleoptrata (Linnaeus, 1758)

E.C. / 2004

J. Jaques / 2014

Scutovertex minutus (C. L. Koch, 1836)

Scutovertex sculptus Michael, 1879

\section{Segestria sp*}

Sitophilus granarius (Linnaeus, 1758)

Smaris sp.

Sphaerophoria rueppellii (Wiedemann, 1830)

Sphaerophoria scripta (Linnaeus, 1758)

Sphenella marginata (Fallen, 1814)

Spinibdella sp.

Spinturnicidae sp.

Steatoda sp.*

Stegelleta ophioglossa Andrassy, 1967

Stegelletina devimucronata (Sumenkova, 1964)

Stegobium paniceum (Linnaeus, 1758)

Stigmaeus sp.

Stigmatogaster dimidiatus (Meinert, 1870)

Stomoxys calcitrans (Linnaeus, 1758)

Sympetrum fonscolombii (Selys, 1840)

Syritta pipiens (Linnaeus, 1758)

Syrphus ribesii (Linnaeus, 1758)

Tarsonemidae sp.

Tarsotomus hurcules (Berlese, 1882)

Tentyria pazi Español, 1958
E. Morano / 2016

E.C. / 2007

S. Montagud / 2011

G. Ros /2014

E. Morano / 2016

E.C. / 2004

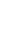


Tetranychidae

Helicidae

Thomisidae

Thripidae

Tortricidae

Tenebrionidae

Ceratozetidae

Trombidiidae

Tephritidae

Tephritidae

Tydeidae

Phytoseiidae

Phytoseiidae

Phytoseiidae

Erebidae

Nymphalidae

Nymphalidae

Noctuidae

Hypogastruridae

Hygromiidae

Xiphinematidae

Gnaphosidae

Oribatulidae

Oribatulidae
Tetranychidae sp.

Theba pisana (O.F. Muller, 1774)

Thomisus onustus Walckenaer, 1805

Thrips tabaci Lindeman, 1889

Tortricidae sp.

Tribolium castaneum (Herbst, 1797)

Trichoribates trimaculatus (C. L. Koch, 1836)

Trombidiidae sp.

Trupanea amoena (Frauenfeld, 1857)

Trupanea stellata (Fuesslin, 1775)

Tydeus kochi (Oudemans, 1928)

Typhlodromus (Anthoseius) foenilis Oudemans, 1930

Typhlodromus (Anthoseius) phialatus Athias-Henriot, 1960

Typhlodromus (Anthoseius) rhenanoides Athias-Henriot, 1960

Utetheisa pulchella (Linnaeus, 1758)

Vanessa atalanta (Linnaeus, 1758)

Vanessa cardui (Linnaeus, 1758)

Xanthodes albago (Fabricius, 1794)*

Xenylla humicola (O. Fabricius, 1780)

Xerocrassa molinae (Hidalgo, 1883)

Xiphinema sp.

Zelotes sp.*

Zygoribatula frisiae (Oudemans, 1900)

Zygoribatula lenticulata Minguez \& Subias, 1986
E.C. $/ 2006$

E. Morano / 2016

S. Montagud / 2010

S. Montagud / 2016

E.C. / 2006

J. Jaques / 2016

E.C. / 2009

E.C. / 2009

S. Montagud / 2010

E.C. / 2004

E. Morano / 2016
20 


\section{ANNEX 2.3.}

Catálogo de invertebrados terrestres de las Islas Columbretes (IG = Illa Grossa; $M C=$ Mancolibre; MS = Mascarat; ST = Senyoreta; Fe = Ferrera; Fo = Foradada), ordenados alfabéticamente por Phylum, clase, orden, familia y especie, año de primera observación en la isla o islote indicados, referencia de la fuente en la que se publicó dicha primera observación y si ha sido observado (+) o no (-) en el presente estudio.

Se añade un ${ }^{*}$ a aquellos taxones que se han catalogado por primera vez en una isla o ${ }^{* *}$ en dos islas, y se subraya las especies endémicas.

Las referencias de la columna "fuente" son: ALS,95 = Habsburgo-Lorena, 1895; Arias,71 = Arias, 1971; B,98 = Bordera, 1998; Bru,13 = Bru, 1913; CC,02 = Cartagena \& Galante, 2002; C,69 = Compte, 1969; Col.ICB = Colección ICBiBe; Col.R.V. = Colección Roger y Laura Vila; CPP,06 = Castilla et al, 2006; CPE,04 = Castilla et al, 2004; DEA,08 = Mestre-Forés \& Ferragut, 2008 (Anexo 2.4); Esp,58 = Español, 1958; GB,74 = Gadea, 1974; GM,91 = García-Marí et al. 1991; G.LI.,01 = Gorochov \& Llorente, 2001; GP,04 = Prieto et al, 2004; J,52 = Jaeckel, 1952; MOyP,11 = Martínez-Ortí \& Puente, 2011; MM,03 = Melià, 2003; MMG,17 = Mestre-Forés et al, 2017 (Capítulo 2 de esta tesis); NEL,15 = Navarro et al, 2015; PB,00 = Pérez-Bañón, 2000; PLI,87 = Pinedo \& Llorente, 1987; R,91 = Robles, 1991: 


\begin{tabular}{|c|c|c|c|c|c|c|c|}
\hline Phylum & Clase & Orden & Familia & Especie & Isla/1a cita & Fuente & Obs. \\
\hline Arthropoda & Arachnida & Araneae & Araneidae & Argiope bruennichi (Scopoli, 1772) & IG/2000 & $\mathrm{CPE}, 04$ & + \\
\hline \multirow[t]{3}{*}{ Arthropoda } & Arachnida & Araneae & Araneidae & Argiope lobata (Pallas, 1772) & IG/2000 & CPE,04 & + \\
\hline & & & & & $\mathrm{MC} / 2006$ & CPP,06 & + \\
\hline & & & & & Fo/2009 & MMG,17 & + \\
\hline Arthropoda & Arachnida & Araneae & Araneidae & Argiope trifasciata (Forskal, 1775)* & IG/2006 & MMG,17 & + \\
\hline Arthropoda & Arachnida & Araneae & Araneidae & Neoscona subfusca (C.L. Koch, 1837)* & IG/2009 & MMG,17 & + \\
\hline Arthropoda & Arachnida & Araneae & Clubionidae & Clubiona sp.* & IG/2009 & MMG,17 & + \\
\hline Arthropoda & Arachnida & Araneae & Dysderidae & Dysdera crocata C.L. Koch, 1838 & IG/1957 & Esp,58 & + \\
\hline Arthropoda & Arachnida & Araneae & Dysderidae & Dysdera cf. crocota* & IG/2009 & MMG,17 & + \\
\hline Arthropoda & Arachnida & Araneae & Gnaphosidae & Zelotes sp.* & IG/2008 & MMG,17 & + \\
\hline Arthropoda & Arachnida & Araneae & Miturgidae & Cheiracanthium angulitarse Simon, 1878 & IG/1957 & Esp,58 & - \\
\hline Arthropoda & Arachnida & Araneae & Nemesiidae & Nemesia sp.* & IG/2009 & MMG,17 & + \\
\hline Arthropoda & Arachnida & Araneae & Philodromidae & Philodromus glaucinus Simon, 1870 & IG/1957 & Esp,58 & - \\
\hline Arthropoda & Arachnida & Araneae & Pholcidae & Pholcus sp. & $\begin{array}{l}\text { IG/1892 } \\
\text { (por E.Boscà) }\end{array}$ & Esp,58 & + \\
\hline Arthropoda & Arachnida & Araneae & Salticidae & Cyrba algerina (Lucas, 1846) & IG/1957 & Esp,58 & - \\
\hline Arthropoda & Arachnida & Araneae & Salticidae & Salticus confusus Lucas, 1846 & IG/1957 & Esp,58 & - \\
\hline Arthropoda & Arachnida & Araneae & Segestriidae & Segestria sp.* & IG/2009 & MMG,17 & + \\
\hline Arthropoda & Arachnida & Araneae & Sicariidae & Loxosceles rufescens (Dufour, 1820) & IG/1894 & $\begin{array}{l}\text { Esp,58 (citada } \\
\text { como } \\
\text { L.distincta) }\end{array}$ & - \\
\hline Arthropoda & Arachnida & Araneae & Therediidae & Steatoda sp.* & IG/2008 & MMG,17 & + \\
\hline Arthropoda & Arachnida & Araneae & Thomisidae & Thomisus onustus Walckenaer, 1805 & IG/1957 & Esp,58 & + \\
\hline Arthropoda & Arachnida & Pseudoscorpiones & Cheliferidae & Rhacochelifer maculatus (L. Koch, 1873) & IG/1957 & Esp,58 & - \\
\hline Arthropoda & Arachnida & Pseudoscorpiones & Chernetidae & Pselaphochernes lacertosus (L. Koch, 1873) & IG/1957 & Esp,58 & - \\
\hline Arthropoda & Arachnida & Pseudoscorpiones & Garypidae & Garypus beauvoisii (Audouin, 1826) & IG/1985 & $\begin{array}{l}\text { GM,91 (citada } \\
\text { como } \\
\text { G.littoralis) }\end{array}$ & + \\
\hline Arthropoda & Arachnida & Pseudoscorpiones & Garypidae & Garypus sp. & IG/2009 & MMG,17 & + \\
\hline Arthropoda & Arachnida & Scorpiones & Buthidae & Buthus occitanus (Amoreux, 1789) (*en MC) & $\begin{array}{l}\mathrm{IG} / 1856 \\
\mathrm{MC} / 1988\end{array}$ & $\begin{array}{l}\text { ALS,95 } \\
\text { MMG,17 }\end{array}$ & $\begin{array}{l}+ \\
+\end{array}$ \\
\hline
\end{tabular}




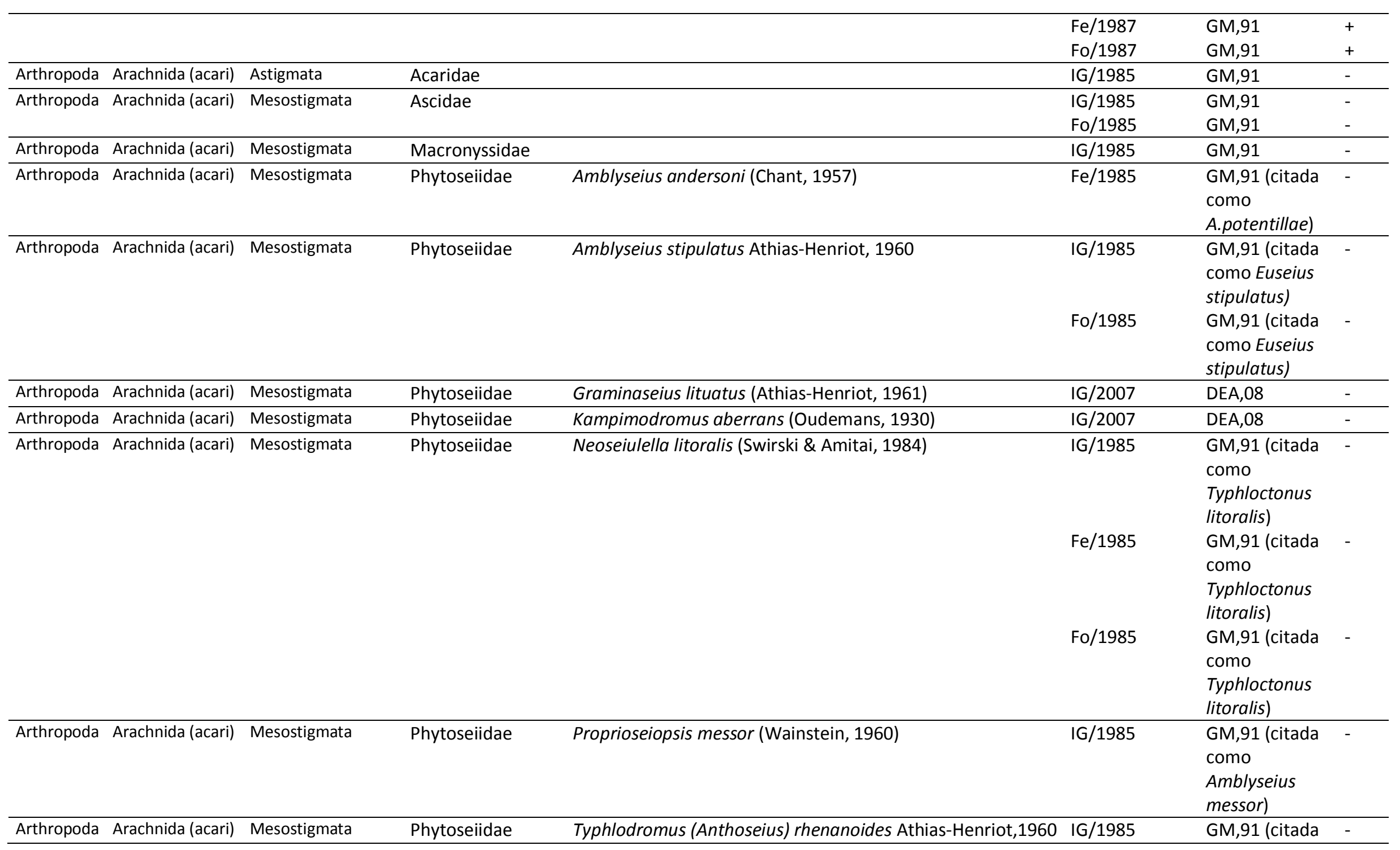




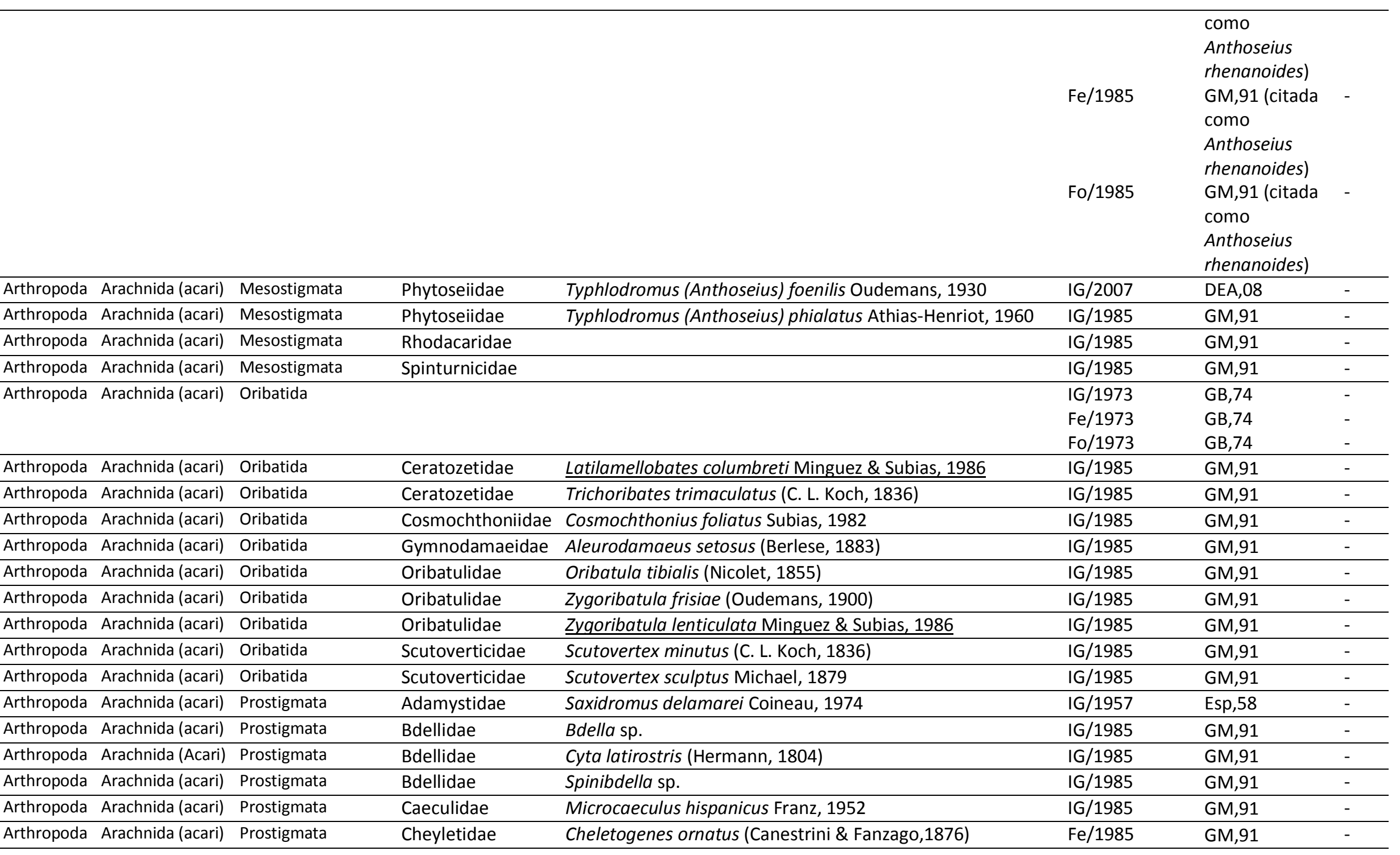




\begin{tabular}{|c|c|c|c|c|c|c|c|}
\hline Arthropoda & Arachnida (acari) & Prostigmata & Cheyletidae & Cheletomimus sp. & IG/1985 & GM,91 & - \\
\hline Arthropoda & Arachnida (acari) & Prostigmata & Cheyletidae & Microcheyla parvula Volgin, 1966 & IG/1985 & GM,91 & - \\
\hline Arthropoda & Arachnida (acari) & Prostigmata & Cryptognathidae & Cryptognathus sp. & IG/1985 & GM,91 & - \\
\hline \multirow[t]{2}{*}{ Arthropoda } & Arachnida (acari) & Prostigmata & Cunaxidae & Cunaxoides biscutum (Nesbitt, 1946) & IG/1985 & GM,91 & - \\
\hline & & & & & $\mathrm{Fe} / 1985$ & $\mathrm{GM}, 91$ & - \\
\hline Arthropoda & Arachnida (acari) & Prostigmata & Eriophyidae & Eriophyes sp. & IG/1985 & GM,91 & - \\
\hline \multirow[t]{2}{*}{ Arthropoda } & Arachnida (acari) & Prostigmata & Erythracaridae & Tarsotomus hurcules (Berlese, 1882) & IG/1985 & $\begin{array}{l}\text { GM,91 (citada } \\
\text { como } \\
\text { Absoloniana } \\
\text { diversipes) }\end{array}$ & - \\
\hline & & & & & Fo/1985 & $\begin{array}{l}\text { GM,91 (citada } \\
\text { como } \\
\text { Absoloniana } \\
\text { diversipes) }\end{array}$ & - \\
\hline Arthropoda & Arachnida (acari) & Prostigmata & Erythraeidae & Abrolophus sp. & IG/1985 & GM,91 & - \\
\hline Arthropoda & Arachnida (acari) & Prostigmata & Linotetranidae & Linotetranus cylindricus Berlese, 1910 & IG/1985 & GM,91 & - \\
\hline Arthropoda & Arachnida (acari) & Prostigmata & Nematalycidae & & IG/1985 & GM,91 & - \\
\hline Arthropoda & Arachnida (acari) & Prostigmata & Raphignathidae & & IG/1985 & $\mathrm{GM}, 91$ & - \\
\hline Arthropoda & Arachnida (acari) & Prostigmata & Smarididae & Smaris sp. & IG/1985 & GM,91 & - \\
\hline Arthropoda & Arachnida (acari) & Prostigmata & Stigmaeidae & Stigmaeus sp. & IG/1985 & GM,91 & - \\
\hline Arthropoda & Arachnida (acari) & Prostigmata & Tarsonemidae & & IG/1985 & GM,91 & - \\
\hline Arthropoda & Arachnida (acari) & Prostigmata & Tenuipalpidae & Cenopalpus pterinus Pritchard \& Baker, 1958 & IG/1985 & GM,91 & - \\
\hline \multirow[t]{2}{*}{ Arthropoda } & Arachnida (acari) & Prostigmata & Tetranychidae & & IG/1985 & GM,91 & - \\
\hline & & & & & Fo/1985 & GM,91 & \\
\hline Arthropoda & Arachnida (acari) & Prostigmata & Trombidiidae & & IG/1985 & $\mathrm{GM}, 91$ & - \\
\hline Arthropoda & Arachnida (acari) & Prostigmata & Tydeidae & Lorryia ferula Baker, 1944 & IG/1985 & $\begin{array}{l}\text { GM,91 (citada } \\
\text { como } \\
\text { Paralorrya } \\
\text { ferula) }\end{array}$ & - \\
\hline Arthropoda & Arachnida (acari) & Prostigmata & Tydeidae & Lorryia formosa Cooreman, 1958 & IG/1985 & GM,91 & - \\
\hline \multirow[t]{2}{*}{ Arthropoda } & Arachnida (acari) & Prostigmata & Tydeidae & Tydeus kochi (Oudemans, 1928) & IG/1985 & GM,91 & - \\
\hline & & & & & Fo/1985 & $\mathrm{GM}, 91$ & \\
\hline Arthropoda & Chilopoda & Geophilomorpha & Himantariidae & Stigmatogaster dimidiatus (Meinert, 1870) & IG/1957 & Esp,58 & - \\
\hline
\end{tabular}




\begin{tabular}{|c|c|c|c|c|c|c|c|}
\hline Arthropoda & Chilopoda & Lithobiomorpha & Lithobiidae & Lithobius lusitanus Verhoeff, 1925 & IG/1957 & $\begin{array}{l}\text { Esp,58 } \\
\text { (citada como } \\
\text { L.stramineus) }\end{array}$ & + \\
\hline Arthropoda & Chilopoda & Lithobiomorpha & Lithobiidae & Lithobius sp. & IG/2009 & MMG,17 & + \\
\hline Arthropoda & Chilopoda & Scolopendromorpha & Cryptopidae & Cryptops sp. & IG/2009 & MMG,17 & + \\
\hline Arthropoda & Chilopoda & Scolopendromorpha & Cryptopidae & Cryptops trisulcatus Brolemann, 1902 & IG/1957 & Esp,58 & - \\
\hline Arthropoda & Chilopoda & Scutigeromorpha & Scutigeridae & Scutigera coleoptrata (Linnaeus, 1758) & IG/1957 & Esp,58 & + \\
\hline Arthropoda & Insecta & Coleoptera & Anobiidae & Anobium punctatum (De Geer, 1774) & IG/1957 & Esp,58 & - \\
\hline Arthropoda & Insecta & Coleoptera & Anobiidae & Lasioderma redtenbacheri (Bach, 1852) & IG/1957 & Esp,58 & - \\
\hline Arthropoda & Insecta & Coleoptera & Anobiidae & Stegobium paniceum (Linnaeus, 1758 & IG/1964 & $\mathrm{C}, 69$ & - \\
\hline Arthropoda & Insecta & Coleoptera & Anobiidae & Oligomerus ptilinoides (Wollaston, 1854) & IG/1957 & Esp,58 & - \\
\hline Arthropoda & Insecta & Coleoptera & Apionidae & Kalcapion semivittatum (Gyllenhal, 1833) & IG/1957 & $\begin{array}{l}\text { Esp,58 (citada } \\
\text { como Apion } \\
\text { semivittatum) }\end{array}$ & - \\
\hline Arthropoda & Insecta & Coleoptera & Brostrichidae & Scobicia chevrieri (Villa \& Villa, 1835) & IG/1964 & C,69 & - \\
\hline Arthropoda & Insecta & Coleoptera & Carabidae & Cryptophonus tenebrosus (Dejean, 1829) & Fo/1964 & $\mathrm{C}, 69$ & - \\
\hline Arthropoda & Insecta & Coleoptera & Carabidae & Masoreus wetterhallii (Gyllenhal, 1813) & IG/1957 & Esp,58 & - \\
\hline Arthropoda & Insecta & Coleoptera & Cerambycidae & Arhopalus rusticus (Linnaeus, 1758) & IG/1957 & $\begin{array}{l}\text { Esp,58 (citada } \\
\text { como } \\
\text { Criocephalus } \\
\text { rusticus) }\end{array}$ & - \\
\hline Arthropoda & Insecta & Coleoptera & Cerambycidae & Arhopalus syriacus (Reitter, 1895)* & IG/2009 & MMG,17 & + \\
\hline Arthropoda & Insecta & Coleoptera & Chrysomelidae & Acanthoscelides obtectus Say, 1831 & IG/1964 & $\mathrm{C}, 69$ & - \\
\hline Arthropoda & Insecta & Coleoptera & Chrysomelidae & Bruchus rufimanus Bohemann, 1833 & IG/1957 & Esp,58 & - \\
\hline Arthropoda & Insecta & Coleoptera & Chrysomelidae & Cryptocephalus fulvus (Goeze, 1777) & IG/1957 & Esp,58 & - \\
\hline Arthropoda & Insecta & Coleoptera & Coccinellidae & Coccinella septempunctata Linnaeus, 1758* & $\mathrm{Fe} / 2006$ & MMG,17 & + \\
\hline Arthropoda & Insecta & Coleoptera & Coccinellidae & Rodolia cardinalis (Mulsant, 1850)** & $\begin{array}{l}\text { IG/2001 } \\
\text { Fo/1996 }\end{array}$ & $\begin{array}{l}\text { MMG,17 } \\
\text { MMG,17 }\end{array}$ & + \\
\hline Arthropoda & Insecta & Coleoptera & Cryptophagidae & Micrambe ulicis (Stephens, 1830) & IG/1957 & $\begin{array}{l}\text { Esp,58 (citada } \\
\text { como } \\
\text { M.obcordata) }\end{array}$ & - \\
\hline Arthropoda & Insecta & Coleoptera & Curculionidae & Hypothenemus eruditus Westwood, 1836 & IG/1957 & $\begin{array}{l}\text { Esp,58 (citada } \\
\text { como }\end{array}$ & - \\
\hline
\end{tabular}




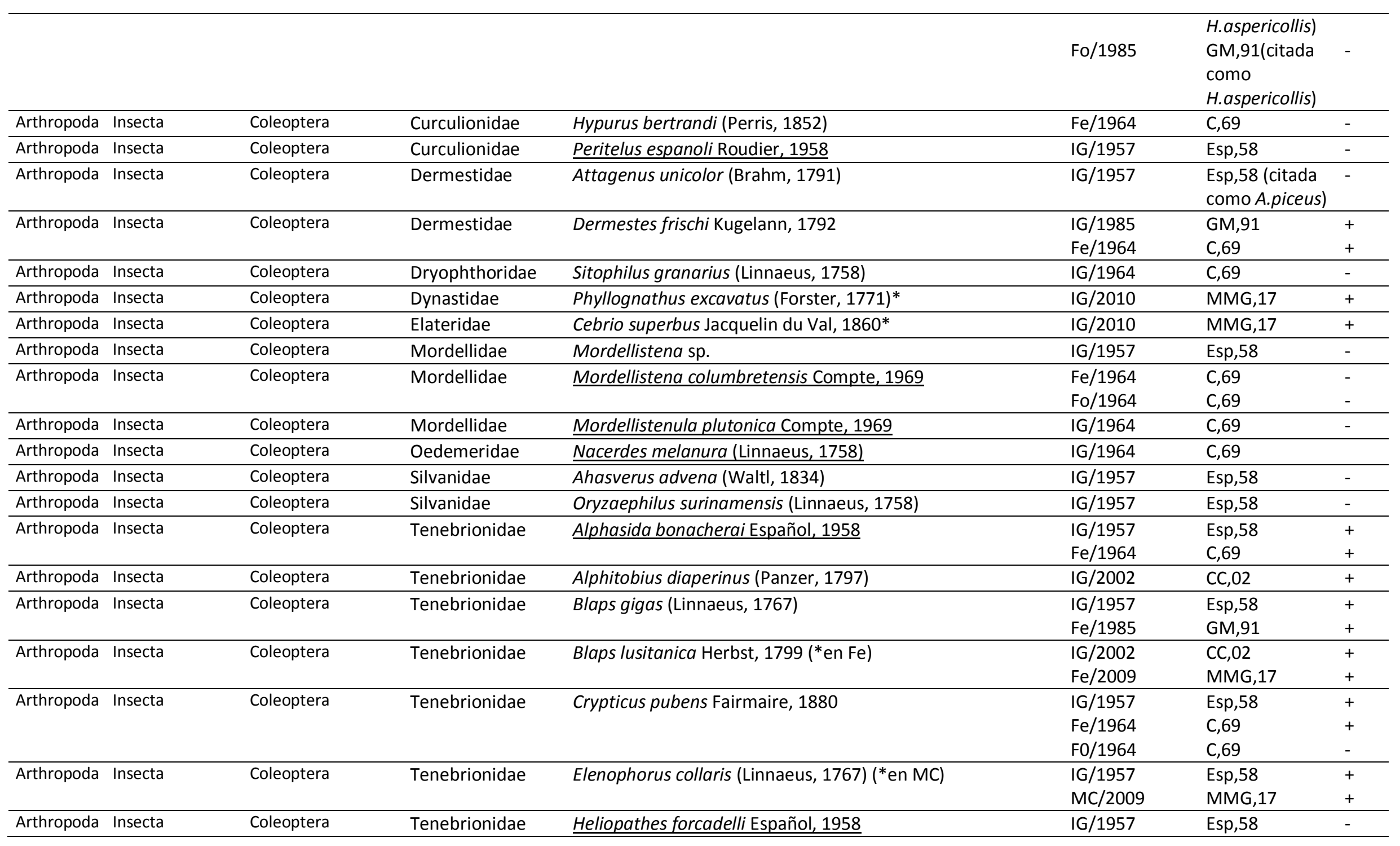




\begin{tabular}{|c|c|c|c|c|c|c|}
\hline & & & & $\mathrm{Fe} / 1964$ & C,69 & - \\
\hline & & & & Fo/1964 & $C, 69$ & - \\
\hline \multirow[t]{2}{*}{ Arthropoda Insecta } & Coleoptera & Tenebrionidae & Heliopathes littoralis Español, 1958 & $\begin{array}{l}\text { IG/1894 } \\
\text { (citada como } \\
\text { H.ibericus en } \\
\text { ALS,95) }\end{array}$ & Esp,58 & + \\
\hline & & & & Fo/1964 & C,69 & + \\
\hline \multirow[t]{4}{*}{ Arthropoda Insecta } & Coleoptera & Tenebrionidae & Pimelia interjecta Solier, 1836(*en MC,Fe) & $\begin{array}{l}\text { IG/1887 } \\
\text { (citada como } \\
P . \text { criba } \\
\text { elevata en } \\
\text { ALS,95) }\end{array}$ & Esp,58 & + \\
\hline & & & & MC/2009 & MMG,17 & + \\
\hline & & & & $\mathrm{Fe} / 2008$ & MMG,17 & + \\
\hline & & & & Fo/1964 & $C, 69$ & + \\
\hline \multirow[t]{4}{*}{ Arthropoda Insecta } & Coleoptera & Tenebrionidae & Scaurus rugulosus Solier, 1838 (*en MC) & IG/1957 & Esp,58 & + \\
\hline & & & & $\mathrm{MC} / 2009$ & MMG,17 & + \\
\hline & & & & $\mathrm{Fe} / 1964$ & $C, 69$ & + \\
\hline & & & & Fo/1964 & C,69 & + \\
\hline \multirow[t]{3}{*}{ Arthropoda Insecta } & Coleoptera & Tenebrionidae & Scaurus vicinus Solier, 1838 (*en Fe,Fo) & $\begin{array}{l}\text { IG/1894 } \\
\text { (citada como } \\
\text { S.tristis en } \\
\text { ALS,95) }\end{array}$ & Esp,58 & + \\
\hline & & & & $\mathrm{Fe} / 2010$ & MMG,17 & + \\
\hline & & & & Fo/2010 & MMG,17 & + \\
\hline \multirow[t]{5}{*}{ Arthropoda Insecta } & Coleoptera & Tenebrionidae & Tentyria pazi Español, 1958 & IG/1957 & Esp,58 & + \\
\hline & & & & MS/1985 & GM,91 & - \\
\hline & & & & $\mathrm{MC} / 1964$ & C,69 & + \\
\hline & & & & $\mathrm{Fe} / 1964$ & $C, 69$ & + \\
\hline & & & & Fo/1964 & $C, 69$ & + \\
\hline Arthropoda Insecta & Coleoptera & Tenebrionidae & Tribolium castaneum (Herbst, 1797) & IG/1964 & C,69 & - \\
\hline Arthropoda Insecta & Collembola & Hypogastruridae & Xenylla humicola (O. Fabricius, 1780) & IG/1957 & $\begin{array}{l}\text { Esp,58 (citada } \\
\text { como } \\
\text { X.maritima) }\end{array}$ & - \\
\hline
\end{tabular}




\begin{tabular}{|c|c|c|c|c|c|c|c|}
\hline Arthropoda & Insecta & Dermaptera & Forficulidae & Forficula auricularia Linnaeus, 1758 & IG/1957 & Esp,58 & + \\
\hline Arthropoda & Insecta & Dictyoptera & Blattidae & Blatta orientalis Linnaeus, 1758 & IG/1957 & Esp,58 & + \\
\hline Arthropoda & Insecta & Dictyoptera & Blattidae & Periplaneta americana (Linnaeus, 1758)* & IG/2010 & MMG,17 & + \\
\hline Arthropoda & Insecta & Diptera & Asilidae* & & Fo/2008 & MMG,17 & + \\
\hline Arthropoda & Insecta & Diptera & Calliphoridae & Calliphora sp. & $\begin{array}{l}\text { IG/1894 } \\
\text { (citada como } \\
\text { C. } \\
\text { erythrocephala } \\
\text { en ALS,95) }\end{array}$ & Esp,58 & - \\
\hline Arthropoda & Insecta & Diptera & Calliphoridae & Lucilia caesar (Linnaeus, 1758) & IG/1985 & GM,91 & - \\
\hline Arthropoda & Insecta & Diptera & Calliphoridae & Lucilia sericata (Meigen, 1826)* & IG/2009 & MMG,17 & + \\
\hline Arthropoda & Insecta & Diptera & Muscidae & Stomoxys calcitrans (Linnaeus, 1758) & IG/1957 & Esp,58 & - \\
\hline Arthropoda & Insecta & Diptera & Scathophagidae & Scathophaga stercoraria (Linnaeus, 1758) & $\begin{array}{l}\text { IG/1985 } \\
\text { Fe/1985 } \\
\text { Fo/1985 }\end{array}$ & $\begin{array}{l}\text { GM,91 } \\
\text { GM,91 } \\
\text { GM,91 }\end{array}$ & $\begin{array}{l}- \\
- \\
-\end{array}$ \\
\hline Arthropoda & Insecta & Diptera & Syrphidae & Chrysotoxum intermedium (Meigen, 1822) & IG/1998 & $\mathrm{PB}, 00$ & - \\
\hline Arthropoda & Insecta & Diptera & Syrphidae & Episyrphus balteatus (De Geer, 1776) & $\begin{array}{l}\mathrm{IG} / 1985 \\
\mathrm{Fe} / 1985 \\
\text { Fo/1985 }\end{array}$ & $\begin{array}{l}\text { GM,91 } \\
\text { GM,91 } \\
\text { GM,91 }\end{array}$ & $\begin{array}{l}+ \\
- \\
-\end{array}$ \\
\hline Arthropoda & Insecta & Diptera & Syrphidae & Eristalis similis (Fallen, 1817) & IG/1998 & $\mathrm{PB}, 00$ & - \\
\hline Arthropoda & Insecta & Diptera & Syrphidae & Eristalis sp. & IG/2009 & MMG,17 & + \\
\hline Arthropoda & Insecta & Diptera & Syrphidae & Eristalis tenax (Linnaeus, 1758) & IG/1998 & $\mathrm{PB}, 00$ & + \\
\hline Arthropoda & Insecta & Diptera & Syrphidae & Eupeodes corollae (Fabricius, 1794) & IG/1998 & PB,00 & - \\
\hline Arthropoda & Insecta & Diptera & Syrphidae & Helophilus trivittatus (Fabricius, 1805) & IG/1998 & $\mathrm{PB}, 00$ & - \\
\hline Arthropoda & Insecta & Diptera & Syrphidae & Meliscaeva auricollis (Meigen, 1822) & IG/1998 & $\mathrm{PB}, 00$ & - \\
\hline Arthropoda & Insecta & Diptera & Syrphidae & Scaeva albomaculata (Macquart, 1842) & IG/1998 & $\mathrm{PB}, 00$ & - \\
\hline Arthropoda & Insecta & Diptera & Syrphidae & Scaeva mecogramma (Bigot, 1860) & IG/1998 & $\mathrm{PB}, 00$ & - \\
\hline Arthropoda & Insecta & Diptera & Syrphidae & Scaeva pyrastri (Linnaeus, 1758) & $\mathrm{Fe} / 1985$ & $\begin{array}{l}\text { GM,91 (citada } \\
\text { como } \\
\text { Lasiopticus } \\
\text { pyrastri) }\end{array}$ & - \\
\hline Arthropoda & Insecta & Diptera & Syrphidae & Sphaerophoria rueppellii (Wiedemann, 1830) & IG/1998 & PB,00 & - \\
\hline Arthropoda & Insecta & Diptera & Syrphidae & Sphaerophoria scripta (Linnaeus, 1758) & IG/1998 & PB,00 & - \\
\hline
\end{tabular}




\begin{tabular}{|c|c|c|c|c|c|c|c|}
\hline Arthropoda & Insecta & Diptera & Syrphidae & Syritta pipiens (Linnaeus, 1758) & IG/1998 & PB,00 & - \\
\hline \multirow[t]{3}{*}{ Arthropoda } & Insecta & Diptera & Syrphidae & Syrphus ribesii (Linnaeus, 1758) & IG/1985 & $\mathrm{GM}, 91$ & - \\
\hline & & & & & $\mathrm{Fe} / 1985$ & GM,91 & - \\
\hline & & & & & Fo/1985 & $\mathrm{GM}, 91$ & - \\
\hline \multirow[t]{2}{*}{ Arthropoda } & Insecta & Diptera & Tephritidae & Campiglossa producta (Loew, 1844) & Fo/1985 & $\begin{array}{l}\text { GM,91 (citada } \\
\text { como }\end{array}$ & - \\
\hline & & & & & & $\begin{array}{l}\text { Paroxyma } \\
\text { producta) }\end{array}$ & \\
\hline Arthropoda & Insecta & Diptera & Tephritidae & Sphenella marginata (Fallen, 1814) & Fo/1985 & GM,91 & - \\
\hline Arthropoda & Insecta & Diptera & Tephritidae & Trupanea amoena (Frauenfeld, 1857) & IG/1985 & GM,91 & - \\
\hline Arthropoda & Insecta & Diptera & Tephritidae & Trupanea stellata (Fuesslin, 1775) & Fo/1985 & GM,91 & - \\
\hline Arthropoda & Insecta & Embioptera & Embiidae & Embia ramburi Rimski-Korsakow, 1905 & IG/1957 & Esp,58 & - \\
\hline Arthropoda & Insecta & Embioptera & Oligotomidae & Haploembia solieri (Rambur, 1842) & IG/1957 & Esp,58 & - \\
\hline Arthropoda & Insecta & Hemiptera & Anthocoridae & & IG/2010 & MMG,17 & + \\
\hline \multirow[t]{2}{*}{ Arthropoda } & Insecta & Hemiptera & Anthocoridae & Orius lindbergi Wagner, 1952 & IG/1957 & $\begin{array}{l}\text { Esp,58 (citada } \\
\text { como }\end{array}$ & - \\
\hline & & & & & & O.ovatus) & \\
\hline \multirow[t]{2}{*}{ Arthropoda } & Insecta & Hemiptera & Aphididae & Aphis sp. & IG/1985 & GM,91 & - \\
\hline & & & & & Fo/1985 & GM,91 & - \\
\hline Arthropoda & Insecta & Hemiptera & Aphididae & Chaetosiphon alpestre Hille Ris Lambers, 1953 & $\mathrm{Fe} / 1985$ & GM,91 & - \\
\hline Arthropoda & Insecta & Hemiptera & Aphididae & Clypeoaphis suaedae Mimeur, 1934 & IG/1996 & $\begin{array}{l}\text { MM,03 (citada } \\
\text { como } \\
\text { Brachyunguis } \\
\text { (Xerophilaphis) } \\
\text { suaedus) }\end{array}$ & - \\
\hline Arthropoda & Insecta & Hemiptera & Aphididae & Hyalopterus pruni (Geoffroy, 1762) & IG/1985 & GM,91 & - \\
\hline Arthropoda & Insecta & Hemiptera & Aphididae & Myzus persicae Sulzer, 1776 & IG/1985 & GM,91 & - \\
\hline Arthropoda & Insecta & Hemiptera & Asterolecaniidae & Planchonia arabidis Signoret, $1876^{*}$ & IG/2011 & MMG,17 & + \\
\hline \multirow[t]{2}{*}{ Arthropoda } & Insecta & Hemiptera & Cicadellidae & Agallia brachyptera (Boheman, 1847) & IG/1985 & GM,91 & * \\
\hline & & & & & Fo/1985 & $\mathrm{GM}, 91$ & \\
\hline Arthropoda & Insecta & Hemiptera & Cicadellidae & Agallia hispanica Horvath, 1900 & IG/1957 & Esp,58 & * \\
\hline Arthropoda & Insecta & Hemiptera & Cicadellidae & Circulifer dubiosus (Matsumura, 1908) & IG/1985 & $\begin{array}{l}\text { GM,91 (citada } \\
\text { como }\end{array}$ & * \\
\hline
\end{tabular}




\begin{tabular}{|c|c|c|c|c|c|c|c|}
\hline & & & & & & $\begin{array}{l}\text { Neoaliturus } \\
\text { dubiosus) }\end{array}$ & \\
\hline Arthropoda & Insecta & Hemiptera & Cydnidae & Byrsinus pilosulus (Klug, 1845) & IG/1957 & $\begin{array}{l}\text { Esp,58 (citada } \\
\text { como Aethus } \\
\text { pilosulus) }\end{array}$ & + \\
\hline Arthropoda & Insecta & Hemiptera & Cydnidae & Cydnus aterrimus (Forster, 1771)* & IG/2009 & MMG,17 & + \\
\hline Arthropoda & Insecta & Hemiptera & Cydnidae & Ochetostethus nanus (Herrich-Schäffer, 1834) & IG/1985 & $\begin{array}{l}\text { GM,91 (citada } \\
\text { como Sehirus } \\
\text { nanus) }\end{array}$ & - \\
\hline \multirow[t]{3}{*}{ Arthropoda } & Insecta & Hemiptera & Margarodidae & Icerya purchasi Maskell, 1878* & IG/2000 & MMG,17 & + \\
\hline & & & & & Fo/1996 & MMG,17 & - \\
\hline & & & & & $\mathrm{Fe} / 1997$ & MMG,17 & - \\
\hline Arthropoda & Insecta & Hemiptera & Miridae & Lygus pratensis (Linnaeus, 1758) & IG/1957 & Esp,58 & - \\
\hline Arthropoda & Insecta & Hemiptera & Miridae & Orthotylus moncreaffi (Douglas \& Scott, 1874) & IG/1957 & Esp,58 & - \\
\hline Arthropoda & Insecta & Hemiptera & Miridae & Plagiognathus sp. & IG/1985 & $\mathrm{GM}, 91$ & - \\
\hline Arthropoda & Insecta & Hemiptera & Nabidae & Nabis punctatus A. Costa, 1847 & IG/1957 & $\begin{array}{l}\text { Esp,58 (citado } \\
\text { como } \\
\text { N.feroides) }\end{array}$ & - \\
\hline Arthropoda & Insecta & Hemiptera & Pentatomidae & Brachynema cinctum (Fabricius, 1775)* & IG/2009 & MMG,17 & + \\
\hline Arthropoda & Insecta & Hemiptera & Pentatomidae & Nezara viridula (Linnaeus, 1758)* & IG/2009 & MMG,17 & + \\
\hline Arthropoda & Insecta & Hemiptera & Pentatomidae & Sciocoris macrocephalus Fieber, 1851 & IG/1985 & GM,91 & - \\
\hline Arthropoda & Insecta & Hemiptera & Pseudococcidae & Phenacoccus sp. & IG/1985 & GM,91 & - \\
\hline Arthropoda & Insecta & Hemiptera & Pyrrhocoridae & Pyrrhocoris apterus (Linnaeus, 1758)* & IG/2004 & MMG,17 & + \\
\hline Arthropoda & Insecta & Hemiptera & Pyrrhocoridae & Scantius aegyptius (Linnaeus, 1758) & IG/1957 & Esp,58 & + \\
\hline Arthropoda & Insecta & Hemiptera & Pyrrhocoridae* & & Fo/2009 & MMG,17 & + \\
\hline Arthropoda & Insecta & Hemiptera & Reduviidae & Reduvius personatus (Linnaeus, 1758) & $\mathrm{Fe} / 1985$ & GM,91 & - \\
\hline Arthropoda & Insecta & Hemiptera & Rhopalidae & Brachycarenus tigrinus (Schilling, 1829) & IG/1957 & Esp,58 & - \\
\hline Arthropoda & Insecta & Hymenoptera & Apidae & Amegilla sp. & IG/98 & $\mathrm{PB}, 00$ & - \\
\hline Arthropoda & Insecta & Hymenoptera & Apidae & Bombus terrestris (Linnaeus, 1758) & IG/98 & $\mathrm{PB}, 00$ & - \\
\hline Arthropoda & Insecta & Hymenoptera & Formicidae & Messor bouvieri Bondroit, 1918* & IG/2010 & MMG,17 & + \\
\hline Arthropoda & Insecta & Hymenoptera & Formicidae & Messor sp.* & Fo/2009 & MMG,17 & + \\
\hline Arthropoda & Insecta & Hymenoptera & Formicidae & Pheidole pallidula (Nylander, 1849) & IG/1957 & Esp,58 & + \\
\hline
\end{tabular}




\begin{tabular}{|c|c|c|c|c|c|c|c|}
\hline Arthropoda & Insecta & Hymenoptera & Ichneumonidae & Fianoniella stenognatha Bordera, 1998 & IG/1998 & $\mathrm{B}, 98$ & - \\
\hline Arthropoda & Insecta & Hymenoptera & Ichneumonidae & Ophion sp. ${ }^{*}$ & IG/2010 & MMG,17 & + \\
\hline Arthropoda & Insecta & Hymenoptera & Vespidae & Polistes sp.* & IG/2009 & MMG,17 & + \\
\hline Arthropoda & Insecta & Lepidoptera & Crambidae & Palpita vitrealis (Rossi, 1794)* & IG/2012 & MMG,17 & + \\
\hline Arthropoda & Insecta & Lepidoptera & Erebidae & Catocala coniuncta (Esper, 1787)* & IG/2010 & MMG,17 & + \\
\hline Arthropoda & Insecta & Lepidoptera & Erebidae & Ophiusa tirhaca (Cramer, 1773)* & IG/2011 & MMG,17 & + \\
\hline Arthropoda & Insecta & Lepidoptera & Erebidae & Utetheisa pulchella (Linnaeus, 1758) & IG/1957 & Esp,58 & + \\
\hline Arthropoda & Insecta & Lepidoptera & Geometridae & Gymnoscelis rufifasciata (Haworth, 1809) & IG/1985 & GM,91 & - \\
\hline Arthropoda & Insecta & Lepidoptera & Geometridae & Idaea seriata (Schrank, 1802) & IG/1985 & GM,91 & + \\
\hline Arthropoda & Insecta & Lepidoptera & Geometridae & Idaea sp. & IG/2010 & MMG,17 & + \\
\hline Arthropoda & Insecta & Lepidoptera & Geometridae & Rhodometra sacraria (Linnaeus, 1767)* & IG/2009 & MMG,17 & + \\
\hline Arthropoda & Insecta & Lepidoptera & Lycaenidae & Lampides boeticus (Linnaeus, 1767)* & IG/2012 & MMG,17 & + \\
\hline Arthropoda & Insecta & Lepidoptera & Noctuidae & Anarta sodae (Rambur, 1829) & IG/1985 & $\begin{array}{l}\text { GM,91 (citado } \\
\text { como Discestra } \\
\text { sodae) }\end{array}$ & - \\
\hline Arthropoda & Insecta & Lepidoptera & Noctuidae & Autographa gamma (Linnaeus, 1758) & IG/1985 & GM,91 & + \\
\hline Arthropoda & Insecta & Lepidoptera & Noctuidae & Helicoverpa armigera (Hübner, 1808)* & IG/2009 & MMG,17 & + \\
\hline Arthropoda & Insecta & Lepidoptera & Noctuidae & Heliothis peltigera (Denis \& Schiffermüller, 1775)* & IG/2010 & MMG,17 & + \\
\hline Arthropoda & Insecta & Lepidoptera & Noctuidae & Mniotype spinosa (Chrétien, 1910)* & IG/2008 & MMG,17 & + \\
\hline Arthropoda & Insecta & Lepidoptera & Noctuidae & Mythimna vitellina (Hübner, 1808)* & IG/2010 & MMG,17 & + \\
\hline Arthropoda & Insecta & Lepidoptera & Noctuidae & Noctua comes Hübner, 1813 & IG/1957 & $\begin{array}{l}\text { Esp,58 (citado } \\
\text { como } \\
\text { Triphaena } \\
\text { comes) }\end{array}$ & - \\
\hline Arthropoda & Insecta & Lepidoptera & Noctuidae & Phlogophora meticulosa (Linnaeus, 1758) & IG/1985 & GM,91 & - \\
\hline Arthropoda & Insecta & Lepidoptera & Noctuidae & Xanthodes albago (Fabricius, 1794)* & IG/2009 & MMG,17 & + \\
\hline Arthropoda & Insecta & Lepidoptera & Nymphalidae & Danaus chrysippus (Linnaeus, 1758) & IG/1985 & $\mathrm{GM}, 91$ & + \\
\hline Arthropoda & Insecta & Lepidoptera & Nymphalidae & Vanessa atalanta (Linnaeus, 1758) & IG/1985 & GM,91 & + \\
\hline Arthropoda & Insecta & Lepidoptera & Nymphalidae & Vanessa cardui (Linnaeus, 1758) & IG/1957 & Esp,58 & + \\
\hline Arthropoda & Insecta & Lepidoptera & Oecophoridae & & IG/1994 & $\begin{array}{l}\text { Col.ICB (citado } \\
\text { como } \\
\text { Depressaridae) }\end{array}$ & - \\
\hline
\end{tabular}




\begin{tabular}{|c|c|c|c|c|c|c|c|}
\hline Arthropoda & Insecta & Lepidoptera & Pieridae & Colias croceus (Fourcroy, 1785) & IG/1978 & $\mathrm{GM}, 91$ & + \\
\hline Arthropoda & Insecta & Lepidoptera & Pieridae & Pieris rapae (Linnaeus, 1758) & IG/2012 & Col.R.V. & - \\
\hline Arthropoda & Insecta & Lepidoptera & Plutellidae & Plutella xylostella (Linnaeus, 1758) & IG/1985 & GM,91 & - \\
\hline Arthropoda & Insecta & Lepidoptera & Pterophoridae & Agdistis neglecta Arenberger, 1976* & IG/2010 & MMG,17 & + \\
\hline Arthropoda & Insecta & Lepidoptera & Pterophoridae & Emmelina monodactyla (Linnaeus, 1758)* & IG/2010 & MMG,17 & + \\
\hline Arthropoda & Insecta & Lepidoptera & Pyralidae & Aglossa pinguinalis (Linnaeus, 1758) & IG/1985 & GM,91 & + \\
\hline Arthropoda & Insecta & Lepidoptera & Pyralidae & & IG/2013 & MMG,17 & + \\
\hline Arthropoda & Insecta & Lepidoptera & Sphingidae & Acherontia atropos (Linnaeus, 1758) & IG/1978 & GM,91 & + \\
\hline Arthropoda & Insecta & Lepidoptera & Sphingidae & Agrius convolvuli (Linnaeus, 1758)* & IG/2008 & MMG,17 & + \\
\hline Arthropoda & Insecta & Lepidoptera & Sphingidae & Macroglossum stellatarum (Linnaeus, 1758) & IG/1894 & ALS,95 & + \\
\hline Arthropoda & Insecta & Lepidoptera & Tortricidae & & IG/1994 & Col.ICB & - \\
\hline Arthropoda & Insecta & Neuroptera & Chrysopidae & Chrysopa sp. & IG/1957 & Esp,58 & - \\
\hline \multirow[t]{3}{*}{ Arthropoda } & Insecta & Neuroptera & Chrysopidae & Chrysoperla carnea (Stephens, 1836) & IG/1957 & $\begin{array}{l}\text { Esp,58 (citado } \\
\text { como Chrysopa } \\
\text { carnea) }\end{array}$ & + \\
\hline & & & & & $\mathrm{Fe} / 1957$ & $\begin{array}{l}\text { Esp, } 58 \text { (citado } \\
\text { como Chrysopa } \\
\text { carnea) }\end{array}$ & - \\
\hline & & & & & Fo/1985 & $\begin{array}{l}\text { Esp, } 58 \text { (citado } \\
\text { como Chrysopa } \\
\text { carnea) }\end{array}$ & - \\
\hline Arthropoda & Insecta & Odonata & Aeshnidae & Anax imperator Leach, 1815 & IG/1985 & GM,91 & - \\
\hline Arthropoda & Insecta & Odonata & Aeshnidae & Anax parthenope (Selys, 1839)* & IG/2004 & MMG,17 & + \\
\hline Arthropoda & Insecta & Odonata & Coenagrionidae & Ischnura elegans (Vander Linden, 1820)* & IG/2013 & MMG,17 & + \\
\hline Arthropoda & Insecta & Odonata & Libellulidae & Crocothemis erythraea (Brullé, 1832) & IG/1985 & GM,91 & - \\
\hline Arthropoda & Insecta & Odonata & Libellulidae & Sympetrum fonscolombii (Selys, 1840) & IG/1985 & GM,91 & + \\
\hline Arthropoda & Insecta & Orthoptera & Acrididae & Anacridium aegyptium (Linnaeus, 1764) & IG/1957 & Esp,58 & + \\
\hline Arthropoda & Insecta & Orthoptera & Bradyporidae & Parasteropleurus sp.** & $\mathrm{Fe} / 2009$ & MMG,17 & + \\
\hline Arthropoda & Insecta & Orthoptera & Gryllidae & & IG/2009 & MMG,17 & + \\
\hline Arthropoda & Insecta & Orthoptera & Gryllidae & Gryllus bimaculatus De Geer, 1773* & IG/2008 & MMG,17 & + \\
\hline Arthropoda & Insecta & Orthoptera & Gryllidae & Oecanthus pellucens (Scopoli, 1763)* & IG/2007 & MMG,17 & + \\
\hline
\end{tabular}




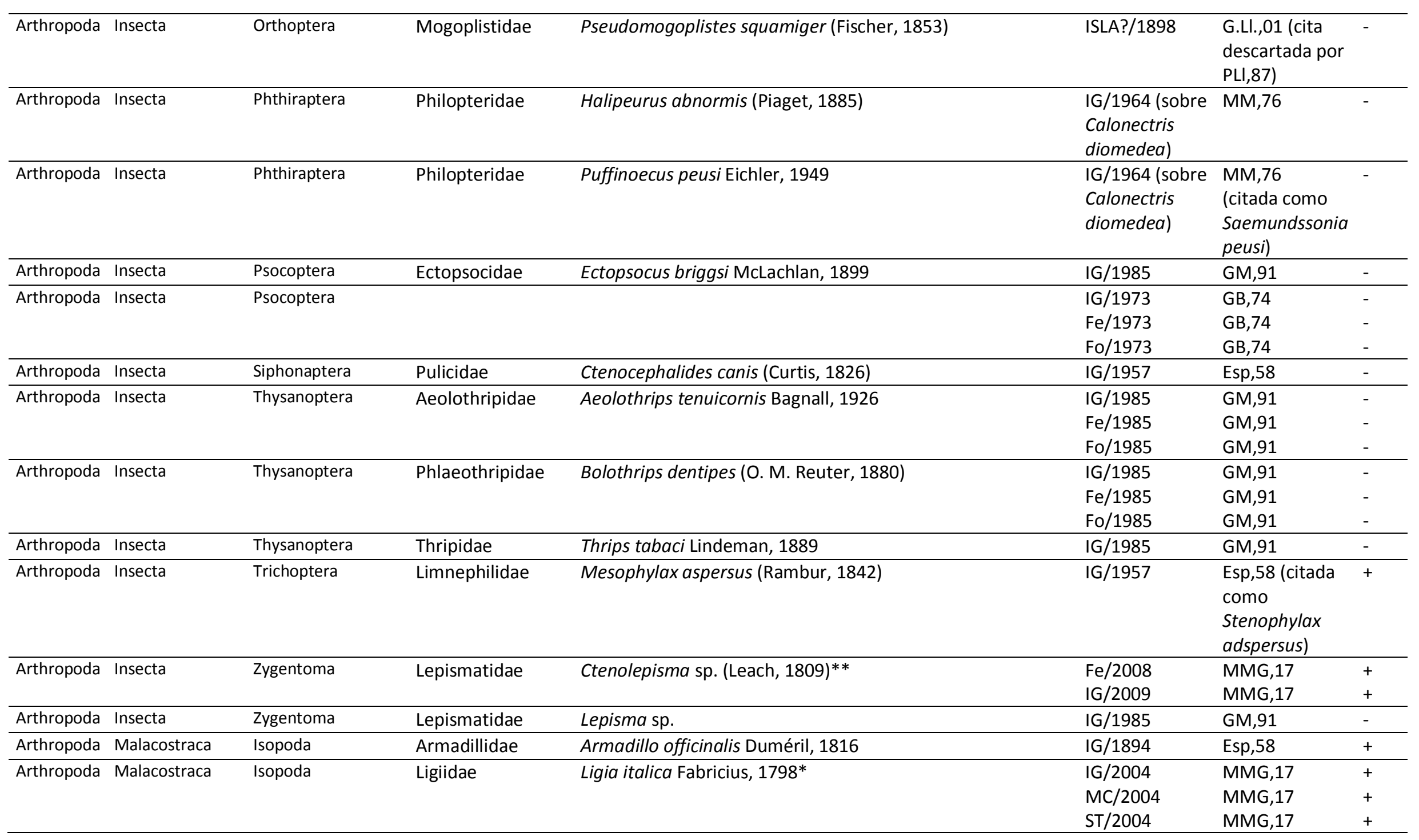




\begin{tabular}{|c|c|c|c|c|c|c|c|}
\hline & & & & & $\mathrm{Fe} / 2004$ & MMG,17 & + \\
\hline & & & & & Fo/2004 & MMG,17 & + \\
\hline Arthropoda & Malacostraca & Isopoda & Porcellionidae & Acaeroplastes melanurus (Budde-Lund, 1885)* & IG/2004 & MMG,17 & + \\
\hline Arthropoda & Malacostraca & Isopoda & Porcellionidae & Porcellio violaceus Budde-Lund, 1879 & IG/1957 & Esp,58 & - \\
\hline Arthropoda & Malacostraca & Isopoda & Porcellionidae & Porcellionides sexfasciatus (Koch, 1847) & IG/1957 & $\begin{array}{l}\text { Esp,58 (citada } \\
\text { como } \\
\text { Metoponorthus } \\
\text { sexfasciatus) }\end{array}$ & - \\
\hline Mollusca & Gastropoda & Neotaenioglossa & Pomatiidae & Pomatias elegans (O.F. Muller, 1774) & $\begin{array}{l}\text { IG/1983† } \\
\text { MC/1983† } \\
\text { Quizás extinto }\end{array}$ & $\mathrm{R}, 91$ & - \\
\hline Mollusca & Gastropoda & Pulmonata & Ferussaciidae & Ferussacia folliculus (Gmelin, 1791) & IG/1894 & ALS,95 & + \\
\hline Mollusca & Gastropoda & Pulmonata & Helicidae & Cornu aspersum (O.F. Muller, 1774) & $\begin{array}{l}\mathrm{IG} / 1894 \\
\mathrm{MS} / 2012 \\
\text { ST/2012 }\end{array}$ & $\begin{array}{l}\text { ALS,95 } \\
\text { IP,17 } \\
\text { IP,17 }\end{array}$ & $\begin{array}{l}+ \\
- \\
-\end{array}$ \\
\hline Mollusca & Gastropoda & Pulmonata & Helicidae & Eobania vermiculata (O.F. Muller, 1774) & IG/1957 & Esp,58 & - \\
\hline Mollusca & Gastropoda & Pulmonata & Helicidae & Theba pisana (O.F. Muller, 1774) & $\begin{array}{l}\text { IG/1894† } \\
\text { Quizás extinto }\end{array}$ & $\begin{array}{l}\text { ALS,95 (citada } \\
\text { como Helix } \\
\text { pisana) } \\
\text { R,91 }\end{array}$ & - \\
\hline Mollusca & Gastropoda & Pulmonata & Hygromiidae & $\underline{\text { Xerocrassa molinae (Hidalgo, 1883) }}$ & $\begin{array}{l}\text { IG/1952 } \\
M C / 1978\end{array}$ & $\begin{array}{l}R, 91 \\
R, 91\end{array}$ & $\begin{array}{l}+ \\
+\end{array}$ \\
\hline Mollusca & Gastropoda & Pulmonata & Lauriidae & Lauria cylindracea (Da Costa, 1778) & IG/1957 & Esp,58 & + \\
\hline Mollusca & Gastropoda & Pulmonata & Limacidae & Lehmannia valentiana (A. Ferussac, 1822) & IG/1990 & $\mathrm{R}, 91$ & + \\
\hline Mollusca & Gastropoda & Pulmonata & Milacidae & Milax gagates (Draparnaud, 1801) & IG/1950 & $\mathrm{J}, 52$ & - \\
\hline Mollusca & Gastropoda & Pulmonata & Milacidae & Milax nigricans (Philippi, 1836) & IG/1952 & $\mathrm{R}, 91$ & - \\
\hline Nematoda & Adenophorea & Plectida & Plectidae & Plectus cirratus Bastian, 1865 & $\begin{array}{l}\mathrm{IG} / 1973 \\
\mathrm{Fe} / 1973 \\
\mathrm{Fo} / 1973\end{array}$ & $\begin{array}{l}G B, 74 \\
G B, 74 \\
G B, 74 \\
\end{array}$ & $\begin{array}{l}- \\
- \\
-\end{array}$ \\
\hline Nematoda & Adenophorea & Plectida & Rhabdolaimidae & Rhabdolaimus terrestris de Man, 1880 & Fo/1973 & GB,74 & - \\
\hline Nematoda & Adenophorea & Dorylaimida & Dorylaimidae & Mesodorylaimus bastiani (Butschli, 1873) & IG/1973 & $\mathrm{GB}, 74$ & - \\
\hline Nematoda & Adenophorea & Dorylaimida & Xiphinematidae & Xiphinema sp. & IG?/1971 & Arias,71 & - \\
\hline Nematoda & Secernentea & Aphelenchida & Aphelenchoididae & Aphelenchoides parietinus (Bastian, 1865) & $\mathrm{Fe} / 1973$ & $\mathrm{~GB}, 74$ & - \\
\hline
\end{tabular}




\begin{tabular}{|c|c|c|c|c|c|c|c|}
\hline Nematoda & Secernentea & Rhabditida & Cephalobidae & Acrobeles complexus Thorne, 1925 & IG/09 & NEL,15 & - \\
\hline Nematoda & Secernentea & Rhabditida & Cephalobidae & Acrobeloides bodenheimeri (Steiner, 1936) & IG/09 & NEL,15 & - \\
\hline Nematoda & Secernentea & Rhabditida & Cephalobidae & Acrobeloides nanus (de Man, 1880) & IG/09 & NEL,15 & - \\
\hline Nematoda & Secernentea & Rhabditida & Cephalobidae & Chiloplacus minimus (Thorne, 1925) & IG/09 & NEL,15 & - \\
\hline Nematoda & Secernentea & Rhabditida & Cephalobidae & Eucephalobus hooperi Marinari-Palmisano, 1967 & IG/09 & NEL,15 & - \\
\hline Nematoda & Secernentea & Rhabditida & Cephalobidae & Stegelleta ophioglossa Andrassy, 1967 & IG/09 & NEL,15 & - \\
\hline Nematoda & Secernentea & Rhabditida & Cephalobidae & Stegelletina devimucronata (Sumenkova, 1964) & IG/09 & NEL,15 & - \\
\hline Nematoda & Secernentea & Rhabditida & Ostellidae & Drilocephalobus moldavicus Lisethkaja, 1968 & IG/09 & NEL,15 & - \\
\hline \multirow[t]{3}{*}{ Nematoda } & Secernentea & Rhabditida & Panagrolaimidae & Panagrolaimus rigidus (A. Schneider, 1866) & IG/1973 & GB,74 & - \\
\hline & & & & & $\mathrm{Fe} / 1973$ & $\mathrm{~GB}, 74$ & - \\
\hline & & & & & Fo/1973 & $\mathrm{GB}, 74$ & - \\
\hline \multirow[t]{3}{*}{ Nematoda } & Secernentea & Tylenchida & Anguinidae & Ditylenchus intermedius (de Man, 1880) & IG/1973 & GB,74 & - \\
\hline & & & & & $\mathrm{Fe} / 1973$ & $\mathrm{~GB}, 74$ & - \\
\hline & & & & & Fo/1973 & $\mathrm{GB}, 74$ & - \\
\hline \multirow[t]{3}{*}{ Nematoda } & Secernentea & Tylenchida & Tylenchidae & Filenchus filiformis (Butschli, 1873) & IG/1973 & GB,74 & - \\
\hline & & & & & $\mathrm{Fe} / 1973$ & $\mathrm{~GB}, 74$ & - \\
\hline & & & & & Fo/1973 & $\mathrm{GB}, 74$ & - \\
\hline
\end{tabular}


ANNEX 2.4 .

Àcars de plantes dels Parcs Naturals de Castelló

Aquest annex és una versió de l'estudi preparat per obtindre el títol de Diploma d'Estudis Avançats (DEA) a la Universitat Politècnica de València l'any 2008. 


\section{Introducció}

La finalitat de la Llei de la Generalitat Valenciana d'Espais Naturals, Llei 11/94 (DOGV, 1995), és la protecció, conservació, restauració, millora i ús sostenible dels espais naturals de la Comunitat Valenciana, per a la qual cosa els criteris a seguir per l'Administració han de ser, entre d'altres, la preservació dels ecosistemes i el manteniment dels processos i relacions ecològiques que permeten el seu funcionament, la conservació dels recursos naturals, la preservació de la diversitat genètica i de la singularitat i bellesa dels paisatges, i també dels valors científics i culturals del medi natural i l'ús social dels espais naturals, des del punt de vista de l'estudi, l'ensenyança i el gaudi ordenat de la naturalesa.

Els artròpodes, i entre ells els àcars, són un grup d'animals extraordinàriament diversos i rics en espècies, així com uns excel·lents indicadors del grau d'alteració dels ecosistemes terrestres, per la qual cosa el seu estudi permet no sols conèixer espècies desconegudes fins ara en els ecosistemes naturals, sinó també valorar el seu nivell de conservació i detectar nous enclavaments d'interès per a la seua futura protecció. En l'àmbit mundial, els àcars oribàtids que viuen en el sòl s'han utilitzat tant en sistemes agrícoles com en boscos i praderies per a valorar els canvis produïts en aquests ecosistemes per les pràctiques culturals (Adán et al., 1991; Behan-Pelletier, 1999; Arroio et al., 2003, 2005), I'alteració o la substitució de boscos naturals amb espècies al-lòctones o les conseqüències dels incendis forestals (Iturrondobeitia et al., 1997; Van Straalen, 1997; Moraza, 2006).

En la vegetació s'hi troba també una rica i variada comunitat d'àcars que viu sobre les fulles, tiges, branques i fruits. Aquests àcars s'han estudiat amb detall en els ecosistemes agrícoles, ja que algunes espècies són plagues importants dels cultius, mentre que altres són enemics naturals que s'utilitzen en el control biològic de les primeres. No obstant això, el coneixement que es té dels àcars de les plantes d'ecosistemes naturals no alterats en l'àmbit mundial, i en particular en la Comunitat Valenciana és molt escàs. Un dels grups més abundants i comuns en les plantes en tot el món són els fitoseids (família Phytoseiidae), àcars depredadors molt apreciats en l'agricultura com a agents de control biològic de plagues. En aquest treball s'han estudiat les comunitats d'àcars que viuen a les plantes dels parcs naturals de la província de Castelló, amb especial èmfasi en les espècies de fitoseids.

La província de Castelló huit dels vint-i-dos espais naturals de la Comunitat Valenciana protegits baix la figura de parcs naturals. Açò dóna una idea de la riquesa biològica d'aquesta província que reuneix enclavaments insulars, litorals i serres d'interior fins a altures de 1800 metres. El coneixement de la flora i la fauna d'aquestes comarques és necessària per valorar 
l'originalitat i la importància dels espais naturals, així com per a establir mesures que protegisquen adequadament la seua biodiversitat. Malgrat que la vegetació, en general, i alguns grups d'animals són bastant coneguts, molts invertebrats que es troben en aquests enclavaments protegits $\mathrm{i}$, en particular, l'acarofauna que viu sobre les plantes és pràcticament desconeguda, excepte a les Illes Columbretes.

García-Marí i col-laboradors (1991) van publicar un catàleg d'espècies d'artròpodes de les illes Columbretes basat en dos expedicions en què es va visitar I'Illa Grossa, la Ferrera i la Foradada l'any 1985, així com observacions realitzades per Víctor Navarro, de I'Estació Ornitològica de l'Albufera, entre els anys 1978 i 1985. En total, van identificar 87 espècies d'artròpodes, dels quals 29 espècies eren Acariformes, dos d'elles àcars nous per a la Ciència: els oribàtids Zygoribatula lenticulata Mínguez \& Subías, 1986, y Latilamellobates columbreti Mínguez \& Subías, 1986. Llevat d'alguna informació puntual de la Tinença de Benifassà (Ferragut, 1991), no hi ha cap altre catàleg d'àcars dels espais naturals protegits a la província de Castelló.

L'objectiu d'aquest treball va ser l'estudi i la catalogació de les espècies d'àcars, i en particular de la família Phytoseiidae, de la vegetació dels espais naturals protegits de la província de Castelló. En primer lloc es varen fer estudis taxonòmics i faunístics per a conèixer les espècies presents i la seua originalitat. En segon lloc es va estudiar alguns aspectes ecològics, com el coneixement de les espècies clau de cada hàbitat i les relacions que s'estableixen entre els àcars i les plantes en les quals viuen. Ambdues contribucions permetran aportar nous criteris per a la valoració d'aquests espais naturals i caracteritzar noves àrees d'interès especial per a la seua conservació.

\section{Material i Mètodes}

Àrees objecte de l'estudi

A la província de Castelló hi ha huit espais naturals protegits integrats en la xarxa valenciana de parcs naturals (PN) (Figura 1), que representen una mostra variada d'ecosistemes amb característiques climàtiques, edàfiques i de vegetació molt diferents: 1) Illes: Reserva Natural Illes Columbretes, 2) Humedals: Parc Natural Prat de Cabanes-Torreblanca, 3) Serres litorals: Parc Natural Serra d'Irta, 4) Serres d'interior: Parc Natural Desert de les Palmes, Parc Natural Serra d'Espadà, Parc Natural Serra Calderona, Parc Natural Penyagolosa i Parc Natural Tinença de Benifassà. D'aquests 8 enclavaments s'ha eliminat el Parc Natural de la Serra Calderona, ja que tan sols un xicotet percentatge de la seua superfície es troba dins de la província de 
Castelló i, a més a més, és un ecosistema ja representat per altres serres d'interior, sobretot pel P.N. Serra d'Espadà. A continuació s'enumera, breument, algunes de les característiques d'aquests espais naturals.

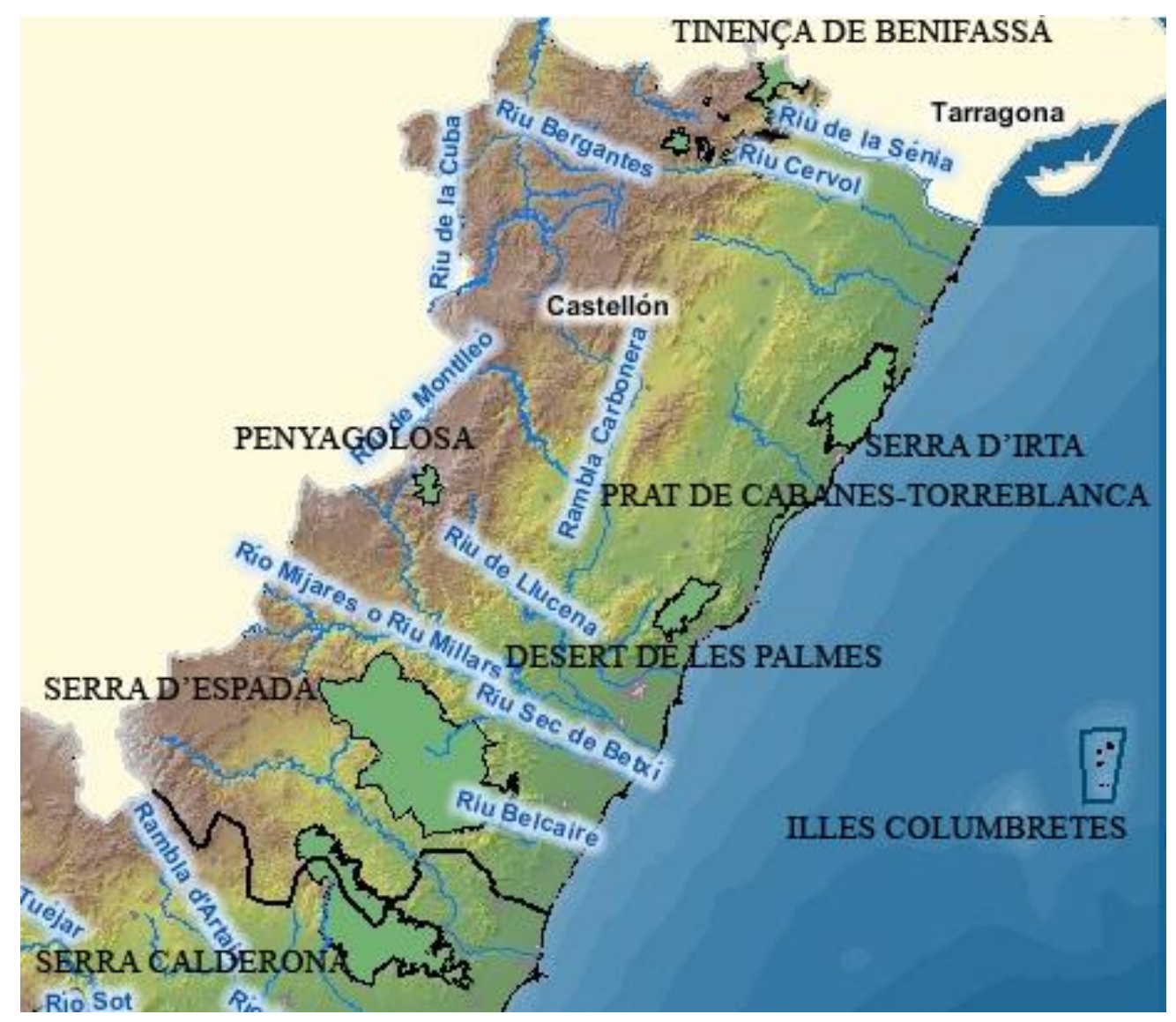

Figura 1. Localització geogràfica dels espais naturals protegits de la província de Castelló. Font: arxiu C.I. Columbretes

\section{Reserva Natural de les Illes Columbretes}

Les Columbretes són l'arxipèlag més singular de la Comunitat Valenciana i un dels menuts espais insulars de major interès ecològic de la Mediterrània, ja que són el millor exemple de vulcanisme de les terres valencianes, amb 19 ha de superfície emergida. Estan formades per una sèrie d'illots i esculls situats a 30 milles de la costa de Castelló, i reunits en 4 grups, als quals els dóna nom el major illot de cadascun dels grups: I'Illa Grossa, la Ferrera, la Foradada i el Carallot. La vegetació presenta un clar gradient entre les zones més pròximes al mar i les situades en cotes més elevades i protegides. Sols les espècies més resistents a la salinitat, com el fenoll marí (Crithmum maritimum L.) i la safanòria marina (Daucus gingidium L.), colonitzen 
els penya-segats més pròxims a la mar, mentre que a les partes altes s'estén un matollar nitrohalòfil dominat per la salat verd (Suaeda vera) o els caps blancs de Columbretes (Lobularia maritima columbretensis), aquest últim, endemisme de l'arxipèlag. Existeix una altra planta endèmica, l'alfals arbori (Medicago citrina), que, malgrat que se'n troba algun exemplar a les Pitiüses i a l'illot de la Mona de Xàbia, presenta a Columbretes la seua major població. Cal citar, també, la cambronera (Lycium intricatum) i la bufera (Withania frutescens), espècies pròpies de climes àrids i secs que troben en Columbretes la població més septentrional (Fabregat \& López-Udias, 2011).

\section{Parc Natural del Prat de Cabanes-Torreblanca}

Aquest espai, amb poc més de 900 ha de superfície, és la principal zona humida de la província de Castelló i un dels hàbitats humits menys alterats de la Comunitat Valenciana. La seua importància en l'àmbit mundial està reconeguda amb la inclusió a la Llista d'Aiguamolls d'Importància Internacional. Es tracta d'un prat pantanós, separat de la mar per una restinga de graves, en avançat estat de rebliment natural. La zona de llacunes està ocupada per canyissars i saladars. En la zona central es troba un canyissar halòfil que discorre paral·lel a la costa, on destaca la presència de Phragmites australis (Cav.) Trin. subsp. australis, Typha angustifolia L. subsp. australis (Schum. et Thonn.) Graebn. i Scirpus lacustris L. subsp. tabernaemontani (C. C. Gmelin) Syme; i vàries comunitats de jonqueres, amb Scirpus litoralis Schrad., Juncus maritimus Lam. i Schoenus nigricans L., entre d'altres espècies; i el mansegar, amb Cladium mariscus (L.) Pohl. Darrere del cordó de graves es troben restes de vegetació sobre dunes estabilitzades i alguns exemplars de càdec de mar (Juniperus oxycedrus L. subsp. macrocarpa (Sibth. et Sm) Ball.), espècie molt escassa al litoral espanyol (Generalitat, 2015).

\section{Parc Natural de la Serra d'Irta}

Està format per una serra que discorre paral-lela a la costa al llarg de $15 \mathrm{Km}$ pràcticament inalterats, on es troben penya-segats, platges i cales, i una superfície protegida d'unes 12000 ha. La formació vegetal dominant és un matollar mediterrani amb margalló (Chamaerops humilis) i pinedes de pi blanc (Pinus halepensis Miller), que han substituït els alzinars, vegetació potencial de la serra. Les pinedes estan acompanyades de llentiscle (Pistacia lentiscus), arçot (Rhamnus lycioides L. subsp. lycioides) i coscoll (Quercus coccifera L.). La vegetació més pròxima a la mar es caracteritza per les comunitats de Limonium (Limonium spp.) i fenoll marí (Crithmum maritimum). 


\section{Parc Natural del Desert de les Palmes}

Forma una serra litoral paral-lela la costa, amb abundants crestes i roquissars que alberga interessants plantes i comunitats vegetals que creixen en sòls calcaris i silícics, i amb una superfície protegida de 3200 ha. Malgrat els incendis i els pocs fragments de boscos i matollars ben estructurats, la seua flora supera les sis-centes espècies de plantes vasculars. La major part del territori està ocupat per un matollar dominat per labiades, cistàcies i la lleguminosa Anthyllis cytisoides L. Hi ha pinedes de pi pinastre (Pinus pinaster Aiton), sobre terrenys silicis d'arenisques roges, i de pi blanc (Pinus halepensis). En alguns enclavaments hi ha restes de boscos amb arbocer (Arbutus unedo L.), llorer bord (Viburnum tinus L.), bruc (Erica arborea L.), matapoll (Daphne gnidium L.), aladern (Rhamnus alaternus L.), galzeran (Ruscus aculeatus L.), ginebre (Juniperus oxycedrus), llentiscle (Pistacea lentiscus) i margalló (Chamaerops humilis), o enfiladisses com la rúbia (Rubia peregrina L.), l'eura (Hedera helix L.) o l'arítjol (Smilax aspera L.).

\section{Parc Natural de la Serra d’Espadà}

Es un gran massís muntanyós que presenta espècies de gran interès científic o biogeogràfic entre les que destaquen alguns endemismes valencians. A la zona protegida, 31.180 ha, s'hi troben suredes (Quercus suber L.), una de les formacions més interessants de la Comunitat Valenciana, que representen la vegetació potencial en sòls silicis. Al costat de les suredes, o formant masses boscoses, s'hi troba pi pinastre i carrasques. Altres espècies són els matollars formats per diverses espècies del gènere Cistus, brucs, savines o torviscos. També apareixen arbres o arbusts d'interès com el roure reboll, el teix, el boix, el castanyer, l'arç, el roure valencià (Quercus faginea Lam. subsp. faginea), I'avellaner (Corylus avellana L.), la servera (Sorbus domestica L. i l'arborcer (Arbutus unedo). A pesar del gran incendi que va assolar la serra l'estiu de 2016, cremant 1600 ha, tan sols 700 ha es van cremar dins el parc natural.

\section{Parc Natural del Penyagolosa}

Constitueix una dels últims contraforts del sistema Ibèric i s'eleva fins als $1814 \mathrm{~m}$ d'altitud, amb una superfície protegida de quasi 1100 ha. Conté una rica biodiversitat, resultat de la combinació de climes continental i mediterrani, diferents substrats calcaris i silicis, i la gradació altitudinal de la vegetació. A les cotes més baixes hi creix el pi negre (Pinus nigra Arnold subsp. salzmannii (Dunal) Franco), a la solana i amb substrat silícic, hi trobem el pi pinastre (Pinus pinaster) i en les obagues i terres altes, hi predomina el pi silvestre (Pinus sylvestris L.). També és freqüent observar formacions de savina (Juniperus thurifera L.). Cal destacar la presència de 
roure valencià (Quercus faginea faginea), el teix (Taxus baccata L.) i el roure reboll (Quercus pyrenaica Willd.).

\section{Parc Natural de la Tinença de Benifassà}

En aquest parc de relleu accidentat, d'unes 5000 ha de superfície, es troben els carrascars més importants en estructura i extensió de tot el territori valencià. $\mathrm{Hi}$ ha abundants boscos de pi blanc, pi larici, i silvestre, carrascars (Quercus ilex L.), rouredes i boscos de ribera. Aquestes formacions es troben especialment protegides i representades en tretze micro-reserves de flora, que proporcionen protecció a espècies amenaçades o endèmiques com la carnívora viola de font (Pinguicula dertosensis (Cañig.) Mateo \& M.B. Crespo) o I'arenària (Arenaria conimbricensis). A més a més, repartint-se el territori amb els carrascars en funció de menudes variacions locals en el clima i les característiques del sòl, es troben algunes de les masses millor conservades de roure valencià (Quercus faginea faginea) de la Comunitat Valenciana. És també destacable la presència de considerables extensions de boix (Buxus sempervirens L.) (Generalitat, 2015).

Metodologia dels mostreigs i extracció i preparació dels àcars

Les visites per a la recollida de mostres es va realitzar en tots els parcs naturals durant la tardor de 2007, entre l'1 d'octubre i el 14 de novembre, excepte a les Illes Columbretes, on la visita va ser realitzada el 18 de maig d'aquell any. Prèviament a la recollida de mostres es van obtenir de la Conselleria de Medi Ambient, Aigua, Urbanisme i Habitatge els permisos necessaris per a la recollida de material biològic.

Per a cada data de mostreig es van prendre al voltant de 20-24 mostres de material vegetal a l'atzar, d'uns 200 grams de pes cadascuna, excepte al Prat de Cabanes-Torreblanca i a la Serra d'Irta, on es van recollir 12 i 11 mostres, respectivament, a causa de la proximitat geogràfica d'aquests dos espais protegits. En cada mostreig es va procurar prendre plantes de tots els estrats vegetals, aproximadament un terç de l'estrat arbori, un altre de l'arbustiu i l'altre de I'herbaci, amb la qual cosa es va intentar capturar espècies dels tres estrats, ja que els fitoseids mostren preferències per distintes altures de la vegetació. Es van seleccionar, en cada cas, les espècies vegetals més abundants i representatives de cadascun dels ecosistemes visitats, i no es van recollir espècies vegetals endèmiques o rares, ja que aqueix no era l'objectiu del treball.

Les mostres es van traslladar al laboratori en bosses de paper cartó i es van col·locar durant 72 hores en embuts de Berlese per a extraure'n els àcars. Després de l'extracció, els àcars van ser 
digerits amb líquid de Nesbitt i muntats entre porta i cobre-objectes en el líquid de HeinzePVA.

Tots els exemplars capturats es van identificar fins al nivell de família (d'ordre per als oribàtids), i els fitoseids es van identificar fins al nivell d'espècie, excepte els individus immadurs que són de difícil identificació. Tot el material preparat es troba dipositat en la col-lecció d'àcars del Laboratori d'Acarologia de I'Institut Agroforestal Mediterrani de la Universitat Politècnica de València.

\section{Anàlisi dels resultats}

Els resultats obtinguts després de la identificació dels àcars es van resumir en taules en fulles de càlcul del programa Excel (Material suplementari 2). Per a cadascun dels parcs naturals estudiats s'ha calculat l'abundància de les famílies trobades i l'abundància total i freqüència de les espècies de fitoseids identificades. La freqüència d'aparició d'una espècie, denominada també abundància o importància relativa, es va expressar com un percentatge i es va calcular per la fórmula': $a / n \times 100$; essent $a$ el nombre d'individus de l'espècie en qüestió $\mathrm{i} n$ el nombre total d'individus de totes les espècies capturades a cada parc natural.

\section{Resultats i Discussió}

\section{Abundància de les famílies d'àcars}

En els mostreigs realitzats s'han trobat un total de 15 famílies d'àcars i un subordre, els oribàtids. Cal tenir en compte que aquest subordre agrupa nombroses famílies que no s'han separat en aquest estudi (Taula 1). La família més abundant ha estat la dels fitoseids, amb 620 individus que representen el $36,2 \%$ del total d'àcars. Altres grups que estan ben representats en les plantes mostrejades han estat, tot i que són àcars típics del sòl, els oribàtids $(23,2 \%)$, seguits dels tetraníquids (21\%), els tideids $(9,3 \%)$ i els tenuipàlpids (6\%). Aquests cinc grups suposen més del $95 \%$ del total dels àcars trobats, ja que la resta de famílies són poc nombroses. Aquests grups estan representats en tots els parcs, excepte els tenuipàlpids, que no es van trobar a les mostres de les Illes Columbretes.

Comparant l'abundància entre els distints parcs, i malgrat que el nombre de mostres no va ser exactament el mateix a tot arreu, destaca la Serra d'Espadà, amb prop de 400 àcars i les Illes Columbretes amb 260. Al Prat de Cabanes se n'hi van trobar també 260, tot i que en aquest 
lloc es van recollir únicament 12 mostres, la meitat que en la majoria de parcs. La menor abundància es va registrar a la Serra d'Irta i a Penyagolosa.

Estigmèids i eritrèids són dues famílies que no estaven anteriorment citades al catàleg de Columbretes (García-Marí, 1991) i per tant, noves cites per a les Illes; i igualment, Tetranychus sp. i Bryobia sp. (dues noves cites que no es van poder identificar fins a espècie), cap dels dos gèneres havia estat citat abans a les Columbretes.

Taula 1. Nombre d'individus de cadascuna de les famílies d'àcars (Mesostigmata) trobades en cadascun dels espais naturals mostrejats.

\begin{tabular}{|c|c|c|c|c|c|c|c|c|}
\hline \multirow{2}{*}{ Famílies } & \multicolumn{7}{|c|}{ Parcs Naturals } & \multirow{2}{*}{ Total } \\
\hline & Columbretes & Desert & Penyagolosa & Prat & Espadà & Irta & Tinença & \\
\hline Acaridae & 0 & 4 & 5 & 2 & 0 & 0 & 0 & 11 \\
\hline Bdellidae & 2 & 0 & 3 & 0 & 3 & 0 & 1 & 9 \\
\hline Camerobiidae & 0 & 0 & 0 & 0 & 1 & 0 & 0 & 1 \\
\hline Cheyletidae & 0 & 0 & 0 & 0 & 0 & 2 & 0 & 2 \\
\hline Cunaxidae & 1 & 1 & 0 & 1 & 0 & 0 & 2 & 5 \\
\hline Eritraeidae & 8 & 1 & 0 & 0 & 1 & 0 & 1 & 11 \\
\hline Eupalopesllidae & 0 & 1 & 1 & 1 & 0 & 0 & 8 & 11 \\
\hline Eupodidae & 0 & 5 & 6 & 0 & 1 & 1 & 0 & 13 \\
\hline Oribatida* & 5 & 53 & 77 & 31 & 24 & 91 & 116 & 397 \\
\hline Phytoseiidae & 120 & 54 & 44 & 151 & 184 & 12 & 55 & 620 \\
\hline Ragidiidae & 0 & 0 & 0 & 0 & 0 & 3 & 1 & 4 \\
\hline Stigmaeidae & 2 & 0 & 0 & 0 & 1 & 0 & 0 & 3 \\
\hline Tarsonemidae & 0 & 0 & 0 & 5 & 0 & 0 & 0 & 5 \\
\hline Tenuipalpidae & 0 & 52 & 6 & 19 & 5 & 1 & 19 & 102 \\
\hline Tetranychidae & 60 & 23 & 4 & 5 & 147 & 36 & 85 & 360 \\
\hline Tydeidae & 62 & 15 & 10 & 45 & 23 & 2 & 3 & 160 \\
\hline Total & 260 & 209 & 156 & 260 & 390 & 148 & 291 & 1714 \\
\hline
\end{tabular}

*aquest subordre no es va separar en famílies

\section{Espècies de fitoseids i la seua abundància}

Considerant tots els mostreigs globalment s'han trobat 22 espècies de fitoseids (Taula 2, Material suplementari 1). D'aquestes se n'han determinades fins a nivell d'espècie 20, essentne 15 ja conegudes a la Comunitat Valenciana (Material suplementari 2). Les altres cinc poden considerar-se les més originals des del punt de vista taxonòmic, entre elles Graminaseius lituatus i Typhlodromus foenilis són noves cites per a la Comunitat Valenciana, Kampimodromus ericinus i Neoesiulus leucophaeus són espècies desconegudes fins ara en 
Espanya i Typhlodromus pròxim a recki és, probablement, una espècie nova que no ha estat descrita encara.

Quant a l'abundància, les espècies més nombroses han sigut Neoseiulella litoralis amb 198 individus (32,8\%), Typhodromus pyri amb 145 (24\%) i T. rhenanoides amb 105 (17,4\%). Per a set de les 22 espècies identificades, només se'n va trobar un exemplar.

La major riquesa en espècies s'ha trobat al Desert de les Palmes, amb 10 espècies i al Prat de Cabanes, amb 8. La menor, a les Columbretes i a la Serra d'Irta amb 5 espècies solament. Cap de les espècies s'ha trobat en tots set PNs, essent les més freqüents i repartides $N$. litoralis i $T$. rhenanoides que falten únicament al Parc Natural del Penyagolosa, i Typhlodromus phialatus que no s'ha trobat ni al Prat de Cabanes i ni a la Serra D’Espadà.

Taula 2. Relació de les espècies de fitoseids (Mesostigmata; Phytoseiidae) trobades i abundància en cadascun dels parcs naturals. Riquesa indica el nombre d'espècies que es van trobar en cada parc (Col. = Columbretes; Des. = Desert; Pen. = Penyagolosa; Esp. = Espadà; Tin. = Tinença ) .

\begin{tabular}{lcccccccc}
\hline \multicolumn{1}{c}{ Espècies } & Col. & Des. & Pen. & Prat & Esp. & Irta & Tin. & Total \\
\hline Amblyseius andersoni & 0 & 1 & 0 & 0 & 0 & 0 & 0 & $\mathbf{1}$ \\
Amblyseius sp. & 0 & 3 & 0 & 0 & 0 & 0 & 0 & $\mathbf{3}$ \\
Euseius finlandicus & 0 & 0 & 24 & 0 & 0 & 0 & 5 & $\mathbf{2 9}$ \\
Euseius stipulatus & 0 & 1 & 0 & 0 & 0 & 0 & 0 & $\mathbf{1}$ \\
Graminaseius lituatus & 1 & 0 & 0 & 0 & 0 & 0 & 0 & $\mathbf{1}$ \\
Kampimodromus aberrans & 1 & 0 & 0 & 0 & 1 & 0 & 0 & $\mathbf{2}$ \\
Kampimodromus ericinus & 0 & 3 & 0 & 3 & 1 & 0 & 0 & $\mathbf{7}$ \\
Neoseiulella litoralis & 107 & 12 & 0 & 69 & 5 & 1 & 4 & $\mathbf{1 9 8}$ \\
Neoesiulus leucophaeus & 0 & 0 & 0 & 1 & 0 & 0 & 0 & $\mathbf{1}$ \\
Neoesiulus umbraticus & 0 & 0 & 0 & 1 & 0 & 0 & 0 & $\mathbf{1}$ \\
Phytoseius plumifer & 0 & 0 & 0 & 0 & 0 & 1 & 0 & $\mathbf{1}$ \\
Proprioseiopsis bordjelaini & 0 & 0 & 0 & 5 & 0 & 0 & 0 & $\mathbf{5}$ \\
Typhlodromus (Anthoseius) athenas & 0 & 3 & 0 & 0 & 0 & 1 & 0 & $\mathbf{4}$ \\
Typhlodromus (Anthoseius) foenilis & 1 & 0 & 1 & 0 & 0 & 0 & 0 & $\mathbf{2}$ \\
Typhlodromus (Anthoseius) pròx. a recki & 0 & 0 & 0 & 0 & 2 & 0 & 0 & $\mathbf{2}$ \\
Typhlodromus (Anthoseius) rhenanoides & 7 & 15 & 0 & 7 & 58 & 6 & 12 & $\mathbf{1 0 5}$ \\
Typhlodromus (Anthoseius) sp. & 0 & 0 & 1 & 0 & 0 & 0 & 0 & $\mathbf{1}$ \\
Typhlodromus ( Typhlodromus) laurae & 0 & 0 & 0 & 0 & 0 & 0 & 3 & $\mathbf{3}$ \\
Typhlodromus (Typhlodromus) phialatus & 2 & 4 & 5 & 0 & 0 & 3 & 13 & $\mathbf{2 7}$ \\
Typhlodromus (Typhlodromus) pyri & 0 & 0 & 11 & 12 & 111 & 0 & 11 & $\mathbf{1 4 5}$ \\
Typhloseiella isotricha & 0 & 9 & 1 & 50 & 0 & 0 & 0 & $\mathbf{6 0}$ \\
Typhloseiulus carmonae & 0 & 1 & 0 & 0 & 0 & 0 & 4 & $\mathbf{5}$ \\
$\quad$ Abundància & $\mathbf{1 1 9}$ & $\mathbf{5 2}$ & $\mathbf{4 3}$ & $\mathbf{1 4 8}$ & $\mathbf{1 7 8}$ & $\mathbf{1 2}$ & $\mathbf{5 2}$ & $\mathbf{6 0 4}$ \\
$\quad$ Riquesa & $\mathbf{5}$ & $\mathbf{1 0}$ & $\mathbf{6}$ & $\mathbf{8}$ & $\mathbf{6}$ & $\mathbf{5}$ & $\mathbf{7}$ & \\
\hline
\end{tabular}


La freqüència d'aparició de cada espècie en cadascun dels parcs s'ha representat a les Figures 2 i 3. A les comarques litorals i a les Illes Columbretes, l'espècie dominant va ser $N$. litoralis, que va representar el 90\% dels fitoseids en Columbretes i gairebé la mitat al Prat de Cabanes. Solament a la Serra d'Irta, I'abundància va ser menor, essent els substituida per $T$. rhenanoides. També al Desert de les Palmes, situat molt a prop de la mar, aquestes dues espècies són les predominants, que en conjunt suposen més del $52 \%$ dels fitoseids. En els parcs muntanyencs de l'interior de la província, la predominància de les espècies canvia, a I'Serra d'Espadà és T. pyri l'espècie dominant i al Penyagolosa, Euseius finlandicus, mentre que a la Tinença de Benifassà tres espècies del gènere Typhlodromus, T. phialatus, T. pyri i $T$. rhenanoides són les més abundants.

Es confirma la presència de les espècies Neoseiulella litoralis, Typhlodromus (Typhlodromus) phialatus i Typhlodromus (Anthoseius) rhenanoides a Columbretes, que jan va ser incloses al catàleg de l'any 1991, i n'apareixen tres de noves: Graminaseius lituatus, Kampimodromus aberrans i Typhlodromus (Anthoseius) phoenilis.

\section{Plantes hoste dels fitoseids}

Les taules del Material suplementari 2 permeten comprovar algunes relacions interessants entre les espècies de fitoseids i les plantes sobre les quals es van trobar. Dues de les espècies, $N$. litoralis i $T$. rhenanoides ocupen gran part de les comunitats vegetals mostrejades, ja que es troben en la majoria de famílies de plantes, excepte en cupressàcies e hipolepidàcies en el cas de la primera espècie i en geraniàcies, palmàcies, malvàcies, umbel.líferes i hipolepidàcies en el de la segona.

Alguns grups de fitoseids pareix que tenen una evident preferència per algunes famílies de plantes, com és el cas de les pinàcies, on gairebé tots els exemplars capturats pertanyen a sis espècies del gènere Typhlodromus. Algunes espècies sembla que tenen, també, preferència per determinades espècies de plantes. És el cas de $K$. ericinus, que s'ha trobat solament en cistàcies del gènere Cistus i Typhloseiella isotricha que apareix, gairebé exclusivament, sobre la composta Ditricchia viscosa. 


\section{Tots els PN}

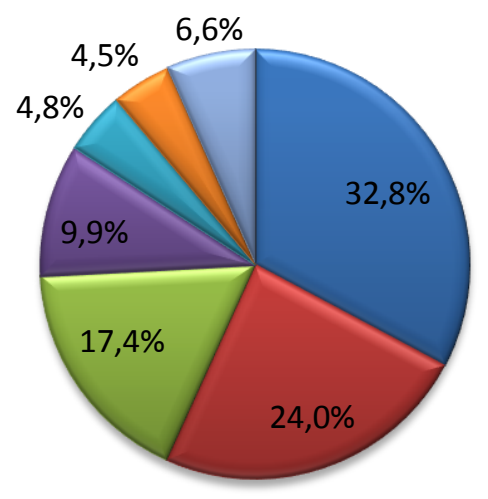

$\square$ Neoseiulella litoralis

- Typhlodromus (Typhlodromus) pyri

$\square$ Typhlodromus (Anthoseius) rhenanoides

- Typhloseiella isotricha

$\square$ Euseius finlandicus

$\square$ Typhlodromus(Typhlodromus) phialatus

$\square$ Altres

\section{Illes Columbretes}

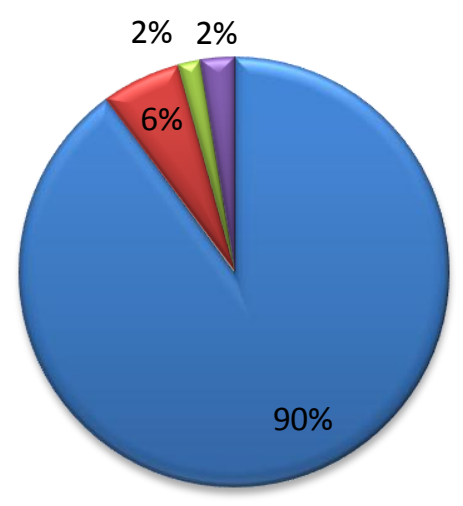

\section{$\square$ Neoseiulella litoralis}

$\square$ Typhlodromus (Anthoseius) rhenanoides

$\square$ Typhlodromus (Typhlodromus) phialatus

$\square$ Altres

\section{Desert de les Palmes}

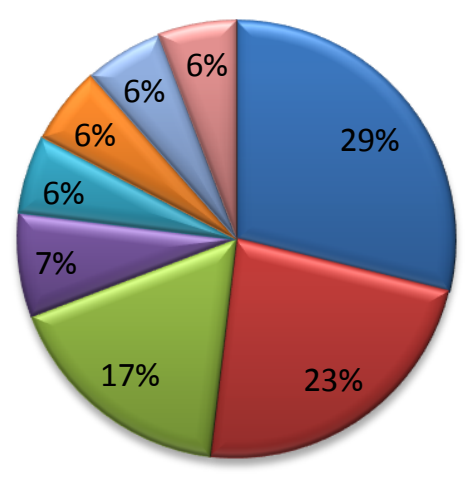

- Typhlodromus (Anthoseius) rhenanoides

- Neoseiulella litoralis

$\square$ Typhloseiella isotricha

- Typhlodromus (Typhlodromus) phialatus

$\square$ Amblyseius sp.

$\square$ Kampimodromus ericinus

$\square$ Typhlodromus (Anthoseius) athenas

$\square$ Altres

\section{Penyagolosa}

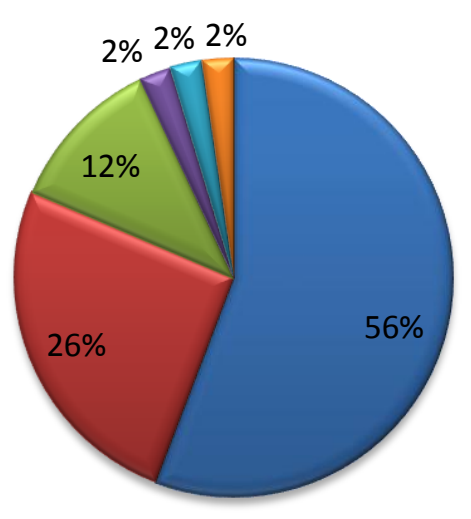

Euseius finlandicus

- Typhlodromus (Typhlodromus) pyri

$\square$ Typhlodromus(Typhlodromus) phialatus

- Typhlodromus (Anthoseius) phoenilis

$\square$ Typhlodromus (Anthoseius) sp.

$\square$ Typhloseiella isotricha

Figura 2. Freqüència d'aparició de les principals espècies de fitoseids en la vegetació dels parcs naturals, de les Illes Columbretes, del Desert de les Palmes i del Penyagolosa (els colors no corresponen a la mateixa espècie sinó al \%, de major a menor, començant pel blau fosc). 
Prat de CabanesTorreblanca

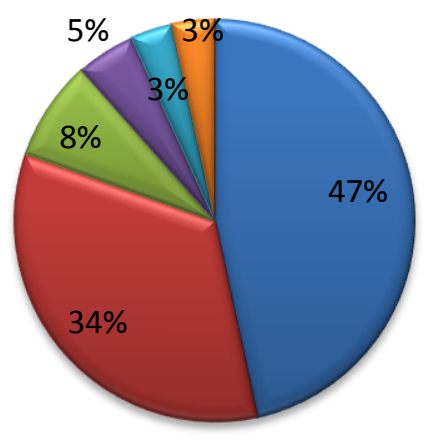

$\square$ Neoseiulella litoralis - Typhloseiella isotricha $\square$ Typhlodromus (Typhlodromus) pyri - Typhlodromus (Anthoseius) rhenanoides $\square$ Proprioseiopsis bordjelaini $\square$ Altres

\section{Serra d'Espadà}

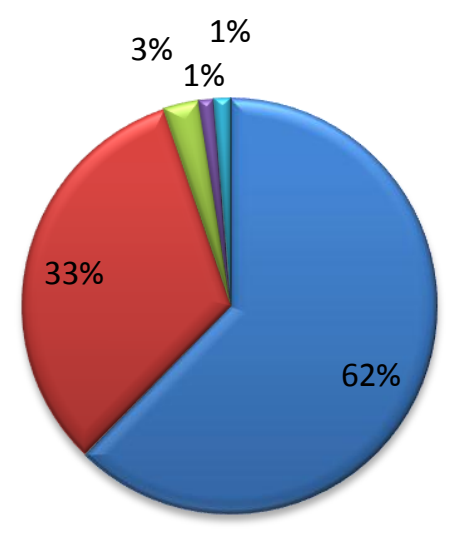

- Typhlodromus (Typhlodromus) pyri $\square$ Typhlodromus (Anthoseius) rhenanoides $\square$ Neoseiulella litoralis Typhlodromus (Anthoseius) próximo a recki $\square$ Altres

\section{Serra d'Irta}

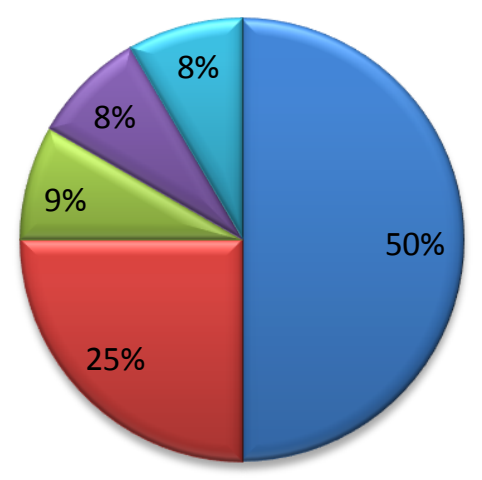

$\square$ Typhlodromus (Anthoseius) rhenanoides $\square$ Typhlodromus (Typhlodromus) phialatus $\square$ Neoseiulella litoralis

$\square$ Phytoseius plumifer

$\square$ Typhlodromus (Anthoseius) athenas

\section{Tinença de Benifassà}

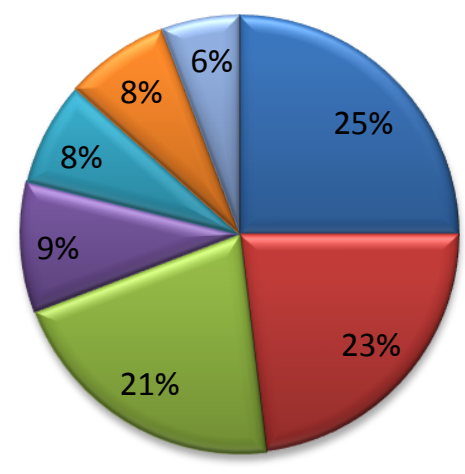

\yphlodromus (Typhlodromus) phialatus

$\square$ Typhlodromus (Anthoseius) rhenanoides

$\square$ Typhlodromus (Typhlodromus) pyri

$\square$ Euseius finlandicus

$\square$ Neoseiulella litoralis

$\square$ Typhloseiulus carmonae

$\square$ Typhlodromus (Typhlodromus) laurae

Figura 3. Freqüència d'aparició de les principals espècies de fitoseids en la vegetació del Prat de Cabanes-Torreblanca, Serra d'Espadà, Serra d'Irta i Tinença de Benifassà (els colors no corresponen a la mateixa espècie sinó al \%, de major a menor, començant pel blau fosc). 
Algunes de les plantes mostrejades acullen una comunitat rica de fitoseids que es compon de diverses espècies. Sobre la composta Santolina chamaecyparisssus L. s'han capturat 26 fitoseids (en una sola mostra) pertanyents a 4 espècies, Typhlodromus phialatus, T. pyri, T. rhenanoides i Euseius finlandicus. S. chamaecyparisssus és un element íbero-magrebí que acull una entomofauna molt rica i original.

Alguns enclavaments particulars dins de les àrees mostrejades tenen interès ja que acullen espècies de distribució eurosiberiana, alguns dels quals no s'havien trobat fins ara a la Comunitat Valenciana. Al Desert de les Palmes, alguns barrancs situats en zones d'obaga, fresques i més humides, com el Paratge de Les Santes, presenten restes de zones boscoses compostes per espècies com arbocer, llorer bord, bruc, boix, savina i surera. Sobre aquestes plantes s'han capturat espècies pròpies de latituds més fredes, com Euseius finlandicus, Amblyseius andersoni i Amblyseius herbicolus, aquesta última espècie capturada a la mateixa zona en un mostreig previ al de la tardor.

Per últim, cal destacar la presència d'una probable espècie endèmica que s'ha capturat sobre surera, un dels arbres més emblemàtics dels ecosistemes naturals valencians. Aquesta nova espècie, classificada provisionalment com a Typhlodromus pròxim a recki, s'ha capturat en els PN del Desert de les Palmes i la Serra d'Espadà.

\section{Conclusions}

Als Parcs Naturals de la província de Castelló hem trobat amb aquest mètode una quantitat molt més gran d'àcars de les famílies Phytoseiidae i Tetranychidae i del subordre Oribatida $(80,4 \%)$. També, quant a quantitat de fitoseids, hem trobat que només tres espècies, Neoseiulella litoralis, , Typhodromus pyri i T. rhenanoides, representen el 74,2 \% dels tots fitoseids trobats. A banda d'haver citat per primera vegada dues espècies de fitoseids a la Comunitat Valenciana i dues més a Espanya, també hem trobat Typhlodromus pròxim a recki, probablement, una espècie nova que no ha estat descrita encara. 


\section{Material suplementari 1}

Placa dorsal, plaques ventrals, espermateca i placa ventroanal dels àcars:

- Typhloseiella isotricha

- Kampimodromus aberrans

- Euseius finlandicus

- Euseius stipulatus

- Neoseiulus umbraticus

- Graminaseius lituatus

- Amblyseius andersoni

- Phytoseius plumifer

- Proprioseiopsis bordjelaini

- Typhlodromus phialatus

- Typhlodromus pyri

- Typhlodromus (Anthoseius) athenas

- T. (A.) foenilis

- T. (A.) rhenanoides

- Typhloseiulus carmon

- Neoseiulella litoralis

excepte placa ventroanal de Typhloseiulus carmon. 


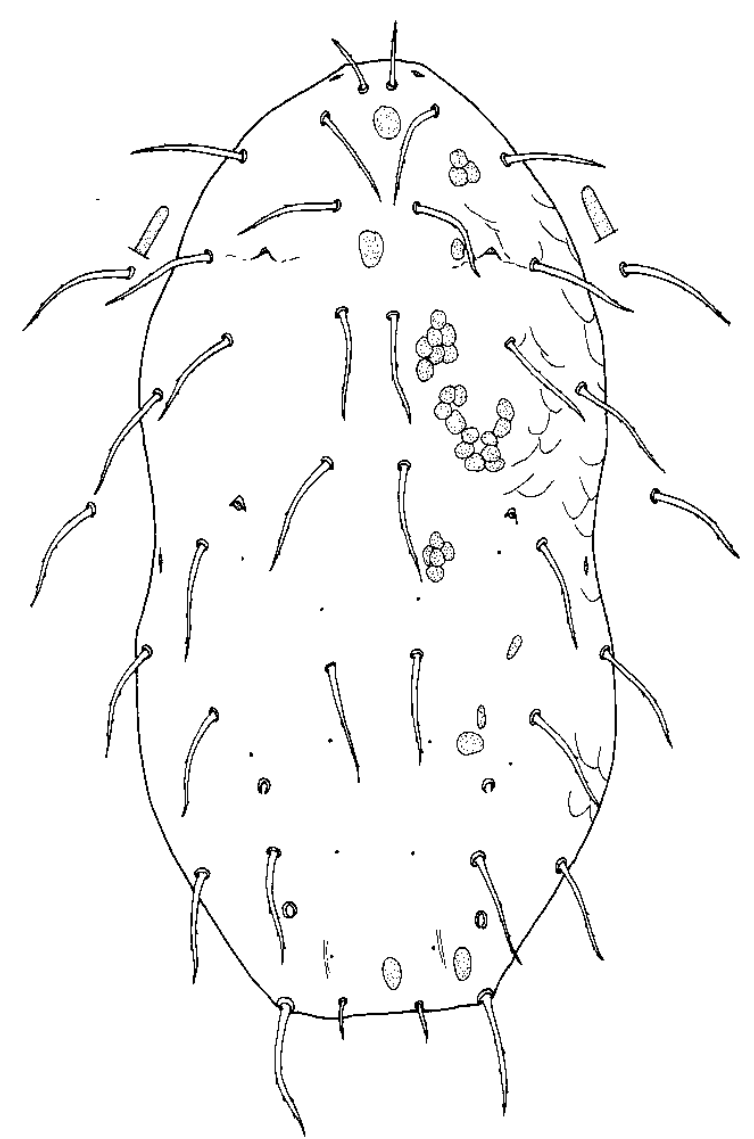

C

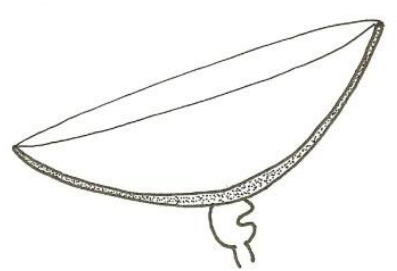

b

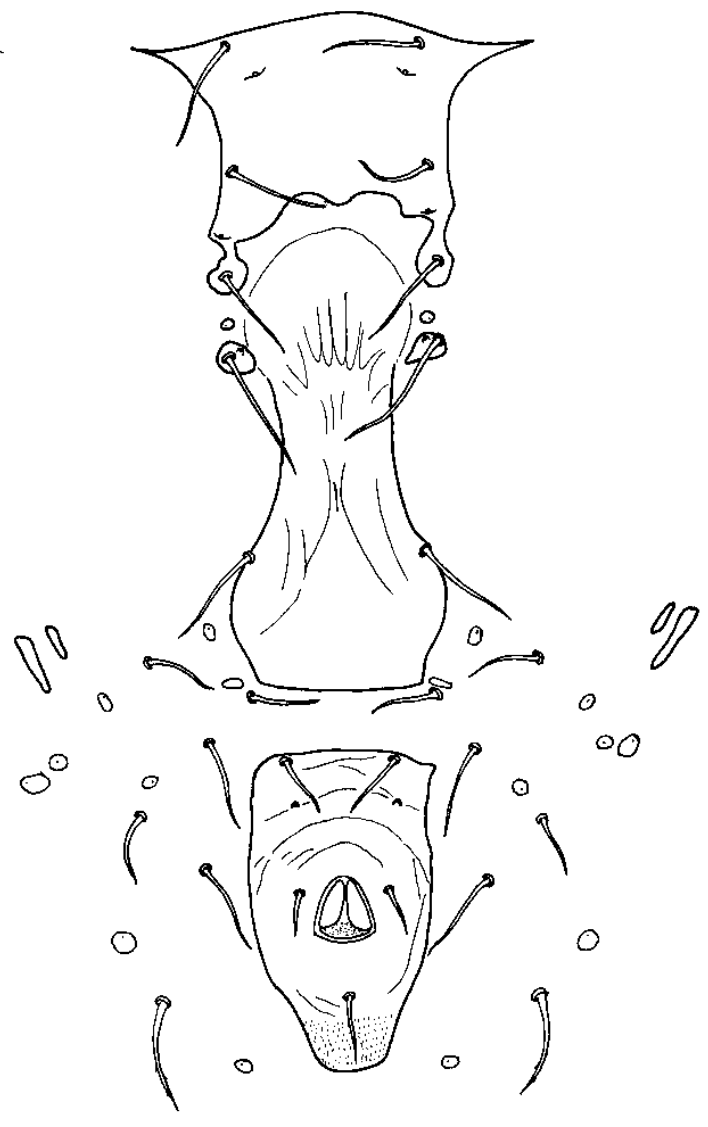

d

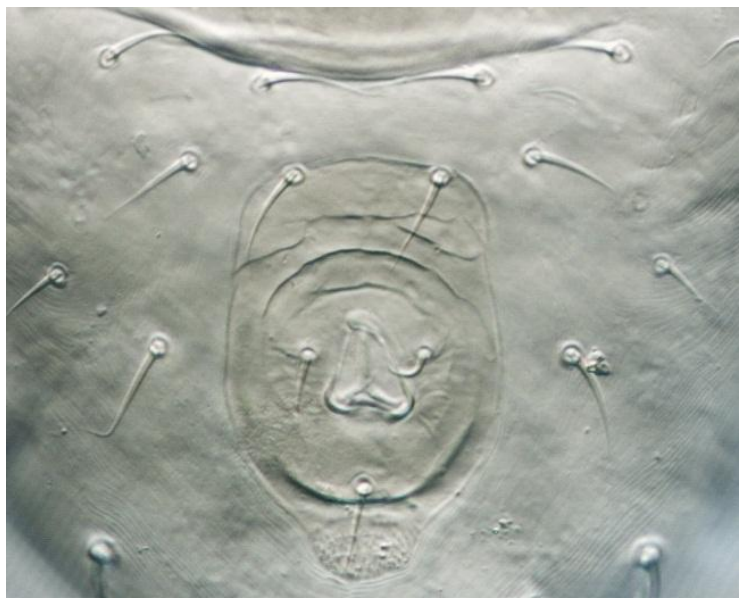

Figura 1. Placa dorsal (a), plaques ventrals (b), espermateca (c) i p. ventroanal (d) de Typhloseiella isotricha.Imatge cedida per Francisco Ferragut. 
a

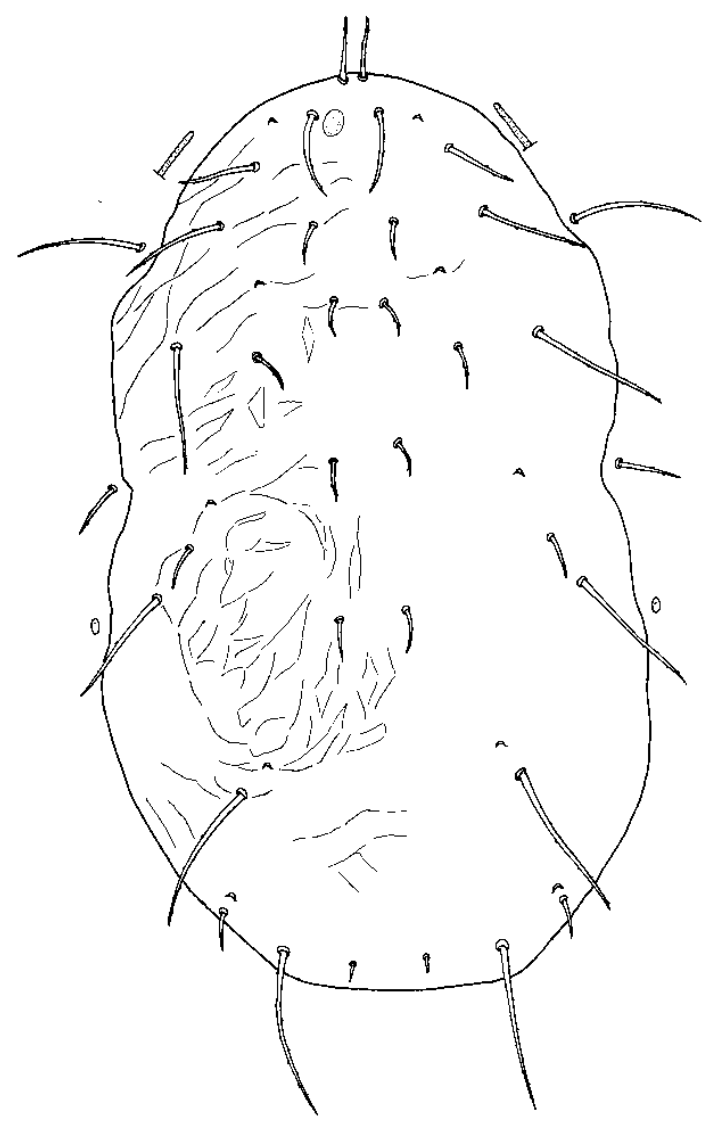

C
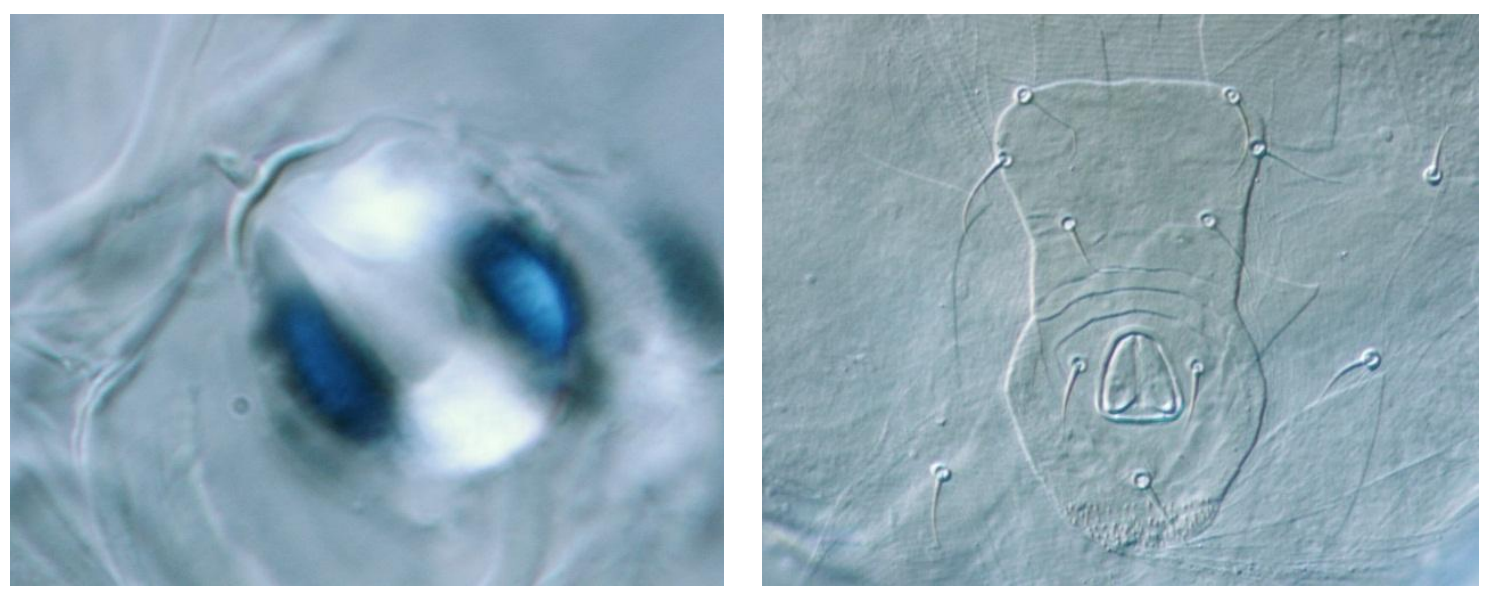

Figura 2. Placa dorsal (a), plaques ventrals (b), espermateca (c) i p. ventroanal (d) de Kampimodromus aberrans. Imatge cedida per Francisco Ferragut. 


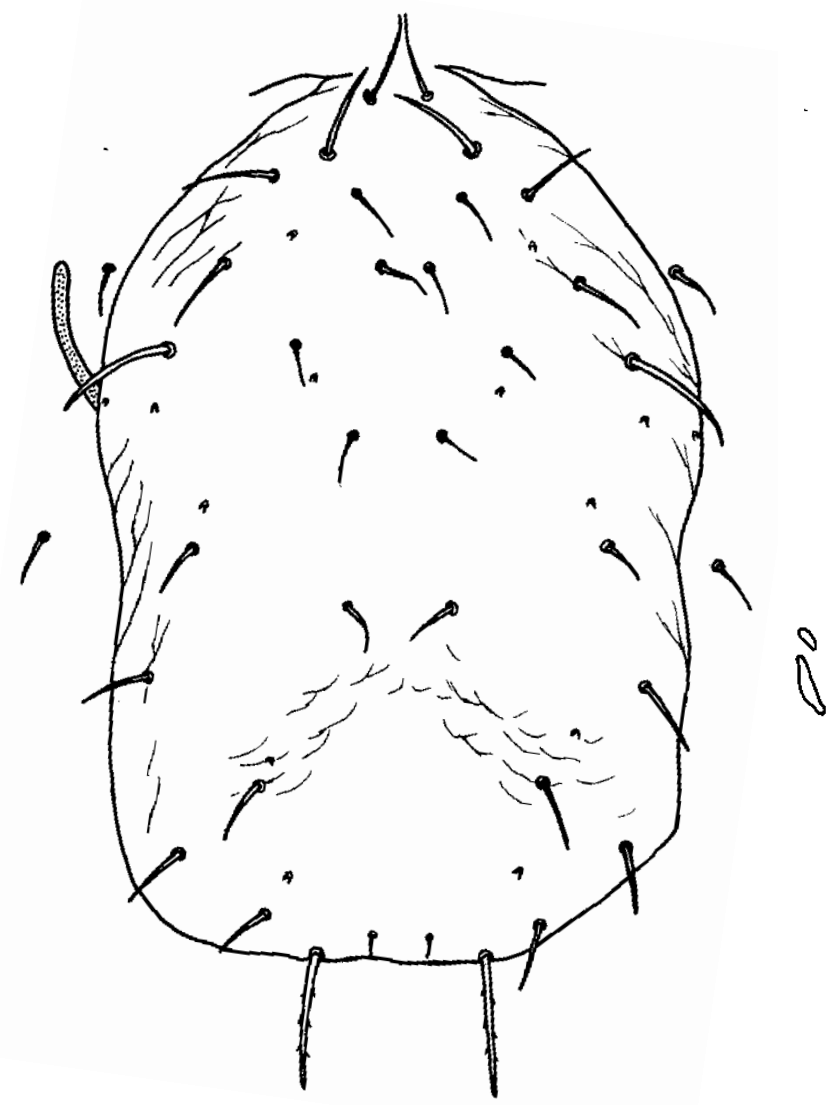

C

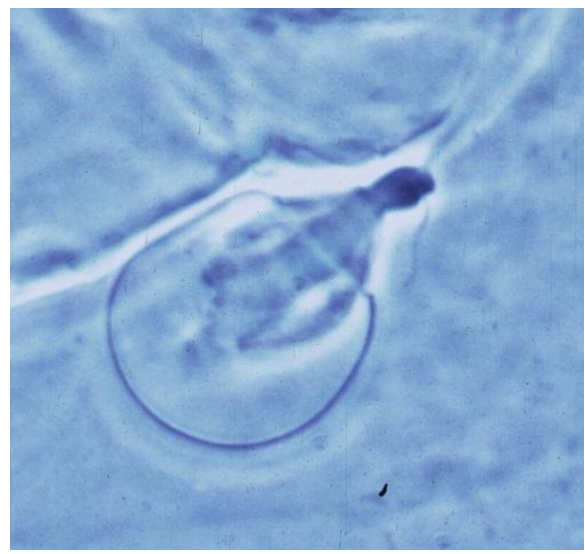

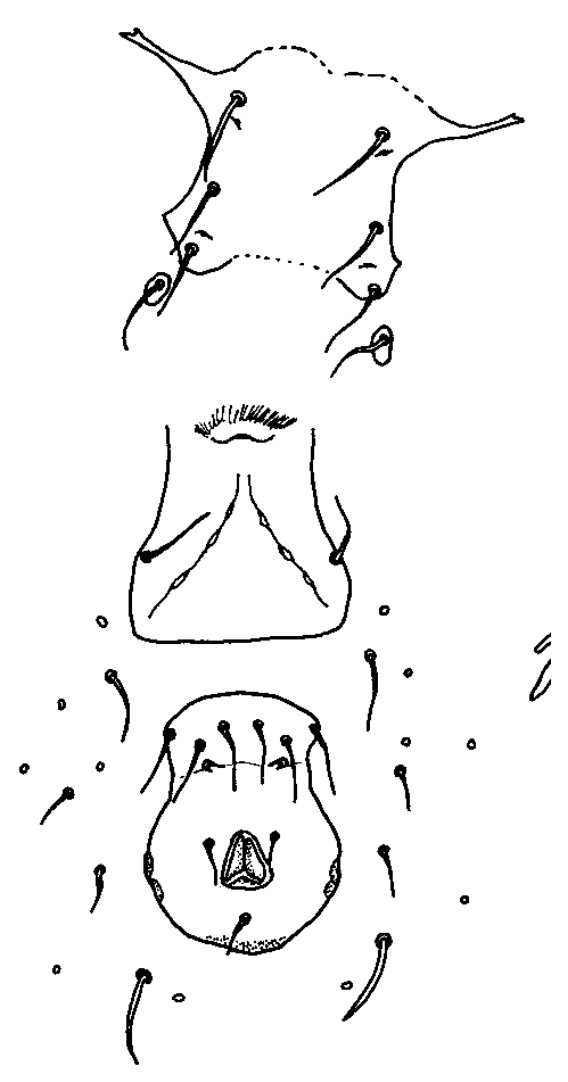

$d$

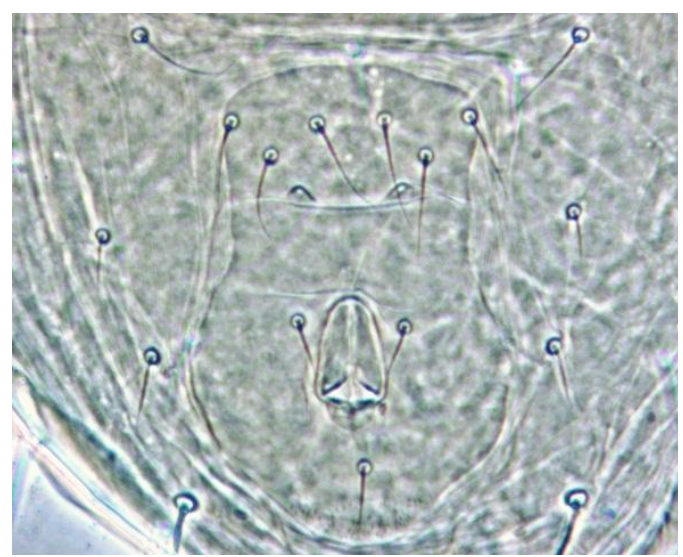

Figura 3. Placa dorsal (a), plaques ventrals (b), espermateca (c) i p. ventroanal (d) de Euseius finlandicus. Imatge cedida per Francisco Ferragut. 
a

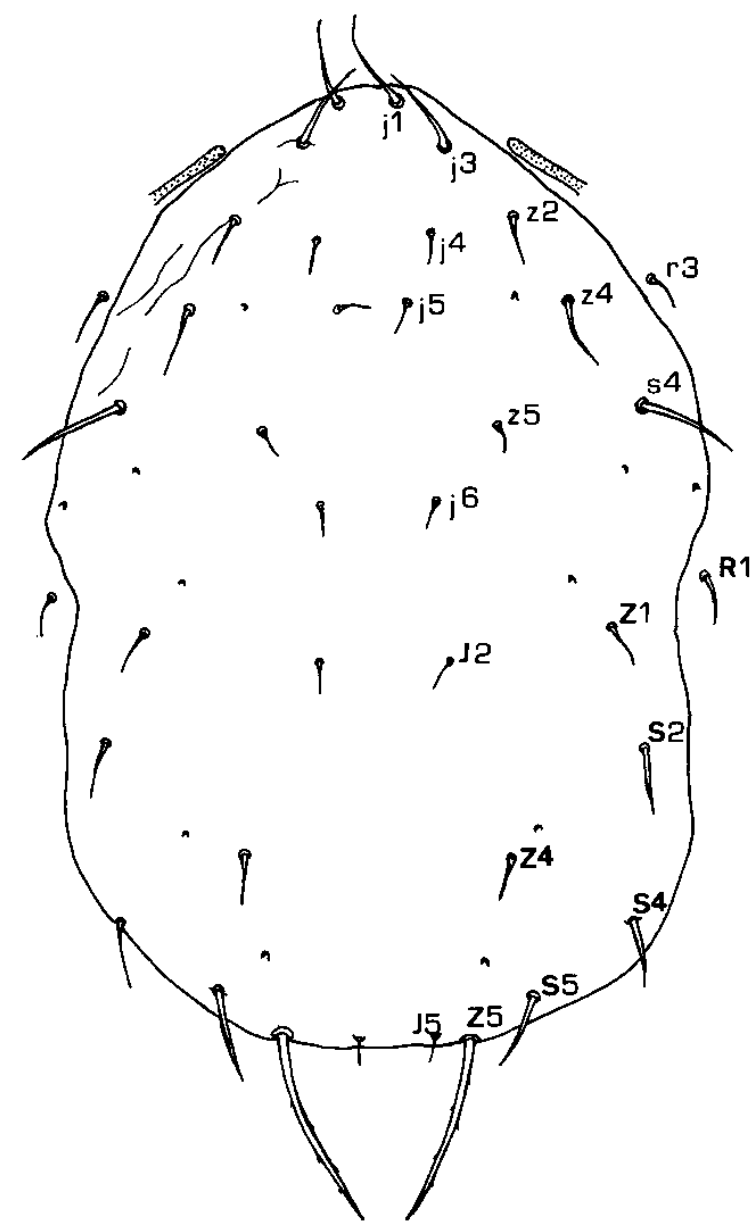

C

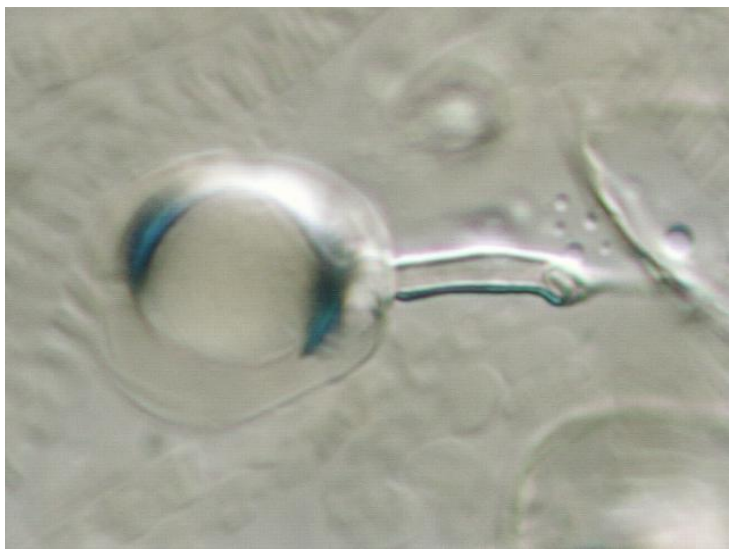

b
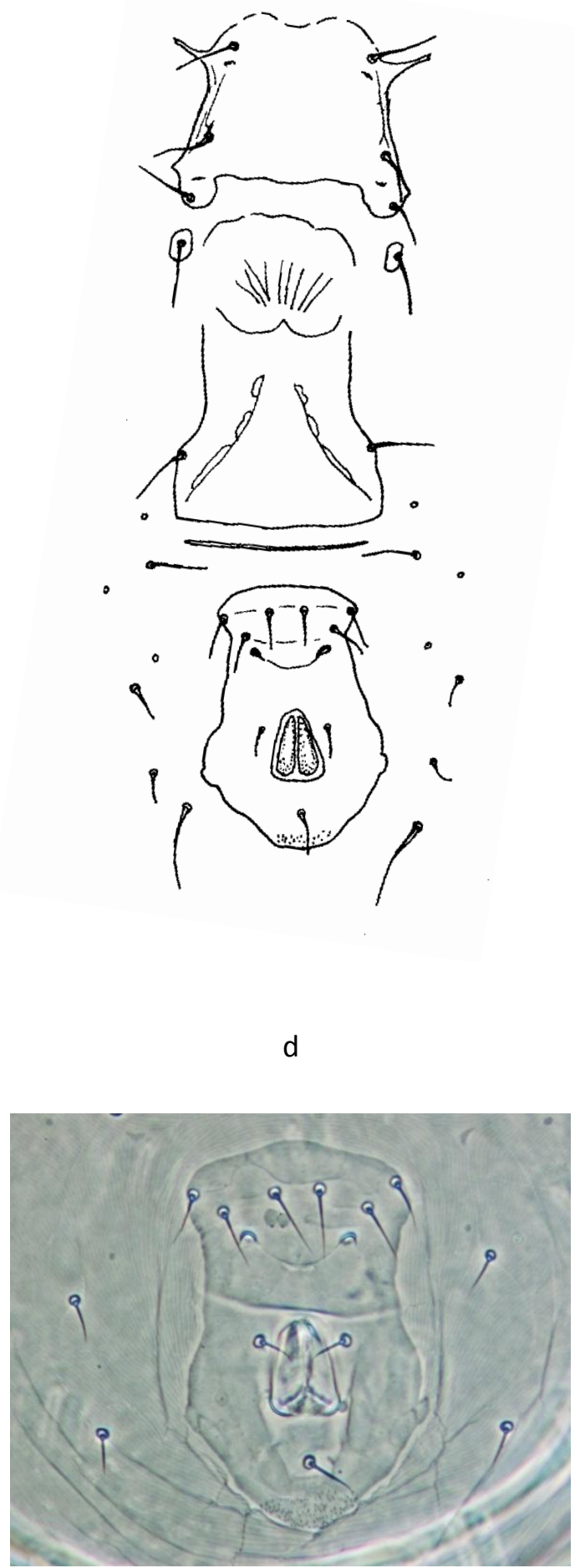

Figura 4. Placa dorsal (a), plaques ventrals (b), espermateca (c) i p. ventroanal (d) de Euseius stipulatus. Imatge cedida per Francisco Ferragut. 


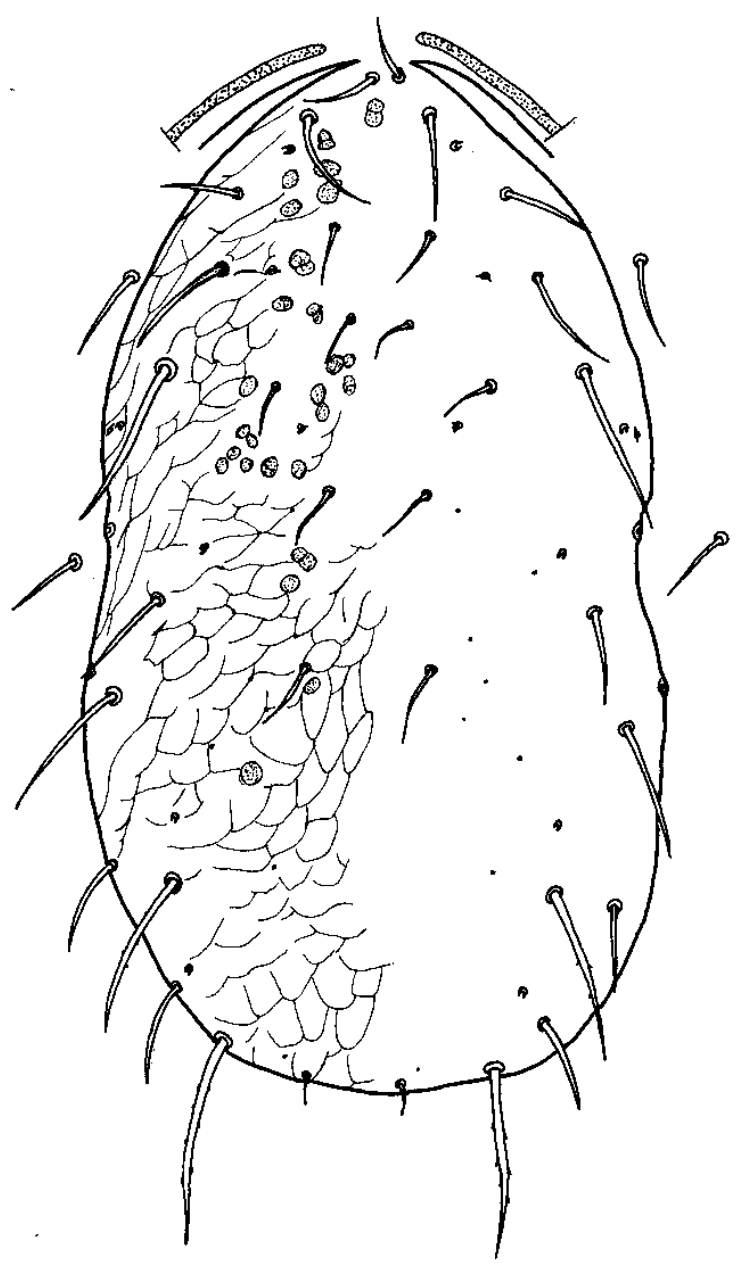

C

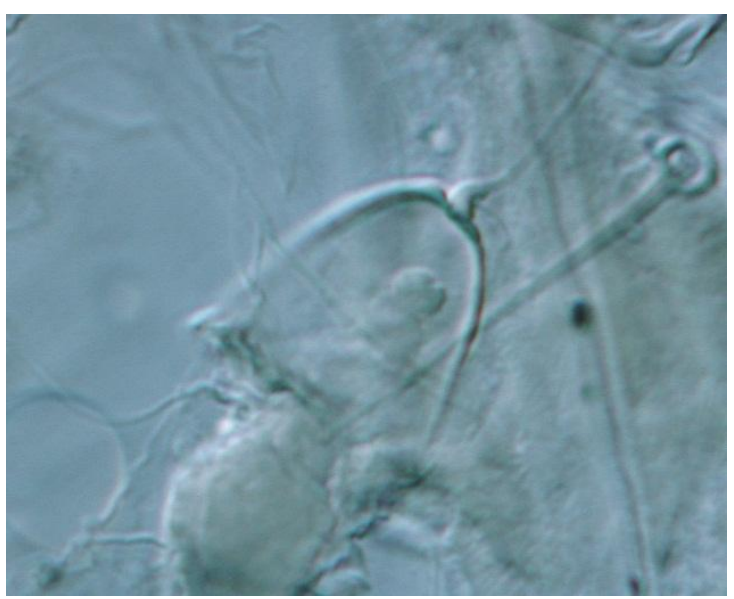

b

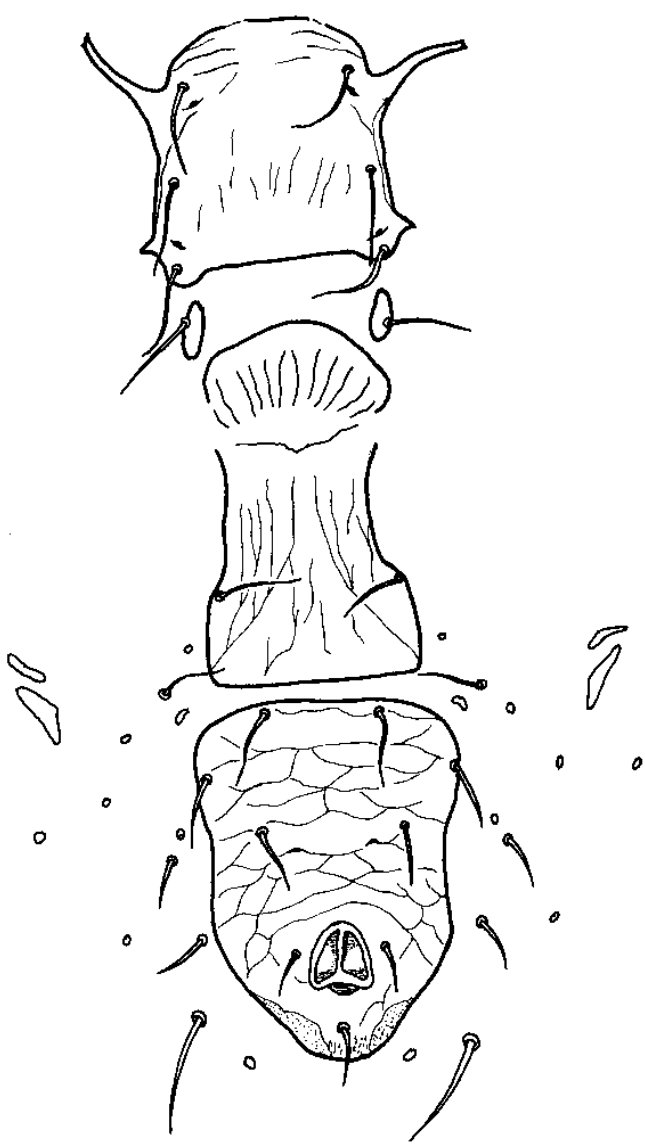

d

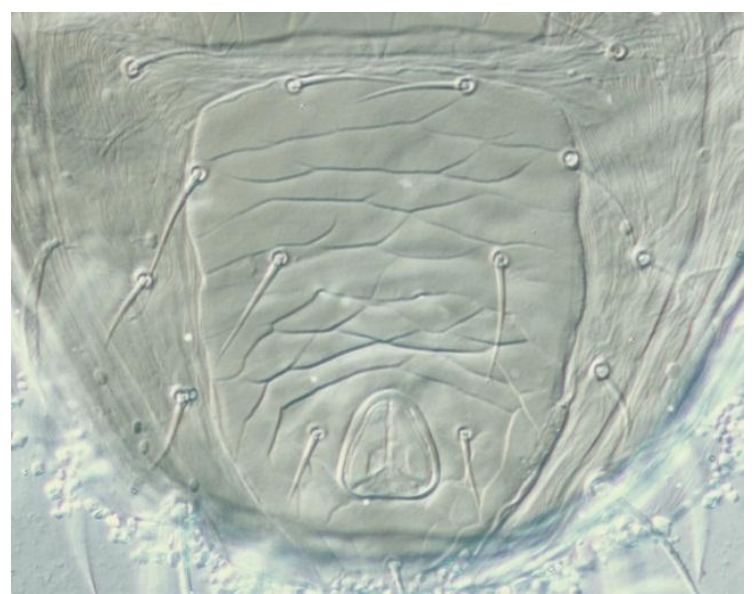

Figura 5. Placa dorsal (a), plaques ventrals (b), espermateca (c) i p. ventroanal (d) de Neoseiulus umbraticus. Imatge cedida per Francisco Ferragut. 

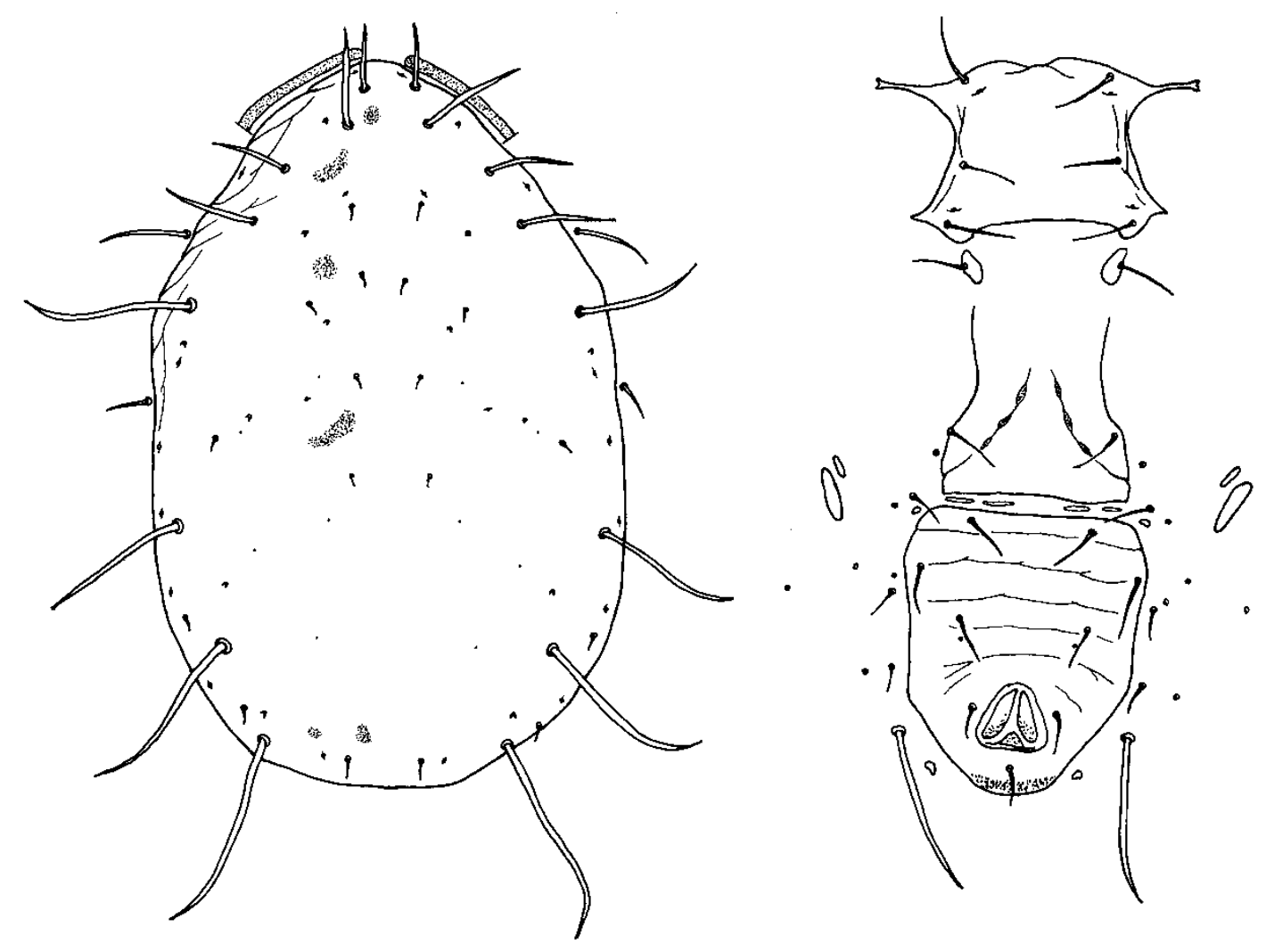

C

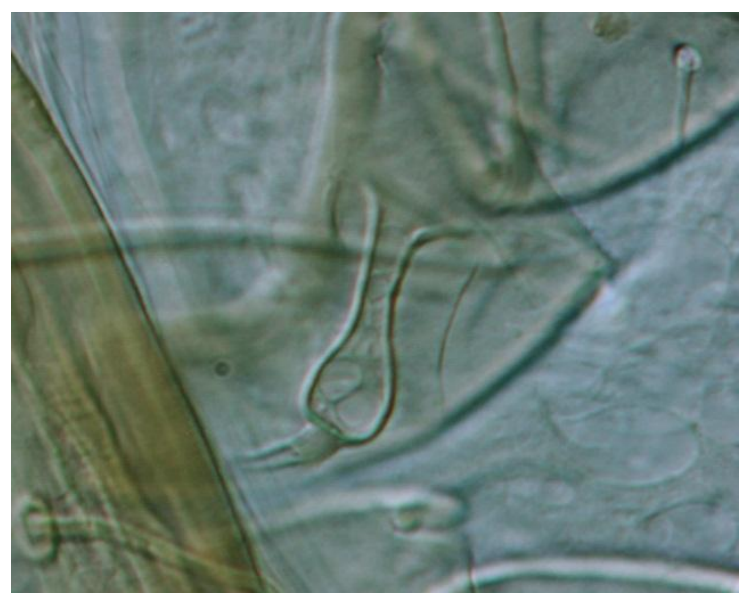

Figura 6. Placa dorsal (a), plaques ventrals (b) i espermateca (c) de Graminaseius lituatus. Imatge cedida per Francisco Ferragut. 
a

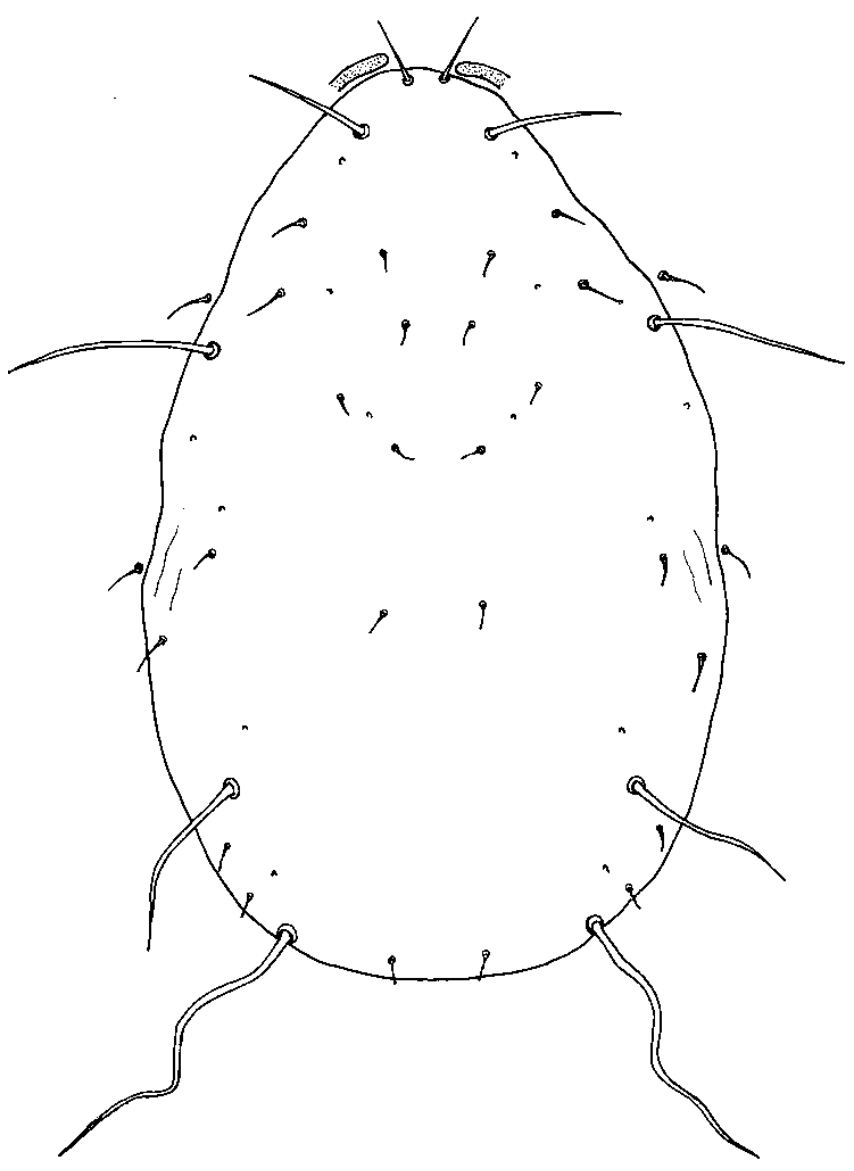

C

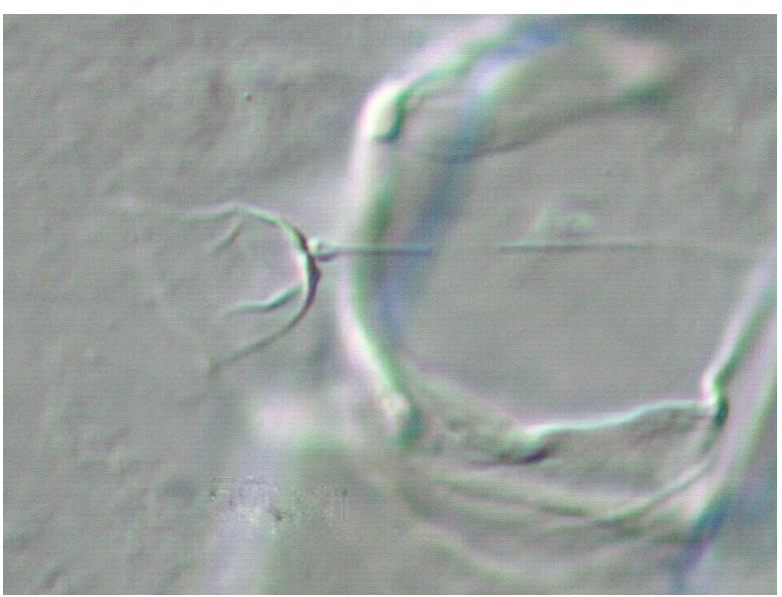

b

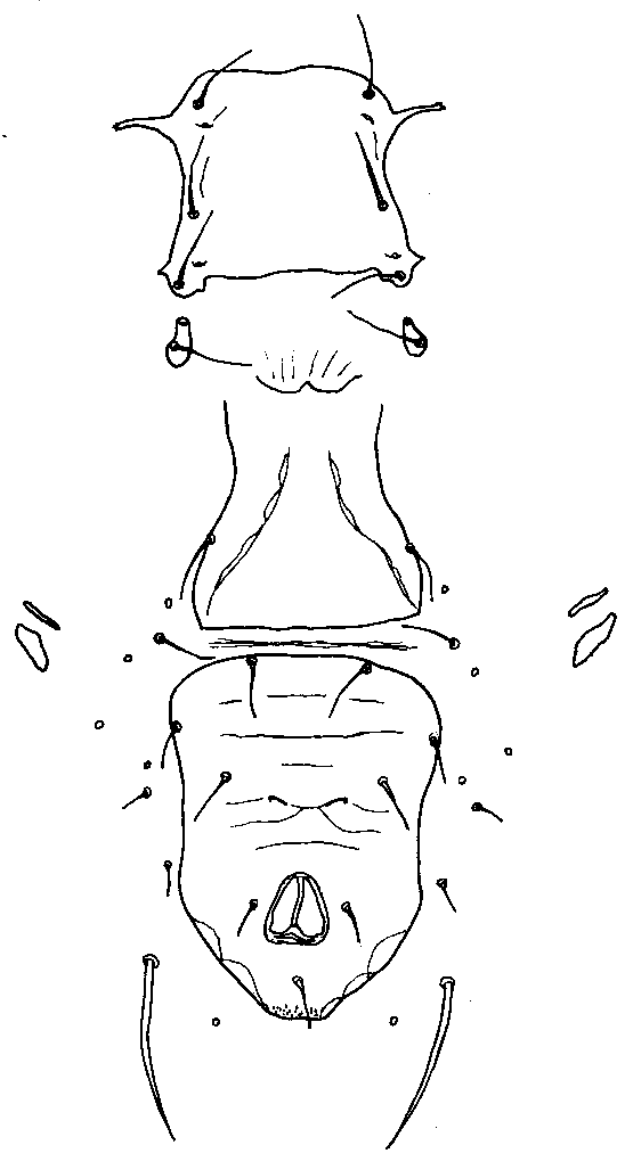

d

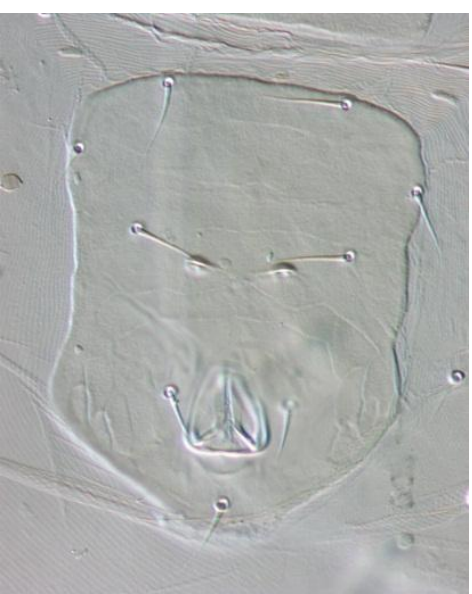

Figura 7. Placa dorsal (a), plaques ventrals (b), espermateca (c) i p. ventroanal (d) de Amblyseius andersoni. Imatge cedida per Francisco Ferragut. 


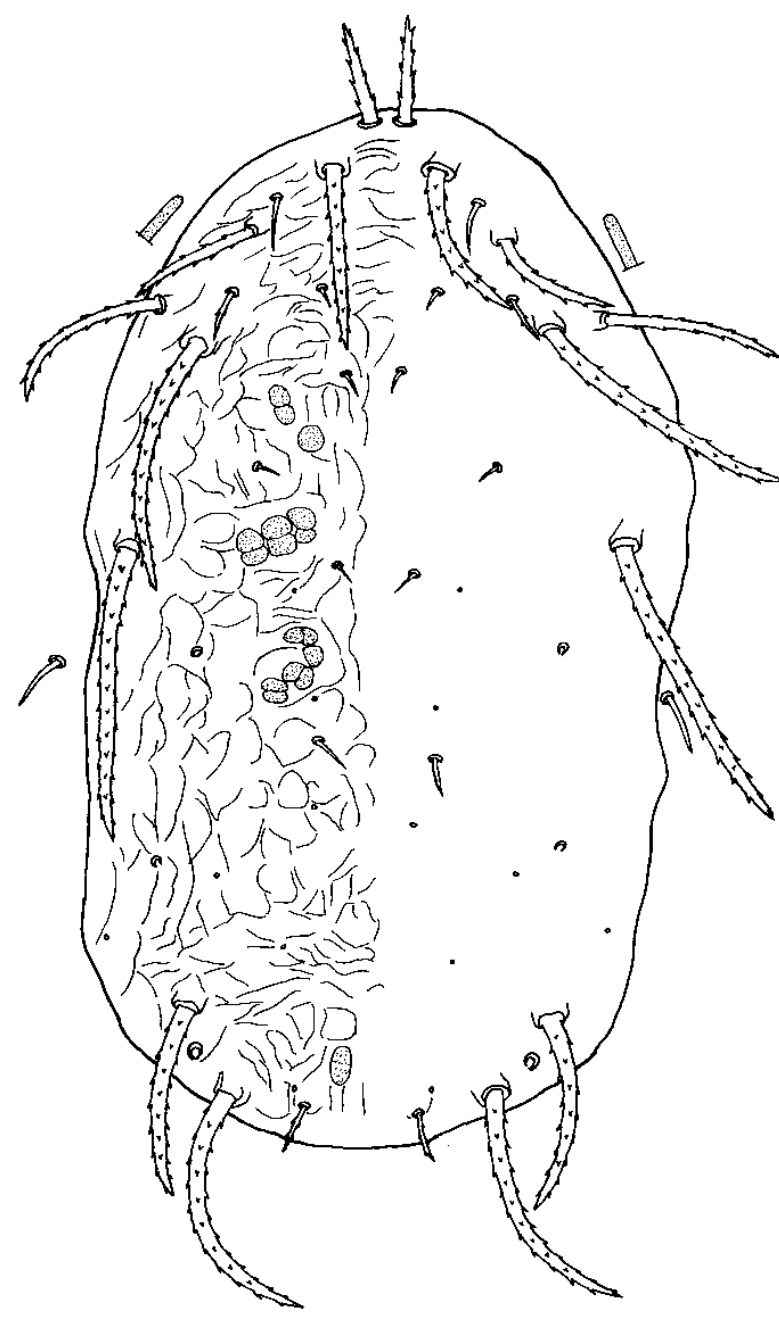

C

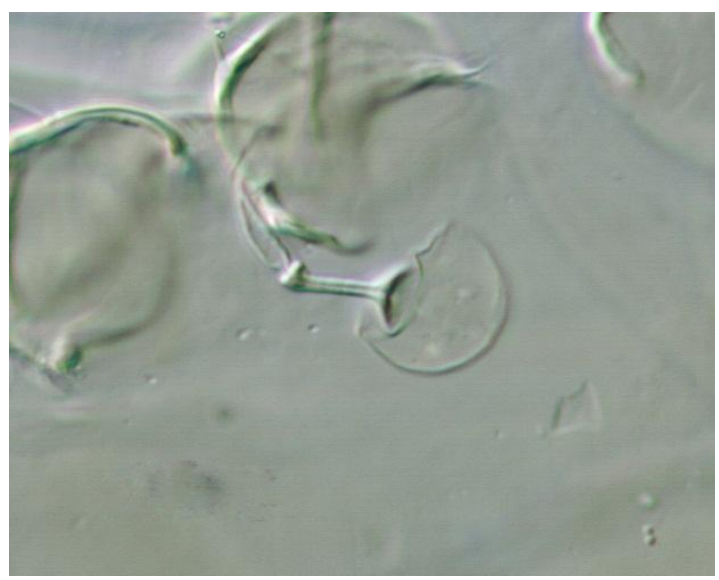

b
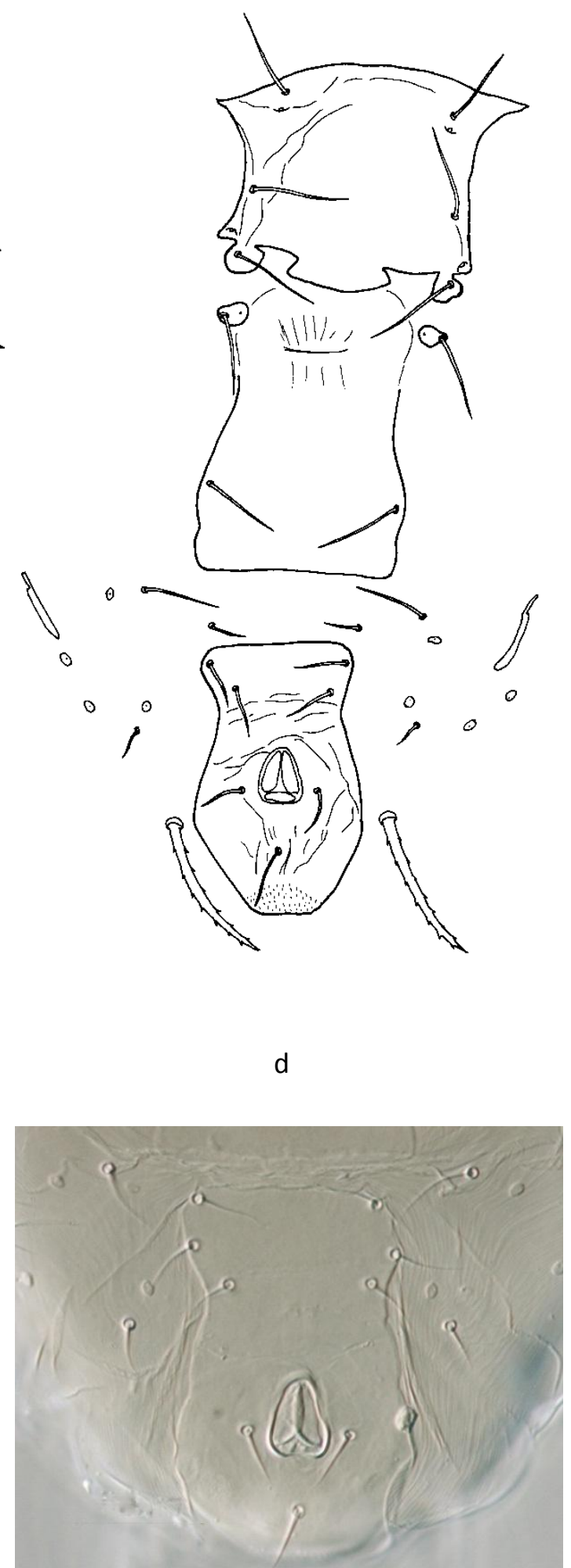

Figura 8. Placa dorsal (a), plaques ventrals (b), espermateca (c) i p. ventroanal (d) de Phytoseius plumifer. Imatge cedida per Francisco Ferragut. 

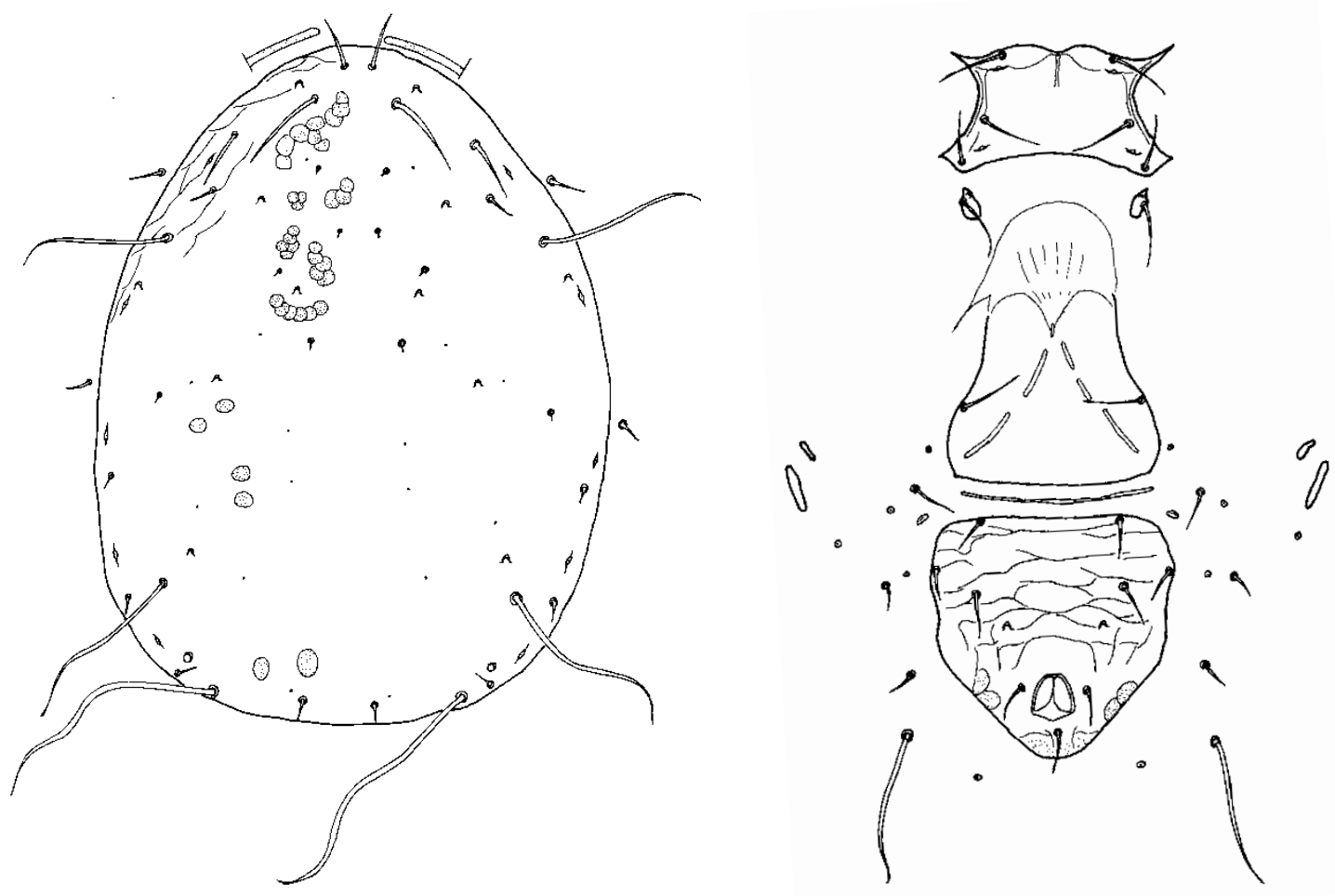

C

d
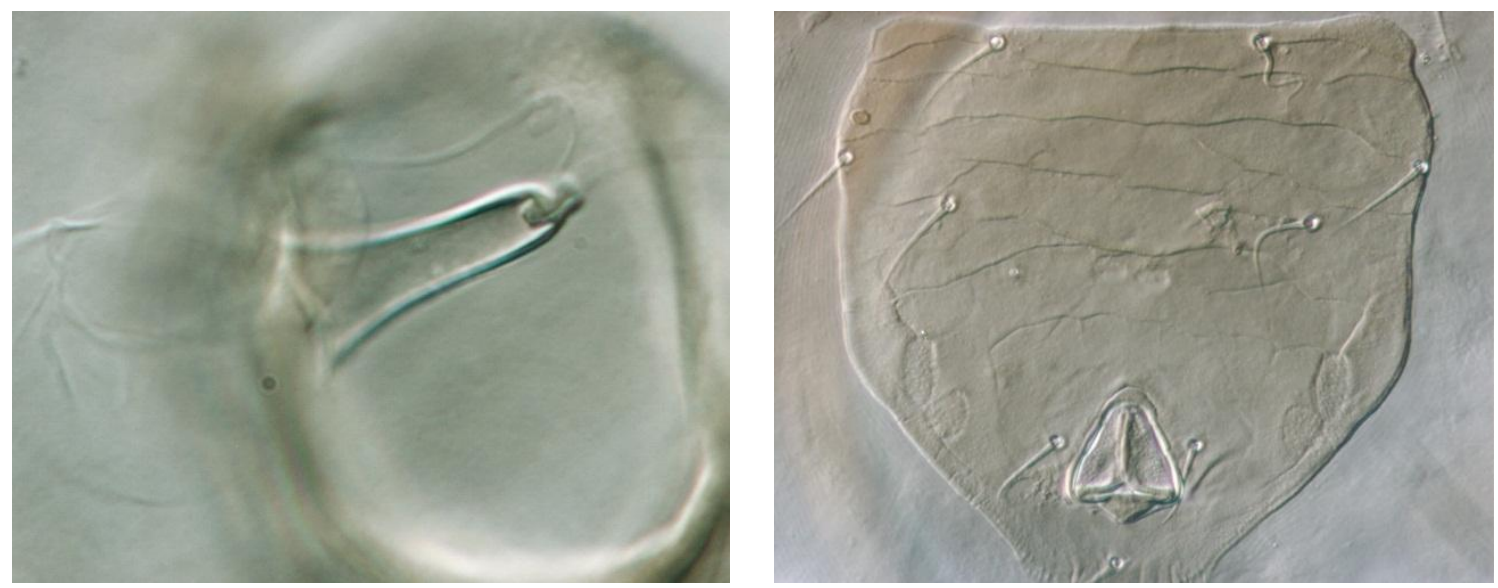

Figura 9. Placa dorsal (a), plaques ventrals (b), espermateca (c) i p. ventroanal (d) de Proprioseiopsis bordjelaini. Imatge cedida per Francisco Ferragut. 


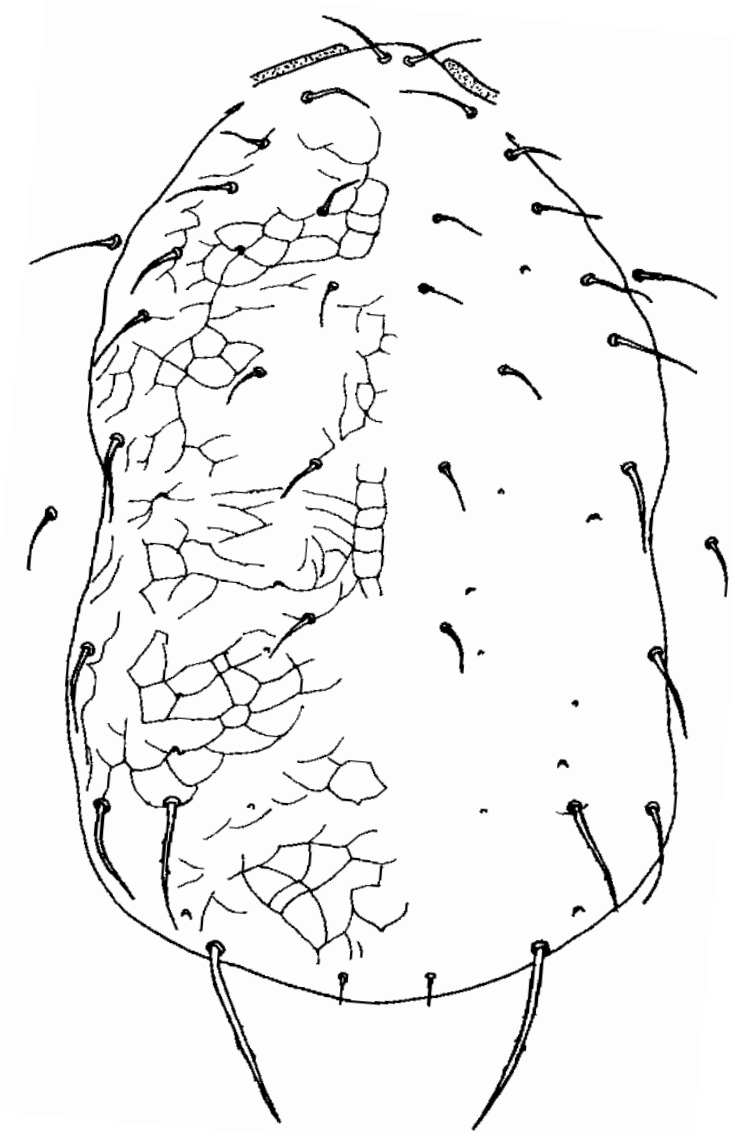

C

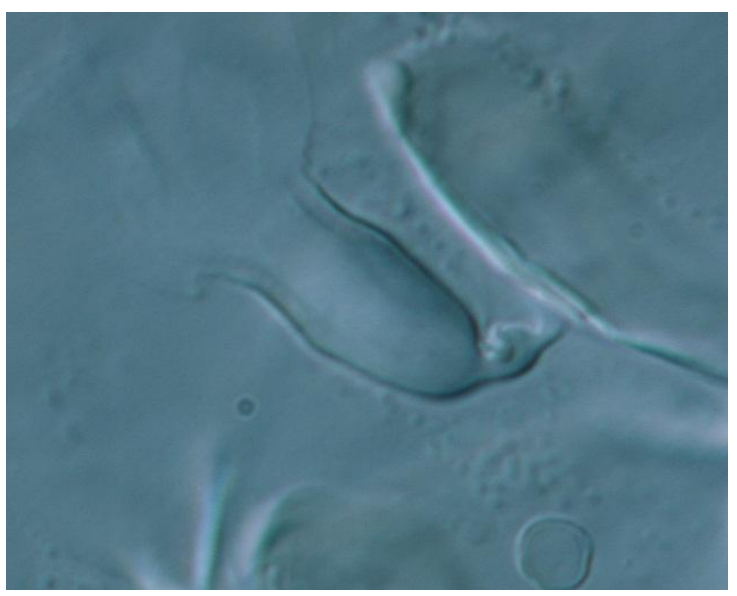

b

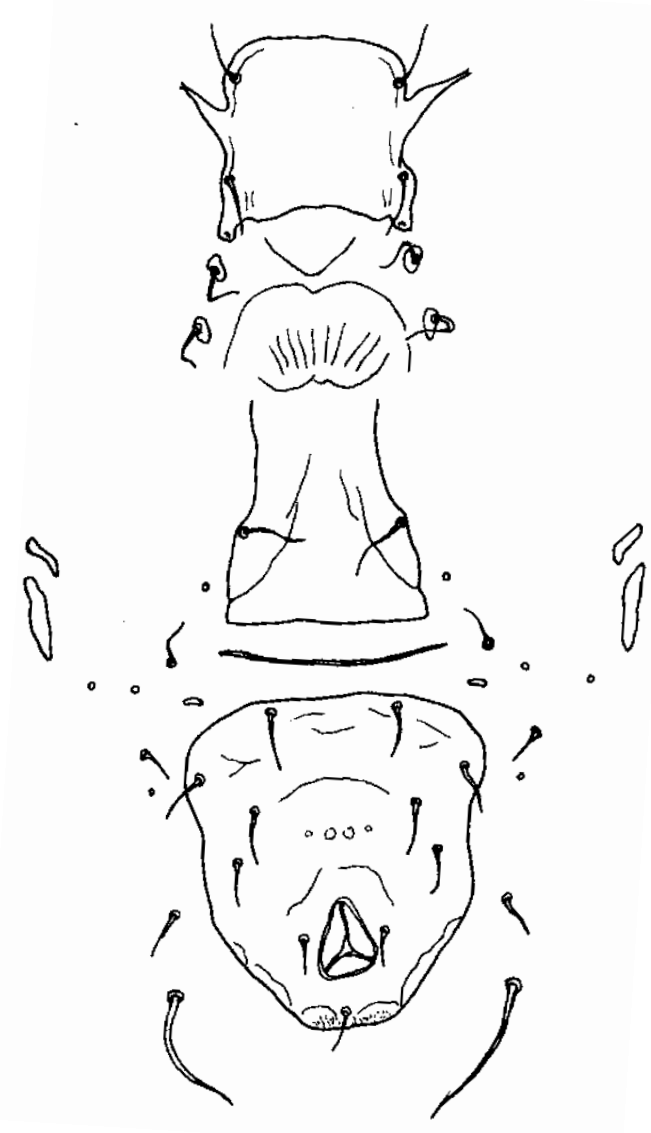

d

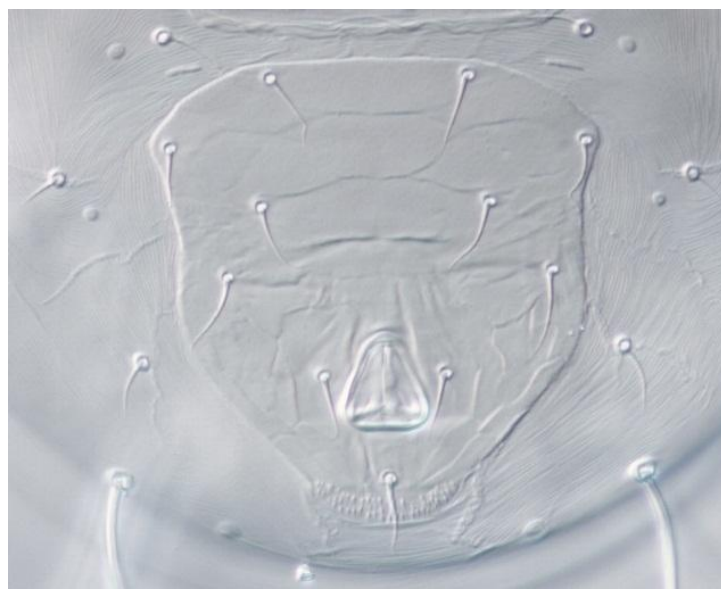

Figura 10. Placa dorsal (a), plaques ventrals (b), espermateca (c) i p. ventroanal (d) de Typhlodromus phialatus. Imatge cedida per Francisco Ferragut. 
a

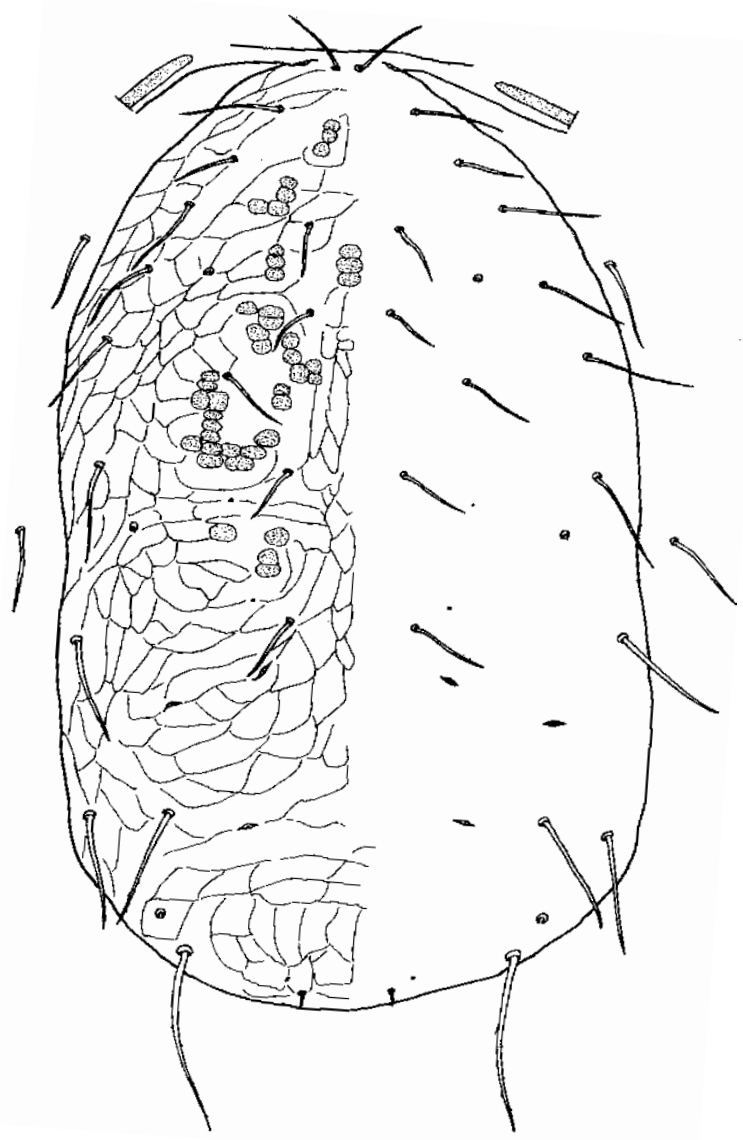

C

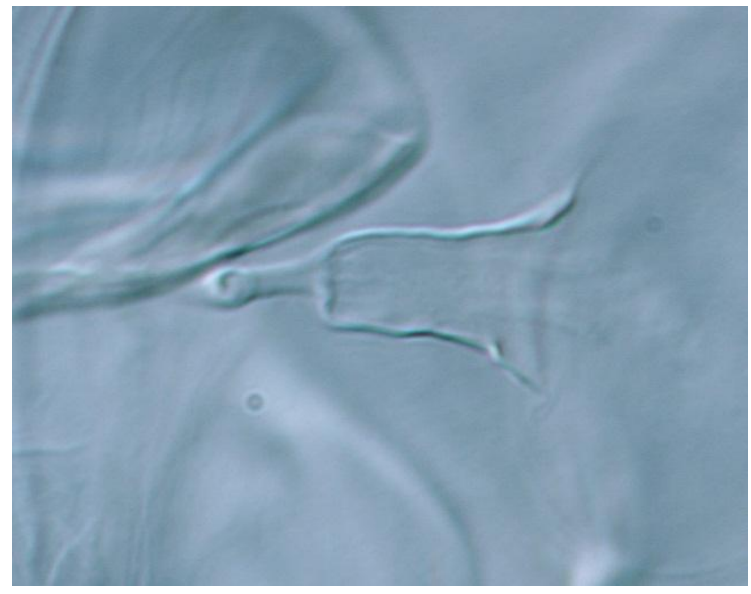

b

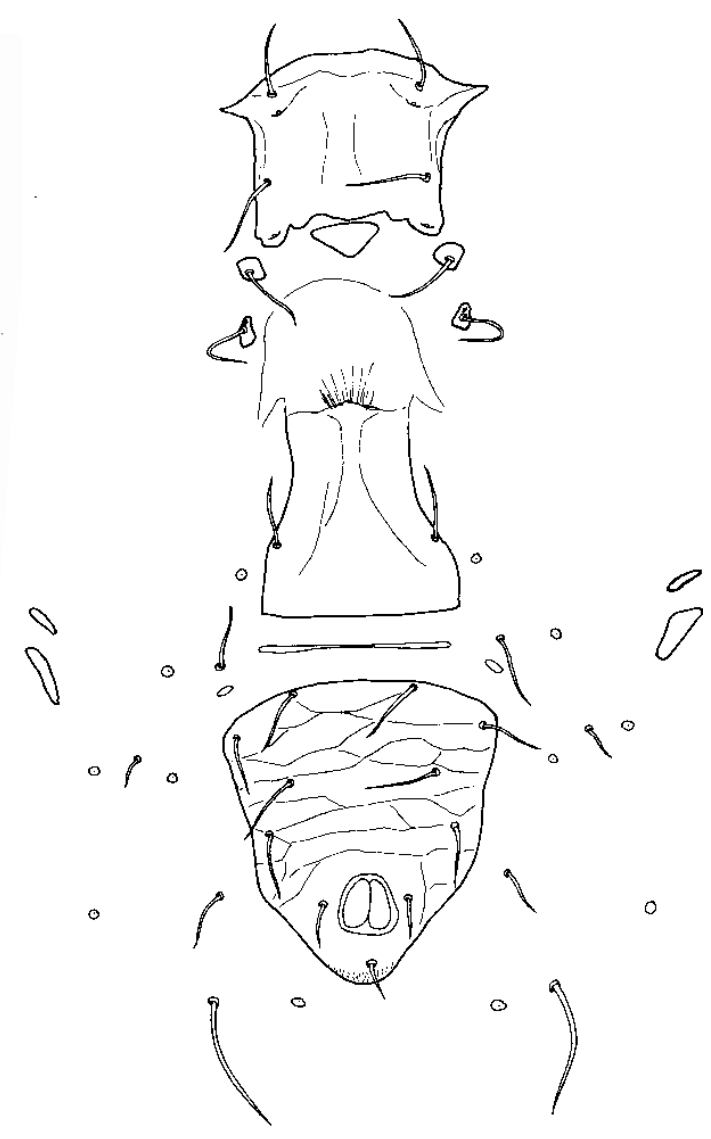

d

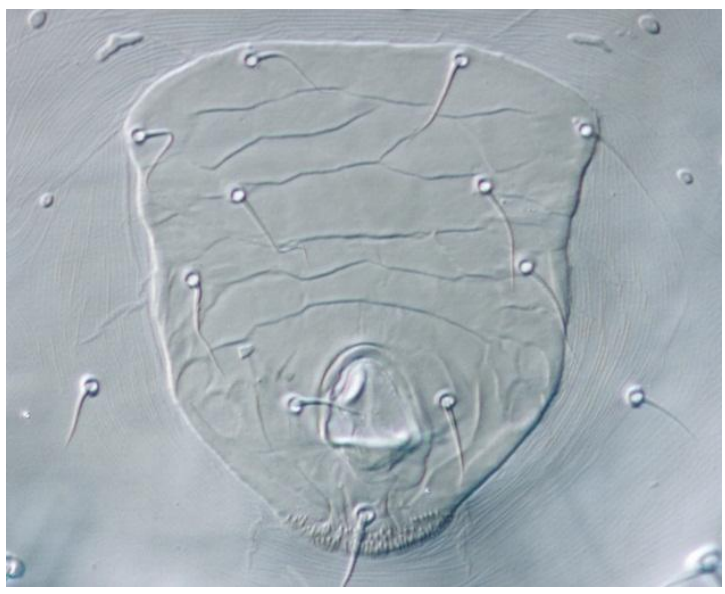

Figura 11. Placa dorsal (a), plaques ventrals (b), espermateca (c) i p. ventroanal (d) de Typhlodromus pyri. Imatge cedida per Francisco Ferragut. 


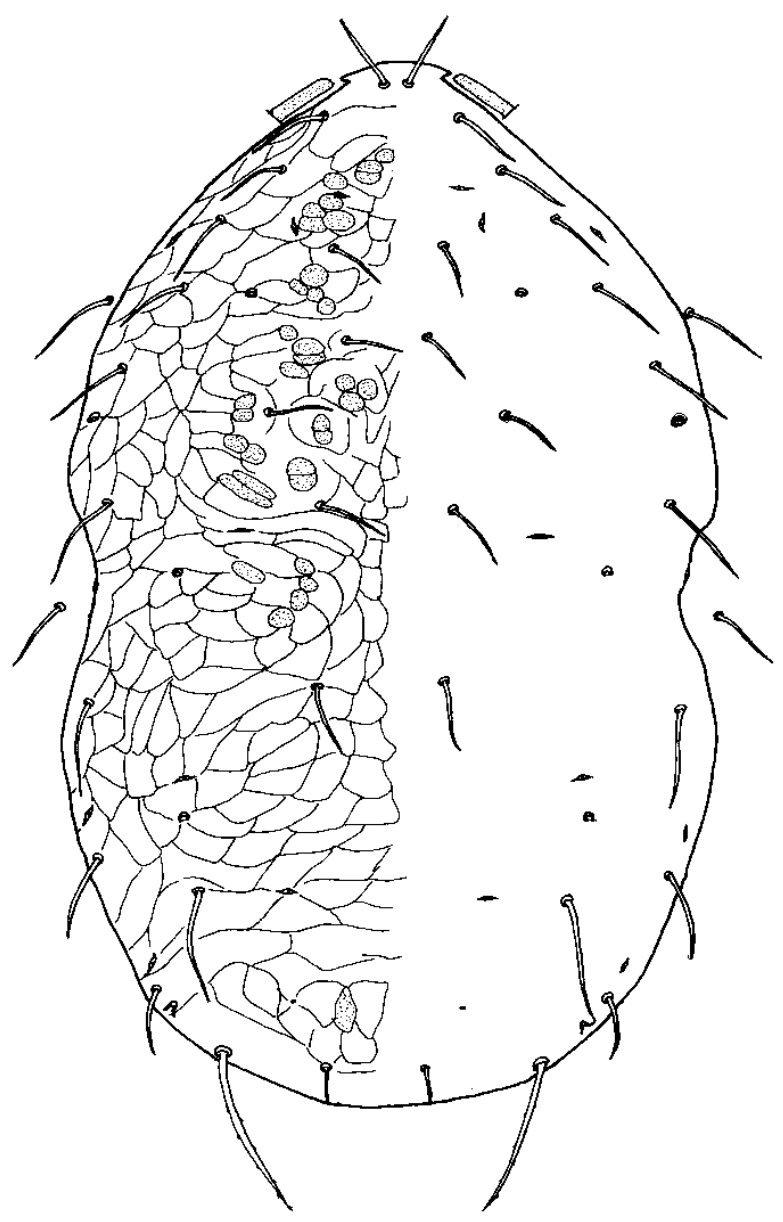

C

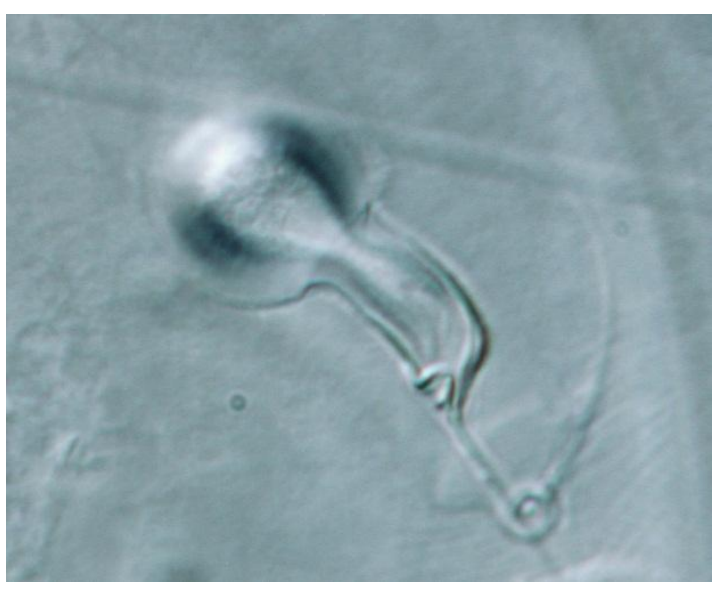

b
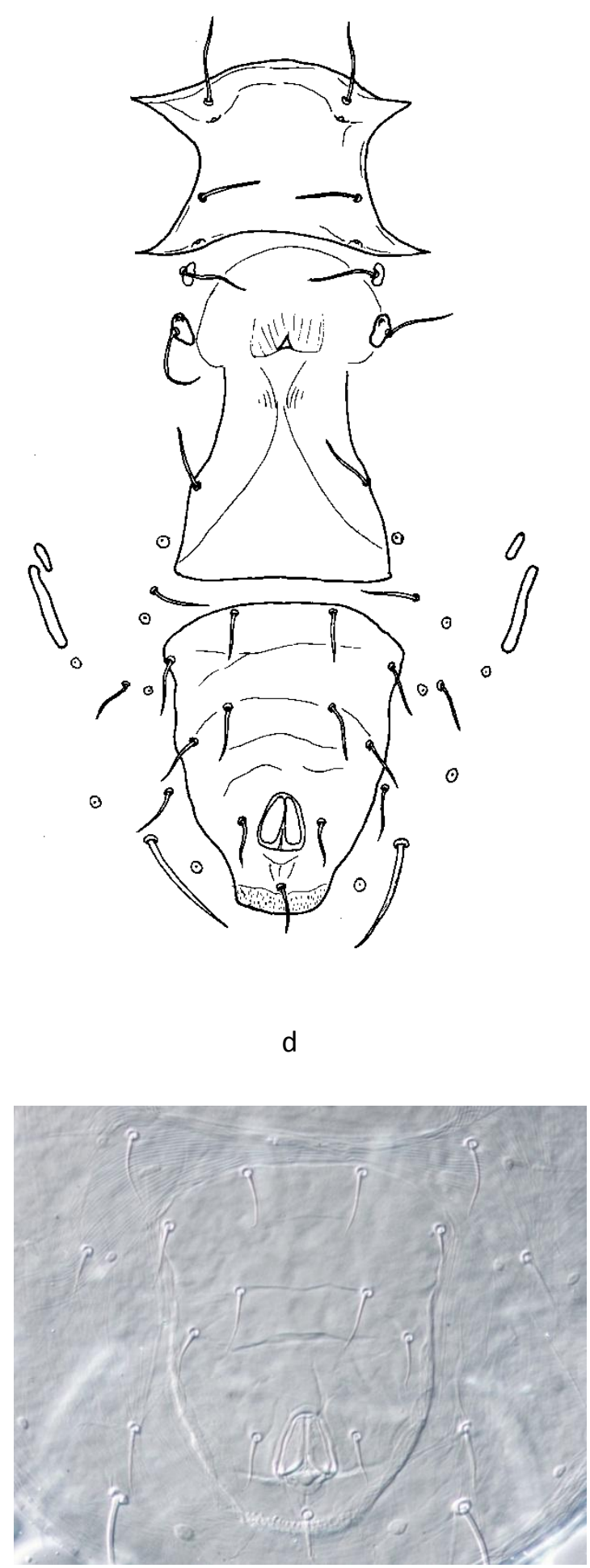

Figura 12. Placa dorsal (a), plaques ventrals (b), espermateca (c) i p. ventroanal (d) de Typhlodromus (Anthoseius) athenas. Imatge cedida per Francisco Ferragut. 


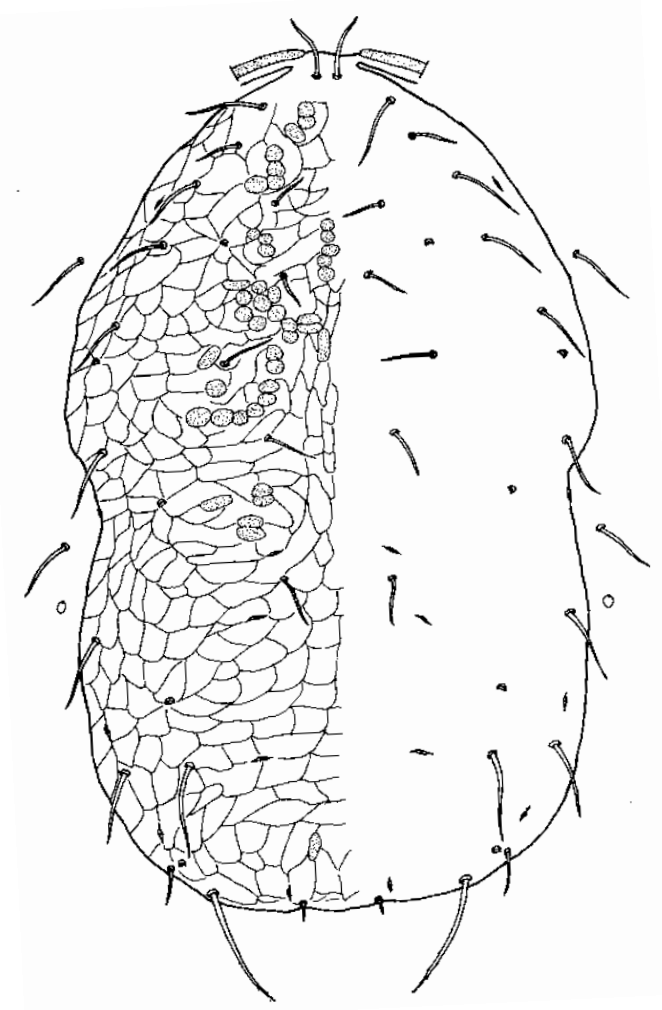

C

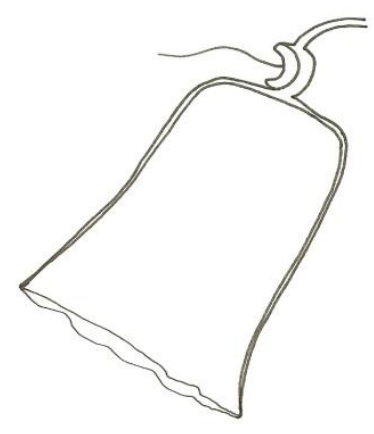

b
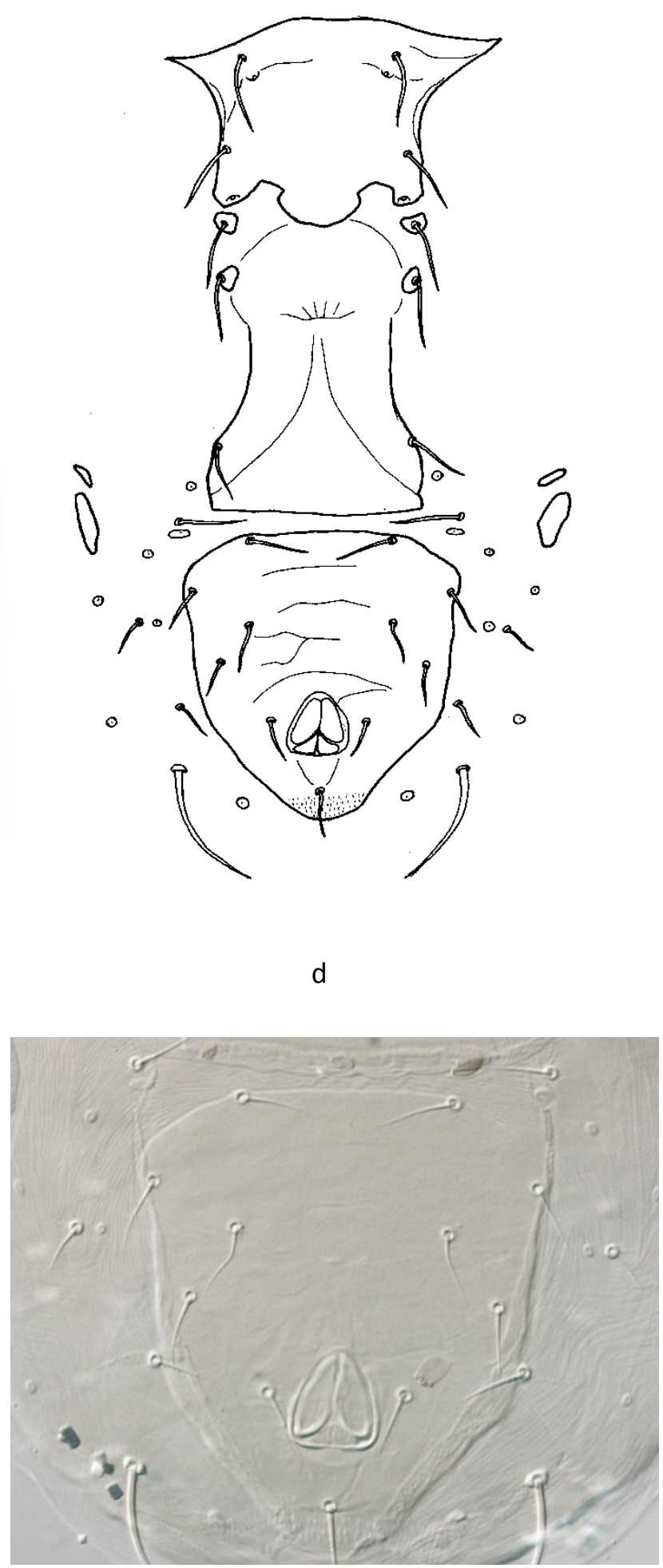

Figura 13. Placa dorsal (a), plaques ventrales (b), espermateca (c) i p. ventroanal (d) de $T$. (A.) foenilis. Imatge cedida per Francisco Ferragut. 
a

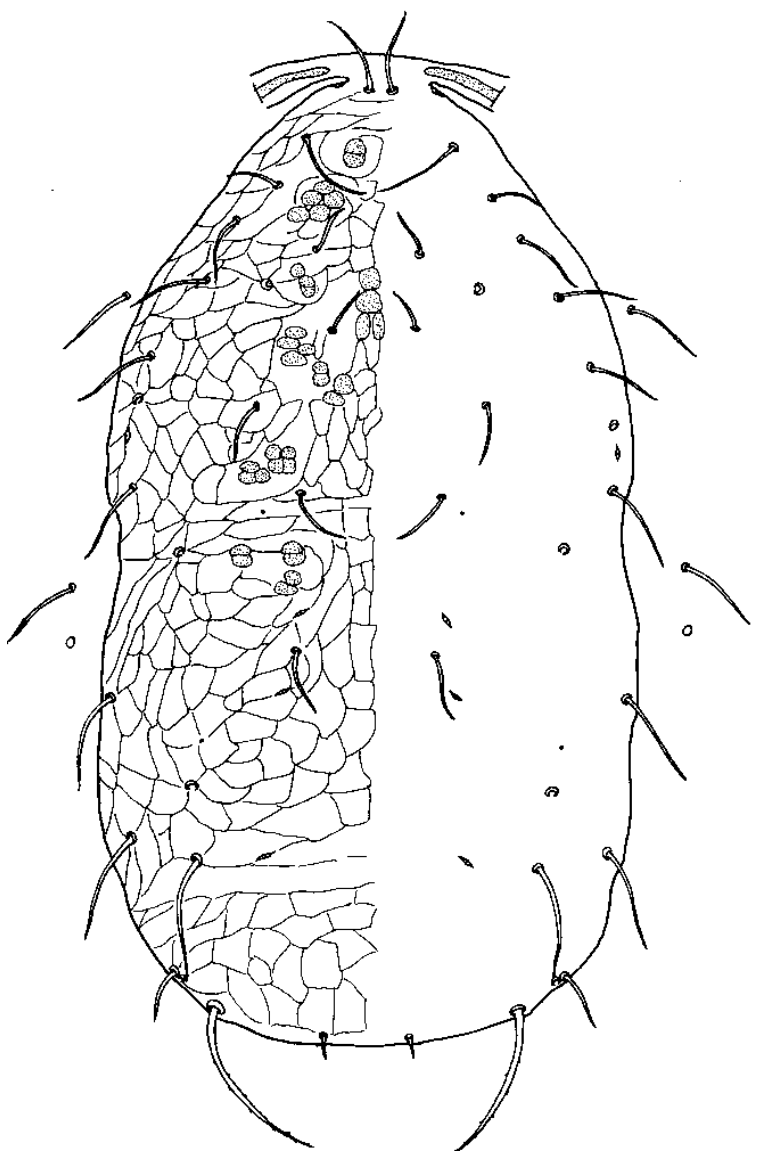

C

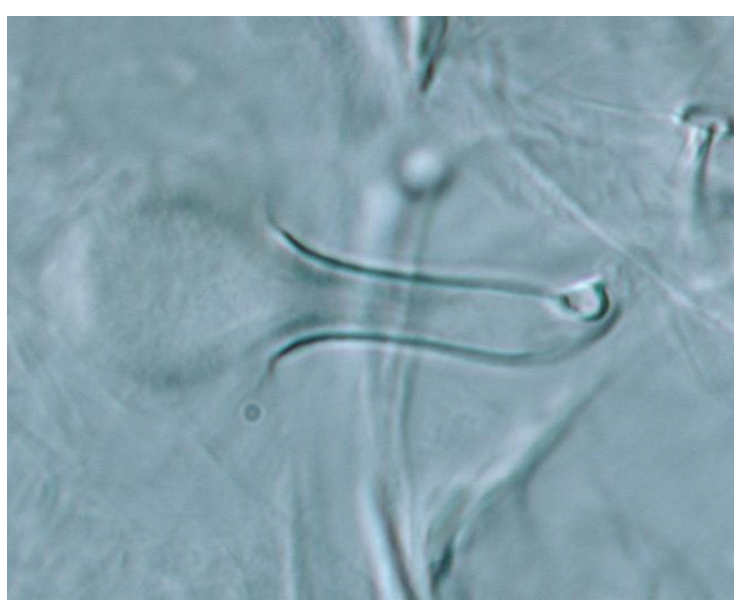

b
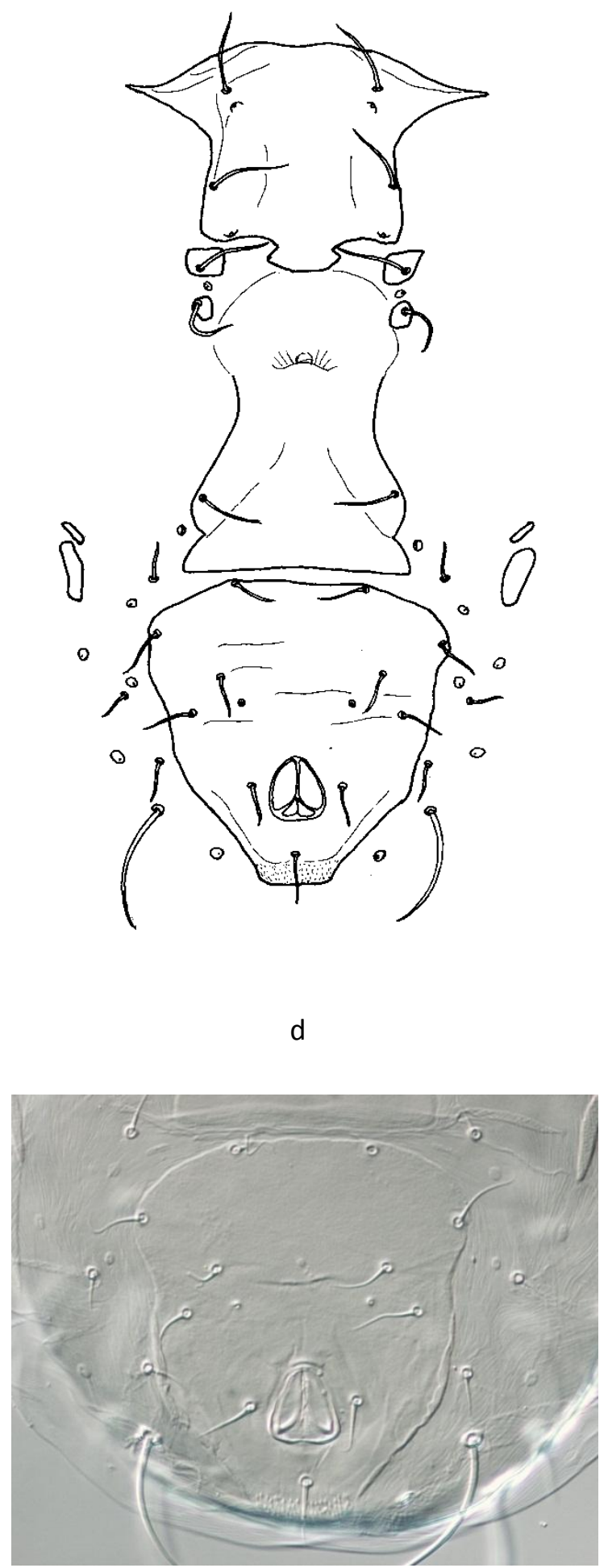

Figura 14. Placa dorsal (a), plaques ventrals (b), espermateca (c) i p. ventroanal (d) de T. (A.) rhenanoides. Imatge cedida per Francisco Ferragut. 
a

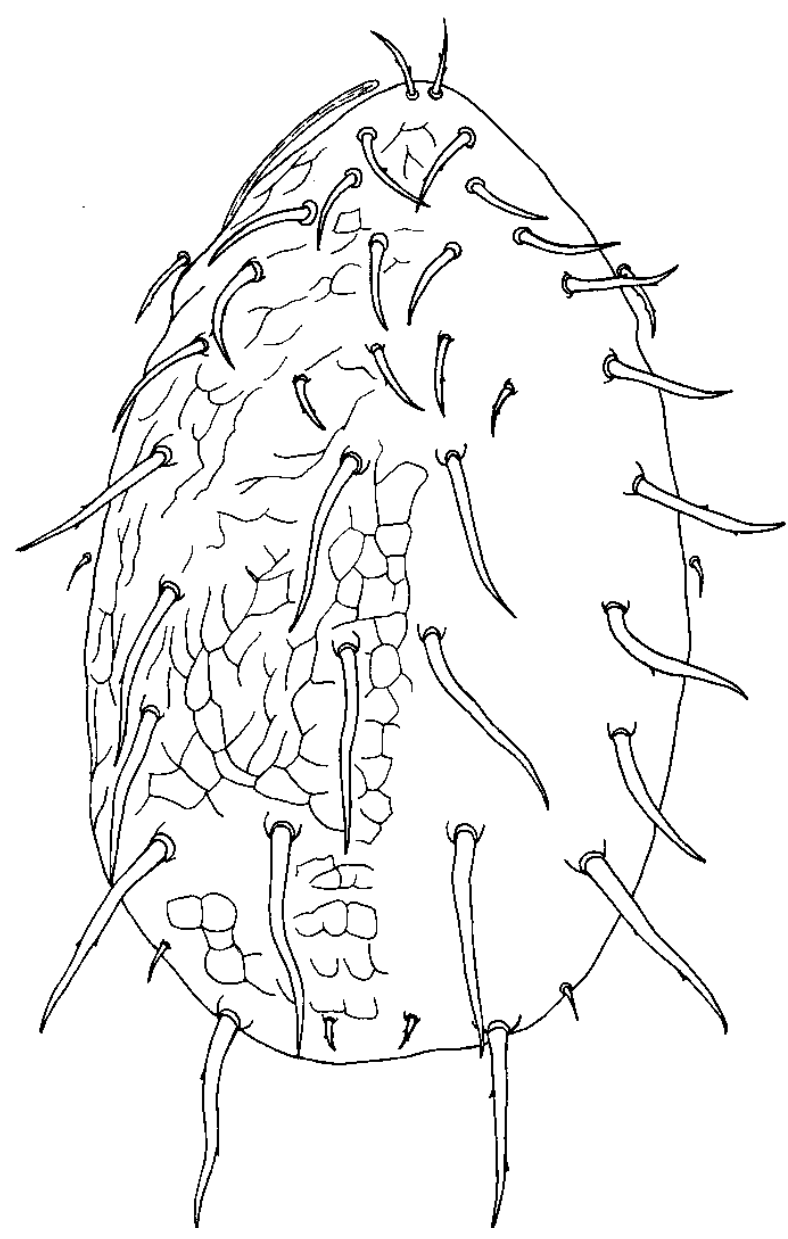

b

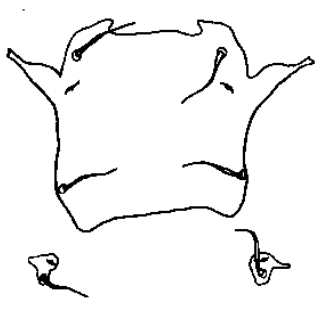

$\rightarrow 11 / 1,0$
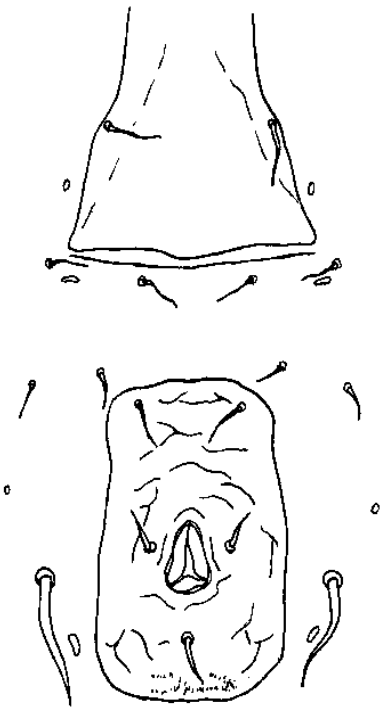

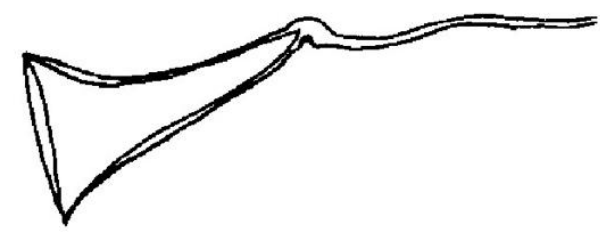

Figura 15. Placa dorsal (a), plaques ventrals (b) i espermateca (c) de Typhloseiulus carmon. Imatge cedida per Francisco Ferragut. 
a

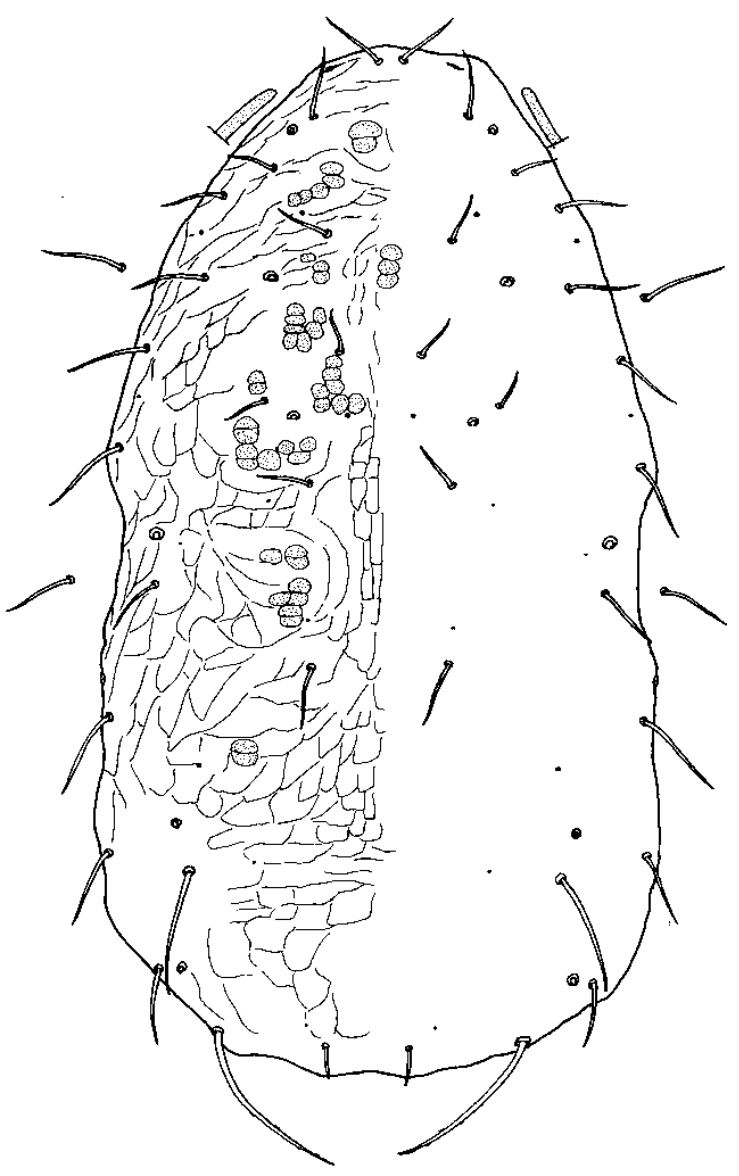

c

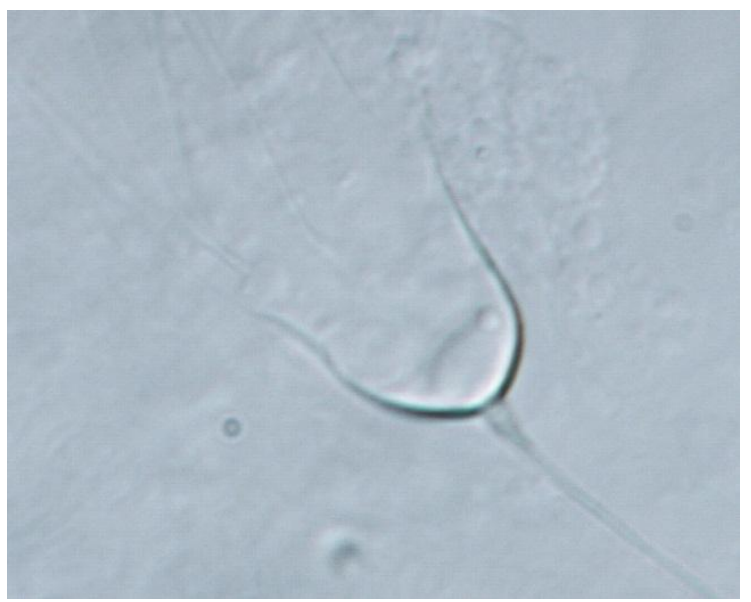

b
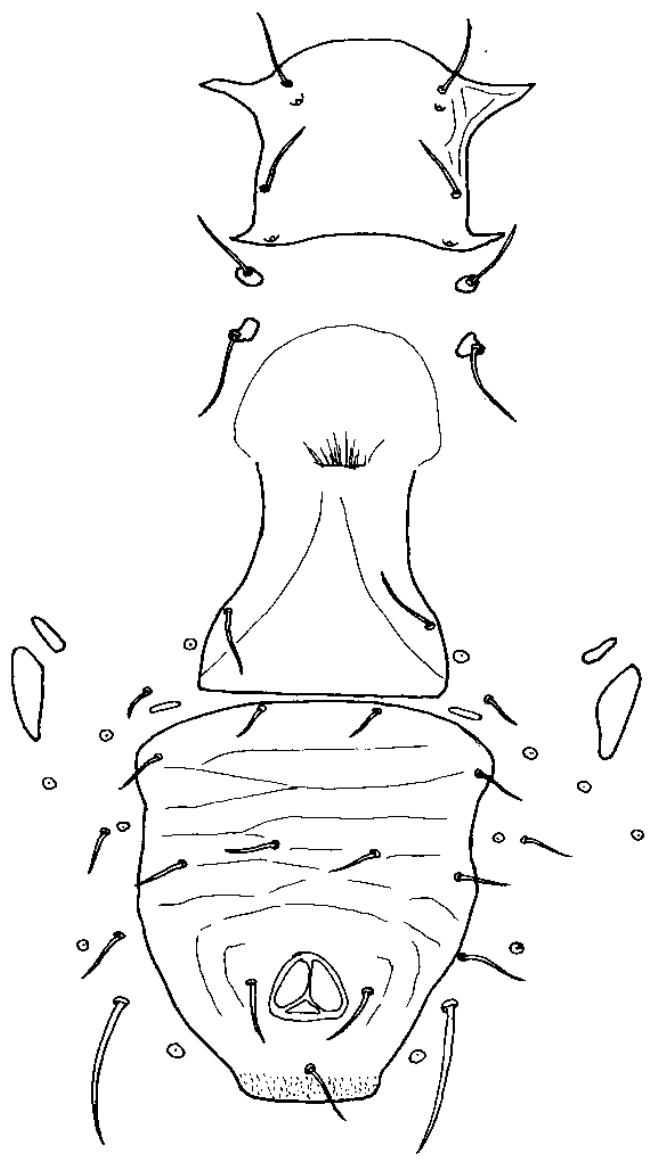

d

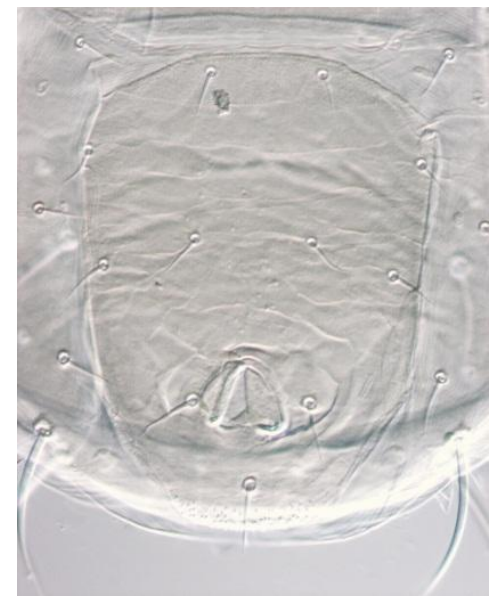

Figura 16. Placa dorsal (a), plaques ventrals (b), espermateca (c) i p. ventroanal (d) de Neoseiulella litoralis. Imatge cedida per Francisco Ferragut. 


\section{Material suplementari 2.}

Nombre d'individus de cadascuna de les espècies d'àcars trobades i planta hoste en cadascun dels següents espais naturals de la província de Castelló (mostre entre parèntesi la data de recollida de mostres): Reserva Natural de les Illes Columbretes (18/5/2007), Parc Natural del Desert de Les Palmes (8/10/2007), Parc Natural del Penyagolosa (28/10/2007), Parc Natural del Prat de Cabanes-Torreblanca (14/11/2007), Parc Natural de la Serra d'Espadà (1/10/2007), Parc Natural de la Serra d'Irta (14/11/2007), Parc Natural de la Tinença de Benifassà $(7 / 12 / 2007)$ 
RESERVA NATURAL ILLES COLUMBRETES (18/5/2007)

\begin{tabular}{|c|c|c|c|c|c|c|}
\hline Mostra & Família Planta & Espècie Planta & Família & Gènere & Espècie & Abundància \\
\hline 1 & Gramineae & $\begin{array}{l}\text { Piptatherum } \\
\text { miliaceum }\end{array}$ & Phytoseiidae & $\begin{array}{l}\text { Typhlodromus } \\
\text { (Anthoseius) }\end{array}$ & phoenilis & 1 \\
\hline 2 & Leguminosae & Medicago citrina & Phytoseiidae & Typhlodromus & rhenanoides & 7 \\
\hline 2 & Leguminosae & Medicago citrina & Phytoseiidae & Neoseiulella & litoralis & 5 \\
\hline 2 & Leguminosae & Medicago citrina & Tydeidae & & & 12 \\
\hline 2 & Leguminosae & Medicago citrina & Stigmeidae & & & 2 \\
\hline 2 & Leguminosae & Medicago citrina & Eritraeidae & & & 1 \\
\hline 3 & $?$ & $?$ & Phytoseiidae & Kampimodromus & aberrans & 1 \\
\hline 4 & Solanaceae & Lycium intricatum & Tydeidae & & & 23 \\
\hline 5 & Solanaceae & Withania frutescens & & & & 0 \\
\hline 6 & Malvaceae & Lavatera arborea & Phytoseiidae & Neoseiulella & litoralis & 33 \\
\hline 6 & Malvaceae & Lavatera arborea & Phytoseiidae & Graminaseius & lituatus & 1 \\
\hline 6 & Malvaceae & Lavatera arborea & Tetranychidae & Tetranychus & $s p$. & 1 \\
\hline 6 & Malvaceae & Lavatera arborea & Eritraeidae & & & 1 \\
\hline 6 & Malvaceae & Lavatera arborea & Tydeidae & & & 8 \\
\hline 7 & Chenopodiaceae & Atriplex halimus & Phytoseiidae & Neoseiulella & litoralis & 3 \\
\hline 7 & Chenopodiaceae & Atriplex halimus & Phytoseiidae & $\begin{array}{l}\text { Typhlodromus } \\
\text { (Typhlodromus) }\end{array}$ & phialatus & 1 \\
\hline 7 & Chenopodiaceae & Atriplex halimus & $?$ & & & 1 \\
\hline 8 & Chenopodiaceae & Suaeda vera & Tydeidae & & & 12 \\
\hline 8 & Chenopodiaceae & Suaeda vera & Cunàxido & & & 1 \\
\hline 9 & Cruciferae & $\begin{array}{l}\text { Lobularia maritima } \\
\text { columbretensis }\end{array}$ & Tetranychidae & Tetranychus sp. & & 40 \\
\hline 9 & Cruciferae & $\begin{array}{l}\text { Lobularia maritima } \\
\text { columbretensis }\end{array}$ & Eritraeidae & & & 2 \\
\hline 10 & Euphorbiaceae & Euphorbia terracina & Phytoseiidae & Neoseiulella & litoralis & 1 \\
\hline 10 & Euphorbiaceae & Euphorbia terracina & Tetranychidae & Tetranychus sp. & & 17 \\
\hline 11 & Gramineae & $\begin{array}{l}\text { Brachypodium } \\
\text { distachyon }\end{array}$ & Phytoseiidae & & & 1 \\
\hline 11 & Gramineae & $\begin{array}{l}\text { Brachypodium } \\
\text { distachyon }\end{array}$ & Phytoseiidae & Neoseiulella & litoralis & 1 \\
\hline 11 & Gramineae & $\begin{array}{l}\text { Brachypodium } \\
\text { distachyon }\end{array}$ & Phytoseiidae & Typhlodromus & phialatus & 1 \\
\hline 12 & Malvaceae & Lavatera arborea & Phytoseiidae & Neoseiulella & litoralis & 3 \\
\hline 13 & Gramineae & Lamarckia aurea & Phytoseiidae & & & 1 \\
\hline 13 & Gramineae & Lamarckia aurea & Tydeidae & & & 1 \\
\hline 14 & Umbelliferae & Daucus gingidium & Phytoseiidae & Neoseiulella & litoralis & 16 \\
\hline 14 & Umbelliferae & Daucus gingidium & Tydeidae & & & 6 \\
\hline 15 & Malvaceae & Lavatera mauritanica & & & & 0 \\
\hline 16 & Chenopodiaceae & Suaeda vera & Phytoseiidae & Neoseiulella & litoralis & 6 \\
\hline 16 & Chenopodiaceae & Suaeda vera & Tetranychidae & Bryobia & $s p$. & 2 \\
\hline 17 & Aizoaceae & $\begin{array}{l}\text { Mesembryanthemum } \\
\text { nodiflorum }\end{array}$ & Phytoseiidae & Neoseiulella & litoralis & 3 \\
\hline 18 & Gramineae & Brachypodium & Oribatida* & & & 4 \\
\hline
\end{tabular}




\begin{tabular}{|c|c|c|c|c|c|c|}
\hline & & distachyon & & & & \\
\hline 19 & Geraniaceae & Erodium chium & Phytoseiidae & Neoseiulella & litoralis & 34 \\
\hline 21 & Labiatae & $\begin{array}{l}\text { Lobularia maritima } \\
\text { columbretensis }\end{array}$ & Bdellidae & & & 2 \\
\hline 21 & Labiatae & $\begin{array}{l}\text { Lobularia maritima } \\
\text { columbretensis }\end{array}$ & Eritraeidae & & & 2 \\
\hline 21 & Labiatae & $\begin{array}{l}\text { Lobularia maritima } \\
\text { columbretensis }\end{array}$ & Oribatida* & & & 1 \\
\hline 22 & Malvaceae & Lavatera arborea & Phytoseiidae & Neoseiulella & litoralis & 2 \\
\hline 23 & Solanaceae & Hyoscyamus albus & & & & 0 \\
\hline 24 & Urticaceae & Parietaria judaica & Eritraeidae & & & 2 \\
\hline
\end{tabular}

PARC NATURAL DESERT DE LES PALMES $(8 / 10 / 2007)$

\begin{tabular}{|c|c|c|c|c|c|c|}
\hline Mostra & Família Planta & Espècie Planta & Família & Gènere & Espècie & Abundància \\
\hline 1 & Leguminosae & $\begin{array}{l}\text { Anthyllis } \\
\text { cytisoides }\end{array}$ & & & & 0 \\
\hline 2 & Gramineae & Varies & Oribatida* & & & 3 \\
\hline 2 & Gramineae & Varies & Tetranychidae & Bryobia & $s p$. & 1 \\
\hline 2 & Gramineae & Varies & Tetranychidae & SchizoTetranychus & $s p$. & 1 \\
\hline 2 & Gramineae & Varies & Tetranychidae & & & 1 \\
\hline 3 & Pinaceae & Pinus halepensis & Tetranychidae & Tetranychus & $s p$. & 1 \\
\hline 3 & Pinaceae & Pinus halepensis & Phytoseiidae & $\begin{array}{l}\text { Typhlodromus } \\
\text { (Typhlodromus) }\end{array}$ & phialatus & 3 \\
\hline 4 & Palmae & $\begin{array}{l}\text { Chamaerops } \\
\text { humilis }\end{array}$ & Tydeidae & & & 2 \\
\hline 4 & Palmae & $\begin{array}{l}\text { Chamaerops } \\
\text { humilis }\end{array}$ & Phytoseiidae & Neoseiulella & litoralis & 1 \\
\hline 5 & Cistaceae & Cistus albidus & Tydeidae & & & 3 \\
\hline 5 & Cistaceae & Cistus albidus & Oribatida* & & & 1 \\
\hline 5 & Cistaceae & Cistus albidus & Tetranychidae & & & 12 \\
\hline 5 & Cistaceae & Cistus albidus & Phytoseiidae & Neoseiulella & litoralis & 1 \\
\hline 5 & Cistaceae & Cistus albidus & Phytoseiidae & $\begin{array}{l}\text { Typhlodromus } \\
\text { (Anthoseius) }\end{array}$ & rhenanoides & 1 \\
\hline 6 & Cistaceae & Cistus salvifolius & Phytoseiidae & Kampimodromus & ericinus & 3 \\
\hline 6 & Cistaceae & Cistus salvifolius & Tenuipalpidae & Tenuipalpus sp. & & 1 \\
\hline 7 & Cistaceae & $\begin{array}{l}\text { Cistus } \\
\text { monspeliensis }\end{array}$ & Oribatida* & & & 1 \\
\hline 7 & Cistaceae & $\begin{array}{l}\text { Cistus } \\
\text { monspeliensis }\end{array}$ & Phytoseiidae & Neoseiulella & litoralis & 7 \\
\hline 7 & Cistaceae & $\begin{array}{l}\text { Cistus } \\
\text { monspeliensis }\end{array}$ & Tetranychidae & Tetranychus sp. & & 1 \\
\hline 8 & Fagaceae & Quercus suber & & & & 0 \\
\hline 9 & Ericaceae & Erica arborea & & & & 0 \\
\hline 10 & Gramineae & Diverses & Tetranychidae & Bryobia & $s p$ & 3 \\
\hline 10 & Gramineae & Diverses & Oribatida* & & & 3 \\
\hline
\end{tabular}




\begin{tabular}{|c|c|c|c|c|c|c|}
\hline 11 & Rosaceae & Rubus ulmifolius & Tenuipalpidae & & & 38 \\
\hline 11 & Rosaceae & Rubus ulmifolius & Phytoseiidae & $\begin{array}{l}\text { Typhlodromus } \\
\text { (Anthoseius) }\end{array}$ & rhenanoides & 4 \\
\hline 11 & Rosaceae & Rubus ulmifolius & Phytoseiidae & Euseius & stipulatus & 1 \\
\hline 11 & Rosaceae & Rubus ulmifolius & Eupodidae & & & 2 \\
\hline 12 & Caprifoliaceae & Viburnum tinus & Phytoseiidae & Neoseiulella & litoralis & 3 \\
\hline 12 & Caprifoliaceae & Viburnum tinus & Oribatida* & & & 1 \\
\hline 13 & Fagaceae & $\begin{array}{l}\text { Quercus } \\
\text { coccifera }\end{array}$ & Oribatida* & & & 1 \\
\hline 14 & Liliaceae & Smilax aspera & Oribatida* & & & 3 \\
\hline 15 & Fagaceae & Quercus faginea & Phytoseiidae & $\begin{array}{l}\text { Typhlodromus } \\
\text { (Anthoseius) }\end{array}$ & rhenanoides & 7 \\
\hline 15 & Fagaceae & Quercus faginea & Phytoseiidae & Typhloseiulus & carmonae & 1 \\
\hline 15 & Fagaceae & Quercus faginea & Phytoseiidae & Amblyseius & andersoni & 1 \\
\hline 15 & Fagaceae & Quercus faginea & Oribatida* & & & 1 \\
\hline 16 & Anacardiaceae & $\begin{array}{l}\text { Pistacea } \\
\text { lentiscus }\end{array}$ & Phytoseiidae & $\begin{array}{l}\text { Typhlodromus } \\
\text { (Anthoseius) }\end{array}$ & athenas & 3 \\
\hline 16 & Anacardiaceae & $\begin{array}{l}\text { Pistacea } \\
\text { lentiscus }\end{array}$ & Tydeidae & & & 2 \\
\hline 16 & Anacardiaceae & $\begin{array}{l}\text { Pistacea } \\
\text { lentiscus }\end{array}$ & Erithraeidae & & & 1 \\
\hline 17 & Pinaceae & Pinus pinaster & Tenuipalpidae & & & 13 \\
\hline 17 & Pinaceae & Pinus pinaster & Tydeidae & & & 2 \\
\hline 17 & Pinaceae & Pinus pinaster & Oribatida* & & & 34 \\
\hline 17 & Pinaceae & Pinus pinaster & Eupallopeslidae & & & 1 \\
\hline 17 & Pinaceae & Pinus pinaster & Phytoseiidae & $\begin{array}{l}\text { Typhlodromus } \\
\text { (Anthoseius) }\end{array}$ & rhenanoides & 3 \\
\hline 18 & Gramineae & Diverses & Oribatida* & & & 3 \\
\hline 18 & Gramineae & Diverses & Tetranychidae & Oligonichus & & 2 \\
\hline 18 & Gramineae & Diverses & Acaridae & & & 4 \\
\hline 18 & Gramineae & Diverses & Eupodidae & & & 2 \\
\hline 18 & Gramineae & Diverses & Cunaxidae & & & 1 \\
\hline 18 & Gramineae & Diverses & Phytoseiidae & Amblyseius & $s p$ & 3 \\
\hline 18 & Gramineae & Diverses & Tydeidae & & & 6 \\
\hline 19 & Caprifoliaceae & $\begin{array}{l}\text { Lonicera } \\
\text { implexa }\end{array}$ & Tetranychidae & & & 1 \\
\hline 19 & Caprifoliaceae & $\begin{array}{l}\text { Lonicera } \\
\text { implexa }\end{array}$ & Eupodidae & & & 1 \\
\hline 19 & Caprifoliaceae & $\begin{array}{l}\text { Lonicera } \\
\text { implexa }\end{array}$ & Phytoseiidae & & & 1 \\
\hline 20 & Coriariaceae & $\begin{array}{l}\text { Coriaria } \\
\text { myrtifolia }\end{array}$ & Phytoseiidae & & & 1 \\
\hline 20 & Coriariaceae & $\begin{array}{l}\text { Coriaria } \\
\text { myrtifolia }\end{array}$ & Oribatida* & & & 1 \\
\hline 21 & Compositae & $\begin{array}{l}\text { Dittrichia } \\
\text { viscosa }\end{array}$ & Phytoseiidae & Tiphloesiella & isotricha & 9 \\
\hline 21 & Compositae & $\begin{array}{l}\text { Dittrichia } \\
\text { viscosa }\end{array}$ & Phytoseiidae & $\begin{array}{l}\text { Typhlodromus } \\
\text { (Typhlodromus) }\end{array}$ & phialatus & 1 \\
\hline 21 & Compositae & $\begin{array}{l}\text { Dittrichia } \\
\text { viscosa }\end{array}$ & Oribatida* & & & 1 \\
\hline
\end{tabular}

*aquest subordre no es va separar en famílies 
PARC NATURAL PENYAGOLOSA (28/10/2007)

\begin{tabular}{|c|c|c|c|c|c|c|}
\hline Mostra & Família Planta & Espècie Planta & Família & Gènere & Espècie & Abundància \\
\hline 1 & Gramineae & Diverses & Oribatida* & & & 5 \\
\hline 1 & Gramineae & Diverses & Eupodidae & & & 3 \\
\hline 2 & Cupressaceae & $\begin{array}{l}\text { Juniperus } \\
\text { communis } \\
\text { communis }\end{array}$ & Oribatida* & & & 2 \\
\hline 3 & Pinaceae & Pinus sylvestris & Oribatida* & & & 5 \\
\hline 3 & Pinaceae & Pinus sylvestris & Phytoseiidae & $\begin{array}{l}\text { Typhlodromus } \\
\text { (Typhlodromus) }\end{array}$ & phialatus & 2 \\
\hline 4 & Pinaceae & $\begin{array}{l}\text { Pinus nigra } \\
\text { salzmannii }\end{array}$ & Acaridae & & & 1 \\
\hline 5 & Rosaceae & $\begin{array}{l}\text { Crataegus } \\
\text { monogyna }\end{array}$ & Acaridae & & & 2 \\
\hline 5 & Rosaceae & $\begin{array}{l}\text { Crataegus } \\
\text { monogyna }\end{array}$ & Tydeidae & & & 1 \\
\hline 5 & Rosaceae & $\begin{array}{l}\text { Crataegus } \\
\text { monogyna }\end{array}$ & Tenuipalpidae & & & 1 \\
\hline 6 & Rosaceae & Rosa canina & & & & 0 \\
\hline 7 & Cupressaceae & $\begin{array}{l}\text { Cupressus } \\
\text { arizonica }\end{array}$ & Acaridae & & & 2 \\
\hline 7 & Cupressaceae & $\begin{array}{l}\text { Cupressus } \\
\text { arizonica }\end{array}$ & Oribatida* & & & 1 \\
\hline 8 & Rosaceae & Prunus mahaleb & Phytoseiidae & $\begin{array}{l}\text { Typhlodromus } \\
\text { (Typhlodromus) }\end{array}$ & phialatus & 1 \\
\hline 8 & Rosaceae & Prunus mahaleb & Oribatida* & & & 1 \\
\hline 9 & Pinaceae & Cedrus atlantica & Oribatida* & & & 17 \\
\hline 9 & Pinaceae & Cedrus atlantica & Tydeidae & & & 6 \\
\hline 9 & Pinaceae & Cedrus atlantica & Eupallopeslidae & & & 1 \\
\hline 9 & Pinaceae & Cedrus atlantica & Phytoseiidae & $\begin{array}{l}\text { Typhlodromus } \\
\text { (Typhlodromus) }\end{array}$ & phialatus & 1 \\
\hline 10 & Labiatae & $\begin{array}{l}\text { Satureja } \\
\text { montana }\end{array}$ & Oribatida* & & & 6 \\
\hline 11 & Labiatae & Thymus vulgaris & & & & 0 \\
\hline 12 & Pinaceae & $\begin{array}{l}\text { Pinus nigra } \\
\text { salzmannii }\end{array}$ & Oribatida* & & & 3 \\
\hline 12 & Pinaceae & $\begin{array}{l}\text { Pinus nigra } \\
\text { salzmannii }\end{array}$ & Phytoseiidae & $\begin{array}{l}\text { Typhlodromus } \\
\text { (Anthoseius) }\end{array}$ & phoenilis & 1 \\
\hline 13 & Rosaceae & Prunus mahaleb & Oribatida* & & & 1 \\
\hline 14 & Aceraceae & Acer granatense & Phytoseiidae & Euseius & finlandicus & 3 \\
\hline 14 & Aceraceae & Acer granatense & Phytoseiidae & $\begin{array}{l}\text { Typhlodromus } \\
\text { (Typhlodromus) }\end{array}$ & pyri & 1 \\
\hline 15 & Gramineae & Diverses & Oribatida* & & & 4 \\
\hline 15 & Gramineae & Diverses & Eupodidae & & & 2 \\
\hline 16 & Rosaceae & Rubus ulmifolius & Phytoseiidae & $\begin{array}{l}\text { Typhlodromus } \\
\text { (Typhlodromus) }\end{array}$ & pyri & 8 \\
\hline 16 & Rosaceae & Rubus ulmifolius & Oribatida* & & & 2 \\
\hline 16 & Rosaceae & Rubus ulmifolius & Tetranychidae & Bryobia sp. & & 1 \\
\hline 17 & Ranunculaceae & Helleborus & & & & 0 \\
\hline
\end{tabular}




\begin{tabular}{|c|c|c|c|c|c|c|}
\hline & & foetidus & & & & \\
\hline 18 & Euphorbiaceae & Euphorbia sp. & & & & 0 \\
\hline 19 & Rosaceae & Malus sylvestris & Phytoseiidae & Euseius & finlandicus & 21 \\
\hline 19 & Rosaceae & Malus sylvestris & Phytoseiidae & Tiphloesiella & isotricha & 1 \\
\hline 19 & Rosaceae & Malus sylvestris & Phytoseiidae & $\begin{array}{l}\text { Typhlodromus } \\
\text { (Typhlodromus) }\end{array}$ & pyri & 2 \\
\hline 20 & Pinaceae & Pinus sylvestris & Oribatida* & & & 23 \\
\hline 20 & Pinaceae & Pinus sylvestris & Phytoseiidae & & & 1 \\
\hline 20 & Pinaceae & Pinus sylvestris & Tenuipalpidae & & & 3 \\
\hline 20 & Pinaceae & Pinus sylvestris & Tydeidae & & & 2 \\
\hline 20 & Pinaceae & Pinus sylvestris & Bdellidae & & & 3 \\
\hline 21 & Araliaceae & Hedera helix & Tetranychidae & Bryobia sp. & & 3 \\
\hline 21 & Araliaceae & Hedera helix & Eupodidae & & & 1 \\
\hline 21 & Araliaceae & Hedera helix & Tydeidae & & & 1 \\
\hline 22 & Labiatae & $\begin{array}{l}\text { Lavandula } \\
\text { latifolia }\end{array}$ & Oribatida* & & & 3 \\
\hline 23 & Cupressaceae & $\begin{array}{l}\text { Juniperus } \\
\text { communis } \\
\text { communis }\end{array}$ & Tenuipalpidae & & & 2 \\
\hline 23 & Cupressaceae & $\begin{array}{l}\text { Juniperus } \\
\text { communis } \\
\text { communis }\end{array}$ & Phytoseiidae & $\begin{array}{l}\text { Typhlodromus } \\
\text { (Anthoseius) }\end{array}$ & $s p$. & 1 \\
\hline 23 & Cupressaceae & $\begin{array}{l}\text { Juniperus } \\
\text { communis } \\
\text { communis }\end{array}$ & Phytoseiidae & $\begin{array}{l}\text { Typhlodromus } \\
\text { (Typhlodromus) }\end{array}$ & phialatus & 1 \\
\hline 23 & Cupressaceae & $\begin{array}{l}\text { Juniperus } \\
\text { communis } \\
\text { communis }\end{array}$ & Oribatida* & & & 4 \\
\hline
\end{tabular}

*aquest subordre no es va separar en famílies

PARC NATURAL PRAT DE CABANES-TORREBLANCA (14/11/2007)

\begin{tabular}{|c|c|c|c|c|c|c|}
\hline Mostra & Família Planta & Espècie Planta & Família & Gènere & Espècie & Abundància \\
\hline 1 & Thimelaeaceae & $\begin{array}{l}\text { Thymelaea } \\
\text { hirsuta }\end{array}$ & Phytoseiidae & Proprioseiopsis & bordjelaini & 5 \\
\hline 1 & Thimelaeaceae & $\begin{array}{l}\text { Thymelaea } \\
\text { hirsuta }\end{array}$ & Phytoseiidae & Neoesiulus & leucophaeus & 1 \\
\hline 1 & Thimelaeaceae & $\begin{array}{l}\text { Thymelaea } \\
\text { hirsuta }\end{array}$ & Tydeidae & & & 3 \\
\hline 1 & Thimelaeaceae & $\begin{array}{l}\text { Thymelaea } \\
\text { hirsuta }\end{array}$ & Oribatida* & & & 1 \\
\hline 2 & Cupressaceae & $\begin{array}{l}\text { Juniperus } \\
\text { macrocarpa }\end{array}$ & & & & 0 \\
\hline 3 & Labiatae & $\begin{array}{l}\text { Rosmarinus } \\
\text { officinalis }\end{array}$ & Tenuipalpidae & & & 15 \\
\hline 3 & Labiatae & $\begin{array}{l}\text { Rosmarinus } \\
\text { officinalis }\end{array}$ & Phytoseiidae & $\begin{array}{l}\text { Typhlodromus } \\
\text { (Anthoseius) }\end{array}$ & rhenanoides & 7 \\
\hline
\end{tabular}




\begin{tabular}{|c|c|c|c|c|c|c|}
\hline 3 & Labiatae & $\begin{array}{l}\text { Rosmarinus } \\
\text { officinalis }\end{array}$ & Tenuipalpidae & & & 4 \\
\hline 4 & Cistaceae & Cistus salvifolius & Tydeidae & & & 14 \\
\hline 4 & Cistaceae & Cistus salvifolius & Phytoseiidae & Kampimodromus & ericinus & 3 \\
\hline 4 & Cistaceae & Cistus salvifolius & Phytoseiidae & Neoseiulella & litoralis & 4 \\
\hline 5 & Leguminosae & Ononis natrix & Phytoseiidae & Neoseiulella & litoralis & 41 \\
\hline 5 & Leguminosae & Ononis natrix & Phytoseiidae & Tiphloesiella & isotricha & 5 \\
\hline 5 & Leguminosae & Ononis natrix & Phytoseiidae & $\begin{array}{l}\text { Typhlodromus } \\
\text { (Typhlodromus) }\end{array}$ & pyri & 3 \\
\hline 5 & Leguminosae & Ononis natrix & Acaridae & & & 2 \\
\hline 5 & Leguminosae & Ononis natrix & Tydeidae & & & 2 \\
\hline 6 & Compositae & Inula crithmoides & Oribatida* & & & 24 \\
\hline 6 & Compositae & Inula crithmoides & Tydeidae & & & 1 \\
\hline 6 & Compositae & Inula crithmoides & Cunaxidae & & & 1 \\
\hline 6 & Compositae & Inula crithmoides & Phytoseiidae & Neoseiulella & litoralis & 7 \\
\hline 7 & Compositae & Dittrichia viscosa & Phytoseiidae & Tiphloesiella & isotricha & 45 \\
\hline 7 & Compositae & Dittrichia viscosa & Phytoseiidae & Neoseiulella & litoralis & 6 \\
\hline 7 & Compositae & Dittrichia viscosa & Phytoseiidae & Neoesiulus & umbraticus & 1 \\
\hline 7 & Compositae & Dittrichia viscosa & Oribatida* & & & 1 \\
\hline 7 & Compositae & Dittrichia viscosa & Tydeidae & & & 20 \\
\hline 8 & Gramineae & $\begin{array}{l}\text { Phragmites } \\
\text { communis }\end{array}$ & Phytoseiidae & & & 3 \\
\hline 8 & Gramineae & $\begin{array}{l}\text { Phragmites } \\
\text { communis }\end{array}$ & Tydeidae & & & 5 \\
\hline 8 & Gramineae & $\begin{array}{l}\text { Phragmites } \\
\text { communis }\end{array}$ & Tarsonemidae & & & 5 \\
\hline 9 & Chenopodiaceae & $\begin{array}{l}\text { Sarcocornia } \\
\text { fruticosa }\end{array}$ & Phytoseiidae & Neoseiulella & litoralis & 3 \\
\hline 10 & Ciper aceae & $\begin{array}{l}\text { Scirpus } \\
\text { tabernaemontani }\end{array}$ & Phytoseiidae & $\begin{array}{l}\text { Typhlodromus } \\
\text { (Typhlodromus) }\end{array}$ & pyri & 9 \\
\hline 10 & Ciper aceae & $\begin{array}{l}\text { Scirpus } \\
\text { tabernaemontani }\end{array}$ & Phytoseiidae & Neoseiulella & litoralis & 8 \\
\hline 10 & Ciper aceae & $\begin{array}{l}\text { Scirpus } \\
\text { tabernaemontani }\end{array}$ & Tetranychidae & Bryobia & $s p$ & 3 \\
\hline 10 & Ciper aceae & $\begin{array}{l}\text { Scirpus } \\
\text { tabernaemontani }\end{array}$ & Eupalopesllidae & & & 1 \\
\hline 10 & Ciper aceae & $\begin{array}{l}\text { Scirpus } \\
\text { tabernaemontani }\end{array}$ & Oribatida* & & & 1 \\
\hline 11 & Ciper aceae & Ligeum spartum & & & & 0 \\
\hline 12 & Palmae & $\begin{array}{l}\text { Chamaerops } \\
\text { humilis }\end{array}$ & Tetranychidae & Tetranychus & $s p$ & 2 \\
\hline 12 & Palmae & $\begin{array}{l}\text { Chamaerops } \\
\text { humilis }\end{array}$ & Oribatida* & & & 4 \\
\hline
\end{tabular}

*aquest subordre no es va separar en famílies 
PARC NATURAL SERRA D'ESPADÀ (1/10/2007)

\begin{tabular}{|c|c|c|c|c|c|c|}
\hline Mostra & Família Planta & Espècie Planta & Família & Gènere & Espècie & Abundància \\
\hline 1 & Cistaceae & $\begin{array}{l}\text { Cistus } \\
\text { monspeliensis }\end{array}$ & & & & 0 \\
\hline 2 & Cistaceae & Cistus albidus & Phytoseiidae & Kampimodromus & ericinus & 1 \\
\hline 3 & Fagaceae & Quercus suber & Phytoseiidae & & & 1 \\
\hline 3 & Fagaceae & Quercus suber & Stigmeidae & & & 1 \\
\hline 3 & Fagaceae & Quercus suber & Cameróbido & & & 1 \\
\hline 4 & Caprifoliaceae & Viburnum tinus & Phytoseiidae & Neoseiulella & litoralis & 1 \\
\hline 4 & Caprifoliaceae & Viburnum tinus & Phytoseiidae & $\begin{array}{l}\text { Typhlodromus } \\
\text { (Anthoseius) }\end{array}$ & rhenanoides & 8 \\
\hline 5 & Liliaceae & $\begin{array}{l}\text { Ruscus } \\
\text { aculeatus }\end{array}$ & Phytoseiidae & $\begin{array}{l}\text { Typhlodromus } \\
\text { (Anthoseius) }\end{array}$ & rhenanoides & 5 \\
\hline 5 & Liliaceae & $\begin{array}{l}\text { Ruscus } \\
\text { aculeatus }\end{array}$ & Bdellidae & & & 2 \\
\hline 5 & Liliaceae & $\begin{array}{l}\text { Ruscus } \\
\text { aculeatus }\end{array}$ & Tydeidae & & & 9 \\
\hline 5 & Liliaceae & $\begin{array}{l}\text { Ruscus } \\
\text { aculeatus }\end{array}$ & Oribatida* & & & 2 \\
\hline 6 & Rosaceae & $\begin{array}{l}\text { Rubus } \\
\text { ulmifolius }\end{array}$ & Tenuipalpidae & & & 4 \\
\hline 6 & Rosaceae & $\begin{array}{l}\text { Rubus } \\
\text { ulmifolius }\end{array}$ & Phytoseiidae & $\begin{array}{l}\text { Typhlodromus } \\
\text { (Typhlodromus) }\end{array}$ & pyri & 2 \\
\hline 6 & Rosaceae & $\begin{array}{l}\text { Rubus } \\
\text { ulmifolius }\end{array}$ & Phytoseiidae & Neoseiulella & litoralis & 1 \\
\hline 7 & Labiatae & Mentha sp. & Oribatida* & & & 1 \\
\hline 7 & Labiatae & Mentha sp. & Tetranychidae & Tetranychus & & 1 \\
\hline 7 & Labiatae & Mentha sp. & Phytoseiidae & $\begin{array}{l}\text { Typhlodromus } \\
\text { (Typhlodromus) }\end{array}$ & pyri & 8 \\
\hline 8 & Gramineae & Diverses & Oribatida* & & & 5 \\
\hline 8 & Gramineae & Diverses & Eritreido & & & 1 \\
\hline 8 & Gramineae & Diverses & Bdellidae & & & 1 \\
\hline 8 & Gramineae & Diverses & Tetranychidae & Bryobia & & 1 \\
\hline 9 & Salicaceae & Salix sp. & Oribatida* & & & 2 \\
\hline 9 & Salicaceae & Salix sp. & Tydeidae & & & 1 \\
\hline 10 & Leguminosae & $?$ & Tydeidae & & & 6 \\
\hline 10 & Leguminosae & $?$ & Phytoseiidae & Kampimodromus & aberrans & 1 \\
\hline 10 & Leguminosae & $?$ & Phytoseiidae & Neoseiulella & litoralis & 1 \\
\hline 11 & Ericaceae & Erica arborea & Tenuipalpidae & & & 1 \\
\hline 11 & Ericaceae & Erica arborea & Oribatida* & & & 3 \\
\hline 11 & Ericaceae & Erica arborea & Phytoseiidae & $\begin{array}{l}\text { Typhlodromus } \\
\text { (Anthoseius) }\end{array}$ & rhenanoides & 45 \\
\hline 12 & Hipolepidaceae & $\begin{array}{l}\text { Pteridium } \\
\text { aquilinum }\end{array}$ & Tydeidae & & & 2 \\
\hline 12 & Hipolepidaceae & $\begin{array}{l}\text { Pteridium } \\
\text { aquilinum }\end{array}$ & Oribatida* & & & 1 \\
\hline 12 & Hipolepidaceae & $\begin{array}{l}\text { Pteridium } \\
\text { aquilinum }\end{array}$ & Eupodidae & & & 1 \\
\hline
\end{tabular}




\begin{tabular}{|c|c|c|c|c|c|c|}
\hline 12 & Hipolepidaceae & $\begin{array}{l}\text { Pteridium } \\
\text { aquilinum }\end{array}$ & Phytoseiidae & $\begin{array}{l}\text { Typhlodromus } \\
\text { (Typhlodromus) }\end{array}$ & pyri & 99 \\
\hline 13 & Anacardiaceae & $\begin{array}{l}\text { Pistacia } \\
\text { terebinthus }\end{array}$ & Tetranychidae & & & 4 \\
\hline 13 & Anacardiaceae & $\begin{array}{l}\text { Pistacia } \\
\text { terebinthus }\end{array}$ & Phytoseiidae & Neoseiulella & litoralis & 1 \\
\hline 14 & Pinaceae & Pinus pinaster & & & & 0 \\
\hline 15 & Pinaceae & $\begin{array}{l}\text { Pinus } \\
\text { halepensis }\end{array}$ & Phytoseiidae & Typhlodromus & & 1 \\
\hline 16 & Compositae & $\begin{array}{l}\text { Dittrichia } \\
\text { viscosa }\end{array}$ & Phytoseiidae & $\begin{array}{l}\text { Typhlodromus } \\
\text { (Typhlodromus) }\end{array}$ & pyri & 2 \\
\hline 16 & Compositae & $\begin{array}{l}\text { Dittrichia } \\
\text { viscosa }\end{array}$ & Phytoseiidae & Tiphloesiella & isotricha & 4 \\
\hline 17 & Pinaceae & Pinus pinaster & & & & 0 \\
\hline 18 & Gramineae & Diverses & Tydeidae & & & 1 \\
\hline 18 & Gramineae & Diverses & Oribatida* & & & 6 \\
\hline 19 & Labiatae & $\begin{array}{l}\text { Thymus } \\
\text { vulgaris }\end{array}$ & Oribatida* & & & 1 \\
\hline 19 & Labiatae & $\begin{array}{l}\text { Thymus } \\
\text { vulgaris }\end{array}$ & Tetranychidae & Tetranychus sp. & & 138 \\
\hline 20 & Labiatae & $\begin{array}{l}\text { Lavandula } \\
\text { stoechas }\end{array}$ & Phytoseiidae & Neoseiulella & litoralis & 1 \\
\hline 21 & Fagaceae & Quercus suber & Tydeidae & & & 4 \\
\hline 21 & Fagaceae & Quercus suber & Tetranychidae & Oligonichus & ilicis & 1 \\
\hline 21 & Fagaceae & Quercus suber & Phytoseiidae & $\begin{array}{l}\text { Typhlodromus } \\
\text { (Anthoseius) }\end{array}$ & near recki & 2 \\
\hline 22 & Gramineae & Diverses & Oribatida* & & & 3 \\
\hline 22 & Gramineae & Diverses & Tetranychidae & Tetranychus sp. & & 1 \\
\hline 22 & Gramineae & Diverses & Tetranychidae & $\begin{array}{l}\text { SchizoTetranychus } \\
\text { sp. }\end{array}$ & & 1 \\
\hline
\end{tabular}

*aquest subordre no es va separar en famílies

PARC NATURAL SERRA D'IRTA (14/11/2007)

\begin{tabular}{|c|c|c|c|c|c|c|}
\hline Mostra & Família Planta & Espècie Planta & Família & Gènere & Espècie & Abundància \\
\hline 1 & Palmae & $\begin{array}{l}\text { Chamaerops } \\
\text { humilis }\end{array}$ & & & & 0 \\
\hline 2 & Labiatae & Erica multiflora & Phytoseiidae & $\begin{array}{l}\text { Typhlodromus } \\
\text { (Anthoseius) }\end{array}$ & rhenanoides & 5 \\
\hline 2 & Labiatae & Erica multiflora & Tenuipalpidae & & & 1 \\
\hline 2 & Labiatae & Erica multiflora & Oribatida* & & & 1 \\
\hline 3 & Pinaceae & $\begin{array}{l}\text { Pinus } \\
\text { halepensis }\end{array}$ & & & & 0 \\
\hline 4 & Gramineae & Diverses & Phytoseiidae & $\begin{array}{l}\text { Typhlodromus } \\
\text { (Anthoseius) }\end{array}$ & rhenanoides & 1 \\
\hline 4 & Gramineae & Diverses & Tetranychidae & SchizoTetranychus & $s p$ & 36 \\
\hline 4 & Gramineae & Diverses & Cheyletidae & & & 1 \\
\hline
\end{tabular}




\begin{tabular}{|c|c|c|c|c|c|c|}
\hline 4 & Gramineae & Diverses & Ragididae & & & 3 \\
\hline 4 & Gramineae & Diverses & Tydeidae & & & 1 \\
\hline 4 & Gramineae & Diverses & Oribatida* & & & 86 \\
\hline 5 & Fagaceae & $\begin{array}{l}\text { Quercus } \\
\text { coccifera }\end{array}$ & & & & 0 \\
\hline 6 & Cistaceae & $\begin{array}{l}\text { Cistus } \\
\text { monspeliensis }\end{array}$ & & & & 0 \\
\hline 7 & Leguminosae & Ulex parviflora & Oribatida* & & & 2 \\
\hline 8 & Pinaceae & $\begin{array}{l}\text { Pinus } \\
\text { halepensis }\end{array}$ & Phytoseiidae & $\begin{array}{l}\text { Typhlodromus } \\
\text { (Anthoseius) }\end{array}$ & athenas & 1 \\
\hline 8 & Pinaceae & $\begin{array}{l}\text { Pinus } \\
\text { halepensis }\end{array}$ & Phytoseiidae & $\begin{array}{l}\text { Typhlodromus } \\
\text { (Typhlodromus) }\end{array}$ & phialatus & 2 \\
\hline 8 & Pinaceae & $\begin{array}{l}\text { Pinus } \\
\text { halepensis }\end{array}$ & Phytoseiidae & Neoseiulella & litoralis & 1 \\
\hline 8 & Pinaceae & $\begin{array}{l}\text { Pinus } \\
\text { halepensis }\end{array}$ & Oribatida* & & & 1 \\
\hline 8 & Pinaceae & $\begin{array}{l}\text { Pinus } \\
\text { halepensis }\end{array}$ & Eupodidae & & & 1 \\
\hline 9 & Cupressaceae & $\begin{array}{l}\text { Juniperus } \\
\text { oxycedrus }\end{array}$ & & & & 0 \\
\hline 10 & Gramineae & $\begin{array}{l}\text { Hyparrhenia } \\
\text { hirta }\end{array}$ & Phytoseiidae & $\begin{array}{l}\text { Typhlodromus } \\
\text { (Typhlodromus) }\end{array}$ & phialatus & 1 \\
\hline 10 & Gramineae & $\begin{array}{l}\text { Hyparrhenia } \\
\text { hirta }\end{array}$ & Phytoseiidae & Phytoseius & plumifer & 1 \\
\hline 10 & Gramineae & $\begin{array}{l}\text { Hyparrhenia } \\
\text { hirta }\end{array}$ & Tydeidae & & & 1 \\
\hline 10 & Gramineae & $\begin{array}{l}\text { Hyparrhenia } \\
\text { hirta }\end{array}$ & Cheyletidae & & & 1 \\
\hline 10 & Gramineae & $\begin{array}{l}\text { Hyparrhenia } \\
\text { hirta }\end{array}$ & Oribatida* & & & 1 \\
\hline 11 & Anacardiaceae & $\begin{array}{l}\text { Pistacia } \\
\text { lentiscus }\end{array}$ & & & & 0 \\
\hline
\end{tabular}

*aquest subordre no es va separar en famílies

PARC NATURAL TINENÇA DE BENIFASSÀ (7/12/2007)

\begin{tabular}{|c|c|c|c|c|c|c|}
\hline Mostra & Família Planta & Espècie Planta & Família & Gènere & Espècie & Abundància \\
\hline $1 \mathrm{i} 2$ & Pinaceae & Pinus nigra & Phytoseiidae & $\begin{array}{l}\text { Typhlodromus } \\
\text { (Typhlodromus) }\end{array}$ & laurae & 3 \\
\hline 1 i 2 & Pinaceae & Pinus nigra & Phytoseiidae & $\begin{array}{l}\text { Typhlodromus } \\
\text { (Anthoseius) }\end{array}$ & rhenanoides & 5 \\
\hline 1 i 2 & Pinaceae & Pinus nigra & Tenuipalpidae & & & 6 \\
\hline 1 i 2 & Pinaceae & Pinus nigra & Cunaxidae & & & 2 \\
\hline 1 i 2 & Pinaceae & Pinus nigra & Bdellidae & & & 1 \\
\hline 1 i 2 & Pinaceae & Pinus nigra & Ragididae & & & 1 \\
\hline 1 i 2 & Pinaceae & Pinus nigra & Oribatida* & & & 12 \\
\hline 3 & Pinaceae & Pinus sylvestris & Tenuipalpidae & & & 5 \\
\hline
\end{tabular}




\begin{tabular}{|c|c|c|c|c|c|c|}
\hline 3 & Pinaceae & Pinus sylvestris & Oribatida* & & & 3 \\
\hline 4 & Gramineae & Diverses & Oribatida* & & & 12 \\
\hline 5 & Compositae & $\begin{array}{l}\text { Santolina } \\
\text { chamaecyparissus }\end{array}$ & Phytoseiidae & $\begin{array}{l}\text { Typhlodromus } \\
\text { (Typhlodromus) }\end{array}$ & phialatus & 12 \\
\hline 5 & Compositae & $\begin{array}{l}\text { Santolina } \\
\text { chamaecyparissus }\end{array}$ & Phytoseiidae & $\begin{array}{l}\text { Typhlodromus } \\
\text { (Typhlodromus) }\end{array}$ & pyri & 6 \\
\hline 5 & Compositae & $\begin{array}{l}\text { Santolina } \\
\text { chamaecyparissus }\end{array}$ & Phytoseiidae & $\begin{array}{l}\text { Typhlodromus } \\
\text { (Anthoseius) }\end{array}$ & rhenanoides & 3 \\
\hline 5 & Compositae & $\begin{array}{l}\text { Santolina } \\
\text { chamaecyparissus }\end{array}$ & Phytoseiidae & Euseius & finlandicus & 5 \\
\hline 5 & Compositae & $\begin{array}{l}\text { Santolina } \\
\text { chamaecyparissus }\end{array}$ & Eupalopesllidae & & & 8 \\
\hline 5 & Compositae & $\begin{array}{l}\text { Santolina } \\
\text { chamaecyparissus }\end{array}$ & Tetranychidae & Bryobia & $s p$ & 4 \\
\hline 6 & Buxaceae & $\begin{array}{l}\text { Buxus } \\
\text { sempervirens }\end{array}$ & Oribatida* & & & 0 \\
\hline 7 & Fagaceae & Quercus coccifera & Phytoseiidae & & & 3 \\
\hline 7 & Fagaceae & Quercus coccifera & Tenuipalpidae & & & 1 \\
\hline 7 & Fagaceae & Quercus coccifera & Tydeidae & & & 1 \\
\hline 8 & Fagaceae & Quercus ilex & Phytoseiidae & $\begin{array}{l}\text { Typhlodromus } \\
\text { (Typhlodromus) }\end{array}$ & pyri & 5 \\
\hline 8 & Fagaceae & Quercus ilex & Phytoseiidae & Neoseiulella & litoralis & 1 \\
\hline 8 & Fagaceae & Quercus ilex & Phytoseiidae & Typhloseiulus & carmonae & 1 \\
\hline 8 & Fagaceae & Quercus ilex & Tetranychidae & & & 2 \\
\hline 9 & Gramineae & Diverses & Oribatida* & & & 23 \\
\hline 9 & Gramineae & Diverses & Phytoseiidae & $\begin{array}{l}\text { Typhlodromus } \\
\text { (Anthoseius) }\end{array}$ & rhenanoides & 3 \\
\hline 9 & Gramineae & Diverses & Tetranychidae & Bryobia & $s p$ & 3 \\
\hline 10 & Ranunculaceae & $\begin{array}{l}\text { Helleborous } \\
\text { foetidus }\end{array}$ & & & & 0 \\
\hline 11 & Cupressaceae & $\begin{array}{l}\text { Juniperus } \\
\text { oxycedrus } \\
\text { oxycedrus }\end{array}$ & Phytoseiidae & $\begin{array}{l}\text { Typhlodromus } \\
\text { (Anthoseius) }\end{array}$ & rhenanoides & 1 \\
\hline 11 & Cupressaceae & $\begin{array}{l}\text { Juniperus } \\
\text { oxycedrus } \\
\text { oxycedrus }\end{array}$ & Oribatida* & & & 1 \\
\hline 12 & Cupressaceae & $\begin{array}{l}\text { Juniperus } \\
\text { oxycedrus } \\
\text { oxycedrus }\end{array}$ & Oribatida* & & & 5 \\
\hline 12 & Cupressaceae & $\begin{array}{l}\text { Juniperus } \\
\text { oxycedrus } \\
\text { oxycedrus }\end{array}$ & Tenuipalpidae & & & 6 \\
\hline 12 & Cupressaceae & $\begin{array}{l}\text { Juniperus } \\
\text { oxycedrus } \\
\text { oxycedrus }\end{array}$ & Phytoseiidae & Typhlodromus & phialatus & 1 \\
\hline 12 & Cupressaceae & $\begin{array}{l}\text { Juniperus } \\
\text { oxycedrus } \\
\text { oxycedrus }\end{array}$ & Tydeidae & & & 2 \\
\hline 12 & Cupressaceae & $\begin{array}{l}\text { Juniperus } \\
\text { oxycedrus } \\
\text { oxycedrus }\end{array}$ & Tetranychidae & & & 1 \\
\hline 13 & Pinaceae & Pinus sylvestris & Tenuipalpidae & & & 1 \\
\hline 14 & Gramineae & Hyparrhenia hirta & Tetranychidae & Oligonichus & & 74 \\
\hline 14 & Gramineae & Hyparrhenia hirta & Tetranychidae & Typhlodromus & phialatus & 1 \\
\hline
\end{tabular}


Annexos

\begin{tabular}{|c|c|c|c|c|c|c|}
\hline 15 & Gramineae & Hyparrhenia hirta & Oribatida* & & & 12 \\
\hline 16 & Cupressaceae & $\begin{array}{l}\text { Juniperus } \\
\text { oxycedrus } \\
\text { oxycedrus }\end{array}$ & Phytoseiidae & Typhloseiulus & carmonae & 3 \\
\hline 17 & Cupressaceae & Pinus halepensis & Eritreidae & & & 1 \\
\hline 18 & Gramineae & Pinus halepensis & Phytoseiidae & Neoseiulella & litoralis & 1 \\
\hline 18 & Gramineae & Pinus halepensis & Oribatida* & & & 38 \\
\hline 19 & Gramineae & Satureja innota & Oribatida* & & & 9 \\
\hline 20 & Ericaceae & Erica multiflora & Phytoseiidae & Neoseiulella & litoralis & 2 \\
\hline 20 & Ericaceae & Erica multiflora & Oribatida* & & & 1 \\
\hline
\end{tabular}

*aquest subordre no es va separar en famílies 
Annexos

ANNEX 3.1.

Les làpides del cementeri de Columbretes: imatges i textos conforme a la posició a la corresponent làpida, ordenades cronològicament per data de defunció (la làpida del bebè Aurelio, que va morir l'any 1953, es va col-locar l'any 2011, com a conseqüència de l'estudi d'aquesta tesi) 


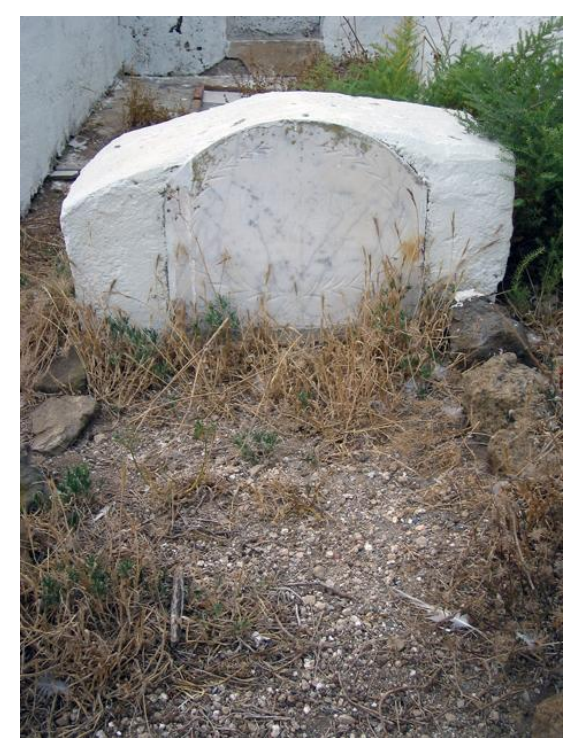

O

D. M.

EL ÁNGEL

MIGUEL GARAU

SUVIO AL CIELO EL 26 DE MARZO

DE 1892

A LA EDAD DE 26 MESES

SUS DESCONSOLADOS PADRES

LE DEDICAN ESTE RECUERDO

(làpida gravada amb errada ortogràfica)

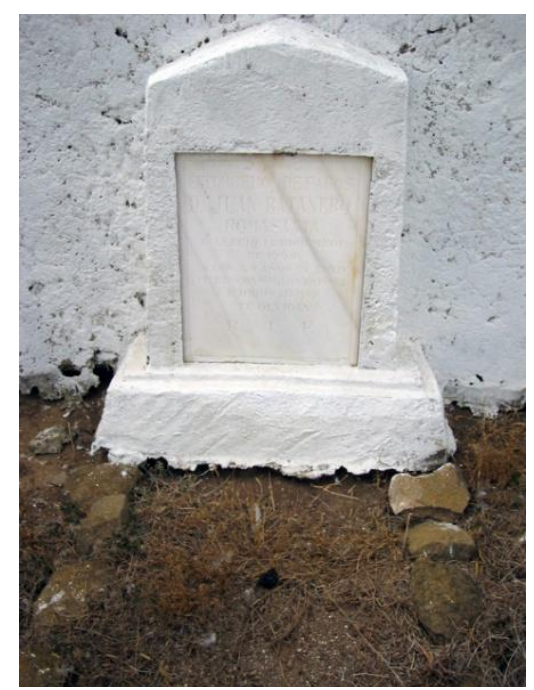

EL TORRERO DE FAROS

D. JUAN BATANERO ROMASANTA

FALLECIO 14 DICIEMBRE

DE 1908

A LOS 48 AÑOS DE EDAD

TU DESCONSOLADA ESPOSA

E HIJOS JAMÁS

TE OLVIDAN

R. I. P.

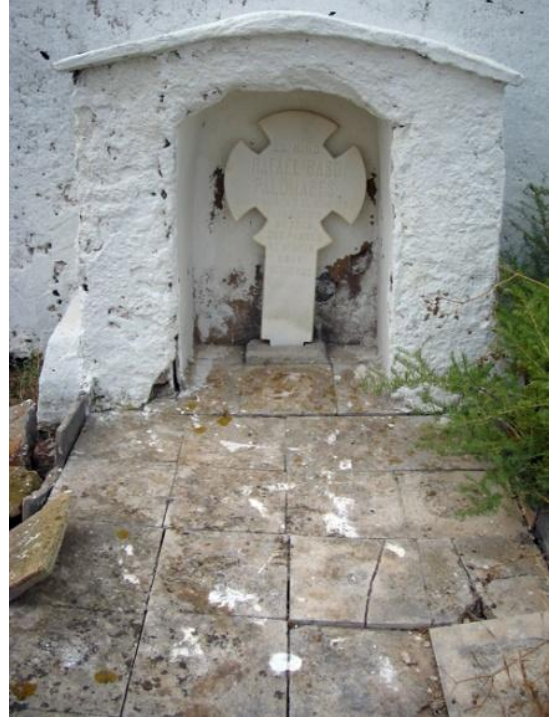

EL NIÑO

RAFAEL BASO

PALOMARES

SUBIO AL CIELO EL 22-05-1907

A LOS 3 MESES

DE EDAD.

SUS PADRES

LE DEDICAN

ESTE

RECUERDO.

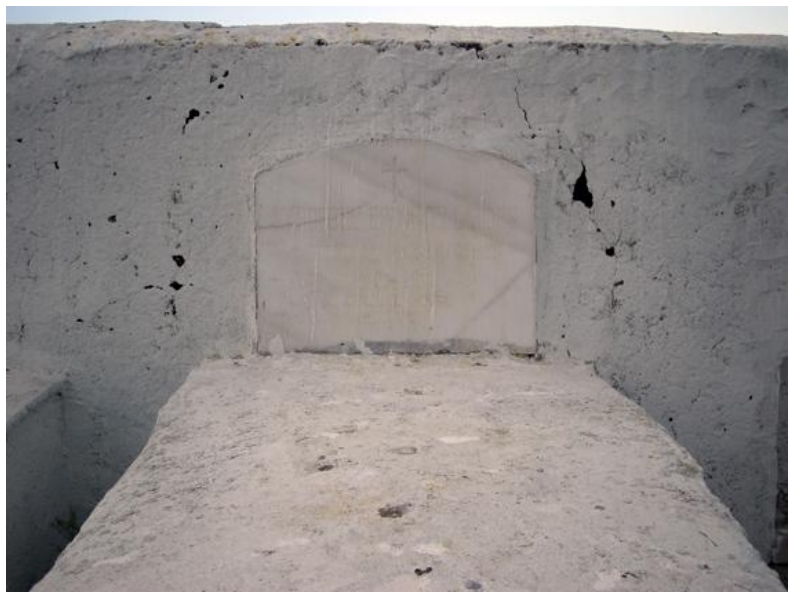

$\dagger$

MERCEDES ESCORTELL RIBES

† EN ESTA ISLA EL 20 MAYO 1920

EDAD 11 AÑOS

R.I.P.

RECUERDO 


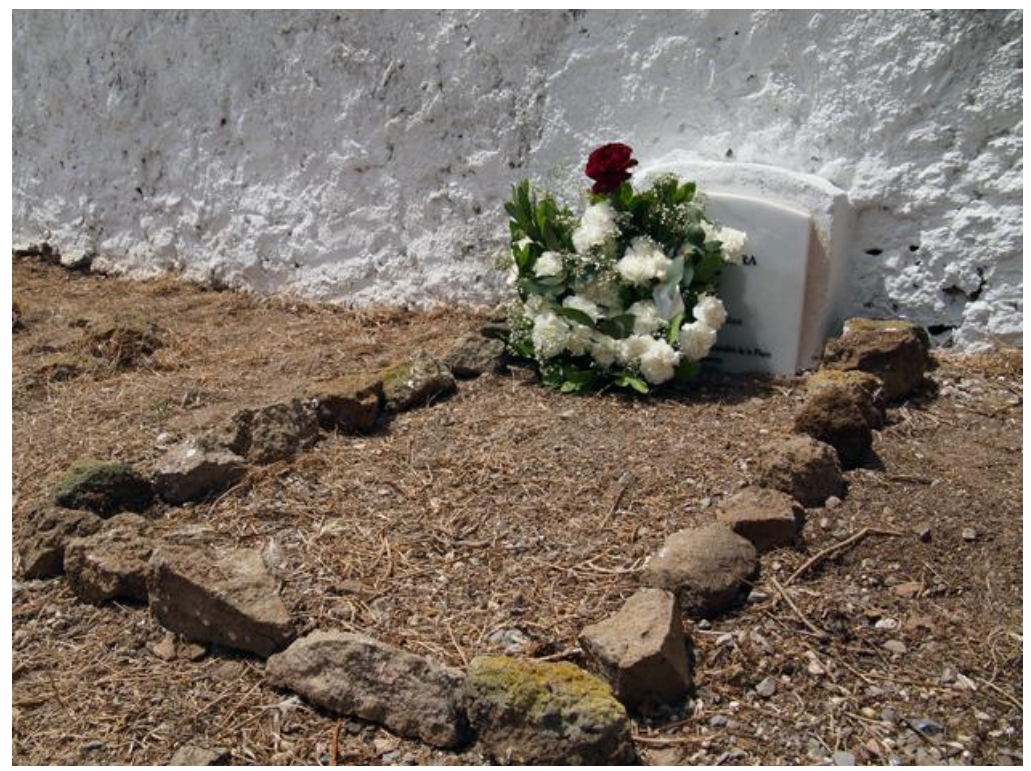

$\dagger$

AURELIO

ZACARÍAS GUERRA

Columbretes

13 - 10 - 1953

$15-10-1953$

D.E.P.

Tus padres no te olvidan

En memoria del 10 niño inscrito en Castellón de la Plana Nacido en Columbretes

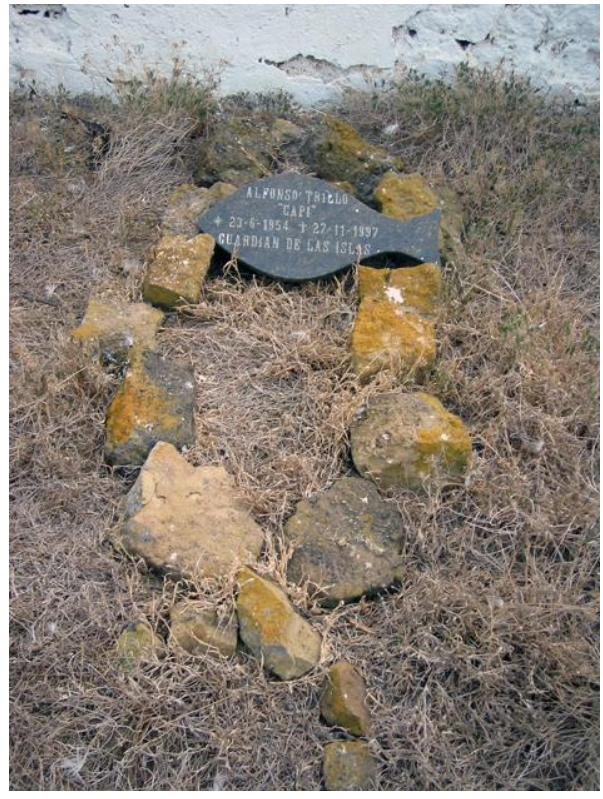

ALFONSO TRILLO

"CAPI"

*23-6-1954 + 27-11-1997

GUARDIAN DE LAS ISLAS 
Annexos

ANNEX 3.2.

Llistat de la informació bàsica a obtindre en les entrevistes realitzades als contactes (familiars de faroners, pescadors i altres persones relacionades amb les Columbretes) 
Entrevistes als familiars dels faroners:

- Nom i cognoms. Relació amb l'Illa (faroner, pescador,...).

- Nom dels familiars que hi vivien. Relació amb l'Illa (faroner, pescador,...).

- Dates d'estada en Columbretes (al menys any i duració).

- Amb qui va coincidir en l'llla.

- Far: com estava, com es distribuïen les famílies, habitacions del far, hi havia aljub baix de l'edifici? I a l'esplanada sud?, tipus de combustible i on es guardava,...

- Casernes: com estaven, estàncies, Verge dels Desemparats?, magatzem,...

- Menjar: d'on el treien, horta (què hi cultivaven), recol-lectaven llavors de l'Illa?, etc.

- Pescaven?: com, què i quant.

- Caçaven o agafaven ous?: conills, pardals, ous de baldrigues o gavines, etc.

- Aigua: aljubs, cisternes, manteniment d'estos. D'on bevien?

- Vaixell amb queviures: nom, cada quant anava, què hi portava, etc.

- Com recorda les plantes de la Illa (figueres paleres,...).

- Com recorda la fauna de la llla (escorpins, aus, serps,...).

- Quins animals domèstics hi havia?

- I la fauna marina: recorda dofins o balenes?

- Quant a l'aspecte de l'Illa, aprecia diferències?

- Com estava el far: altures, pati interior, casetes en explanades, etc.

- Treball al far: com, espills per veure la llum a la nit?, etc.

- Cementeri: com estava, recorda qui hi havia soterrat?,...

- Infraestructures a l'Illa a més del far i les casernes: verge, aljubs, etc.

- Quin és el seu millor record?, i el pitjor?

- Anècdotes que hi va viure o que li'n van contar:

- Recorden l'anècdota del bebè de Dolores?

- Experiències de temporals i penúries $(f a m, . .$.$) . Recorden l'anècdota de la xiqueta que$ es volien menjar?

- Experiències amb escorpins. Quants en mataven cada dia i com. Com dormien (tines a les potes dels llits), portaven calçat adequat?

- Aigua curativa a l'aljub.

- Submarí afonat.

- Altres:

- Com era la rutina diària?

- Com s'entretenien: cartes, visites de pescadors, etc.

- Es banyaven a la mar?

- Què feien si es posaven malalts?

- Cerimònies religioses?

- Saben alguna cosa sobre un aristòcrata que hi va anar a finals del s. XIX? (I'Arxiduc Lluís Salvador).

- Conclusió: va ser feliç en Columbretes?, o: si hagués de resumir els dies a Columbretes en una frase què diria?... 
Entrevistes als pescadors $i$ a altres persones relacionades amb la mar:

- Nom i cognoms. Relació amb l'Illa (faroner, pescador,...).

- Lloc d'origen.

- Faroners amb qui coincidien a les Columbretes i tipus de relació que tenien.

- Dates d'anada a les illes, $o$ anys aproximats.

- Relació amb altres pescadors de la zona.

- Tipus de pesca practicada i espècies de peixos que agafaven.

- Quant de temps passaven a les Columbretes sense tornar a casa.

- Recorden si utilitzaven les Casernes com a magatzem, el forn o la capelleta de la Mare de Déu?

- Com s'abastien de menjar? Incloïa intercanvi o quelcom semblant amb els faroners?.

- Caçaven o agafaven ous?: conills, pardals, ous de baldrigues o gavines, etc.

- Utilitzaven els aljubs i cisternes de les illes per obtenir aigua?

- Desembarcaven sovint a terra?, i si és així, com recorden les plantes i el paisatge de l'llla (figueres paleres,...) i com recorden la fauna de l'llla (escorpins, aus, serps,...).

- I la fauna marina: recorda dofins o balenes?

- Quin és el seu millor record?, i el pitjor?

- Anècdotes que hi va viure o que li'n van contar:

- Naixements i/o morts.

- Experiències de temporals i penúries (fam,...).

- Experiències amb escorpins.

- Aigua curativa a l'aljub.

- Naufragis.

- Grans pesqueres.

- Altres:

- Com era la rutina diària?

- Com s'entretenien: cartes, visites de pescadors, etc.

- Es banyaven a la mar?

- Què feien si es posaven malalts?

- Cerimònies religioses?

- Saben alguna cosa sobre un aristòcrata que hi va anar a finals del s. XIX? (I'Arxiduc Lluís Salvador).

- Hi havia contraban?

- Conclusió: va ser feliç en Columbretes?, o: si hagués de resumir els dies a Columbretes en una frase què diria?... 


\section{ANNEX 3.3.}

Transcripcions, anotacions, extractes o resums de les entrevistes realitzades $\mathrm{i}$ àudios aconseguits, i data de realització, ordenades per ordre cronològic de la investigació (la 12 i part de la 15 van ser realitzades i cedides per col-laboradors):

\section{ÍNDEX :}

1. AURELIO ZACARÍAS NARANJO, FARONER: entrevista a la dona, Dolores Guerra Guerrero, $17 / 06 / 2011$

2. HIGINIO GARCÍA BLASCO, FARONER: entrevista a les netes, Encarna, Mercé i Vicentica García Gallén, 26/08/2011

3. JOSÉ GOZALBO, AJUDANT DE FARONER: entrevista a la dona, María Valero, i el fill, Jose Maa Gozalbo Valero, 21/11/2011

4. JOSÉ LLORENÇ SOL, FARONER: entrevista a la filla, Pepita Llorenç Arrufat, 21/11/2011

5. JUAN DEL BOSQUE GUTIÉRREZ, FARONER: entrevista a la dona, Manuela Arribas, $13 / 12 / 2011$

6. FAMÍLIA GANDOLFO, FARONERS: entrevista al descendent, Javier Zea Gandolfo, 20/01/12

7. ANTONIO MARTÍNEZ MONTO, FARONER: entrevista a la filla, Pilar Martínez, 23/01/2012

8. JUAN GELLIDA MASIP, PATRÓ DE VAIXELL D'ABASTIMENT: entrevista a la dona, Mạeresa Lluch, 31/01/2012

9. TOMÁS MANCISIDOR ARIAS-VALDÉS, FARONER: entrevista a la dona, Carmen Barreña, 30/04/2012

10. MÀXIM FALLADA SOLÉ, PESCADOR ESPORTIU, 18/06/2012

11. RAMÓN ROIG MONTEAGUT, FARONER: entrevista al fill, Ramón Roig Sospedra, $05 / 11 / 2012$

12. "FOGASSA", FAMILIAR DE PESCADORS MALLORQUINS, 09/01/2013

13. JOSÉ HIERRO DELGADO, FARONER: entrevista a Luisa Gutiérrez Hierro, neboda de María Hierro Viera, filla del faroner, realitzada i facilitada pel nebot/net de María, Gerardo Morales Gutiérrez i alguns extractes del seu llibre "Orígenes del apellido Hierro en Canarias".

14. FRANCESC GRIMALT ALOU, FARONER: entrevista a la neta, Margarita Grimalt (realitzada en 1984 per Marc Ordeix), a la besneta, Mercé Rigó, i al net, Francesc Grimalt, 28/08/2014

15. XISCO PÉREZ, PESCADOR DE L'ALCÚDIA, MALLORCA: entrevista realitzada el 28/08/2014 a la Confraria de Pescadors de L'Alcúdia

16. FRANCISCO DEL RÍO DE LA BARRERA, FARONER: entrevista als besnets, Alicia Fernández del Río I Gustavo Chao, 03/11/2014 


\section{AURELIO ZACARÍAS NARANJO, FARONER: entrevista a la dona, Dolores Guerra Guerrero,} $17 / 06 / 2011$

En el cas de Dolores Guerra, l'entrevista prèvia la vam gravar amb càmera de vídeo. A continuació mostrem la relació d'informació que ens va donar:

- Any d'estada a Columbretes i duració.

- Nom del seu home, faroner.

- Amb qui va coincidir a l'llla.

- Com es distribuïen les famílies a l'illa i com s'organitzaven amb el menjar. Què menjaven i què tenia Bonachera a l'hort.

- Distribucions de les estàncies de les Casernes i Far.

- Anècdota del naixement prematur del bebè i possible causa

- Anècdota de la visita del metge. Guardia civil. El que va cobrar el metge.

- Paper de l'home en el part.

- On i com està soterrat el bebè.

- Registre del bebè a Castelló.

- Experiència de temporals i penúries per fam durant 15 dies: anècdota de les llentilles que quedaven fins el dia que va arribar el vaixell de subministrament $\mathrm{i}$ anècdota de I'ofrena d'oli a la Verge dels Desemparats de la capella.

- Anècdota del vaixell de subministrament i com va haver de desembarcar el menjar.

- Experiències amb escorpins. La quantitat que mataven tots els dies i com dormien.

- Us de les cisternes, aljubs i que si en bevien l'aigua.

Cal destacar la informació del fill, Aurelio Zacarías Guerra, que va nàixer a Columbretes el dia 13 d'octubre de 1953 cap a l'1 de la matinada i va morir dos dies després, el 15 d'octubre, cap a les 22:30 - 23h. Ella no va saber que el bebè es va quedar a l'illa fins un temps després de la mort. L'home va haver de fer de "comadrona, enterrador y cura" (segons Dolores el bebè va ser batejat).

A més del que està gravat a l'entrevista prèvia, també ens va comentar el següent:

Després del que va succeir al seu fill a l'illa, per poder comunicar-se, van demanar una ràdio, perquè no en tenien. Ella ja no estava a l'illa però sap que finalment no van portar la ràdio, al contrari, van portar a la verge del Carme. Ella ho deia un poc amb rialla: "Home, jo soc creient i em fa molta il/lusió que porten la verge però... podrien haver portat millor la ràdio!". 
Li va contar el faroner Bonachera que al cementeri hi havia dues làpides de nàufrags.

A l'esplanada sud del far hi havia una caseta que usaven per a guardar el petroli que aleshores alimentava el far ja que dins del far no hi havia lloc. Ella recordava que es pujaven unes escales construïdes (no tallades a la roca) a l'entrar a eixa caseta del petroli i que a més estava la caseta meteorològica.

En eixa caseta, a més, posaven un joc d'espills perquè, així, els faroners pogueren veure durant les nits, des del seu llit, si el far estava encés o no. Així no havien d'alçar-se cada vegada per a comprovar-ho.

Entre les vivendes i el far no recorda cap pati interior.

A l'illa tan sols hi havia malves. De vegetació, res més.

Ella mai va baixar a banyar-se al Rossí, es banyaven a Tofiño (de totes maneres no va estar ací a l'estiu).

Utilitzaven les casernes de magatzem.

Vivien 3 famílies al far: Bonachera, Guzmán i l'home de Dolores.

Ella creu que se li va avançar el part als 6 mesos i mig a causa d'un esglai que va tindre: un faroner va tindre un atac d'epilèpsia que va impressionar molt a Dolores perquè pensava que volien matar al seu home. Pareix que aquest faroner no va avisar del seu problema quan el van contractar ja que, si ho haguera dit, no l'hagueren contractat. Després d'aquest incident, les autoritats competents el van destinar a terra.

El seu home, quan ella va començar a sentir-se malament amb les contraccions, li deia que seria dolor de panxa per un empatx de taronges.

Deien que l'aigua de l'aljub del sud de l'llla Grossa tenia propietats miraculoses. Ella no recordava l'aljub amb sostre, no obstant això ens deia que ella es va assentar a l'ombra (havia de tindre sostre perquè, a més, recorda que es va ficar dins, que baixava uns escalons). Deien que a aquest aljub s'arreplegaven aigües que eixien de la roca, per filtració, que hi havia com un brollador.

Pescaven calamars, llagostes i mers, que després portaven a port per a ser venuts. Rares vegades menjaven ells d'aquests pesqueries, només si per mala mar no podien portar-les a terra. Com els va passar una vegada, es van repartir els quilos de calamars entre les 3 famílies, 
va acabar tan farta de calamars que deixava que se li cremaren al foc. Cada dia Bonachera i algun dels altres faroners se'n anaven a pescar.

Tenien gallines i no hi havien conills.

De vegades menjaven baldrigues. Bonachera baixava als nius i les agafava. També els ous de gavines i els pardalets migratoris.

Els portaven el menjar cada 15 dies i si hi havia mala mar el vaixell no anava. Han passat diverses fams canines, especialment va haver-hi una en la que ella recorda que al final va arribar el vaixell un dia de mala mar i els van tirar els queviures pel Rossí lligats amb cordes: malla amb creïlles, taronges i oli.

Li va encendre una "mariposa" amb oli a la Verge dels Desemparats (que estava a la capella que hi havia a les casernes), que era molt guapa, en agraïment perquè almenys ella no va morir al part. Després, amb la fam canina, farts de menjar tan sols llentilles amb aigua, va baixar un dia amb les altres xiques i els va dir "ahora veréis"... I van entrar dins la capella. Va parlar amb la verge dient-li que a ella, allà al cel, segur que no li faltava res però que ells, ací, estaven passant fam. Així que li va prendre prestat l'oli de la palometa i li va dir a la verge que, quan vinguera el vaixell de subministrament ella li'I tornaria. I així ho va fer. I la Verge no es va enfadar.

El metge no volia vindre a atendre-la quan va tindre el problema del part. El seu home i Bonachera van anar amb la barqueta a buscar-lo (11 hores d'anada i tornada). Es veu que la Guàrdia Civil el va obligar a anar a l'illa. Creu Dolores que va cobrar molt per no fer res (unes 14.000 pts!) . El metge pensava que haurien de portar-se'n a la dona a parir a terra i ho veia molt difícil. Ella no va tindre cap problema en el part. El problema va ser que es va avançar i el bebè era molt xicotet (6,5 mesos d'embaràs). Potser a terra I'hagueren pogut salvar però a l'illa no. Ella pensava que se I'havien portat a terra, al xiquet quan va morir. Però no, el van soterrar al cementeri, entrant, a la dreta. Es va assabentar un temps després. El seu home no li ho va dir per a què no tinguera tanta pena ja que segur que haguera volgut estar al cementeri tot el temps. Al final es va assabentar perquè va veure uns papers sobre la taula del seu home en els què li demanaven que diguera exactament el lloc on havien soterrat al xiquet.

En abandonar el metge l'illa el xiquet encara estava viu i quan van arribar a terra el van inscriure al registre civil de Castelló de la Plana.

Sobre Bonachera deia que era molt simpàtic i que li agradava molt beure i anar descamisat. 
El faroner fotografiat a la sala de visites de l'illa Grossa, que està a una barqueta amb un gos, un xiquet i una dona és Guzmán amb la seua dona i fill. Ella tenia molt bon record d'ell.

Guzmán i la seua dona tenien un xiquet que vivia amb els seus avis al Grau per por als escorpins (a Castelló o a Orpesa) , no recorda.

Posaven tines a les quatre potes del llit per a què no hi pujaren els escorpins.

\section{HIGINIO GARCÍA BLASCO, FARONER: entrevista a les netes, Encarna, Mercé i Vicentica} García Gallén, 26/08/2011

Les netes d'Higinio ens expliquen que el seu avi va treballar durant 10 anys al far de Columbretes, en la dècada dels anys 20 , junt amb el faroner, Baldomero Castelló.

Son pare, Vicente García Horts, també va viure a l'illa durant 10 anys (recorden que amb 14 anys estava a l'illa).

Durant eixa dècada, vivien 3 mesos a l'illa i descansaven tres mesos. Vivien a Vinaròs. Ara les tres germanes viuen a S. Carles de la Ràpita.

Els relleus els feien amb una "balandra".

Son pare junt amb el seu germà i les dos filles de Baldomero van prendre la comunió, els 4 junts, a l'illa. Anys després, son tio i una de les filles de l'altre faroner es van casar. Així que una de les filles de Baldomero es va convertir en la seua tia.

Recorden que un xiquet va agafar meningitis a l'illa i es va salvar gràcies a què li van donar banys d'aigua molt calenta intercalats amb banys d'aigua freda.

3. JOSÉ GOZALBO, AJUDANT DE FARONER: entrevista a la dona, Da María Valero, i el fill, Jose Ma Gozalbo Valero, 21/11/2011

Ens expliquen la dona i el fill de José que van estar a l'illa 8 vegades en 5 anys, la primera en 1962 o 1963. El fill, Jose Mạ, hi va estar amb 12 anys. 
La primera cosa que ens diu la dona és que va ser molt feliç en els seus dies a Columbretes, "la mes feliç del món", perquè no li faltava de res.

José va treballar amb els faroners: Juan del Bosque, Restituto Degrado, Tomás Mancisidor i Roque Serrano. L'ajudant de l'altre torn era José Mir.

Feien estades d'un mes a l'illa, els relleus eren el 4 i 24 . Junt amb el relleu els portaven queviures, i al mig, el 14 també els en portaven.

A continuació mostre per temàtiques la informació proporcionada.

Treball: Cada dia a les 17:00 contactaven amb Bonachera, que estava a terra, per donar-li el comunicat diari. Si hi havia alguna necessitat, Bonachera la coordinava des de terra.

Torn de treball: Mitjanit el faroner, mitjanit l'ajudant. Per encendre el far sempre estaven els dos. Conten que son pare (ajudant) tenia sobre l'armari un espill per a controlar si el far s'apagava. Cap a l'any 1963 es va canviar el combustible del far a gas i van vindre de Madrid a canviar-ho.

Distribució al far: A la planta baixa: entrant a la dreta estava l'habitació de Roque Serrano, i a l'esquerra, el magatzem amb els motors i l'emissora. A la primera planta: a la dreta, sobre I'habitació de Roque, la de l'altre faroner, i a l'esquerra, la de l'ajudant. L'habitació més fresqueta era on guardaven el menjar.

Entreteniments: Els pescadors pujaven a la vesprada a "fer la partideta" i els pujaven peix. Ja de nit, i amb un calçat adequat els xiquets eixien a matar escorpins (70-80 diaris). Amb canya $i$ ham pescaven des de Tofiño i l'escala del Rossí.

Pesca: Venien a pescar de Vinaròs la llagosta (embarcació "Mar de Plata"); de Barcelona venien amb iots grans i més luxosos. Recorda com va veure traure un mer de $14 \mathrm{~kg}$.

Aus: en època de pas de pardals (tords) no donaven a l'abast agafant, pelant, netejant i fregintlos. Es passaven el dia sencer fent aquesta activitat. Una vegada fregits els guardaven per menjar-se'l en una altra ocasió.

Cementeri: sap que hi havia 3 xiquets, i sobre el tema de Dolores, creu recordar que una xica va arribar embarassada i que el xiquet va nàixer i va morir a l'illa.

Alimentació: Conta que els va tocar passar uns Nadals i que no els va faltar de res, "fue todo estupendo, la mesa estaba completísima". Van compartir taula i menjar amb Roque Serrano i 
després de la fartanera van eixir a passejar. Recorda un "arrocito estupendo" que feien amb els pardalets fregits, caragols i carrancs que agafaven per la Cova del Tabac. De tant en tant Roque caçava algun conill que els donava. No menjaven ous de gavina. L'aigua de l'aljub era molt bona, quan entraven de torn el primer treball del xiquet era omplir un depòsit que tenien d'aigua de l'aljub per a anar gastant-lo. Les Casernes estaven pràcticament destruïdes, no recorda molt la capella que hi havia de la Mare de Déu dels Desemparats, diu que potser no tinguera sostre. L'hort no el gastaven.

Hi havia pocs conills i moltes sargantanes.

A I'hora de descarregar material i pujar-lo al far no disposaven de carro, es feia a mà.

Anècdotes: El seu fill menor va aprendre a nadar a la badia de Tofiño: li posaven una corda amb suros al voltant de la cintura i el tiraven a l'aigua. Els seus fills i marit es banyaven, ella no. El mateix fill xicotet un dia després de jugar al parxís, es va tallar en la cama amb el tauler, un tall important del que encara té la marca. El pare es va desmaiar. Juan del Bosque el va curar $\mathrm{i}$ el va cosir (amb grapes), l'endemà era el dia de relleu i una vegada a terra, el metge que els atenia va dir que "millor no ho hauria fet ni ell mateix". María tenia una ràdio "Gran Vals", que encara conserva la família, i conta que amb ella era capaç de sintonitzar-la per a sentir el que es parlava cada dia a les 17:00 amb Bonachera.

El metge que va atendre al xiquet després del tall, que estava en medicina general al Grau, era José Sanahuja, el mateix metge que va haver d'anar a l'illa a atendre a Dolores el dia del part.

Les tempestes eren molt grans. Havien de posar barres a les portes per a poder tancar-les bé $\mathrm{i}$ que no s'obriren.

La dona de Roque Serrano no va estar a l'illa, no va coincidir amb ells.

\section{JOSÉ LLORENÇ SOL, FARONER: entrevista a la filla, Pepita Llorenç Arrufat, 21/11/2011}

Pepita era la filla petita del faroner i l'única filla que restava amb vida. Ella va viure a Columbretes. Tenia 85 anys quan li vam fer l'entrevista prèvia. Les germanes majors tenien 11 i 9 anys més que ella.

José va nàixer l'any 1882 i la seua defunció va tindre lloc l'any 1946. 
Era Tècnic de senyals marítimes.

Ens narra com son pare guardava caixes ordenades de documents i fotografies del seu treball $\mathrm{i}$ que segur hi hauria coses de Columbretes, però una bomba de la Guerra Civil va destrossar tot aquest arxiu.

Un dia del mes de maig una música els va despertar, era una barca que portava uns músics que anaven a rondar la mare perquè era típic en aquest mes cantar cançons a les dones.

En referència als escorpins ens diu textualment que: "Hi havia més que pedres" i "Si no el toques no alça la cueta".

Comenta que sempre la família hi parlava de la qualitat del peix fresc "que anava de la barca al plat".

Tots els diumenges acudien a l'illa el seu oncle Salvador Solsona i altres amics a passar el dia i pescar, entre estos amics estava el Dr. José Alegret (metge tocòleg), pare de D. José Ma Alegret, també metge que tenien la clínica al carrer Saragossa de Castelló, on creu que actualment continua vivint la família.

Un dels nets del faroner, que és qui va contactar amb nosaltres per donar-nos el contacte de sa tia Pepita per a què participara en el documental, ens va mostrar fotos del seu avi però en cap estava a Columbretes. Junt amb aquestes fotografies hi ha una que ens crida l'atenció. És d'un grup nombrós d'homes en el que a nosaltres ens pareix que és Columbretes. El nét no sap per què la família tenia aquesta foto, on està presa, ni qui són, però nosaltres veiem que al peu de la foto posa el següent text: "Tripulación del vapor italiano Cornigliano hundido por un submarino austriaco". De seguida vam reconèixer el nom del vaixell i el relatiu a aquest afonament: al juny de 1916 (I Guerra Mundial) aquest vapor va ser afonat per un submarí austríac, va caldre auxiliar tota la tripulació (ho van fer els faroners que hi havia a Columbretes en eixe moment).

Pel que li contem al nét d'aquest faroner, el seu avi devia de tindre en el seu poder aquesta foto perquè va estar a l'illa durant aquest fet, per la qual cosa ajudaria també a la tripulació (guardant com a record la foto).

Li preguntem a Pepita sobre l'anècdota però diu que ella no recorda res al respecte. 


\section{JUAN DEL BOSQUE GUTIÉRREZ, FARONER: entrevista a la dona, Manuela Arribas,}

Manuela ens fa saber que Juan va estar dos anys a l'illa i guarda molt bon record, va arribar amb 27 anys i amb una filla de nou mesos. Ens parla del conegut Restituto Degrado, ens diu que ha mort però que té els contactes dels fills. Ens diu també que l'avi del seu home (Juan Gutiérrez Perlasia) va participar en la construcció del far de Columbretes, i un fill d'aquest (Fernando) també va ser faroner a l'illa.

6. FAMÍLIA GANDOLFO, FARONERS: entrevista al descendent, Javier Zea Gandolfo, 20/01/12

Javier Zea Gandolfo ens conta que els Gandolfo són una família de gran tradició de faroners. L'única de la família que hi va viure a les illes i queda viva és Lola i tenia aleshores uns 83 anys. Viu a Roquetas (Almeria).

Javier diu que li han contat moltes històries de les illes. Entre d'altres que el naixement d'Aurelio va ser prematur després d'una festeta al far amb balls. Que el van portar a Castelló i al no poder pagar una incubadora el van tornar a portar a les illes. Li van escalfar el llit amb estufes de gasoil però va morir i el van soterrar dins un pot d'oli. També parla dels pots a les potes dels llits i altres anècdotes menors.

Ens envia digitalitzades valuoses fotografies antigues de faroners i familiars a Columbretes, on indica el nom de cadascú.

\section{ANTONIO MARTÍNEZ MONTO, FARONER: entrevista a la filla, Pilar Martínez, $23 / 01 / 2012$}

Pilar va estar a l'illa de menuda, des de l'any 1943 fins el 1951, aproximadament (dels 7 als 14 anys). Quan li vam fer l'entrevista prèvia tenia 77 anys.

El pare de Pilar, Antonio Martínez Monto, va nàixer al Grau de Castelló; la mare del faroner era de cognom Monto Boira i el pare (avi de Pilar) era del Grau i capità de cabotatge. La mare de Pilar es deia Pilar Silvestre. Té una germana, Ana, un poc major que ella. 
Tenien un gos blanc que surt a alguna de les fotos que ens va cedir, que va viure els 8 anys amb Pilar a Columbretes. Va morir atropellat a S. Carles de la Ràpita.

Pilar tenia dos anys quan va esclatar la guerra civil. Son pare va estar destinat a Cap de Creus, que era molt perillós durant la guerra, pels bombardejos, per això va demanar el destí a Columbretes, pensant que seria un lloc més segur.

Antonio va fer batxiller i va acabar la carrera de faroner (es necessitava el batxiller) perquè son pare el va obligar a estudiar. Però no va continuar per a ser enginyer perquè estos passaven molt de temps a l'oficina i el que ell volia era treballar a l'aire lliure ("li agradava més el camp que l'oficina"). Podia haver-ho fet perquè era molt llest, va ser el primer de la seua promoció. (NOTA: diu que té una llibreta de son pare on anotava els comptes i apunts diaris del far).

Durant els huit anys que van estar a l'illa, habitualment es feien dos mesos seguits i un de descans, per tant el normal era que hi haguera dos faroners a l'illa i un descansant, però com les condicions/circumstàncies en aquella època de postguerra (època de fam i escassetat) eren més benignes a les illes que a terra i ja que si estaves allí, es gastaven pocs diners, era habitual que qui havia de descansar no se n'anara a terra. Per tant a l'illa hi havia al mateix temps tres famílies convivint. Ells mateix van estar dos anys i mig seguits a l'illa, al principi.

El pare va triar el destí de Columbretes, per a fugir de les dures condicions de la postguerra a la península. A l'illa es comptava amb un aïllament favorable d'aquestes condicions i de menjar (peix) abundant. Una vegada al mes arribava el vaixell de subministrament, compraven les coses bàsiques (fesols, etc). Tenien 14-16 gallines i un gall, cinc cabres i un xoto.

Ens presenta a son pare com a un aventurer i ens ensenya fotos que ho corroboren. Va estar destinat a un far de Guinea al qual havia d'arribar caminant, travessant la selva cada vegada. Ens mostra una foto amb un goril/la mort. Va arribar a agafar la malària i va estar 3 setmanes en coma. Patronejava velers. Tenia molta relació amb un amic alemany. Abans d'estar destinat a Guinea va estar al far d'Alegranza, Canàries, després va estar 2 o 3 anys a Guinea, on ja estava amb la seua dona i la seua primera filla, Ana. Després va estar al Cap de Creus i després a Columbretes. Era esportista, corria carreres: va arribar a fer-se famós per guanyar les carreres pedestres (així es deien) de Castelló i Barcelona.

En una ocasió, en plena guerra civil, estant a Cap de Creus, havien eixit els quatre del far perquè l'anaven a bombardejar, escapant a un lloc pròxim. Com no paraven de bombardejarlo, son pare va decidir anar fins al far per apagar el llum del far. Així ho va fer, es va jugar la 
vida tornant al far en ple bombardeig i va apagar el llum d'aquest; els enemics van pensar que I'havia inutilitzat i se'n van anar.

Recorda que la vida als fars era una vida molt dura, sobretot al principi, perquè no hi havia metges,... Recorda especialment dura l'estada al far d'Alegranza, a Canàries, on ho van passar malament.

Pilar ens diu que l'època de Columbretes la recorda com la millor època de la seua vida. Encara que ens transmet que el no haver anat al col-legi ha sigut un trauma que ha arrossegat des de llavors. El pare, de nit, els posava deures.

Van treballar amb els faroners Gandolfo i Ramón Roig, que era de Sta. Magdalena de Polpís (fills: José Roig, ja mort, era metge estomatòleg, Ramón i Ana Mą). Aquest últim va haver de deixar el treball i tornar a terra per un patiment estomacal.

Quan van arribar a l'illa la dona de Ramón Roig, Pilarín, estava a terra donant a llum (a la seua filla Ana María) i Ramón estava a l'illa amb els seus dos fills (José i Ramoncín). Els andalusos Gandolfo van arribar després. Els adults no tenien massa bona relació, els xiquets sí.

Recorda netejar els prismes de la llanterna, un treball que costava molt perquè a son pare li agradava que tot estiguera perfecte. No tenien emissora. Quan hi havia previsió de temporal, molt habitual a l'hivern, baixaven ella i son pare a pujar l'embarcació.

Durant tots els anys que van estar al far van anar canviant d'habitació i de planta segons anaven pujant per l'escalafó. Des de la pitjor habitació de la planta baixa (part sud, perquè la que dóna al nord, que consideraven la pitjor, estava deshabitada), fins a la millor de la primera (part sud). Pujant pel camí, en arribar a l'esplanada, hi havia la caseta d'apers i maquinària (també hi guardaven el petroli) a l'esquerra i dos xicotetes casetes o barraquetes, una davant de l'altra, de les quals, la que estava a la dreta de l'esplanada (la que està més prop de la badia) la feien gastar de dutxa, perquè el pare va preparar un poal amb una carxofa. Davall la barraqueta que està més al nord creien que podia haver-hi un aljub, però no està segura. Al forn del far feia el pa per a una setmana, no gastaven el de les casernes. Hi havia un pessebre al costat dels galliners.

Recorda que hi havia un xicotet aljub a l'esplanada oest del far.

A continuació es mostra per temàtiques la informació proporcionada. 
Entreteniments, caça i pesca: Els pescadors pujaven a sovint, els portaven peix i a canvi els faroners els donaven ous, oli i aigua. Els xiquets: ella i el fill de Ramon Roig (Ramoncín) anaven a caçar escorpins, de nit i de dia perquè els buscaven davall les pedres. Diuen que van fer una bona neteja. Amb ceps també agafaven multitud de pardalets durant el pas migratori. Pescaven a Tofiño i al Rossí, segons el tipus de peix. A l'hivern, de nit, pescaven els calamars. Donat que ella va aprendre a remar es va fer imprescindible per a son pare i l'acompanyava, una vegada que ell encenia el far, de nit o de bon matí. Anaven amb el bot "calafateado" (fet per un calafatador del Grau). A ella li encantava fer coses "de xics", ens conta Pilar. Mai tenia por. Recorda que amb 9-10 anys ja es quedava sola a la barca a la nit i no tenia por. Al Rossí pescaven xopes.

El pare era aficionat a tocar l'harmònica i una bandúrria que ell mateix es va fabricar, i la mare (amb educació musical) cantava. El pare encara que molt seriós i formal en el treball també li agradava disfressar-se i fer bromes a qui convivia amb ells. El pare es construïa les seues pròpies embarcacions i també va fer un "mirafondo". Antonio era un manetes, aventurer i divertit.

Fauna: Veien molts dofins però no recorda balenes. Els dofins, almenys uns 6, els acompanyaven al costat de l'embarcació quasi fins a la costa als trajectes des de Columbretes. També recorda moltes tintoreres per l'escala del Rossí. No caçaven ni gavines ni baldrigues, tampoc consumien els seus ous (es coneix que potser estava prohibit). Si que caçaven aus migratòries a l'època de pas. Recorda que els tords arribaven esquelètics. També comenta que hi havia un mur de pedra de femer i molta gallinassa, excrements de gallina, on es reproduïen molts cuquets dels quals s'alimentaven les "terreroles" (Calandrella brachidactila, o pot ser que es referira a la terrera o a la bisbita) per això estos pardals estaven sempre grossets.

No hi havia conills. Ells tenien $14-16$ gallines i 1 gall, 5 cabres i 1 cabrit. Les gallines posaven ous 5 dies seguits. Els escorpins eren capaços de matar una gallina, que moria a l'acte. Les gallines també caçaven escorpins, agafant-los per la cua.

Cementeri: recorda que li van contar que hi havia un bebè, un nàufrag i creu que l'esposa d'un faroner. Hi havia làpides velles. Els xiquets furgant un dia als voltants del cementeri, van trobar una gerra amb restes humanes en el seu interior (no eren de bebè), van trobar una tèbia.

Illa: hi havia un pontet de fusta per la zona de les columnes, per a espentar el xicotet bot. La zona de mar davall les columnes es gastava com a embarcador i com a zona de bany per als 
xiquets. Allí hi havia molts eriçons. També hi havia un altre pont que unia l'esplanada del far amb l'aljub d'aquest.

Recorda que la terra era arenosa i hi havia molts forats (diu que potser allí s'amagaven les colobres en el passat). A la part més alta li deien "Monte Colibre".

Encara no hi havia norais a l'illa.

La cova del Tabac era una cova, encara no l'havien dinamitada (tot i que no ens ho va dir molt convençuda).

Pescadors: Venien a pescar de Vinaròs, Benicarló i Mallorca. Recorda especialment l'educació i bones maneres dels pescadors mallorquins de Pollença i l'Alcúdia (que pescaven Ilagosta), i tant bé que cuidaven de les seues embarcacions (8-10 $\mathrm{m}$ d'eslora), eren molt nets i molt educats. Desembarcaven els aparells (canyes brutes, juncs, cordells, cordes,...) i els netejaven a les Casernes, al llavador (aljub); també es llavaven la roba. Quan havien fet tots els treballs de pesca i altres s'assentaven a preparar nanses per a pescar llagosta (es pesca a l'estiu).

El comportament dels pescadors mallorquins contrastava amb el dels pescadors de València i la costa de Castelló, que eren mal educats, segons Pilar.

Recorda el "Braulio" de Vinaròs, una "envià" (era la barca que anava i venia), a la qual reconeixien pel so "de latas". El "Pepe" de València (anaven el "Pepe" i un altre vaixell igual del qual no recorda el nom; ambdós eren dos germans de València).

Recorda el pas de paquebots que anaven carregats de taronges i mandarines. Alguns paraven. Mitjançant senyals amb banderins, el vaixell indicava a son pare que s'acostara a arreplegar-les i aquest amb el seu xicotet bot anava a buscar-les. Els pescadors els portaven peix i rebien ous, aigua, aspirines, amoníac (en fi, qualsevol cosa que tingueren els faroners).

Alimentació/pesca: No recorda cap escassetat, tenien menjar suficient. Inclús, de vegades tenien tal excés de pesca que havien de tirar caixes de peix "barranc abaix". La fruita i verdura fresca eren un bé molt preat.

Per a pescar els calamars posaven els arts davall la barca, just davall la quilla, amb tires de fusta engrosada, i amb unes corrioles ho pujaven i baixaven.

Amb el mirafondo fet per son pare, passejaven per la badia i veien les cabres passar per davall. Llagostes no en veien. 
Hi havia moltíssims mers. Quan pescaven amb el mirafondo, seleccionaven la zona segons el peix que rondava i després pescaven, posant una cinta que feia son pare per les nits. Son pare va preparar amb pèls un aparell de fusta amb tres caragols, lligava el pèl i feia una "cameta". Unint 3 o 4 d'aquests feia una més grossa, lligades amb nusos mariners, era molt fort. De carnada per al mer utilitzaven polps o sépies un poc durs. Deixava la corda solta, així, quan la picaven es tensava, així, tan sols des de dalt amb la barca podien distingir si hi havia peix o no. Així, una vegada van pescar en un vol un mer de $33 \mathrm{Kg}$. Amb aquesta tècnica, una vegada en compte d'un mer van agafar un polp enorme. Era tan gran que, quan ho van tirar dins de la barca i se n'anaven cap al port, va començar a agafar-se'ls per les cames i per l'embarcació amb les seues ventoses. A son pare li va agafar molt fort una cama, amb les ventoses, i van haver d'acostar-se a les embarcacions que hi havia a la badia i des d'una d'aquestes li van tirar un doll de vinagre a la cama de son pare i se'ls va soltar.

\section{Al Rossí baixaven a pescar xopes, dentones,...}

Tot el peix que aconseguien, ja fora peix per a ells o del que els donaven els pescadors, el preparaven de diferents maneres per a conservar-lo, normalment el posaven a assecar a la planta baixa del far, la part que dóna al nord, on no vivia ningú:

- quan tenien excés de sardina, per a la seua conservació ("Sardinas de bota"), son pare ho posava a un paper d'estrassa (assecant) amb sal, damunt les sardines, una altra vegada sal, formant unes quantes capes; i per damunt uns contrapesos (utilitzaven els contrapesos que s'usaven en el mecanisme del far perquè rodara la llanterna).

- les xopes, que pescaven amb canya, les salaven i les feien com l'abadejo.

- els sorells els orejaven. Els posaven amb aigua, sal i pebre roig i dos dies a l'aire.

- els calamars (es pesquen a l'hivern) els deixaven assecar i quan tenien ocasió els enviaven a la llotja de Vinaròs, amb açò es treien un sobresou (amb els calamars i altres tipus de peix).

Casernes: estaven abandonades, hi havia 2 o 3 vivendes que ningú utilitzava. Recorda que a una de les instal-lacions hi havia una capella que tenia diverses imatges: Sant Antoni, Sant Josep i un parell de quadres de sants fets amb escates de peix. Recorda una verge però no sap quina era.

No hi havia hort. Una vegada es va fer utilitzant unes parets que ja estaven quan van arribar ells (potser foren d'un antic hort), però no va prosperar res. Un estiu per variar, els pares van habilitar una de les estades de les Casernes i hi van baixar a estiuejar. 
Vegetació: No hi havia figueres de pala al camí, potser haguera alguna a la zona nord del far. Pilar recorda que no hi havia llenya, només hi havia matolls en forma de floricol (plantes arrodonides) que feien uns palets. Estos palets secs els utilitzaven per al braser i per al forn per a fer pa.

\section{Anècdotes: Ens en conta moltes:}

Recorda els temporals des de l'illa i les tempestats i el vent al far. Recorda un dia que va bufar de tal manera al far que encara amb les barres de ferro que posaven en portes i finestres, el vent va doblegar una barra i va obrir la finestra. Estaven les dos germanes soles perquè els pares devien d'estar a Castelló (no recorda bé). Vivien a la 2a planta, part sud (la millor), estaven a "I'habitació dels enginyers" (la que utilitzaven estos quan estaven a l'illa) i la seua germana va passar un esglai molt gran. Ella no, perquè diu que era molt valenta, inclús va fer broma amb la seua germana en ple vendaval espantant-la dient-li que hi havia una mà darrere d'ella. "iQuin crit va pegar!" - recorda Pilar. Al final els va ajudar Gandolfo a tancar la finestra.

A l'hora de descarregar material i pujar-lo al far si que disposaven d'un carret, del que normalment tirava un adult, perquè mula només hi havia quan, una vegada a l'any, arribaven un grup d'obrers, l'enginyer i un ajudant, que portaven una mula, la qual descarregaven amb la grua i que junt amb el carro pujava els materials al far.

Un dia descarregant la mula amb la grua al port, els va caure a l'aigua!!

A ella i al seu company de batalles/aventures (Ramoncín), els anomenaven "Tarzán y su compañera". Ramoncín, fill de Ramón Roig, tenia 2 o 3 anys menys que Pilar.

Al gos li van picar els escorpins 12 vegades, quan li picaven estava dos dies udolant. A Pilar li van picar tres vegades, recorda cridar i sentir molt de dolor. També recorda els crits dels mariners quan els picaven. Li van contar que un mariner a qui li va picar un escorpí, va ser portat a terra i va morir. No sap si per aquest motiu, però així li van dir que havia passat. Només tenien amoníac que servia per a les picadures de vespa però no feia res per a les picadures d'escorpí. L'experiència els va ensenyar que el millor per a evitar el dolor era ficar el peu (ja que normalment era a aquesta zona on els picaven) en aigua bullint, per molt bullint que estiguera l'aigua no la notaven, i els calmava el dolor. També diu que els quedaven marques. Una vegada van veure sobre el llit de la germana un escorpí, amb el que el pare va decidir posar les potes dels llits dins de pots grans de llet condensada als que posaven petroli. 
Diu que els escorpins solien veure's caminant pel sòl contra la paret del far, no a "campo través" per l'esplanada.

Quan va esclatar la II Guerra Mundial, ells pel seu aïllament (no tenien telèfon ni emissora per a comunicar-se), no es van assabentar, però van començar a veure avions que sobrevolaven les illes. Recorda que un dia van passar centenars d'avions en direcció Sud-Nord. A Cap de Creus havien aprés a diferenciar el so de quan anaven carregats de bombes i quan anaven buits. El so era diferent. Els xiquets no eren molt conscients de què passava però recorda que els adults deien "On aniran estos fills de puta?"

Durant la II Guerra Mundial, de la que es van assabentar poc, apareixien surant diferents coses que suposaven un al-licient i que creaven unes expectatives que a un lloc com l'illa venien bé. Els mariners contaven que s'havien trobat or, garrafes d'oli,... Per exemple, una vegada va aparèixer una caixa enorme surant fora de la badia i van eixir a buscar-la amb la barqueta. Cadascun imaginava que podia ser una cosa: ella, que era xicoteta, volia una caixa plena de nines; la seua germana, que ja tenia uns 14 o 15 anys, somiava amb una caixa plena de vestits. Finalment quan van arribar a per ella li van donar la volta i estava buida... "quin desencant!", però ja havien passat un dia diferent. Una altra vegada va aparèixer una llanda del que pareixia menjar envasat, la van trobar els mariners però no la volien perquè s'havia donat algun cas d'enverinament (intoxicació) per consumir un oli que va aparèixer d'aquesta manera, i li la van donar a son pare. Va resultar ser una espècie de paté que estava boníssim. El primer dia els va donar a provar només un poc, i a l'endemà, al veure que no havia passat res, ho van consumir amb tranquil/litat. Una altra vegada va caure del cel un paracaigudes que van rescatar, i la tela impermeable i resistent va donar per a molt: les dones es van fer davantals, es van fer braguers per a les mames de les cabres (per a què no les arrossegaren pel sòl), i van utilitzar les cordes i cordells per a multitud de coses, tot es va aprofitar.

Durant el pas d'aus migratòries, que els xiquets caçaven amb ceps, li va voler gastar una broma a Ramoncín. Va trobar un tord mort d'uns quants dies (ja feia olor) i el va col·locar al cep com si haguera caigut (com a esquer gastaven cucs que creixien davall els excrements de les gallines), ella junt amb sa mare i germana es van amagar al far i per la finestra veien a Ramoncín com va arribar a veure el cep i com es va posar de content amb la seua captura, els va portar la presa tot eufòric i la mare després d'agafar el pardal i notar l'olor li va dir que eixe animal portava temps mort, però el pobre xiquet no s'ho podia creure.

Per a arribar a l'illa tardaven quatre hores amb un vaixell de pesca que feia molta mala olor. 
Una vegada els va visitar un cosí i va caure a l'aigua, i recorda al xiquet que venia amb l'embarcació "Pepe" de València que el va rescatar. El pare de Pilar li va fer una creu de fusta de penjoll com a agraïment.

La mare tenia atacs de nervis que feien que perguera el coneixement, i només li donava el temps just per arribar al llit, es quedava inconscient i açò podia inclús durar un parell de dies. En més d'una ocasió van arribar a pensar que estava morta. Recorda que tot açò va començar a Columbretes, i recorda la impotència i l'angoixa que sentien ja que no podien cridar a ningú. Un metge de Tortosa li va diagnosticar que els atacs eren de tipus nerviós i li va donar un tractament.

El pare una vegada va enviar la dentadura d'un denton a un familiar dentista per si li servia per a algun pacient.

Una vegada entre les tres dones, mare i filles, van pescar un denton enorme, de $5 \mathrm{Kg}$, al Rossí. Estaven molt contentes perquè era un denton a qui son pare feia temps que volia pescar però se li resistia!! I elles ho van aconseguir amb una xicoteta canya i un salabre. Recorda que l'animal va picar a la canyeta i que estirant ella no el podien traure, sa mare va demanar a Pilar que anara corrent a buscar un salabre amb el qual, per fi, el van aconseguir pujar a terra. Quan va baixar son pare al Rossí no li van dir res i van esperar a veure la seua reacció quan es donara compte del peix que tenien dins del poal. Hi havia rialletes, ell preguntava però no li deien res, de tant en tant sentia cuejar al peix dins del poal i per fi va aguaitar a veure'l. No va donar crèdit al que va veure!!! era el peix que portava temps intentant pescar al Rossí i les seues xiques ho havien aconseguit. Què contents es van posar. Aquesta era l'anècdota que a sa mare, durant tota la seua vida, més li va agradar recordar.

El pare era propens a disfressar-se, es va disfressar de bisbe amb el que tenia per allí (amb un cobertor i dos estoretes de peu de llit; abans s'havia preparat una gorra de cartó amb purpurina a manera de mitra, i el pal d'una cortina era el bastó i bàcul de bisbe) , i com Ramón Roig patia de l'estómac, una vegada es va disfressar d'aquesta manera i el va aguaitar a la porta del lavabo per a donar-li una benedicció quan Ramón isquera.

Un dia de temporal, estant els mallorquins (als quals tenien molt d'afecte) a l'illa perquè no se'n van poder anar a causa del mal temps, van pescar una tortuga i van decidir fer una menjar especial (guisat), ajuntant-se tots per a menjar. Recorda que els va costar molt matar l'animal i que ella se'n va anar lluny fins que tot açò havia passat perquè no li agradava que mataren als animals. Després del menjar, el pare es va retirar i amb l'ajuda de Pilar es va disfressar com un 
turista anglès: ulleretes de fil d'aram, calçó curt, prismàtics (se'ls va fer amb dos potes de metall d'algun llit), bigot, gorra, etc... i va aparèixer pujat per l'aljub del far, els comensals el van veure per la finestra i no donaven crèdit al que estaven veient $\mathrm{i}$ a com havia arribat un turista a l'illa en les condicions de mar que hi havien. El "turista" va tocar a la porta i li van obrir, amb accent anglès va començar a quedar-se amb ells $i$ van tardar a adonar-se de qui era... Al final, amb una pera d'aigua que portava els va tirar un doll $i$ tots ho van passar molt bé. Després d'aquest dinar, quan van poder, els mallorquins van partir cap a Mallorca, i al temps van saber que l'embarcació havia naufragat i tota la tripulació s'havia ofegat. La data d'aquest naufragi va ser d'un parell d'anys abans de que ella se n'anara de l'illa, per tant, cap a l'any 1949*.

Aïllament: ens conta que estaven molt més aïllats a Columbretes que a qualsevol altre far. Per exemple, conta que sa mare es va posar de part estant a l'illa Alegranza, al far. Tampoc tenien emissora però son pare va fer una gran foguera per a cridar als de la costa, que van anar a arreplegar-los. La seua dona va arribar a donar a llum a la ciutat. A Columbretes ni això es podia!!

*Sobre el naufragi vam trobar informació al Ilibre de Francesc Canuto Bauçà, "Toponímia i talasonímia mallorquina als Columbretes", de la Universitat de les Illes Balears (p.31), 1994:

"Las barcas son "San Salvador" y "San Bruno" que volvían de Columbretes y como llevaban arroz de estraperlo no quisieron entrar en el puerto Sóller y naufragaron en el año 1942."

Tripulants: Francesc Vera, "Gasparó" (patró); Joan, "Batlet"; Esteve, "Xarpat"; Martí, "Llana"; Miquel, "Xarpat"(va sobreviure); Pere, "Pollet" (va sobreviure); Gaspar, "Gasparó" (va sobreviure), i un tal "Bota".

*Fogassa ens diu que els seus germans anaven a pescar a Columbretes als anys 40 i també van escoltar parlar de la notícia que 2 barques de I'Alcúdia havien naufragat. La notícia es va estendre ràpidament per Mallorca, entre els pescadors. 


\section{JUAN GELLIDA MASIP, PATRÓ DE VAIXELL D’ABASTIMENT: entrevista a la dona, MaTeresa Lluch, 31/01/2012}

Maria Teresa ens explica que Juan era el patró de l'embarcació "Alcón" que va ser el vaixell d'abastiment des de l'últim trimestre de 1956 fins als anys 70. El van retirar als 70 però el vaixell estava en males condicions des de l'any 67. L'"Alcón" el va posar el Ministeri (Costes). Abans d'anar aquesta embarcació, els subministraments els portaven amb barques de pesca.

El seu home va estar navegant des dels 14 anys. Als 29-30 va aconseguir la plaça de I'"Alcón". Llavors es van casar, el 02/01/1957.

MํTeresa va nàixer l'any 1933 (el 2 de desembre). Ara té 78 anys. Recorda que va estar per primera vegada a Columbretes amb 14 anys (1948), de fadrina. Va ser amb la "Favorita" (barca de pesca de "los Favoritos" del Grau) i més gent del Grau, va prendre el bany amb Coro Bonachera (filla del faroner Bonachera) i se'n van tornar el mateix dia.

Sa mare tenia una botiga d'alimentació al Grau i els guardes de Columbretes compraven a la seua botiga des que el seu marit portava l'Alcón.

Estaven els faroners: Serrano, de Castelló, Agustí Albiol, de Vinaròs, José Mir Primavera i Bonachera, que estava fix allà, potser per voluntat pròpia, no ho sap.

Quan va morir el xiquet de Dolores, ella era molt joveneta i no ho recorda bé.

\section{TOMÁS MANCISIDOR ARIAS-VALDÉS, FARONER: entrevista a la dona, Carmen Barreña, $30 / 04 / 2012$}

Tomás Mancisidor era de Vinaròs. Carmen Barreña, la dona, de Conca. Quan van decidir casarse, ella li va posar la condició de que deixara la marina mercant. Així es va fer faroner per poder estar amb la família.

Van estar entre l'any 61 i 64 . Feia torns de 30 dies, rellevant-se amb Roque Serrano.

Hi havia un peó: José Mir. S'encarregava de mantenir i canviar el far. En eixos anys va ser quan van substituir el sistema de petroli per acetilè. 
A l'Illa, Tomás escoltava "Radio Praga" en temps de Franco. Era la seva manera d'informar-se. La ràdio era un objecte important per a ells, la seva forma de mantindre contacte amb l'exterior.

Tomás va demanar el canvi des del far d'Andratx per estar més prop de Vinaròs.

El subministrament es feia cada 10 dies. Un dia de temporal, arribant a l'Illa, va caure un mariner del vaixell de subministrament $i$ es va ofegar.

Conten que en ocasions van atendre a pescadors que es posaven malalts.

I sembla que als xiquets els instruïa la mare i alguns mariners, que els ensenyaven a llegir i escriure.

En aquells anys, les casernes es gastaven de magatzem dels mariners, on guardaven les arts.

José Mir tenia gran afició a caçar amb cepet i capturava molts tords.

Es duien medicaments per a les emergències.

Tomás va morir als 33 anys d'un atac al cor a Vinaròs, pocs dies després de tornar de Columbretes, mentre llegia al llit un llibre de primers auxilis.

Carmen associa Columbretes a la cançó del Cola Cao i a la ràdio novel·la "Matilde, Periquito i Periquín i recorden com per la nit havien de fer servir quinqué per fer llum.

\section{MÀXIM FALLADA SOLÉ, PESCADOR ESPORTIU, 18/06/2012}

Màxim és de Reus i té una botiga de pesca a Cambrils. Ara té 78 anys i encara treballa. La seua dona s'anomena Francisca Sans i també es troba a l'entrevista.

Anava a Columbretes a fer pesca esportiva amb la seua embarcació motora Thunnus (van ser dues, la primera d'11 metres d'eslora i la segona, de 12,5 m, s'anomenaven Thunnus les dos). Màxim conta que va començar a anar a Columbretes a finals dels anys 60 (entre el 65 i el 70, no recorda bé) i va deixar d'anar-hi quan es van protegir, al 1988. Des de llavors ja no ha tornat. 
Diu que haurà anat més de 100 vegades a les illes. Anaven des de Cambrils i estaven a les illes de 2 dies fins a una setmana. Moltes vegades portava als seus fills que eren xicotets, Patricia $i$ Màxim Jr. Ells van començar a anar amb 6 o 7 anys.

A continuació mostre per temàtiques la informació proporcionada.

Època amb faroners: Llavors a l'illa treballava el faroner Roque Serrano que era casat amb una mestra de Castelló. Estava amb un ajudant però no es parlaven (no és Bonachera). Aleshores Roque estava a l'illa de manera contínua i cada 10 o 15 dies li portaven el menjar. Diu Màxim que Roque era tinent de la legió i es veu que va demanar una excedència per a fer-se faroner. Diu que Roque coneixia de memòria els productes de farmàcia, els compostos,... Ens relata com ells cuidaven al faroner, li portaven fruita, pa i whisky. El volien molt.

No sap com vivien. Tenia horts xicotets. Hi havia un hort prop del far, davall de la cisterna. L'aigua de la cisterna era boníssima.

Hi havia molt poca vegetació. No sabia què menjaven els conills que hi havia per allí assilvestrats; diu que potser s'alimentaren de les algues que hi havia al costat de la mar.

Època sense faroners: Màxim recorda que, en l'època en què ja no hi havia faroners, abans de la protecció, havia pintades al far i que al cementeri algunes tombes estaven obertes.

Llavors Roque anava a l'illa de vacances, a l'agost, amb la seua família. Durant el temps en què es feien pràctiques militars (de dilluns a divendres) no es podia estar a les illes. Comenta que quan van tirar l'"obús de la Foradada" ell estava allí.

Recorda que als anys 70 va haver-hi una convenció de radioaficionats. Des de Columbretes, els radioaficionats van contactar amb un capellà d'Almassora, que era un company seu d'escola (van anar junts al col-legi a Reus), amb el rei de Jordània, el rei Juan Carlos I i altres personalitats.

Màxim critica el que feien la resta de pescadors perquè a ell li agraden molt els animals i la naturalesa. Diu que ell s'enfadava molt amb la resta de pescadors perquè, per exemple, feien massacres de llagostes o mataven a les àguiles pescadores (segurament serien falcons d'Eleonora). Diu que a ell no li agrada matar peixos. Una vegada va salvar una tortuga enganxada a un palangre.

La pesca: En maig hi havia tonyinaires. Es pescava també molta llagosta i sardina. De tant en tant es pescava coral de manera il.legal (la capitana del vaixell era una xica). A la Ferrera hi 
havia musclos i clòtxines. A la bocana de l'Illa Grossa hi havia molts calamars (pescaven amb una calamarera).

La navegació: Màxim és patró. Diu que al principi coneixien la posició a la mar per les emissores de ràdio. A l'embarcació portaven $1500 \mathrm{Kg}$ de gel per a mantindre la fruita. Des de Cambrils fins a les illes hi havia 72 milles a rumb 1960 ( $m$ 'ho diu de memòria). Eixien de nit $\mathrm{i}$ amb la seua motora els costava unes 6 o 7 hores arribar-hi. Quan fondejaven a la badia havien de parar atenció perquè si el vent bufava pel primer quadrant allò es posava "como una olla". I cada 2 hores feien vigilància.

El busseig: Ell feia vídeo submarí amb una cambra igual que la que usava Cousteau. Diu que Columbretes és el lloc on ell ha trobat l'aigua més clara. Normalment navegava amb un metge. Portaven aparell amb oxigen. En fi, sempre anaven molt preparats.

\section{Animals terrestres a l'illa:}

- Sargantanes.

- Escorpins, que els mataven per la nit.

- Conills blancs.

- 30.000 gavines!!!

- A la nit cridaven uns "moltxons" (baldrigues).

- Huit o deu àguiles pescadores (segurament, falcons d'Eleonora).

Li van contar que molts anys arrere uns alemanys van portar 10 o 12 porcs. Llavors ja no hi havia.

\section{Anècdotes:}

L'ajudant de Roque va aparèixer un dia mort a l'illa, assentat, pescant amb la canya.

En el far hi havia un WC al final d'un Ilarg i estret corredor. Al llarg d'aqueix corredor hi havia 12 poals plens d'aigua. Quan usaves el vàter havies de tirar l'aigua de l'últim poal i després desplaçar-los tots, un a un, cap avant per a omplir el poal d'aigua que havies gastat i deixar-lo l'últim. Si no, Roque s'enfadava molt.

En una ocasió quan els seus fills encara eren xicotets estaven fondejats dins de la badia, els tres sols, i cap a les 7 del matí va aparèixer un submarí! Era de color negre no portava bandera. No podien eixir de la badia perquè el submarí es va quedar al bell mig. Van eixir quatre oficials i sis o set mariners del submarí. Va ser un esglai. 
Una nit que estaven a una mitja milla de l'Illa Grossa, pescant, va veure un platet volador (un OVNI). Diu que l'aparell va aparèixer, va mirar per allí i se'n va anar volant en direcció a Eivissa. Després d'allò diu que a la televisió va eixir un comandant de l'empresa Ibèria que va contar que havia vist o li havien seguit uns ovnis. Era eixa mateixa nit.

Bussejant va estar a punt d'ofegar-se. Encara sort que ell és molt tranquil, seré, i així va poder contar-la. Es va posar un cinturó amb ploms que no era el d'ell (es va equivocar). Anava amb equip "Nemrod", tot lligat, antic, d'aquell temps. Portava massa plom i no podia pujar perquè estava tot lligat. Per a eixir va haver d'anar caminant pel sòl del fons de la badia fins a la paret i després es va enfilar per ella fins que va eixir, tot ensangonat (dels arraps amb la paret), però va eixir. Eixa va ser l'última vegada que va bussejar amb botelles.

Ha salvat a gent a la mar moltes vegades (15 o 20 vegades!). Per exemple, a poc més de 50 milles de Columbretes van salvar unes quantes persones i les van portar fins a I'Ametlla. Una altra vegada es va trobar a un alemany que ja estava morat però seguia viu. El va fregar amb alcohol.

Ens va comentar que hi ha un petrolier afonat a $82 \mathrm{~m}$. de profunditat entre Columbretes $\mathrm{i}$ Benicarló. Cada 2 o 3 minuts solta taca de gasoil o de "alguna cosa així".

\section{RAMÓN ROIG MONTEAGUT, FARONER: entrevista al fill, Ramón Roig Sospedra, $05 / 11 / 2012$}

Ramón Roig, el fill, va nàixer el 23 d'abril de 1937, i son pare, l’any 1903 aproximadament. Tenia 1 germà major i té una germana.

Son pare va començar sobre el 1935 a treballar a Columbretes, abans de la guerra civil, però no sap les dates exactes. Va estar fins 1945 més o menys, quan Ramón tenia uns 8 anys. Després van anar a la suplència de Castelló. La família guarda bon record. Son pare va morir poc després de deixar Columbretes.

Hi va estar amb Bonachera.

Ell va passar dues etapes. Una fins als 8 anys, que se'ls va passar jugant, i una altra durant un estiu als 16 anys, que la va passar amb el seu germà pescant. Va gaudir molt d'eixe estiu. 
A continuació mostre per temàtiques la informació proporcionada.

El treball de faroner: Feien torns de nit. Anava amb un sistema de rellotge de corda, de contrapès. El pujaven amb un molinet fins la cúpula i al baixar el contrapès, la llanterna rodava.

El llum es feia pujant petroli amb una bomba de pressió. Duïen unes camisses com les llàmpares "Petromax" però més grans. S'havia de tindre molta cura. Sols tocar la camisa es trencava.

Hi havia torns de treball. Els faroners tapaven les finestres de la cúpula del far durant el dia per evitar que el sol el deteriorara.

Durant eixos anys sempre hi havia tres faroners amb les seues famílies. Dos mesos treballant $\mathrm{i}$ un mes de vacances. Després aquest sistema va canviar. L'últim any de son pare a les illes sols hi havia un faroner i un ajudant per torn i les famílies sols hi anaven a l'estiu (cap el 1945).

Roque Serrano anava cada 15 dies a fer revisions després de què van fer automàtic el sistema d’iluminació del far.

Diu Ramón que primer anava amb petroli, i quan es va automatitzar amb plaques solars va perdre potència.

Parla de la pèrdua d'importància dels fars actualment degut a les noves tecnologies.

Recorda molades de tords contra el far. Un dia van omplir tres caixons de tords morts a l'esplanada.

També recorda el forn de llenya.

Quan ell estava a l'illa hi havia dues famílies a les illes i una altra a terra per tornar-se. Hi havia molt bona relació entre les famílies.

Té molt bon record. Els seus pares deien que sense fills no hagueren tornat a la península.

Medi natural: la vegetació estava seca a l'estiu, però a la primavera era florida.

Hi havia figues paleres i una figuereta que algú va plantar. La primera vegada que va estar no estaven estes plantes.

La sosa (Suaeda vera), que hui en dia cobreix gran part de l'llla, es gastava per a llenya per al forn de pa. 
Bonachera va soltar conills que van arrasar l'illa, menjant-se tot els brots de les plantes.

La pluviometria influïa molt en l'aspecte de l'illa.

Ell ha viscut temporals on les ones han passat d'una banda a l'altra de l'Illa Grossa. Li deien el temporal de la Puríssima. Són temporals descomunals i impressionants. Explica com són els temporals. Eixos dies els pares no els deixaven eixir de casa. El pare no es fiava.

Construccions: diu que les casernes es van fer per una reparació de far. Eren tres casetes, cadascuna per un faroner, una capelleta i un forn. Es van utilitzar fins que es van acabar les obres del far. Després les van abandonar. Ramon les va trobar ja en ruïnes.

Ramon ens comenta que ell estava a l'Illa quan es va fer la pista des de les escales del port al far. "El formigó el va fer a mà un geperut que treballava més que una formigonera". I també hi estava quan van muntar una grua que estava a meitat de camí. Però quasi que no es gastava mai. Es feia tot a mà. La grua que estava més a prop de la mar se la va endur un temporal.

L'aljub del far era exclusiu per al far. El de les casernes era per a rentar. Front al far, a l'esplanada, hi havien dues casetes, una servia de parallamps.

Els temporals duraven de cinc a sis dies, i es quedaven aïllats del tot. Ramon comenta que ha vist temporals que duraven dies en els que els mariners s'havien de refugiar darrere de la Mare de Déu. Aleshores no hi havia norais, però modelaven la roca per fer amarraderos. Aguantaven el temporal amb el motor en marxa fins a 48 hores. No hi va viure cap naufragi.

L' imatge de la verge del Carme es va posar després d'estar Ramon a l'illa la primera vegada. La segona vegada que hi va anar ja estava. No va coincidir amb la col·locació.

Animals/alimentació/pesca: Recorda que cada 10 dies anava la barca d'abastiment ("Jaume Mases"), dels Gallen.

Quan els temporals no deixaven arribar el subministrament, s'ho tenien que enginyar. Quan això passava no es podia pescar, sobre tot en temporals de llevant. Inventaven coses per poder menjar. I podia passar que dies abans hagueren tingut que tirar llagostes perquè hi havia moltes.

Ell la va arribar a odiar, la llagosta. Els mallorquins venien a pescar amb nanses I quan se'ls trencaven les banyes, li les donaven als faroners, que es fartaven. No hi havia nevera, si sobraven les donaven a les gallines. Però podia ocórrer que un dia tires llagostes i que tres dies després no tingueren de menjar. 
Sa mare li deia al pare que no pescara meros massa grans per ser greixosos.

Tenien 2 cabres.

Cada faroner tenia el seu hortet, molt menut. Es regava amb aigua de l'aljub de les casernes, que també es gastava per rentar la roba. Hi havia un llavador allí mateix.

Tenien galliners, soltaven les gallines i algunes morien per alacrà. De vegades pensàvem que havia mort alguna gallina però la realitat és que estava lloca i tornava quan naixien els pollets.

El govern subministrava tot el que demanaven sense restriccions. En un moment d'escassesa general, allà en tenien de tot, coses fins i tot luxoses (sucre, arròs, llet condensada, farina...). Allí anava tot a preu de tassa, molt barat. Als faroners els subministraven café, un luxe asiàtic, que era dificilíssim de trobar, tot el que necessitaven per poder fer les guàrdies de nit. De vegades els mariners pujaven i sa mare feia café, un luxe, i els mariners els hi donaven peix, tant que de vegades en tenien que tirar. Son pare era molt obert.

Diu que la seva afició de cafeter li bé de l'Illa. De vegades es quedava de guàrdia amb son pare fins fer-se el café. Després, a dormir. Tenien quinqués.

Ramon ens parla de les tintoreres de la escala del Rossí, i que ell també es banyava al Rossí.

Els homes no tenien afició a jugar a cartes. Més a pescar amb un botet i nanses. Dins el port hi havia moltes cabres. Recorda anar amb barca i un mirafondos, amb un fil amb plom i un cotó embolicat i un tros de peix. Els pescaven. Els conservaven dins una bossa de xarxa amarrada al port. Poques vegades anaven a les altres illes.

La mare cosia, es reunien les dones, feien les feines de casa. Guisaven amb fogonets de petroli, cuina econòmica de llenya. La vida era molt tranquil.la.

Pescadors: La relació amb els mariners era molt bona. Es passaven la fosca allí... 15 o 20 dies. Els convidaven a dinar o sopar. Quan els pescadors tenien algun problema, acudien als faroners. "Teníem ferramentes i teníem aparells de mesures meteorològiques. Mon pare ajudava a reparar les barques perquè el seu avi era calafatador i ell sabia d'aquest ofici. Quan un mariner es feia mal, l'ajudàvem. Al far teníem una farmaciola prou bona per l'època. Els meus pares van tindre molt bona amistat amb alguns d'ells després de deixar l'Illa".

Recorda un dia de dinar amb pescadors de Pollença. Tenien amistat. Anaven a Columbretes amb unes barquetes menudes, súper carregats de tot el necessari per a fer la temporada. Ho 
deixaven a les casernes. Anaven amb canyes i tot per fer nanses. Quan acabaven de treballar, de vesprada, acudien a les casernes a fer més nanses.

Però hi va succeir un naufragi que els va afectar molt. Ho recorda perfectament. Els mallorquins a la península compraven coses per endur-se a Mallorca a la fi de la campanya (oli, arròs...). Es van anar amb una barqueta a remolc carregats de queviures. Els va pillar un temporal davant de Sóller. Van morir dos o tres: Francisco i un mariner, almenys. L’altre soci, Pedro, es va salvar. Després els mariners van viure a Vinaròs. Ramon ha tingut amistat amb els seus fills.

També anaven barques de pesca de fanal des de València i Vinaròs. Parla dels Boluda, que han segut sempre armadors $i$ tenien barques de fanal.

Parla de l'envià, com la barca correu. Diu que de vegades no cabien dins del port de la quantitat de barques que hi havia.

Un mallorquí que deien Vicenç anava a pescar letxes amb una xarxa moruna. Diu que les tintoreres entraven dins del port a menjar les letxes de la moruna.

Els submarinistes pescaven molt i van fer maleses.

Anècdotes: Recorda alguns altres xiquets, i recorda a Pilar (Pilarín). Que era de la seva edat. A ell li deia Ramoncin. Eren molt amics, anaven sempre junts. "Estàvem tot el dia junts. Els pares ens van fer unes engronsadores baix. A nadar, poc". El van ensenyar a nadar amb una corda al port. Les mares no sabien nadar. Les dones es posaven a remulla a unes bassetes al port.

No veu a Pilarín des de que se'n van anar de Columbretes. Sap d’ella però mai han coincidit.

Per la nit els pares els passaven la lliçó "i calbot va i calbot ve".

Els xiquets feien el que volien. Jugaven amb alacrans. A son pare li van picar set vegades, al seu germà tres a ell una. Sempre picaven per descuit, al vestir-se per exemple. A l'esplanada del far de nit podien matar fins 30 en una nit. Ell ha conegut el far sense el camí actual. Sempre anaven amb sabates perquè sempre xafaven alacrans segur. On més hi havia era a la zona de les casernes. Quan van fer les obres del far, a les casernes van viure dos mesos. Un dia va dormir amb un alacrà baix del coixí. Conta com posaven pots de la Lechera a les potes del llit. Però podien pujar per les mantes.

Parla de jocs i de sargantanes. Les agafaven amb una rajola, una tomata i un cordell. Les soltaven a lluitar amb els alacrans. Conclusió: estaven convençuts que les sargantanes 
ressucitaven perquè les deixaven d'un dia a l'altre i desapareixien, fins que van veure un falconet que se les menjava.

Quan van utilitzar les illes de camp de tir, ell ja no hi estava.

Les guerres: Son pare es va fer un aparell de ràdio galena i així es va assabentar de que havia esclatat la guerra civil. No va tardar molt en anar al far del Grau, potser com a ajudant. Els van re ubicar fins el final de la guerra.

Ens comenta que el pailebot que els duia a Columbretes el van afonar a la Guerra Civil. Durant la guerra es va abandonar la barca, deien que no funcionava. El Canarias va afonar la balandra. Els van detindre i després els van soltar.

Diuen que a l'illa es va refugiar un senyor a una cova i que va estar uns dies. El va veure un avió de reconeixement i el van detindre. Però no recorda més.

Ell recorda els avions al Grau, però no a Columbretes durant la Guerra Civil. Però de la II Guerra Mundial si recorda avions passant-ne. Prop de l'Illa hi havia un avió afonat de la Guerra Civil, prop de la punta del port. En la II Guerra Mundial, la barca "Paca", de Jaume Mases, va passar sobre una mina. Una vegada van aparèixer una gran quantitat de bidons d'un vaixell que es va afonar per una mina. També van aparèixer 3 mines. Una la van explotar a la Ferrera. Els mariners del Grau van colllaborar a buscar les mines. El Governador els va oferir més ració de pa, però els mariners van dir que pa no, que un bou embolat, que va pagar el governador.

Molts estius els passava a l'illa i a l'hivern de vegades anava a terra. Son pare va triar Columbretes perquè estava treballant a Tenerife però era de Peníscola i sa mare, de Sta. Magdalena. Van voler anar més a prop de sa casa. Això va ser abans de la guerra.

\section{ANTONI CERDÀ SIMONET "FOGASSA", FAMILIAR DE PESCADORS MALLORQUINS, 09/01/2013}

Aquesta entrevista la va gravar en vídeo la neta de "Fogassa" i ens la va fer arribar. Les preguntes li les va fer ella mateix en base a preguntes que li vam passar.

"Fogassa" té 86 anys. Els seus germans majors, tenien un parell d'anys més que ell, pescaven a Columbretes feia uns 70 anys, cap als anys 40 , quan tindrien al voltant de 18 anys. 
Volem que ens parle del naufragi de les barques mallorquines que ens han contat abans Pilar Martínez i Ramon Roig. "Fogassa" ens diu que els germans li van contar que les dos barques naufragades, que eren de L'Alcúdia, es van perdre a causa d'un fort temporal. Una d'elles va naufragar per Cala Figuera. La notícia va arribar ràpidament a tots els pescadors.

Transcripció de l'entrevista realitzada per la seva neta:

- $\quad$ Com et dius?

- $\quad$ Toni Cerdà Simonet.

- $\quad$ Eres pescador de tota la vida?

- $\quad$ Nooo. Vaig pescar amb els meus germans fins que vaig fer un servici (segurament es refereix al servei militar). No ens deixaven anar muntats en cap barca d'arrossegament de Palma. Havia de fer un "servici" allà. Quan vaig ser a fer el servici vaig passar a la base. Que anava amb la "Pollença" (nom d'un vaixell).

- $\quad$ De les Illes Columbretes, tu mai vas ser allí?

- $\quad$ No, mai, anaven els meus germans.

- $\quad$ Què explicaven els teus germans sobre les Columbretes?

- $\quad$ Eren unes illes en què si feia mal temps havien d'estar a un costat i si feia bon temps anaven a l'altre. Pescaven a la "escallà".

- $\quad$ I quins peixos pescaven?

- $\quad$ Llagostes.

- Com les pescaven?

- $\quad$ Amb nanses.

- $\quad$ Recordes que et parlaren sobre algun naufragi per les Columbretes?

- Ells van arribar bé. Però sí que es van perdre dos barques que pescaven a Columbretes, que eren de l'Alcúdia. Jo ja vivia "aquí" quan es van perdre.

- Quant temps estaven a Columbretes quan anaven allí a pescar?

- 3 mesos. 
- Quins mesos?

- D'abril a juny. Calia anar allí quan feia bon temps, no es podia estar allí quan hi havia temporals.

- Què feien amb les llagostes que pescaven?

- Les portaven a Vinaròs, que està prop de Columbretes. Es veuen les illes des d'allí.

- $\quad$ Quin tipus de vida portaven els teus germans quan estaven a Columbretes?

- $\quad$ Només anaven a la costa quan havien de vendre les llagostes. Eren 4 per a portar-les $i$ es quedaven dos a terra.

- $\quad$ Com es deien els teus germans que pescaven a Columbretes?

- $\quad$ Tomeu i Biel. Anaven amb dos mariners més però no recorde qui eren.

- D'on eren els pescadors que anaven a les Columbretes?

- $\quad$ De L'Alcúdia i d'El Moll (Pollença).

- Hi havia dofins, balenes,...?

- $\quad$ Només sé que ells pescaven llagostes i havien de calar quan anaven a per la llagosta allà.... Per sant Joan és quan estaven allí, que era quan el preu de la llagosta era alt a Barcelona i per aquella zona.

*Un dels germans era Bartomeu Cerdà Simonet, també amb el malnom de "Fogassa", nascut a 1916. Bartomeu ix nomenat al Ilibre de Francesc Canuto Bauçà, "Toponímia i talasonímia mallorquina als Columbrets", de la Universitat de les Illes Balears, p.15. 1994, com a pescador del Port de Pollença. 
13. JOSÉ HIERRO DELGADO, FARONER: entrevista a Luisa Gutiérrez Hierro, neboda de María Hierro Viera, filla del faroner, realitzada i facilitada pel besnebot de Maria, Gerardo Morales Gutiérrez $\mathbf{i}$ alguns extractes del seu llibre "Orígenes del apellido Hierro en Canarias" (no publicat).

Gerardo Morales Gutiérrez, natural i veí de Gran Canària i que per la rama materna havia tingut al menys sis familiars faroners, feia més de 30 anys que està investigant i elaborant l'obra "Orígenes del apellido Hierro en Canarias", que no havia publicat. D'aquesta obra, facilitada per l'autor, són els següents extractes:

"En el libro de Miguel Ángel Sánchez Terry, titulado "Los faros españoles: Historias y evolución" editado en 1991 por el Ministerio de Obras Públicas y Transportes, Madrid, se relata lo siguiente: "... los hechos sucedieron en las islas Columbretes a raíz de un temporal que hizo naufragar un vapor contra ellas. Ayudados por el torrero y su familia, la tripulación ganó tierra firme en espera de la llegada de los auxilios y sin posibilidad de aviso. Los días pasan y el temporal no amaina, haciendo imposible la arribada de ningún buque. Agotadas las provisiones y perdida la esperanza, piensan en utilizar la hija del torrero como alimento. Al fin, cuando la situación es desesperada, el tiempo amaina y vienen a recogerlos..."

"Mi tía abuela, doña María Hierro Viera, esposa, madre, hija y nieta de torreros, me contó que entre la mesa y el mantel escondían harina, y por la noche la amasaban con agua y don José y su esposa doña Agustina se la daban, por la noche, a sus tres hijos. El patrón del buque naufragado, les decía: ese niño está muy gordito y colorado, no tiene cara de hambre, tengan cuidado, porque gente de la tripulación pretende comérselo. Doña María, mi tía-abuela, creía recordar que se referían al hijo Juan, el menor de los tres."

“También, mi tía, doña Luisa Gutiérrez Hierro, me narró lo siguiente:

"... estaban en un faro por el Mediterráneo, era una isla pequeñita, dicen que no había sino el faro, unos corrales y las casetas, y el barco venía a servir el faro, como siempre. Dicen que lo servían por un mes, claro, si en ese mes, se moría alguno, allí lo encontrarían muerto, claro...

Bueno, pero con la mala suerte, que un barco que venía perdiéndose se acercó al faro y cerquita del faro, el barco se fue a pique... icon 18 hombres! ... , y tuvieron tan eso, que saltaron de la lancha y le dieron pá fuera, porque si no,... cogerían pescado... o alguna cosa, pero no podían hacer nada; los primeros días muy bien, había comida, pero ya se fueron haciendo muchos días, muchos días, que la comida se iba siendo poca, y...,ya abuelo tuvo que decirles que buscaran ...algo que freir; claro, el faro trabajaba con aceite, no como hoy, y... 
cogían ratones para freírlos, cogían esas aguas vivas que hay en los charcos, que son así, como redondas; les daban harina, porque harina si tenían, un poco, y la mojaban, y... con eso iban escapando... i Pero ya los últimos días,... ya ni se levantaban! Abuela... guardaba en los paños del faro, que yo me acuerdo de verlos, harina, y a la media noche le hacía algo a los hijos, polianas,... yo no sé cómo le llamaban;... y estaban algo más animosos.

Los marineros les decían, ustedes están comiendo, porque están más animosos que nosotros. $Y$ a nuestra bisabuela le dijo (el patrón): mire, usted tenga cuidado con ese niño, (que era abuelo), tenía seis años, dice, iporque cualquier día se lo comemos! iMisté, los tenían trancaos que no los dejaba ni salir!.... Y así fue, que estaban ya casi muertos cuando apareció el barco; el barco tenía costumbre que izaba bandera y el faro le contestaba. Y.. .i contestó el faro, pero con un nudo en la punta de la bandera!...era una sábana blanca ... Eso parece que es una señal mala... Y el patrón cuando venía llegando, que saltaban en la lancha, dicen que les dijo, iquiten esa bandera de horror!, porque como los ví a todos alli, ino sabía lo que pasaba!... Dice abuelo, isúbase usted pa tierra, pa que vea!

iiCasi muertos, estiraos allí, uno paquí y otro palli!!

Los cogieron y los llevaron pa ..., pa la tierra de ellos. Ya las mujeres tenían luto, porque apareció la lancha... pues en ellos ya no pensaban..."

Del DIARIO MERCANTIL de València (publicació de 27/04/1865) en relació a aquest naufragi prop de Columbretes, font: Hemeroteca de la Biblioteca Històrica de la UNIVERSITAT DE VALENCIA), transcrit per Gerardo Morales Gutiérrez:

" Naufragio. Anteayer tarde fuimos testigos de una escena en extremo conmovedora y que sembró la alegría en la vecina población marítima, a cuyo seno volvían unos cuantos marineros, que ya eran tenidos por muertos.

Hace 45 días salió del Puerto del Grao el laud Felipa, con cargo para Tarragona y Villanova. Descargó en estos puertos, y de regreso para Valencia le sorprendió un temporal a la altura del cabo de Oropesa, y habiéndosele roto al buque una tabla, hizo agua y se fue a pique, cerca de las islas Columbretes.

Los seis marineros, entre ellos un niño, que lo tripulaban, se salvaron en el bote, y por la noche se encontraron junto a aquéllas islas. Desembarcaron en la mayor de ellas, que como las demás, está inhabitada e inculta, no encontrando más provisiones que las pocas que tenía el 
torrero del faro en ella situado.

Algunos días pudieron subsistir con estas provisiones, pero al cabo se concluyeron, y los pobres marineros se encontraron en la situación más desesperada, teniendo que apelar a la caza de ratones y a comer yerbas silvestres, para no morir de hambre.

Veintinueve días hacía que estaban en aquella isla, y ya se hallaban extenuados algunos de ellos, cuando afortunadamente acertó el lunes a pasar por aquellas aguas el vapor Amparo, que al mando del capitán don José Rivas, que de nuestro puerto se dirigía al de Ibiza. Los náufragos vieron descender del cielo la Providencia con la llegada del Amparo, donde generosamente fueron acogidos, volviendo atrás el vapor para traerlos a sus hogares.

Ayer tarde llegaron al Grao, y la alegría que produjo su vuelta a sus familias, amigos y a toda la población, puede apreciarse considerando que la destrucción del buque, cuyos restos habían sido vistos, había hecho creer en la muerte de los tripulantes, hasta el punto de que sus parientes vestían ya de luto, y con los trajes de luto fueron a recibir a aquellos infelices náufragos que parecían volver de otro mundo."

14. FRANCESC GRIMALT ALAU, FARONER: entrevista a la neta, Margarita Grimalt (realitzada l'any 1984 per Marc Ordeix), a la besneta, Mercé Rigó, i al net, Francesc Grimalt, $28 / 08 / 2014$

MARGARITA GRIMALT: Marc ens fa arribar un CD amb l'entrevista que li va fer a Margarita l'any 1984, a Canàries, per col·laborar amb la investigació.

Margarita parla del faroner com "el abuelito".

Van estar dues vegades a l'Illa, la primera va ser quan van coincidir amb l'Arxiduc però no conten res d'açò. Margarita era molt menuda i té més records de la segona estada que va ferhi, ja amb 14 o 15 anys.

Parlen de la gran quantitat de llagostes que hi havia, tantes que es podien arreplegar directament amb un salabre. A més van tindre un viver de cigales, però conte que "degué obrir-lo algú i van acabar morint totes". 
I d'allí, son pare va ser destinat a Botafoc.

Al Ilarg de tot l'àudio conte el recorregut del faroner Grimalt pels fars en què van viure. Hi ha algunes anècdotes gracioses però no van succeir a Columbretes.

Anys més tard van tornar a Columbretes.

Després d'anar a Columbretes per primera vegada, el seu avi i la família van estar als fars de Botafoc, Capdepera, Port Colom (on va nàixer la mare de Margarita), Cap de sant Antoni, Peníscola, Orpesa, Cala Figuera, Montjuic i Benicarló.

Després el van destinar a Isla de la Rúa però per no haver d'anar fins a La Coruña, va triar Columbretes de nou, donat que hi havia una vacant. Francesc per tractar d'evitar-ho va intentar anar a treballar a un far de descans donat que tenia 16 anys de servici i ja li podia pertocar. Però Orpesa, que era al que podia optar, finalment li'l van concedir a un altre company i, per tant, va haver d'anar-hi a Columbretes, on van estar 27 mesos.

Margarita recorda la sensació en arribar a Columbretes, "iqué manera de llorar! Y ver cómo se alejan las barcas y tú te quedas en esas peñas. Te podías morir, no hace nada de gracia".

Deia Margarita: " $Y$ cuando hace viento!, allí encima de aquel faro!, allí todo temblaba, todas las ventanas temblaban, parecía que ibas en tren. Y las ventanas tenían que tenerlas bien cerradas porque hay escorpiones ("alacrans"), para que no entraran tapaban las ventanas. Pero aún así una noche entraron 4 escorpiones dentro de la casa, y sacábamos el farol. Porque allí hay un farol que siempre lo dejabas para poder subir a la torre del faro, para vigilar que la luz siguiera encendida. Iba con petróleo entonces, ponían una mecha dentro de otra, una mecha dentro de la otra,... Y el aparato era molt gordo es de primer orden. Hay de primera, segunda y tercera categoría. El far era de primera categoría, con gran alcance para los vaixells. Hay mucha actividad dentro de un faro".

Els relleus de treball al servici del far per la nit eren des que s'encenia fins a les $22 \mathrm{~h}$, de les $22 \mathrm{a}$ les $2 \mathrm{~h}$ del matí i de les $2 \mathrm{~h}$, fins que es fera de dia. Qui havia apagat el llum, al dia següent descansava i no feia res fins el següent dia, que era qui encenia el far.

"Y una vez mi padre recibió el servicio a las 2 de la mañana y estaba escribiendo porque al día siguiente venía un vaixell y estaba escribiendo a los niños, uno estaba de maestro en la provincia de Lleida y el otro, Bertomeu (él no fue a Columbretes), en el colegio de Benicarló. Estaba con tu madre (de Marc, l'entrevistador), que tenía 4 años cuando fuimos, y yo, 14. $Y$ empezó la guerra en el 1914 allá. Y al final estuvimos 27 meses sin salir". 
"Y alli, de nombre "Papa Lluna", venían barcos de contrabandistas. Cuando no podían faenar por la luna, venían allá. Allá nunca venía el barco del "mandatario" por eso venían..."

"Y nosotros éramos 3 chicas y 3 chicos: José, Pilar, Paca, Paco, Manolo, Alfredo, Lolita. Al mayor le llamaban Federico, Masso, Luis... había tres o cuatro. Y por la tarde venían a visitarles. Había dos fareros más jóvenes que vivían abajo, en las casernas. Allí es donde guardaban el petróleo y estaba la "Mare de Deu del Desemparats". Y en el faro sólo había una planta y estaban allí los dos fareros más viejos".

"Y un día Masso, no recuerdo su nombre, puede ser Vicente, (Toni le llamaba "la tia Pudenta" le llamaba así porque siempre estaba desagradable). Venían los niños a coger la merienda y Luis siempre decía "tinc faaam, tinc faaam" y el pequeño siempre decía "tin gana, tinc gana!". Pero allí tenías la comida contada, no había mucha. Y el abuelito les daba un tazón de leche, porque nosotros teníamos una cabra. No había ningún animal más, sólo nuestra cabra".

"Y el tío Juan encargó un corderito "matador" para Pascua. Y todos lo queríamos más que a la vida a aquel corderito. Jugábamos a ser pastoras y le llamábamos y contestaba "beeeeh" y enseguida venía. Aquella isla tenía forma de herradura, y fuimos a pasear hasta la otra punta. Y el abuelito le daba maíz por las tardes e íbamos allá y la ordeñábamos. Venía al faro y entraba e iba por el pasillo con ella, llamaban a la puerta donde estaba el abuelito y hacían "beeeeh" y el abuelito le ponía el maíz delante, mientras tanto la ordeñaba y luego se volvía. A él le gustaba pasear con nosotros y si no, estaba solitario por el faro. $Y$ a veces nos íbamos todos a pasear con la cabra y el corderito".

"Pero el corderito se hizo grande y pensaron en matarlo, la tía María y tu madre (de Marc, l'entrevistador). Pero como mi hermana y yo llorábamos no lo mataron. Pero cuando se tuvieron que ir de la isla nadie tenía dinero para que dejáramos al cordero y a la cabra, y no vino nadie que tuviera. A un farero joven que les relevó, le dejaron las cuatro o cinco gallinas que tenían y no se las pudo pagar porque no tenía dinero. Les envió el dinero después, cuando cobró".

"Los fareros no ganaban casi nada de dinero. Nosotros aún teníamos un poquito de dinero gracias a que teníamos algunas tierras de huerta (almendras y algarrobas cada año) que nos daban algo pero los otros no tenían nada más que su paga. No sé cómo podían vivir".

"En Columbretes a veces pasábamos hambre. Para comer a veces encargábamos bacalao por miedo a pasar hambre; porque no te podías acercar al mar siempre, así al menos teníamos bacalao. Si teníamos pescado comíamos pescado pero no teníamos siempre. En invierno no te 
podías acercar al mar. Hijita mía, teníamos unas cuantas gallinas, comíamos un par de huevos, la leche de la cabra. Y el pan lo hacíamos allá. Teníamos horno y nos llevaban una saca de harina y hacíamos pan mientras hubiera harina".

"Había un farero que tenía muchos hijos y sólo tenía su paga; y no le enviaban lo que pedía. Le enviaban lo que sabían que cobraba".

Margarita explica que tenien una caixa a terra (al lloc on passaven els encàrrecs, com els llibres),i ells tenien una clau i els de terra una altra. Aleshores feien la comanda i els la posaven dins la caixa tancada amb clau i els l'enviaven a Columbretes.

"En Columbretes había una casa y el vaixell venía de Valencia. Era un remolcador que se Ilamaba "Salvora" y venía de Valencia (era "Sal" pero le Ilamaban "Salvora"). Cada 15 días venía el barco. Al patrón le llamaban "Alampó". Tenía una mujer que siempre estaba jugando a las cartas y el hijo que también jugaba a cartas toda la tarde; y la hija hacía de señorita y el hijo paseaba por ahí. Alli solo trabajaba el padre, que estaba en un astillero".

"A Columbretes una vez nos trajeron el cajón con la carne podrida, azul, negra, y la tiraron a la mar, porque ya hacía días que estaba dentro del cajón porque al ayudante no le vino bien partir, o no sé si es que hizo mal tiempo. La cuestión es que aquella carne la tiraron al mar y no tuvimos nada para comer durante toda esa quincena".

"Y sí que había aves de paso, que había a veces para cazar, una codorniz, una tórtola, una paloma marina, estorninos, animales de paso. Había temporadas que estaba lleno pero había veces que no había nada, ni uno. Tan sólo había escorpiones y lagartijas. Lagartijas sí que había muchas. A veces no podías pasar hacia allá. Y cuando había temporal los golpes de mar pasaban por encima de la isla, por la zona centro del puerto, que allí es más bajita la isla, por alli pasaban y salpicaban fuerte".

"Y eso es lo que teníamos. Y el "mantenim", antes de acabar el mes, antes de acabar la quincena ya no tenía azúcar, ni tenía café, sopa, arroz. Y venía a pedirnos y le dábamos lo que teníamos porque allí o comíamos todos o no comía nadie. Allá tenías que tener para todos. Si tú tenías dos y el otro no tenía nada, pues le dabas".

"Una vez estuvo 23 días sin venir el vaixell porque hacía mal tiempo".

"Una vez el abuelito hizo unos versos, esta vez que estuvo el barco 23 días sin venir, mientras estaba de servicio allá arriba en la torre. Porque en la torre, arriba del todo, debajo del aparato, tenían como una estancia pequeñita, un saloncito, con una mesita donde poder 
escribir cuando estaba el farero de servicio, y el abuelito le escribió los versos a la madre. No sé si aún deben de estar o no, los versos a la Mare de Dèu" (Annex 3.5).

I de Columbretes se'n van anar a Tarragona.

MERCÉ RIGÓ: Besneta del faroner.

Sa mare va estar a Columbretes amb 4 anys i no recordava res però sa tia, Margarita Grimalt, la segona vegada que va estar-hi era l'any 1914, amb 14 i 15 anys. Per tant ella és la que li va contar les històries que ens transmet Mercé.

Li deia sa tia que a Francesc li deien "roques blanques" de malnom.

Els faroners anaven amb tota la família als fars on eren destinats. Ells van estar a 20 fars. I quan van entrar a Columbretes hi van estar 23 mesos sense eixir d'allí. Hi havien 4 faroners, 21 persones. Dos dels faroners estaven a les casernes, on hi havia una capella.

Era una illa d'1'5Km tan sols. Era terrible quan se n'anaven els vaixells $i$ es quedaven sols, ploraven moltíssim.

L'illa representava la carència però també el poder ajudar-se els uns als altres i els conflictes, per exemple, explicava sa tia Margarita que tota la relació que tenien era amb contrabandistes i mariners. "Allí feien concerts i ella va aprendre a tocar la guitarra i cantaven a diverses veus. Cantava molt bé".

"Es feien disfresses amb escates de peix i les portaven al cementeri. Al cementeri van trobar un crani i esquelet, separats".

"Tenien gallines i una cabra que es deia Paloma i picava a la porta amb les banyes".

Cada 15 dies els portaven el menjar, dins una caixa de metall amb clau. Però en portaven a cada faroner segons el que cobrava, no segons els fills que tenia. I un en tenia molts de fills i no li arribava per a tota la quinzena i els xiquets li demanaven i la dona de Francesc els donava de menjar. Repartien tot com podien. "Un faroner tenia sis fills, dos d'ells, cegos, i a la xiqueta cega, quan fregava (el sòl) li picaven els escorpins. Tenien allí nitrat de plata". Parla de quan estos xiquets es van fer majors.

Li va parlar de l'arxiduc Lluïs Salvador i l'arribada a l'illa amb el vaixell NIXE 
Li contava Margarita a Mercé algunes anècdotes.

Quan hi havia temporals, tot tremolava.

Quan no tenien menjar agafaven els pardals que queien. Pescaven amb trampes, agafaven saques de llagostes.

El seu avi va anar a pescar una vegada i a la tornada li va caure tot a la mar.

Francesc es va fer faroner per a eixir de Mallorca, perquè era aventurer, i era una manera de no ser llaurador. "Havien de fer torns al far a la nit i aprofitava per a escriure, això li va servir per a culturitzar-se. Tot l'aspecte cultural i artístic és gràcies al far. A nosaltres ens ha servit com a mite, i els mites són molt importants per a la vida".

Mercé ens transmet el que va sentir en la seua primera visita a Columbretes l'any 1990. "És com un mite per tot el que representa: bellesa natural i de tragèdia familiar". "Jo crec que n’hi ha gent que no saben ni què són les Columbretes".

Diu que la seua tia Margarita va viure fins als 90 anys d'edat però era una persona que sempre estava malalta. Però recordava les illes amb nostàlgia, per exemple, contava que a Columbretes és on va tindre els seus primers nuvis, fills de faroners. Però Mercé creu que pot ser li va repercutir en els problemes psicològics que va tindre la resta de la seua vida.

FRANCESC GRIMALT: Net del faroner.

Columbretes va ser el primer destí del seu avi. Va anar-hi amb dos fills, oncles de Francesc. La segona vegada que va anar-hi van estar 26 mesos. Era un far de primera categoria i necessitava quatre faroners.

Les històries les coneix per son pare i Margarita, la tia.

L'illa tenia forma de ferradura, d'un kilòmetre de llargària. Tots havien de trobar-se per allí per la qual cosa no tenien més remei que dur-se bé.

El vaixell de subministrament de menjar anava cada 15 dies des de Castelló, el vaixell de petroli per al far anava des de València i menys vegades que l'altre.

Francesc composava versos (Annex 3.5). A Francesc net també, pel seu avi, li havien eixit ganes de fer poesia. "Era una avi saleroso". 
L'arxiduc Lluís Salvador va estar a l'illa la primera vegada que l'avi de Francesc va estar allí. Era un gran dibuixant.

Una vegada van anar Francesc i un company faroner mallorquí, Massanet, a pescar a rem i amb el vent, de poc no poden tornar. Massanet deia "mala fi faça el bot de Massanet" i Francesc li va dir que deixara de dir això.

Anys després, les vegades que son pare (el fill de Francesc) volia estar a soles deia que això era per haver viscut a Columbretes, "que li eixia".

Quan va anar-hi la primera vegada amb el seu vaixell Francesc, el net, va alçar una pedra i hi havia dos d'escorpins. Va anar amb balandre des de Tarragona, les va veure a l'horitzó i tot se li va despertar, li va parèixer meravellós, com recuperar les converses amb son pare. Li pareixen molt boniques les Columbretes, des de fora i des de dins. "No es pot explicar com vaig quedar d'impressionat. I demà mateix hi tornaria"

Gràcies a aquest avi que va voler estudiar, hui ell pot ser un metge. I el seu avi va estudiar perquè el va animar un altre faroner. Va demanar permís a son pare i li va dir que estudiara però treballara al camp també.

"A la nostra família parlar de Columbretes... ens entusiasma".

\section{XISCO PÉREZ, PESCADOR DE L'ALCÚDIA, MALLORCA: entrevista realitzada el 28/08/2014} a la Confraria de Pescadors de L’Alcúdia.

Xisco ens explica que les barques anaven de Mallorca a Columbretes, com anaven, i que venien la llagosta a Vinaròs. I que una dona va morir.

Pescaven a Columbretes i feien intercanvi amb els faroners, d'aigua, per exemple.

Les barques tornaven a l'agost de Columbretes, pels temporals. Allí guanyaven el doble que faenant a Pollença, per això hi anaven.

Sempre va haver-hi molt bona relació amb els faroners. La meitat dels pescadors de Pollença anaven. Pujaven a sopar, però sempre quedava un de guàrdia a la barca. Comenta que hui en dia els pescadors sense televisor ni mòbil no hi anirien però llavors amb res anaven allí mesos $\mathrm{i}$ 
ho passaven molt bé. I els pescadors que anaven quasi tots els dies des d'allà a Vinaròs, els portaven coses als faroners.

Quan va estar a Columbretes l'any 1975 van haver de passar una odissea les barques, carregades, per a anar-hi i tornar d'allí, amb tot el que portaven. Pareixia un miracle que no passara res, excepte eixa anècdota que seguidament ens conta.

Va contar l'anècdota del naufragi de la barca dels mallorquins, de la qual tenim referències per Pilar Martínez, Ramon Roig i Antoni Cerdà. La barca va naufragar perquè portava oli de castelló (de contraban), si hagueren entrat a Soller no haguera passat res. Però el patró va decidir seguir, una actitud normal, inclús ara. Van perdre un home i, donant voltes per a trobar-lo, un colp de mar va ficar aigua al motor. A vela van aconseguir entrar a Cala Figuera i es va salvar un.

L'avi de Xisco era fillol de l'arxiduc Lluís Salvador perquè el seu besavi era carrabiner i es veu que tenien relació per les finques.

16. FRANCISCO DEL RÍO DE LA BARRERA, FARONER: entrevista als besnets, Alicia Fernández del Río i Gustavo Chao, 03/11/2014

ALICIA FERNANDEZ-DEL Río: Cosina de Gustavo i neta de Julia, filla del faroner Francisco del Río.

Consideren les Columbretes com a lloc mític. Al nord d'Espanya no es coneixen gens.

A la seua família sempre s'ha parlat d'una anècdota que va succeir al seu besavi i la família quan hi eren al far de Columbretes. La història tenia a veure amb pirates.

Els van narrar que un vaixell de pirates va naufragar i els faroners els van rescatar però es van ajuntar molta gent al far i van arribar dies de mala mar en els quals no podien anar a buscar-los i els subministres es van anar acabant. I es veu que algun d'ells va dir que podrien menjar-se a la filla de Francesc. Finalment no va passar res, van poder anar a rescatar-los des de terra. Però eixa xiqueta va morir i està soterrada a un cementeri que hi havia a unes illes molt menudes anomenades Columbretes. 
Annexos

"La profesión de farero tiene algo de aventura que te llama mucho la atención cuando eres niña. Vemos el hecho como algo heroico. ¿Dónde estaba este hombre para que le pasara esto? Y pensar que teníamos un familiar enterrado en una isla, con lápida o sin..."

GUSTAVO FERNANDEZ: Cosí d’Alicia i net de Carmen, filla del faroner Francisco del Río.

Ens relata Gustavo que un dia van veure un suplement del periòdic ABC, de l'any 1954, on es parlava d'una xiqueta soterrada a Columbretes, lloc on els faroners vivien completament aïllats. Llavors se'n van assabentar i els familiars els van contar la història.

Comenta, junt amb Alícia, la història del temporal i el problema amb els pirates.

Li va fer molta il·lusió saber que la història era real.

"La gente mayor nos emocionamos, cuando menos te lo esperas te quedas roto porque te emocionas (...) Yo temo que me emocione cuando llegue a las Columbretes. Tendré que quedarme callado. Siendo no tener ya edad para bucear porque tengo entendido que aquello es una preciosidad".

Tots els de la seua família són mariners, els agrada la mar, els vaixells, veure els noms dels vaixells dels pescadors. I això els passa a tots els de la seua família, quan l'única relació que té la seua família amb la mar és eixa (referint-se al besavi i la seua història), i que "muchos pasaron el mar, pero esa es otra historia". 


\section{ANNEX 3.4.}

Informació obtinguda als arxius del Port de Castelló, ordenada cronològicament, sobre els següents faroners de Columbretes ( $s$ 'indica l'any en què va començar a treballar a Columbretes):

1884. Hernández Navarro, José

1889. Androver Antich, Bartolomé

1890. Fernández i Martín, Eustaquio

1891. Garau Melis, Clemente

1891. Martínez Vázquez, Juan

1894. Mayans Tur, Francisco

1895. Campos i Muñoz, José

1896. Mayans Manresa, Francisco

1896. Verger Reynés, Francisco

1897. Adover i Manresa, Miguel

1898. Prats i Torres, Antonio

1898. Hernández Martínez, Josep
1899. Esbert Campos, Cipriano

1902. Chorat Sorá, Eduardo

1905. Torres Pujol, Bartolomé

1905. Maragón Martínez, Juan

1909. Massanet Amengual, Antonio

1909. Benager Roselló, Juan

1910. Vallés Ceballos, Joaquín

1911. Acuña Campoy, Antonio

1912. Galvez Mena, Pedro

1924. Fernández Sempere, Ángel

1945. Salvatierra Llanos, José

1946. Sánchez Romero, Manuel 


\section{Hernández Navarro, José}

Tècnic mecànic de senyals marítimes. Torrer de fars de tercera.

NOMENAMENT: 17 de novembre de 1884.

- Arriba a Columbretes des de "Punta de Llobregat"

- Substitueix al Sr. Peris

- L'enginyer encarregat del far, li fa l'entrega de l'habitació + mobles + efectes

- 9/03/1886: se li nomena torrer suplent de la província de València

- 27/05/1886: abandona Columbretes

- 16/03/1887: el traslladen al Grau para substituir per infermetat a Benito Rodríguez (per fístula a la cara i perquè va a operar-se)

- Sou: 1250 pesetes

- 28/08-28/09 de 1887: al Cabanyal substituint a Pedro Segura

- 12/08/1887: augment de sou, 1290 pesetes

- 11/02/1888 - 19/3/1888: Arriba altra vegada a Columbretes a substituir a Miguel Torrandell

- 27/07/1889: Ascens a torrer de segona. El traslladen al Far de Roses (Girona). Sou 1500 pesetes

- 23/08/1889: Cessament com a torrer suplent

CESSAMENT: 19 de març de 1888.

\section{Androver Antich, Bartolomé}

Tècnic de senyals marítimes. Torrer de fars de tercera.

NOMENAMENT: 4 d'octubre de 1889.

- El Director General Interí d'Obres Públiques és Manuel Pardo

- L’Enginyer en Cap de primera classe es Narciso Aparicio i Solís (València)

- El torrer té un sou de 1250 pesetes a l'any

CESSAMENT: 9 de novembre de 1889. És traslladat a Cabrera.

Va estar a Columbretes 35 dies. 


\section{Fernández i Martín, Eustaquio}

Tècnic mecànic de senyals marítimes. Torrer de fars de segona.

NOMENAMENT: 13 de març de 1890.

- El torrer Manuel Lorenzo González sol-licita relleu, i aquest es desplaça a Vinaròs

- Eustaquio procedix de Vinaròs

- Es considera que el far de Vinaròs pertany a Castelló i el de Columbretes a València

- Sou: 112,40 pesetes de nòmina

- Nascut a Xerès

CESSAMENT: 7 de gener de 1891.

- 1898 : ja es torrer de primera amb sou de 2000 pesetes

- 9/4/1899: està a Tabarca i demana poder servir en "Fars de descans", al-legant que ha estat a Columbretes

\section{Garau Melis, Clemente}

Tècnic de senyals marítimes.

Hi ha informació de l'11/12/1891 al 25/12/1891.

NOMENAMENT: 30/11/1891 - 11/12/1891:

- 17/11/1891: nomenat torrer de la classe de tercers

- 04/12/1891: el destinen a Columbretes amb data 30/11/1891. El 04/12 és la data del registre d'entrada (Direcció d’Obres Públiques, València), signa: Enginyer en Cap de la província de València.

- 04/12/1891: registre d'eixida del NOMENAMENT

- Sou anual: 1.950 pesetes

- 11/12/1891:

- Pressa de possessió del seu destí

- Signa declaració de no tindre fills en edat d'anar a Primària (art.2,3 i 5, Llei 9/09/1857)

- Firma de Ricardo Bruquetas i Casal (Enginyer en Cap de segona classe del Cos Nacional d'Enginyers de Camins, Canals i Ports i cap d'aquesta província): certifica que el 30/11/1891 ha pres possessió del seu destí a Columbretes 
- Declaració de Clemente de que pot prendre el lloc de destí

- 24/02/1890: en document amb aquesta data posa:

- Clemente és "cabo" primer de la Companyia del 8 é Batalló d'artilleria de Plana

○ Fill de Miguel i Magdalena

- Natural de Capdepera (Mallorca)

- Ofici: llaurador

- Estat: solter

VACANCES/PERMISOS: 06/04/1892 - 18/06/1892:

- 07/04/1892: data de registre d'entrada (València). Indica que el 27/03/1892 mor el fill de Clemente a Columbretes (NOTA: a la làpida posa que va morir el 26/03/1892, Figura 4.9 i

\section{Annex 4.1)}

Segons apareix a un ofici d'Obres Públiques, es comenta que després de la defunció del menut Miguel, aprofitant un vaixell que estava a la badia es tracta d'enviar un ofici per a que li donen permís al torrer per a acompanyar a la seua dona fins València per a embarcar-la cap a Mallorca. Front a la impossibilitat, el torrer de primera dona permís a Garau per a què se'n vaja. Se suposa que la defunció està enregistrada a València. L'Enginyer en Cap justifica la marxa i l'aprova dient que el servei no queda minvat i li pareix bé la decisió del torrer de primera.

1/05/1892: Sol-licita i se li concedix un permís d'un mes per qüestions de salut. En un informe de l'Enginyer Ricardo Braguetas i Casal, indica que efectivament les illes pateixen un gran aïllament i que tan sols estan habitades per torrers i les seues famílies. Segons S'hi indica, el xiquet va morir als 25 mesos.

1/06/1892: S'aprova el seu trasllat a Formentera (es signa el 15 de juny).

*Segons la publicació de Francesc Canuto Bauçà, 1994, "Toponímia i talasonímia mallorquina als Columbrets, el fill de Climent mor de "pigota", és a dir, de xarampió.

\section{Martínez Vázquez, Juan}

Tècnic mecànic de senyals marítimes.

NOMENAMENT: Donat d'alta al servei actiu el 22/08/1891. 
- 31/10/1891: ¿ं? Columbretes

- 01/10/1891: se li concedix un mes de pròrroga per a la pressa de possessió

- 16/10/1891: “Orden de la Direcció General d’Obres Públiques” (Manuel Mariategui i Vinyals, Comte de San Bernardo): NOMENAMENT de Juan com a Torrer de fars de classe de tercers amb el sou de 1250 pesetes, amb destí a Columbretes. Mateixa data: pressa de possessió

- És solter i és el seu primer destí. Al ser el primer destí se li remet un llibre (model no1) diari de servei del torrer (el rep el 20/10/1891)

NOTES: Fill de Juan i María, de Màlaga. Va obtindre el no 256 (05/06/1880) al reemplaço de 1880. El mosso va ser exceptuat per l'Ajuntament el 6 de febrer.

CESSAMENT: 12/11/1891: sol-licita llicència il-limitada per a atendre i cuidar a la seua anciana mare (mala salut, viuda i sense cap altre fill). Se li concedix el 17/11/1891. El 04/12/1891 cessa.

\section{Mayans Tur, Francisco}

Torrer de segona.

- 5/01/1894: s'aprova el seu trasllat a Columbretes, que ell mateix havia sol-licitat. Prové del far de Tazones (Astúries)

- El seu trasllat a Columbretes es fa amb el vapor "Activo"

- Conviu amb el torrer de primera Miquel Massanet

- Ambdós es van de Columbretes a l'hora (pareix que el 9 de gener de 1895 s'aproven els trasllats). Massanet, al far de Conillera i Mayans, al de Cabrera

19/01/1895, cessa a Columbretes.

\section{Campos i Munyoz, José}

Torrer de tercera. 1895/96.

- 6/02/1895: carta de la Direcció General amb el seu NOMENAMENT com a torrer de tercera de Columbretes

- Sou de 1250 pesetes anuals 
- 23/02/1895: fa declaració de no tindre incompatibilitats per a exercir a Columbretes i de no tindre fills en educació primària

16/06/1896: Cessa a Columbretes.

Ja fora de Columbretes (tot i que no es precisa des de quin far ho sol-licita), demana un certificat d'haver estat destinat a Columbretes per a reforçar la seua petició de trasllat a un far de descans.

\section{Mayans Manresa, Francisco}

- Està a Columbretes entre 28/02/1896 i 5/02/1897

- Substituix a Juan Antonio Sancho Espinosa i es substituït per Miguel Adover

- Ve de Punta Grossa (Múrcia)

- Abans d'anar a Columbretes demana servir a un far de descans, però no té dret, donat què no reunix les condicions ni el temps de servei

- Haver servit a Columbretes donava dret a un lloc a far de descans.

- Després és traslladat al far dels Penjats (Balears)

\section{Verger Reynés, Francisco}

Tècnic mecànic de senyals marítimes. Torrer de fars de tercera.

NOMENAMENT: 11 de juliol de 1896.

- Viudo, arriba a Columbretes amb un fill de 10 anys: Juan Verger (hi ha carta del mestre del xiquet)

- Sou anual 1.250 pesetes

- 9/03/1897: per infermetat en la vista, per a consultar a un facultatiu sol-licita trasllat amb el vapor "Activo", després de la consulta sol-licita la baixa d'1 mes amb sou i se li concedix. El 30/04, ordre de tornar a Columbretes ja restablert

- 14/08/1897: trasllat a Conillera (Eivissa)

- 20/08/1897: cessament a Columbretes

- 24/10/1901: torna a Columbretes des del far de Cabo Mayor (Santander) per permuta amb Antolin Algarri i Pedreguera 
- 20/09/1903: sol-licita trasllat al nou far de Canet (està d' obres), i que se li tinga en compte el temps passat a Columbretes

- Ascens d'escala a torrer de segona amb la categoria d'oficial cinqué de l'administració, i amb sou de 1500 pesetes

- Data d'ascens: 19/01/1904

- 8/11/1904: sol-licita de nou trasllat per reiteració de la mateixa infermetat que ja va patir, a un far on puga obtindre "servei de facultat i farmàcia", vol far a València, Castelló o Balears

- 6/02/1905: sol-licita trasllat per tercera vegada, al-legant la infermetat

- 22/07/1905: el torrer encarregat escriu que aquest faroner embarca amb la seua família camí del far de Cavalleria (Menorca). Escriu i narra el seu impecable comportament durant tots aquestos anys.

CESSAMENT: 26 de juliol de 1905.

\section{Adover i Manresa, Miguel}

- Substituix a Francisco Mayans Torres

- Està a Columbretes entre 15/02/1897 i 10/02/1898

- És el sisé torn del far i li correspon a la Província Marítima de Castelló

\section{Prats i Torres, Antonio}

Tècnic de senyals marítimes. Torrer de fars de segona.

NOMENAMENT: 29 de juliol de 1898.

- Arriba a les illes com a faroner de segona suplent

- Arriba procedent de les illes Formigues (Múrcia)

- 2/08/1899: ja està al Grau (mitjançant una permuta amb el faroner Antonio M. Ignias i demana que "se li dispensa l'edat dels seus 2 fills, aspirants a torrers, per a fer les pràctiques necessàries"

- 6/09/1901: es va a Cap de Creus

CESSAMENT: 27 de juliol de 1899. 


\section{Hernández Martínez, Josep}

Tècnic mecànic de senyals marítimes.

NOMENAMENT:

- 11/10/1894: cessa a Tarragona i pren possessió a València

- 16/03/1898: li concedeixen la permuta (D.G. Obres Públiques) que havia sol-licitat amb el faroner Vicente Ribas i García, que està a Columbretes; ell està al far de Cullera (ambdós de la prov. València). És torrer de tercera.

- 28/03/1898: cessa a Cullera

- 05/04/1898: pressa de possessió a Columbretes

- 13/09/1899: permuta amb Francisco Tarín Oliver del far de Cabo de las Huertas (prov. Alacant). El dia 15, l’Enginyer en Cap informa que si, que hi ha que concedir-li-la

NOTA: en 1898 tenia 38 anys i estava casat (per tant, va nàixer en 1860).

CESSAMENT: el 06/10/1899 cessa a Columbretes perquè es va accedir a la seua sol-licitud de permuta el dia 22/09/99.

- Cullera: $11 / 10 / 1894-28 / 03 / 1898$

- Columbretes: 05/04/1898-06/10/1899

- Hortes (Alacant)

Pareix ser que quan estava a Cullera, abans de Columbretes, el 24/09/1894 va demanar permuta al far de Fangal (província de Tarragona) per Emilio Hernández i Navarro (torrer de tercera).

\section{Esbert Campos, Cipriano}

NOTA: té 51 anys en 1919 (per tant va nàixer en 1868) i és casat. Va nàixer un 30 de setembre.

Va estar a Columbretes des del 12/08/1895.

07/09/1899: És torrer de tercera afectat al far de Columbretes. S'acorda que passe a continuar els seus serveis al far d’Orpesa (prov. Castelló) (DG, 24/08/1899).

20/09/1899: Cessa a Columbretes. 
Per tant, el 24 d'agost va ser traslladat a continuar prestant serveis al far d'Orpesa (pressa possessió el 2 d'octubre).

29/02/1901: Sol-licita ser destinat des d'Orpesa a algun far de la prov. CS o a Columbretes (prov. Val.) si hi ha vacant, quan li donen un ascens (que es troba pròxim).

08/06/1901: Li ascendixen a Torrer segona ja que hi ha una vacant y ell es el primer del seu escalafó. Sou: 1500 pesetes Ocupa la vacant de Miguel Sancho Gili, Torrer de fars de la classe segona, oficial cinqué d'Administració.

19/06/1901: Cipriano, torrer de segona, passa a continuar els serveis a Columbretes (València), accedint a la seua sol-licitud. Pressa possessió i destí el 22/06/1901. Cessa a Orpesa el 06/07/1901.

El 16 d'agost de 1915 està al far de Cullera (província de València) i demana un certificat de què va treballar a la província de Castelló de 1899 a 1901.

Al llarg de la seua vida va ascendent per l'escalafó fins ser Torrer Major de Fars en 1930.

No torna a Columbretes. La majoria del servei va ser al far de Borriana.

NOTA sobre sous anuals:

- 1901 , torrer de segona: 1500 pesetes

- 1919 , torrer de primera: 5000 pesetes

- 1930, Torrer Major de Fars, Cap de Negociat de tercera classe: 6000 pesetes

- 1931, Torrer Major de Fars, Cap de Negociat de segona classe: 8000 pesetes

NOTA: el 30/09/1932 es jubila al complir l'edat reglamentària de jubilació forçosa, 67 anys. Però trobem una contradicció ja que si va nàixer en 1868, es jubila amb 64.

CURIOSITAT: dret de sufragi, 31/03/1918.

\section{Chorat Sorá, Eduardo}

Torrer de segona.

28/2/1902: Està a Columbretes Juan Hernández Vallés, qui permuta el destí amb Chorat, que estava al far d'en Pou (Balears). 
A l'expedient apareix un tal Leandro Chorat i Torrat, també faroner de Columbretes, en un document de 22/12/1903.

14/04/1915: Apareix una carta seua des del far dels Penjats (Formentera) demanant el trasllat donat que es troba "atxacós" i li resulta penós exercir la seua missió als fars dels tres primers ordres per la dificultat en l'assistència mèdica. Demana trasllat per al qual al-lega que ha estat a Columbretes entre el 20/03/1902 i el 12/04/1904. Demana servir en fars de descans.

1917: Ja és faroner de primera (9/07/1917 està a Borriana).

1918: El sou de torrer de primera és de 3500 pesetes anuals.

\section{Bartolomé Torres Pujol}

Substitueix a Juan Socías Salvá.

Prové del far de Mouro (Santander).

Està a Columbretes entre el 17 d'agost de 1905 i el 29 d'octubre de 1914, en diverses etapes.

1905. Maragón Martínez, Juan.

Tècnic en senyales marítimes.

Hi ha poca documentació.

4/01/1906: És traslladat de Peníscola a Columbretes.

Demana anar-se'n el 10/02/1908, encara que no apareix més documentació al respecte.

\section{Massanet Amengual, Antonio}

Torrer de tercera.

30/03/1909: S'aprova el seu trasllat a Columbretes.

- Segons pareix, hi va estar en diverses ocasions, al menys en dues, doncs apareix un nou nomenament el 30/03/1914. Prové de Punta Grossa (Eivissa) 
- 12/06/1911: trasllat des de Columbretes a Cap Salines (Balears)

- En 1911 ja apareix com a torrer de primera

- El 20/02/1915 apareix com a afecte a Columbretes però es trasllada a Punta Grossa

1909. Benager Roselló, Juan

Prové del far de Isla Lobeira (A Coruña) i és destinat a Columbretes el 3/03/1909. Està a Columbretes fins 3/01/1912.

Marxa a les Illes Formigues.

Es fa referència a la Ordre de 17 d'agost de 1905 relativa al far de les illes Columbretes.

1910. Vallés Ceballos, Joaquín

Ve del far d'Alegranza (Canàries).

Ingressa a Columbretes el 9/11/1910.

- En 1912 se li concedix permuta amb Juan Bautista Marco, que estava a Orpesa

- Intercanvien els destins

- Com a curiositat, hi ha una carta de l'Enginyer en Cap Luis Dicenta Lloret justificant la no assistència a les eleccions municipals de 12/11/1911, per estar eixe dia a les illes

\section{Acunja Campoy, Antonio}

A penes hi ha informació. Sols que el 5/12/1911 s'aprova el seu trasllat a Columbretes. És de Tarifa.

Únicament apareix un document on se li eximix del servei militar perquè "ja l'ha pagat".

\section{Gálvez Mena, Pedro}

Tècnic mecànic de senyals marítimes. Torrer de fars de tercera. 
NOMENAMENT: 28 de octubre de 1912.

- Arriba a les illes com a torrer de tercera suplent des de Huelva

- Canvi per permuta con torrer de mateixa classe, Antonio Acunja Campoy

- Deixa Columbretes perquè ha sol-licitat "Ilicència il-limitada" per a poder atendre assumptes personals

- és el Ministre de Foment qui signa aquests llicències

CESSAMENT: 8 de novembre de 1912.

\section{Fernández Sempere, Ángel}

Va estar a Columbretes des del 16/02/1924.

09/01/1924: L’Enginyer en Cap de O.P. de Castelló demana al “Ordenador de Pagos" del Ministeri de Obres Públiques la conveniència de que es destine a l'Estació radiotelefònica del Far de Columbretes (Castelló) a un Torrer Radio Telegrafista.

25/01/1924: El cessen del seu lloc a Santander on estava de suplent interí.

16/02/1924: Pressa possessió al far de Columbretes.

- 15/09/24: es va per vacances (1 mes). Un dia d'aqueix mes l'ingressen a l'exèrcit sense saber quan va a tornar a l'Illa. NOTA: aquesta data podria no ser correcta

- 08/10/24: suplica un mes de llicència per infermetat, per a poder portar a terme el tractament

- 14/10/24: se li concedixen 30 dies de llicència amb sou

- 04/11/24: estant en us de la llicència, per R.O. del Ministeri de la Guerra queda inclòs a la llista d'incorporació a files de instrucció dels individus excedents de la quinta del 23. Ha d'incorporar-se al $12^{\text {é }}$ Regimento d'Artilleria Lleugera de la guarnició de Vicàlvar. Aleshores tenia la categoria d'Auxiliar de primera Classe d'Administració afecte al far de Columbretes

- 11/11/24: declarat excedent forçós per a complir els deures militars

- 17/01/1925: concedixen el reingrés al servei actiu de l'Estat (funcionari)

- 04/08/25: demana certificat del temps i serveis prestats a Columbretes (Àngel està a Alacant) 
En aquest certificat parla d'Àngel com a Torrer Auxiliar: servei com a encarregat de l'estació radiotelefònica de Columbretes:

- $16 / 02 / 1924-13 / 11 / 1924$

- 10/01/1925-15/05/1926: aquesta data és la del seu cessament (passa a "supernumerari" al far del port d'Alacant) (se la havia destinat a aquest far el dia 12/05, per concurs)

\section{Salvatierra Llanos, José}

Tècnic de Senyals Marítimes.

NOMENAMENT: 3 de setembre de 1945.

- 16/07/1945: se li reclama des d’Anaga (Tenerife), després de quedar-se dues vegades desert Columbretes

- Sol-licita llicència per infermetat però no se li concedix perquè des de què se li reclama fins a la seua incorporació se li suposa temps de recuperació

- Sou 12000 pesetes

- 4/09/1945: certificat mèdic: Aortitis amb bronquitis crònica + hernia inguinal esquerra

- 7/09/1945: quan porta 4 dies a Columbretes sol-licita llicència per infermetat. Se li concedix 1 mes amb sou complet

- 8/09/1945: carta confidencial de l'enginyer als seus superiors explicant les especials condicions de Columbretes: aïllament i desembarcament, pel que creu oportú que se li concedisca la baixa a aquest torrer

- 1/10/1945: sol-licita altre destí per no haver-se recuperat o un altre mes de baixa amb mig sou. Se li concedix

- 7/11/1945: se li concedix una segona pròrroga

- Després seguix insistint en un trasllat degut ales condicions de salut, però li diuen que quan acabe aquesta segona pròrroga o se presenta las dependències $\mathrm{o}$ es procedirà segons procedix. No es presenta i és cessat, passant a ser supernumerari dins la seua categoria

CESSAMENT: 8 de desembre de 1945. 


\section{Sánchez Romero, Manuel}

05/1946 - 12/1949.

En 1946 estava al far de Portman (Múrcia), considerat de descans. En maig (17/04), se li nomena torrer de Columbretes, on deurà romandre al menys 2 anys.

- 23/05/1946: I'Enginyer en Cap sol-licita per a Manuel Sánchez el racionament extraordinari assignat al personal de Columbretes segons el nombre de familiars i servents. Sol-licitud dirigida al governador civil, tot i que no especifica quantitats ni nombre de familiars

- 17/06/1948: sol-licita trasllat al far electrificat de Cadis (Tarifa) y l'Enginyer en Cap informa favorablement i el veu capacitat per a eixe treball. Hi ha una nova petició el 5 de agosto

- 9/08/1948: nova carta favorable de l'Enginyer en Cap, tot i què diu que si s'haguera d'anar, no hi ha substitut per a cobrir Columbretes

- 3/09/1948: se li nega el trasllat, dient que no porta els dos anys que li corresponen a les Columbretes

- 11/01/1949: se li nomena "Segon del cos", amb 8.400 pessetes de salari anual

- 13/06/1949: sol-licita trasllat a Ceuta

- 2/09/1949: se li demana que faça una substitució al port de Castelló per a cobrir una baixa. Ho fa mentre gaudix de la seua "llicència reglamentària" (NOTA: suposem que són dies de descans després de l'estància a Columbretes)

- 29/10/1949: torna a sol-licitar un trasllat, aquesta vegada sol-licita els fars de Garrucha (Almería), Matxitxaco i Rosas (Biscaia) i Silleiro (Pontevedra)

- 28/11/1949: es nomenat torrer de Matxitxaco, considerat "far aïllat", per 2 anys 7/12/1949: Cessa al far de Columbretes. 
ANNEX 3.5.

Alguns poemes inspirats en les Illes Columbretes 
1. Versos del faroner Francisco Grimalt Alou, 1894, facilitats pel seu net Francesc Grimalt Sancho:

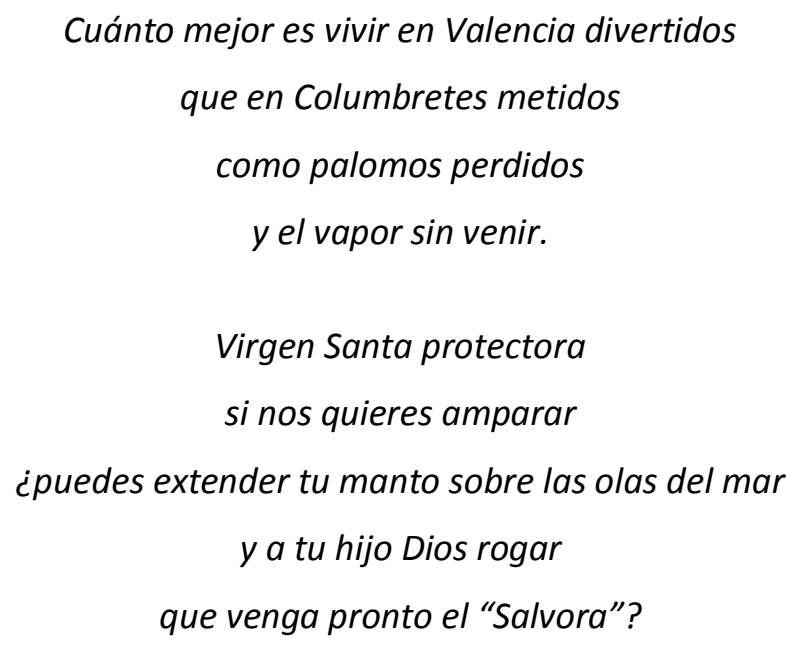

2. Extracte de "El Torrero: Poema", de Julio Fernández-Puente Varo, 1903, facilitats per Gerardo Morales, besnét de José Hierro Delgado, faroner de Columbretes en 1864:

\section{EL TORRERO: POEMA}

\section{CANTO SEGUNDO}

15

En la roca solitaria, con luz incierta y dudosa, un hombre cava una fosa y murmura una plegaria: y en su misión funeraria que ejerce mal que le cuadre, aunque su pecho taladre tan terrible desventura, se ve que a una criatura va a enterrar su mismo padre.

Es el Torrero sin calma que abatido y desolado, donde flores ha sembrado entierra su hija del alma. allí consiguió la palma 


$$
\begin{gathered}
\text { con su martirio postrero, } \\
\text { y dando un iay! Lastimero } \\
\text { sigue Ilorando entretanto... } \\
\text { iQue allí, nadie seca el llanto } \\
\text { del desgraciado Torrero! }
\end{gathered}
$$

3. "A la Virgen de las Islas Columbretes", de Carmen Gómez López (Carmiña), dona del faroner Francisco Bonachera, 1954. Extret de "La Virgen en las Columbretes" (no publicat) de Sergi Ferrer:

\section{A LA VIRGEN DE LAS ISLAS COLUMBRETES}

Perdida entre las rocas ribereñas

bordeada de mar y blanca espuma

levantas tu silueta entre las peñas

en solitaria atalaya sus enseñas

son el mar, los vientos y las brumas.

$Y$ cuando en gigantesca turbonada

el mar incomprensible se enfurece, el silbido ululante, la algarada

del mar entre las peñas reflejada,

con imponentes ecos se extremece.

Eres Tu, la Virgen marinera, la Virgen Reina del mar, la Divina compañera que atudas a señalar.

Tiende la noche su negro manto y el faro lanza rayos de luz.

Dirige al barco que en lontananza navega raudo con la esperanza que en ese barco, llegaras Tú.

Vienen con rumbo a las Columbretes muchas barcas acompañan 
al barco que trae la Virgen.

Sea de Dios alabada.

En ese sublime instante

en que sales de tu tierra.

En ese sublime instante

en que el pueblo te contempla, nosotros, somos del faro, te decimos bienvenida seas, acompáñanos en estas islas que siempre vemos desiertas.

4. "Al peu del far de les Illes Columbretes", de Josep Porcar (Porcar, 2007).

\title{
AL PEU DEL FAR DE LES ILLES COLUMBRETES (Illa Grossa)
}

\author{
Ací l’illa \\ és el tresor. \\ Ací podríem viure \\ tancats fora \\ del món, entre arínjols \\ i margallons, més enllà \\ d'on solament som \\ crits llunyans d'enyors \\ traïts, torbats flameigs \\ i podridures, de la ferida \\ sal, fúria, sements \\ de qui? \\ Prescindible tot, \\ sèquies, pous, semàfors \\ en roig, tindríem la set de l'aigua, \\ la sang salada, els somnis esvarats, \\ i seríem sempre el far \\ d'homes remots.
}




\author{
Quantes illes, \\ quants llibres, \\ quins ulls falcats \\ a la riba dels morts \\ hem abandonat \\ sempre a l'encalç \\ dels vells tresors?
}

5. "Les Columbretes", de Xavier Gimeno Alonso, 2009, de l'associació castellonenca Cardona Vives (Gimeno, 2009):

\title{
LES COLUMBRETES
}

Al llunt, a la mar hi han unes Illes

per les aigües blaves bramen les tonyines.

il una sireneta em demana a mi

que vol que la busque demà de matí...!

Demà de matí yo m'embarcaré

i en la vela a l'aire,

i en la vela a l'aire,

a l'llla aniré.

I en el Bergantí o en la Foradà
la meua sirena
la meua sirena

esperant-me està.

Puix les Columbretes, en mig de la mar,

estan sempre quetes al que vullga anar.

¡l les sirenetes, que viuen allí,

esperen inquietes que vaja un fadrí...! 
6. Prosa a la "Mae de Deu Cagaeta", de Joan Castany, ornitòleg que ha treballat en nombroses ocasions en els estudis d'aus migratòries a les Columbretes, escrits l'any 1991:

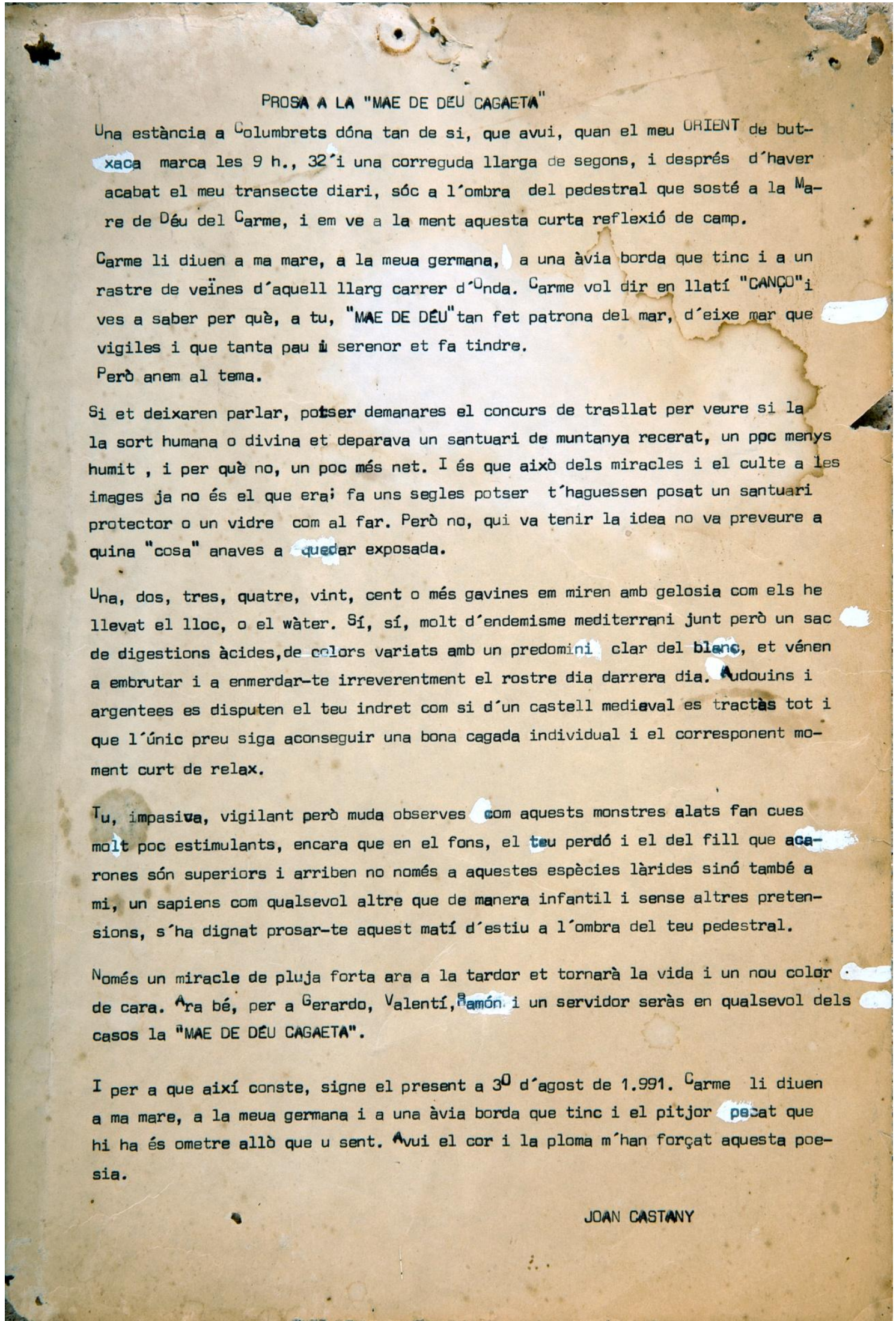




\section{ANNEX 3.6.}

Faroners que van exercir a les Illes Columbretes (elaboració pròpia amb material inèdit, material recopilat en aquesta investigació i material de l'arxiu del Port de Castelló) deixant en blanc els anys dels quals ens falta la informació; any d'entrada i de cessament i, en alguns casos, categoria professional: TMSM=Tècnic mecànic de senyals marítimes; TF=Torrer de fars; PA= Peó auxiliar i DS=Dependent de servei (segons documentació aportada per l'arxiu del Port de Castelló); i alguns comentaris 


\begin{tabular}{clcc}
\hline Any & $\begin{array}{c}\text { Faroners que estaven } \\
\text { treballant a Columbretes }\end{array}$ & $\begin{array}{c}\text { 1a presa de possessió a } \\
\text { Columbretes }\end{array}$ & $\begin{array}{c}\text { Últim cessament a } \\
\text { Columbretes }\end{array}$ \\
\hline $\mathbf{1 8 6 1}$ & López Sanmartín, Domingo & López Sanmartín, Domingo & \\
\hline & $\begin{array}{l}\text { López Sanmartín, Domingo, } \\
\text { Del Río Barrera, Francisco } \\
\text { Miranda Ortiz, Simón }\end{array}$ & & \\
\end{tabular}

1863

López Sanmartín

Domingo i Díaz, Enrique

González, Pedro Antonio (no sabem la data de pressa de possessió) Lucas, Dámaso (no sabem la data de pressa de possessió)

López Sanmartín, Domingo

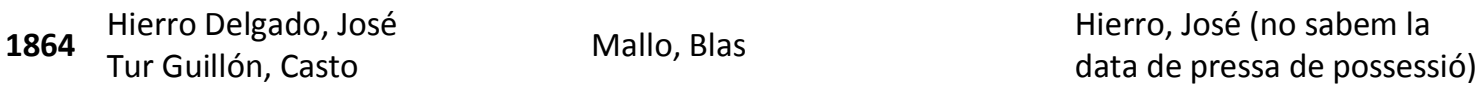

Díaz, Enrique

López Sanmartín, Domingo

Hierro Delgado, José

1865 Del Río Barrera, Francisco

Tur Guillón, Casto

Giménez Ortiz, Sebastián

1866 López Sanmartín, Domingo

1867 López Sanmartín, Domingo

García Vallejo, José

1868

López Sanmartín, Domingo

García Vallejo, José

1869

López Sanmartín, Domingo

García Vallejo, José

1870 López Sanmartín, Domingo

García Vallejo, José

1871 López Sanmartín, Domingo

1872 López Sanmartín, Domingo

Plaza Vilanova, Miquel

1873 López Sanmartín, Domingo

1874 López Sanmartín, Domingo

Manoquín, Juanol

López Sanmartín, Domingo

1875

Company, Andrés

Armengot, Miguel

Peris, Gaspar (no sabem la

data de pressa de

possessió); Vilanova, Miguel

876

Gimeno, Miguel (no sabem

la data de pressa de

possessió)

Manoquín, Juanol

1877

Salaverría, José María

Company, Andrés

Armengot, Miguel

Salaverría, José María

1878

1879

Hernández Martínez, José

(TMSM)

Masanet, Juan

Hernández Martínez, José

Mallo, Blas 
Oribe, Manuel

\begin{tabular}{|c|c|c|c|}
\hline 1880 & $\begin{array}{l}\text { Cifre Sala, José; } \\
\text { Ibarra, Lucas } \\
\text { Nogueira, Luis Mariano }\end{array}$ & $\begin{array}{l}\text { Nogueira } \\
\text { Marco } \\
\text { Iborra }\end{array}$ & $\begin{array}{l}\text { Masanet, Juan } \\
\text { Oribe, Manuel }\end{array}$ \\
\hline 1881 & $\begin{array}{l}\text { Cifre Sala, José } \\
\text { Peris, Gaspar } \\
\text { Marco, Juan Bautista } \\
\text { Ibarra, Lucas } \\
\text { Nogueira, Luis Mariano } \\
\text { Roig, Juan }\end{array}$ & $\begin{array}{l}\text { Hernández Vallés, Juan (TMSM) } \\
\text { Roig; Torrandell i Puig, Miguel }\end{array}$ & $\begin{array}{l}\text { Nogueira } \\
\text { Marco } \\
\text { Iborra }\end{array}$ \\
\hline 1882 & & & Roig \\
\hline 1883 & Peris & & \\
\hline 1884 & Hernández Navarro, José & & \\
\hline 1885 & Hernández Navarro, José & Hernández Navarro, José Emilio & \\
\hline 1886 & Hernández Navarro, José & Esbert, Antonio & \\
\hline 1887 & Torrandell, Miguel & & $\begin{array}{l}\text { Esbert, Antonio } \\
\text { Juan i Soler, Sebastian (no } \\
\text { sabem la data de pressa de } \\
\text { possessió) }\end{array}$ \\
\hline 1888 & Hernández Navarro, José & $\begin{array}{l}\text { Fernández Martín, Eustaquio } \\
\text { (TMSM) (¿Vinarós?) } \\
\text { Mayans Torres, Francisco } \\
\text { (TMSM) }\end{array}$ & \\
\hline 1889 & $\begin{array}{l}\text { Hernández Navarro, José } \\
\text { Lorenzo González, Manuel } \\
\text { Androver Antich, Bartolomé }\end{array}$ & $\begin{array}{l}\text { Androver Antich, } \\
\text { Bartolomé(TMSM) } \\
\text { Lorenzo González, Manuel } \\
\text { Manzanero, Jerónimo (falta } \\
\text { data de cessament) } \\
\text { Cifre, José }\end{array}$ & $\begin{array}{l}\text { Androver Antich, Bartolomé } \\
\text { (iva estar només } 5 \text { dies!) }\end{array}$ \\
\hline 1890 & $\begin{array}{l}\text { Grimalt, Francesc } \\
\text { Fernández Martín, Eustaquio }\end{array}$ & $\begin{array}{l}\text { Fernández Martínez, Eustaquio } \\
\text { Pérez del Río, José } \\
\text { Tauler i Vila, Juan }\end{array}$ & $\begin{array}{l}\text { Lorenzo González, Manuel } \\
\text { Cifre, José }\end{array}$ \\
\hline 1891 & $\begin{array}{l}\text { Garau Melis, Clemente } \\
\text { Orfila Gornés, Llorenç } \\
\text { Martínez Vázquez, Juan }\end{array}$ & $\begin{array}{l}\text { Garau Melis, Clemente (TMSM) } \\
\text { Martínez Vázquez, Juan (TMSM) } \\
\text { Mas i Boscanà, Sebastián } \\
\text { (TMSM) } \\
\text { Orfilia Igornés, Lorenzo } \\
\text { Vinué, Pedro }\end{array}$ & $\begin{array}{l}\text { Martínez Vázquez, Juan } \\
\text { Fernández Martínez, } \\
\text { Eustaquio } \\
\text { Pérez del Río, José } \\
\text { Tauler i Vila, Juan }\end{array}$ \\
\hline 1892 & Garau Melis, Clemente & $\begin{array}{l}\text { Esbert Campos, Cipriano } \\
\text { Sendra } \\
\text { Sala, J. }\end{array}$ & $\begin{array}{l}\text { Garau Melis, Clemente } \\
\text { Mas i Boscanà, Sebastián } \\
\text { Orfilia Igornés, Lorenzo } \\
\text { Hernández Navarro, José } \\
\text { Emilio }\end{array}$ \\
\hline 1893 & & $\begin{array}{l}\text { De la Moral, Remigio } \\
\text { Lezas, Julián }\end{array}$ & $\begin{array}{l}\text { Sendra } \\
\text { Sala, J. }\end{array}$ \\
\hline 1894 & $\begin{array}{l}\text { Grimalt Alou, Francisco Mayans } \\
\text { Tur, Francisco } \\
\text { Massanet, Miquel }\end{array}$ & $\begin{array}{l}\text { Grimalt Alou, Francisco (TF) } \\
\text { Mayans Tur, Francisco (TMSM) } \\
\text { Verdú Lucas, Mariano (TMSM) } \\
\text { Massanet, Miquel }\end{array}$ & $\begin{array}{l}\text { De la Moral, Remigio; Lezas, } \\
\text { Julián; Vinué, Pedro }\end{array}$ \\
\hline 1895 & $\begin{array}{l}\text { Campos Muñoz, José } \\
\text { Esbert Campos, Cipriano }\end{array}$ & $\begin{array}{l}\text { Campos i Muñoz, José (TMSM) } \\
\text { Sancho, Juan } \\
\text { Mestre, Juan }\end{array}$ & $\begin{array}{l}\text { Mayans Tur, Francisco } \\
\text { Massanet, Miquel } \\
\text { Sancho, Juan } \\
\text { Mestre, Juan }\end{array}$ \\
\hline
\end{tabular}




\begin{tabular}{|c|c|c|c|}
\hline 1896 & $\begin{array}{l}\text { Campos Muñoz, José } \\
\text { Sancho Espinosa, Juan Antonio } \\
\text { Verger Reynés, Francisco } \\
\text { Esbert Campos, Cipriano; } \\
\text { Mayans Manresa, Francisco }\end{array}$ & $\begin{array}{l}\text { Verger Reynés, Francisco } \\
\text { (TMSM) } \\
\text { Mayans Torres, Francisco }\end{array}$ & Campos i Muñoz, José \\
\hline 1897 & $\begin{array}{l}\text { Mayans Manresa, Francisco } \\
\text { Mayans Torres, Francisco } \\
\text { Verger Reynés, Francisco } \\
\text { Rivas García, Vicente } \\
\text { Viñas, Jaime } \\
\text { Torrandell, Miguel } \\
\text { Esbert Campos, Cipriano } \\
\text { Adrover Manresa, Miguel }\end{array}$ & $\begin{array}{l}\text { Adrover Manresa, Miguel } \\
\text { (TMSM) }\end{array}$ & $\begin{array}{l}\text { Mayans Torres, Francisco } \\
\text { Verger Reynés, Francisco }\end{array}$ \\
\hline 1898 & $\begin{array}{l}\text { Adrover Manresa, Miguel } \\
\text { Hernández Martínez, Josep } \\
\text { Ribas García, Vicente } \\
\text { Viñas, Jaime; Torrandell, Miguel } \\
\text { Esbert Campos, Cipriano } \\
\text { Prats Torres, Antonio }\end{array}$ & $\begin{array}{l}\text { Prats i Torres, Antonio (TMSM } \\
\text { suplente) } \\
\text { Hernández Martínez, Jose }\end{array}$ & $\begin{array}{l}\text { Fernández Martín, Eustaquio } \\
\text { (¿Borriana?) } \\
\text { Adrover Manresa, Miguel }\end{array}$ \\
\hline 1899 & $\begin{array}{l}\text { Prats Torres, Antonio } \\
\text { Tarín Oliver, Francisco } \\
\text { Esbert Campos, Cipriano } \\
\text { Hernández Martínez, Josep } \\
\end{array}$ & $\begin{array}{l}\text { Tarín Oliver, Francisco (TMSM) } \\
\text { (en altre arxiu consta que va } \\
\text { entrar en 1906) }\end{array}$ & $\begin{array}{l}\text { Esbert Campos, Cipriano } \\
\text { Hernández Martínez, Jose }\end{array}$ \\
\hline \multicolumn{4}{|l|}{1900} \\
\hline 1901 & $\begin{array}{l}\text { Verger Reynés, Francisco } \\
\text { Esbert Campos, Cipriano } \\
\text { Hernández Vallés, Juan } \\
\text { Algarri i Pedreguera, Antolín }\end{array}$ & $\begin{array}{l}\text { Esbert Campos, Cipriano (TF) } \\
\text { Verger Reynés, Francisco } \\
\text { (segona entrada) }\end{array}$ & Prats Torres, Antonio \\
\hline 1902 & $\begin{array}{l}\text { Verger Reynés, Francisco } \\
\text { Chorat Sorá, Eduardo }\end{array}$ & Chorat i Sorá, Eduardo (TMSM) & Hernández Vallés, Juan \\
\hline 1903 & $\begin{array}{l}\text { Verger Reynés, Francisco } \\
\text { Chorat Sorá, Eduardo } \\
\text { Chorat Torrat, Leandro }\end{array}$ & $\begin{array}{l}\text { Gómez Ortiz, Francisco (TF) } \\
\text { (¿Oropesa?) }\end{array}$ & \\
\hline 1904 & $\begin{array}{l}\text { Verger Reynés, Francisco } \\
\text { Benuassar, Martín } \\
\text { Baso García, Santos } \\
\text { Chorat Sorá, Eduardo } \\
\end{array}$ & $\begin{array}{l}\text { Torres Pujol, Bartolomé (en } \\
\text { altre arxiu consta que va entrar } \\
\text { en 1905) }\end{array}$ & Chorat i Sorá, Eduardo \\
\hline 1905 & $\begin{array}{l}\text { Verger Reynés, Francisco } \\
\text { Benuasar, Martín } \\
\text { Baso García, Santos } \\
\text { Socías Salvá, Juan } \\
\text { Torres Pujol, Bartolomé }\end{array}$ & $\begin{array}{l}\text { Torres Pujol, Bartolomé (TMSM) } \\
\text { Moragón Martínez, Juan } \\
\text { (TMSM) (¿Peníscola?) } \\
\text { Baso García, Santos (TMSM) }\end{array}$ & $\begin{array}{l}\text { Verger Reynés, Francisco } \\
\text { Verdú Lucas, Mariano } \\
\text { (¿Borriana?) } \\
\text { Torrandell i Puig, Miguel } \\
\text { Melià Bayona, Narciso }\end{array}$ \\
\hline 1906 & $\begin{array}{l}\text { Maragón Martínez, Juan } \\
\text { Baso García, Santos } \\
\text { Tarín i Oliver, Francisco }\end{array}$ & $\begin{array}{l}\text { Moragón Martínez, Juan (en } \\
\text { altre arxiu consta que va entrar } \\
\text { en 1905) } \\
\text { Tarín i Oliver, Francisco } \\
\text { Batanero Romasanta, Juan }\end{array}$ & $\begin{array}{l}\text { Melià Bayona, Narciso } \\
\text { Torres Pujol, Bartolomé }\end{array}$ \\
\hline 1907 & $\begin{array}{l}\text { Baso García, Santos } \\
\text { Maragón Martínez, Juan } \\
\text { Tarín Oliver, Francisco }\end{array}$ & & \\
\hline
\end{tabular}




\begin{tabular}{|c|c|c|c|}
\hline 1908 & $\begin{array}{l}\text { Baso García, Santos } \\
\text { Maragón Martínez, Juan } \\
\text { Tarín Oliver, Francisco } \\
\text { Batanero Romasanta, Juan }\end{array}$ & & $\begin{array}{l}\text { Batanero Romasanta, Juan } \\
\text { (mort a l'illa el 14/12/1908, } \\
\text { soterrat al cementeri amb } \\
\text { làpida) DEP. }\end{array}$ \\
\hline 1909 & $\begin{array}{l}\text { Baso García, Santos } \\
\text { Massanet Amengual, Antonio } \\
\text { Tarín Oliver, Francisco } \\
\text { Benager Roselló, Juan }\end{array}$ & $\begin{array}{l}\text { Massanet Amengual, Antonio } \\
\text { José (TMSM) } \\
\text { Bennaser Roselló, Juan (TMSM) }\end{array}$ & Baso García, Santos \\
\hline 1910 & $\begin{array}{l}\text { Olmos Visconti, Eduardo } \\
\text { Llorenç Sol, José } \\
\text { Massanet Amengual, Antonio } \\
\text { Vallés Ceballos, Joaquín } \\
\text { Tarín Oliver, Francisco } \\
\text { Benager Roselló, Juan }\end{array}$ & $\begin{array}{l}\text { Vallés Ceballos, Joaquín (TMSM) } \\
\text { Ribas, Vicente }\end{array}$ & Moragón Martínez, Juan \\
\hline 1911 & $\begin{array}{l}\text { Llorenç Sol, José } \\
\text { Massanet Amengual, Antonio } \\
\text { Vallés Ceballos, Joaquín } \\
\text { Acuña Campoy, Antonio } \\
\text { Benager Roselló, Juan }\end{array}$ & $\begin{array}{l}\text { Acuña Campoy, Antonio } \\
\text { (TMSM) } \\
\text { Baso Asensi, Federico (TMSM); } \\
\text { Gómez Pérez, Julián (TMSM) }\end{array}$ & $\begin{array}{l}\text { Massanet Amengual, } \\
\text { Antonio José } \\
\text { Ribas, Vicente }\end{array}$ \\
\hline 1912 & $\begin{array}{l}\text { Llorenç Sol, José } \\
\text { Benager Roselló, Juan } \\
\text { Vallés Ceballos, Joaquín } \\
\text { Acuña Campoy, Antonio } \\
\text { Gálvez Mena, Pedro } \\
\text { Bautista Marco, Juan }\end{array}$ & $\begin{array}{l}\text { Olmos Visconti, Eduardo } \\
\text { (TMSM) } \\
\text { Gálvez Mena, Pedro (TMSM) } \\
\text { Maurí Martínez, José }\end{array}$ & $\begin{array}{l}\text { Acuña Campoy, Antonio } \\
\text { Olmos Visconti, Eduardo } \\
\text { Bennaser Roselló, Juan } \\
\text { Gálvez Mena, Pedro } \\
\text { Vallés Ceballos, Joaquín } \\
\text { Bautista Marco, Juan (falta la } \\
\text { data d'entrada) }\end{array}$ \\
\hline 1913 & $\begin{array}{l}\text { Llorenç Sol, José } \\
\text { Tarín Oliver, Francisco }\end{array}$ & & Gómez Pérez, Julián \\
\hline 1914 & $\begin{array}{l}\text { Llorenç Sol, José } \\
\text { Grimalt, Francesc } \\
\text { Baso Asensi, Federico } \\
\text { Torres Pujol, Bartolomé } \\
\text { Massanet Amengual, Antonio }\end{array}$ & $\begin{array}{l}\text { Massanet Amengual, Antonio } \\
\text { José (2a entrada) }\end{array}$ & $\begin{array}{l}\text { Torres Pujol, Bartolomé ( } 2 \underline{a} \\
\text { eixida constatada, faltaria } \\
\text { una } 2^{a} \text { entrada) } \\
\text { Vallés Ceballos, Joaquín }\end{array}$ \\
\hline 1915 & $\begin{array}{l}\text { Llorenç Sol, José } \\
\text { Massanet Amengual, Antonio }\end{array}$ & $\begin{array}{l}\text { Alegre Fabregat, Francisco } \\
\text { (TMSM) } \\
\text { Ferdiani Garbarino, Francisco } \\
\text { (TMSM) } \\
\text { Perlés Llopis, José (TF) } \\
\text { Marí Tur, Juan } \\
\text { Llorenç Sol, José } \\
\text { Alegre Fabregat, Francisco }\end{array}$ & $\begin{array}{l}\text { Ferdiani Garbarino, } \\
\text { Francisco } \\
\text { Grimalt Alou, Francisco } \\
\text { Massanet Amengual, } \\
\text { Antonio José } \\
\text { Baso Asensi, Federico } \\
\text { Llorenç Sol, José (va estar } \\
\text { només } 1 \text { mes) }\end{array}$ \\
\hline 1916 & Llorenç Sol, José & & Tarín Oliver, Francisco \\
\hline 1917 & Llorenç Sol, José & $\begin{array}{l}\text { Maurí Martínez, José (TF) (2a } \\
\text { entrada) }\end{array}$ & \\
\hline 1918 & $\begin{array}{l}\text { Llorenç Sol, José } \\
\text { Escortell Ripoll, Josep }\end{array}$ & $\begin{array}{l}\text { Puig Ramírez, Francisco (TMSM) } \\
\text { Escortell Ripoll, José }\end{array}$ & Puig Ramírez, Francisco \\
\hline 1919 & $\begin{array}{l}\text { Llorenç Sol, José } \\
\text { Escortell Ripoll, Josep }\end{array}$ & Olmos Visconti, Eduardo & Marí Tur, Juan \\
\hline 1920 & $\begin{array}{l}\text { Llorenç Sol, José } \\
\text { Escortell Ripoll, Josep }\end{array}$ & & Maurí Martínez, José \\
\hline 1921 & $\begin{array}{l}\text { Perles, José } \\
\text { García Blasco, Higinio }\end{array}$ & García Blasco, Higinio (TF) & Perlés Llopis, José \\
\hline
\end{tabular}


Escortell Ripoll, Josep

1922

García Blasco, Higinio

Escortell Ripoll, Josep

García Blasco, Higinio

Escortell Ripoll, Josep

Escortell Ripoll, Josep

1924 Fernández Sempere, Ángel

García Blasco, Higinio
Castelló Pérez, Baldomero (TF)

Gómez Olmos, Carmelo

Gómez Olmos, Carmelo

(aspirante a torrero)

Roig Montagut, José Ramon

(TMSM) (¿Peñíscola?) Olmos Visconti, Eduardo

Callau Cros, Juan Luis

Fernández Sempere, Ángel

(TMSM)

Fernández Sempere, Ángel

Escortell Ripoll, José

\begin{tabular}{|c|c|c|c|}
\hline 1925 & $\begin{array}{l}\text { Fernández Sempere, Ángel } \\
\text { García Blasco, Higinio }\end{array}$ & $\begin{array}{l}\text { Fernández Sempere, Ángel ( } 2 \text { a } \\
\text { entrada) }\end{array}$ & \\
\hline 1926 & $\begin{array}{l}\text { Alegre, Francisco } \\
\text { Ruiz Ferreres, Agustín } \\
\text { Fernández Sempere, Ángel } \\
\text { García Blasco, Higinio }\end{array}$ & $\begin{array}{l}\text { García Orts, Manuela } \\
\text { (dependiente de servicio) DONA }\end{array}$ & Fernández Sempere, Ángel \\
\hline 1927 & $\begin{array}{l}\text { Alegre, Francisco } \\
\text { Ruiz Ferreres, Agustín } \\
\text { García Blasco, Higinio }\end{array}$ & & \\
\hline 1928 & García Blasco, Higinio & & \\
\hline 1929 & García Blasco, Higinio & & \\
\hline 1930 & García Orts, Francisco & & \\
\hline 1931 & & & $\begin{array}{l}\text { Gómez Ortiz, Francisco } \\
\text { (¿Benicarló?) }\end{array}$ \\
\hline 1932 & & & Esbert Campos, Cipriano \\
\hline \multicolumn{4}{|l|}{1933} \\
\hline 1934 & Roig Montagut, Ramon & $\begin{array}{l}\text { Roig Montagut, Ramon } \\
\text { Castelló Gómez, Josefa (DS) } \\
\text { DONA }\end{array}$ & $\begin{array}{l}\text { Castelló Gómez, Josefa } \\
\text { García Blasco, Higinio }\end{array}$ \\
\hline 1935 & Roig Montagut, Ramon & & Castelló Gómez, Josefa \\
\hline 1936 & $\begin{array}{l}\text { Castelló Pérez, Baldomero } \\
\text { Roig Montagut, Ramon }\end{array}$ & & \\
\hline 1937 & Castelló Pérez, Baldomero & & Alegre Fabregat, Francisco \\
\hline \multicolumn{4}{|l|}{1938} \\
\hline 1939 & & Castelló Gómez, José (TMSM) & Castelló Gómez, José \\
\hline 1940 & Roig Montagut, Ramon & & Castelló Pérez, Baldomero \\
\hline 1941 & Roig Montagut, Ramon & $\begin{array}{l}\text { Martínez Monto, Antonio } \\
\text { (TMSM) } \\
\text { Poza Fernández, Juan (TMSM) }\end{array}$ & $\begin{array}{l}\text { Poza Fernández, Juan } \\
\text { Callau Cros, Juan Luis }\end{array}$ \\
\hline 1942 & $\begin{array}{l}\text { Roig Montagut, Ramon } \\
\text { Martínez Monto, Antonio }\end{array}$ & Bonachera López, José & \\
\hline 1943 & $\begin{array}{l}\text { Roig Montagut, Ramon } \\
\text { Martínez Monto, Antonio }\end{array}$ & & $\begin{array}{l}\text { Bonachera López, José (va } \\
\text { estar menys d'un mes) }\end{array}$ \\
\hline 1944 & $\begin{array}{l}\text { Roig Montagut, Ramon } \\
\text { Martínez Monto, Antonio }\end{array}$ & & $\begin{array}{l}\text { Poza Fernández, Juan (esta } \\
\text { eixida no coincideix amb } \\
\text { l'altre llistat) }\end{array}$ \\
\hline 1945 & $\begin{array}{l}\text { Roig Montagut, Ramon } \\
\text { Salvatierra Llanos, José } \\
\text { Martínez Monto, Antonio }\end{array}$ & $\begin{array}{l}\text { Salvatierra Llanos, José (TMSM) } \\
\text { Gutiérrez Gracia, Juan }\end{array}$ & \\
\hline
\end{tabular}




\begin{tabular}{|c|c|c|c|}
\hline 1946 & $\begin{array}{l}\text { Roig Montagut, Ramon Sánchez } \\
\text { Romero, Manuel } \\
\text { Martínez Monto, Antonio }\end{array}$ & $\begin{array}{l}\text { Sánchez Romero, Manuel } \\
\text { (TMSM) } \\
\text { Gandolfo Fernández, Serafín } \\
\text { (TMSM) }\end{array}$ & $\begin{array}{l}\text { Sánchez Romero, Manuel (hi } \\
\text { ha una altra eixida en 1949); } \\
\text { Roig Montagut, Ramon } \\
\text { Salvatierra Llanos, José } \\
\text { Gutiérrez Gracia, Juan }\end{array}$ \\
\hline 1947 & $\begin{array}{l}\text { Sánchez Romero, Manuel } \\
\text { Martínez Monto, Antonio }\end{array}$ & & \\
\hline 1948 & $\begin{array}{l}\text { Sánchez Romero, Manuel } \\
\text { Martínez Monto, Antonio }\end{array}$ & $\begin{array}{l}\text { Gutiérrez Perlasia, Fernando } \\
\text { (TMSM) }\end{array}$ & Martínez Monto, Antonio \\
\hline 1949 & $\begin{array}{l}\text { Sánchez Romero, Manuel } \\
\text { Martínez Monto, Antonio }\end{array}$ & & Sánchez Romero, Manuel \\
\hline 1950 & & $\begin{array}{l}\text { Gandolfo Fernández, Luis } \\
\text { (TMSM) } \\
\text { Bonachera Vázquez, Francisco } \\
\text { (en l'altre llistat posa 1951) }\end{array}$ & \\
\hline 1951 & & $\begin{array}{l}\text { Bonachera Vázquez, Francisco } \\
\text { (TMSM) } \\
\text { Serrano Adell, Roque (TMSM) }\end{array}$ & $\begin{array}{l}\text { Gutiérrez Perlasia, Fernando } \\
\text { (hi ha una } 2^{a} \text { data eixida) }\end{array}$ \\
\hline 1952 & & & $\begin{array}{l}\text { Bonachera Vázquez, } \\
\text { Francisco }\end{array}$ \\
\hline 1953 & $\begin{array}{l}\text { Zacarías Naranjo, Aurelio } \\
\text { Gandolfo Martínez, Luis } \\
\text { Bonachera, Francisco }\end{array}$ & $\begin{array}{l}\text { Zacarías Naranjo, Aurelio } \\
\text { (TMSM) } \\
\text { Bonachera Vázquez, Francisco }\end{array}$ & $\begin{array}{l}\text { Gandolfo Fernández, Luis } \\
\text { Gandolfo Fernández, Serafín }\end{array}$ \\
\hline 1954 & $\begin{array}{l}\text { Zacarías Naranjo, Aurelio } \\
\text { Gandolfo Martínez, Luis } \\
\text { Bonachera, Francisco } \\
\text { Guzmán Albiol, José Antonio }\end{array}$ & $\begin{array}{l}\text { Guzmán Albiol, José Antonio (en } \\
\text { l'altre llistat posa que va entrar } \\
\text { al 1956) }\end{array}$ & $\begin{array}{l}\text { Zacarías Naranjo, Aurelio } \\
\text { Roig Montagut, José Ramon } \\
\text { (Jefatura O.P.) } \\
\text { Bonachera Vázquez, } \\
\text { Francisco }\end{array}$ \\
\hline 1955 & Serrano Adell, Roque & $\begin{array}{l}\text { Cuesta de los Ríos, Gonzalo } \\
\text { (TMSM) } \\
\text { Bonachera Vázquez, Francisco } \\
\text { De Grado Martínez, Restituto }\end{array}$ & Cuesta de los Ríos, Gonzalo \\
\hline 1956 & $\begin{array}{l}\text { Guzmán Albiol, José Antonio } \\
\text { Serrano Adell, Roque }\end{array}$ & $\begin{array}{l}\text { Guzmán Albiol, José Antonio } \\
\text { (TMSM) }\end{array}$ & \\
\hline 1957 & Serrano Adell, Roque & & $\begin{array}{l}\text { Alegre Fabregat, Francisco } \\
\text { (¿Puerto de Castellón?) } \\
\text { Guzmán Albiol, José Antonio } \\
\text { Gutiérrez Perlasia, Fernando }\end{array}$ \\
\hline 1958 & $\begin{array}{l}\text { Del Bosque Gutiérrez, Juan } \\
\text { Serrano Adell, Roque } \\
\text { Bonachera, Francisco }\end{array}$ & $\begin{array}{l}\text { Del Bosque Gutiérrez, Juan (TF) } \\
\text { Serrano Adell, Roque }\end{array}$ & \\
\hline 1959 & $\begin{array}{l}\text { Del Bosque Gutiérrez, Juan } \\
\text { Serrano Adell, Roque }\end{array}$ & & $\begin{array}{l}\text { Bonachera Vázquez, } \\
\text { Francisco }\end{array}$ \\
\hline 1960 & $\begin{array}{l}\text { Del Bosque Gutiérrez, Juan } \\
\text { Serrano Adell, Roque }\end{array}$ & & Del Bosque Gutiérrez, Juan \\
\hline 1961 & $\begin{array}{l}\text { Mancisidor Arias-Valdés, Tomás } \\
\text { Serrano Adell, Roque }\end{array}$ & $\begin{array}{l}\text { Mancisidor Arias-Valdés, Tomás } \\
\text { (TMSM) }\end{array}$ & $\begin{array}{l}\text { Mancisidor Arias-Valdés, } \\
\text { Tomás } \\
\text { De Grado Martínez, } \\
\text { Restituto }\end{array}$ \\
\hline
\end{tabular}




\begin{tabular}{|c|c|c|c|}
\hline 1962 & $\begin{array}{l}\text { Gozalbo, José } \\
\text { Del Bosque Gutiérrez, Juan } \\
\text { Serrano Adell, Roque } \\
\text { Mancisidor Arias-Valdés, Tomás }\end{array}$ & & \\
\hline 1963 & $\begin{array}{l}\text { Gozalbo, José } \\
\text { Serrano Adell, Roque } \\
\text { Mancisidor Arias-Valdés, Tomás }\end{array}$ & & \\
\hline 1964 & $\begin{array}{l}\text { Mancisidor Arias-Valdés, Tomás } \\
\text { Serrano Adell, Roque } \\
\text { Gozalbo, José }\end{array}$ & & $\begin{array}{l}\text { Mancisidor Arias-Valdés, } \\
\text { Tomás (en l'altre llistat posa } \\
\text { 1964) }\end{array}$ \\
\hline 1965 & $\begin{array}{l}\text { Albiol Martorell, Agustín } \\
\text { Gozalbo, José } \\
\text { Serrano Adell, Roque }\end{array}$ & $\begin{array}{l}\text { Albiol Martorell, Agustín (PA) } \\
\text { Ariño Rubio, Juan; Trillo Trillo, } \\
\text { Juan }\end{array}$ & $\begin{array}{l}\text { Albiol Martorell, Agustín } \\
\text { Serrano Adell, Roque }\end{array}$ \\
\hline 1966 & $\begin{array}{l}\text { Gozalbo, José } \\
\text { Serrano Adell, Roque }\end{array}$ & Bonachera Vázquez, Francisco & \\
\hline 1967 & $\begin{array}{l}\text { Gozalbo, José } \\
\text { Serrano Adell, Roque }\end{array}$ & & Ariño Rubio, Juan \\
\hline 1968 & Serrano Adell, Roque & & $\begin{array}{l}\text { Martínez Monto, Antonio } \\
\text { (no coincideix amb l'altre } \\
\text { llistat, 1948) }\end{array}$ \\
\hline 1969 & Serrano Adell, Roque & & \\
\hline 1970 & Serrano Adell, Roque & & \\
\hline 1971 & Serrano Adell, Roque & Guzmán Albiol, José Antonio & \\
\hline 1972 & $\begin{array}{l}\text { Bonachera, Francisco } \\
\text { Serrano Adell, Roque }\end{array}$ & & \\
\hline 1973 & $\begin{array}{l}\text { Bonachera, Francisco } \\
\text { Serrano Adell, Roque }\end{array}$ & Ulecia Lemos, Ignacio & \\
\hline 1974 & $\begin{array}{l}\text { Bonachera, Francisco } \\
\text { Serrano Adell, Roque }\end{array}$ & & $\begin{array}{l}\text { Bonachera Vázquez, } \\
\text { Francisco (ha entrat i eixit } 4 \\
\text { vegades) }\end{array}$ \\
\hline 1975 & $\begin{array}{l}\text { Bonachera, Francisco } \\
\text { Serrano Adell, Roque }\end{array}$ & & $\begin{array}{l}\text { Guzmán Albiol, José Antonio } \\
\text { Trillo Trillo, Juan }\end{array}$ \\
\hline 1983 & & & Ulecia Lemos, Ignacio \\
\hline 1988 & & & Serrano Adell, Roque \\
\hline 1990 & & Sanjosé Del Barrio, Javier & \\
\hline 1992 & & & Sanjosé Del Barrio, Javier \\
\hline
\end{tabular}

L'any 1975 es va automatitzar el far de Columbretes i va deixar d'haver-hi un servei de faroners de manera continuada a les Illes, de tota manera, segons l'arxiu del port, hi havia alguns faroners inscrits encara a aquest far, que són els que apareixen a la taula a partir de 1976. 


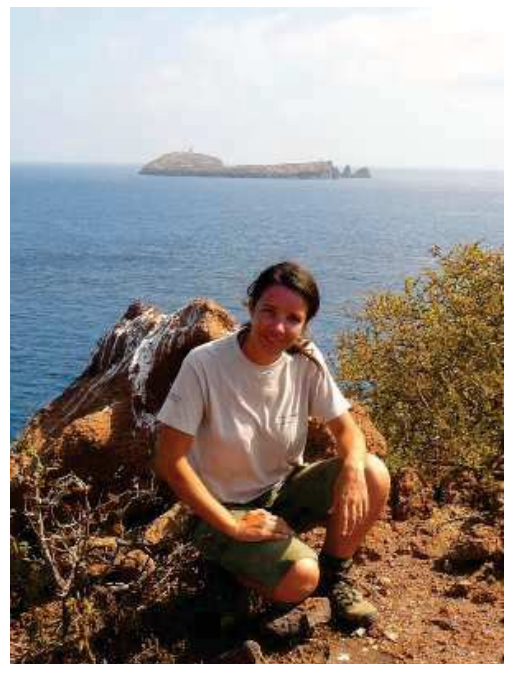

Eva Mestre-Forés és enginyera agrònoma per la Universitat Politècnica de València i actualment treballa com a agent mediambiental de la Generalitat Valenciana.

Ha treballat de monitora i tècnica mediambiental a la Reserva Natural de les Illes Columbretes des de l'any 2000 fins 2014 (l'estiu de 1998, de voluntària), i al Parc Natural del Desert de les Palmes els anys 2001 i 2002. 
El present estudi pretén actualitzar els coneixements sobre la història natural i la història humana de les llles Columbretes.

El llibre conté tres capítols en els quals destaquen la nova caracterització climatològica de les Columbretes, els llistats d'invertebrats terrestres presents a cadascuna de les illes i la recopilació d'històries antigues contades de primera mà per faroners i familiars que van habitar a les llles.

Als annexos podem trobar, entre d'altres, el primer catàleg d'invertebrats no marins de les Columbretes, l'estudi d'àcars fitoseids o la primera recopilació dels faroners que hi van prestar servei. 